\title{
THE ROLE OF THE
}

\section{PHYSICAL ENVIRONMENT}

IN ANCIENT GREEK SEAFARING.

JAMES MALCOLM MORTON

Ph.D.

UNIVERSITY OF EDINBURGH

1998

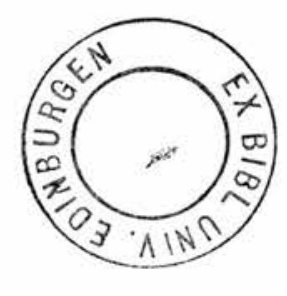


DECLARATION OF ORIGINALITY.

This thesis has been composed by the candidate, and is entirely his own work. $S$ 


\section{ACKNOWLEDGEMENTS}

In the first place I must thank my wife, Angie, and secondly my supervisors, Dr.

Robin Barber and Gordon Howie, for their support, advice, and goodwill, which has continued unabated since I embarked on my Ph.D., and without which I would have lost my bearings long ago. Like the navigators who are the focus of this thesis, I have often reassessed my position and my outlook, and have made various changes of direction during my journey over the past five years, and here again I must acknowledge the help of all of those guides whose local knowledge, whether academic or geographic, has helped me to steer my course, and whose hospitality has greeted me at various ports of call: Chris Cassels, Dr. Betsy Gebhard, John and family in Emborio (Chios), Niko Laos and family in Athens and in the Mani, Ian Morrison, Haydar Namli, the Odyssey flotilla, Bill Phelps, Rob Schumacher, Ann Thomas, and all those other friends who have made my time in Edinburgh and in Greece so rewarding. In addition I am grateful to the administrators of the Hector and Elizabeth Catling Bursary, and of the George C. Scott Fund, without whose help my visits to Greece would have been far shorter and far fewer. 


\begin{abstract}
The geological history of Greece has produced a generally highly indented coastline, with many islands lying in the neighbouring seas; some coastal areas, however, feature long stretches of high cliffs, or of sandy shallows. Marine erosion has further developed coastal indentation, and has produced many typical erosion features. Sea currents around Greece, which are governed by the inflows of water into the Mediterranean at Gibraltar and at the Hellespont, are regular, owing to the weakness of Mediterranean tides, and are strongest in straits and off major headlands. The Greek climate is also regular, falling into two distinct seasons; summer features strong, regular, northerly winds, clear skies, and great heat and drought, while winter is typified by eastwards-moving depressions which bring strong, stormy, and unpredictable winds, as well as cloud and rain, especially in coastal areas, where winds blowing off the sea meet land barriers (ch.1).
\end{abstract}

Such topographical, oceanographic, and meteorological conditions meant that headlands and straits were areas of particular navigational difficulty. Yet these same conditions entailed a ready availability of shelter, in natural harbours, in river mouths, and behind promontories and islands. Areas composed of unbroken cliffs, or of flat, featureless shallows, on the other hand, afforded no such shelter (ch.2).

The physical environment thus also strongly influenced the routes taken by mariners, especially with regard to the degree to which ships 'hugged the coast'. Headlands and islands were the principal points at which major changes of direction were made, and, along with some other prominent topographical features, took on the role of milestones and landmarks, for which they were well suited. Incidental structures such as towers, tombs, and temples, took on similar roles, and were particularly important in inshore navigation. Where, due to distance or darkness, terrestrial landmarks were not visible, sailors' knowledge of other aspects of the physical environment was of paramount importance for safe and successful navigation (ch.3).

Thus the physical environment had a great influence upon ancient Greek sailing practices. Given the limitations of ancient maritime technology, knowledge of the topography, meteorology, oceanography, and even the ecology of the local environment (and the dissemination of knowledge regarding unfamiliar environments) was indispensable, enabling sailors to anticipate the weather and sailing conditions likely to be encountered at different times and in different places, and so to take to the seas in as safe and as practical a way as possible (conclusions, appendices). 


\section{TABLE OF CONTENTS}

Declaration of Originality. $\quad$ p.1

Acknowledgements. $\quad$ p.2

$\begin{array}{ll}\text { Abstract. } & \text { p.3 }\end{array}$

$\begin{array}{ll}\text { Introduction. } & \text { p.7 }\end{array}$

The scope of the thesis.

The extent of change in the physical environment since antiquity. p.12

Sources of evidence and information. $\quad$ p.15

$\begin{array}{ll}\text { Maps, indices, and transliteration. } & \text { p.16 }\end{array}$

Chapter 1: The physical environment of ancient Greek $\begin{array}{ll}\text { seafaring. } & \text { p.17 }\end{array}$

Introduction. $\quad$ p.17

The development of the Greek coastline. $\quad$ p.17

The geological formation of the Greek coastline. p.17

Erosion and the formation of local coastal topographies. p.21

Headlands and Bays. $\quad$ p.23

Caves and related features.

Cliffs.

Natural Harbours. p.27

Offshore rocks and islands. $\quad$ p.28

Deposition. p.31

Oceanographic conditions in the vicinity of Greece. p.33

Wave formation. p.33

Wave refraction. p.34

Waves against an indented coastline. $\quad$ p.36

Waves against cliffs.

Currents in the Greek Seas.

Currents in the Aegean, Ionian, and Adriatic Seas. p.41

Currents at headlands. p.41

Currents through straits.

$\begin{array}{ll}\text { Tides. } & \text { p.47 }\end{array}$

Meteorology and the Greek coastline. p.48

The annual weather cycle in Greece. $\quad$ p. 48

The Etesians. $\quad$ p.49

Cyclonic winds: the Bora and the Sirocco. p.50

Land and sea breezes. p.52

Valley and mountain winds.

Canalling and Squalls: the effect of barriers on winds. p.57

Cloud formation, fog, and rainfall. $\quad$ p.61

Chapter 2: The topography of ancient Greek seafaring. $\quad$ p.66

Introduction. $\quad$ p.66

$\begin{array}{ll}\text { Promontories and Headlands. } & \text { p.67 }\end{array}$

Dangers associated with the topography of headlands. p.68

Dangers associated with sea conditions around headlands. $\quad$ p.72 
$\begin{array}{ll}\text { Dangers associated with winds around headlands. } & \text { p.74 }\end{array}$

$\begin{array}{ll}\text { Malea. } & \text { p.78 }\end{array}$

$\begin{array}{ll}\text { Straits. } & \text { p.82 }\end{array}$

$\begin{array}{ll}\text { Problems related to currents in straits. } & \text { p.82 }\end{array}$

Phormio, the land breeze, and the funnelling of winds through straits. p. 87

$\begin{array}{ll}\text { Themistocles and the sea breeze. } & \text { p.89 }\end{array}$

Difficulties caused by unpredictable winds in straits. p.90

$\begin{array}{ll}\text { Rocks and reefs in straits. } & \text { p.93 }\end{array}$

Bays and the availability of shelter. $\quad$ p.95

The importance of natural areas of shelter. p.95

Natural Harbours. p.97

$\begin{array}{ll}\text { Shelter behind headlands. } & \text { p.98 }\end{array}$

$\begin{array}{ll}\text { Shelter in river mouths. } & \text { p.102 }\end{array}$

$\begin{array}{ll}\text { Shelter behind islands. } & \text { p.104 }\end{array}$

Factors limiting the degree of shelter to the lee of headlands and offshore islands. $\quad$ p.106

$\begin{array}{ll}\text { Areas offering particularly effective shelter. } & \text { p.110 }\end{array}$

$\begin{array}{ll}\text { Shoals and deposition. } & \text { p.117 }\end{array}$

$\begin{array}{lr}\text { Harbourless coasts. } & \text { p.121 }\end{array}$

Chapter 3: Sailing routes and navigation. $\quad$ p.127

$\begin{array}{ll}\text { Coastal seafaring - a question of degree. } & \text { p.127 }\end{array}$

$\begin{array}{ll}\text { Geographical factors affecting coastal sailing. } & \text { p.128 }\end{array}$

Geographical factors affecting open-sea sailing. p.133

Other factors affecting the question of coastal v. open-sea sailing. p.135

$\begin{array}{ll}\text { Deciding between the coastal and the open-sea route. } & \text { p.139 }\end{array}$

Finding the most economical route: coastal routes. p.142

Finding the most economical route: open-sea routes. p.145

$\begin{array}{ll}\text { Characteristics of sailing directions and routes. } & \text { p.154 }\end{array}$

$\begin{array}{ll}\text { Headlands and islands as turning points. } & \text { p.158 }\end{array}$

Headlands, islands, and other topographical features as milestones. p.161

$\begin{array}{ll}\text { Coastal navigation. } & \text { p.166 }\end{array}$

Headlands, islands, and other topographical features as coastal

Artificial and incidental coastal landmarks. $\quad$ p.172

$\begin{array}{ll}\text { Coastal landmarks and inshore navigation. } & \text { p.176 }\end{array}$

$\begin{array}{ll}\text { Navigation out of sight of the coast. } & \text { p.179 }\end{array}$

$\begin{array}{ll}\text { Navigation of coastal waters in fog or at night. } & \text { p.179 }\end{array}$

$\begin{array}{ll}\text { Beacons. } & \text { p. } 182\end{array}$

$\begin{array}{ll}\text { Navigation on the open seas. } & \text { p.185 }\end{array}$

\section{$\begin{array}{lr}\text { Conclusions. } & \mathbf{p . 1 9 5}\end{array}$}

The role of the physical environment in ancient Greek seafaring. p.195

The maritime functions of specific features of coastal topography. p.195

General meteorological and oceanographic considerations. $\quad$ p.199

$\begin{array}{ll}\text { The living environment. } & \text { p.202 }\end{array}$ 
$\begin{array}{ll}\text { The physical environment and human technology. } & \text { p.203 }\end{array}$

$\begin{array}{ll}\text { Interrelationships. } & \text { p.203 }\end{array}$

Knowledge of the local environment. p.211

Appendix 1: Sailing seasons, winter sailing, and night sailing. $\quad$ p.221

$\begin{array}{ll}\text { The sailing season. } & \text { p.221 }\end{array}$

Winter sailing. p.223

$\begin{array}{ll}\text { Night sailing. } & \text { p.226 }\end{array}$

Appendix 2: The seaworthiness of Greek ships, in the context

$\begin{array}{ll}\text { of the Mediterranean environment. } & \text { p.231 }\end{array}$

$\begin{array}{ll}\text { The Mediterranean as a seafaring environment. } & \text { p.231 }\end{array}$

$\begin{array}{ll}\text { Ancient Greek attitudes towards seafaring. } & \text { p.235 }\end{array}$

$\begin{array}{ll}\text { The seaworthiness of Greek ships. } & \text { p.237 }\end{array}$

$\begin{array}{ll}\text { Oared warships. } & \text { p.240 }\end{array}$

$\begin{array}{lr}\text { Merchant ships. } & \text { p.242 }\end{array}$

$\begin{array}{ll}\text { Conclusions. } & \text { p.243 }\end{array}$

Appendix 3: Weather prediction. $\quad$ p.246

$\begin{array}{ll}\text { Weather prediction and the physical environment. } & \text { p.247 }\end{array}$

$\begin{array}{ll}\text { The role of birds in weather prediction. } & \text { p.252 }\end{array}$

$\begin{array}{ll}\text { Other animals in weather prediction. } & \text { p.254 }\end{array}$

Weather prediction during the winter-summer and summer-winter
transitions. p.254

The role of migratory birds in predicting seasonal transitions. p.256

$\begin{array}{ll}\text { The end of summer and the autumn migration of cranes. p.258 } & \end{array}$

The end of winter, swallows' spring migration, and the 'bird winds'. p.262

$\begin{array}{ll}\text { Plants as signals of changing seasons. } & \text { p.267 }\end{array}$

\section{Appendix 4: Terrestrial and 'socio-maritime' functions of}

features of coastal topography.

Coastal settlements and natural indentations.

p. 268

Religious associations of headlands, islands, and straits.

p. 268

The military and naval significance of headlands, offshore islands, and straits. $\quad$ p. 272

The role of headlands in fishing.

The role of headlands and offshore islands in colonisation.

Notes.

Illustrations.

Geographical Indices.

Index Locorum.

Sources.

Bibliography.

Maps are contained within a pocket inside the back cover. 


\section{INTRODUCTION}

\section{The scope of the thesis.}

In essence, this thesis has been written as an investigation into the relationship between human activity in ancient Greece and the physical environment in which that activity took place. Clearly such a topic is far too large to be treated in its entirety as the subject of a $\mathrm{PhD}$, and this thesis in effect constitutes a 'case study', focusing on ancient Greek seafaring and its physical environment.

My original intention was to submit a thesis investigating similarities between various coastal sanctuaries of Poseidon which appeared to share a number of common characteristics in addition to their patron deity: principal among these characteristics were their topographic locations, dedications apparently related to maritime activities, and certain mythological themes. Topographic location concerned not simply the coastal site, but more specifically a position on a headland at the tip of a promontory. The mythological themes in question related to maritime activity, and particularly either to death by drowning or to survival from such a fate - e.g. the death and burial of Menelaos' steersman Phrontis at Sounion (Hom.Od.3.278), and Arion of Methymna's miraculous dolphin-aided escape from drowning and return to land at Tainaron (Hdt.1.23; fig.57). Maritime dedications at these sanctuaries seemed to suggest that the mythological traditions and topographical positions of the sanctuaries were linked in a manner relating to the fears and concerns of mariners in these areas. Of related interest were many other coastal sanctuaries of Poseidon, and also other headlands, often the sites of sanctuaries of other deities, where tradition preserves myths concerning drowning and other maritime concerns - e.g. Nisos' daughter Skylla, drowned by Minos and washed ashore at Cape Skyllaion in the Argolic peninsula (Paus.2.34.7, Str.Geog.8.6.12f.), and Britomartis' journey from Crete to the site of the sanctuary of Aphaia on Aigina (Paus.2.30.3) (for these sites, see fig.1).

One of my basic concerns in this study, and probably the most fundamental, was to investigate the significance of headlands in ancient Greek seafaring, in an attempt to 
explain the position of these sanctuaries and the maritime themes seen in their mythology and dedications. As this investigation proceeded, it quickly became apparent that the maritime significance of different topographical features of the coast was strongly reflected not only in the position of sanctuaries on headlands, but also in those of sanctuaries in other typical coastal positions, along straits and on offshore islands, as well as at harbours. This study of the significance of coastal topography in ancient seafaring, originally intended as a preliminary to a discussion of sanctuaries of Poseidon, is now presented as effectively the subject of this entire thesis. The religious and other terrestrial and 'socio-maritime' functions of different features of coastal topography are still discussed within this thesis (app.4), but only to the extent that they in some way reflect upon seafaring and navigational practices.

It should be noted immediately that, as an influential factor in ancient Greek seafaring, coastal topography is inseparably linked to other aspects of the physical environment that had a fundamental influence upon the practices of ancient Greek seafarers. Thus although the coastal topography of the mainland and islands of ancient Greece originated in massive geological upheavals, it has been significantly affected by the sea through marine erosion. Again, coastal topography has such an important effect on the oceanographic and meteorological phenomena occurring within its vicinity that to a large extent its influence on ancient Greek seafaring can only be fully understood in terms of oceanography and meteorology. Thus, in general, the significance of coastal topography in ancient Greek seafaring can only properly be understood by reference to the geology, meteorology and oceanography of Greece as a whole, for these are the factors which determine the relative 'character', in seafaring terms, of different topographical features of the coast and indeed of the open seas. For this reason, the subject of this thesis is taken to be the whole physical environment of ancient Greek seafaring, including sea-animals and birds, and man-made coastal structures existing within that environment, to the extent that these provided ancient Greek mariners with clues and information that helped them to better understand their seafaring world. 
It is clear that the physical environment had an enormous influence upon seafaring in ancient Greece, not only because any human activity is to a greater or lesser extent influenced by all aspects of its environment, but because the technology available to ancient Greek seafarers was limited: apart from their various types of vessels, which themselves were in many ways rudimentary, almost the only piece of technological equipment available to mariners was the sounding lead and line, by which the depth of water in coastal areas could be measured. Seafaring therefore was intimately tied to the physical environment, which always had to be respected, accounted for, and exploited wherever possible ${ }^{1}$. This was particularly the case in navigation, where the compass remained unknown throughout antiquity. However, because of this relationship between the technological resources involved in any activity and the influence of the physical environment upon that activity, which might be described as being inversely proportional, it has also been necessary to take these technological considerations into account. The main consideration here is the extent to which the performance capabilities of ancient Greek ships brought their crews freedom from the influence of dominant aspects of the physical environment such as prevailing wind and current patterns, and periods of dangerously severe weather. Having said that, a far larger part of this thesis has to address issues which are either related to the very lack of available technology, or unconnected to any technological considerations: examples of the first type include how ancient Greek seafarers navigated, predicted weather, and identified and avoided approaching hazards without any technological help, while examples of the second type include ways in which mariners exploited their physical environment to their own advantage, and ways in which the physical environment influenced seafaring neither 'positively' nor 'negatively', but merely by distinguishing seafaring in ancient Greece from seafaring in other localities and in other ages.

For reasons which are logistical as well as academic, I have limited the detailed discussion of the physical environment of ancient Greek seafaring, which appears in chapter one, to mainland Greece, the Aegean and its coasts, the Ionian and Adriatic Seas and the islands therein, and the Bosporos/Hellespont breach which connects the Aegean to the Black Sea. Of course it would never have been possible to write this 
thesis without also discussing other areas to which the ancient Greeks regularly sailed - particularly the Black Sea, Italy and Sicily, and parts of northern Africa, and it is hoped that reference to the entries for these areas in the geographical index will partly compensate for the lack of space devoted specifically to a description of their physical environment.

I have also elected not to impose strict chronological limits to the subject of this thesis, apart from that implicit in the term 'ancient Greek seafaring'. The principal reason for this is the relative lack of development or change in either the physical environment or maritime technology during the whole period from the reformation of the Greek world in the Dark Age to the Hellenistic period, and to a lesser extent on into the Roman Empire ${ }^{2}$. While the geographical horizons of Greek mariners did expand during this time, the Mediterranean physical environment in which they by and large operated remained to all intents and purposes unchanged. Where there are technological developments, i.e. in changing ship types and in the development of artificial harbour-works, I have endeavoured to take these into account to whatever extent they had a significant effect of the ancient Greek seafarer's relationship with his physical environment. An advantage to maintaining a broad chronological range has been that a wider range of evidence has been available than would otherwise have been the case, and this is especially important in an area of study where directly relevant primary evidence is in short supply. A brief survey of the index locorum will show that many of the principle sources of literary evidence come from classical and pre-classical Greece (especially Herodotos, Homer, Thucydides), but that some from the Hellenistic period (Anthologia Palatina (a collection of authors from all periods of antiquity, but principally Hellenistic), Apollonius of Rhodes' Argonautica, Aratos' Phaenomena) and even the Roman era (particularly Strabo's Geography) have also proved to be particularly illuminating ${ }^{3}$.

It is also important to point out that while topics such as the physical environment, the nature and performance of ancient ships, and sailing routes in the ancient Mediterranean are all of fundamental significance to this thesis, none of these are in 
themselves the subject of the thesis, nor even of much of the new and independent research contained within the thesis. Instead, this thesis is offered as an interdisciplinary study exploring the relationships between these aspects of the environment, of technology, and of human activity. Particularly in the cases of the physical environment and of maritime technology, the descriptive discussion within the thesis is largely built up from research and discussion already published by scientists, archaeologists, and historians (\#s 1 and 3 in 'Sources of evidence' below), with my own input being primarily concerned with the depth and extent to which different aspects of these issues have had initially to be discussed for the purposes of this thesis. My own independent research and analytical discussion has focused mainly upon primary geographical, archaeological, and particularly literary evidence concerning seafaring in ancient Greece (\#s 2 and 4 in 'Sources of evidence' below), interpreting this in the light of current knowledge regarding the physical environment and ancient maritime technology.

Notes and references will make it clear to the reader that many of the individual observations and points made in this thesis, particularly in chapter two, have similarly been discussed by earlier classical archaeologists, ancient historians, and particularly historical geographers such as Cary, Semple, and Rouge (i.e. \#3 in 'Sources of evidence' below). However, it should also be clear that a) in most cases these earlier studies have not been concerned with the underlying geological, meteorological, and oceanographic principles which resulted in the natural environment having such an important influence upon seafaring in ancient Greece, and b) that none of these works constitutes a comprehensive study of the relationship (in ancient seafaring) between physical environment and human activity in the way that this thesis attempts to: rather, these earlier works concentrate on specific details of, for example, ship construction, or sailing and trade routes, or historical events, or the seafarers themselves, in which geography appears as an informative background; in the present study, these roles are reversed, with specific ship types, trade routes, historical events, seafarers, and the 
like being discussed only insofar as they inform us about the relationship between the physical environment and human activity.

Many other points in this thesis, on the other hand, have received only passing mention, or none at all, in earlier historians' works. One such topic is 'coastal seafaring'. Many ancient historians have put forward their opinions as to whether ancient Greek sailors 'hugged the coast', but very few attempts have been made actually to define rather vague terms such as 'coastal seafaring' and 'hugging the coast', nor to define anything but the most simplistic ways in which 'coastal sailing' may be distinguished from 'open-sea sailing'. Similarly I have attempted to investigate many other points more fully than has been done heretofore, such as the use of landmarks in inshore navigation, and the extent to which some forms of (weather) prophecy according to animal behaviour may be based upon sound zoological observation as opposed to superstitious belief. Another significant difference between this thesis and earlier historical studies is that comparatively recent developments in our understanding of the physical processes by which today's seas and continents came into being (e.g. plate tectonics), and by which the activity of the seas and the winds are regulated (e.g. turbulence in restricted areas of water and wind), have here been introduced into the discussion.

\section{The extent of change in the physical environment since antiquity.}

One further point must be made before going on to discuss the sources of evidence used in this thesis. This concerns the extent to which the physical environment of Greece has altered between ancient times and the present day. So many of the more striking aspects of the physical environment referred to in ancient sources remain prominent features of today's physical environment - the high degree of coastal indentation, the prevalence of northeasterly winds (ancient Etesians, modern Meltemi) and clear skies during summer, the fierceness of Aegean squalls, the refluent currents of the Euripos, for example - that classical historians and archaeologists have long assumed that most aspects of the physical environment, particularly its climate and weather, have not changed since significantly ancient times, as McCaslin has noted ${ }^{4}$. 
In respect of climate and weather, this assumption has fairly recently been shown to be justified by Murray's analysis and comparison of modern and ancient winds in the Mediterranean (Murray (1987)). He reaches the conclusion that there has been no overall change in the meteorological conditions of the Mediterranean as a whole, and only slight ones, if any, in the local wind and climate conditions affecting particular areas of the Mediterranean, so that "we are fully justified, therefore, in applying modern wind data to the problems of classical antiquity." 5 . The climate may have been slightly cooler and wetter during the first millennium BC, but not to such an extent that meteorological conditions were fundamentally different in any significant way ${ }^{6}$.

As for sea conditions, we can also be confident that there has been little change in the Mediterranean since antiquity. Locally, the state of the sea, particularly its waves and currents, are heavily dependent upon the prevailing winds, and as these remain unchanged, so their effect upon the sea will also have remained the same. For the Mediterranean as a whole, the circulation of currents is dependent upon the overall influx of water from the Black Sea (through the Hellespont), the Atlantic Ocean (through the Strait of Gibraltar), and river mouths: Pryor has noted that the amount of water entering the Mediterranean through rivers has probably decreased since ancient times, due to the heavier demands now put upon rivers before they reach the sea, but also that this difference would have no significant effect upon the inflow of waters through the Hellespont and Strait of Gibraltar, nor therefore upon the circulation of currents in the Mediterranean as a whole ${ }^{7}$.

Coastal topography seems to be the area of the physical environment most likely to have undergone notable changes since ancient times. During the present epoch, overall sea levels have risen roughly one metre per millennium, so that sea levels may have been two to three metres lower during the first millennium BC than they are now. At a local level, this has led to some significant topographical changes, such as the conversion of Onougnathos, near the southeast tip of the Peloponnese, from a headland to an offshore island, the peninsula connecting the headland to the Malea promontory having been inundated by the sea (fig. 61$)^{8}$. Tectonic activity - 
earthquakes, landslips, etc. - has in some places lowered the coastline further still in relation to sea level, while elsewhere the result has been to uplift the coastline relative to sea level ${ }^{9}$. Sediment carried by rivers from the hinterland and then deposited on the sea floor at the river mouths has also led to the natural reclamation of land from the sea, especially where large rivers lead into relatively narrow sheltered bays where the sediments settle easily, e.g. at the mouth of the Axios (mod. Vardar) in the Thermaic Gulf at the northwest corner of the Aegean, and at the mouths of the rivers Cayster and Maeander in Asia Minor, where once coastal cities, such as Ephesos, now stand some miles from the coast (fig. 2$)^{10}$. So too natural marine erosion of the coast has slowly but continually progressed, so that coastal features typically associated with marine erosion will now be more highly developed.

However, nothing fundamental has changed about the overall topographical nature of the coastline in Greece. The topographical character of large stretches of coastline is unchanged, and the types of topographical features we encounter on these coasts remain exactly the same ${ }^{11}$; it is only in the form of specific individual topographical features that change has notably occurred, and as we are, in this thesis, concerned primarily with the types of topographic features that mariners encountered at different points along the coasts and islands of Greece, this does not present us with serious problems. Firm conclusions can still be reached regarding the general character, in relation to seafaring, of specific long stretches of coast, and regarding the significance, again in relation to seafaring, of the types of topographic feature commonly encountered along Greek coasts. It is only when dealing with individual named sites that we need to be careful: where a feature of today's Greek coastline is cited as an example or illustration of the type of topographic feature typically found on the ancient coastline, it is important only to ensure that the example or illustration is a fitting one; however, where we are discussing a specific topographic feature of the ancient coast, it is important not to assume that the form and appearance of that feature remains the same today as it did in antiquity, and care must be taken in using the evidence of the modern coastline to draw conclusions regarding the state of that same part of the coast in ancient times. 
These problems need present little difficulty: they have been circumvented here by greatly limiting discussion of specific features of the coast to those a) which are known, from ancient sources, to have maintained essentially the same form since ancient times, or b) which are known to have changed only by an insignificant degree. By 'essentially the same form; and 'an insignificant degree', I mean to indicate areas where no changes have occurred that would have made a practical difference to the significance of that coastal feature to an ancient mariner: thus, where a rocky headland has been eroded back a few more metres since antiquity, but the erosion features on that headland remain of the same type, I do not consider any significant change to have taken place. Likewise where cliffs tens or even hundreds of metres high have effectively been slightly foreshortened by the c. $2 \mathrm{~m}$. rise in sea level, this clearly has had no meaningful impact upon the topographic significance of those cliffs. In the case of uplift and submergence, it is very often the case that the contours or outline of the coast remains unchanged, with bays just becoming slightly deeper or shallower, headlands rising slightly more or less out of the water, etc. ${ }^{12}$ : again this only involves a significant change where, for example, access for ships to shelter in such a bay has been cut off, or alternatively opened up for the first time. Where significant changes have occurred in specific coastal features discussed in this thesis, I have endeavoured to indicate and account for these changes in the text or the notes. Otherwise, evidence concerning the modern physical environment of the Mediterranean has been taken to be equally applicable to the ancient world.

\section{Sources of evidence and information.}

This thesis is based upon four main sources of evidence and information ${ }^{13}$ :

1. Modern scientific and geographic treatises on geology, erosion, oceanography, meteorology, and other aspects of the physical environment and processes, combined with other modern works dealing with these topics with specific reference to the Mediterranean region, and particularly those areas inhabited by the ancient Greeks. 
2. A wide range of source material, particularly ancient literature, that has been independently analysed and appraised by the author. Often this has resulted in the discussion of passages, and even of some authors, not previously dealt with in studies of ancient seafaring and geography, but there are also many cases of new or more developed interpretations of passages previously discussed by authors of works included in section 3 below.

3. Modern studies, based upon ancient sources and archaeological evidence, concerning seafaring and the natural environment in ancient Greece, including studies of ancient ships. The capabilities and seaworthiness of ancient Greek ships are matters which are clearly relevant in considering the problems which the environment posed to ancient mariners, and opinions are accordingly expressed on these, particularly in Appendix 2.

It should be stressed however that these cannot be offered as being definitive. Modern opinion is divided on a number of issues, in some respects perhaps irremediably so. Often this is largely due to the nature of the evidence: reconstructions based on archaeological evidence rarely lead to conclusions entirely in agreement with those drawn from analyses of ancient literary descriptions of ships at sea, which themselves often seem contradictory. In the case of some issues of considerable interest, we are confronted by a basic lack of evidence on both the archaeological and literary fronts. This being so, it was apparent that knowledge of ship capabilities and seaworthiness could not offer a secure starting point for the present study, and that the investigation of scientific data on environmental conditions would form a sounder foundation on which to base the research. This accorded with my aim of investigating ancient seafaring from an environmental perspective, and although opinions regarding ancient ships clearly remained relevant to the study, care was taken not to place undue weight on such views.

4. Fieldwork conducted in Greece, principally involving investigation of a large number of coastal sites of archaeological, historical, geological, oceanographic, and/or 
meteorological significance. Photographs taken at these sites constitute a large proportion of the illustrations to this thesis.

\section{Maps, indices, and transliteration.}

The perspective from which this thesis has been written means that individual locations and literary sources are not fully investigated at one single point, but may be discussed at various different points throughout the thesis, geographical and literary indices have been included to allow reader quickly to gather together all references to any particular location. Also, because stress is often placed upon the geographical relation of one location to another, a series of twelve maps has been included.

While the English spelling of Greek personal names, especially those of ancient authors, has generally followed commonly recognised forms, it seemed more important in this thesis to standardise more formally the transliteration of ancient and modern place names. For this reason most Greek names for places, winds, etc. have been transliterated in accordance with Gleichen and Reynolds (1951) pp.52-6; generally, exceptions have only been made where a markedly different spelling is so common that a name might go unrecognised if transliterated under this system. Thus Brundisium is preferred to Brentesion, Cyaneae to Kuaneai, Piraeus to Peiraieus, Scamander to Skamandros, Syracuse to Surakousai, etc. 


\section{CHAPTER ONE.}

\section{THE PHYSICAL ENVIRONMENT OF ANCIENT GREEK SEAFARING.}

\section{Introduction.}

It is well known that much of the Greek coastline is highly indented and characterised by its alternating headlands and inlets, and that the seas around Greece contain many larger and smaller rocky islands (fig. 3$)^{14}$. Such a coastal and marine topography is largely the product of considerable folding, faulting, crustal movement and submergence which has affected Greece in the past, and which continues to a lesser extent today ${ }^{15}$. In its turn, this highly distinctive form of coastline has a great effect upon the meteorological and oceanographic conditions in its vicinity. The purpose of this chapter is to examine the geology, topography, oceanography, and meteorology of the Greek coasts, islands, and seas, and thus to provide a firm basis from which to interpret the role of the physical environment in ancient Greek seafaring.

\section{THE DEVELOPMENT OF THE GREEK COASTLINE.}

\section{The geological formation of the Greek coastline (fig.3).}

The Mediterranean Sea occupies a depression between the continental masses of Africa and Eurasia. It was formed during the Tertiary period from a much larger expanse of water, the Tethys Sea, as the African shield gradually moved northwards, thrusting up and buckling the accumulated sediments on the sea-floor to form mountains. This process, known as the Alpine orogeny, was the most recent significant period of mountain-building in the Mediterranean area, and it was during this period that the major rock formations of Greece were laid down in successive ranges running in a NW-SE direction, the youngest of which formed the Ionian islands off the west coast of Greece ${ }^{16}$. Subsequently, however, extensive faulting caused major upheavals in the mountains of Greece, with some sections being thrust up as 
long chains of peaks or as individual "horsts", and others sinking to form deep 'rift' valleys between the raised heights ${ }^{17}$ (fig.4.i). In this way a system of mountain chains, ridges and valleys developed, which was then partially submerged, owing to a combination of land subsidence and rising sea levels after the end of the last ice age ${ }^{18}$. The ancient Greeks were certainly aware that their homeland had had such a turbulent history, but not surprisingly they never fully explained the geological developments involved. Nevertheless, some evidence was available, such as the marine material and whole beaches which were clearly to be seen at considerable heights above sea level. Scholars such as Eratosthenes quite rightly sought to explain these features as originating in a period when the sea level was higher in relation to the land masses: in Strabo's account of the views of earlier geographers (including Eratosthenes), the accretion of sediments on the sea floor is even put forward as the main cause of such changes in sea level, although the role of such sediments is misunderstood. In particular, only the possibility that the sea had risen, even if as a result of movements of the sea bed, was considered; there is little discussion of the theory that whole land masses could be elevated or depressed as a result of geological and tectonic forces ${ }^{19}$.

These geological and tectonic upheavals resulted in the general form of the Greek coastline as we now know it, with mountain ridges remaining above water in the form of elongated promontories, their slopes running straight down to the sea, and often continuing under the water as steeply shelving sea-beds. The rift valleys have been partially or totally submerged, forming the deep bays separating these promontories. The west coast of Asia Minor is very similar to that of mainland Greece in these respects $^{20}$. In the same period, the area of the Aegean was almost totally submerged, with only the mountain tops remaining above water in the form of the Cyclades and other Aegean islands (fig. 3$)^{21}$.

Submergence, in effect the inundation of the land by the sea, has thus had a very large impact on the form and outline of Greece and the Aegean and its coasts. Again, while lacking a proper understanding of the underlying geological principles, the Greeks recognised this significance of the sea: in describing the general outline of southern 
Europe, for example, Strabo followed many previous geographers in describing a general land mass from which a number of peninsulas (Iberia, Italy, Greece, etc.) protruded southwards into the Mediterranean $\mathrm{Sea}^{22}$; concerning Greece in particular Strabo is more explicit:

'It is the sea that mostly delineates and gives shape to the land, creating bays and seas and straits, and likewise isthmuses and peninsulas and promontories. Both the mountains and the rivers also have a part in this, for through such things the land masses, nations, favourable positions of cities, and the other various features of which our geographical map is full, are comprehended.' (Str.Geog.2.5.17: compare Geog.8.1.3, quoted below, p.167)

Following the general orientation of Greece as a whole, there is a repetitive NW-SE trend in the orientation of most of the mountainous blocks and major fault lines that run through Greece and the Aegean ${ }^{23}$. Such orientation can be seen, for instance, in the mountain ranges and intervening valleys of the southern Peloponnese. To the east the depressed Eurotas valley, Plain of Helos, and Lakonian Gulf separate Taygetos from the elevated Parnon range. To the west the valley of Messenia and the Messenian Gulf separate Taygetos from Aigaleon, Ithome and the other heights forming the southern extremity of the westernmost, and most recent, mountain chains on mainland Greece, which stretch northwest as far as Epeiros and Dalmatia ${ }^{24}$. Similar progressions of ridges and depressions can be identified throughout Greece; here is Strabo on Boiotia:

'The next plains in order, in the interior, are hollows enclosed from all other quarters [i.e. other than from the direction of the sea] by mountains, with those of Attica to the south, and those of Phokis to the north. And from the west, a little above the Krisaian Sea, Kithairon falls across...' (Str.Geog.9.2.15)

Strabo describes the faulted nature of the landscape, if unknowingly, when he speaks of "hollows" which are surrounded on all sides apart form the coast by mountains. This is an accurate description of the rift valley which undergoes depression while the surrounding land remains at its original elevation. 
One effect of the profound faulting in the Greek mountains, and of its general NW-SE alignment, is that on the Greek coastline major promontories tend to point $\mathrm{SE}^{25}$, and to be roughly aligned with their neighbours, from which they are separated by deep gulfs. Thus the southern Peloponnese, delineating the SE face of all peninsular Greece, is particularly heavily indented, with the Akritas, Tainaron, and Malea promontories and the Argolic peninsula separated by the deep Gulfs of Messenia, Lakonia and Argos (map 9), as is commented upon by pseudo-Scymnus:

'The Peloponnese lies next, with deep gulfs and many promontories; Malea, the greatest, and the one called Tainaron.' (ps-Scymn.Perieg.511)

The promontories and intervening bays of the Chalkidike, on the north coast of the Aegean, form another clear example (map 5).

On the other hand, sections of coast facing NE or SW tend to present far more uniform fronts, often following the line of a mountainous ridge forming part of a NWSE orientated block, or lying on a similarly orientated fault line, the land on one side of which has undergone submergence ${ }^{26}$. Thus the east coast of the Peloponnese, along the line of the Parnon range, is relatively straight, cliff-bound and almost harbourless (map 9), as are the coast of Epeiros and the NE coasts of Thessaly and Euboia (map $7)^{27}$. Thus Strabo refers to the straightness and northwesterly strike of the coast from Sounion to Thessalonikeia:

'We were talking about how the coast from Sounion to Thessalonikeia stretches northwards, inclining a little to the west, and having the sea to the east.' (Str.Geog.9.2.1)

Herodotos completes the description in a passage in which he implicitly remarks upon the lack of harbours along the coast southeast of Thessalonikeia. Here Xerxes is addressed by his uncle Artabanus at the Hellespont, before his fleet sets off to sail round the north and east coasts of the Aegean:

'In all the wide sea there is not, I imagine, a harbour large enough to receive your vessels in case a storm arise, and can afford them a sure 
protection. And yet you will want not one such harbour only, but many in succession along the whole coast by which you are about to make your advance. In default then of such harbours it is well to bear in mind that chances rule men and not men chances.' (Hdt.7.49)

The speech is clearly designed with hindsight by Herodotos, as part of an attempt to show that the destruction of the Persian fleet in a storm, while moored offshore near Cape Sepias on the Thessalian coast (Hdt.7.188f.), was divine retribution for the earlier arrogance and hubris of Xerxes, who had, amongst other follies, ignored both the danger and the gods of the sea from the very start of his invasion of Europe ${ }^{28}$. Therefore, while Artabanus speaks of the lack of harbours along the whole coast by which Xerxes will advance, we may assume that Herodotos is implicitly and particularly referring to the lack of harbours on the Thessalian seaboard, where the Persian fleet would subsequently be destroyed. On the west coast of Asia Minor, the mountainous blocks and fault patterns have a predominantly E-W orientation, so that the promontories also generally run out westwards, while north and south facing coasts tend to be less indented ${ }^{29}$.

\section{Erosion and the formation of local coastal topographies.}

While these regional geological factors determine the general outline of Greece, and of the islands and coasts of the Aegean, local geological factors also have to be taken into account. Of overwhelming importance here is the sedimentary origin and nature of most of the rock found in Greece, and of the preponderance of limestone and other calciferous rocks ${ }^{30}$. The susceptibility of such rocks to erosion has had a very significant effect on the form of the Greek coastline ${ }^{31}$.

Sedimentary rocks are usually stratified, as a consequence of having formed through successive accretions of layers, or strata of sediments on the sea bed ${ }^{32}$. The rock strata rarely retain their original horizontal positions, but become folded, twisted, and dipped (inclined at an angle to the horizontal) by tectonic activity ${ }^{33}$. These processes often leave belts of strata exposed at surface level, and thus open to erosion (figs.6, 7). The various strata are generally composed of different types of sedimentary rocks - limestone, sandstones, shales, or conglomerates, which differ in their resistance to 
erosion. Depending on their alignment and degree of exposure, these differences in the physical qualities of the strata can have a strong effect on the development of local geology and topography, especially in coastal areas. Tectonic disturbance, alongside the process of drying, also produces fault lines in sedimentary rocks called "joints", which generally lie at right angles to the stratification (figs.5, 8, 9). The erosion of sedimentary rock is greatly accelerated by water penetrating these joints and other such points of weakness (fig.20) ${ }^{34}$.

Erosion of the coast is primarily achieved by wave action, and proceeds most quickly against softer strata, joints, and other areas of weakness ${ }^{35}$. While Homer is familiar with many of the coastal features which result from marine erosion, he shows little, if any, understanding of the processes by which these features are produced. Later Greeks, however, clearly new of the principle of marine erosion:

'..... certain hollow in the broken cliff, rent asunder by the mighty rolling swell of the waves, a shelter for purple fishers.' (Eur.I.T.262f.)

'Priapos, who delights in the sea-worn ( $\dot{\alpha} \lambda \hat{\imath} \xi \alpha \vee \tau o \varsigma)$ rocks of this island near the coast, and in its rugged peak...' (Anth.Pal.6.89)

'A $\lambda \hat{i} \xi \alpha \vee \tau o \zeta$, derived from $\alpha \lambda \varepsilon \omega$ (to 'grind' or 'bruise'), clearly gives the sense of the rocks having been physically eroded by the action of the waves ${ }^{36}$.

The topographical features and coastal contours produced by erosion depend very much on the nature and condition of the rock being eroded. The thickness of the strata in the rock, the relative resistance of the different strata to erosion, the frequency of joints, the angle of dip, and the orientation of the joints and faults relative to the general orientation of the coastline all strongly influence the developed form of the eroded coastline. In general the fact that softer strata are more rapidly and intensely eroded from the sea than the harder strata leads to developed indentation of the coast ${ }^{37}$. 


\section{Headlands and Bays.}

Where the strata are set at an angle to the coast (transverse or discordant, as opposed to longitudinal/concordant), or alternatively where a number of different rock types are interspersed, the softer rock will be eroded, eventually forming hollowed-out inlets or bays, while the harder rock endures as headlands (figs.11, 12) ${ }^{38}$. Indentations also develop where joints and fissures in the rock face are not only eroded by seawater, but also expand as a result of immense pressures generated when pockets of air are trapped in them by breaking waves ${ }^{39}$. The size of inlets produced depends on the thickness of the strata, the relative resistance to erosion of the harder and softer strata, and the frequency and alignment of the joint ${ }^{40}$, but the general result is a series of smaller headlands and indentations (fig.8) which, along with those preserving the natural contours of submerged mountain slopes, line the shores of the major regional features of the Greek coastline described above. It is not uncommon for fairly long stretches of coastline to consist entirely of such alternating headlands and bays, as at the southern end of Euboia, an area fittingly known to the ancient Greeks as the 'Hollows of Euboia' because of its progressions of indentations (fig. 13) ${ }^{41}$.

\section{Caves and related features.}

Where the strata are narrower, or the joints closer together, the general face of the coastline is often preserved, with the points of weakness being hollowed out at sea level to form marine caves (figs.6, 20) ${ }^{42}$. This tendency is strongest in areas where the strata are dipped at steep angles ${ }^{43}$, and progressions of such marine caves are again fairly common features of Greek coasts, as, for example, the coast of the Tainaron peninsula in the southern Peloponnese (fig.7). The Greeks were familiar with the formation of such caves through erosion by the waves, as is clear from another passage in the Anthologia Palatina:

'Hermes, who dwells in this wave-beaten hollowed-out cave

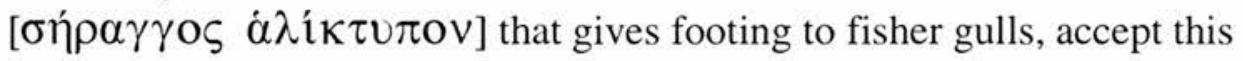
fragment of the great seine worn by the sea and scraped often by the rough beach.' (Anth.Pal.6.23) 
The term ' $\sigma \bar{\eta} \rho \alpha \gamma \xi$ ' on its own denotes a cave produced through erosion by the sea, being derived from $\sigma \alpha i \rho \omega$, 'to sweep away', and in turn giving the derivative

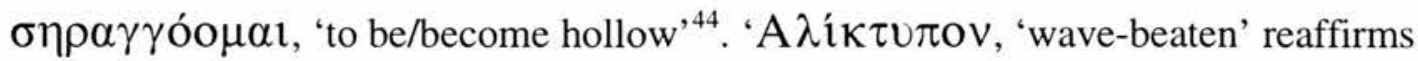
the sea as the agent of erosion.

Quintus of Smyrna describes the erosion of coastal caves in more detail, correctly marking the tendency for such caves to be formed from weak points at sea level in cliffs which otherwise are comparatively resistant to erosion:

'And his groaning never died down, on account of his ulcerous black wound, which reached right to the bone, festering on the upper side, and with baneful pains eating away from below. Just as when, on an overhanging crag in a heavily breaking sea, a steep rock is inundated by the sea and heavily undercut despite its resilience, and as it is struck by the wind and the furious wintry storm, clefts are hollowed out, being eaten away from below by the sea, thus did the festering wound spread from under his foot.' (Quintus Smyrnaeus, Fall of Troy 9.374-384)

As promontories narrow towards the headlands at their extremities, it becomes progressively easier for waves to erode such caves right through from one side of the promontory to the other, producing a wave-tunnel. As erosion proceeds, the wavetunnel becomes an arch, and the roof of the arch may eventually collapse, leaving a new foreshortened headland fronted by one or more islets, stacks or pinnacles (fig.6) ${ }^{45}$. Stacks may also be formed directly, with no intermediate cave or arch, through erosion of joints or fault lines which cut right across headlands, and which therefore can be attacked on both sides of the promontory simultaneously (fig.14) ${ }^{46}$. Strabo again shows considerable insight into, or at least interest in the origins of such inshore islets, and he correctly sees many of them as originally having been part of the mainland. Here he is discussing the geography of Italy, but his remarks could be equally well suited to the coastlands, particularly the headlands, of Greece:

'And in fact Prochyte and Pithekoussai are detached fragments of the mainland, as are Kapreai, Leukosia, the Sirens, and the Oinotrides.....It is more plausible that those islands out in the open sea rose up from the deep, whereas it is more reasonable to consider those lying off a headland 
and separated from the mainland merely by a strait to have been broken away from there.' (Str.Geog.6.1.6)

\section{Cliffs.}

Most cliffs which lie on faulted coasts came into existence when the local fault line initially appeared, with the land on one side slipping, or the land on the other side rising, or both, creating a vertical or near-vertical interface between the two areas ${ }^{47}$ (fig.4.ii). The difference in height between the land on either side of a fault line can be very large, and the transition from one to the other very abrupt. After submergence, the resulting sea-cliffs may rise to great heights and plunge directly into deep water, depending on the severity of the fault and the degree of submergence which has occurred $^{48}$. As noted above, much of the contour of the Greek coastline, whether smooth or indented, is the result of the submergence of rock formations which exhibit strong faulting, and therefore such steep cliffs plunging into deep water, often affected by subsequent erosion, are not uncommon around Greek shores (fig.15). Images of such cliffs abound in Greek literature: here Homer describes the coast of Scheria, where Odysseus has somehow to make landfall:

'Nowhere doth there appear a way to come forth from the grey sea. For without are sharp crags, and around them, the wave roars foaming, and the rock runs up sheer, and the water is deep close in shore, so that in no wise is it possible to plant both feet firmly and escape ruin.'

(Hom.Od.5.410-4)

High cliffs are particularly prominent around Samothrace, Leukas (fig.20), Euboia, Thessaly and the Hellespont. Cliffs plunging immediately to deep waters are found in the Aegean, e.g. at Samos, but are particularly associated with the southern and western coasts of the Peloponnese, the Ionian islands, and the west coast of Greece (intermittently) as far north as Dalmatia, as these areas border on that area of the Mediterranean where the deepest soundings are found, descending to over $4000 \mathrm{~m} .{ }^{49}$. The deepest coastal soundings tend to be found off faulted headlands ${ }^{50}$. 
Cliffs may also be formed on coasts which do not lie on fault lines, but came into existence through submergence. Where the rock is largely homogeneous and has relatively few indentations, very long stretches of cliff-bound coast can be produced as a direct result of wave action continually foreshortening a coastline which originally sloped down to the sea $^{51}$ (fig.16.ii). Along indented coastlines, rocky headlands, although not being worn away as quickly as the bays separating them, often feature such wave-cut cliffs (figs.17, 18). In Greece wave-cut cliffs are usually composed of limestone and other calciferous rocks, as these predominate in nearly all areas ${ }^{52}$.

However, cliffs which owe their origin to erosion by the waves rather than location on a fault line tend not to plunge directly into deep water. This is due to the fact the formation of the cliff face is the result of the erosion of the hill slopes along the coast. As in the erosion of marine caves, and related features (see above, p.23f.), erosion starts by at sea level, cutting a notch in the rock (figs.11, 19), and so undermining the rock above (see Quintus Smyrnaeus, Fall of Troy 9.374-384, quoted above, p.24). As erosion proceeds, the coastline recedes above water, while little significant erosion takes place below sea-level, preserving the submarine rock, and resulting in a rocky shelf just below sea level which stretches from the original line of the shore to the base of the eroded and continually retreating cliff-face ${ }^{53}$ (fig.16). Another contributory factor in this process is the gradual build up, in the coastal waters, of rocks and other material which has been eroded or broken away from the cliff face (figs.10, 12). Such rocky platforms at sea level can also be found along faulted cliff coasts, although they tend to be less developed in such areas because of their different mode of origin (figs.8, 16.i, 21). Homer again is familiar with such coastal features; witness, for example, the rocks and reefs he includes in his description of the coast of Scheria, part of which was quoted above. Here is the rest of the relevant passage:

'But when he was as far away as a man's voice carries when he shouts, and heard the boom of the sea against the reefs - for the great wave thundered against the dry land, belching upon it in terrible fashion, and all things were wrapped in the foam of the sea; for there were neither harbours where ships might ride, nor roadsteads, but projecting headlands and reefs and jagged rocks - then the knees of Odysseus were loosened and his heart melted.....' (Hom.Od.5.400-7) ${ }^{54}$ 
In stratified rock, the degree of inclination of the developed cliffs is related to the angle of dip of the strata, which also affects the degree of indentation in the cliffs (figs.7, $8,10,13)^{55}$.

\section{Natural Harbours.}

Where cliffs contain joints or other weak points susceptible to erosion, the resulting breaks in the cliffs are very often useless as harbours, forming instead caves or craggy inlets cut off from the interior, with entrances in very shallow, rocky water (figs.9, 13). This is particularly true of cliffs which lie along fault lines (fig.8) ${ }^{56}$. However, it is possible for well-protected coves to be produced through the erosion either of cliff faces, if the stratification is concordant with the coast ${ }^{57}$, or of other types of coast where softer materials appear sporadically amongst harder coastal rocks. In such places, if the waves penetrate through a joint, an area of soft material, or a gap (or local fault) in the hard rock of the coast, and reach softer rock behind, this weaker material tends then to be easily and extensively eroded to produce a natural harbour which is far more expansive than the narrow break in the cliffs which connects it to the open $\mathrm{sea}^{58}$. Such harbours often combine gentle slopes on the landward side (giving access to the hinterland) with sheltering cliff-walls on the seaward side (figs.11, 22, 23). In the Odyssey, Homer describes two such natural harbours, the first in the land of the Laestrygonians (located in Sicily according to later Greeks), the second in Ithaka:

'When we came there, into an admirable harbour, on both sides of which a precipitous cliff ran without a break, and projecting headlands jut out at the mouth, face to face with one another, so that the way in is narrow, then they all steered their curved ships in, and indeed the ships were moored close together inside the recessed harbour; for in fact no wave, neither large nor small, ever spread across it, but there was a glassy calm all around. But I alone kept my black ship outside, against the last point of land, tying the stern cables to a rock. Then I took position, going up to a high rugged look-out point.' (Hom.Od.10.87-97)

'There is in the land of Ithaka a certain harbour of Phorkys, the old man of the sea, and at its mouth two projecting headlands sheer to seaward, but sloping down on the side toward the harbour. These keep back the great waves raised by heavy winds without, but within the benched ships 
lie unmoored when they have reached the point of anchorage.' (Hom.Od.13.96ff.)

The first passage emphasises the presence of such a natural harbour in an area which is otherwise cliff-bound, not only in the direct reference to the enclosing cliffs, but also in the 'rugged height' which Odysseus takes advantage of as a lookout. In the second passage we have again steep cliff faces protecting the harbour to seaward, but also the more gently sloping terrain which surrounds the harbour itself.

\section{Offshore rocks and islands.}

Offshore rocks and islands are very common in Greek coastal waters. Many are clearly a result of the original emergence and later submergence which produced the Greek coastline as we now know it, but how frequently they appear in any one region depends upon whether the coastline in that region is concordant or discordant (see above, p.23), and also whether or not it lies along the line of a fault.

Faulted coastlines are the least likely to have associated offshore rocks and islands, as the depressed area on the seaward side of the fault line has generally been submerged far below sea level ${ }^{59}$. This is not to say that islands cannot originate in faulting (fig.4.iii) - Samothrace, Lesbos, Lemnos, and Thasos, for example, are surviving portions of an ancient block, the rest of which underwent submersion to become the northern Aegean Sea ${ }^{60}$. However there is no geological reason why such islands should generically tend to be close to the faulted coastline of the mainland; as noted above, plunging cliffs and deep water close in to the shore, rather than a fringe of islands in shallow water, are the characteristics of a fault coastline (figs. 15, 21).

Concordant coastlines may feature offshore islands strung out along the coast, formed by the ridges of mountain ranges which are otherwise completely submerged. The channels separating such islands from the mainland are formed through the submergence of intervening valleys ${ }^{61}$. The numerous islands of the Dalmatian coastline are obvious examples, being in fact the most recently formed folds of the mountain ranges of which peninsular Greece is comprised; the islands share the familiar NW-SE 
alignment of the mainland ranges. Further south, the Ionian islands, running from Corcyra southwards to Zakynthos, have similar origins (fig.3). Homer's description of Ithaka as one of the 'islands that slope down to the sea' which are more suitable for goats than for horses and chariots (Od.4.605f.) reflects the rocky and steeply sloping nature of such submerged mountain ridges ${ }^{62}$. On other concordant stretches of the Greek and Aegean coasts (e.g. Thessaly, NE Euboia), such islands are far rarer due to the predominance of fault coastlines. The erosion of concordant coastlines can result in rocky outcrops running parallel to the coast where harder strata have resisted erosion (see below).

Offshore rocks and islands are however most commonly associated with discordant coastlines, typified by their progressions of alternating headlands and bays. In particular, they are to be found extending out to sea from headlands, prolonging the line of the promontories (fig.26). Such rocks and islands may have been split off from the headlands through erosion (see figs.21, 25, and above, p.24f.), but many, especially the larger islands, are the result of submergence. The mountain ridges which form the promontories continue on beyond the headland as submarine ridges, and high points of land on these submerged mountain ridges may remain above water, as offshore islands in straits (fig.28) or off headlands, or just below sea level, as rocky shoals ${ }^{63}$. Thus various strings of Aegean islands, particularly in the Cyclades block (e.g. southern Euboia - Andros - Tenos - Mykonos), are in fact the peaks of drowned sections of folded mountains ranges which are structurally connected and continuous with the mountains of the mainland (figs. 3,27$)^{64}$. Again such offshore islands are more likely to be found off areas of coast which shelve gradually into the sea than off sections of fault coastline which immediately fall away to deep water. Onougnathos, off the east coast of Malea, is an example of a headland which has, since antiquity, become an island through submergence (fig.61).

In a passage which has already been partially quoted (above, p.24f.), Strabo shows some insight into the origins of offshore islands, and distinguishes between 'islands in the high seas' and 'islands separated from the mainland merely by a strait': 
'And in fact Prochyte and Pithekoussai are detached fragments of the mainland, as are Kapreai, Leukosia, the Sirens, and the Oinotrides. Yet, on the other hand there are islands which rose out of the sea, just as occurs even now in many places; for it is more plausible that those islands out in the open sea rose up from the deep, whereas it is more reasonable to consider those lying off a headland and separated from the mainland merely by a strait to have been broken away from there.' (Str.Geog.6.1.6)

The distinction made by Strabo between these two types of islands and their origins is significant, if rudimentary. While his idea of how islets can be broken away from the mainland is very undeveloped, the basic principle is correct, and he is right to associate such islets with promontories or headlands, with which they were indeed once connected. Likewise Strabo is justified in arguing that islands much further away from the coast cannot have been broken away from the mainland, but his claim that these islands came into being through emergence, rather than submergence, of which he seems ignorant, can only be sustained in the case of volcanic islands (on which see Str.Geog.1.3.16). Volcanic islands are not uncommon in the Aegean, particularly along the fault lines which lie between major tectonic zones. The clearest example of such a fault line runs southeast from the Saronic Gulf, skirts round the southern edge of the Cyclades, and then curves northwards towards the southeastern point of Asia Minor. Virtually all of the islands within this belt, including Aigina, the Methana peninsula, Kalauria (Poros), Melos, Kimolos, Thera (Santorini), Nisyros, and Telos, are wholly or partially of volcanic origin (fig. 3$)^{65}$.

As noted above, offshore rocks, and sometimes even small islands, may result from erosion as well as from submergence. This is most common in areas where the coast is composed mainly of relatively soft, easily erodable rocks, resulting in a gradually but continually receding shoreline. Outcrops or strata of harder rock which are more resistant to erosion will remain as offshore rocks (figs.8, 29), or as reefs stretching far out to sea, while the softer rock around them is worn away, as in the Chian strait separating Chios from Asia Minor (fig. 30$)^{66}$. 


\section{Deposition.}

Along coastlines, material can be deposited, as well as eroded, by the sea. Most deposited material originates in detritus brought down to the sea by rivers such as the Maeander, the Cayster, the Axios (mod. Vardar) and the Spercheios, with their evergrowing coastal plains (above, p.14, fig.2), and the Achelous, the mouth of which is fringed by a series of mud flats and spits (Thuc.2.102.2-5) ${ }^{67}$. Strabo explains Homer's erroneous statement (Od.4.354-7), spoken through the mouth of Menelaos, that the island of Pharos was in the open sea, a day's sailing from Egypt, by arguing that Homer knew that in Menelaos' time the island of Pharos must have been further from the coast than in his own day ${ }^{68}$. Whatever the accuracy of this argument, Homer's familiarity with the deposition of river-borne detritus is made clear in his account of Achilles' duel with the Scamander (see Hom.Il.21.316-323).

Deposition occurs not only around river mouths, but at any sheltered point on a coast which is subject to longshore drift. Longshore drift is the transportation of marine sediment along the coast by the nearshore currents which are produced when waves approach and strike the coast at an angle (see below p.41f. and n.104; fig.31). In sheltered areas - river mouths, bays, or any area particularly well-protected by a headland - these currents and waves are slowed and dissipated, and the sediments they carry are deposited on the sea floor, eventually building up to form such features as beaches, spits, bars, mud-flats, marshes, and lagoons (fig.36) ${ }^{69}$. One of the most extensive such area on Greek coastlands is along the western coast of the Peloponnese, south of Cape Ichthys in Eleia. Here the relative shelter from winds and currents found along the concave coast below the headland promote deposition of sediments, some of which are carried down from the Alpheios and other rivers in the vicinity, the rest being a by-product of the erosion of the relatively soft sedimentary rocks in the area, intensified by heavy rainfall ${ }^{70}$. Long beaches, shoals, and bars are the result: these have also produced lagoons and mud-flats by cutting off areas of water from the sea (figs.18, 33) ${ }^{71}$. The surface contours of banks of deposited sediment are subject to periodic change, relative to fluctuations in local climatic conditions (fig.53) ${ }^{72}$. Here Strabo discusses some prominent areas of deposition in Greece where 
land forms have changed, mainly through the linking of islands to the mainland by a spit, which in this position is known as a "tombolo" ${ }^{, 73}$ :

'And as for the Piraeus, it was because the Piraeus was formerly an island and lay 'over against' $[\pi \varepsilon \rho \alpha \nu]$ the mainland, they say, that it got the name it has; but contrariwise Leukas, since the Corinthians cut a canal through the isthmus, has become an island, though it was formerly a headland. Here then a partition cut by hand has been made....And too one of the Echinades islands, which used to be called Artemita, has become part of the continent; and they say that still others of the little islands about the mouth of the Achelous have suffered the same change from the silting up of the sea by the river: and the rest of them too, as Herodotos says [Hdt.2.10] are in the process of fusion with the continent. Again there are certain Aitolian promontories which were formerly islands....Antissa was formerly an island, as Myrsilus says; and since Lesbos was formerly called Issa, it came about that this island was called Antissa; but now Antissa is a city of Lesbos. ${ }^{, 74}$ (Str.Geog.1.3.18f. (parts))

Where coastal currents meet or are diffused, deposition may result in the formation of a low sandy promontory, or a spit or a chain of low sandy islands leading off from the headland of an existing promontory. Such features can be seen, for example, in Cape Drepanon in the northwest Peloponnese, Cape Posidhi on the west coast of the Chalkidike (ancient 'Poseidonion': fig.53), Cape Kenaion, the northwest point of Euboia (fig.34), where the deposited material comes mainly from the outlet of the Spercheios river on the mainland opposite, or in the tongues of low land stretching out from the headlands of Achaia on the north coast of the Peloponnese, formed by river silt, and accordingly called 'taeniae' by the ancient Greeks ${ }^{75}$. 


\section{OCEANOGRAPHIC CONDITIONS NEAR THE GREEK COASTS.}

\section{Wave formation.}

Waves are primarily generated by the action of the wind on the surface of the sea, and, if unobstructed, travel in the same direction as the wind which produces them, gaining strength and height as long as the wind continues in the same direction ${ }^{76}$. This was common knowledge in ancient Greece, and is referred to many times by Homer in his metaphorical descriptions of scenes from the Trojan $\mathrm{War}^{77}$ :

'And as when a great billow of the broad-waved sea sweeps down over the bulwarks of a ship, whenso it is driven on by the might of the wind, which above all makes the waves swell; even so did the Trojans with a great cry rush down over the wall.' (Hom.Il.15.381-4)

Herodotos also shows familiarity with the process in this passage, where Artabanus addresses Xerxes:

'..even as the sea, who is of all creatures the most serviceable to man, is hindered (they say) from following his natural bent, by the blasts of winds that fall upon him.' (Hdt.7.16)

In open water, the direction in which waves advance will be maintained even if the wind which originally produced them changes direction, in which case a second body of waves, travelling in a different direction from the first, may be produced ${ }^{78}$. Such a crossing of two bodies of wind-generated waves travelling in different directions through the same waters also features in metaphorical descriptions of events from the Trojan War:

'But chief in power still the Aethiops were. Crashed they together as when surges meet on the wild sea, when, in a day of storm, from every quarter winds to battle rush.' (Quintus Smyrnaeus, Fall of Troy 2.216ff.)

However, once a wave enters shallow water and 'makes contact' with the sea floor, it loses its constant form and direction, and undergoes refraction ${ }^{79}$. Refraction changes the direction, speed, height, and steepness of a wave. 


\section{Wave refraction.}

Parts of a wave which enter shallow water are forced to slow down, while the portion of the wave which remains in deep water continues at constant speed. Thus as a wave in deep water advances at an angle upon a relatively straight shoreline, moving over a shelving sea bed, the parts of the wave furthest from the coast will approach the shore at a faster rate than the parts of the wave which are closer in. The result is that the section of the wave in deeper water 'catches up' the sections already in shallower water, and the wave thus 'bends' to align itself with the contours of the sea bed (fig.35). As the water gets progressively shallower and the waves slow down, the distances between successive waves decreases, and the proportion of the wave above the level water mark increases, with the result that the waves grow progressively higher and steeper ${ }^{80}$, until eventually they can no longer retain their wave form, and collapse as breakers. The growth in height and steepness is most marked where the sea floor is very steep ${ }^{81}$, and where the waves coming from deep water are long and low ("swells") ${ }^{82}$. With the increase in height comes an increase in the energy within the wave crest. This energy is then dissipated upon breaking ${ }^{83}$. The heightening and steepening of waves as they approach the shore is commonly referred to in ancient literature as early as the Iliad:

'..like a crag sheer and great, hard by the grey sea, that abides the swift paths of the shrill winds and the swollen waves [ $\kappa u ́ \mu \alpha \tau \dot{\alpha} \tau \varepsilon$ $\tau \rho \circ \varphi o ́ \varepsilon v \tau \alpha]$ that belch forth against it; even so the Danaans withstood the Trojan steadfastly.' (Hom.Il.15.619-622; compare Il.4.422-6, quoted below, p.36)

The Greek term here translated as wave, $\kappa u ́ \mu \alpha$, itself illustrates the ancient Greeks' familiarity with the fact that waves heighten and steepen as they cross shallowing

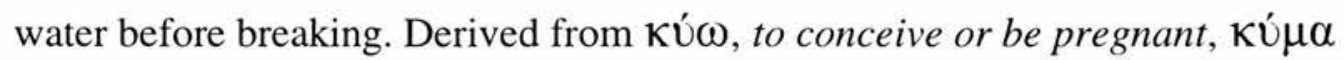
denotes something swollen, and is used specifically of breakers and of swells ${ }^{84}$. Swells appear swollen because they stand out in an otherwise calm sea, but breakers are also $\kappa u ́ \mu \alpha \tau \alpha$ in the sense that the process that leads to their breaking is precisely one of swelling up as they advance over shoal water. The fact that the swelling is a precursor 
to the bursting and discharge of that swollen form may also extend the parallelism with the image of pregnancy.

In theory a wave will break when the depth of undisturbed water becomes roughly equal to the height of the wave crossing it, so that where the sea remains very shallow as it recedes from the coast, waves may start to break far from the shore, forming 'rollers ${ }^{85}$. In practice, however, various factors influence the point at which a wave approaching the coast will break. The steeper the slope of the sea bed, the deeper the water in which the wave will break ${ }^{86}$. Likewise, waves backed by an on-shore wind or current will break earlier than they normally would, while those faced by an off-shore wind or an opposing current will be further heightened and break considerably later ${ }^{87}$. In this passage the effect of a contrary wind is described, or even exaggerated, again as a metaphor for exploits which took place during the Trojan War:

'Recoiling back they fell, as waves onrolled by Boreas foaming from the deep to the strand, are caught by another blast that whirlwind-like leaps, in a short lull of Boreas, forth, smites them full-face, and hurls them back from the shore.' (Quintus Smyrnaeus, Fall of Troy 11.226-232)

Wave refraction comes into effect any time the depth of water falls to around or below half of the distance between wave crests ${ }^{88}$. Whether or not any point on the sea floor induces wave refraction therefore depends on the length of the waves crossing it at a given time: the greater the wavelength, the greater the depth of water in which the wave will start to be refracted. Thus wave refraction and breaking can take place over submerged rocks and ridges as well as on nearly all forms of coastline. Strabo describes some such submerged rocks off Pharos island at the entrance to the harbour of Alexandria:

'Of the extremities of Pharos, the eastern one lies closer to the mainland, and to the promontory opposite it (the promontory called Lochias), and thus makes the harbour narrower at the mouth; and in addition to the narrowness of the intervening passage, there are also rocks, some under the water, and others projecting out of it, which at all hours roughen the waves that strike them from the open sea.' (Str.Geog.17.1.6) 


\title{
Waves against an indented coastline.
}

The effects of wave refraction along an indented coastline depend very much on the direction from which the waves approach the coast. If they approach the coast head on, and the contours of the sea bed run parallel to the line of the coast, then the energy of the waves will be concentrated around the headlands and dissipated in the bays $^{89}$ (fig.32). The Greeks' early, and continuing, familiarity with the convergence of waves around headlands is displayed in the following passages:

\begin{abstract}
'As when on a sounding beach the swell of the sea beats, wave after wave, before the driving of the west wind; out on the deep at the first it is gathered in a crest, but thereafter it is broken upon the land and thundereth aloud, and roundabout the headlands it swells and rears its

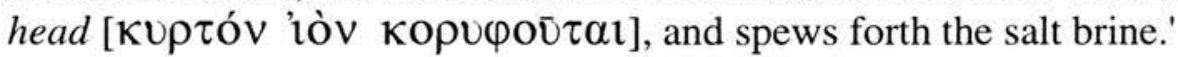
(Hom.Il.4.422-6)

'Now when gleaming dawn with bright eyes beheld the lofty peaks of Pelion, and the calm headlands were being drenched as the sea was ruffled by the winds, then Tiphys awoke from sleep; and at once he roused his comrades to go on board and ready the oars.' (Ap.Rhod.Arg.1.519-23: see n.420)

We have already seen that waves grow taller and steeper before breaking. However here Homer mentions this 'swelling' in respect of waves which are about to break specifically against headlands, and not against the land generally. The distinction is an accurate one, for waves tend to grow larger when breaking against headlands, and to dissipate when approaching bays. This happens because, on a typical submerged coastline, the mountain ridges forming the promontories continue under water as submarine ridges, while the intervening valleys likewise continue on as submarine valleys: as waves approach such a coast, they undergo refraction in the relatively shallow water over the submarine ridges long before they do so in the relatively deeper waters over the submarine valleys ${ }^{90}$. This causes the waves to turn towards the headlands and the shallow water in front of them, with the result that a far larger proportion of the wave breaks against the shores of the headland than would do against the same distance of shoreline on a flat coast. Parts of the wave which had originally been heading towards the bays are refracted towards the headlands, leaving 
a relatively small part of the wave to break eventually against the much longer shores of the bays. Moreover, while those wave sections which are refracted towards a headland are forced to contract laterally and grow higher as they close in upon the convex form of that headland, those wave sections which continue on into the concave shoreline of the bays must expand laterally to do so, and lose height in the process $^{91}$. The greatly diminished height and force of waves which have to pass headlands before entering a bay is clearly described in Homer's descriptions of natural harbours (Hom.Od.10.87-97, 13.96ff., quoted above, p.27f.; compare fig.37).

Whatever angle waves approach an indented coast from, they will still undergo refraction and eventually break in the shallow waters around the promontories before doing so in the bays. Knowledge that it is the headlands which are always struck (first) by waves, regardless of the direction from which the waves and the winds driving them approach the coast, can be seen in the following passage:

'..and the Argives shouted aloud as a wave against a high headland when the south wind comes and makes it swell - even against a jutting crag $[\pi \rho \circ \beta \lambda \eta \tau \imath \sigma \kappa о \pi \varepsilon \dot{\varepsilon} \lambda \omega]$ by the waves of all the winds that come from this side or from that.' (Hom.Il.2.394-7)

However if approaching the coast at an angle, the waves can only break against the lee, or sheltered side of any promontory, by first making contact with the exposed side of the promontory, and then being refracted around the headland and into the sheltered area behind. If the coast changes direction too abruptly on rounding the headland of the promontory, or the sea floor falls away too steeply from the coast, waves which strike one side of a promontory at a considerable angle may not be refracted around to the other, more protected side at all, but instead break contact with the shore and head off again into deep water. This is particularly true of very short waves, for these can only start to undergo refraction when very close to the shore, too late to make the abrupt change of direction into the bay beyond the headland. Longer waves, which start to undergo refraction in much deeper water, and which therefore have more time to turn to face the line of the coast, will however be 
refracted around the headlands and onto the more sheltered sides of the promontories, as will waves whose initial angle of approach to the coast is less severe. Likewise, if the sea floor drops only gently away from the coast, and if the promontory terminates in a broad rounded headland rather than a sharp pointed one, waves are far more likely to be refracted around the headland into the sheltered area in its lee.

Nevertheless, the sudden and extensive lateral expansion of the end of the wave as it is refracted around the headland and onto the lee shore of the promontory causes a significant decrease in the height and energy of that part of the wave, so that the breakers striking the sheltered side of the promontory are far less powerful than those striking its exposed side (fig.26). The further the end of the wave progresses along the lee shore, the greater is the lateral expansion of the wave and the dissipation of energy through breaking, and thus as it advances the wave crest gets increasingly lower and less forceful ${ }^{92}$. The calm waters subsequently found behind headlands are clearly described in this passage of Diodorus the Periegete ( FGrH $372 \mathrm{~F} 35$ ), quoted by Plutarch:

\footnotetext{
'At the Grand Harbour of the Piraeus, a sort of elbow juts out from the headland of Alkimos, and when you have rounded this elbow, on the inner side where the sea is calm, there is a large foundation of masonry and the altar-like structure upon this is the tomb of Themistocles.' (Plut.Them.32.5)
}

The same considerations mean that waves approaching an island will tend to turn towards and break heavily against the exposed shore, but will only break against the opposite, sheltered, side of the island if, and after, they have then been refracted right around the island's perimeter, during which time they will lose a considerable part of their mass and energy, and may lose contact with the coast completely (fig.37).

\section{Waves against cliffs.}

Where the coastline is steep and the sea drops away sharply to deep water, waves will not begin to break while still some distance out to sea, but will strike directly against the coast, hardly having 'felt' the bottom at all. In this situation none of the energy within the waves is dissipated through refraction, and the final heightening and 
steepening of the wave before breaking can be very considerable. Even low swells can thus produce high and forceful breakers when striking cliffs ${ }^{93}$. Such breakers are highly destructive, and also produce large amounts of spray, as the waves' constituent water particles retain all of their energy up to the point of impact, when they are freed from their oscillating orbits inside the wave and are thrown forwards and upwards with great force, as is observed in the following passage ${ }^{94}$ :

'The hollow caves beneath the rugged cliffs rumbled as the sea came surging in; and the white foam of the dashing wave spurted high above the cliff.' (Ap.Rhod.Arg.2.568f.)

In extreme situations where vertical cliffs fall straight into very deep water, as is most common along a fault coastline, the waves striking the cliffs may not break at all, but rather be reflected back off the cliff face into the path of the next incoming wave ${ }^{95}$. Reflected waves meeting incoming waves become an abnormally heightened to the extent that they may break in conditions where they would not normally have done $\mathrm{so}^{96}$.

In contrast, waves tend not to be reflected back from cliffs which have been heavily eroded by the sea. They are prevented from doing so by the submarine shelves which typically stretch out just below sea level in front of eroded cliffs (see above p.26, and fig.8). Once the waves meet the shallow water above the submarine shelf, they immediately begin to break, with the result that the whole of the shelf comes to be covered in the confused water and foam produced by the breaking waves, as is clearly described by Apollonius of Rhodes:

'They made harbour at dawn by the Cape of Acherousias. This lofty headland, with its sheer cliffs, looks out across the Bithynian Sea. Beneath it at sea level lies a solid platform of smooth rock on which the rollers break and roar...' (Ap.Rhod.Arg.2.728-32)

\section{Currents in the Greek Seas.}

The strength and direction of currents in the seas around Greece are closely tied in with those of the Mediterranean Sea as a whole, which are in turn largely determined 
by the fact that this sea is almost completely land-locked, cut off from the strong currents of the oceans, and set within a hot latitude. These factors lead to very high levels of evaporation and, correspondingly, of salinity ${ }^{97}$. Of the $115400 \mathrm{~m}^{3}$ of water which evaporate from the Mediterranean Sea every second, only a little over a quarter is replaced by the outflow of rivers and by precipitation. This leaves a massive nett loss of water which can only be replaced by a compensating inflow of waters through the channels connecting the Mediterranean to other seas, of which there are only two, the Hellespont/Bosporos breach leading to the Black Sea, and the Strait of Gibraltar leading to the Atlantic Ocean ${ }^{98}$. However the flow of water through these straits is not a simple one-way movement in the direction of the Mediterranean Sea: because the water in Mediterranean is more saline, and therefore denser, than that of the Atlantic and the Black Sea, there is actually an interchange of waters, with a current of fresher, less dense water flowing into the Mediterranean Sea at surface level, below which a denser, more saline undercurrent flows out of the Mediterranean Sea and into the Atlantic at Gibraltar, into the Black Sea at the Hellespont ${ }^{99}$. Thus, the inflow of surface waters through the Strait of Gibraltar, which is far more significant than the Hellespont in this respect, not only offsets just over $70 \%$ of the total amount of water lost from the Mediterranean Sea through evaporation, but also compensates for the outflow of more saline waters via the deep undercurrent which also flows through the Strait of Gibraltar.

This massive inflow of surface waters sets in motion a current which runs at an average rate of c. 3 knots at Gibraltar (becoming faster in summer, when evaporation in the Mediterranean is at a maximum), from where it follows the relatively unobstructed path eastwards across the southern part of the Mediterranean, between the shores of Africa to the south and Sardinia, Sicily, Crete, and the extremities of Italy and Greece to the north. From Egypt it turns northward along the east coast of the Mediterranean, and westward along the south coast of Asia Minor ${ }^{100}$. The completion of this anticlockwise circulation of surface waters in the Mediterranean is hampered by the far more irregular coastline of southern Europe (fig.39). 


\section{Currents in the Aegean, Ionian, and Adriatic Seas (fig.39).}

On reaching Crete and the southeastern fringe of the Aegean, the current returning along the south coast of Asia Minor comes up against the northern limits of the main eastwards moving current, and so is deflected northwards, up the west coast of the Asia Minor. From the northeast Aegean the outflow of the Black Sea (via the Hellespont) sets a strong current towards the southwest Aegean ${ }^{101}$. This Hellespontine current, along with the main Mediterranean current moving eastwards along the southern fringe of the Aegean, and the current which moves northwards along the west coast of Asia Minor, completes an anticlockwise circulation of currents in the Aegean (fig.39). On reaching, and passing between the southern Peloponnese (Malea) and western Crete, the Hellespontine current meets the main eastwards moving Mediterranean current. This prevents the Hellespontine current from continuing towards the southwest, and diverts it northwards, up the west coast of the Greek mainland and into the Adriatic Sea. Being thus prevented from spreading out into the open sea, this current passing along the southern and western shores of Greece is strongest nearest the shore ${ }^{102}$. Continuing up the western coast of Greece, the current rounds the head of the Adriatic, and then proceeds southwards down the east coast of Italy, thus again producing an anticlockwise circulation of currents in both the Adriatic Sea, and also the Ionian Sea, where the main eastwards moving Mediterranean current again provides the southern arc of the circular progression of currents. The Aegean, Adriatic, and Ionian Seas, then, all feature an anticlockwise circulation of currents ${ }^{103}$.

\section{Currents at headlands.}

The deep-sea currents circulating in the Aegean and Adriatic Seas, are defined by the oceanography and meteorology of the Mediterranean Sea as a whole. However in addition to these deep-sea currents, there are also 'nearshore' currents in shallower coastal waters, and these are primarily induced by the action of waves striking the coast at an angle: water cast upon the shore by a breaking wave is prevented from freely flowing straight back out to deep water by next incoming waves, and consequently most of this trapped water escapes by moving along the coast 
('longshore drift': see fig.31), in the direction of the incoming waves, until it reaches a point where there is access to deeper water. Deep-sea currents predominate wherever the water remains deep enough for the shorebound waves not to break, and therefore how near to the shore these deep water currents reach depends in effect upon the size of the waves approaching the shore, and upon how rapidly the sea floor drops away from the shoreline: they are most likely to be found near stretches of coast where the sea floor drops away immediately, as on a fault coastline, and when there is very little wave action. In general though, wave-induced near-shore currents predominate in coastal waters, their strength and direction varying relative to the angle at which the waves approach the coast ${ }^{104}$.

Promontories, by their very nature, protrude into the open sea, and by doing so form obstacles in the path of nearshore currents moving laterally along the coast. The more a promontory protrudes into the sea, the greater is the volume of current-driven coastal water which has to work its way round the headland in which it terminates. Near-shore currents tend to be strongest around headlands because it is only by rounding the headlands that all of the water accumulating in the bays can escape. Having rounded such a headland though, the current, no longer obstructed and channelled in one direction, begins to dissipate and weaken, and it is at this point that the deposition of sediments carried by the currents may occur, leading eventually to the developed depositional features associated with headlands ${ }^{105}$. Moreover, promontories are also the points on the coast most likely to be exposed to deep-sea currents, especially if the coastline is faulted. Thus Thyrides (now 'Cavo Grosso'), a massive, cliff-bound faulted block which protrudes from the west coast of the Tainaron peninsula in the southern Peloponnese, is described by Strabo (Geog.8.5.1) as $\dot{\rho} \circ \omega \delta\rceil \varsigma \kappa \eta \mu$ vó $\varsigma$ - 'a precipitous rock exposed to the currents of the sea'. The headlands of promontories, then, tend not only to be the points on the coast off which the strongest currents are found, but also to be areas where different types of currents (i.e. deep-sea and nearshore currents) meet. 
Furthermore, the convergence of waves upon headlands and their divergence in bays (see above p.36ff.) leads not only to the energy of the waves being concentrated around the headlands, but also the mass of water they transport being gathered there in disproportionately large quantities for the length of coastline involved. This constant build up of waters around headlands is dissipated either by nearshore currents which follow on round the coast, or by rip currents which stream forcibly back through the breakers into deeper water ${ }^{106}$. The fact that the rip currents so produced are irregular and flow in a different, or even opposite, direction to that of the approaching waves, means that they especially add not only to the strength but also to the confusion of currents around headlands.

Currents around headlands can also be confused or complicated by the meeting of the different deep-sea currents flowing in the waters on either side of the promontory. As the pattern of deep-sea currents is governed by the oceanography of the Mediterranean as a whole, and not by local factors, this is likely only to affect major promontories on the Greek coastline. One such was Cape Malea in the southeast Peloponnese, where the currents of the Aegean and Ionian Seas meet ${ }^{107}$. Recognition of such alterations in the strength and direction of deep-sea currents around major promontories can be seen in the tendency for the ancient Greeks to use major promontories (or long islands) as the boundaries of the various 'seas' into which they divided Greek waters ${ }^{108}$ :

'The Thracian Chersonesos forms three seas: the Propontis in the north, the Hellespont in the east, and the Melas Gulf in the south [the directions are confused; for the currents, see below, p.73.].' (Str.Geog.7.fr.52 (53))

'Sounion divides the Aegean from the Myrtoan, Cretan, and Libyan Seas.' (Str.Geog.7.7.4)

Because Greek coasts tend to be highly indented (above, p.17), they feature many such headlands with strong and uncertain currents offshore ${ }^{109}$. Familiarity with the increased strength of currents around headlands, particularly where two headlands approach one another to form a strait, can be seen in the following passage: 
'Now in the Thracian Bosporos, whenever the current runs down strongly from the Black Sea, the crabs try to make headway by forcing their way against the current. Understandably, though, the current breaks too strongly round the headlands. It will consequently not only force the crabs back, but even turn them up on end if they try to go against it. However, they are aware of these dangers beforehand, and whenever they come close to the headland, each one heads for some sheltered recess and waits for the others. Once they have assembled at this spot, they crawl up and onto the land and scramble over the cliffs, and thus by land they pass that point where the sea has the strongest currents and is most forceful. And so then, coming away from the headland, having successfully passed it by, they go back down into the sea again.' (Ael.On Animals 7.24)

\section{Currents through straits.}

The Aegean Sea is infested with islands, and bordered on three sides by continental land masses, on the fourth by the long island of Crete. This situation can restrict the free movement of waves and currents, causing rougher waters ${ }^{110}$. In this respect the Aegean's many straits are highly significant, as they provide important passageways for currents which would otherwise be further restricted, but instead stream through the openings with increased force and speed (fig.40).

In the Hellespont/Bosporos breach, waters coming into the Mediterranean from the Black Sea are carried in the upper, surface currents, while the smaller quantities of water leaving the Mediterranean form a deeper undercurrent (above, p.40). While far more water is drawn into the Mediterranean through the Strait of Gibraltar than through the Hellespont/ Bosporos breach ${ }^{111}$, a great current is nevertheless induced in the latter owing to its shallowness and narrowness: although the Propontis is heavily faulted and reaches depths of over $1000 \mathrm{~m}$., the exits to the north (Bosporos) and south (Hellespont) are no more than river valleys which were inundated by the waters of the Aegean and Black Seas with the post-glacial rise in sea level. Thus the depth of water at the Bosporos sill is only $37 \mathrm{~m}$., at the Hellespont $70 \mathrm{~m} .{ }^{112}$. At their narrowest, moreover, the Bosporos is under $800 \mathrm{~m}$. wide, the Hellespont under $1500 \mathrm{~m}$. Under these restricted conditions the surface current in the Hellespont runs at an average rate of around three knots, rising to five knots in the narrower sections, in the Bosporos at four or five knots, rising to six or seven. Meanwhile in the recessed bays 
along the shores, the steady flow of the current is disrupted and standing eddies develop. The surface current also increases in speed from north to south, as its depth becomes increasingly shallower ${ }^{113}$.

The division of the water flowing through the strait into an upper and a lower current running in opposite directions is complicated by what is known as the Coriolis force, by which the rotation of the earth has an effect upon the circulation of sea currents. In straits, the Coriolis force causes a slight displacement of the waters of the upper current towards one shore, and of the waters of the lower current towards the opposite shore. In the Bosporos, the strength of the current and the width of the strait are such that, unusually, the lower current at times actually appears on the surface of one side of the strait ${ }^{114}$. This rising up of the lower current towards the surface was known to the ancient Greeks, and is referred to by Apollonius of Rhodes:

'....hemmed in on both sides by rugged cliffs, while an eddying current from below was washing against the ship as she moved on, they went forward sorely in dread...' (Ap.Rhod.Arg.2.550ff.)

The surface current running out from the Hellespont is strong enough to cover the length of the Aegean, just as the Gibraltar current reaches the far end of the Mediterranean (fig.39). From its outflow at the Hellespont, the current runs southwestwards, passing either side of Lemnos, and then crossing the relatively open seas to reach the Magnesian coast of Thessaly and the islands of Euboia, Andros, Tenos, and Mykonos, which present a continuous barrier running NW-SE, broken only by the narrow straits dividing the islands from each other and Euboia from Thessaly (fig.40). As these straits, together with the wider one separating Mykonos from Ikaria to the east, are the only means by which the Hellespont's outflow can continue its southwestward progression, they are continually visited by strong currents $^{115}$. The Doro channel, separating Euboia from Andros, in particular receives nearshore currents which are produced when the Hellespontine current runs into the wide gulf in the east coast of Euboia between the Chersonesos and Kaphereus promontories, and finding its passage blocked, runs southeast along the coast to 
Kaphereus, where it swings round to the southwest and passes through the Doro channel. These nearshore currents run at a rate of up to three knots, and contribute to a current in the Doro channel which at times reach seven knots ${ }^{116}$. Such channelling of nearshore currents through straits occurs wherever island coasts face in the direction of a prevailing current, so that all currents passing southwards or southwestwards through the straits between Aegean islands are strengthened in this way.

That currents are generally strengthened when channelled through narrow straits was common knowledge to the ancient Greeks. Polybius, for example, notes how the current in the Bosporos strengthens as it flows through the narrowest sections of the strait (Pol.4.43.3-10, 16.29.8-14) ${ }^{117}$, while Aristotle remarks upon how currents which are imperceptible in the open sea are clearly visible when flowing through narrow channels (Arist.Met.354a6-11), and Theophrastos notes that, like a current of water, winds are always more forceful when passing through narrow passages (Theophr.Vent.29: see fig.38.iii).

In the eastern Aegean, the northward flowing current, running up the west coast of Asia Minor, passes both sides of Samos, and flows through the strait separating that island from the mainland at a rate of 3 to 4 knots, far faster than the average rate at which the current approaches the strait from the more open waters to the south ${ }^{118}$. Further north, the same current reaches the strait separating Chios from Asia Minor, where it meets the southwards flowing current from the Hellespont. The current here can run northwards or southwards, depending on the season, and on the strength and direction of the prevailing wind ${ }^{119}$ (fig.40).

Straits with alternating currents can be found elsewhere in the Mediterranean, and there are particularly well-known and complex examples at the Euripos, the narrowest point in the Euboian Sound, and the Straits of Messina, separating Sicily from Italy. The Straits of Messina are $3.5 \mathrm{~km}$ wide at their narrowest, at which point a submarine ridge rises to within $100 \mathrm{~m}$. of the surface. Here currents again flow in different directions simultaneously, and there is considerable turbulent mixing of these two 
currents. Tidal forces (as noted by Eratosthenes - Str.Geog.1.3.11f.) and atmospheric conditions also cause considerable fluctuations in the flow of waters through the strait, and again, as in the Bosporos, currents along the shore may run contrary to the main surface current, which flows from north to south at an average of roughly four knots, rising to over six in certain tidal conditions. The Euripos is even more constricted, being only c. $40 \mathrm{~m}$ wide and a few metres deep. Here the current flows in only one direction at a time, but changes direction several times a day at irregular intervals, at rates of up to eight knots. The fluctuations in the Euripos current are mainly the result of the different states of the tide in the waters to the north and to the south of the narrows at Chalkis, although the massing of water in the channels by the winds is another factor ${ }^{120}$.

\section{Tides (fig.39).}

Because the Mediterranean Sea is virtually land-locked, its tides are weak, only having a significant effect in areas which are particularly sensitive to sea-level fluctuations, such as the extensive shallows in the Gulf of Syrtis on the northern coast of Africa, where the Argo was swept ashore and stranded at high tide (Ap.Rhod.Arg.4.1240-1271) or deep narrow bays and straits, where the tidal waters are funnelled into narrower and narrower channels ${ }^{121}$. To this effect, some of the greatest tidal movements in the Mediterranean occur in the northern Adriatic, and tides are also notable in the Corinthian Gulf, where the current in the narrows can reach two knots, and changes direction in accordance with the ebb and flow of the tide. Herodotos notes the considerable tides in the deep Thermaic Gulf in the northwest Aegean (8.129) and in the region of Thermopylai in the Euboian Sound (7.198). As noted above, the tides are also at least partly responsible for refluent currents of the Euripos and the Straits of Messina. Otherwise tides in the Mediterranean are most significant for their absence, allowing currents generally to run more regularly and evenly throughout the day and indeed the seasons, and also facilitating processes of deposition, as sediments are less likely to be washed away once laid down ${ }^{122}$. 


\section{METEOROLOGY AND THE GREEK COASTLINE.}

\section{The annual weather cycle in Greece.}

Meteorological conditions in the Mediterranean are very stable during the summer months, the climate being governed by the presence of a high pressure system ('anticyclone') to the west, centred over the Azores, and a low pressure system ('cyclone' or 'depression') to the east, extending from Pakistan to Sudan. As, in the northern hemisphere, the winds of an anticyclone circulate in a clockwise direction, and those of a depression in an anticlockwise direction, these two weather systems entail strong and steady winds blowing across the Mediterranean from north to south $^{123}$ (fig.41). Clear skies, great heat and drought also attend the Mediterranean summer, especially in the east, as the sun stands very high in the sky, and the anticyclone over the Azores, acting as a barrier, diverts northwards those cooler and wetter westerly airstreams arriving from the Atlantic ${ }^{124}$.

From late September the depression over southern Asia is succeeded by the monsoon, while the high pressure over the Azores begins to dissipate. This brings an end to the settled conditions of the summer and increasingly allows westerly airstreams and depressions from the Atlantic to enter the Mediterranean, to which they are attracted by the low relief and moist warm air of the sea basin ${ }^{125}$.

This warm air is a direct consequence of the warmth of the Mediterranean Sea itself. As the Mediterranean is virtually an enclosed sea, and its waters circulate and mix with those of the oceans only very slowly, even the surface layers retain a constant and unusually high temperature all year round. In winter this leads to rising currents of warm air, and consequently the development of low pressure across the whole Mediterranean basin ${ }^{126}$. Meanwhile during autumn, anticyclones develop over the Sahara and, more significantly, over the Eurasian land mass. Both of these high pressure areas tend to fend off the depressions advancing from the Atlantic, and this, together with the low pressure conditions already present in the Mediterranean, leads to a steady progression of eastwards-moving depressions, with the associated cloudy 
and stormy conditions, traversing the Mediterranean with increasing regularity throughout winter ${ }^{127}$ (fig.42). To the observer on the ground, the passage of a depression, with its anticlockwise circulation of winds, entails the development and strengthening initially of southerly winds, blowing from Africa, which then, as the depression passes eastwards, veer round to become northerlies blowing from continental Europe, which then gradually weaken as the depressions passes away eastwards $^{128}$ (fig.41).

As winter turns to summer, the high pressure anticyclone over the Eurasian land mass weakens, so that depressions, in any case becoming less frequent, increasingly take a more northerly route over continental Europe ${ }^{129}$. During such periods, when the summer high pressure anticyclone over the Azores region of the Atlantic is not yet fully established, and there are breaks between successive passing depressions, weak ridges of high pressure may develop, stretching from east to west across the Mediterranean. The southern shores of Europe, lying below the northern flanks of such ridges of high pressure, experience light westerly winds (ancient Zephyros) under these conditions. Depressions, with their southerly and northerly winds, continue to cross the Mediterranean, but their frequency tails off through April and May, and from June onwards summer's northerlies prevail at nearly all times ${ }^{130}$.

Thus the Mediterranean climate has two main seasons, the summer, with its stable hot and dry conditions and northerly winds, and the winter, characterised by the frequent passage of eastwards moving depressions with attendant storms. Autumn and spring are in effect periods of transition between these two seasons, and have little distinct climatic character of their own.

\section{The Etesians.}

As in most of the Mediterranean region, summer in Greece sees by far the most stable climatic conditions. The Azores anticyclone to the west and, more importantly, the Asiatic depression to the east result in hot, clear and dry conditions with steady winds known to the ancient Greeks as the Etesians ${ }^{131}$ : most often thought of as 
northeasterlies, these can in fact blow from anywhere between NW and NE, the precise direction at any particular place and time depending upon small fluctuations in atmospheric conditions and also upon local topography, which can influence the flow and direction of winds ${ }^{132}$. Strong enough to penetrate as far as Egypt and Libya from the continental interior of southeastern Europe, the Etesians regularly blow so violently in the Aegean and adjacent waters as to produce considerable storms ${ }^{133}$.

\section{Cyclonic winds: the Bora and the Sirocco.}

In contrast to the steady Etesians associated with the Mediterranean summer, the typical winter winds are far more varied in direction and duration. This is because, in contrast to the static and unchanging atmospheric pressure conditions of summer, the winter period is characterised by depressions which move eastwards at variable speeds (fig.42): as noted above, the passage of a depression over Greece brings winds which are initially southerly and then veer round to become northerly (fig.41). Variations in a depression's size and rate of eastwards progression affect the duration of the different winds it brings: the larger and slower moving a depression is, the longer the winds from any one direction will last. Depressions in the Mediterranean may even stop progressing eastwards at all for a few days, because of their tendency to stabilise over the warm and humid sea basins which feed them, just as areas of high pressure tend to develop over land masses ${ }^{134}$. Thus in any of the deep recesses of the northern Mediterranean, i.e. the Tyrrhenian, Adriatic, or Aegean Seas, depressions may halt temporarily, unable to proceed against the areas of high atmospheric pressure over the land masses to the east (Italy, Greece, and Asia Minor). In such situations, the winds associated with the depression may remain fairly constant, although gradual changes in the coastal interface between areas of high and low pressure will effect changes in wind strength and direction ${ }^{135}$. Even when progressing eastwards across the Mediterranean, depressions tend to follow the warm water surface, being fended off by the highs over the land masses. Thus rather than cross northern Greece, depressions in the Adriatic tend to move south and then head eastwards around the narrower Peloponnese. On reaching the west coast of Asia Minor, and the associated high pressure there, depressions again tend to be diverted northwards or southwards 
of the land mass ${ }^{136}$ (fig.42). The most significant winds associated with the passage of depressions over Greece are the northerly Bora (and kindred winds) and the southerly Sirocco.

The Bora is a cold wind which blows from a northerly direction down across the Adriatic Sea. It is most commonly associated with the combination of high pressure over the continental interior of Europe, and the passage of a depression through the northern Adriatic. As the Adriatic is on the principal route of depressions crossing the Mediterranean, these conditions are by no means uncommon, especially during winter, when there is generally an extensive area of high pressure over Europe. These areas of high and low pressure are normally kept separate from each other by the formidable barrier of the Alps. However, as a depression passes over the Adriatic, the winds in its rear, behind the cold front, draw in air from the north, inducing the passage of cold air from the high pressure area over Europe, across the Alps, and down into the low pressure area over the Adriatic ${ }^{137}$. Indeed the very contrast between the warm air and low pressures of the northern Adriatic and the cold air and high pressure over and behind the Alps can itself induce a 'home grown' depression or start the Bora blowing even in summer, for then the shallow waters of the northern Adriatic are particularly hot, producing warm humid air and low pressures in the skies above ${ }^{138}$. Under these conditions, the warm Adriatic air tends to rise, while the chilled air over the Alps, far denser that the warm air below, descends into the Adriatic basin, often in very fierce gusts $^{139}$. A similar effect may be produced by the advance of a cold front towards the Alps from the northwest: the Alps block the passage of the main airstream, while on either flank strong and cold winds spill over, in the form of the Mistral to the west, and the Bora to the east; depressions may develop from the turbulence and instability in these winds, caused by their forceful and erratic passage over the Alps ${ }^{140}$.

The Bora may blow with great violence right across the Adriatic, from its northeast coasts to Italy ${ }^{141}$. Drawing air from over the continental interior of Europe, it is generally a very cold wind, especially in comparison with the generally warm Adriatic. The initial passage over the Alps tends to remove humidity from the wind, which is

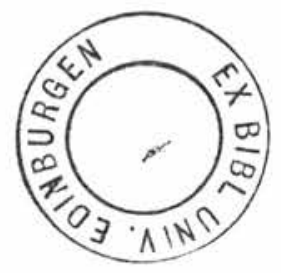


therefore dry and often accompanied by clear skies ${ }^{142}$. From the high pressure areas over southeastern Europe, similar winds, such as the modern Livas, and the ancient Boreas, Thraskias and Hellespontias, blow down through the river valleys in the mountains, across the coastal plains of Macedonia, Thrace and Thessaly, and onto the Aegean Sea ${ }^{143}$ (fig.43).

The Sirocco, also known as the Khamsin in Egypt and the Leveche in the eastern Mediterranean, is a hot wind blowing from Africa northwards towards Europe (fig.41). Corresponding to the ancient Greek Notos and Lips, this is in fact the southerly to southwesterly wind associated with the warm front to the fore of depressions crossing the Mediterranean ${ }^{144}$. Like the Bora, the Sirocco blows from an area of continental high pressure to an area of maritime low pressure, and, as the warm front passes, builds up such force that, especially in late winter and early summer, it reaches the southern shores of Europe ${ }^{145}$. However, unlike the Bora, the Sirocco is hot and dusty, as it originates in the Sahara region, and so readily absorbs moisture as it crosses the sea, often arriving at the southern coast of Europe accompanied by cloud or haze ${ }^{146}$. Being associated with depressions which run the whole length of the Mediterranean, and coming from the relatively flat and open coast of Africa, the Sirocco runs northwards to Europe from nearly every part of the northern coast of Africa, unlike the Bora and similar winds, which only occur where there are suitable gaps in the high mountain barriers and peninsulas lining the southern fringes of Europe. Thus the Sirocco affects not only one part of Greece, but its whole southern fringe from the Adriatic to Rhodes and Asia Minor, even reaching as far as the northern coast of the Aegean ${ }^{147}$.

\section{Land and sea breezes.}

Land and sea breezes are localised coastal winds which alternate in a daily cycle, and develop most strongly in temperate countries ${ }^{148}$. Their occurrence is due to the different rates at which land and sea heat up during the day, and cool off at night, a process known as diurnal heating and cooling: from sunrise, land surfaces heat up more quickly than that of the sea, because the sea tends to a) reflect more sunlight, b) 
lose heat through evaporation and mingling with cooler waters, and c) become heated to a greater depth, being transparent to heat and light. For the same reasons, the land cools off more quickly than the sea at night, especially as only its surface tends to heat up, unlike the sea ${ }^{149}$.

While these temperature differences make little difference to air pressure at groundand sea-level, the higher daytime temperature over land does lead to correspondingly higher air pressures higher up in the atmosphere. Once a significant difference in air pressure has developed, a flow of air is set in motion from the high pressure area over the land to the low pressure area over the sea. This in turn induces an updraught of warm air from the land, and a compensating flow of air at ground level from sea to land known as the sea breeze. The overall result is a circular wind pattern, rising from the land, moving out to sea, descending to sea level, and then flowing back to land (fig.44).

At night the land cools more quickly than the sea, so that a few hours after sunset, the sea retains far more heat than the land. This temperature contrast again induces higher air pressure up in the atmosphere over the warmer surface, now the sea, and the circular wind pattern is again set in motion, with the breeze at ground level now flowing from land to sea, and therefore termed the land breeze ${ }^{150}$ (fig.44).

In Greece, land and sea breezes are well developed and very regular, especially in summer and in calm conditions ${ }^{151}$ (fig.43). Sea breezes start to blow in late morning, a few hours after sunrise, increasing in strength throughout the afternoon. At sundown the sea breeze soon dies down, and after a few hours of intervening calm, the land breeze begins ${ }^{152}$. While weaker than the sea breeze, especially in cloudy conditions, the land breeze can still reach $25 \mathrm{~km}$. or more out to sea, especially when bolstered by mountain winds (on which see below) ${ }^{153}$. The land breeze continues until sunrise, when another period of calm precedes the return of the sea breeze in late morning.

Familiarity, from an early date, with the daily cycle of strong land and sea breezes around the coasts of Greece is suggested at Hom.Il.11.619-22, where Nestor and his 
squire Eurymedon go specially to the sea-shore to cool themselves off in the breeze there. Much later, Aristotle and Theophrastos sought to explain the mechanics of land and sea breezes (see Arist.Probl.26.4f., 40, Theophr.Vent.26, 27, 53). Although they failed to identify the different rates at which land and sea heat up and cool down over the period of a day as the crucial factor in the development of these breezes, they were clearly very familiar with their general characteristics, such as the particular strength they develop in bays (Arist.Probl.26.40; for this aspect, see below, p.55 and n.158), the fact that the land breeze is generally the weaker (Theophr.Vent.26), and the daily cycle in which they alternate (Theophr.Vent.53) ${ }^{154}$.

\section{Valley and mountain winds.}

Valley and mountain winds, like land and sea breezes, result from variations in the rates at which different parts of the earth's surface (and the air in contact with it) heat up during the day and cool off at night (diurnal heating and cooling). Valley winds, also known as anabatic winds, and mountain, or katabatic, winds are related to differences between the relief, degree of exposure, and diurnal rates of heating and cooling of valley floors and slopes on the one hand, and of the mountain chains and ridges which enclose them on the other.

During the day, air in the bottom of a valley is heated up by the convex landform which encloses it on three sides and shelters it from the winds. The convex mountain peaks and ridges above, on the other hand, contain far less surface area in proportion to the mass of air around them, while any heat the air does manage to accumulate is generally dissipated into the wider atmosphere by strong winds ${ }^{155}$. Thus during the day, the air in a valley floor tends to heat up much more than the air in the colder, more exposed layers above. This warmer valley air forms the valley wind blowing up the valley axis, and is replaced by the colder denser air above, which descends vertically to ground level. At night the air surrounding the mountain peaks and ridges loses what heat it has at a considerably faster rate than that in the valleys, and this warmer valley air is then displaced upwards by the mountain wind, cold dense air from the mountain tops which rolls down into the valleys and continues on down their 
axes ${ }^{156}$. Thus in any complete day mountain and valley winds tend to occur as follows: after sunrise diurnal heating begins, and by late morning is sufficiently developed to set valley winds in motion; these increase in strength through the period of greatest diurnal heating in late afternoon, and then ebb away after sunset. Later in the evening, diurnal cooling comes into effect, and mountain winds begin to blow down the valley axis, increasing in intensity through the period of maximum diurnal cooling until sunrise, when they fade away as diurnal heating begins again, soon bringing renewed valley winds ${ }^{157}$. This daily cycle is comparable to that of alternating land and sea breezes.

Unlike land and sea breezes though, mountain and valley winds are not intrinsically associated with coastlands. However, in Greece, the commonly submerged and highly indented coastlines and the mountainous nature of many islands (for which see above, pp.17f., 28ff.), mean that mountain and valley winds are to be found as commonly around the coasts and islands of Greece as they are over the mountains of the interior. Mountain and valley winds occurring along the coasts of Greece tend to coincide with and reinforce land and sea breezes, producing winds which blow continually from the mountainous interior, down through the valleys and across the bays which meet them, and on out to sea during the night and early morning, and in the opposite direction from late morning until early evening ${ }^{158}$. The daily occurrence of such combinations of mountain winds and land breezes is noted by Apollonius of Rhodes:

'Yet once the rolling swell of the sea had been aroused by the strong breezes which blow down from rivers in the evening, they grew tired and rested.' (Ap.Rhod.Arg.1.1159ff.)

In this passage, the evening winds which blow specifically 'from rivers' (غ̀ $\kappa$ $\pi \mathrm{o} \tau \alpha \mu \omega \bar{\omega})$ across the sea are clearly to be distinguished from land breezes in general, which blow with even strength all along the coast, regardless of the presence of rivers. The significance of rivers is that they follow the valley floors down which mountain winds blow. When these mountain winds reach the coast at the point where the rivers discharge into the sea, they add their force to the local land breezes, which 
therefore merit the adjective $\zeta \alpha \chi \rho \eta \varepsilon$ $\sigma \imath v$, here translated simply as 'strong'. For this reason, Aristotle (Probl.26.30) and Theophrastos (Vent.53) also particularly connect land breezes with river valleys.

Even without thus combining with land and sea breezes, valley winds and more particularly mountain winds can exert a strong influence on meteorological conditions around the coastal waters of Greece. Thus the Bora in the Adriatic, and the Livas, a corresponding wind which blows down the other side of the mountainous interior of northern Greece peninsula across the plains of Thessaly and the coastlands of Macedonia, both depend not only upon general meteorological conditions in the Mediterranean as a whole, but also upon the local contrast between the cold high pressure air which sits over the continental interior and the warmer more humid air to be found over the coastal plains and the seaboard. Thus they may be classified as katabatic mountain winds, along with the many other strong winds which blow down onto the coastal waters around Greece from a high mountainous interior. Note in particular the ancient Strymonian wind, named after the river Strymon, the route of which the wind followed from the Macedonian mountains down across the coastal plain and out over the Aegean (see p.114f.).

These mountain winds may even blow by day as well as by night, owing to the sharpness of the contrast between the warm and low-lying coastal waters and the very cold and high mountainous coastlands ${ }^{159}$. This tendency to spring up at any time of the day, and in variable climatic conditions, may be why Theophrastos (Signs 35) describes northerly and northwesterly winds such as the Thraskias (again corresponding to the modern Livas) as ones which "come on top of other winds when these are still blowing ${ }^{160}$. Such winds are likely to be particularly strong where the coast faces south ${ }^{161}$, as the katabatic mountain wind will then blow from the north, coinciding with the orientation of the prevailing winds. Theophrastos, while showing little understanding of the meteorological processes which bring katabatic winds into effect, does realise that a nearby coastline, with its warm humid air and land and sea breezes, can reinforce the strength of such winds: 
'Of the remaining signs some belong specially to all such lands as contain high mountains and valleys, especially where such mountains extend down to the sea; for when the winds begin to blow, the clouds are thrown against such places.....and as they become laden with moisture they settle down in the hollows because of their weight.' (Theophr.Signs 3)

\section{Canalling and Squalls: the effect of barriers on winds.}

When winds crossing the sea meet obstacles such as peninsulas, islands, or any high coastline, the airstream at sea level is displaced horizontally, vertically, or in both directions, and this causes turbulence. How a wind is displaced when passing an obstacle, and the degree of turbulence caused by that displacement, depend upon three factors: the wind's speed, the orientation and form of the obstacle, and the relative stability of the $\operatorname{air}^{162}$. Of these three factors, the second determines the way in which the wind is displaced: relief features which are oriented at right angles to the wind direction force the oncoming wind to rise up and cross directly over the obstacle, i.e. the wind is vertically displaced (fig.45); relief features which are oriented along a direction parallel to, or nearly parallel to the direction of the wind, tend to deflect the onrushing wind to either side, i.e. the wind is horizontally displaced (fig.46). Apollonius of Rhodes clearly describes such horizontal displacement by the northwards-oriented Karambis peninsula on the southern shores of the Black Sea:

'Opposite Helike the Bear there is a foreland called Karambis, steep on every side, and presenting to the sea a lofty pinnacle which splits the windstream from the north in two.' (Ap.Rhod.Arg.2.360ff.)

The forms of turbulence experienced by a displaced wind depend on whether the wind has been horizontally or vertically displaced: vertical displacement causes considerably more turbulence than horizontal displacement ${ }^{163}$.

The turbulence caused by vertical displacement of a wind stems from the fact that friction and other factors arising from contact with the earth's surface causes winds to travel more slowly at ground level than in higher levels of the atmosphere ${ }^{164}$. Where a moderate wind's path is unobstructed, as on the open sea, the different layers of air in the wind barely mix or interfere with each other, but flow steadily and horizontally, 
the higher levels of air passing over the lower and slower levels of air. However, where an obstacle vertically displaces air at ground level, layers of wind travelling at different speeds are forced to penetrate and pass through each other, causing turbulence ${ }^{165}$. In contrast to the generally steady speed and direction of a nonturbulent wind, turbulent wind streams feature lulls, gusts, eddies, and other irregularities in their speed and direction ${ }^{166}$.

The degree of turbulence caused by the vertical displacement of winds crossing an obstacle in their path is, as mentioned above, dependent upon the overall speed of the wind and the relative stability of the air. Wind speed has a direct relationship to turbulence, faster speeds causing greater degrees of turbulence ${ }^{167}$. Air stability is a more complicated matter, stable air and unstable air causing different forms of turbulence ${ }^{168}$.

These differences stem from the contrasting ways in which stable and unstable air behave once they have risen and passed over an obstacle, as when the lower levels of air in a wind crossing the sea are forced to rise to pass over a peninsula or large island standing in their path. Stable air will tend to flow back down the lee side of the obstacle and return to sea level. This descent however is not steady and even, but comes in gusts and lulls ${ }^{169}$. This turbulent descent of air into areas apparently protected from winds by high relief was noted by Theophrastos:

'Localities protected against the north wind (and winds in general) are for that reason windier because it happens that the wind is gathered aloft and in a sense overflows and descends in a body. Wherever the wind presses downward, it rushes below in concentration. In such cases squalls ensue. Here sudden storms and concentrations of wind occur, so that when the wind breaks forth, it has the effect of a shock. For concentrated wind is powerful and continuous, as with whirlwinds. Thus these and like phenomena take place because of local features.' (Theophr.Vent.34)

The overall speed and strength of the descending wind depend upon the degree of stability of the air, and the turbulent effects are not simply restricted to the immediate vicinity, but continue for some distance downwind, as the initial descent can set in 
motion a series of eddies or waves in the atmosphere to the lee of the obstacle. In these eddies, air from sea level is constantly interchanging with air from higher in the atmosphere, producing further turbulent gusts which strike the sea as squalls, often in a direction opposite to that of the prevailing winds ${ }^{170}$ (figs.45, 47.ii).

Unstable air, on the other hand, continues to rise higher into the atmosphere, even once the obstacle causing it to start rising has been passed. The continued ascent is accompanied by increasing levels of condensation, and, given a high enough degree of instability, eventual formation of cumulonimbus cloud with accompanying rainfall ${ }^{171}$. Such rain tends to fall in concentrated bursts, and is accompanied by cold downdraughts of air which spread out on striking the sea, producing squally conditions over a considerable distance ${ }^{172}$. The turbulence produced by unstable air is therefore often associated with thunderstorms, in areas where these are commonly to be found, particularly the west coast of Greece ${ }^{173}$. Homer describes such squalls accompanying a thunderstorm:

'And they came like a blast from grievous winds, that first rushes immediately earthwards under the thunder of Father Zeus, then with a fearful roar strikes the sea, and therein are many seething waves of the loud-roaring sea, arched and white-crested, some out in front, and yet others to the rear.' (Hom.Il.13.795ff.)

Thus, in both stable and unstable conditions, some degree of air turbulence, producing squally conditions at sea level, is likely to be experienced in the lee of islands and peninsulas which impede the progress of winds crossing the sea, especially as sea winds generally run faster than those on land. The relative stability of the air mainly affects the forms of turbulence which occur. High levels of evaporation from the Mediterranean Sea, and the sea's unusually high temperature $\left(\mathrm{c} .13^{\circ} \mathrm{C}\right.$, rising to $20^{\circ} \mathrm{C}$ in surface waters during the summer months), compounded particularly in summer by the effects of diurnal heating, tend to promote unstable conditions (see n.168). However, it is very difficult to generalise about or predict the forms of turbulence which will result from a wind crossing any peninsula or island, owing to the number of variables which affect the process: air temperature, wind speed and direction, form 
and orientation of obstacles, humidity, degree of diurnal heating (which varies in intensity not only at different times of the year but also at different times of day), etc. Thus, despite being very common, and often very intense, in the seas around Greece, especially under the influence of strong winds such as the Etesians and even the southerly Sirocco, turbulence in the lee of peninsulas and islands is highly irregular and unpredictable, with lulls interspersed between gusts and squalls of varying strength, direction, and duration ${ }^{174}$. The height, abruptness, and cliffy nature of many Greek coasts intensifies the violence of these squalls. Yet at the same time, the lees of islands and peninsulas can also become areas of complete or near complete calm if displaced air, near the transition between stability and instability, neither returns to sea level nor continues rising after the obstacle in question has been passed ${ }^{175}$.

Turbulence in horizontally displaced air is most likely to be found where two neighbouring obstacles funnel air through the intervening gap, as in cliffbound straits and deep bays flanked by high peninsulas (fig.46). Such 'funnelling', where large masses of air are forced to pass through constricted areas, can greatly increase the strength of winds, and produce the violent gusts and lulls typical of turbulent air, as is most famously demonstrated by the Mistral, which blows down through the Rhone valley in France with great violence. The Greek Bora, Livas, and Meltemi, and their ancient counterparts are all meteorologically related to the Mistral, and where these winds pass through such constricted spaces, such as straits, correspondingly violent winds are to be found:

'For a wind passing through a gap is always more forceful and vigorous like a current of water. Concentrated, it has more thrust. That is why, when there is a calm elsewhere, wind is always present in narrow passages.' (Theophr.Vent.29).

The passage of the Etesians through the Bosporos and Hellespont is one excellent example of many be found around the Greece's highly indented coasts and islands ${ }^{176}$. The direction of funnelled winds may also change to conform to the contours of the valleys and straits they pass through ${ }^{177}$. 


\section{Cloud formation, $\operatorname{fog}^{178}$, and rainfall.}

Ascending air currents are fundamental to the production of rain. As air rises, its temperature falls, and consequently its capacity to absorb and hold water vapour decreases ${ }^{179}$. As the ascent continues, temperature eventually descends to what is known as the dew point, where the air is saturated with water vapour, and any further temperature decrease causes water vapour to condense into small droplets, producing cloud $^{180}$. Given sufficient condensation, the water droplets become large enough to fall freely to earth as rain. Aristotle's explanation of the causes of cloud and rain, despite its limitations, shows considerable insight and accuracy ${ }^{181}$ :

'The earth is at rest, and the moisture about it is evaporated by the sun's rays and the other heat from above and rises upwards: but when the heat which caused it to rise leaves it, some being dispersed into the upper region, some being quenched by rising so high into the air above the earth, the vapour cools and condenses again as a result of the loss of heat and the height and turns from air into water: and having become water falls again onto the earth. The exhalation from water is vapour; the formation of water from air produces cloud.' (Arist.Met.346b24-33, compare 359b34ff.)

When air is particularly warm, and humidity close to saturation point, even a slight degree of cooling, such as occurs at night, can precipitate cloud formation ${ }^{182}$. In Greece, this commonly occurs at sea level around coasts during summer, when daytime temperatures soar, allowing the heated air to absorb great amounts of the water evaporated from the Mediterranean (see above, pp.39f., 58f., n.168). Nighttime cooling then causes this water to be precipitated as fog, which is simply lowlying cloud. When daylight returns, rising temperatures tend to cause the fog to vaporise and be reabsorbed into the atmosphere (i.e. to 'burn off'), or to rise on thermal air currents, becoming (stratus) cloud $^{183}$.

Generally, however, air only reaches the dew point when cooled considerably through being forced to rise some distance. Such ascents can be instigated by three different factors: convection, frontal systems, and relief ${ }^{184}$. 
Convectional ascent occurs when air at ground level becomes so hot that it begins to rise through the cooler and denser air above ${ }^{185}$, but often the rising air is not sufficiently heated, or the atmosphere is too stable, for the ascent to continue to the point where condensation and rainfall occur ${ }^{186}$. Convectional currents strong enough to precipitate rain are mainly associated with areas subject to high degrees of diurnal heating, which produces hot air at ground level and so tends to promote unstable conditions $^{187}$. In Greece, such conditions only occur during summer, at the hottest part of the day (late afternoon), and over land surfaces, which heat up more quickly, and more intensely, than the surface of the sea (see above, p.52f.) ${ }^{188}$. Convectional rainfall in fact rarely ever occurs over the Mediterranean Sea, and, even over the Greek mainland, makes little significant contribution to overall rainfall levels ${ }^{189}$.

Frontal ascent may occur at both warm and cold fronts, where bodies of warm air come into contact with, and rise over, bodies of colder air ${ }^{190}$. In the Mediterranean, warm and cold fronts, and their associated rain, are generally only to be found within depressions, and so also mainly during winter. Depressions in the Mediterranean, as they move eastwards, tend to follow the warm and humid gulfs of the sea, avoiding expansive land masses, so that any rainfall they produce falls mainly over the sea and coastal areas $^{191}$. However, as the warm air of Mediterranean depressions, being drawn in from the high pressure region over the Sahara (above, pp.48f., 52), is relatively stable even after its passage over the sea, while the cold air drawn into the depression from the high land of Europe (above, pp.48f., 51f.) is warmed both adiabatically (by its descent to sea level, for which see n.168) and through contact with the warm sea, the temperature contrast between the hot and cold sectors in Mediterranean depressions is often relatively slight, so that the warm air rises only slowly and, being relatively stable, may never attain the height necessary for cloud formation and rainfall ${ }^{192}$.

Most rainfall in the eastern Mediterranean is, nevertheless, produced by depressions, but is primarily associated with the ascent of cold, rather than warm, sectors of air. This cold air, drawn in from continental Europe, becomes much warmer and more 
humid on crossing the Mediterranean (which, even in winter, retains a high surface temperature of around $13^{\circ} \mathrm{C}^{193}$ ), and so tends to become markedly unstable $\mathrm{e}^{194}$. This instability causes the air to continue rising through the atmosphere to levels where condensation and rainfall occur ${ }^{195}$, but only after some other impetus has initiated an ascent. Around Greece this impetus nearly always takes the form of a relief feature blocking the path of the depression ${ }^{196}$, which, as noted above (pp.57-60), will deflect approaching airstreams upwards, thus initiating the self-perpetuating ascent of humid and unstable air in the cold sectors of depressions, and eventually resulting in rainfall ${ }^{197}$. Such relief-induced rainfall, termed 'orographic' because of the role of mountains in its development ${ }^{198}$, accounts for most of the precipitation which visits the eastern Mediterranean ${ }^{199}$. Given the high relief of much of the Greek coastline, and the mountainous nature of many Greek islands and peninsulas (above, pp.17-20, $28 \mathrm{ff}$.), orographic rain in Greece is closely associated with the coasts, especially the coast of the Adriatic, down which the principal depression tracks run, and, for similar reasons, the west coast of Asia Minor $^{200}$ (fig.48).

Although the cold fronts in depressions are the source of most orographic rainfall ${ }^{201}$, the high relief of the Greek coastline can also precipitate rainfall from any hot, humid, and therefore unstable wind coming off the $\operatorname{sea}^{202}$. Such winds include the hot Sirocco, which becomes very humid as it crosses the Mediterranean from the south, and the summer Etesians, where these meet high coastlines such as that of Euboia after becoming humidified while crossing the Aegean $^{203}$ (fig.48). In summer, sea breezes bringing hot and moist air from the sea may also precipitate afternoon thunderstorms along high and abrupt coastlines ${ }^{204}$ (fig.49). In ancient Greece the development of clouds around or above mountain tops was recorded as a precursor of rainfall by authors as early as Archilochus. This was noted by Theophrastos, who repeatedly cites such a system of forecasting, mentioning the Sirocco as a wet rainbearing wind (Signs 20,35), and noting the significance of clouds gathering over Euboia under the influence of winds coming off the Aegean (Signs 22) ${ }^{205}$. 
Orographic rain is abundant not only in that it accounts for the greater part of all rainfall in Greece, but also in that it falls in concentrated bursts over a relatively small number of days in the year ${ }^{206}$, tending to appear in the form of thunderstorms. In Greece, thunderstorms, and the cumulonimbus clouds producing them, are particularly common because of the instability of the winds striking the coast, and the great height to which many sections of coast abruptly rise ${ }^{207}$. Atmospheric instability causes vertically displaced air to continue rising even after the barrier initially displacing it has been passed, whereas stable air returns to its original level ${ }^{208}$. The continued ascent of unstable air is further prolonged by the process of condensation itself, which occurs particularly rapidly and extensively because of these winds' great heat and humidity ${ }^{209}:$ when water vapour condenses into droplets, heat is released and is immediately absorbed by the surrounding air. This absorption of heat partly compensates for the falling temperature of the rising unstable air, thus keeping it hotter and less dense than the atmosphere around it, and so fuelling its continuing ascent ${ }^{210}$. Hot, humid, and unstable air may thus rise thousands of feet above the barrier which initiated its ascent, puffing into the distinctive cumulonimbus cloudform (fig.49), and continually condensing more and more water vapour, which turns into increasingly larger droplets.

The point at which these water droplets start to fall as rain depends not only upon their size, but also upon the speed at which the air is ascending: raindrops cannot fall faster than 24' per second, and if the air is ascending at a faster rate than this, rain will not fall, but will instead continue to be blown upwards ${ }^{211}$. Here the degree of instability in the air is again vital to thunderstorm development, for the more unstable the air is, the more rapid is its ascent. Likewise the height and abruptness of the barrier are crucial ${ }^{212}:$ high and steep Greek coasts, especially the west coast (above, p.25), which is exposed to the depressions moving down through the Adriatic (above, pp.50ff., 62f.), cause rapid and abrupt ascents of air which help to delay the descent of condensed water droplets. The raindrops grow ever larger, eventually reaching an unsustainable size (over 1/4" diameter) and splitting apart. This releases electrical 
energy, which gradually accumulates until it is dissipated as lightning with attendant thunder ${ }^{213}$.

As noted above (pp.57-60), rising air currents are highly turbulent, with heavy gusts and lulls, and it is during the lulls in the ascent that the accumulated raindrops manage to fall to earth. Thus rainfall from thunderstorms does not fall at a continuous rate, but in spasmodic and extremely heavy bursts ${ }^{214}$. As barriers such as high coasts temporarily impede the horizontal progress of the lower levels of airstreams, air currents to the rear of those actually striking the barrier can also be forced to rise, so that rain falls not only over the coastal barrier, but also on the waters and coastlands in front of $\mathrm{it}^{215}$. At the same time, areas to the lee of such barriers are markedly drier, as winds precipitate virtually all of their humidity while crossing the barrier ${ }^{216}$. One further factor promoting coastal rainfall is the high level of salt carried in winds coming off the Mediterranean (Arist.Probl.26.17 comments upon the unpleasant smell of the southerly Notos), as such microscopic particles are vital to the condensation process $^{217}$. The resulting briny taste of much Greek rainwater is commented on by Theophrastos (Signs 25). 


\section{THE TOPOGRAPHY OF ANCIENT GREEK SEAFARING.}

\section{Introduction.}

The purpose of this chapter is to discuss the role and significance of different types of topographical feature in ancient Greek seafaring, or, to put it another way, how the concerns and actions of the ancient Greek seafarer varied according to his topographical position. As mentioned at the outset of this thesis (pp.7f., 17), coastal topography has a strong effect upon local meteorology and oceanography, and for this reason, the present chapter is structured according to the various categories of topographical features commonly to be found around the coasts of Greece, as described in chapter one. Meteorological and oceanographic phenomena which are strongly connected with one or more features of local topography will be discussed alongside, and in relation to, those topographical features. On the other hand, those meteorological and oceanographic phenomena which are not so closely tied to local topographical features, such as prevailing winds and the general set of deep-sea currents in and around Greece, will be discussed in relation to the geological character of Greece as a whole, with which they are more closely associated. Minor topographical features, such as caves, reefs, and offshore rocks, are generally discussed in relation to the larger topographical features around which they are found (e.g. headlands, straits, and cliffs).

While many individual geographical areas or features undoubtedly had a particular influence on seafaring practices both locally and in a wider geographical sense, the significance of these individual locations is not here discussed exhaustively and in isolation. Rather, where relevant, historical and archaeological evidence concerning particular geographical locations is used to provide the information from which an account of the significance of different types of topographical feature will be built up. By relating the relevant evidence concerning one specific geographical area or feature to the characteristics of the general topographical class(es) to which that feature or 
area belong, it is possible both to come to a fuller understanding of the historical significance of the particular geographical area or feature in question, and also to make more general conclusions as to the role and significance which ancient Greek seafarers attributed to the different types of topographical features they commonly encountered in the Mediterranean environment.

This discussion of the role and significance of different types of topographical features in ancient Greek seafaring will also entail considerable reference to and further discussion of the ideas and information presented in chapter one. The geological, topographical, meteorological, and oceanographic information provided there will form the frame of reference within which the relationship between the ancient seafarer and the topography of his natural environment will be explored and discussed. In this way, by reconciling specific historical and archaeological evidence with a more general geographical analysis of the physical character of the Mediterranean, it is hoped that clearer and more thorough conclusions may be reached than would be the case if material evidence concerning specific geographical localities and their seafaring associations was simply discussed in isolation.

\section{PROMONTORIES AND HEADLANDS.}

In Greek literature, promontories, and the headlands in which they terminate, are probably mentioned more commonly than any other natural features of coastal topography, with the possible exception of straits. The frequency with which they are mentioned, and the wide range of literature in which they commonly appear, suggest that promontories and headlands were of some significance in Greek life and thought. One reason for this, more fully discussed in the next chapter (cf. esp. pp.142-154), is that headlands, more than anywhere else (again with the possible exception of straits), were the points at which ancient mariners tended to come closest to the coast midvoyage. Nevertheless, there are other good reasons why headlands and promontories appear so commonly in literature, for they also often had important military, religious, 
and other functions ${ }^{218}$. However these various associations of headlands were often interrelated, and information regarding the navigational significance of promontories and headlands can be gleaned from many of the literary passages in which such features of the coast are mentioned.

It is clear that, when approaching and passing promontories and particularly headlands, ancient mariners had to take into account various considerations, some relating to the local topography, and other relating to the various influences which that topography exerted upon local meteorology and oceanography. The strength of these influences tends to vary in accordance with the size of the promontory in question, larger promontories and more abrupt headlands tending to have a more pronounced effect upon winds, waves, and currents than smaller promontories and less abrupt headlands. Overall, however, ancient Greek sailors found sailing conditions around headlands complicated and difficult in comparison to the conditions they generally encountered at other areas of the coast ${ }^{219}$.

\section{Dangers associated with the topography of headlands.}

Even without related meteorological and oceanographic complications, promontories themselves were often problematic for sailors; the difficulties lay less in the form of the actual promontory as in the contours of the sea bed falling away from its shores. It has been shown that faulting and submergence in Greece have resulted in a highly indented coastline featuring major promontories predominantly aligned on a roughly NW-SE axis (above, p.17ff.), and that such major elements of coastal topography themselves feature many lesser headlands and indentations formed by erosion of the stratified sedimentary rock of which much of the Greek coastline is composed (p.21ff.). Promontories which originated through the submergence of a mountain ridge retain their mountainous form both above and below water, so that their typically steep lateral slopes continue underwater as steeply shelving seabeds, while the central ridge leading down to the promontory's headland is prolonged by a submarine ridge, again usually with steeply sloping sides (p.18). The waters in front of headlands were therefore areas where the sea floor could rise rapidly to the surface 
from great depth, while peaks on the submerged ridges were occasionally not fully submerged, but remained above water as offshore islands (p.28ff., fig.26). More dangerous than clearly visible islands were areas where the submarine ridge did not quite break the surface of the water, but instead supported submerged rocks which posed a serious threat to ships (below, p.129f.).

Submerged and sea-washed rocks were clearly not exclusively found around headlands, but ancient Greek sailors did strongly associate the two with each other, as can be seen in traditions relating to the mythological Skylla. While most famously associated with the passages of Odysseus (Hom.Od.12.200ff.) and of Jason (Ap.Rhod.Arg.4.920ff.) through the Straits of Messina, there were other traditions regarding the monster, and indeed when Aeschylus (Agam.1233f.) talks of ' $a$ Skylla ( $\Sigma \kappa \cup ́ \lambda \lambda \alpha \nu \tau \imath \nu \grave{\alpha}$ ), tenanting the rocks, a pest of mariners', the term 'Skylla' appears to be less the name of a specific mythological character and more a generic term for the monsters that symbolised the dangers of rocky coasts, and the dread mariners felt when sailing in their vicinity ${ }^{220}$. In any case, the locality actually called 'Skyllaion' after the monster of the Odyssey and the Argonautica, at the northern entrance to the Straits of Messina, was a high and rocky promontory (Str.Geog.6.1.5: $\pi \dot{\varepsilon} \tau \rho \alpha \chi \varepsilon \rho \rho \circ \vee \eta \sigma i \zeta o v \sigma \alpha \dot{v} \psi \eta \lambda \eta ́)$ which mariners clearly held in fear. Moreover, the only other locality known as Skyllaion was also a promontory, acute and with numerous rocky islets in the waters in front of it. Situated in the Argolic peninsula, at the southwest entrance to the Saronic Gulf, this second Skyllaion promontory was said to be where the body of the drowned Skylla (here the treacherous daughter of Nisos of Megara, cast into the sea by Minos) was washed $u^{221}$. Despite the different aetiologies developed for the two promontories, it seems clear that the name Skyllaion was consciously associated with promontories where the rocky coast, and possibly other factors, posed a threat to those sailing the seas nearby $^{222}$.

However, submerged rocks and shallow reefs were not only found at promontories produced by submergence; they were also found where outcrops of hard durable rock 
had resisted erosion while the softer rock around them had been worn back along a retreating shoreline (p.31, see fig.29). Such rocks and reefs might be found along any stretch of coast that was open to erosion and featured a variety of rock types, some of which would resist erosion more than others (see fig.30). Such variegated rock coasts were most commonly composed of the stratified sedimentary rock which predominates throughout Greece, but also included areas where hard volcanic rocks were present (for which see p.30). A good example of an eroded coastline fronted, especially off the promontories, by submerged rocks and reefs is the island of Aigina in the Saronic Gulf, the southern part of which is predominantly volcanic, the northern sedimentary; ancient and modern commentaries alike stress the danger that such rocks pose to mariners, and the care which must be taken when sailing in their vicinity:

'Of the Greek islands, Aigina is the most difficult of access, for it is surrounded by sunken rocks [ $\pi \varepsilon \dot{\varepsilon} \rho \alpha 1 \quad 0 \% \alpha \lambda o 1]$ and reefs which rise up

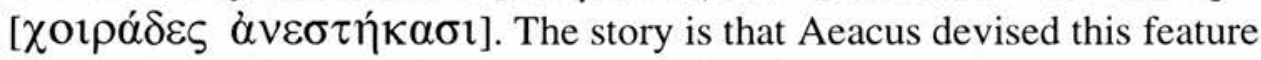
of set purpose, because he feared piratical raids by sea, and wished the approach to be perilous to enemies.' (Paus.2.29.6)

'Chandler, who coasted along Aegina [Aigina], says: "Our crew was for some time engaged in looking out for one of the lurking shoals, with which it is environed. These, and the single rocks extant above the surface, are so many in number, and their position so dangerous, that the navigation to Aegina was antiently [sic] reckoned more difficult than to any other of the islands." ' (Frazer (1898) vol.3, p.262, on Paus.2.29.6)

'Both these capes [Cape Pyrgos, the southerly point of Aigina, and Cape Andonis, in the northwest of the island] are surrounded by shoal water and should not be approached too near...Cape Turlo, the northeastern point of Aigina, is cliffy on the east face and the shore for half a mile seaward is bordered by rocks above water, sunken and awash, to a distance of nearly 2 cables [roughly 400 yards].....About two thirds of a mile westward of Cape Turlo is Nisidia, a small islet connected with the shore by rocks; both Cape Turlo and Nisidia are surrounded by rocks and should be given a wide berth.' (Mediterranean Pilot IV, p.121)

Even experienced mariners might not easily remember the position of so many unmarked submerged rocks with any accuracy (see Hdt.7.179 quoted below, p.94), 
and sailors had to rely on spotting them from the deck before it was too late to take evasive action. Given that ancient ships did not stand particularly high out of the water (below, p.238f.), and that even in summer the seas were likely to be raised and choppy under the influence of the forceful Etesians, spotting underwater rocks from aboard ship was a difficult task, responsibility for which fell to the crew member who came second only to the helmsman in rank and probably also in experience ${ }^{223}$. This was the proreus ( $\pi \rho \omega \rho \varepsilon \cup ́ \varsigma)$ or prorates ( $\pi \rho \omega \rho \alpha \dot{\tau} \tau \varsigma)$, who was stationed in the foredeck of the ship, often on a raised platform called the $i k r i a($ I $\kappa \rho \alpha)$ to aid his vision, and who was generally responsible for all look-out duties ${ }^{224}$ :

'...Tiphys is pilot [kubernetes] of the ship; he is said to have been the first of men to have been bold enough for the art which was still then mistrusted; and Lynkeus son of Aphareus is stationed at the prow, a man gifted in seeing far ahead and in peering deep down into the depths, always the first to discern submerged reefs and the first to salute land as it dimly appears on the horizon.' (Philos.Imag.2.15)

Some areas of the coast, particularly where the state of the coastline had come about both through the submergence of a faulted mountainous area and as a result of the subsequent marine erosion of the stratified rock of which that mountain was composed, were so infested with reefs and submerged rocks over such a wide area that mariners reacted not by maintaining a lookout for hidden dangers but simply by avoiding the area altogether whenever possible, or passing it at a very safe distance. Along such coasts, erosion produced long progressions of alternating rocky headlands and equally rocky inlets where no landfall was to be found even if a ship were to successfully negotiate the rocks and reefs in front of the coast. The names of such areas often reflect their eroded and indented nature. Thus Ipnoi ( $\ \pi$ Vor), 'the Ovens', 'one of the rugged places in the region of Pelion' (Str.Geog.9.5.22), and the

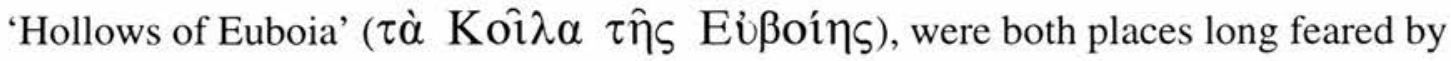
mariners, where the Persian navy, less well informed and lacking local guides, came to grief $^{225}$. The Hollows of Euboia (fig.13) may also be understood to be the site of the wreck of the Greek fleet returning from Troy, which turned shorewards from the open sea in expectation of finding the shelter indicated by Nauplius' (false) beacons on 
Kaphereus promontory, north of the Hollows (Str.Geog.8.6.2, Eur.Troad.84, Hel.766f., 1126-31). Here, on the west coast of the Aegean, the topographic dangers were compounded by the prevailing winds and currents, which were onshore (see below, pp.75f., 106ff.); on the Aegean's east coast, the dangers from offshore rocks and reefs were just as great, but the more favourable current (flowing northwards, so generally as a counter to the northerly winds - see pp.40f., 46), and the shelter available in the bays between the major promontories and offshore islands (see below, p.99) allowed this coast to be navigated relatively safely.

\section{Dangers associated with sea conditions around headlands.}

The contours of the sea bed along a submerged and indented coastline cause waves to converge around headlands and to be dissipated in bays (p.36f., fig.32). Because of this, and because headlands often protrude into the open sea, where particularly large waves are to be found (p.33), any difficulties that waves presented to ancient Greek mariners, e.g. casting water over the gunwales or through oarports (p.238f.), were likely to be most problematic at headlands. Moreover, the depth of water in which waves begin to break increases with their height (p.34f.), so that, in the vicinity of headlands, breakers and surf (which cause greater problems to mariners than properly formed waves) will often be found further from the coast than in other areas. This is especially the case where headlands were fronted by shallow reefs or a submarine ridge lying not far beneath the surface of the water even when some distance from the coast, and causing waves to break over them even in fairly settled conditions. Such areas of coastal surf were rightly seen by ancient sailors as dangerous areas to be avoided whenever possible (see p.130f.). Larger waves than normal were also likely to be produced as a result of the meeting of winds (for which see p.74) and of currents (below) at headlands, for these meetings cause wave crests to be further elevated, and troughs to be further deepened. Theophrastos thus noted that conflicting winds over the sea produced dangerously large waves:

'When they come into contact with each other, great waves arise, since the sea is pushed together, and many waterspouts occur, by which ships are wrecked. Usually when such a collision of winds occurs, great waves 
are caused and a great storm arises, as when people speak of the winds fighting when they blow against each other...' (Theophr.Vent.53f.)

Currents also tend to be strengthened and often complicated around headlands. Headlands are not only more exposed to deep sea currents than other areas of the coast, but may also, especially if they stand at the end of major promontories, be points where deep sea currents strengthen or meet, in which case the set of the current may not always remain constant and predictable (p.41ff.). Thus the Thracian Chersonesos separated the strong currents flowing into the Aegean from the Hellespont from the calmer waters of the Melas Gulf, and the promontory, like others in similar positions, was therefore seen as the dividing line between different local 'seas' (p.43). Apollonius of Rhodes notes the changing currents as the headland is rounded:

'Thence [from Samothrace] did they row with eagerness over the depths of the Black Sea [i.e. the Gulf of Melas], having on the one side the land of the Thracians, on the other Imbros to the north ${ }^{226}$; and as the sun was just setting, they reached the foreland of the Chersonesos. There a strong south wind blew for them; and raising the sails to the breeze they entered the swift stream of the maiden daughter of Athamas [the Hellespont]...' (Ap.Rhod.Arg.1.922-8)

Nearshore currents resulting from longshore drift also commonly increase the complexity and force of currents around headlands, and produce rip currents transporting large amounts of water back out to the open sea, against the general flow of the prevailing current (p.41f.). Waves also heighten where currents flowing in different directions meet (p.35, n.87). Such complications clearly added to the difficulties facing mariners who were used to currents which elsewhere were gentle and predictable (see pp.231-4), and generally caused little inconvenience. The rougher conditions to be found around headlands are reflected in names such as Plemmyrion, a cape adjoining the harbour of Syracuse, named after the strong tidal current ( $\pi \lambda \eta \dot{\mu} \mu \bar{\nu} \rho \alpha, \pi \lambda \eta \mu \mu \bar{\nu} \rho \dot{i} \varsigma$ ) found there (fig.56.i), and Araxos, the 'wave-breaker' (from $\alpha \dot{\rho} \alpha \dot{\sigma} \sigma \omega)$, the northwest cape of the Peloponnese ${ }^{227}$. 


\section{Dangers associated with winds around headlands.}

Winds are also likely to be particularly strong and often confused around headlands, where the full force of winds blowing unimpeded off the sea are felt. Some promontories were named after a wind to which they were notoriously exposed, as in the case of (Epi)Zephyrion near Lokris in southern Italy (Str.Geog.6.1.7, Scymn.Perieg.311f.), Zephyrion in Cilicia on the southern coast of Asia Minor (Str.Geog.14.2.20, 5.4, Scylax Perip.85), and Zephyrios Limen on the eastern shores of the Black Sea (Scylax Perip.72) ${ }^{228}$. Similarly in the oracle recorded by Ephorus which instructs Poseidon to cede Delphi to Apollo in return for Tainaron, Delphi merits the description 'most holy', while Tainaron is simply 'windy' (Str.Geog.8.6.14:

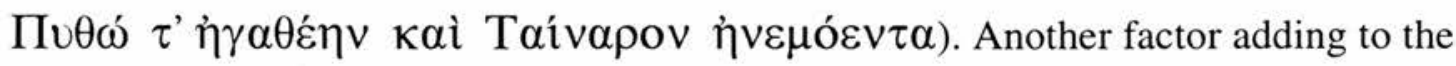
confusion of winds around headlands is that winds coming from different directions may meet at headlands. Sometimes a new wind that sailors encountered on rounding a headland happened to blow in just the direction in which they wanted to sail. Such was the southwest wind which helped mariners sailing from Sicily and southern Italy towards Greece (and see Ap.Rhod.Arg.1.922-8, quoted above, p.73):

\footnotetext{
'As one sails from Rhegion towards the east, at a distance of 50 stadia, one comes to Cape Leukopetra (so called from its colour), in which, it is said, the Apennine mountain terminates. Then comes Herakleion, which is the last cape of Italy and inclines toward the south; for on doubling it one immediately sails with the southwest wind as far as Cape Iapygia, and then veers off, always more and more, towards the northwest in the direction of the Ionian Gulf.' (Str.Geog.6.1.7)
}

Likewise Xenophon recognises the benefits to be had from the different winds blowing on either side of Sounion, the extremity of the Attic peninsula ${ }^{229}$ :

'Though Attica is no island, yet we have the same benefit of trading with all winds, for we are bounded on two sides by the sea.' (Xen.W\&M.1.1)

However, such beneficial winds were not found at all headlands, and equally only hindered those sailing along the same route but in the opposite direction, against the wind. Moreover, while such winds might have been useful in sailing to and from 
headlands, the area around the headland, where the winds actually met, was likely to be difficult to navigate. Also, even where only one wind prevailed, considerable turbulence, stormy weather or even thunderstorms, may be produced where a strong sea wind meets a steeply rising coast (pp.57-65), as is reflected in the names of (Akro)Keraunia, 'Cape Thunder' (Str.Geog.6.3.5, Scylax Perip.27f., Propert. El.1.8.13f., 2.16.3), a dangerous and often storm-ridden headland of northwest Greece between Corcyra and Apollonia, and Cheimerion, 'the Stormy Cape' (Str.Geog.7.7.5, Paus.8.7.2, Thuc.1.30, 46), found further south, opposite Corcyra ${ }^{230}$.

Where prevailing winds struck directly against one flank of a promontory, the vertical displacement of those winds caused sometimes turbulent and squally conditions on the lee, or sheltered side of the promontory (p.57ff.). Such alignment of promontories relative to the direction of prevailing winds is especially common around the Aegean, where most promontories of mainland Greece and many islands extend towards the southeast (p.18f., maps 3, 5, 7, 9), and the promontories of Asia Minor extend towards the west (p.21, fig.46, map 11). Most of these promontories obstruct the passage of the prevailing Etesians, blowing down from the northern quarter (p.48ff., fig.41). Ships attempting to round such promontories in either direction encountered many difficulties.

Thus ships sailing from the lee to the exposed side of the promontory had the difficult task of rounding the headland against the wind, and, if successful, then risked being blown back onto the exposed side of the promontory. Ships sailing up the coast of Asia Minor towards the Hellespont found it particularly difficult to round the Lekton promontory because of the fierce winds that they encountered at the headland as they left the shelter of the Bay of Adramyttion, south of the Troad peninsula ${ }^{231}$.

Meanwhile, ships sailing with the wind also faced the same risk of being blown onto the exposed side of the promontory as they approached its headland, past which, once reached, the wind would safely drive them. Odysseus describes being shipwrecked in just this way. Being keen not to reveal the location of his ship to Polyphemus, 
Odysseus instead claims to have lost it. His fictional explanation of how this happened, which is presumably intended to be characteristically credible and believable, involves shipwreck on a headland in strong winds, i.e. we are to presume that such disasters at headlands were by no means uncommon or implausible. We may also note that the rocks which we have seen to be characteristic of headland topography (pp.24f., 29f.) are also said to be instrumental in the destruction of the ship - had Odysseus described being driven onto an area of the coast not typically associated with rocks, he may have had more trouble explaining the utter destruction of his ship; thus the hero has composed his story with typical cunning:

'My ship Poseidon, the earthshaker, dashed to pieces, casting her upon the rocks at the border of your land; for he brought her close to the headland, and the wind drove her in from the sea.' (Hom.Od.9.283-6)

Quintus Smyrnaeus describes the dangers of strong winds blowing onto exposed rocky headlands even more graphically:

\begin{abstract}
'backward they sank, and fast she [Penthesileia] followed, as a towering surge chases across the thunder-booming sea a flying bark, whose white sails strain beneath the wind's wild buffeting, and all the air maddens with roaring, as the rollers crash on a black foreland looming on the lee where long reefs fringe the surf-tormented shores.' (Quintus Smyrnaeus Fall of Troy 1.318-23)
\end{abstract}

Where prevailing winds blew not against one side of a promontory, but directly onto its headland and up its spine, ships rounding the headland in either direction had first to reach far enough out to sea, against the wind, to ensure that they would not be blown directly onto the headland or the rocks in front of it as they rounded it.

In addition to prevailing winds like the Etesians, the Bora, or the Sirocco, local breezes may also complicate wind patterns at headlands. Thus when land and sea breezes, often strengthened by mountain and valley winds, are channelled through bays hemmed in by high promontories on either side (p.55), they will spill out around the headlands in which those promontories terminate. 
All of these factors concerning the topography of headlands, and the waves, currents, and winds to be found in their vicinity, combined to create sailing conditions which were not only very difficult, but were also far harder to predict than was the case at other points on the coast. In strong winds from any direction, sailors were wise to pass headlands at some considerable distance if at all possible, to avoid coming too close to the coast or the rough and rocky waters nearby ${ }^{232}$. Failing to do so caused the disaster which befell the Persian fleet at Mount Athos in 492 BC (fig. 50):

'Crossing then over from Thasos, they voyaged near the land as far as Akanthos, and putting out from thence, they would have rounded Athos. But as they sailed, there brake upon them a north wind [Boreas] great and irresistible, and dealt very roughly with them, driving many of their ships upon Athos; 300, it is said, is the tale of the ships that perished, and more than 20000 men. For inasmuch as these coasts of Athos abounded in wild beasts, some were carried of by these and so perished; others were dashed against the rocks; and those of them that could not swim perished by reason of that, and others again by the cold.' (Hdt.6.44)

High seas and dangerous currents are found off Mt. Athos ${ }^{233}$, while Herodotos mentions the rocks along the coast. These certainly played their part in the destruction of the fleet, but it was strong winds that initially caused the disaster. The wind in question was Boreas, a fierce northerly produced by the same juxtaposition of cold dry high pressure air over the continental interior and warmer moist low pressure air over the sea which gives rise to the violent Bora in the Adriatic (p.51f.). Although Darius had earlier sent a reconnaissance party on a periplus of the Greek seaboard (Hdt.3.134ff.), the Persians apparently remained unaware of the threat posed by Boreas in the northern Aegean. This is all the more remarkable, given that the danger was well known to the Greeks, and that strong northerlies (Boreas, and predominantly the Etesians) prevail all through the summer months in the Aegean. As the Persian fleet was sailing from Akanthos, on the coast north of the Athos promontory, down to the headland at its tip, and given that, like most major Greek promontories (see p.19), Athos extends in a southeasterly direction, the Persian fleet was always in danger of being blown directly onto its northeastern shore if a northerly wind sprang up while they were sailing so near to the coast (see p.75). A far safer route from Thasos would 
have been to sail directly to Athos in a southerly direction, and so to approach the headland of Athos from the east. Rather than having to sail down the northeastern coast of the promontory from Akanthos, the Persian fleet could thus have approached the headland from the open sea, and so avoided coming close to land at all.

When Darius invaded Greece the following year, he decided not to risk the passage round Athos again (Hdt.6.95: fig.50). During Xerxes' invasion, the problem was circumvented by means of a canal cut across the isthmus at the base of the promontory, near Akanthos (Hdt.7.22ff.). However, as noted above (p.75), the combination of strong northerly winds and long rocky promontories stretching in a southeasterly direction is, in the Aegean, by no means confined to Athos, and Xerxes effectively made exactly the same mistake by not only having his fleet sail down the coast of Magnesia ('a coast with terrible winds ( $\alpha i \gamma \imath \alpha \lambda$ ó $\delta \delta \sigma \eta ́ v \varepsilon \mu o v)$ ': Ap.Rhod.Arg.1.593), but then actually having it anchor off Cape Sepias and the coastline stretching away to the northwest (fig.50). The fleet, tucked in against a rocky and harbourless northeast-facing shoreline (for the rocky 'Ipnoi', see above, p.71), was again vulnerable to winds blowing from the north or east, and again disaster ensued (Hdt.7.188f.).

\section{Malea.}

Of all Greek headlands, Malea, the southeastern tip of Lakonia, clearly had the worst reputation, and with good reason, for it was a steep and relatively harbourless promontory (fig.51), and its position meant that winds and currents in its vicinity were always likely to be strong. The whole area around the three southerly promontories of the Peloponnese, namely Malea, Tainaron, and Akritas, was the meeting place for the currents and the winds of the Aegean, the Adriatic, and the Ionian Seas.

Thus all three promontories lay on the principal track followed by depressions moving out of the Adriatic Sea in winter (p.50ff., fig.42), and so were frequently crossed by storms, and were exposed to the southerly and southwesterly rainbearing winds which blew from Africa, usually in association with the warm fronts of depressions (pp.48f., 
52). The northerly Bora, blowing from the Adriatic in association with the cold fronts to the rear of depressions (pp.48f., 51f.), blew at full force straight off the sea against Akritas, the westernmost of the three promontories, and, after having been funnelled down the long valleys and Gulfs of Messenia and Lakonia, against Tainaron and Malea. The Etesians and other northeasterlies blowing from the Aegean struck Malea most forcefully, although again, funnelling down the gulfs of Lakonia and Messenia brought the winds also to Tainaron and Akritas. At Malea the Etesians blew with their natural northeasterly orientation, and thus struck straight across the promontory, which, like the promontories of Athos and Magnesia, extended in a southeasterly direction. Thus, here again, ships were in danger of being blown against the exposed northeastern face of the promontory, while, on the opposite side, the Etesians, having crossed the high ground, fell down upon the surface of the sea in gusts and squalls. Around the headland itself, Etesians blowing straight off the Aegean met those which had been funnelled down the Lakonian Gulf, and which, following the orientation of that gulf, blew as northwesterlies (for such re-orientation of funnelled winds, see p.60). Thus at Malea northeasterly meets northwesterly, the former usually predominating, with the two then continuing southwards together. Winds at these headlands were further complicated by the strong land and sea breezes which blow in and out of the Lakonian and of Messenian Gulfs whenever they are not overpowered by stronger winds ${ }^{234}$. Little wonder, then, that Strabo (Geog. 8.6.20) described the

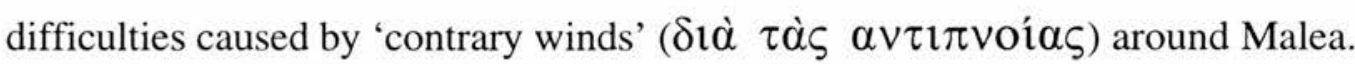

Regarding currents, the area south of the Peloponnese was where the current moving southwestwards from the Aegean through the gap between the Peloponnese and Crete encountered the current flowing eastwards across the central and southern Mediterranean from Gibraltar, and so was diverted northwards around the Peloponnese into the Adriatic. The current flowing out of the Aegean, being increasingly repelled and counteracted the further south it progresses, tends to be strongest in the north, i.e. along the coasts of Malea, Tainaron, and Akritas, and up the western face of the Peloponnese (p.41, figs.39, 40). Thus as well as being exposed to fierce winds, the whole of the southern Peloponnese, and particularly Malea, where 
the strait between the Peloponnese and Crete was narrowest, was an area of high seas where currents were stronger, and also less predictable, than in most other areas of the Mediterranean. The meeting of major currents and winds in this area caused further inconvenience because of the particularly large waves which occurred as a result (see below, p.81, for the waves 'swollen to huge size, like unto mountains' encountered by Menelaos at Malea).

Thus Malea deserved its bad reputation. Indeed the whole area south and west of the Peloponnese was subject to fearsome northerly winds during the summer sailing season, when ships could even be blown all the way to Africa against their will. Thus in 413 BC nine hundred Spartan and Boiotian hoplites sailing in merchant ships from Tainaron to Sicily encountered winds which forced them off course as far as Libya (Thuc.7.19, 50). Meanwhile the Corinthian fleet in the Adriatic with which this force was to rendezvous, had earlier been 'caught and driven out to sea by the wind which blows very strongly in these parts when it sets in from the north [the Bora]. After an extremely stormy passage he [Gylippos, the commander of the fleet] got back again to Tarentum [Taras].' (Thuc.6.104) ${ }^{235}$. Similarly, Ap.Rhod.Arg. 4.1240ff. describes how Jason was blown from the northwest Peloponnese to Libya by stormy northerlies.

In the tales of Jason that Herodotos was familiar with, however, it was from Malea, rather from the northwest Peloponnese, that the Argo was blown to Libya by northerly winds (Hdt.4.179, quoted below, p.119). In many ways, Herodotos' version is the more typical, for Malea more than anywhere else was associated with tales of mariners being blown hopelessly off course, possibly because it was at Malea that

ships sailing out of the Aegean first entered this area of furious winds:

'Just as in early times the Strait of Sicily [Straits of Messina] was not easy to navigate, so also the high seas, and particularly the sea beyond Malea were not, on account of the contrary winds, and hence the proverb 'But when you double Malea forget your home'. At any rate, it [the diolkos at the Isthmus of Corinth] was a welcome alternative, for the merchants both from Italy and from Asia, to avoid the voyage to Malea and to land their cargoes there.' (Str.Geog.8.6.20: comp. Anth.Pal.7.584) 
Some merchants, however, continued to use the Malea route, and their relief and pride at repeatedly surviving the journey is easily discernible in the epitaph on the tomb of a merchant from Hierapolis in Karia, which reads simply 'Flavius Zeuxis, merchant who travelled round Cape Malea seventy-two times to Italy. ${ }^{236}$. Just how old the proverb quoted by Strabo was by the time he recorded it is not clear, but Bacchylides had long since likewise seen Malea as symbolic of sudden danger:

\begin{abstract}
'But, as oft at Malea, the god sends sudden stress of trouble on the children of a day. Thou lookest to the needs of the time: our life is short...' (Bacc.Ep.3.72-4) ${ }^{237}$
\end{abstract}

Earlier still, Homer knew well of the dangers of Malea. In the Odyssey, the headland appears no less than four times as the place at which mariners are blown off course by forceful winds. First (Od.3.276-300) Nestor describes how Menelaos, after passing Sounion (the headland where he lost his steersman Phrontis, "who excelled the tribes of men in piloting a ship when the storm winds blow strong'), carried on to Malea, where terrible winds, and waves 'swollen to huge size, like unto mountains', forced him off course, half his fleet being wrecked on a Cretan headland, the rest, including Menelaos' own ship, being driven all the way to $\mathrm{Egypt}^{238}$. When Agamemnon tries to round Malea, on the other hand, he is blown in the opposite direction, all the way back to the Argolic peninsula, before the winds change and he reaches home (Od.4.512-522); this episode may reflect real problems faced by mariners rounding Malea from the northeast when the southwesterly Sirocco reached full force. Later Odysseus tells how, even during a period of relatively fair weather, 'the wind and the current and the north wind Boreas beat me back as I was rounding Malea, and drove me from my course past Kythera' (Od.9.76ff.), and when, in the guise of Aethon, he tries to explain to Penelope how a Cretan might have news of Odysseus, he 'explains', again credibly, that Odysseus was blown off course all the way to Crete when trying to round Malea en route for Troy (Od.19.185ff., quoted below, p.95).

This last episode is the only one of the four from the Odyssey in which a ship is attempting to round Malea from the west. Just as it was hard to round Malea from the 
northeast if a southwesterly happened to be blowing, as in Agamemnon's case, so the passage from the west was greatly hampered by the Etesians which normally prevailed around Malea ${ }^{239}$. According to Herodotos, this was how the Corcyraeans justified the failure of their sixty ships to appear at the battle of Salamis (Hdt.7.168f.); the Corcyraeans may have been telling the truth here, or simply covering up the fact that they had wanted to wait until a clear victor, Greek or Persian, had emerged before committing themselves to either side, but if the latter, then their story merely reaffirms the dangers associated with Malea, and shows that the Corcyraeans, as well as the Cretans and Odysseus, knew how to tell plausible and convincing lies.

\section{STRAITS.}

As noted above (p.67), straits are mentioned very commonly in ancient literature, and were one of the features of coastal topography which mariners most regularly and most closely encountered during their voyages. The main hazards facing mariners in straits are the strength and fluctuations of the current, the strength of the winds blowing through the strait, the number and force of squalls blowing across the strait from high land along its edges, and submerged or awash rocks. These hazards made straits places of particular difficulty for ancient seamen ${ }^{240}$, as is suggested by Pindar's reference (I.4.56f.) to 'Alkmene's son [Herakles], who to Olympos passed, after he had tracked out all the lands and even the cliff-girt level of the foaming sea, and had tamed the wild straits for the seamen.'

\section{Problems related to currents in straits.}

Currents in the seas around Greece are generally quite weak ${ }^{241}$, but run more strongly through the straits separating islands from each other and from the mainland, and in narrow channels connecting large bodies of water, such as the Hellespont/Bosporos breach, and the mouth of the Corinthian Gulf (pp.44-47). These strengthened currents, which increased the difficulty of travelling in any direction other than that in which the current set, clearly had to be dealt with carefully in straits, where the 
expanse of the open sea was reduced to narrow channels, and room for manoeuvre was thereby restricted. That being said, in many straits the increased strength of the current alone would not have endangered or seriously delayed mariners and their ships, although added factors such as winds might complicate matters. Where currents in straits did cause mariners problems, this was normally due to one or both of two reasons: either the current was so unusually strong that ships found it difficult to make headway against, and possibly were hard to control even when sailing with the current, or else the current was not a simple one-way flow but featured surface eddies or occasional complete reverses of flow, making it especially difficult for mariners to predict when and how best to navigate the strait with safety ${ }^{242}$.

Where currents are relatively weak, and winds variable, the direction of the current in a strait can vary with that of the wind or the state of the tide, as in the Chian Strait (p.46), in the mouth of the Corinthian Gulf (p.47), and in the Corcyra channel ${ }^{243}$ (fig.40). Stronger refluent currents are not common in the Mediterranean (as they are mainly a product of tidal forces, which are relatively weak in this enclosed sea), but exist at the Euripos and the Straits of Messina (p.46f.). There is little evidence that the Euripos' refluent currents (fig.38) were considered a particular danger to shipping, despite the force of the current and the narrowness of the strait there (c. $40 \mathrm{~m}$.). With the direction of the current changing several times a day, ships could avoid having battle against a strong current simply by waiting for its direction to change, when the passage could be made with a following current.

In complete contrast to the lack of perceived danger at the Euripos, the Straits of

Messina were celebrated for their danger, being identified with the strait of Skylla and Charybdis through which both Odysseus (Hom.Od.12.73-110, 230-59) and Jason (Ap.Rhod.Arg.4.920ff.) had to pass. In these mythological accounts, the real nature and danger of the refluent currents are obscured by the exaggerated and symbolic way in which the strait is described. This exaggeration, in the Odyssey at least, may be due to the fact that the Straits of Messina were, in Homer's day, still on the periphery of 
the known world, where real geographical knowledge tended to merge with fantastic accounts of the mythological world. In reality, of course, ships chose to sail through the strait rather than having to make the long trip around Sicily, but the strong currents, which at times exceed six knots, and the whirlpools and rip currents that were brought about by tidal changes, with which Greek sailors were largely unfamiliar (see pp.133f., 231ff.), did constitute one of the greatest dangers ancient Greek sailors were ever likely to face ${ }^{244}$. Thus both Thucydides and Strabo remark upon the dangers sailors faced in navigating the channel, particularly the whirlpool which had been identified with the Homeric Charybdis:

'Now the strait is that arm of the sea between Rhegion and Messene, at the point where Sicily is nearest the mainland; and it is the Charybdis, so called through which Odysseus is said to have sailed. On account of its narrowness and because the water falls into it from two great seas, the Etruscan [Tyrrhenian] and the Sicilian, and is full of currents, it has naturally been considered dangerous.' (Thuc.4.24)

\begin{abstract}
'Messene is situated in a gulf of Pelorias, which bends considerably towards the east and forms an armpit so to speak; but though the distance across to Messene from Rhegion is only sixty stadia, it is much less from Columna.....And in the ship channel, only a short distance off the city, is to be seen Charybdis, a monstrous deep into which the ships are easily drawn by the refluent currents of the strait and plunged prow-foremost along with a mighty eddying of the whirlpool.' (Str.Geog.6.2.3)
\end{abstract}

As noted above (p.83), the sheer velocity of the current in some straits caused serious difficulties for seafarers. This is especially true of the strong currents found in straits connecting the Mediterranean to other bodies of water, i.e. the Straits of Gibraltar and the Bosporos/Hellespont breach. The Straits of Gibraltar were for long seen as a point through which it was too dangerous to sail (p.231), and this was not solely due to the more dangerous conditions to be found beyond the Straits, in the Atlantic, but also because of the difficulty of navigating the Straits themselves. This difficulty was due largely, especially when sailing westwards towards the Atlantic, to the strong surface current flowing eastwards into the Mediterranean at a rate of roughly six knots ${ }^{245}$. 
The Hellespont and Bosporos straits, which were of far more nautical, commercial and strategic importance to the Greeks than the Straits of Gibraltar, also feature surface currents of six knots (p.44f.; faster where jutting headlands decrease the width of the channel - p.46), flowing southwestwards from the Black Sea to the Aegean. Currents of such strength flowing through narrow straits were not only dangerous, but were also very difficult for ancient ships to make headway against. There were counter-currents running against the main flow (p.44f.), with the help of which ships could more easily progress up the bays and backwaters of the channel, but there was no such help to hand at the headlands, where the strait was most constricted and the current ran most forcefully. Heavily manned oared ships, such as pentekonters and triremes, could pass through the Bosporos with difficulty ${ }^{246}$; sailing ships, however, could not pass through the Hellespont and particularly the Bosporos against the prevailing northeasterly Etesians, without the use of supplementary oars, with which many merchant ships, including all holkades, were not equipped. The Etesians here were not only a problem in their own right, but also caused the current in the straits to strengthen ${ }^{247}$, and sailing northwards through the Bosporos was only possible on those days when strong diurnal breezes ${ }^{248}$, or else southerly or westerly winds, blew. Southerly winds do generally blow on a significant number of days in each month in summer, but ships would often have had to wait a week or more for them to appear. Southerly winds were much more common in winter and, along with westerly winds, in spring, when the Etesians were interspersed between the light westerly winds that accompany returning high pressure conditions, and cyclonic winds, including the southerly Sirocco, which may blow with great force during the passage of warm fronts $^{249}$. The importance of these winds in easing the northerly passage of ships through such a strategically and commercially important sea-lane may have been one reason why some sailors would continue to make voyages both before the onset, and after the end, of the more settled conditions of summer proper (for sailing outwith the summer months, see pp.223-6). For exactly the same reasons then, Philip II of Macedon chose to wait until either the establishment of the Etesians or the onset of winter conditions before attacking pro-Athenian cities around the Hellespont 'at a time when we [the Athenians] could not possibly reach the seat of war.' (Dem.4.31; 
compare Dem.8.14). Here Demosthenes may be exaggerating the difficulty of reaching the northern Aegean and the Hellespont during winter and summer, (p.243, and n.509), but this passage does show that the autumn and especially the spring periods were especially important in the navigation of the Hellespont and Bosporos: in summer the Etesians were powerful headwinds to face, and in winter, although southerly winds at times prevailed, conditions were often too stormy for sailing.

Thus the passage of the Argo through the Hellespont, a mythological event which Carpenter suggests might celebrate or be inspired by the first real voyage by a Greek ship to the Black Sea ${ }^{250}$, was, according to two different sources, completed by just such a combination of south wind, sail, and oar as would have been necessary for any sailing ship to overcome the strong currents:

'And just as the sun was setting they reached the foreland of the [Thracian] Chersonesos. There they met a strong wind from the south, set their sail to it and entered the swift current of the Hellespont, which takes its name from Athamas' daughter. By dawn they had left the northern sea; by nightfall they were coasting the Rhoiteian shore, inside the straits, with the land of Ida on their right. Leaving Dardania behind, they set course for Abydos, and after that they passed in turn Perkote, Abarnis with its sandy beach, and sacred Pityeia. Before dawn Argo by dint of sail and oar was through the darkly swirling Hellespont.' (Ap.Rhod.Arg.1.925-35)

'From under their swift hands the rowing proceeded tirelessly. Sped by the breezes of the South Wind [Notos], they came to the mouth of the Inhospitable Sea [Black Sea]...' (Pind.P.4.202ff.)

Currents as strong as those found in the Hellespont and Bosporos occur elsewhere in the Aegean, at points where the strong outflow from the Hellespont is funnelled through relatively narrow gaps, particularly the straits separating the islands of Euboia, Andros, Tenos, and Mykonos, which together present a barrier lying directly in the path of the current running down from the northeast.(p.45, fig.40). In the Doro channel separating Andros from Euboia, through which all the waters striking the long northeast coast of Euboia are channelled (p.46), the current may rise to seven knots, a rate that even triremes may have had difficulty overcoming ${ }^{251}$. 


\section{Phormio, the land breeze, and the funnelling of winds through straits.}

Currents in straits and elsewhere do not always run at a constant speed, but are influenced by the wind (see, for example, p.46). Thus a following wind will increase the speed of the current, while a headwind will slow the current. This is particularly significant in the Aegean, as the prevailing northeasterly Etesians thus strengthen the current flowing southwestwards through straits such as the Hellespont and the Doro channel. When passing through the narrow gaps formed by straits, funnelling intensifies the strength of these winds ${ }^{252}$, and the combined effect of current and wind regularly prevented shipping from proceeding up straits, as in the case of the Greek fleet arriving at the Hellespont from Mykale in 479BC (Hdt.9.114). Likewise, ships unable to pass northwards through the Doro channel may have resorted to the Bay of Karystos for shelter, or sought an alternative route through one of the island straits to the southwest, or through the Euboian sound (fig.47.i) ${ }^{253}$.

During the Peloponnesian War, the funnelling of winds and the channelling of waters through straits was apparently used to great effect by the Athenian general Phormio $^{254}$, who, with twenty triremes, was sent to Naupaktos to guard the entrance to the Corinthian Gulf in 429 BC (Thuc.2.69.1). Faced with the challenge of engaging forty-seven Peloponnesian ships, in order to prevent them from leaving the Gulf and reaching their allies in Akarnania, Phormio was understandably keen to exploit not only the tactical superiority of his own ships (compounded by the extra weight burdening the Peloponnesian ships, which were carrying troops and supplies and had hoped to avoid a naval encounter ${ }^{255}$ ), but also the inferior training and discipline of the Peloponnesian crews (for which see Thuc.2.84, 87), by forcing them to fight in difficult weather conditions. However, the scope for exploiting weather conditions in this way may have at first appeared limited, for in the waters off the west coast of Greece currents were generally weaker than those in the Aegean (where they were strengthened by the outflow from the Hellespont), while summer winds in the Corinthian Gulf are generally light and variable ${ }^{256}$, unlike the strong, often stormy Etesians encountered in the Aegean. Given this apparent problem, the position at which Phormio had stationed himself, by the narrows at the entrance to the Corinthian 
Gulf, was either a very fortunate choice or a well planned one, for here was one area where stronger currents and winds might be expected ${ }^{257}$.

Tidal fluctuations in the Corinthian Gulf not only cause the current to flow more strongly in the narrows than it does along the coasts to the north and south, but also to reverse direction as the tide flows in and out of the gulf (p.47). Winds at the narrows are also the result of conditions further inside the Gulf, where a history of faulting and geological uplift has resulted in a high and steep mountainous coastline on both the north and the south, broken only by occasional river valleys. These valleys, stretching from high and exposed mountain ridges straight down to the coast, and generally protected from prevailing winds by the mountains that enclose them, develop strong mountain and valley breezes which reinforce the land and sea breezes, producing strong winds blowing alternately landwards and seawards ${ }^{258}$. One effect of strong valley/sea breezes blowing inland from the Gulf is inevitably that wind is drawn into the Gulf through the narrows by Naupaktos, while similarly, when the mountain/land breezes blow into the gulf from the high land all along its shore, one result is that a distinct wind then blows out of the Gulf and is channelled through the narrows. Thus develop the daily alternation of winds blowing into and out of the Gulf, as noted by Curtius and by Leake (n.257 above), and exploited by Phormio ${ }^{259}$. Mountain/land breezes start developing a few hours after sunset and increase in strength through the night, peaking around sunrise (p.53ff.): this is the hour that Phormio waits for, hoping to feel the wind blow out from the narrows:

'The Peloponnesians drew up their ships in as large a circle as they could, prows outward, sterns inward.....As for the Athenians, drawn up in single column they kept sailing round the Peloponnesian fleet in a circle, hemming it into a narrower and narrower space, always just grazing by and giving the impression that they would charge at any moment. But orders had been given by Phormio not to attack until he should give the signal; for he hoped that the enemy's ships would not keep in line, like infantry on land, but would fall foul of one another, and also be thrown into confusion by the small boats, and then if the breeze for which he was waiting while he sailed round, which usually blew from the gulf towards dawn, should spring up, they would not remain steady for any length of time. As for the attack, he thought that was in his power whenever he chose, since his ships were better sailers, and that then was the most 
favourable moment for it. So when the wind began to come up, and the ships, already hemmed in a narrow space, were being thrown into confusion both by the violence of the wind and the pressure of the small boats.... and finally, when the inexperienced rowers, unable to get their oars clear of the water in a heavy sea, were rendering the ships less obedient to the helmsman, then at this critical moment Phormio gave the signal.' (Thuc.2.83.5-84.3)

In Thucydides description, the Peloponnesian crews find not only the wind but also the 'heavy sea' (' $\varepsilon \vee \kappa \lambda \cup ́ \delta \omega \vee \imath)$ troublesome. This rough water, not previously mentioned, nor here explained, will have been caused by the strengthening wind. All winds cause the seas to roughen and waves to grow (p.33f.), but equally significant here is the fact that the wind has a marked effect on the current flowing through the narrows, at times even influencing the direction of flow ${ }^{260}$, as occurs at some other straits (p.46, and below, p.91). If the current were flowing westwards, out of the Gulf, at the time of the battle, then it would be strengthened by the following wind, while if it were flowing eastwards, into the Gulf, then wind would effectively slow the waves and increase their height, causing the surface of the water to become rougher and choppier; either way, the sea would become more problematic for inexperienced rowers. Moreover, in the open waters outside the narrows, where the waves have more space to expand, the wind blowing out of the Gulf has more effect upon the sea than it does in the narrows ${ }^{261}$. Thus Phormio's desire to fight in the open water outside the narrow strait at Rhion (Thuc.2.83.2) not only allows him to exploit his better trained crews and faster, less burdened, $\operatorname{ships}^{262}$, but also further intensifies the difficulties caused to his enemy by the poor sailing conditions.

\section{Themistocles and the sea breeze.}

Fifty years earlier, during the Persian Wars, the Greeks had preferred to fight their sea battles in straits, for then they were not only outnumbered, but also facing an enemy whose crews were equally well, if not better, trained, and whose ships were faster ${ }^{263}$. Using similar tactics to Phormio, however, Themistocles is said to have exploited not only the topography of Salamis, where the Persian fleet became cramped and disorganised in the narrow strait between the island and the mainland (fig.28), but also 
the sea breeze, which caused much more problems for the taller and already disorganised Persian ships than it did for the less cramped and lower Greek ships:

'Themistocles is thought to have divined the best time for fighting with no less success than the best place, inasmuch as he took care not to send his triremes bow on against the barbarian vessels until the hour of the day had come which always brought the breeze fresh from the sea and a swell rolling through the strait. This breeze wrought no harm to the Hellenic ships, since they lay low in the water and were rather small; but for the barbarian ships, with their towering sterns and lofty decks and sluggish movements in getting under way, it was fatal, since it smote them and slewed them round broadside to the Hellenes, who set upon them sharply...' (Plut.Them.14f.)

This is the only ancient source other than Thucydides' description of Phormio's campaign in the Corinthian Gulf in which a naval commander exploits diurnal breezes to disorganise an enemy fleet. Some modern commentators have doubted the authenticity of one or other of the passages, arguing that the one must have been derived from the other. However, there is no concrete evidence for this ${ }^{264}$, and given that all ancient Greek sailors were familiar with land and sea breezes, making regular use of them to leave and approach harbours and to sail up and down coasts (pp.109f., 223,233 ), it would rather seem natural for naval commanders to exploit predictably deteriorating weather conditions if this would be advantageous over an enemy who had expected calm weather and who would be less able to deal with the rougher conditions.

\section{Difficulties caused by unpredictable winds in straits.}

As mentioned above (p.89), strong winds can influence the direction of currents flowing through straits. In the Aegean, this phenomenon is most common off the coast of Asia Minor (e.g. in the Chian and Samian straits), where currents are relatively weak, and winds strong but changeable (fig.s. 40, 41, 43): once the forceful current from the Strait of Gibraltar has traversed the entire length of the Mediterranean and returned along the southern shores of Asia Minor, it is significantly weakened, and runs northwards up the western coast of Asia Minor with no great force, until finally it is overcome by the southwesterly outflow from the Hellespont. 
Meanwhile summer's northeasterly Etesian winds, being impeded by the east-west orientation of the high and faulted coastal peninsulas of western Asia Minor, are not so prevalent as they are elsewhere in the Aegean, while in the steep valleys and bays between these peninsulas strong land and sea breezes (easterlies and westerlies) develop. The southerly sirocco is also common from July onwards, while winter winds generally are strong and changeable ${ }^{265}$ (figs.41, 43).

According to which of these various winds is blowing at any given time, the current in the Chian strait may run northwards or southwards, that in the Samian strait eastwards or westwards ${ }^{266}$ (fig.40). The strong current which develops under, and flows in the same direction as, any strong wind that chances to arise in the strait of Chios makes sailing against the wind, which was not easy at the best of times, effectively impossible ${ }^{267}$. Moreover, when such winds and currents do develop, they greatly increase the difficulty of safely reaching shelter ${ }^{268}$, especially for those unfamiliar with the local waters: when an Athenian fleet chanced upon three Chian triremes in the strait of Chios in 422/1B.C., the Chians escaped thanks to the timely arrival of stormy winds which caused the wreck of some of the Athenian ships:

'In the meantime the Athenian armament also left Korykos, and as it was rounding the point of Argennon [a promontory in the strait: see map 2] met with three Chian ships of war; and no sooner did they see them than they made pursuit. Now a great storm $(\chi \varepsilon 1 \mu \omega \vee \mu \varepsilon \gamma \alpha \varsigma)$ came on, and the Chian ships with great difficulty escaped to the harbour; but of the Athenian ships the three that had pursued most hotly were wrecked and cast ashore at the city of Chios, where the men aboard were either captured or put to death; the rest of the fleet escaped to the harbour called Phoinikous that lies at the foot of Mt. Mimas.' (Thuc.8.34)

The Mt. Mimas mentioned at the end of this passage also appears in Homer (Od.3.172), when the Greeks returning from Troy had to decide between crossing the open sea from Lesbos to Geraistos, in Euboia, or sailing 'to landward of Chios past windy Mimas', i.e. through the Chian strait, a passage apparently regarded as no less dangerous than the passage over the open sea to Euboia (p.155ff. $)^{269}$. Mimas is called

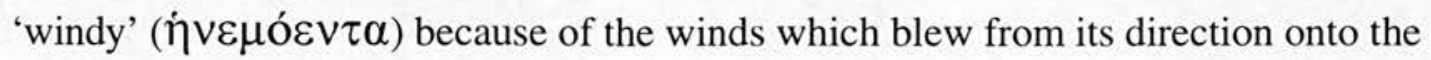


strait below; a similar situation is suggested by the 'windy heights' (ǎ $\rho \alpha \iota \varsigma$

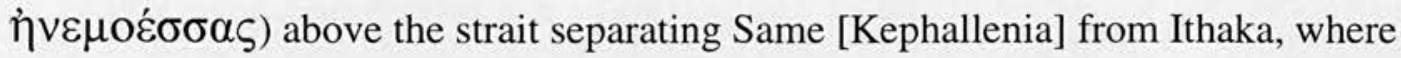
Penelope's wooers planned to ambush Telemachus (Hom.Od.16.364f.). Such winds falling from high land onto the straits below may include fierce gusts of katabatic winds blowing from cold mountainous interiors towards the warmer sea (for which see pp.51f., 56), or squalls blowing down the lee side of heights over which winds were forced to rise (for which see p.58ff.) ${ }^{270}$. Katabatic winds and squalls, blowing not through the strait but across it, or down onto it from high land above, posed a particular danger to ships because of the restricted nature of straits:

\begin{abstract}
'About the same time [ $88 \mathrm{BC}$ ] the land forces of Mithridates set sail in merchant vessels and triremes and a storm $(\pi v \varepsilon u \hat{} \mu \alpha)$ blowing from Kaunos drove them towards Rhodes. The Rhodians promptly sailed out to meet them, fell upon them while they were still scattered and suffering from the effects of the tempest (í $\pi$ ò $\kappa \lambda \hat{U} \delta \omega \nu 0 \zeta$ ), captured some, rammed others, and burned others, and took about 400 prisoners.' (App.Mith.Wars.12.26)
\end{abstract}

Here again a wind appears unexpectedly, descending coastal slopes to strike down across a strait, causing the restricted waters there to roughen (Kaunos lies in a river valley leading from the mountainous interior of Asia Minor down to the coast across the strait from Rhodes; for the connection of river valleys with diurnal and katabatic winds such as the Strymonian, see p.55f.). The confusion caused by the resulting squally winds and choppy sea can clearly be seen in their effect upon the Mithridatic fleet; the advantage again turns to those familiar with such unpredictable local sailing conditions.

In the Aegean, squalls were particularly feared on south-facing coasts (see below, p.106). Straits lying directly south of a high island or peninsula, such as those separating Samos from Asia Minor, and the Argolic peninsula from its various offshore islands, were therefore particularly dangerous, being vulnerable to squalls and yet offering little room for manoeuvre ${ }^{271}$. Similarly, though the heights of Euboia protected the Euboian Sound from the northeasterly Etesians, so that larger harbours 
such as Aulis became standard gathering places for fleets, and the whole strait became an important route whereby ships could reach the northern Aegean without having to struggle against contrary winds and seas (particularly in the Doro channel, for which see p.87, fig.47.i), the squalls which blew down from the high land on either side of the strait posed their own danger to ships sailing up this narrow and winding channel $^{272}$ (fig.47.ii). Equally problematic could be the calms which may also occur in such straits (pp.58,60), such as that which was said to have caused so much distress by preventing the Greek fleet from sailing for Troy from Aulis (Eur.Iph.A.9ff., 87-93, 350-360).

\section{Rocks and reefs in straits.}

In straits, a ship's room for manoeuvre is often fairly restricted, and may be further diminished by reefs, submerged rocks, and rocky outcrops and islets. Thus the problems often caused by winds in the Chian strait were exacerbated by rocks and shoals, and by submerged reefs which rise up to within four feet of the surface and stretch out up to 900 yards from the shore (see p.30f., n.66, and fig.30). The real danger posed by these combined hazards is evident in the many ancient wrecks, including at least four from the classical period, located on the Chian side of the channel $^{273}$.

Rocks and reefs produced by erosion, such as those in the Chian strait, are not unusual. Straits formed through submergence also commonly have outcrops, often islets rather than rocks, which remained above or just below sea level when the land around was submerged. Thus islets in the straits separating Andros from Tenos to the south, and southern Euboia to the north, partially obstruct the passages between these islands, and so increase the dangers facing mariners, especially at night (fig.27). At Helike in Achaia, where submergence occurred in historical times, even man-made structures underwater inconvenienced mariners:

'For the sea was raised by an earthquake, and it submerged Helike, and also the temple of Helikonian Poseidon...Eratosthenes says that the ferrymen say that there was a bronze Poseidon in the strait, standing erect, 
holding a hippocamp in his hand, which was perilous for those who fish with nets.' (Str.Geog.8.7.1f.)

In straits attracting a particularly heavy volume of maritime traffic, the position of dangers such as reefs and submerged rocks not surprisingly became well known, to the extent that the rocks themselves were often given distinctive names. This applied not only to large and obvious obstructions, such as the Cyaneae at the northern entrance to the Bosporos, which were named, like many other landmarks (p.169ff.), after their colour, but also to small, even submerged, rocks which sailors in the vicinity had to be aware of. Thus in the northern reaches of the Euboian Sound were reefs known, presumably from their shape, as 'the Ass of Antron' (Str.Geog.9.5.14; Antron being the nearest coastal settlement to the danger), and further east, between Magnesia and Skiathos, 'the Ant' (Hdt.7.183). The positions of these reefs, and countless others like them, were no doubt well known to local mariners, but for those unfamiliar with the locality, however observant, they could spell disaster ${ }^{274}$. Thus ten ships scouting for the Persian fleet advancing towards Artemision fell foul of the Ant, and had to rely upon local knowledge to safely relocate it:

'But Xerxes' fleet set forth from the city of Therma, and the ten swiftest of the ships laid their course straight for Skiathos..... Three of the ten foreign ships ran foul of the reef called the Ant, between Skiathos and Magnesia. The foreigners then brought a pillar of stone and set it on the reef $^{275}$; and presently, when their course was plain before them, the whole fleet set forth and sailed from Therma, eleven days after the king had marched thence. Pammon of Skyros it was who showed them where the reef lay, in the strait itself.' (Hdt.7.179, 183) 
BAYS AND THE AVAILABILITY OF SHELTER.

\section{The importance of natural areas of shelter.}

The strength and regularity of the Etesians, though fundamentally important in maintaining ancient maritime traffic, were also distinctly problematic, and at times even dangerous, for sailors. During the summer sailing season, conditions are commonly held to have been continuously 'safe' for seafaring, yet at this time of year the Etesians often blow with such strength as to constitute a formidable wind storm, and to raise heavy seas, while even thunderstorms, with their attendant squalls, are not uncommon $^{276}$. In such conditions, and also when seeking shelter from other winds, or for any other reason, it was important for sailors to be able to quickly locate an area that could provide a safe haven, even if reaching that haven entailed some risk. Thus while some of Menelaos' ships, blown off course by the Etesians at Malea, were dashed against the rocky Cretan coast (Hom.Od.3.276-300, see p.81), Odysseus, in the guise of Aethon, tells how, when he was helplessly blown from Malea to Crete, he managed to save his ship by bringing it to a point on the coast where he might find some shelter, and where there were no rocks on which to run aground ${ }^{277}$ :

'....for the force of the wind had brought him [Odysseus] too to Crete, as he was making for the land of Troy, and drove him out of his course at Malea. So he anchored his ships at Amnisos, where is the cave of Eileithyia, in a difficult harbour, and hardly did he escape the storm.' (Hom.Od.19.185ff.)

Homer and Hesiod were barely familiar with man-made harbours: in their writings, ships were normally simply beached and secured in place (Hom.Od.1.485f.,

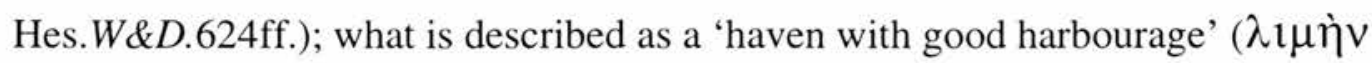

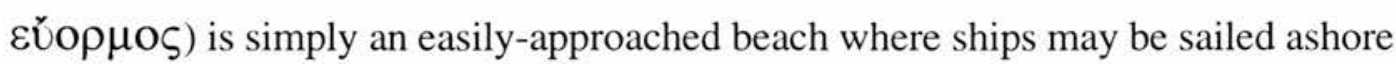
(Hom.Od.9.135-51), while a fjord-like inlet or a naturally eroded cove ranks as a

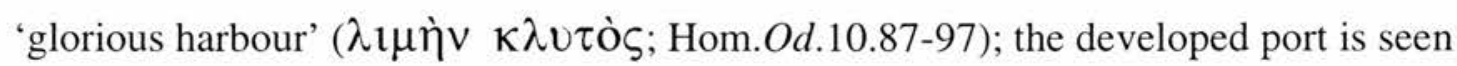
only in Scheria, the land of the Phaeacians, whose maritime culture surpasses that of normal men by far (Hom.Od.6.262-5). This state of affairs probably reflects the real situation in eighth and seventh century Greece, with some coastal and island 
communities having invested considerable resources into constructing piers or breakwaters, as at Delos, while others, probably the majority, continued to rely upon the naturally sheltered inlets they had grown up next to ${ }^{278}$ (fig.52). The first historically attested attempt to build anything like a completely artificial harbour was that of Polycrates of Samos, c.530B.C. (Hdt.3.45, 60) ${ }^{279}$, and even although artificial harbours then soon became far more common, ships often still had to rely on finding areas of the coast where the natural topography created sheltered conditions, especially during bad weather, for man-made harbours were clearly never so numerous that one was always within reach of any ship caught in a serious storm at sea and desperate for shelter as soon as possible. Again, even when within easy reach, man-made harbours were of no use to warships and other craft that found themselves seeking shelter off a hostile coast; these had instead to find some uninhabited shore where they could land unnoticed. Particularly large fleets were unlikely to find any harbour large enough to accommodate them, whether in friendly waters or hostile (see Artabanus' advice to Xerxes (Hdt.7.49), quoted at p.20f.). When no port was available, the only alternative to finding a naturally sheltered point on the coast was to ride out storms on the open sea. This could lead to disaster (witness the wrecking of the Persian fleet off Cape Sepias: Hdt.7.188f. and above, pp.71f., 77f.), and was always the last resort ${ }^{280}$, especially for warships (see p.241):

'However the Maronites arrayed their ships against us in defence of that place, and offered battle, and our men were tired out with their long voyage and with towing the ships from Thasos to Stryme; besides, it was stormy and the place offered no harbour, and it was impossible to go ashore and get a meal, for the country was hostile and all about the wall bands of mercenaries and barbarians lay encamped; so we were forced to lie at anchor all night long in the open sea without food and without sleep, keeping watch lest the ships of the Maronites should attack us in the night. Nor was this all. It was our lot to have by night rain and thunder and a violent wind at that season of the year (for the time was just at the setting of the Pleiades [the second half of October]); so can you not imagine, men of the jury, what despondency fell upon our men and what an amount of desertion I had to face after this?' (Dem.50.22f.) 
Given that riding out the night on the open seas was thus so problematic, and that man-made harbours were often unavailable or inaccessible for political or logistical reasons, the high degree of indentation on most of the major peninsulas and islands of Greece (pp.17, 20f., 23) was vitally important in that it provided a wealth of inlets and bays where ships could shelter during storms, or be beached or moored for overnight stops or when not in use. (For areas such as Thessaly and Epeiros, where there are long stretches of coast composed entirely of unbroken cliffs and rocks (pp.21, 25ff.), offering little hope of finding shelter in bad weather, see below, pp.121-6)

\section{Natural Harbours.}

In the absence of a suitable man-made harbour, the most attractive alternative was the kind of natural harbour, produced by marine erosion, which is twice described by Homer, but is nevertheless uncommon, appearing only where the stratification or faulting (or both) of the local geology is suitably aligned (above, p.27f., where the Homeric passages, Od.10.87-97, 13.96ff., are quoted). One example of such a harbour was Emborio on the southeast coast of Chios. Here a small bay is well protected on either side by two hills running down to the coast, and forming headlands that enclose the entrance to the harbour (fig.11). The large proportion of imports amongst the dedications at the nearby sanctuary suggests that merchant traders headed for the emporion at Chios town who were unable, due to adverse winds and currents, to beat up the strait between island and mainland, may have sought shelter in this natural harbour while waiting for the wind in the strait to change ${ }^{281}$.

Another natural harbour took its name from the protection it offered from the open

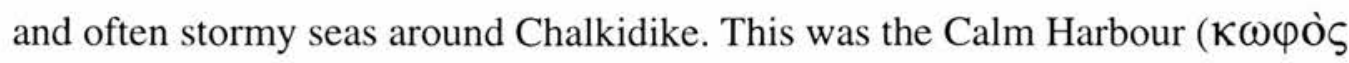
$\lambda \iota \mu \eta ́ v$ : Str.Geog.7.fr.32) in the region of Torone, proverbially noted for its tranquillity (Zen.4.68), used by, amongst others, thirty ships under Cleon in 422B.C. (Thuc.5.2.2), and identified by Leake ${ }^{282}$ (fig.23.ii). Merritt's description of the harbour includes all of the typical features of natural harbours, which appealed to 
sailors so much because they provided not only excellent shelter in all weather, but also ready access to the interior ${ }^{283}$.

Two of the best-known natural harbours in Greece are Zea and Mounychia in the Piraeus, formed through the erosion of the limestone of the Akte peninsula and of Mounychia hill, and also of the softer rocks and the sedimentary material (deposited by the Kephissos river) between these two points. Both harbours have the familiar oval shape, with headlands stretching across the mouth from either side, leaving only a relatively narrow gap for winds and waves to penetrate (fig.23.i). Because of the quality of the shelter it naturally provides, Zea may have been the first of the Piraeus' three harbours to be artificially developed to accommodate expanding Athenian naval interests in the early fifth century BC., despite being far smaller than the 'Grand Harbour' (Mغ́ $\gamma \alpha \varsigma \Lambda 1 \mu \eta ́ v)$ (see further below, p.111ff.).

However, especially during storms, entry through the often narrow entrances that protect and shelter such natural harbours may be dangerous, making this type of refuge less attractive. Thus at Emborio the entrance to the harbour is only thirty yards across, while the narrow entrance and shallow waters of the inlet at Perachora, in the Corinthian Gulf, would only have admitted a few lemboi (ships' launches), the ships themselves being anchored in the wider bay outside, where some shelter was at least available from northerly and northwesterly winds ${ }^{284}$.

\section{Shelter behind headlands.}

A more common strategy was to find an area of coastal water that might be relatively easily approached through heavy seas and winds, but where, once entered, conditions were calmer and less exposed. Here ships might be able to land, or else ride at anchor, until the weather had improved. Very often, such sheltered areas were located in bays flanked by high promontories which blocked the path of strong winds (p.57ff.), and diminished the force of large waves (p.36ff. $)^{285}$. The dissipation of waves in bays protected by promontories in this way, through expanding laterally and bending to conform to the contours of the sea bed, made sitting at anchor, and especially landing 
on beaches, far less dangerous, and recognition of this fact is implicit in the 'receding

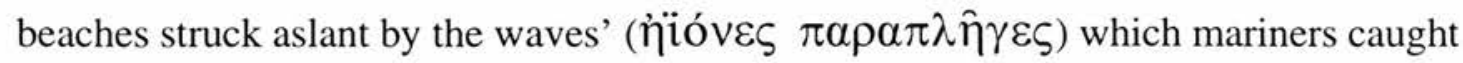
in storms were said to seek (Hom.Od.5.418, 440) ${ }^{286}$.

The shelter available behind promontories was especially useful where the winds and currents at the headlands of those promontories were too strong for ships to advance against, as commonly occurred at the southern entrances to the Hellespont ${ }^{287}$ and to the Doro channel (above, p.87; see further below); elsewhere around the Greek coasts, the areas of calm behind promontories were taken advantage of wherever they occurred, both as regular harbours and as temporary refuges in which to ride out rough weather, especially where there was little alternative to be found ${ }^{288}$.

Thus along the west coast of Asia Minor the promontories, which have a primarily east-west orientation (pp.18, 21), formed barriers against the prevailing northerlies (above, p.91), and were thus not surprisingly used for shelter by ancient vessels sailing northwards ${ }^{289}$. Elsewhere in the Aegean, the headlands that ships most frequently sheltered behind were, again, those offering most protection from the prevailing northeasterly Etesians. As they tend to stretch from northwest to southeast (p.18f.), many Aegean promontories were suitably aligned to receive the direct blasts of the Etesians on their northeast flanks, while sheltering any ships on their lee side, to the southwest; thus the Bay of Karystos, lying directly behind Geraistos, the southeasterly point of Euboia, was a convenient place of shelter for ships which were unable to proceed northwards against the current and the wind in the Doro channel (see above, and fig.47.i). For ships that could not even reach Euboia against the Etesians, shelter could be taken at Sounion, the southeast extremity of Attica. Here ships unable to round the headland might lie at anchor in, or run ashore on the sandy beach of, the bay on the west side of the promontory, now known as Legrena Bay (fig.54). A second, much narrower bay on the northeast side of the promontory, just behind the headland, was less suitable as a place of shelter than Legrena bay, but nevertheless proved a valuable alternative during the southerly and westerly winds to which Legrena Bay was exposed (for which see below, p.108f.) ${ }^{290}$. 
Across the channel to the southeast of Sounion, the northern end of Keos was equally difficult to pass from south to north because of the same northeasterly currents and winds. Equivalent to Geraistos' Karystos Bay, and Sounion's Legrena Bay, was the large natural harbour of Koressia on the northwest coast of Keos, where ships unable to proceed further northwards might take shelter, and which in fact functioned as the main port of the island ${ }^{291}$. The development of such sheltered bays from areas of temporary shelter for shipping unable to round a negotiate headland or strait to more formal harbours and ports, was by no means unusual: during the classical period or later, for example, a ship-shed was constructed at Legrena Bay, for the use of the two guardships stationed at Sounion $^{292}$.

So too, in the Gulf of Argos, good shelter was available for ships in the lee of the high promontory of Palamidhi which protrudes from the southeastern shores of the gulf. In this gulf, the northeasterly Etesians tend to be less dominant, and also therefore less problematic, than the daily sea breeze which blows northwards up the gulf and across the plain of Argos (below, p.108). Not surprisingly then, it was on the sheltered, northern, side of the Palamidhi promontory that the town of Nauplia grew up. The maritime significance of the port-town's sheltered position is clear: originally one of the seven members of the 'Kalaurian Amphictyony' (Str.Geog.8.6.14), a maritime league founded in the seventh century BC or earlier, Nauplia was taken over by its larger neighbour Argos, and was subsequently used as that town's naval base $(\text { Str.Geog.8.6.2) })^{293}$.

In northwest Greece, where the southwestwards-facing coast is predominantly concordant, cliffy, lacking in indentations (p.20), and exposed to the full force of Adriatic winds (for which see p.50ff.), refuge was available in the deep bay of Orikos, formed and protected by the northwestwards-running promontory of Keraunia (for which see p.20, with n.25):

'When the wave carries your ship out to sea, may I not see any dropping of such winds as bring you, after safely rounding Keraunia with your oars, to Orikos' calm haven.' (Propert.El.1.8.13f..) 
Much of the west coast of the Peloponnese is likewise high, straight, and lacking in indentations, and is exposed not only to the fierce weather that descends from the Adriatic but also to that coming from the open seas to the south and west (e.g. the Sirocco) (figs.41, 43). It is therefore significant that the best harbour in the area, at Pheia, owed its advantages to the protection afforded by nearby Ichthys, the only significant promontory for some distance in either direction, especially to the south (figs.33, 35). Here ships caught in rough weather might find shelter by rounding the headland and entering the harbour, as did an Athenian fleet in 431B.C., when caught out by a gale while raiding Pheian territory southeast of the Ichthys promontory ${ }^{294}$ :

\begin{abstract}
'While they [the Peloponnesians] were still in Attica, the Athenians sent off round the Peloponnese the fleet of one hundred ships..... The Athenians then weighed anchor and continued their cruise along the coast, and putting in at Pheia in Elis ravaged the land for two days....But a heavy gale of wind arose, and since they were exposed to the storm in a harbourless region, most of them embarked on their ships and sailed round the promontory called Ichthys into the harbour at Pheia.'
\end{abstract}

(Thuc.2.23, 25 (parts))

Again during the fifth century BC, if not before, Naupaktos, on the northwest coast of the Corinthian Gulf, developed an important role as a harbour and naval base at a strategic point. This harbour town stood in a long bay which stretched away roughly northeastwards from, and so was sheltered from westerly winds by, the northern of the two headlands forming the strait of Rhion at the mouth of the gulf. At Naupaktos itself, moreover, a recess in the coast formed a small natural harbour offering further protection from winds from virtually all directions. This was, then, where Phormio made his base during the Peloponnesian War (above, p.87f.), and the town was also coveted by the Aitolians for its maritime aspect ${ }^{295}$. Throughout antiquity, however, the area must generally have been used for shelter by ships, for not only are there few good harbours anywhere along the shores of the Corinthian Gulf, but the area of Naupaktos offered the last sheltered stopping point for ships sailing out of the gulf, and the first for those having just entered ${ }^{296}$. 


\section{Shelter in river mouths.}

Hom.Od.19.185ff. (quoted above, p.95) describes how Odysseus escaped from the storm which had carried him from Malea to Crete by taking shelter in the 'difficult harbour' ( $\lambda \bar{\tau} \mu \eta \dot{v} \chi \alpha \lambda \varepsilon \pi$ ó $\varsigma$ ) of Amnisos, which is in fact simply a river mouth (see n.277). Again, after the raft on which he left Kirke's island has been destroyed in a terrible storm sent by Poseidon, Odysseus seeks shelter in a river mouth on the coast of Scheria (Hom.Od.5.441ff.). Homer's description of the harbourless, cliffbound, and rocky coast which greets Odysseus (Hom.Od.5.400-7) has already been quoted (pp.25, 26f.), and against this background, in the absence of any other suitable indentations, the advantages of seeking shelter or even coming ashore in a river mouth become apparent:

'Nowhere doth there appear a way to come forth from the grey sea. For without are sharp crags, and around them, the wave roars foaming, and the rock runs up sheer, and the water is deep close in shore, so that in no wise is it possible to plant both feet firmly and escape ruin. As I try to come ashore a great wave may seize me and dash me against the jagged rock, and so shall my effort be in vain.' (Hom.Od.5.410-416)

Odysseus is indeed then cast against a rock, and swept back out to sea by the retreating wave, but he is eventually saved:

'Then surely would unfortunate Odysseus have perished beyond his fate, had not flashing-eyed Athene given him presence of mind. Making his way out of the surge where it belched upon the shore, he swam outside, looking continually toward the land in hope to find shelving beaches and harbours of the sea. But when, as he swam, he came to the mouth of a fair-flowing river, where seemed to him the best place, since it was smooth of rocks, and there was shelter from the wind there, he knew the river as he flowed forth, and prayed to him in his heart......and the god at once made his current cease, and checked the waves, and made a calm before him, and brought him safely to the mouth of the river.'

(Hom.Od.5.436-44, 451ff.)

Here Homer has the river-god actively intervene to bring Odysseus safely to shore, but the passage also clearly describes the advantages of either coming ashore or sheltering in a river mouth. Thus whereas the coast roundabout is steep and rocky, the 
river mouth is neither, but instead features, like most river mouths, a gently sloping river bed. For a ship approaching land in stormy conditions, smooth and soft riverbeds have obvious advantages over most other parts of the shoreline, especially where there is a danger of offshore or coastal rocks: deposition of sediments in front of a river mouth (for which see p.31) could lead to the danger of running aground, but grounding on silt was always preferable to grounding on rocks. Moreover, calm waters might appear at river mouths not only through divine intervention: outflow from rivers tends to retard the breaking of waves (p.35), and so to produce areas of less rough water, whereas elsewhere along the rocky coast the waves break right against the shore, giving the most difficult conditions in which to attempt to land.

A further advantage noted by Homer is that there is shelter from the wind in the river mouth. Some shelter might be found behind the raised river banks to either side, but rarely, presumably, from very strong winds, and never from diurnal breezes blowing along the river valleys (for which, see p.55f.). Soft riverbeds, and the calmer waters found in front of estuaries, are real advantages to ships and men alike, but for shelter from the wind, it would more helpful if the river were sheltered by a projecting headland:

'During the night the wind ceased and at dawn they gladly reached the haven of the Acherousian headland....And here is the outfall of the river Acheron which bursts its way through the headland and falls into the Eastern sea [Black Sea], and a hollow ravine brings it down from above. In after times the Nisaean Megarians named it Soonautes when they were about to settle in the land of the Mariandyni. For indeed the river saved them with their ships when they were caught in a violent tempest. By this way the heroes took the ship through the Acherousian headland and came to land over against it as the wind had just ceased.' (Ap.Rhod.Arg.2.727f., $743-51)^{297}$

'....and on the same day they rounded the distant headland of the Amazons that guards their harbour ( $\lambda \iota \mu \varepsilon v \eta \dot{o} \chi 0 \vee)$...In the bay of this headland, at the outfall of the Thermodon, they ran ashore, for the sea was rough for their voyage.' Ap.Rhod.Arg.2.964f., 970f.) 


\section{Shelter behind islands.}

Like promontories, islands present barriers which break the force of strong sea winds (p.57ff.), while their curving coastlines reduce the size and strength of waves as they progress from the exposed to the sheltered shores of the island (p.38, fig.37). Thus ancient ships found shelter in the lee of islands as well as behind promontories. However, while this practice has been widely accepted by modern scholars ${ }^{298}$, and influenced the routes followed by ancient Greek mariners (pp.141, 152-8), explicit testimony of this important function of islands in ancient seafaring is rare in ancient literature (but see below, pp.110,113-6, on harbours protected by offshore islands), in contrast to the ample literary evidence for the equivalent use of headlands. Nevertheless, the importance and widespread use of this strategy for escaping storms at sea should not be doubted ${ }^{299}$, especially with regard to any offshore islands standing opposite the kind of faulted, cliffy, and harbourless coasts that in Greece typically face northeastwards or southwestwards (p.18f.), and which become extremely dangerous lee shores for any ships caught in the coastal waters during onshore winds (for examples, see above, p.75-8). Thus the great rock of Monemvasia, off the east coast of the Parnon peninsula in the southeast Peloponnese, provided invaluable shelter from strong winds for ships that might otherwise have been wrecked on this harbourless and rocky coast onto which the Etesians blew at full force ${ }^{300}$. We have also already noted (above, pp.87, 93) the use of the Euboian Sound as a means by which ships reached the northern Aegean, because of the shelter that the high land of Euboia provides from the Etesians (fig.47.i), which, on the exposed northeast coast of the island, as on the unprotected coast of Magnesia to the north, create dangerous sailing conditions (again, see p.76ff. above).

One passage containing important evidence of this function of islands is the account, in the Acts of the Apostles, of Paul's voyage from Caesarea to Rome (fig.55):

'Leaving Sidon we sailed under the lee of Cyprus because of the head winds, then across the open sea off the coast of Cilicia and Pamphylia, and so reached Myra in Lykia.....For a good many days we made little headway, and we were hard put to it to reach Knidos. Then, as the wind continued against us, off Salmone [Salmonion] we began to sail under the 
lee of Crete, and, hugging the coast, struggled on to a place called Fair

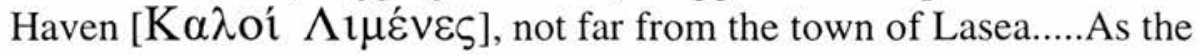
harbour was unsuitable for wintering, the majority were in favour of putting to sea, hoping, if they could get so far, to winter at Phoinix, a Cretan harbour facing southwest and northwest. When a southerly breeze sprang up, they thought that their purpose was as good as achieved, and, weighing anchor, they sailed along the coast of Crete, hugging the land. But before very long a violent wind, the Northeaster as they call it, swept down from the landward side. It caught the ship and, as it was impossible to keep head to wind, we had to give way and run before it. As we passed under the lee of a small island called Kauda, we managed with a struggle to get the ship's boat under control. When they had hoisted it on board, they made use of tackle to brace the ship. Then, afraid of running onto the sandbanks of Syrtis, they put out a sea anchor and let her drift...' (Acts 27.1-18 (parts))

At three points during this voyage the author stresses the shelter to be found by sailing under the lee (i் $\pi \mathrm{o} \pi \lambda \dot{\varepsilon} \omega$, $\dot{0} \pi \mathrm{O} \tau \rho \dot{\varepsilon} \chi \omega)$ of islands. Sailing to leeward of Cyprus, and later Crete, is explicitly stated to be the crew's response to the

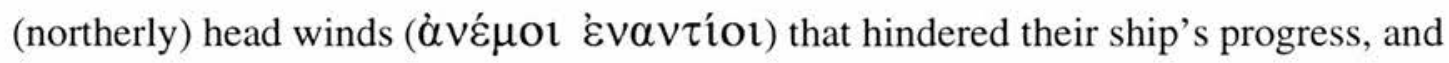
might otherwise have driven it onto the north coasts of those islands. The ship is said to start sailing under the lee of Crete as soon as it reaches Salmonion (the northeastern promontory of the island), thus underlining not only the shelter to be had in the lee of islands, but also that available immediately upon rounding a headland (above, pp.98-101). The ship hugs the coast, maximising the degree of shelter to be gained from the island, and so reaches the harbour near Lasea. Before reaching Phoinix, near the western end of Crete, winds from the northern quarter again appear, and the crew have no choice but to let the ship sail with the wind. Only upon reaching relative shelter in the lee of the small island of Kauda, around thirty miles south of Crete, do the crew actually manage to take action to protect the vessel against the storm and to avoid being swept into Syrtis (for the dangers of Syrtis, see below, pp.119 (the 'Tritonian Lake': see n.336), 133, 232f.). Thus in this passage we see evidence not only of the shelter that islands provided from storm winds, but also of the extent to which that shelter could mean the survival of a ship that might otherwise have been lost. 
Factors limiting the degree of shelter to the lee of headlands and offshore islands.

While headlands and islands may provide shelter from strong prevailing winds, the protection thus provided is clearly neither complete nor guaranteed to last any great length of time. Winds obstructed by a promontory or island may still appear fitfully on the far side of such obstacles in the form of squalls (p.58ff., 75, 78, figs.45, 46, 47.ii), while a change in wind direction can leave a previously sheltered ship not only exposed to the wind, but also in danger of being blown onto the shore of the island or promontory behind which it had been sheltering.

The frequency and the violence of squalls in the seas around Greece are notorious ${ }^{301}$. In coastal waters they are most commonly encountered around shores facing away from prevailing winds: thus in the Aegean, northerly winds, when vertically displaced on striking the north coasts of islands or promontories, appear fitfully over their peaks, sometimes falling back to sea level in the form of strong squalls along the southern coasts (see also above, p.93, figs. 45,46$)^{302}$. These squalls were an inconvenience, and often a danger, to ships entering harbours on steep south-facing coasts, or attempting to shelter in the lee of islands and promontories ${ }^{303}$. Thus we have already seen (above, p.104f.) the ship on which Paul sailed to Rome attempting, for a while successfully, to avoid strong winds by sailing to the lee of Crete, but eventually northeasterly winds do break over the far side of the island at its western end, where the coast is particularly steep and squalls particularly feared ${ }^{304}$. Likewise, when the Etesians prevented ships from passing northwards through the Doro channel (above, pp.87, 99), the shelter available in the Bay of Karystos was diminished by the squalls which appear over the high land of Euboia and fall back down onto the Bay of Karystos and the whole Euboian Sound (above, p.93, fig.47.ii) ${ }^{305}$. Squalls are particularly notable around Malea, Tainaron, and Akritas, the three southerly peninsulas of the Peloponnese ${ }^{306}$, adding to the difficulties of navigating in that region (for which, see above, pp.78-82). 
For sailors who decided to shelter in the lee of a promontory or of an island for any length of time (e.g. overnight), it would therefore be imperative to attempt to forecast any weather changes likely to occur during that period, because otherwise they might find themselves unable to leave their temporary haven safely, and in an even more dangerous position than they had been previously. The most serious danger was that the wind would reverse direction, forcing the ship onto the very coast that had until then been sheltering it. Even if the ship was not thus wrecked, it would be vulnerable to embayment, and not easily sailed out into open water in order to proceed with its journey or seek better shelter elsewhere. The ship could of course be rowed out to open water (or, in the case of a holkas, be towed), as was standard practice when leaving harbour ${ }^{307}$, but even this was a far more strenuous task against onshore winds, especially for holkades, which had no oars and were at best equipped with a lembos (an oared launch: see p.243). Euripides has Orestes encounter such a problem as he attempts to escape from the Taurians with his sister Iphigeneia (Eur.I.T.1327ff.): the onshore winds in the bay raise great waves which not only prevent the ship from reaching open water, but threaten to cast it upon the rocky shore, even although the ship is in this case equipped with oars ${ }^{308}$ :

'The prow with poles some steadied, some hung up the anchor at the catheads.....Meanwhile a great surge shoreward flung the ship; and, for the maiden feared to wade the surf, Orestes lifted her....Then, with glad gasp loud-bursting from each breast, smote they the brine. The ship made way, while still yet within the bay; but, as she cleared its mouth, by fierce surge met, she laboured heavily; for suddenly swooped a wild gust on the ship, stern-foremost thrusting her. With might and main fought they the waves, but towards the land again the back-sweep drave the ship: then stood and prayed Agamemnon's daughter....The mariners' paean to the maiden's prayer answered, the while with shoulders bare they strained the oar blade deftly to the timing-cry. Nearer the rocks - yet nearer - came the bark....For, if the sea-swell sink not into calm, hope of deliverance have the strangers none.' (Eur.I.T.1350f., 1379-81, 1390-8, 1403-6, 1412f.) ${ }^{309}$

In the seas around Greece, northerly winds are superseded by southerly winds in a short space of time far less often than is the case vice versa ${ }^{310}$. This is clearly because katabatic winds such as the Bora and the Livas, which can appear very suddenly, 
originate and blow from the continental lands north of Greece (pp.51f., 56), and also because southerly winds such as the Sirocco develop gradually under the warm fronts of depressions, and are always then succeeded by the cold front of the same depression, with attendant northerly winds (p.49). Such rapid changes in wind direction, which cause squally conditions at sea and make it very difficult to find any haven that is likely to provide ample shelter from the wind for any length of time, is probably one of the main reasons why the Adriatic, where the Bora can blow at any time of year (above, p.51), was largely avoided by Greek mariners (see below, p.114), and why elsewhere it was only during that part of the year when winds like the Bora were less likely suddenly to appear (i.e. during summer, when the Etesians prevail (pp.48, 49f.)) that seafaring was commonly held to be truly safe (p.221ff. $)^{311}$ : the Etesians do regularly blow strongly enough to cause considerable storms in the Aegean (p.50), but, because they are unlikely to be quickly replaced by winds blowing from the opposite direction, ships can safely shelter from them behind (i.e. southwards of) promontories or islands. Thus the summer storms caused by the Etesians are generally only a danger to ships unable to reach shelter. The storms of winter, on the other hand, pose far more danger, because even if shelter is taken in an area of relative calm, there is no guarantee that the wind will not change to a direction which exposes that area to the full force of the wind, and, in so doing, also cause the waves and the sea generally to become far rougher.

In summer, while the northerly Etesians rarely give way to southerly winds such as the Sirocco, sea breezes develop some strength in coastal areas, particularly in southfacing bays such as the Gulfs of Messenia, Lakonia, and Argos, and the Saronic Gulf (pp.53, 55, fig.43). Blowing more or less northwards against, and occasionally overcoming, the prevailing Etesians, such strong sea breezes can cause difficulties for ships and their crews ${ }^{312}$, and may even prevent ships from entering or exiting gulfs by rounding the headlands in which they terminate. Thus when discussing the delay in Socrates' execution, caused by the failure of the theoric ship to return to the Piraeus from Delos, Plato (Crito 43C-D) indicates that the ship had been delayed at Sounion $^{313}$. Elsewhere (Phaedo 58A-B), Plato explicitly states not only that the 
theoric ship was delayed by contrary winds at Sounion, but also that such delays were far from unusual. To be delayed at the headland of Sounion, en route from Delos to Athens, the theoric ship must have encountered strong southerwesterly winds there, either the Sirocco or the sea breeze, which also blows in this direction in the Saronic Gulf $^{314}$. In late May, when the theoric ship returned, a late depression, with the attendant Sirocco, might still occasionally be encountered, but not with the regularity with which the theoric ship was delayed at Sounion according to Plato Phaedo 58A-B (see p.48f.); the sea breeze would be much more commonly encountered, as the hotter conditions of summer, which strengthen diurnal breezes (p.53), would normally already have arrived, and be building towards that time of year (June/July) during which the sea breeze in the Saronic Gulf blows with maximum strength and duration. The expectation that the ship will return to Athens the following day (Crito 43D) also suggests the diurnal sea breeze, which would die down in the evening until late the following morning, giving the theoric ship ample opportunity to round Sounion; if the ship had been delayed by the Sirocco, its crew would not have been able to predict how long the delay would last with such a degree of certainty.

Southerly sea breezes which blew strongly enough to cause this much inconvenience were also a distinct threat to ships which had taken shelter from northerly winds by entering a protected bay to the south of an island or promontory, such as, at Sounion, Legrena Bay (see above, p.99f.); ships were also ill-advised to shelter too far inside the Bay of Karystos, when the Etesians made it impossible to pass northwards through the Doro channel, because the sea breeze drawn into the bay (fig.43) makes leaving it difficult. Thus Theophrastos notes that 'at Karystos they [the afternoon sea breezes] blow so hard that their strength is extraordinary ${ }^{315}$.

In such situations, it was therefore not only convenient (see below, pp.223, 233), but also a well advised precaution, for ships to leave such bays early in the morning, before the sea breeze had developed, and preferably while the overnight land breeze was still blowing seawards, as Tiphys, the experienced pilot of the Argo, knew ${ }^{316}$ : 
'But straightaway the morning star rose above the topmost peaks and the breeze swept down; and quickly did Tiphys urge them to go aboard and avail themselves of the wind....And the sails were bellied out by the wind, and far from the coast were they joyfully borne past the Poseidian headland.' (Ap.Rhod.Arg.1.1273ff.)

'And on the seventh day they left Drepane [Corcyra]; and at dawn came a fresh breeze from Zeus. And onward they sped, borne along by the wind's breath.' (Ap.Rhod.Arg.4.1223f.)

Such practice was in fact related to standard strategies for entering and leaving harbours. Since ancient Greek sailors were not forced to time their entry to and departure from harbours according to the rise and fall of the tides (p.231f.), they were free to make full use of the land breeze to clear harbour in the early morning, and the sea breeze to return to harbour in the evening. By timing departures from, and entrances to, harbours to coincide with, respectively, land and sea breezes, the potential difficulties of making these manoeuvres against the adverse winds that often prevailed at all other times of the day were avoided.

\section{Areas offering particularly effective shelter.}

Particularly effective protection from winds and waves was available where promontories had accessible inlets on either side of their headland. Where there was such a choice between areas of safe shelter facing in opposite directions, protection could be found from almost any wind, as each area of shelter was shielded from those winds to which the other was exposed. Similarly, good shelter from nearly all winds and from the worst waves was to be found in bays which were partially blocked off from the open sea by an offshore island, for such islands offered protection from winds which would otherwise have blown directly into the bay, threatening to embay or to force ashore any ships sheltering there. Many of the most impressive artificial harbours of the classical period originated in such fortuitous natural havens.

Thus, regarding promontories offering shelter on either side, Strabo argues that these were intentionally developed because of the advantages they conferred upon maritime 
communities, whether civilian, as at Sinope (fig.24.ii) and Amastris on the Black Sea coast, or military, as at Skyllaion, by the Straits of Messina:

'Then one comes to Sinope itself.... The city was founded by the Milesians....Sinope is beautifully equipped both by nature and by human foresight, for it is situated on the neck of a peninsula, and has on either side of the isthmus harbours and roadsteads and wonderful pelamydes [tunny] fisheries.' (Str.Geog.12.3.11)

'After the Parthenios river then, one comes to Amastris...It is situated on a peninsula and has harbours on either side of the isthmus.' (Str.Geog.12.3.10)

'Next after this river comes Skyllaion, a lofty rock which forms a peninsula, its isthmus being low and affording access to ships on both sides. This isthmus Anaxilaos, the tyrant of the Rhegini, fortified against the Tyrrheni, building a naval station there, and thus deprived the pirates of their passage through the strait.' (Str.Geog.6.1.5)

Homer also apparently describes such a pair of harbours facing in opposite directions in Scheria, the land of the Phaeacians, the legendary seafarers who might be expected to have the best of harbours, as well as the best of ships:

'But when we are about to enter the city, about which runs a high wall, a handsome harbour lies on either side of the city, and the way between is narrow, and curved ships are drawn up along the road, for they all have stations for their ships, each man one for himself.' (Hom.Od.6.262-5) ${ }^{317}$

We have already seen (above, p.99f.) that a small inlet on the northeast face of Sounion offered individual ships shelter from the southerly winds to which Legrena Bay, on the opposite side of the promontory, was exposed. Whole seafaring communities, however, needed larger and more reliable port facilities. Thus the community of Hermione, on the south coast of the Argolic peninsula, depended heavily upon the sea, for it had little fertile territory and poor land access to the interior. Here two or more harbours (Paus.2.34.9 simply gives the plural $\lambda \iota \mu \varepsilon v \alpha \varsigma$ ) were formed by the long tongue of land which strikes out eastwards from the coast, 
forming a long bay to the north, and these harbours were not only sheltered by the promontory itself, but also by the capes to the southwest and the fringe of islands to the south, including Hydra and Aperopia (mod. Dokos), which give added shelter from the winds ${ }^{318}$ ).

So too the Athenians had admirable natural harbouring facilities from which they developed the Piraeus port (fig.23.i): Thucydides stresses the original importance of the size and quality of the natural harbour facilities at the Piraeus in the development of Athenian sea-power:

'[Themistocles] considered that the Piraeus, with its three natural

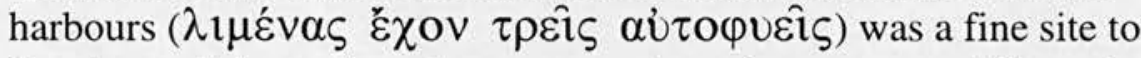
develop and that to have become a nation of seaman would have been a great advantage to the Athenians.... and so he immediately took the first steps in this undertaking. And following his advice they built the wall round the Piraeus...' (Thuc.1.93.3).

The nearby Phaleron Bay provided harbourage in the early period, before the development of the Piraeus proper from the early fifth century BC This bay, through which the Ilissos and the Kephissos rivers emptied into the sea (Str.Geog.9.1.24), formed a long (c. $3 \mathrm{~km}$.) open coast where large numbers of ships could be beached, and smaller vessels could lie at anchor ${ }^{319}$. However, while sheltered by the headlands at either end of the beach (Mounychia and Kolias), Phaleron is exposed to southerly and southwesterly winds, and better shelter was available in the various indentations of the Akte peninsula, adjoining Phaleron Bay on the west.

There were three serviceable harbours, all nearly completely landlocked, with restricted entrances that were narrow in relation to the area of the harbours inside. The two smaller harbours, Zea and Mounychia, were almost perfectly formed natural harbours (above, p.98) which, before being reserved exclusively for the Athenian navy, would have offered excellent shelter for shipping which normally resorted to Phaleron Bay. Mounychia harbour was exposed only to the southeast wind, and then barely so, while Zea harbour, shut in between the western slopes of the Akte 
peninsula and a rocky outcrop to the southwest of Mounychia hill, was especially well protected, and had a narrow and rather long entrance open only to the south ${ }^{320}$.

The third harbour of the Piraeus, the 'Grand Harbour' (Mغ́ $\gamma \alpha \varsigma \Lambda \imath \mu \eta \dot{v})$, is also easily the largest, and lay in the deep inlet between the Akte peninsula and the mainland. Its mouth faces west, and is enclosed to the south by the northwest extremity of the Akte peninsula, to the north by the short southwestwards-running promontory of Eetioneia. While the entrance was some $300 \mathrm{~m}$. wide (before being narrowed by the construction of piers), allowing waves to penetrate far more easily than at Zea or Mounychia, the sheer size of the harbour would have helped to further dissipate waves. That waves penetrating the Grand Harbour tended to subside before reaching its farthest recesses is suggested by the name of a subsidiary indentation at the northern extreme of the harbour, again protected by headlands, known as the

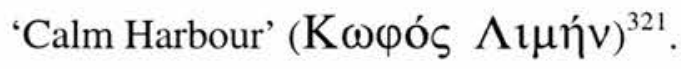

So the Akte peninsula, and the hill of Mounychia to which it was connected, offered not one or two harbourages, but three, all very well protected from wind and wave, and facing in different directions. Thus when weather conditions caused serious difficulties to shipping in Phaleron Bay, shelter could easily be found in the harbours of the Akte peninsula, only one of which was ever likely to be exposed to the weather at any one time ${ }^{322}$.

In addition to such double or even triple harbours protected by promontories, harbours protected by one or more offshore islands offered particularly good protection to shipping in nearly all weather conditions. Thus the harbours of Hermione, standing on the south coast of the Argolic peninsula (see above, p.111), were exposed principally to southerly winds such as the Sirocco blowing off the open sea, but were protected from these winds by the islands of Dokos and Hydra to the south $^{323}$. Northerly winds, such as the Etesians or Bora, might appear in the form of squalls over the high land of the mountainous interior (above, p.93), but there full unimpeded force would not be felt within the harbours, as was also the case at Kaloi 
Limenes ('Fair Havens') on the south coast of Crete, an area likewise partially protected from southerly winds by offshore islands ${ }^{324}$. Elsewhere, however, there were north-facing harbours which were exposed to the full strength of the boisterous northerly winds which prevail in Greece for almost the whole year - the Etesians in summer, the Bora, Livas, and other katabatic winds in winter. Here, protective offshore islands were sorely needed.

It is worth pausing at this point to emphasise the strength and ferocity of these northerly winds. The Etesians can raise considerable storms, forcing vessels, especially sailing ships, to seek temporary shelter (see pp.50, 75f., 82, 85f., 95, 99, 104f.). Katabatic winds such as the Bora (in the Adriatic) and the Livas (in the Aegean) were even more problematic for sailors than the Etesians, not only because of their association with the rainstorms arising from depressions, but also because of their severe and unpredictable nature (for which see pp.51f., 56). These winds were feared with good reason by the ancient Greeks (above, pp.77ff., 107f.) The Bora was one of the reasons why the Adriatic was generally avoided, except to make the direct crossing to Italy from the region of Corcyra ${ }^{325}$. In the Aegean the equivalent winds were Boreas, Thraskias, and the Strymonian wind (Arist.Anem.Thes.973b18f.), blowing from the mountainous interior of northern Greece over the coastal plains and out to sea (fig.43). Descriptions of these winds in ancient sources accurately describe their coldness (Hes.W\&D.504ff., 547ff.), how they cause the sea to roughen dangerously (Hes.W\&D.504ff, Hom.Il.9.4ff.), and how they spring up without warning (Theophr.Signs 35, Aesch.fr.57(127)) $)^{326}$.

In Aeschylus' Agamemnon it was the Strymonian wind from Thrace that prevented the Greek fleet from leaving Aulis, bringing about the sacrifice of Iphigeneia 'to charm the blasts of Thrace' (Aesch.Agam.191ff., 1416ff.), and also caused the wreck of the Greek fleet returning from Troy (Aesch.Agam.653ff.). The description of the wind there as an 'evil shepherd' (Aesch.Agam.657: $\pi 01 \mu \eta ́ v \kappa \alpha \kappa o ́ \varsigma)$ accurately describes the inability of the Greek fleet to determine its own direction of travel, which is entirely dictated by the wind, and by the current which was reinforced by the 
wind, both of which were strengthened as they funnelled through the Doro channel ${ }^{327}$. According to a tradition related by Herodotos, Xerxes, displaying apparently typical ignorance of the danger posed by northerly winds in the Aegean (see above, p.77ff.), decided at Eion on the Strymon to return to Asia Minor by sea, accompanied by many of his nobles. On embarking on the voyage,

'he was caught by a strong wind called Strymonian, that lifted up the waves. This storm bearing the harder upon him by reason of the heavy lading of the ship (for the Persians of his company that were on the deck were so many), the king was affrighted and called to the ship's pilot asking him if there were any way of deliverance' (Hdt.8.118)

The pilot replies that the only hope of survival is to lighten the ship. Xerxes accordingly asks his companions to prove their devotion, and they duly comply by jumping overboard to their deaths. Now lightened, the ship safely reaches Asia, where Xerxes honours the pilot for saving his life, then executes him for causing the deaths of so many Persians. Though this is merely a spurious anecdote reaffirming Greek attitudes towards Persians, particularly Xerxes, the geographical and meteorological basis of the story is entirely plausible.

Harbours in areas where these troublesome northerly winds prevailed preferably faced southwards, so as not to be directly open and vulnerable to them ${ }^{328}$. Where northfacing harbours did develop and prosper, this was often due to the protection afforded by offshore islands (for the case of Pheia, see p.101 with fig.35). Thus the asty of Thasos stood on the island's north coast, and so faced directly towards the Thracian and Macedonian coastlands from which the fearsome northerlies blew most strongly (pp.49f., 56). The town had two harbours, one 'open' (protected only by a mole on one side), the other 'closed' (i.e. protected by an encircling harbour wall) ${ }^{329}$. All ships using the open harbour, or lying to anchor outside the harbour walls, along the long bay to the west $\mathrm{t}^{330}$, while being adequately protected from easterlies and westerlies by the promontories flanking the bay, would have been exposed to violent northerlies were it not for the presence of Thassopoulo, and offshore island which bore the brunt of the wind's force and helped to guarantee the shelter available in the harbour to the 
south $^{331}$ (fig.56.ii). Similarly, many harbours on the south coast of the Black Sea unavoidably faced northwards into the often stormy (see Str.Geog.7.4.3 at p.147 below) prevailing wind (for Sinope, an exception, see p.110f., fig.24.ii). Where the presence of an offshore island offered added shelter to a harbour along this coast, therefore, this was significant enough to be noted in sailing manuals:

'One hundred and fifty stadia from the Black Cape [Melaina] to the Artanes river and region, with a harbour for shipping. Nearby is an island which shelters the harbour.' (Menip.Perg.Perip.5703ff.)

A better-known harbour which was also protected from prevailing northerlies by an off-shore island was Alexandria in Egypt. Here, the island of Pharos was only a short distance from the shore of the Nile delta, and it clearly helped to protect, and even form, the harbour:

'Pharos is an oblong isle, is very close to the mainland, and forms with it a harbour with two mouths; for the shore of the mainland forms a bay, for it thrusts two promontories into the open sea, and between these is situated the island, which closes the bay, for it lies lengthwise parallel to the shore. Of the extremities of Pharos, the eastern one lies closer to the mainland, and to the promontory opposite it (Lochias), and thus makes the harbour narrower at the mouth....' (Str.Geog.17.1.6)

Strabo's description of the position of Pharos is almost identical to Thucydides' description of that of Sphakteria, which protects the bay of Pylos from the prevailing northwesterlies and southwesterlies striking the west coast of Greece (fig.56.iii):

'Now the island called Sphakteria stretches along the mainland, lying quite close to it, and thus makes the harbour safe and the entrances to it narrow; on one side, opposite the Athenian fortifications and Pylos, there is only room for two ships to pass through; on the other side, next to the other part of the mainland, there is room for eight or nine.' (Thuc.4.8.6) ${ }^{332}$ 


\section{SHOALS AND DEPOSITION}

The port of Alexandria was not the only harbour to have benefited from, or, one might even say, owe its existence to the deposition of sediment from river mouths and other sources. In fact, there were many such harbours in the ancient world, including the Piraeus, where the Akte peninsula, originally an island, had been joined to the mainland through the accretion of sediments deposited by the Kephissos and Ilissos rivers (p.32; for other examples, see p.119ff. below).

Deposition does not always have a beneficial effect on harbourage, however. Thus along much of the west coast of the Peloponnese, particularly around Triphylia and northern Messenia, finding anywhere to shelter or land was made difficult by the flat, sandy, and particularly marshy nature of the coastlands there, produced by deposition from the Anigros and other rivers ${ }^{333}$ (figs.18, 33). Here and elsewhere deposition produced extensive coastal shallows (upon which there was a significant danger of running aground), where surging breakers formed far from the coast (due to the shallow depth of water - see p.33ff.), where there was little solid ground upon which to moor ships, and where the flat and straight contours of the coastlands offered no shelter from winds ${ }^{334}$. Nevertheless, ships sailing in such areas, when caught by the unforeseen arrival of onshore winds, or of strong headwinds that prevented the ship from proceedings onwards, had little choice but to drop anchor and hope that they would not drift into disaster ${ }^{335}$. The dangers posed by such shoals, even when considerable caution was shown on the part of the crew, is clearly illustrated in Acts of the Apostles 27, part of which has already been quoted and discussed (above, p.104f.); the excerpt below carries on from that point:

'Next day, as we were making very heavy weather, they began to lighten the ship; and on the third day jettisoned the ship's gear with their own hands.... The fourteenth night came and we were still drifting in the Adriatic Sea. At midnight the sailors felt that land was getting nearer, so they took a sounding and found twenty fathoms. Sounding again after a short interval they found fifteen fathoms; then, fearing that we might be cast ashore upon a rugged coast, they let go four anchors from the stern and prayed for daylight to return....Shortly before daybreak, Paul urged 
them all to take some food....After they had eaten as much as they wanted, they lightened the ship by dumping the grain into the sea. When day broke, they did not recognise the land, but they sighted a bay with a sandy beach, on which they decided, if possible, to run ashore. So they...let her drive to the beach. But they found themselves caught between cross-currents and ran the ship aground, so that the bow stuck fast and remained immovable, while the stern was being pounded to pieces by the breakers....He [the centurion] gave orders that those who could swim should jump overboard first and get to land; the rest were to follow, some on planks, some on parts of the ship...' (Acts 27.18-45 (parts))

This detailed description of the crew's responses to bad weather is of great interest, and little paralleled elsewhere in Greek literature. The ship, carrying two hundred and seventy-six crew and passengers, was heavily laden; even at a stage when there was little chance of running aground, all non-essential goods, and even some of the ship's gear, were jettisoned simply in order to maintain the buoyancy of the ship in the rough waters of the open sea (for this not uncommon practice, see p.242). Although it was dark, the sailors somehow 'felt', or 'conjectured' (1.27: Ú $\varepsilon \varepsilon v o ́ o u v)$ that land was approaching before they had even taken a sounding (for discussion of this point, see p.180ff., and, on the dangers of approaching the coast at night, p.228f.). Anchors were put out, to prevent the ship from drifting onto rocks before daybreak, and even the ship's grain supply was jettisoned, again to lower the risk of running aground (and in the hope that it could be replaced after landfall had been made the next day). After sunrise, the crew identified a sandy bay as a promising landing point, but soon the dangers presented by shallows became all too clear: despite having been lightened as much was possible, the ship ran aground on the sandbanks after having been caught between cross-currents, or 'having fallen into an area between two seas'

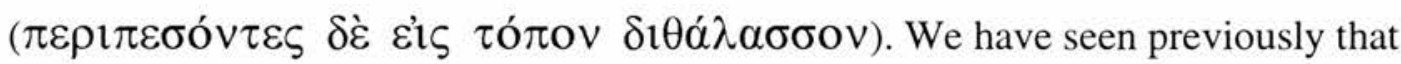
such a term often indicates a meeting of currents moving in different directions (see pp.42f., 73); here the breakers surging in across the shallows from some distance out to sea may well have induced considerable longshore drift and rip tides (see pp.31, 41f.), making the ship hard to control. Once the ship has run aground, the breakers strike the ship with such force that it not only has to be abandoned, but is apparently 
so badly damaged that there are ample planks and other pieces of debris available to allow those passengers who could not swim to get to shore safely.

This passage makes it clear that coastal shallows had to be approached with great caution, because of the danger of running aground. Nevertheless, safe, if complicated passages through such shoals, and likewise through islets produced by deposition, could often, with experience, be found. An example of such a safe passage, discovered through familiarity with a locality, appears in an episode of the story of Jason which occurs as the hero is sailing to Delphi to dedicate a tripod and a hecatomb to Apollo:

'But when in his course he was off Malea, a north wind caught and carried him away to Libya; and before he could spy land, he came into the shallows of the Tritonian lake. There, while yet he could find no way out, Triton (so goes the story) appeared to him and bade Jason give him the tripod, promising to show the shipmen the channel and send them on their way unharmed. Jason did his bidding, and Triton then showed them the passage out of the shallows ( $\tau$ óv $\delta 1 \varepsilon \kappa \pi \lambda$ oov $\tau \hat{\omega} \vee \beta \rho \alpha \chi \varepsilon \dot{\varepsilon} \omega \mathrm{V})$.' (Hdt.4.179: compare Ap.Rhod.Arg.4.1554-83)

In this passage, Herodotos first indicates another dangerous aspect of coastal shallows: the low relief of the coastlands also makes it difficult for the crew to spot land and to calculate their position before the ship enters dangerously shallow waters. Unable to escape the shallows, the Argonauts have to rely upon Triton to show them the diekplous of the shallows, the 'passage through and out'. That the diekplous involved steering a precise course between particular points is shown by the use of the word here, and also by its far more common use to describe a naval manoeuvre wherein warships pass through the gaps between enemy ships drawn up in line abreast. The only other use of the word, to pass through the gaps between the ships upon which the bridge over the Hellespont rested (Hdt.7.36), reinforces this meaning, and in relation to shallows or river deltas, the word diekplous suggests a careful and precise pilotage of a ship through the channels separating the banks, spits, bars and other characteristic deposition features ${ }^{336}$. 
Once established, these passages could be used to reach harbours or possibly lagoons where better quality shelter was available. Thus a diekplous of the Echinades islands, off the coast of Akarnania, would lead to the harbours of Astakos, Oiniadai, and Pleuron near the mouth of the Achelous (map 8). Once a ship had reached these harbours, the islands, bars and sand banks of the Echinades, all of which were built up of sediment and other material deposited by the Achelous ${ }^{337}$, would only serve to better protect it from wind and waves. Thucydides, however, describes the coastal waters in front of the Achelous, and from his description it is clear that much care and attention would have been required to navigate successfully the narrow and winding channels without running aground:

'Most of the Echinades lie opposite to Oiniadai at no great distance from the mouths of the Achelous, so that the river, which is large, keeps making fresh deposits of silt....For the stream $(\dot{\rho} \varepsilon \hat{u} \mu \alpha)$ is wide and deep and turbid, and the islands are close together and serve to bind to one another the bars as they are formed, preventing them from being broken up, since the islands lie, not in line, but irregularly, and do not allow straight channels for the water into the open sea.'(Thuc.2.102.2-5)

Similarly Polybius notes the care required in navigating Lake Maiotis (Sea of Azov), into which the River Tanais (Don) flowed:

'Maiotis is already silted up, for the greater part of it varies in depth between five and seven fathoms, so that men cannot any longer navigate it in large ships without a pilot.' (Pol.4.39ff.)

Occasionally we hear of passages being cut and maintained through areas where deposition had completely obstructed an important waterway. The best known example is the channel cut through the tombolo connecting the northern tip of Leukas to the mainland of Akarnania ${ }^{338}$ (fig.36; for tombolos see p.32). Elsewhere, the eventual connection of an offshore islet to the mainland opposite via a tombolo of deposited sediment was often seen as a positive advantage, in that the protection provided from the weather by the tombolo improved the quality of the area as a harbour. Thus the Akte peninsula of the Piraeus was originally an island which 
became joined to the mainland (pp.32,117), and the resulting peninsula provided three well sheltered harbours (pp.98, 112). Similarly in Lesbos, the city of Mytilene was originally founded on the small offshore island of Antissa, which eventually became connected to the mainland, and in doing so formed two well-protected harbours $^{339}$. At Nisaia, the port town of Megara, the harbour was originally protected by the offshore island of Minoa (Thuc.3.51). As with Antissa, Minoa eventually became linked to the mainland by means of a marshy tombolo, so that when Strabo visited the site he describes 'Cape Minoa, which projects into the sea and forms the harbour at Nisaia' (Str.Geog.9.1.4). However this tombolo cannot ever have become solid enough to resist erosion, as Pausanias, when he visited the site around one hundred and fifty years after Strabo, reported that 'Parallel to Nisaia lies the small island of Minoa.' (Paus.1.44.5) ${ }^{340}$.

In conclusion, it is clear that deposition had various complex effects upon coastal topography, sometimes advantageous to mariners, sometimes detrimental. Spits and tombolos often provided added shelter for shipping, while around extensive shallows ships risked becoming grounded while still some distance offshore, for in such areas tides were stronger (p.47) and breakers found further from the shore (p.44f., and above, p.117f.) than at most other points on Mediterranean coasts. The shallows found in front of some river mouths also clearly detracted from the advantages of using these areas for shelter (on which see above, p.102f). Local knowledge and pilotage were particularly important in such areas, where the contours of the sea bed and the position of spits, bars, and islets tended slowly but constantly to change.

\section{HARBOURLESS COASTS.}

Some stretches of the Greek coastline lacked not only man-made harbours, but also any natural features that might provide shelter for ships during adverse weather. Having discussed the diverse range of topographic features that might offer shelter to ancient Greek sailors (above, pp.95-116), it might seem unlikely that there would be 
many stretches of coast where not one of these features could be found. However, the topographical features to be found on a coast are mainly the result of the geological history of that coast, and indeed of the whole land mass roundabout, and in some parts of Greece, especially where there has been severe faulting ${ }^{341}$, geological processes have resulted in such uninviting harbourless coastlines stretching on for very long distances, providing ships with no safe landfalls for many miles.

In Greece, the many long stretches of coastline that face northeast or southwest (p.17ff., maps) often follow the fault lines separating a raised mountain ridge from a collapsed and subsequently submerged mountain block (p.19ff.). The abruptness of the rifts between such adjacent blocks, and the differences in their elevation after one has sunk and the other been raised aloft, are often such that coastal cliffs not only rise to great heights from sea level, but also sink to great depths underwater (p.25f.). Along such coasts, there are also generally few offshore islands, in contrast to southeasterly facing coasts (p.28ff.). As the NW-SE orientation of the fault lines which produce this type of coast extends throughout Greece, such cliffbound stretches of longitudinal coast may extend for great distances, especially along the lateral flanks (i.e. the Adriatic and Aegean coasts) of peninsular Greece.

Thus the coasts of Epeiros and of Thessaly, the flanks of the major promontories of the Peloponnese, and the long northeast coast of Euboia, feature few promontories, bays, or other forms of indentation (p.20f.): marine erosion may penetrate the cliff faces at joints and other areas of weakness, but owing to the considerable height to which the cliffs rise straight from sea level, and their homogeneous and overwhelmingly rocky nature, any indentations that occur tend to take the form of narrow and rocky creeks and inlets, rather than wider and deeper bights with sloping shores where ships might lie at anchor or run ashore (p.27, fig.8). River estuaries are few, and deposition features do not form easily in the deep waters offshore. The lack of shelter along these coasts is clearly described in piloting handbooks:

'The features characteristic of this coastline [from Tainaron to Dalmatia] are a high and picturesque seaboard, sparsely populated, deep water close 
inshore, and a lofty mountainous interior visible when sixty to eighty miles distant.' (Mediterranean Pilot III, p.1)

'From Cape Doro [Geraistos] at the southeastern end of Euboia, the northeast coast of that island trends in a westerly and then northerly direction and consists principally of high precipitous rocks without even shelter for the smallest description of boats, nor scarcely a place where a boat can land.' (Mediterranean Pilot IV, p.237f.)

'Cape St. George [the southeastern point of Magnesia], from whence the shore continues northwest for seven leagues to Cape St. Catherine; there is no intermediate bay or harbour, but the land is high and the coast steep to. Following the shore, which winds from Cape St. Catherine somewhat semi-circularly for six leagues to Cape Sigri, the features of the coast continue high, precipitous, and steep to.' (New Pilot p.223) ${ }^{342}$

Ships in such areas, when caught in winds that were either onshore or too directly from ahead to allow progress to be made, simply had to drop anchor and hope that the ship would not drift, and that the wind would change before long (see below) ${ }^{343}$. This was a particularly precarious strategy off fault coasts, where, as the sea bed generally falls away rapidly to great depths, ships would have had to sail very close in to the cliffs, in order to sit over the narrow rocky sill (for which see p.26), where water shallow enough for the anchor to make contact could be found.

While the west coast of Asia Minor shares Greece's history of faulting and submergence, the orientation of the faulting is primarily E-W, causing highly developed indentation of the essentially N-S running coastline (p.21, map 11). Thus, although cliffs are common on the west coast of Asia Minor, the high degree of E-W faulting prevents such stretches of cliffbound shore from continuing straight and unbroken for long distances. Thus there are areas of natural shelter, harbourage, and access to the interior, which made this coast a popular area for settlement (in contrast to the poorly-populated faulted coasts of the Greek mainland), despite its faulted and cliffy character. Similarly the north coast of Crete is far from harbourless, but features many shorter stretches of harbourless cliffy coast onto which ships caught in strong northerly winds might be helplessly blown if their anchors did not hold ${ }^{344}$. 
Cliffs formed by the marine erosion of submergence coasts, even when there is no history of faulting (see p.26f.), may also feature very few useful areas of shelter. The rocky shelves which form just below sea level as the cliffs are cut back into the coastline, upon which fragments broken off from the cliffs collect (p.26), pose a very serious threat to any ships attempting to sail, or forced to lie at anchor (see above), in their vicinity. This danger is heightened by the breakers and rough water that cover such shallow shelves of rock (p.39). However, depending on the dip, the width, and the resistance of the rock strata, and on the frequency and orientation of joints in the rock, indentations of varying size and form can be worn into such cliffs by the action of the waves (p.21ff.). Where the rock strata lie roughly parallel, or 'concordant', with the coast, the indentations produced will tend to be fewer and smaller, as also happens where the strata are narrow and all relatively resistant to erosion. However, if the stratification is transverse, lying at an angle to the coast, and there are fairly wide belts of softer rock, or of schist or other easily eroded materials, then fairly wide indentations may be formed (pp.23f., 27). Such indentations (in addition to those not eroded, but simply preserving the original (pre-submergence) contours of the mountain slopes), may appear large enough to shelter ships, but in practice the rocky shores and offshore reefs which are typically to be found around such coastlines often make such indentations dangerous and inaccessible (pp19ff., 22ff.), as do their often narrow entrances (p.98).

Thus the high degree of indentation in the 'Hollows of Euboia' (fig.13), and the many other similar stretches of coast around the shores of Greece, serves not to provide mariners with places of shelter, but merely to give the coast a reputation for inhospitability and danger (p.71f.). On the shore itself, any surface earth was washed away before erosion of the rock commenced, so that the coast consists only of bare rock, sloping into the sea at an angle related to the dip of the strata.

Waves behave rather differently along faulted cliff coastlines. Here the deep water prevents the waves from breaking until very close inshore, or even from breaking at all, in which case they can be reflected back into the next approaching waves (p.38f.). 
As long as ships remain a prudent distance from such cliffs, breakers are unlikely to cause much danger, but the great height of faulted cliffs, and the generally NW-SE orientation of the coastlines they are found on, do substantially increase the problems associated with wind turbulence.

This is because such coasts present formidable barriers to prevailing winds (figs.41, $42,43)$. The southwest-facing coasts of western Greece and the southern Peloponnese stand directly in the path of depressions moving eastwards from the Adriatic, and are particularly associated with the Bora, and vulnerable to the southwesterly Sirocco (pp.49ff. 63, 78ff., 100f., 114) ${ }^{345}$. Meanwhile the northeastfacing coasts of the southern Peloponnese, the Aegean's west coast generally, and also the north coast of Crete, blocked the path of the Etesians in summer (pp.63, 75, $77,79,99 \mathrm{f} ., 104)$ and Boreas and kindred winds in winter (p.51f.). Unable to bypass such long and high coasts, these winds must rise over the cliffs, causing the squalls, calms, eddies, and other forms of turbulence associated with the vertical displacement of winds (p.57ff., figs. 45,46 ). Moreover, where these faulted cliffs are particularly high (for examples, see p.25), the turbulence caused is correspondingly heavy, causing squalls, calms, or both, not only to the lee of promontories, but also in front of all high cliffs, as great streams of air struggle to rise abruptly against a vertical obstacle. Thus Theophrastos (Vent.27) notes the squalls and reverses of wind that occur when northerly winds strike Olympos and Ossa on the Thessalian seaboard. During such turbulent wind conditions, sailing was extremely dangerous in the vicinity of these coasts, making the lack of harbours in the area all the more notable.

Turbulence around these coasts may also, at any time of year, cause thunderstorms (p.59f.), the heavy rain and squalls of which (p.63ff.) pose a further danger to mariners (p.239f.). Thus in Herodotos' account of the Artemision campaign, after the storm off Sepias and the first encounter between the fleets, both the main Persian fleet at Aphetai and the contingent of two hundred ships sailing round Euboia (see fig.50) were caught in northerly winds which produced a thunderstorm at the coast; the main 
fleet, anchored offshore, had no easy time, but for the ships rounding Euboia, which were actually at sea during the storm, the result was disaster:

\begin{abstract}
'When darkness came on, the season then being midsummer, there was abundance of rain all through the night and violent thunderings from Pelion; and the dead and the wrecks were driven towards Aphetai, where they were entangled with the ships' prows and fouled the blades of the oars. The ships' companies that were there were dismayed by the noise of this, and looked in their present evil case for utter destruction; for before they were recovered after the shipwreck and the storm off Pelion, they must next abide a stubborn sea-fight, and after the sea-fight rushing rain and mighty torrents pouring seaward and violent thunderings. Thus did the night deal with them; but to those that were appointed to sail round Euboia that same night was much crueller yet, inasmuch as it caught them on the open sea; and an evil end they had. For, the storm and the rain coming on them in their course off the Hollows of Euboia, they were driven by the wind they knew not whither, and were cast upon the rocks....So these perished at the Hollows of Euboia.' (Hdt. 8.12ff.)
\end{abstract}

Because they are thus exposed not only to the cyclonic winds of winter, but also to the normally benevolent Etesians in summer, the coasts of Euboia and Thessaly deservedly had particularly bad reputations ${ }^{346}$. But there were shorter stretches of equally treacherous northeastwards-facing coastline elsewhere in the Aegean: thus the Persians had also suffered terribly through northeasterly winds blowing onto faulted cliffbound coasts at Mt. Athos in 491B.C. in the Chalkidike (p.77f.), and similarly the dangers which the Etesians posed at Malea were closely connected with the faulting, orientation, cliffs, and lack of harbours on the coast there (p.78ff.). As Xerxes was supposedly warned (Hdt.7.49, quoted at p.21), when sailing along coasts like these, especially given the lack of available shelter, "it is well to bear in mind that chances rule men and not men chances.'. The ancient Greeks accordingly often simply avoided such areas, or at least stood well out to sea when sailing in their vicinity (see above, pp.71, 114). As early as Homer, the impossibility of finding shelter around extensive cliffs had been familiar to all (see Hom.Od.5.400-414, quoted in two parts at pp.25, 27). 


\section{CHAPTER THREE.}

\section{SAILING ROUTES AND NAVIGATION.}

We have investigated elsewhere the ways in which the basic practicalities of simply manoeuvring ancient ships efficiently and safely, were influenced and affected by the time of day and year (app.1), and the topography of a particular area (ch.2). In this chapter we shall be concerned less with the implications of sailing in particular types of area, or at particular times, and more with the practicalities of making complete and often long-distance voyages, in which ships were likely to encounter a considerable variety of topographical features, and meteorological and oceanographic conditions. In connection with this, we shall discuss the types and characteristics of routes followed by ancient Greek sailors, the reasons and principles involved in deciding those routes, and the ways in which crews attempted both to adhere to those routes and to determine their position at any given moment, despite their lack of instruments for measuring time, position, distance, and bearings.

\section{COASTAL SEAFARING - A QUESTION OF DEGREE.}

It is commonly asserted that ancient Greeks seafarers 'crept round' or 'hugged' the shore, rarely, if ever, losing sight of land ${ }^{347}$. Such descriptions conjure up images of ships tortuously following the characteristically intricate and highly indented contours of the Greek coastline (pp.17-22), never daring to venture far from the coast lest some terrible storm should arise on the open sea and bring disaster to the crew. However, in the sixteenth century AD, Spanish ships, despite having traversed the Atlantic, were still following coastal routes when in the Mediterranean ${ }^{348}$, which suggests that the practice of coastwise sailing in the Mediterranean was not due simply to fear ${ }^{349}$. Given that many Greek promontories and islands could be seen from ships fifty, or even one hundred miles away ${ }^{350}$, it is clear that merely remaining within sight of the coast does not necessarily imply a constant effort to stay near to the 
shore. Moreover, given, for example, that no point in the Aegean is more than forty miles from land, that Italy is only forty-five miles distant from Corcyra, with the Italian and Greek peninsulas being visible simultaneously from some parts of the Adriatic, and that sailors crossing the Black Sea also reported seeing its northern and southern shores simultaneously ${ }^{351}$, it is clear that on a typically clear summer's day it would be difficult for any Greek sailor to voyage out of sight of land, unless he were headed for a completely different part of the Mediterranean ${ }^{352}$. In such an environment, where no effort or carefully planned course was needed in order to keep land in view, phrases like 'hugging the shore' should indicate a real desire and an effort to hold the ship not only in sight of, but as near as possible to, the shore. Whether or not this is an accurate characterisation of ancient Greek seafaring is the first point to be addressed here. Was coastal seafaring intentional or simply unavoidable, and just how 'coastal' was it? What were the relative merits of coastal sailing and of 'open-sea' sailing? How can we reconcile the image of creeping coastwise navigation with statements such as 'That the Phoenician and Greek sailors frequently set their ships' prows freely towards the open sea cannot be doubted or denied. ${ }^{, 353}$ ? Did some ship types and sailors tend to hug the coast more than others? In all of these matters, the impact of topography, oceanography, and meteorology will be highlighted.

\section{Geographical factors affecting coastal sailing.}

One beneficial aspect of sailing within immediate reach of the coast is that shelter may be found relatively quickly whenever it becomes imperative to escape changing or deteriorating weather conditions ${ }^{354}$. This advantage would clearly tend to be most valued at the beginning and end of the traditional sailing season, and indeed outside it altogether, when the more changeable weather conditions and the periodic passage of depressions with their various winds (pp.48-54) made it more likely that a ship sailing initially in favourable conditions might find itself overtaken by adverse conditions before the end of its journey (pp.107f., 224f). Even during the summer months, readily available shelter would have been welcome, for even in this season 
thunderstorms occur, and the Etesians can cause dangerous squalls and storms (cf. pp.50, 75f., 82, 85f., 95, 99, 104f., 113, and esp.108).

Land and sea breezes, which developed most strongly during the ancients' summer sailing season (p.53, fig.43), constituted another advantage of coastal sailing. By exploiting these, ships could sail in directions other than that of the northerly Etesians or other prevailing winds: tacking (setting the sail at an angle so that the ship's direction of travel diverges from that of the wind propelling it) meant that land and sea breezes could be used to propel a sailing ship to and fro along the coasts and through the islands of the Mediterranean when the prevailing winds over the open sea were adverse ${ }^{355}$. Likewise, in coastal areas, the dangers arising when prevailing winds die to a calm (for which see below, p.134f.) were avoidable, for, in the absence of other winds, land and sea breezes establish themselves all the more strongly, and they are in any case generally strong during summer, the period at which calms most commonly occur in the seas around Greece ${ }^{356}$.

However, these advantages of coastal sailing were qualified in two ways: firstly, ships faced added complications and dangers when sailing in the relatively shallow water close to the shore; secondly, the topography and alignment of some coasts, rather than enabling ships to evade or overcome adverse weather conditions, tended to exacerbate the dangers caused by those adverse conditions ${ }^{357}$.

Thus coastal topography presented various physical dangers to shipping: ships might run aground and be wrecked on rocky outcrops and wave-cut platforms rising to the surface of the water or lying just below it, or on reefs which in places stretch well over a mile out from the shore (pp.24f., 26, 28-31, 68-72, 93f., 122-6, figs.27, 29, 30); sand banks and shoals, while inflicting less direct physical damage on a grounded ship than solid rocks, were particularly difficult to navigate owing to their tendency to shift under the influence of tides and currents, and could also leave vessels stranded, with no way of replenishing supplies, and exposed to pounding by the breakers which form in such shallow waters (pp.31f., 116ff.). Because such rocky and sandy patches 
only posed a danger to ships if they broke water, or lay close enough to the surface of the water to strike a passing ship's hull, breaking waves, which only occur in relatively shallow water (pp.33ff., 39), were a useful, but not foolproof, indicator of such dangerous points. Thus even in areas of generally deep water, isolated patches of rough water and breaking waves indicated areas to be avoided, where the sea floor rose dangerously close to the surface of the sea, Thus, when 'hugging the coast', ships would never have approached the shore so closely that they entered the area of surf and foam where the waves advancing upon the coast had already broken, unless the ship was to be brought ashore:

\begin{abstract}
'But if you come safely through the Clashing Rocks [Cyaneae] into the Black Sea, sail on with the land of the Bithynians on your right, shunning the coastal surf ( $\dot{\rho} \eta \gamma \mu \hat{\imath} v \alpha \varsigma)$, till you round the mouth of the River Rhebas and the Black Cape [Melaina] and come to harbour in the Isle of Thynias.' (Ap.Rhod.Arg.2.345-350)
\end{abstract}

We have also seen that squalls and calms appearing unpredictably behind high coasts and islands lying in the path of prevailing winds (pp.57-60, figs.45, 46), made navigating and finding shelter in coastal waters more complicated (pp.75, 79, 92f., 105ff., 125, fig.47.ii): on the open seas winds may blow more strongly, but they also tend to do so more steadily and constantly, without the sudden turbulent changes in intensity and direction experienced around coasts (p.57f.). In this respect, strong winds are often less problematic than unpredictable and changeable ones.

Moreover, on some coastlines, most notably straight and cliffy stretches which lay along a major fault line or faced into the prevailing winds, or both, there was a particular lack of sheltering places, natural or artificial, while the land and sea breezes so useful elsewhere were weak if present at all, and particularly dangerous weather conditions often developed, so that being close to the shore only tended to heighten the danger facing a ship and her crew (see pp. 76ff., 121-6).

Such coasts would rarely have been 'hugged' very closely because of this danger of being blown onto a dangerous and harbourless shore by strong prevailing winds. The 
wisdom of those who, being familiar with such areas, avoided them, is put into clear relief by the disasters which overcome the Persian invaders of the early fifth century $\mathrm{BC}$, who were by all accounts unaware of this important aspect of sailing in the Aegean (see pp.71, 77f., 115f., 125f.). In contrast, the actions of Amaratus, the helmsman of the ship on which Bishop Synesius sailed from Alexandria eastwards along the north coast of Africa ${ }^{358}$, exemplify the procedures followed by more experienced sailors in such areas:

'As soon as he had rounded the cape, near you, with the temple of Poseidon [the Poseidonion], he made straight for Taposiris, with all sails spread...This manoeuvre we detected just as the vessel was nearing the reefs, and we all raised so mighty a cry that perforce he gave up his attempt to battle with the rocks. All at once he veered about as though some new idea had possessed him, and went for the open water....Again we make common cause of complaint, and our grievance now is that we have been forced away too far from the shore...."What do we want of the open sea? Let us rather make for Pentapolis, hugging the shore; for then, if indeed we have to face one of those uncertainties which, as you admit, are unfortunately only too frequent on the deep, we shall at least be able to take refuge in some neighbouring harbour".....A gale commenced to blow from the north, and the violent wind soon raised seas mountains high....with great difficulty however we headed her in. Then Amaratus thunders out, "See what it is to be master of the art of navigation! I had long foreseen this storm, and that is why I sought the open. I can tack in now, since our sea room allows us to add to the length of our tack. But such a course as the one I have taken would not have been possible had we hugged the shore, for in that case the ship would have been dashed on the coast.".' (Synesius Letters 4)

This passage is particularly interesting because it features two different aspects of the advantages and disadvantages of coastal sailing. Despite the early scare, Synesius, the non-mariner, maintains the commonly held view that coastal sailing was safer than sailing on the open sea because shelter could be found in the event that a storm arose. However, Amaratus, the experienced sailor, knows the danger of being caught on the coast during strong onshore winds, and takes evasive action as soon as he begins suspecting that northerly winds will soon arrive. The importance to sailors of constantly assessing the state of the weather and of the sea, and of adjusting courses 
to take account of expected changes of sailing conditions, should be noted here, and is discussed further below.

In areas where prevailing winds thus blew directly onshore, danger came not only in the form of the wind itself, but also in the often-accompanying rain and squalls (pp.79, 125.). Rain was a serious problem for ships, especially those with no full deck (p.238ff.), and as rain in the seas around Greece is primarily a coastal phenomenon (p.62f.), rainy weather would tend to discourage coastal sailing and to promote sailing further out to sea, where the rain and associated thunderstorms were far less likely to be encountered. Thus the heavy rainfall and thunderstorms which occur along the eastern coasts of the Adriatic (p.63f.) were another reason why the coastal route around the Adriatic was shunned, in favour of the direct crossing across its mouth (p.114). Likewise, rain is emphasised as one of the contributory factors in the disaster that struck the Persian fleet during storms off the northeast coasts of Thessaly and Euboia (p.125f.).

Thus, in this respect, high cliffbound coasts were particularly dangerous for mariners. Yet coasts that were less sheer and more indented also held their own dangers (above, p.129f.), and even where long stretches of coastline were largely unproblematic, and 'hugging the shore' was generally held to be advantageous, coastal sailing routes still necessarily entailed periodically rounding headlands or passing through enclosed straits, where winds and currents often conspired to produce some of the most difficult sailing and navigational problems known to ancient sailors (pp.67-82 (headlands), 82-94 (straits)).

Tides, which are of no practical significance to ships sailing far from the coast, may also complicate navigation in coastal waters. However, in the virtually landlocked Mediterranean, where tides are negligible (p.47), such complications only affected ancient Greek mariners when they found themselves in those shallow gulfs and narrows where their effects are more pronounced (fig.39). In relatively tideless areas, navigators in the constricted waters of narrow straits had the advantage that the depth 
and breadth of the body of water being traversed, and the strength and direction of its currents, remained to all intents and purposes constant (for the effect of tides upon the strength and direction of currents, see p.47). This in turn might simplify the timing of long distance voyages, and estimations of their duration, to the extent that delays caused by the need to await certain tidal conditions before navigating shallow straits, or indeed harbour entrances (p.231f.), did not occur. However, some straits, such as the Euripos and the Straits of Messina (p.46f.), were exceptional in this sense, for there tidal influences were strongly felt and caused currents of fluctuating strength and direction which permitted safe passage only at certain times (p.83ff., cf. also p.91f. on the wind-rather than tide-governed fluctuations of the current in the Chian Strait).

To the same extent, submerged rocks, reefs, sand banks, and other obstacles always remained under the same depth of water, so that once ancient Greek sailors had become familiar with the locations and depths of such dangers in the waters they regularly sailed, they knew which areas were dangerous and to be avoided. In strongly tidal areas, on the other hand, sailors would have had to be aware both of the state of the tide, and of the various stages during the tidal cycle at which different underwater hazards became shallow enough to strike ships passing over them. This was clearly a far more complicated process, and one more likely to result in potentially disastrous miscalculations ${ }^{359}$. Long, narrow, and relatively shallow gulfs such as the Adriatic, Thermaic, and Syrtis Gulfs, then (p.47), were unusually problematic for coastal sailors, and were often omitted from, or avoided on, coastal sailing routes (for the Adriatic, see p.114; for the Gulf of Syrtis, and tide-related problems specifically concerning departing from and returning to the shore, rather than sailing merely within its vicinity, see p.232f.).

\section{Geographical factors affecting open-sea sailing.}

On the open sea there are no physical impediments to interrupt the progress of winds and waves, which therefore tend to be more powerful than in coastal waters (see pp.32f., 57f.). At the same time, much more time and effort was required for sailors on the open seas than for coastal sailors to reach the shelter of land. Ships on the open 
seas were therefore far more likely than those in coastal waters to be caught in fierce storm winds and high seas, and to find themselves unable to maintain their desired course or to reach shelter. In such situations, ships were forced either to run with the wind, or to face the ship into wind and waves, and so risk being inundated by the waves (p.238ff.). Where, as at Malea, the prevailing winds (here the northerly Etesians) blew towards an area of sea where there was no landfall for a considerable distance, ships might thus be blown off course for days on end, until either the wind abated, leaving the ship possibly lost and drifting helplessly (if there were no oars), or a lee shore appeared, against which the ship could easily be driven by the wind. Such was the predicament facing those aboard the ship taking Paul to Rome (Acts 27.1-45, quoted in two parts at pp.104f., 117): from Crete they were driven across the empty seas to the south and west by fierce northerlies, forced to jettison gear and supplies to keep the ship afloat, and then left drifting for fourteen nights, after which they approached the coast at night, causing the crew to fear being driven blindly onto a rocky shore. After daybreak the ship, having to land to replenish supplies, became grounded, not on rocks, but on shoals, and was destroyed by the breakers (for the dangers of approaching the coast from the open sea during darkness, see p.228f.). Such were the dangers of being caught on the open seas with no immediate recourse to shelter, and in this respect the advantage of sailing near the coast stands out clearly.

Calms also posed a real danger to ancient shipping on the open seas (but rarely did so along coasts; see above, p.129), especially for holkades, which were not equipped with oars (p.243). Calms might cause problems even for oared ships, as having unexpectedly to row long distances was extremely taxing, especially given the generally limited supplies of food and water carried aboard many warships ${ }^{360}$ (p.241).

Nevertheless, when it was possible to forecast, with reasonable certainty, fair weather and following winds for the duration of a prospective voyage, then a route over the open sea might appear more attractive than a coastal route to the same destination: sailing directly across the sea from the point of departure to the destination minimised both the distance travelled and (usually) the amount of time taken to complete the 
journey; the alternative route around an often highly indented coastline would be considerably longer, and take more time. The shorter open-sea route also involved less danger from the elements, to the extent that a faster journey left less time for foul weather to develop.

Likewise, while those sailing out of sight of land did not have the benefit of the profusion of coastal landmarks which elsewhere greatly simplified navigation ${ }^{361}$, alternative navigational strategies existed (for differences between coastal and open sea navigation, see below, pp.175-94), and sailors would only have rejected open-sea routes on navigational grounds when these alternative strategies were also impractical (e.g. in the heavily overcast conditions typical of winter). Moreover, dangerous rocks and shallows were far less common on the open seas than in coastal waters (see above, p.129f.), while winds also tended to be far more regular over the open seas than around coasts and islands, which present barriers and so cause turbulence in airstreams (pp.57-60, figs.45-7), and where diurnal and katabatic breezes cause further fluctuations in wind direction and strength (fig.43). Thus, when the prevailing winds were blowing roughly in the direction in which a crew wished to sail, the open sea route could be far simpler, safer, and more direct than the coastal route, as long as the winds continued blowing both at a reasonable pace, neither dying to a calm nor building to a windstorm, and in the same direction. If, however, the winds changed, then making headway might become almost impossible unless through oar power (for the degree to which ancient sailing ships could sail into the wind, see p.244 and n.577), and the crew might prefer to travel nearer the coast, where there was greater scope for making headway in generally adverse wind conditions (above, p.128f.).

\section{Other factors affecting the question of coastal v. open-sea sailing.}

Technical and human considerations also affected the choice of route. On the technical side, the seaworthiness of a ship was of paramount importance. While merchant ships, for example, could run into difficulties on the open sea (p.242f.), they were nevertheless distinctly better suited to open-sea sailing than triremes and other galleys. Although such heavily-oared warships did not have to rely on their sails, and 
so could row themselves out of a calm, or make headway against adverse winds and currents more easily than even oared merchant ships, (as, for example, in the Hellespont and Bosporos - see p.85f.), they were difficult and impractical to row over long distances of open $\operatorname{sea}^{362}$. They were also far less able to remain at sea for long periods of time, partly because their structures were not suited to the rougher conditions of the open seas, and partly for logistical reasons relating to their large crews (for these aspects of warships, see pp.239-42). Thus open-sea routes on which a few days might elapse between successive landfalls (e.g. when sailing from Greece to Africa, Italy or Sicily) were far more testing and risky for triremes than for merchant ships.

Cargo was also significant, as heavily laden ships were less buoyant, less manoeuvrable, and slower than empty ships, and so were less suited to voyages through the rougher conditions of the open seas ${ }^{363}$. The type of cargo might also affect the choice of route - merchant traders might be content to follow open-sea routes in the knowledge that, should their ship be threatened with inundation on heavy seas, they could maintain buoyancy by jettisoning cargo (the value of jettisoned goods did not have to be repaid to Athenian creditors; see p.242). Jettisoning cargo was at times a life-saving practice (see p.117f.), but not an option for those ships, not only warships but also some civilian vessels, particularly ferries, which carried human rather than inanimate cargoes. Particularly if there were important public figures on board, safety would take a higher priority, and a less exposed coastal route might be preferred, so that the ship could be brought ashore or at least to shelter if dangerous conditions developed ${ }^{364}$.

However, because of the nature of their business, merchantmen too might often have followed coastal routes and made frequent stops. Few simply sailed to a single destination, bought goods, and then sailed straight back to the home port to sell them, in the way many Athenian grain ships could, thanks to the guaranteed home market. Most traders were perforce more itinerant, taking a roundabout route and making frequent stops to sell some goods and buy others ${ }^{365}$. For them, a complete journey 
might involve not one direct passage over the open seas, but a series of legs between successive ports of call. However, while their overall route thus involved numerous stops at points along a coast, the routes between these ports of call might nevertheless be direct, avoiding time-consuming detours around the indentations of the coast.

Experience was vitally important to mariners, and was another factor that might influence the choice of route. It would have been an important factor in, for example, a sailor's ability to accurately predict how long a journey would last (see below, p.188f.), and the weather conditions that were likely to arise as time passed and the ship reached new localities (p.246ff.). Experience was also invaluable when navigating out of sight of the coast, but its prime role in route selection was a psychological one. Those who had little experience of sailing apparently felt relatively safe and secure when sailing in shallow waters, and particularly when within sight of land, but felt correspondingly endangered and insecure when in very deep waters, out of sight of land. We have already seen the contrasting attitudes of the professional sailor Amaratus, who freely set a course for the open seas, and his non-mariner passengers, who wrongly expected coastal sailing always to be the safer option (above, p.131). Athenian triremes may have followed coastal routes more than was logistically necessary because they were commanded by trierarchs, ordinary, if wealthy, Athenian citizens who generally had very little experience of sailing and navigation ${ }^{366}$. Even the crews of Athenian triremes, usually thought of as capable and experienced sailors, were not immune to this fear of deep water and high waves. The extra protection which Chabrias fitted to the sides of his triremes was designed not only to prevent the waves from casting water into the ships and soaking the crews, but also to prevent the sailors from being struck by fear at the sight of the waves ${ }^{367}$.

The Battle of the Frogs and Mice, variously ascribed to Homer and to Pigres, brother of Artemisia of Karia, describes a battle which resulted from the drowning of a mouse, when the frog carrying him dived underwater to escape a water-snake. The author clearly differentiates the attitudes towards sailing of the frog Puff-jaw, an experienced sailor, and of the mouse Crumb-snatcher, an inexperienced sailor: once 
afloat, both are happy as long as they remain in shallow water, but, as the water becomes deeper and land recedes, the inexperienced mouse becomes ever more concerned:

" "The Son of Cronos has given us frogs the power to lead a double life, dwelling at will in two separate elements; and so we both leap on land and plunge beneath the water. If you would learn of all these things, 'tis easy done: just mount upon my back and hold me tight lest you be lost..." ...Now at first, while he [the mouse] saw the land nearby, he was pleased, and was delighted with Puff-jaw's swimming; but when dark waves began to wash over him, he wept loudly and blamed his unlucky change of mind: he tore his fur and tucked his paws in against his belly, while within him his heart quaked by reason of the strangeness ( $\dot{\eta} \eta \dot{\varepsilon i n})$; and he longed to get to land, groaning terribly through the stress of chilling fear. He put out his tail upon the water and worked it like a steering oar, and prayed to heaven that he might get to land.' (Battle of the Frogs and Mice 59-75)

The principal reason why the frog remains calm and the mouse panics is that the frog is experienced on water, the mouse inexperienced. The mouse is not asked to take any active role except to hold on tightly, and thus it is evident that it is not his lack of seafaring skills which makes him afraid, but simply his inexperience of being in deep water far from land, because of which 'his heart quaked by reason of the strangeness

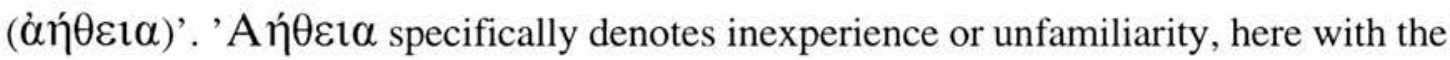
height and darkness of the waves, and thus the author of the passage appears to assume that it was natural and commonplace for those who had little experience of the sea to have an irrational 'fear of the unknown', rather than a rational reaction to any real increased danger, when sailing far from land. This irrational yearning for shallow coastal waters on the part of inexperienced sailors can be seen again in Synesius Letters 4, where the passengers not only prefer to remain close to land when the weather appears to them to be fair (see above, p.131), but also retain this preference even when it is quite clear that conditions are such that it would be much safer if the ship were in deep water, far from inshore dangers. In this passage from the letter, the passengers are at first panic-stricken when an admittedly fierce storm arises while they are on the open sea. However, with its sail and yard-arm ruined, the ship, now at the mercy of the winds and waves, is then driven helplessly onto the rocks, where even 
non-sailors might realise that it was in serious danger of breaking up (even ships beached only on sand could be smashed by the waves - see Acts.27.18-45, quoted above, p.117). Rather than panicking, the passengers are relieved, simply because they have struck the coast and so 'returned' to land:

'The storm opened with north winds and with heavy rain during the moonless night, presently the winds raged without measure, and the sea became deeply churned up. As to ourselves, exactly what you might expect at such a crisis took place. I will not dilate again on the identical sufferings.....We....were carried along during a day and a night, and at the second crowing of the cock, before we knew it, behold we were on a sharp reef which ran out from the land like a short peninsula. Then a shout went up, for someone passed the word that we had gone aground on the shore itself. There was much shouting and very little agreement. The sailors were terrified, whereas we through inexperience clapped our hands and embraced each other. We could not sufficiently express our great joy. And yet this was accounted the most formidable of the dangers that had yet beset us...' (Synesius Letters.4)

If fear of deep water encouraged inexperienced sailors to remain near the coast, the threat of piracy might have encouraged others to keep well out to sea. Pirates apparently tended to favour inshore waters in the vicinity of islands, straits and promontories (partly because merchant shipping was most often and most easily encountered in such areas: see below, p.157f. $)^{368}$, and thus by sailing far from the coast and the pirates' look-outs, crews might hope to avoid interference. This is another reason why warships, which had far less to fear from pirates, might be more inclined to remain in coastal waters for considerable lengths of time than merchant ships (for other reasons, see above, p.135f.). On the other hand, one advantage of remaining in coastal waters was that, should pirates threaten, landfall and the shelter of a regular port could more readily be reached than from the open sea, where there was nowhere to run to ${ }^{369}$.

\section{Deciding between the coastal and the open-sea route.}

There were clearly advantages and disadvantages in both coastal sailing and open sea sailing, and it is wrong to say that either was universally preferred to the other. The choice of route would have been assessed and decided upon by the crew (or just the 
helmsman) every time a ship set sail, judging the relative risks and dangers of the different options, and making specific reference to the capabilities of the ship. Even once initially decided upon, the route would be constantly revised during the journey, as weather conditions, and other factors, developed. At this stage, we can summarise the criteria by which ancient sailors decided on which route to take between any two points.

Firstly, the crew would have to assess their options - did they have a choice of routes, or were conditions such that only one route was practical? The strength and direction of prevailing winds, and the nature of weather conditions likely to be encountered on the trip (as far as these could be predicted - see app.3, esp. pp.246-52), must often have broadly determined the route followed. If the prevailing winds on the open seas were against them, then they might have no choice but to follow a coastal route on which they would be able to exploit land and sea breezes (above, p.128f.) ${ }^{370}$. On the other hand, the crew might decide not even to consider a coastal route, if sections of the coasts they would have to pass offered little shelter and were often attended by dangerous weather conditions (above, p.129f.), but if bad weather was expected generally, then a coastal route might be preferred for the more ready availability of shelter (above, p.128). If weather conditions appeared particularly changeable, as at the end of the summer sailing season (pp.48f., 254ff.), then the choice would be between a shorter open-sea route, in the hope of reaching the destination before the weather deteriorated, or a longer coastal route on which shelter was available if needed. Coasts notorious for their pirates might be avoided by merchant ships (above, p.139), as enemy coasts might be by warships; conversely, warships might also hug the coast, in order to avoid enemies on the open seas (see below, p.179).

The type and condition of the ship and its crew also had to be taken into account different types of ship were more seaworthy than others, and were propelled in different ways, and so were suited to different types of route (above, p.135f.) The age and general condition of individual ships also had to be considered (see, for example, p.242, on omissions from the active list of Athenian triremes), as the severity of 
conditions a ship could tolerate would also influence the route followed, as would the type and amount of cargo carried (above, p.136).

If, having thus assessed the available options, and having taken into account the various physical, human, and technical factors which had a bearing on the ship's performance and safety, the crew still felt that a number of routes were still feasible, then speed might become the deciding factor, especially if the journey had to be completed, or a particular destination reached, by a certain date. Clearly direct routes across the sea involved covering less distance than following the indentations of the coastline, but this does not necessarily mean that open-sea routes took less time to complete than coastal routes. Thus a ship which could make only very slow progress against adverse winds on the open sea might reach its destination sooner if the greater speed it could achieve by exploiting land and sea breezes along the coast more than compensated for the extra distance involved in taking the coastal route.

It is also important to note that the choice between coastal and open-sea routes was one of degree, for ancient sailing routes did not only run either right along the coast, or straight across the middle of the sea. Thus, even when a ship had to follow a coastal route in order to exploit land and sea breezes, the crew could still sail anywhere from the edge of the dangerous inshore zone, where breakers indicated hazardous shallow water (above, p.129f.), to twenty-five kilometres or more out to sea, at which distance Mediterranean land and sea breezes can still be felt in summer (p.53). This facilitated the practice, discussed below (pp.142-5) of not entering bays, but instead cutting directly across their mouths. Equally, warships, which had to make regular stops to rest crews and take on supplies, could still follow essentially open-sea routes by slightly modifying courses to take in convenient islands or headlands where shelter and supplies were available (below, pp.145-54).

The lack of a solid dividing line between coastal sailing and open-sea sailing is clearly illustrated in the extract from Synesius' description of his journey eastwards from Egypt, along the north coast of Africa (Letters 4) quoted above (p.131). At the 
beginning of the voyage, the steersman Amaratus follows the coastline very closely indeed, and Synesius and his fellow passengers clearly expect the voyage to follow a coastal route. However, Amaratus then sails so far out to sea as to encounter the freighters which are following a seemingly standard open-sea route, quite possibly making for the markets of Rome. The important point to note here is that Amaratus has not decided to adopt an open sea route, but is merely modifying his coastal route to take account of impending changes in the weather, so as to avoid being cast upon the rocks, and to facilitate later re-approaching the shore safely. Thus it can be seen that, even when 'hugging the shore', safely negotiating a coastal route could often entail sailing as far from the coast as ships that had no interest in coastal routes.

\section{Finding the most economical route: coastal routes.}

One of the commonest 'compromises' between open-sea and coastal seafaring was, as just noted, to follow the general outline of the coast, but to sail directly across the mouths of often deeply recessed bays, rather than following the longer route around their shores:

\footnotetext{
'Now when the fleet had left Xerxes and sailed through the canal made in Athos (which canal reached to the gulf wherein stand the towns of Assa, Piloros, Singos and Sarte), thence taking on board troops from these cities also, it stood out to sea for the Thermaic Gulf, and rounding Ampelos, the headland of Torone, it passed ( $\pi \alpha \rho \alpha \mu \varepsilon i \beta \varepsilon \tau 0)$ the Greek towns of Torone, Galepsos, Sermyle, Mekyberna, and Olynthos, from all which it received ships and men. This country is called Sithonia. The fleet held a straight course ( $\sigma \cup v \tau \alpha \dot{\alpha} \nu \omega \nu)$ from the headland of Ampelos to Kanastraion, where Pallene runs farthest out to sea, and received ships and men from what is now Pallene, but was formerly called Phlegra, to wit Potidaia, Aphytis, Neapolis, Aige, Therambos, Skione, Mende, Sane. Sailing along this coast [i.e. the west coast of Pallene, north of Kanastraion] they made for the place appointed [Therma], taking troops from the towns adjacent to Pallene and near neighbours of the Thermaic Gulf.' (Hdt.7.122f.)
}

The important point here is that the fleet, which otherwise sticks closely to the coast, picking up troops along the way, cuts straight across $(\sigma \cup v \tau \alpha \dot{\alpha} \mu \nu \omega \mathrm{v})$ the mouth of the Toronaean Gulf, between the headlands of Ampelos and Kanastraion, the one part 
of the journey where it did not have to follow the coast in order to make stops to pick up troop reinforcements ${ }^{371}$. That ships regularly sailed whole journeys by cutting directly from headland to headland in this way, unless they had reason to enter the gulfs enclosed by those headlands (for shelter or to visit a coastal settlement), is clear from this description of the coastal route from Byzantion southwards down the coast of Asia Minor:

'On doubling Lekton one encounters a large wide-open gulf [the Bay of Adramyttion], which is formed by Mt. Ida as it recedes from Lekton to the mainland, and by Kanai, the promontory opposite Lekton on the other side....I have stated in the earlier parts of my work [Geog.2.5.7] that, as one sails from Byzantion towards the south, the route lies in a straight line, first to Sestos and Abydos through the middle of the Propontis, and then along the coast of Asia as far as Karia. It bohooves one, then, to keep this supposition in mind as one listens to the following; and if I speak of certain gulfs on the coast, one must think of the promontories which form them as lying in the same line, a meridian line, as it were

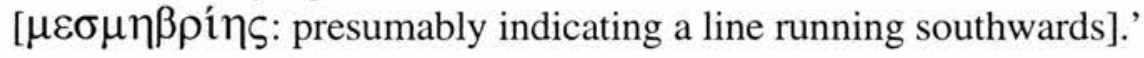
(Str.Geog.13.1.6)

If coastal sailing always entailed following the major contours of the coast, it would clearly be preposterous to claim that the sailing route from Byzantion to Karia lay in a straight line, for the west coast of Asia Minor, as Strabo clearly knew well, is characterised by bays separated by long westwards-extending promontories (pp.18, 21, map 11), such as the Bay of Adramyttion, described here as being bounded by the promontories of Lekton and Kanai. Clearly, to sail down this highly indented coastline while following a straight course, following Strabo, one must simply sail directly between the promontories here described as lying in a straight line.

Cutting directly across the mouths of bays allowed ships to reduce both the overall mileage and duration of voyages, and also the danger of embayment (for which see p.106ff.), without also reducing its ability to exploit land and sea breezes and to reach shelter quickly if necessary ${ }^{372}$. On highly indented coasts, the reduction in mileage was considerable: 
'The perimeter [of the Peloponnese], not following the sinuosities of the gulfs ( $\mu \grave{\eta} \kappa \alpha \tau \alpha \kappa o \lambda \pi \hat{\imath} \zeta o \nu \tau \imath)$, is four thousand stadia, according to Polybius, although Artemidoros adds four hundred more; but following the sinuosities of the gulfs ( $\kappa \alpha \tau \alpha \kappa o \lambda \tau i \zeta o \nu \tau \imath)$, it is more than five thousand six hundred.' (Str.Geog.8.2.1)

When describing an individual gulf, Strabo often caters both for those who might merely sail past the gulf, by giving the distance across its mouth, and for those who might have some business in the gulf, by listing the notable places along its shores, and the distances between them. Such passages thus demonstrate the two different ways of navigating gulfs, and the different distances involved:

'....a promontory called Hydra.....with the opposite promontory Harmatos forms the Elaitic Gulf [on the west coast of Asia Minor]. Now the width of the mouth of this gulf is about eighty stadia, but, including the sinuosities of the gulf, Myrina, an Aiolian city with a harbour, is at a distance of sixty stadia; and then one comes to the harbour of the Achaians, where are the altars of the twelve gods; and then to a town Grynion and an altar of Apollo and an ancient oracle and a costly shrine of white marble, to which the distance is forty stadia; and then seventy stadia to Elaia, with harbour and naval station....' (Str.Geog.13.3.5)

The practice of sailing directly across the mouths of gulfs also explains why geographers commonly describe the headlands lying on either side of a gulf as being 'opposite' each other. Such descriptions appear to be simple and justified geographical observations where the headlands are roughly equidistant from the head of the gulf, as Skyllaion and Sounion are from the head of the Saronic Gulf (Scylax

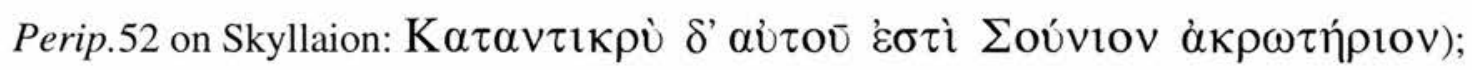
but when the same formula is used of a headlands that lie vastly different distances from the head of the gulf they together enclose, then the expression only really makes sense if understood from the point of view of a mariner approaching the headland at one end of the gulf, and intending to sail straight across to the headland at the other end. Thus when Strabo (Geog. 8.4.5) describes Rhion, near the western tip of the Thuriates (Messenian) Gulf, as being 'opposite Tainaron' ( $\dot{\alpha} \pi \varepsilon v \alpha \nu \tau$ íov Talvápou), he is really describing the maritime topography of the gulf, not simply 
its geography; otherwise, it would have been more accurate to say that Rhion lay opposite Thalamai or Oitylos, the nearest settlements on the east shore of the gulf (map 9).

On many journeys then, ships navigating an indented coastline would only have closely approached the mainland when passing promontories or when entering harbour: at other times they would be in the open waters in front of the bays separating the promontories. As a result, geographers often only mention the promontories and the harbours when describing a barely populated coast as seen from a periplous:

'These cities are far from the sea and thoroughly inland, but as you sail from Patrai to Aigion, the first cape you pass is called Rhion, fifty stades from Patrai. Fifteen stades from the cape is Panormos harbour.' (Paus.7.22.7)

'As one sails from Rhegion towards the east, at a distance of fifty stadia, one comes to Cape Leukopetra (so called from its colour), in which, it is said, the Apennine mountain terminates. Then comes Herakleion, which is the last cape of Italy and inclines toward the south; for on doubling it one immediately sails with the southwest wind as far as Cape Iapygia, and then veers off, always more and more, towards the northwest in the direction of the Ionian Gulf. After Herakleion comes a cape belonging to Lokris, which is called Zephyrion; its harbour is exposed to the winds that blow from the west, and hence the name.' (Str.Geog.6.1.7)

Likewise, when describing the nature and features of Greek coasts, geographers are principally interested in the headlands, and the bays which lie between them (see below, p.167, especially Str.Geog.7.fr.32, 8.1.3).

\section{Finding the most economical route: open-sea routes.}

One of the primary concerns of those crossing wide stretches of open sea was to minimise the distance and the time involved in sailing between one landfall and the next. This was especially important for those ships, essentially warships (p.241), which for logistical reasons had to come ashore at least once every day whenever possible, as is clearly illustrated by the case of the Peloponnesian triremes that were 
blown into unfamiliar waters while ferrying their cargo of hoplites to Sicily during the Peloponnesian War:

'The people of Kyrene had given them two triremes with pilots and...they had gone along the coast to Neapolis.....from which there is the most direct crossing to Sicily, a voyage of only two days and a night.'

(Thuc.7.50)

Even for the crews of merchant ships, which could stay at sea for much longer periods, it was still desirable to cross a wide expanse of sea by the most direct practical route, and as quickly as possible, in order to minimise the effects of navigational errors, especially as the crew could only establish their exact position, and determine the direction in which their final destination lay once they were within sight of the far shore. More importantly, the shorter the crossing, the less time there was for dangerous weather conditions to develop en route, and the sooner the ship could reach the shelter of the coast in the event that such weather conditions did develop: on long journeys lasting some days, it was difficult, if not impossible, to accurately predict how the weather would change before the next landfall was reached, especially if the journey took place outside of the summer sailing season.

On such journeys, then, ships did not simply set straight courses from the port of departure to the port of destination, but followed the coast from the port of departure to the point of land which extended furthest into the open sea in the general direction of the destination. Only then was a course set across the open sea, and this course made for the nearest point of land on the opposite shore (thus minimising the distance of the open-sea crossing), from where the coast would again be followed to the final port of destination. Thus Athene (in the guise of Mentor), when advising Telemachos on how to sail to Ithaka, urges him to make the crossing in the shortest possible time, to make landfall at the first available opportunity, and then to direct the ship along the coast back to the city:

'...sail by night as well as by day, and pray that one of the immortals who keeps and guards you will send a fair wind in your wake. But when you have reached the nearest shore of Ithaka ( $\alpha \dot{u} \tau \dot{\alpha} \rho$ '̇ $\pi \grave{\eta} v \pi \rho \omega ́ \tau \eta v$ 


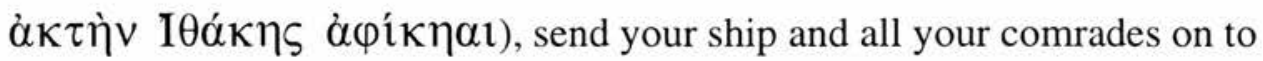
the city, but you yourself go first of all to the swineherd who keeps your swine..' (Hom.Od.15.34-9)

Being the points of land which protrude furthest into the open sea, headlands, especially those standing at the end of major promontories, tended to be the points of land which most closely approached foreign shores, and so were the points at which ships left the relative security of the coastline and struck out across the open $\operatorname{sea}^{373}$, as is clearly indicated in Triton's directions to the Argonauts:

\begin{abstract}
'That is the outlet to the sea.....and that sea stretches away in mist to the divine land of Pelops beyond Crete; but hold to the right, when ye have entered the swell of the sea from the [Tritonian] lake, and steer your course hugging the land, as long as it trends to the north; but when the coast bends, falling away in the other direction, then your course is safely laid for you if ye go straight forward from the projecting cape...' (Ap.Rhod.Arg.4.1572-83)
\end{abstract}

Equally, headlands were also the points at which landfall was made after the open sea had been crossed, and the technique of sailing between headlands was equally adopted when crossing notoriously stormy seas, and when sailing only short distances from the coast, to islands rather than to other parts of the Mediterranean:

'The Tauric seaboard....is rugged and mountainous, and is subject to furious storms from the north. And in front of it lies a promontory which extends far out towards the high sea and the south in the direction of Paphlagonia and the city Amastris; it is called Kriou Metopon. And opposite it lies that promontory of the Paphlagonians Karambis, which, by means of the strait, which is contracted on both sides, divides the Euxine Pontos [Black Sea] into two seas. Now the distance from Karambis to the city of the Chersonesites is two thousand five hundred stadia but the

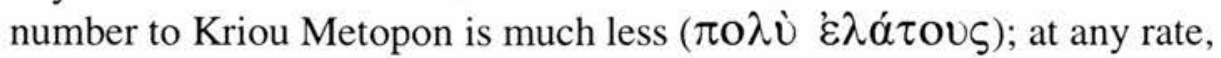
many who have sailed across the strait say that they have seen both promontories, on either side, at the same time.' (Str.Geog.7.4.3) ${ }^{374}$

'...Anemourion, a promontory, where the mainland approaches closest to Cyprus, in the direction of the promontory of Krommyos, the passage across being three hundred and fifty stadia.' (Str.Geog.14.5.3) 
'Kephallenia lies opposite Akarnania at a distance of about fifty (some say forty) stadia from Leukatas [the southernmost headland of Leukas] and around one hundred and eighty from Chelontas [the westernmost headland of the Peloponnese]. (Str.Geog.10.2.15) ${ }^{375}$

That setting courses towards overseas headlands was standard practice for longdistance sailors is implied by Pindar in the following passage,:

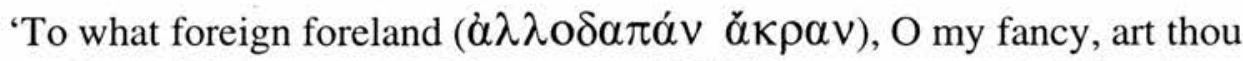
turning aside the course of thy voyage? I bid thee summon the Muse in honour of Aeacus...' (Pind.N.3.26ff.)

In the Homeric Hymn to Dionysos, the Tyrsenian pirates sailing 'swiftly over the wine-dark sea' arrive at a point on the coast where stands a 'jutting headland' (H.H.Dion.1-12). Upon this headland, they find, and capture, Dionysos, whom they assume to be waiting to be taken by ship to Egypt, Cyprus, or some other far-off destination. (H.H.Dion.27ff.). Thus the promontory is here both the point at which sailors reach land from the open sea, and the point from which others aim to sail to foreign lands. This role in the transition between coastal and open-sea sea sailing led to the headland being conceptualised as the point at which mariners lost touch with their homes on the outward legs of journeys, and equally as the point at which they felt that they had reached home again on return journeys. This is reflected in the proverb concerning Malea, the southeasterly headland of the Peloponnese, which marked the boundary of the Aegean Sea ('But when you double Malea, forget your home' - Str.Geog.8.6.20: the passage is fully quoted above, p.80f.), and also in the way Ajax' crewmen, as the chorus of Sophocles' Ajax, express their wish to be home in Athens:

'I wish I were where the wooded cape, beaten by the surf, projects over the sea, beneath the high plateau of Sounion, so that I could salute sacred Athens!' (Soph.Ajax.1216-22)

Another often imperative reason for heading for prominent headlands on a foreign shore was so as to make the earliest possible landfall (a practice referred to in the 
following two quotations), where a substantial meal could be cooked, water supplies could be replenished, proper rest could be had, or shelter from the weather could be found. In the first of the following quotations, we also see characteristic aspects of coastal sailing - after making landfall from the open sea at the headland of Malea, the Cretans next arrive at Tainaron (having thus sailed directly across the mouth of the Lakonian Gulf), where they hope (but fail) to come ashore. From Tainaron they then sail directly to the west coast of the Peloponnese, where the ship arrives at a far larger number of mainland sites, reflecting the less indented character of this part of the seaboard (map 9):

'He [Apollo] became aware of a swift ship upon the wine-like sea, in which were many men and goodly, Cretans from Knossos....These men were sailing in their black ship for traffic and for profit to sandy Pylos...First they passed by Malea, and then, along the Lakonian coast, they came to Tainaron....There they wished to put their ship to shore $^{376}$....But the well-built ship would not obey the helm, but went on its way all along the Peloponnese: and the lord, far-working Apollo, guided it easily with the breath of the breeze. So the ship ran on its course and came to Arene [Samikon] and lovely Argyphea and Thyron, the ford of Alpheios and well-placed Aipy and sandy Pylos and the men of Pylos; past Krounoi it went, and Chalkis and past Dyme and fair Elis ${ }^{377}$...' (H.H.Ap.391-426 (parts))

'Mt. Ida....is defined by its two extreme limits: by the promontory in the neighbourhood of Zeleia and by the promontory called Lekton......Lekton extends to the Aegean Sea, being situated on the paraplous between Tenedos and Lesbos. When the poet says that Hypnos and Hera "came to many-fountained Ida, mother of wild beasts, to Lekton, where first the two left the sea' [Il.14.283] he describes Lekton in accordance with the facts; for....Lekton is the first place of disembarkation from the sea for those who would go up to Mt. Ida.' (Str.Geog.13.1.5)

Diodorus also implies that landing at the first promontory encountered on approaching land from the open sea was a standard and long-established practice:

'The inhabitants of Britain who dwell about the promontory called Belerium [Land's End] are especially hospitable to strangers and have adopted a civilised way of life because of their intercourse with merchants and other peoples.' (Diod.Sic.5.22) ${ }^{378}$ 
Strabo also emphasises the importance of minimising the distance travelled over open seas. Here he describes how ships sailing to Brundisium from the promontory of Keraunia in Epeiros often did not take the direct route, but instead took the shorter passage to Hydros on the easternmost point of Iapygia, the 'heel' of Italy, and then sailed up the coast to their destination:

\begin{abstract}
'Cape Iapygia [is] a huge rock which extends out into the sea towards the winter sunrise [SE]...And with it the Keraunian mountains, likewise, bar the mouth of the Ionian Gulf; the passage across from it both to the Keraunian mountains and to the Lakinion is about 700 stadia.....Thence [from Hydros] to Brundisium [is a distance of] four hundred stadia, and it is an equal distance to the island Sason, which is situated about midway of the distance across from Epeiros to Brundisium. And therefore those who cannot accomplish the straight voyage [from Epeiros to Brundisium] sail to the left [i.e. south] of Sason and put in at Hydros; and then, watching for a favourable wind, they hold their course towards the harbours of the Brentesini.' (Str.Geog.6.3.5)
\end{abstract}

Elsewhere Strabo explains why mariners crossing from Italy to Greece sometimes did not head straight for Keraunia, the nearest point on the Greek mainland, but instead made for Epidamnos:

'The voyage from Brundisium to the opposite mainland is made either to the Keraunian mountains and those parts of the seaboard of Epeiros and of Greece which come next to them, or else to Epidamnos; the latter is longer than the former....... and yet the latter is the usual route, because the city has a good position with reference both to the tribes of the Illyrians and to those of the Macedonians.' (Str.Geog.6.3.8)

While this passage shows that sailing between headlands was not always the practice when crossing seas, it also shows that taking the shortest route possible, i.e. that between opposite headlands, was the norm ${ }^{379}$, and that Epidamnos only became a favoured destination under the Romans, for whom the Illyrian seaboard and Epidamnos (whence the Via Egnatia led to Macedonia) were strategically important. These places were of little importance to earlier Greeks, however, and hence few if any mariners of the Greek period would have sailed from Brundisium for Epidamnos rather than for Keraunia, or somewhere in that vicinity. However when reading this 
passage, it is worth noting how ships sailing over the open seas could make for topographical features other than headlands, but only where those features were of distinct significance to those involved.

Thus when Strabo describes Sicily's Cape Pachynos as pointing towards the Peloponnese, and describes the routes to Tainaron, the southerly point of the Peloponnese, and to the mouth of the Alpheios river, this apparently indicates that those not sailing to northern Greece (normally reached by sailing up the coast of Italy at least as far as Taras before crossing the Ionian Sea) or to eastern Greece, the Aegean, or Asia Minor (reached via Tainaron, to which Strabo gives the distance here), but to the west or the interior of the Peloponnese, would often make for the Alpheios:

'Its [Sicily's] shape is defined by three capes: Pelorias,....Pachynos, which lies out towards the east and is washed by the Sicilian Sea, thus facing towards the Peloponnese and the sea-passage to Crete, and third, Lilybaion, the cape that is next to Libya......Now the distance from Pachynos across to the mouth of the Alpheios is four thousand stadia; but when Artemidoros says that it is four thousand six hundred stadia from Pachynos to Tainaron and one thousand one hundred and thirty from the Alpheios to the Pamisos [which flows into the Messenian Gulf], he seems to me to afford us reason for suspecting that his statement is not in agreement with that of the man who says that the distance to the Alpheios from Pachynos is four thousand stadia.' (Str.Geog.6.2.1)

The Alpheios was certainly important to those Sicilian Greeks who, like many inhabitants of Greek colonies, particularly those in the west, preferred to maintain cultural ties with the Hellenic homeland by attending the pan-Hellenic festival at Olympia, rather than by journeying to their metropolis ${ }^{380}$. Given the general lack of suitable sheltering places on the west coast of the Peloponnese, where marshes and sand flats were common, and headlands and inlets rare (see pp.101, 117, figs.18, 33), the mouth of the Alpheios might also have seemed like one of the better places to seek shelter if a ship arrived off the coast of the Peloponnese in dangerous weather (for sheltering in river mouths, see p.102f.). Clearly, river mouths made poor landmarks in comparison to the high, cliffy headlands which were more commonly 
aimed for, but ships heading for the Alpheios may have first set a course for the nearby headland of Ichthys (for which see p.101), and then turned towards the river mouth when the coast was clearly in view ${ }^{381}$.

The many offshore islands which lie in front of headlands (p.29f.) effectively extended the length of coastline along which ships could pass before having to strike out across the open sea, and similarly provided the first landfalls on the opposite shores. Islands such as Kythera, which lies off the southeast Peloponnese, were accordingly often the first, or even the only, port of call for merchant ships from overseas ${ }^{382}$ :

'In fact they [the Lakonians] took great care of the place, since it was the port for merchant ships from Libya and Egypt and also served as a protection to Lakonia from attack by pirates from the sea...' (Thuc.4.53)

While social and cultural reasons may also be behind the location of this emporium on an offshore island rather than on mainland Lakonia, it is interesting that Thucydides here specifies only merchant ships from Libya and Egypt, and not those from further west. For merchant ships from Egypt and Libya approaching Lakonia from western Crete (another landfall which served to break up the relatively long journey from the southern shores of the Mediterranean: for the importance of such landfalls, see below), Kythera would have been the first available landfall in Lakonian territory. However, ships trading between Lakonia and the western Mediterranean ${ }^{383}$ may not have sailed to Kythera because they could instead make landfall far sooner, upon reaching the Peloponnesian coast from Italy or Sicily. This would explain why Kythera became the port of call for ships from one part of the Mediterranean, but not those from another.

If a prospective open-sea voyage was deemed so long as to be prohibitively dangerous, or impossible for logistical reasons, then deviations could be made from the straightest possible route across the open sea, so as to take in an island where shelter could be found, crews rested, and supplies replenished if necessary. Thus Crete was just noted as a stopping point on the route to Greece from Egypt or Libya; for 
those travelling not to Kythera but to a more northerly destination such as the Saronic Gulf, a further stop before reaching the shores of mainland Greece may have been required. This may often have been made at Melos, involving a slight eastwards deviation for those aiming to hit the coast at Skyllaion or Sounion, the promontories flanking the Saronic Gulf, but also halving the distance to be crossed without a landfall (map 11). Strabo's description of the island admirably recommends it as a stopping place for those finding the crossing between western Crete and the Saronic Gulf too long. Note that the points on the coasts of Crete and of the Saronic Gulf mentioned by Strabo are those that lie closest to one another, forming the shortest crossing:

'....And still nearer to Kimolos and to Crete is Melos, which is more notable than these, and is seven hundred stadia from the Hermionic promontory, the Skyllaion, and almost the same distance from the Diktynnaion [the most northerly point of Crete, situated near the island's western extreme].' (Str.Geog.10.5.1)

Even more useful were those islands lying off longitudinal and especially off faulted coastlines, where shelter tended to be less available, and stormy weather tended to be more common. Thus the Ionian islands off the unwelcoming west coast of Greece were particularly important, providing valuable shelter and the final stopping places for ships about to make the crossing to Italy or Sicily ${ }^{384}$. The different islands served different routes between Greece and Italy. Thus for the shortest and the most northerly crossing, Corcyra, with its large and well sheltered harbours (fig.24.i), narrowed the distance across the Ionian Gulf to Italy to only forty-five miles, and was the principal starting point especially for those heading for Brundisium and the north $^{385}$, although triremes and similar vessels heading for Sicily or southern Italy also used this route in order to avoid a longer passage over the open sea. Thus in his account of the debate over Corcyra's status which preceded the Peloponnesian War, Thucydides first has the Corcyraeans comment upon the island's control of the routes used by fleets sailing between Greece and Sicily, and then has the Corinthians comment upon the way in which the harbours of Corcyra provided an invaluable haven for ships in this otherwise exposed and unwelcoming area ${ }^{386}$ : 
'For Corcyra is favourably situated for a coasting voyage either to Italy or Sicily, so that you could prevent a fleet from coming thence to join the Peloponnesians, or could convey thither a fleet from here: and in other respects it is a most advantageous place.' (Thuc.1.36.2)

'..the insular and independent position of this state...owing to the fact that they resort very little to the ports of their neighbours, but to a very large extent receive into their ports others who are compelled to put in there.' (Thuc.1.37.3)

Those willing to take a slightly longer overseas route than the Corcyra-Cape Iapygia crossing would have taken a more southerly course, sailing from Leukas to Cape Lakinion $^{387}$, or even direct from Zakynthos to Sicily itself (Thuc.6.13.1 distinguishes between the coastal route to Sicily ( $\pi \alpha \rho \dot{\alpha} \gamma \hat{\eta} v)$, passing over the Ionian Sea, and the open-sea route ( $\delta 1 \grave{\alpha} \pi \varepsilon \lambda \dot{\alpha} \gamma o \cup \varsigma)$, across the Sicilian Sea). For those heading from Italy or Sicily to the Aegean, via the southern Peloponnese, a small island off the west coast of Messenia, accordingly called Prote (see p.170f. and n.416 below), was the first landmark and the first available landfall after crossing the Ionian Sea.

\section{CHARACTERISTICS OF SAILING DIRECTIONS AND ROUTES.}

In discussing sea routes between Greece and Italy, it is again apparent that the distinction between coastal sailing and open-sea sailing is easily blurred: not only was the practice of sailing from one headland to another applied equally to crossing a small gulf such as the Toronaean (above, p.142) and to a large gulf such as the Tarentine (Str.Geog.6.3.5, quoted above, p.149f.), but cutting across the Tarentine Gulf, from Cape Lakinion to Cape Iapygia, was also essentially no different from cutting across the Ionian Gulf between the Cape Iapygia and the Keraunian mountains or Corcyra; while the Ionian Gulf is much larger than the Tarentine, and separates two distinct parts of the Mediterranean coast rather than two parts of the coast of Italy, the distance across their mouths is roughly the same, around seven hundred stadia (Str.Geog.6.3.5). For a ship crossing from Corcyra and merely touching the Italian 
coast at Cape Iapygia before immediately then sailing directly across open waters of the Tarentine Gulf to Cape Lakinion, do we say that the ship is sailing 'coastwise' for the whole of the voyage (Both Xenophon (Hell. 6.2.9) and Thucydides (1.36.2) talk

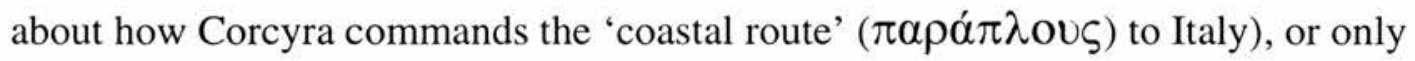
from the point at which Cape Iapygia is reached, or is it still taking an 'open-sea' route until it reaches Cape Lakinion? Any of these descriptions might be justifiably employed. Ships following essentially 'coastal' routes regularly sailed considerable distances out to sea to deal with changing weather conditions or to exploit land and sea breezes (see above, p.141f.), and hence we may reasonably conclude that, for the ancient Greek mariner, the important question was not whether he was sailing an 'open-sea' or a 'coastal' route, but how far from the shore he was, and how easily and how soon he would be able to return to land.

In the Aegean there was very little differentiation between coastal and open-sea sailing, the many long promontories and chains of islands there being used to minimise sailing distances between landfalls:

'In the morning some of us launched our ships upon the bright sea, and put on board our goods and the low-girdled women....and swiftly the ships sailed, for a god made smooth the cavernous sea. But when we came to Tenedos we offered sacrifice to the gods, being eager to reach our homes, howbeit Zeus did not yet purpose our return, stubborn god, who roused evil strife again a second time......and late upon our track came fair-haired Menelaos, and overtook us in Lesbos, as we were debating the long voyage, whether we should sail to seaward of rugged Chios, toward the isle of Psyria, keeping Chios itself on our left, or to landward of Chios past windy Mimas. So we asked the god to show us a sign and he showed it us, and bade us cleave through the midst of the sea to Euboia, that we might the soonest escape from misery. And a shrill wind sprang up to blow, and the ships ran swiftly over the teeming ways, and at night put in to Geraistos. There on the altar of Poseidon we laid many thighs of bulls, thankful to have traversed the great sea. It was the fourth day when in Argos the company of Diomedes, son of Tydeus, tamer of horses, stayed their shapely ships; but I held on toward Pylos, and the wind was not once quenched from the time when the god first sent it forth to blow.'

(Hom.Od.3.150-82) 
Here, on Nestor's return from Troy, in the northeast Aegean, to Pylos, via Malea at the southwest extremity of the Aegean, the first landfall is made at Tenedos, a regular stopping point between the Hellespont, with its strong northerly winds and currents, and the southern Aegean, where less forceful but more variable conditions were found: to those sailing northwards, Tenedos offered a sheltering place where landfall could be made while awaiting favourable conditions for entering the Hellespont (p.99, n.287); for those sailing south, as Nestor and his companions here, the island offered the first of numerous available landfalls where the weather could be assessed and the next leg of the journey planned, and by means of which the long diagonal crossing of the Aegean could be divided into a number of shorter stages. Finding weather conditions too severe to attempt sailing home directly across the Aegean, on account of the 'evil strife' raised by Zeus, Nestor instead opts to make the less exposed and far shorter crossing to the next available landfall, Lesbos.

At Lesbos, Nestor again has to decide between sailing directly across the Aegean or further reducing the distance involved in crossing the Aegean by continuing southwards down the coast of Asia Minor to Chios. Here the dangers of the open sea have to be weighed against those inherent in sailing through the Chian strait, with its awkward and changeable winds and currents (for which see p.91ff.). It would be useful to know the exact nature of the 'sign' that prompts them to take the overseas route: quite possibly it was the 'shrill wind' which carried the ships onward, or a weather sign which indicated the imminent onset of that wind, for a decision on the route would undoubtedly have involved attempting to forecast the coming weather ${ }^{388}$. With a good following wind, and having already significantly reduced the distance to be covered by taking the slight detours to Tenedos and Lesbos, the ships strike out across the Aegean towards the Peloponnese, but again minimise the distance they have to sail between landfalls by stopping at Geraistos, the southeasterly point of Euboia, past which the ships in any case had to sail. Geraistos provided a sheltered landfall right at the most easterly point of the west coast of the Aegean, in an otherwise harbourless and rocky area (see pp.122, 124ff.), and so significantly 
reduced the length of the Aegean crossing. Its importance is reflected in the size of the sacrifices made by Nestor and his companions when they land there.

Thereafter the fair winds continue, and the ships take their separate ways towards their respective homelands. Of particular importance in this passage is the way in which the route is not decided once and for all at Troy, the initial point of departure, but is gradually worked out according to developing weather conditions, with each successive leg of the journey being determined at as late a point as possible, so that weather conditions for each leg may most accurately be forecast. The recurring choice between striking out across the open sea on the one hand, and continuing down the coast to a promontory or island from which the open-sea crossing is significantly shorter, on the other, is also notable, as is the practice of minimising the length of that open-sea crossing by stopping at the first island or promontory encountered once the crossing has been made. Geraistos is a paradigm of such a landfall, for it was not only in Euboia, an offshore island which was reached far sooner than the coast of the mainland, but, moreover, it consisted of a large sheltering bay located on a headland at the extremity of the island, maximising the speed and ease with which landfall could be made after the crossing, and requiring the least deviation from the most economical route southwards towards Attica and the Peloponnese:

'The poet [Hom.Od.3.177f.] ...plainly indicates that the place [Geraistos] is conveniently situated for those who are sailing across from Asia to Attica, since it comes near to Sounion.' (Str.Geog.10.1.7) ${ }^{389}$

Nestor was also very much the paradigm of the wisdom of human experience, and this is also brought out fully here. His name is derived from vó $\sigma \tau$ ○ऽ ('return'), and it is significant that, while the other 'returners' generally encountered disaster on their travels, especially those who followed a similar route to Nestor's but then were wrecked in the disaster at Kaphereus (see p.183), Nestor's successful return is seen here to be the result not only of careful consideration of the attitudes of the gods, but also to careful observation of the weather and weather signs. There is a clear lesson 
here, that cautious and careful attitudes were crucial in successfully choosing the proper timing and route for a dangerous sea-journey.

However, sailing such geographically safe and well-planned routes, on which ships tended to approach the coast only when passing promontories or offshore islands (and when passing through the straits formed by those promontories and offshore islands) came to involve human dangers. Pirates, well aware of the chosen routes preferred by most merchant ships, haunted promontories and islands at the mouths of gulfs precisely because they knew that these were the points on the coast where shipping was most likely to regularly appear, as Ormorod noted ${ }^{390}$. One of the best examples he cites ${ }^{391}$ is in fact an episode from a military blockade rather than an act of piracy (Darius, through his admiral Memnon, attempts to hamper Alexander's progress into Asia by diverting attention to the Aegean): its interest lies not only in the importance of the Sigrion promontory on routes northwards through the Aegean, but also in the fact that the ships sailing there are expressly said to do so directly either from other major promontories, or from one of those offshore islands which was taken in order to reduce the distance a ship had to travel between landfalls ${ }^{392}$ :

'...he [Memnon] put in at Mytilene [in Lesbos].....Part of his fleet guarded the Mytilenean harbour; other ships he despatched to the [westerly] promontory of Lesbos, Sigrion, where cargo vessels from Chios and Geraistos and Malea usually put in, and so he patrolled the coast, to prevent help from coming to Mytilene by sea.' (Arr.Anab.2.1.2)

\section{Headlands and islands as turning points.}

It can be seen, then, that certain characteristics would have been typical of any ancient sea journey, whether 'coastal' or 'open-sea'. Foremost amongst these is a series of legs between headlands and islands. On journeys to a destination that simply lay some distance along a stretch of coast, the headlands involved would have been those which unavoidably had to be rounded in order to reach that destination, while the islands would have been those lying off the coast in question, round which the crew would have to decide whether to sail to seaward or through the strait separating island from mainland. On journeys to destinations that could only practically be reached by sailing 
across the open-sea, as when sailing from Greece to most other parts of the Mediterranean, then the headlands involved would be those between which the crossing of the Mediterranean was made. The islands would be those lying off the promontories between which the sea crossing was made, and any other islands in the open sea close enough to the sailing route to merit a detour in order to rest, shelter and replenish supplies. Of course, as we have already stressed, many journeys involved both 'open-sea' stretches and 'coastal' stretches, but both types of sailing themselves consisted mainly of a series of passages between various headlands and islands, the passages generally being as short and as direct as weather conditions and geography would permit. Sailing closely around the coast of a gulf would often only have happened at the start of a voyage (including relaunching after coming ashore overnight) when the ship navigated from the port of departure to the first of the headlands on the route, and similarly at the end of a voyage (or when an overnight stop was to be made) when the ship rounded the last headland on the route and turned shorewards to land. Thus Plutarch compares the dolphins who rescue Arion from the open sea, bringing him to and then past the headland of Tainaron, and landing him at the small sanctuary of Poseidon in a bay behind the headland (fig.57), to the actions of seamen bringing a ship to harbour from the open sea and then departing again:

'....at last, as the jutting promontory, rugged and lofty, appeared in their path, they rounded it with great caution, and skirted close to the land as if they were bringing a boat safely into harbour....the dolphins drew near together, and with one accord came close to the shore, and deposited on land a human being, in whom was still the breath of life and power to move; then they themselves put forth again towards the promontory....' (Plut.Mor.161F, A (parts))

Clearly, then, headlands and islands were particularly significant in ancient Greek sailing itineraries. They were not only the points at which ships most closely and most commonly approached the coast, but were also the kind of significant topographical feature (along with harbours and the straits formed by offshore islands) towards which a ship's course would be directed at any one time. Furthermore, because sailing routes thus consisted of a series of straight and direct legs between significant topographical 
points on the coast, it was upon reaching these topographical points that the ship's course was altered to direct it towards the next such point on the route ${ }^{393}$. This vivid description of the appearance of a long stretch of coast on the southern shores of the Black Sea clearly illustrates how the ship's course would naturally be changed upon rounding a headland:

'Now there is a headland opposite Helike the Bear, steep on all sides, and they call it Karambis.... When you have rounded it, broad Aigialos [lit. 'the shore/beach'] stretches before you; and at the end of broad Aigialos, at a jutting point of the coast, the waters of the river Halys pour forth with a terrible roar.' (Ap.Rhod.Arg.2.360-7)

As the ship rounds the headland Karambis, a further stretch of shoreline appears, and only then can the ships course be changed, either to head the ship into a point on the coast of Aigialos, or to sail straight on, heading for the furthest visible point of land, the 'jutting point', upon reaching which the ship's course would again be redirected according to the lie of the stretch of coastline that then appeared. Such a direction change at Sounion is here described by Livy:

'The fleets, having captured two important cities of Euboia within a few days, sailed around Sunium [Sounion], the promontory of the land of Attica, and steered towards Kenchreai, the port of the Corinthians.' (Livy.32.17.3)

A series of such direction changes, in this case from east to northeast to northwest, each change being made on reaching the cape to which the ship's course had previously been directed, is clearly noted by Strabo:

'As one sails from Rhegion towards the east, at a distance of fifty stadia, one comes to Cape Leukopetra (so called from its colour), in which, it is said, the Apennine mountain terminates. Then comes Herakleion, which is the last cape of Italy and inclines toward the south; for on doubling it one immediately sails with the southwest wind as far as Cape Iapygia, and then veers off, always more and more, towards the northwest in the direction of the Ionian Gulf.' (Str.Geog.6.1.7) 
Thus on many journeys, headlands and offshore islands were the only points of any particular significance: thus when the Persian fleet proceeded to Athens from Marathon, Herodotos wrote merely that they 'sailed round Sounion' (Hdt.6.115f.:

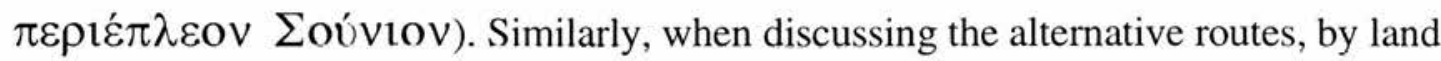
and by sea, by which the Athenians could bring aid to Argos from Aigina, Thucydides described the sea journey from Aigina around the whole Argolic peninsula to Nauplia simply as 'sailing round Skyllaion' ( $\Sigma \kappa \cup ́ \lambda \lambda \alpha \iota \pi \varepsilon \rho 1 \pi \lambda \varepsilon \hat{\imath} v$ : Thuc.5.53).

\section{Headlands, islands, and other topographical features as milestones.}

From the preceding discussion, it is clear that headlands and offshore islands were highly significant as nodal points in the topography of any sea journey. Moreover, particularly because it was at these points that changes of direction were made, mariners came to see any journey as a series of shorter stretches between headlands and islands (and also the harbours and other points where landfall was made), and they accordingly learned, collectively and over time, the distances and directions from one such topographical feature to another. This lore is clearly visible in the sailing manuals which first appeared in Greece from the sixth century B.C. ${ }^{394}$, and which include details of the distances between points which were separated by anything from gulfs only a few kilometres wide, to hundreds of kilometres of open sea.

Although little of the earliest sailing manuals has survived, much of the information of this nature which they contained is preserved in Strabo's Geography, in which the author often discusses the different distances given for the same journey in the works of earlier geographers ${ }^{395}$. Typically, Strabo enumerates the distances from a prominent headland to other significant topographical features further along the coast, and to headlands reached by sailing over the open sea ${ }^{396}$. The following examples (illustrated in fig.58) list the distances between the major headlands, islands, straits (including the diolkos), and harbours passed by ships sailing from western Greece to Attica (either via the Corinthian Gulf and the diolkos at the Isthmus of Corinth, or round the Peloponnese to Schoinous, the harbour nearest the Isthmus) and on into the Aegean: 
'Then comes Araxos, the promontory of the Eleia, one thousand and thirty stadia from the Isthmus [via the Corinthian Gulf].' (Str.Geog.8.7.5)

'From here [Tainaron], the passage towards the south across the sea

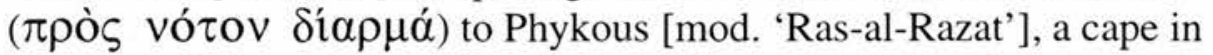
Kyrenaia, is three thousand stadia; and the passage towards the west to Pachynos, the promontory of Sicily, is four thousand six hundred, though some say four thousand; and towards the east to Malea, following the sinuosities of the gulfs ( $\alpha \alpha \tau \alpha \kappa \circ \lambda \pi i \zeta o \vee \tau \imath)$, six hundred and seventy.; and to Onougnathos, a low lying peninsula somewhat this side of Malea, five hundred and twenty; off Onougnathos and opposite it, at a distance of forty stadia, lies Kythera, an island with a good harbour.....and to Korykos, a cape in Crete [also known as Kimaros; the northwest point of the

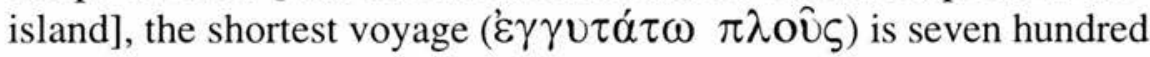
stadia' (Str.Geog.8.5.1)

'...Schoinous, a harbour. From Malea thither the total distance is about eighteen hundred stadia. Near Schoinous is the diolkos...' (Str.Geog.8.6.4)

'...the Piraeus, the sea-port of Athens. It is distant from Schoinous, at the Isthmus, about three hundred and fifty stadia, and from Sounion three hundred and thirty.' (Str.Geog.9.1.2)

'The voyage from Sounion to the southerly promontory of Euboia, which is called Leuke Akte, is three hundred stadia.' (Str.Geog.9.1.22)

'And nearby is the Euripos at Chalkis, to which the distance from Sounion is six hundred and seventy stadia.' (Str.Geog.9.2.8: cf. Scylax Perip.57)

'Off the Trogilian promontory [Mykale, opposite Samos] lies an isle of the same name. Thence the nearest passage across to Sounion is one thousand six hundred stadia; on the voyage one has at first Samos and Ikaria and Korsia on the right, and the Melantian rocks on the left; and the remainder of the voyage is through the Cyclades islands.'

(Str.Geog.14.1.13)

Taken together, these passages list the most important turning points and ports of call on a voyage to the Aegean from either the northwest (Araxos) or the south (Tainaron) of the Peloponnese, the two points on the coast of southern Greece to 
which a ship headed east from Sicily might head, depending on whether it was to pass through the diolkos at the Isthmus of Corinth, or take the southerly route round Malea. Thus Schoinous, the port at the southern, Saronic end of the diolkos, could be reached either from Araxos via the Corinthian Gulf, or from Tainaron via Malea. From there the ship could sail to Piraeus, on to Sounion, and, having rounded that promontory, continue into the Aegean, either to the Euripos, or through the Doro channel at the southeastern end of Euboia ('Leuke Akte'), or through the Cyclades to Samos and the coast of Asia Minor. Those sailing all or just a part of this route could easily compute the distance they would have to sail simply by adding up the distances given for the constituent 'legs' of the journey. For a journey overseas, from Tainaron for example, distances could be calculated, again simply, by adding the distances involved in reaching Tainaron from the port of departure to the distance given for the passage from Tainaron to a headland on the foreign shore being aimed for, and then adding the distance from that headland along the final coastal legs to the port of destination.

Likewise, when calculating the length of the Mediterranean Sea (Geog.2.4.3; fig.59), Strabo simply adds up the distances recorded for individual stretches of the journey, all of which run between headlands, straits, and islands which featured prominently in long-distance sailing routes (apart from the Gulf of Issos, which was included as the easternmost extremity of the Mediterranean Sea). From the Gulf of Issos, Strabo gives the distance to Rhodes (five thousand stadia); thence to Salmonion, the eastern extremity of Crete (one thousand stadia); thence to Kriou Metopon, at the western end of Crete (over two thousand stadia); thence to Pachynos, the easternmost promontory of Sicily (four thousand five hundred stadia); thence to the Straits of Messina (the 'Sicilian Strait') (over one thousand stadia); thence to the Strait of Gibraltar (the 'Pillars of Hercules'; twelve thousand stadia); and thence to the Sacred Cape (C. St. Vincent) of Iberia (around three thousand stadia).

The passage, quoted above (p.161), in which Strabo describes the sailing routes and distances from Tainaron to other headlands around the Mediterranean (Geog. 8.5.1) 
deserves further examination. First he describes the $\pi \rho$ ò $\varsigma$ vó $\tau$ ov $\delta i \alpha \rho \mu \alpha$, or 'southwards crossing' to Phykous in Kyrenaia. Also used of relatively short passages across channels (e.g. the English Channel: Str.Geog.4.5.2), the term $\delta i \alpha \rho \mu \alpha$, related to the verb $\delta 1 \alpha i \rho \omega$ (to separate, remove, or (intr.) cross over), properly describes a passage between two coasts entirely separated by a body of water, as opposed to a passage between two points of the same coast, as when sailing around a bay, or cutting across its mouth. Thus, at Str.Geog.2.5.24 (quoted below, p.189), the

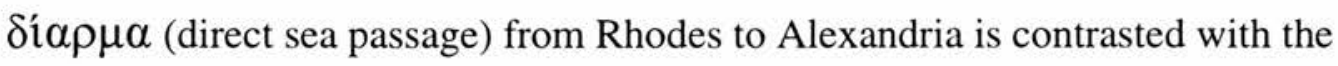
$\pi \varepsilon \rho i ́ \pi$ ous (coastal route).

Elsewhere, Strabo's vocabulary again contrasts these two ways of navigating gulfs. The distance given from Tainaron to Malea is not for a direct route, but for a journey 'following the sinuosities of the gulfs' ( $\kappa \alpha \tau \alpha \kappa \circ \lambda \pi i \zeta o v \tau \imath)$, such as might be taken by a crew stopping at Gythion or another harbour in the Lakonian Gulf (for reaching harbours as the main reason for entering, and following the coasts of gulfs, see above, p.142ff.): the mere use of the term $\kappa \alpha \tau \alpha \kappa o \lambda \pi i \zeta o v \tau \imath$ in this context implies the existence of another way to sail from Tainaron to Malea. Although he does not here give the distance for an alternative direct route to Malea, the terminology he uses elsewhere to denote such direct routes, not entering the gulfs passed, is as simple as

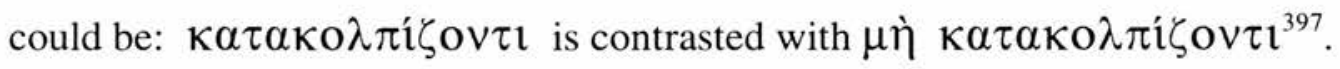

Herodotos, as we have seen (above, p.142; Hdt.7.122), described more explicitly the direct crossing between the headlands forming the mouth of a gulf with the term $\sigma u v \tau \alpha \dot{\alpha} \mu \omega \nu$, 'cutting across', or even 'taking the shortcut'. In place of

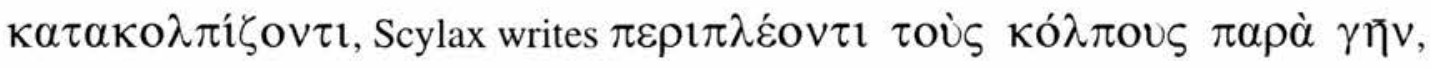
'sailing round the gulfs close to the land' (Scylax Perip.70). Menippus of Pergamon has a similar construction:

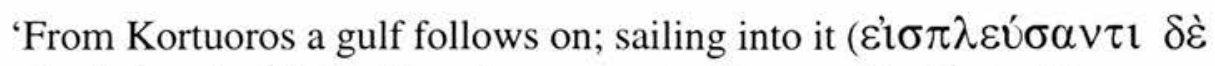
$\alpha \mathfrak{u} \tau \dot{\mathrm{v} v})$ to the Melanthios river comes to sixty stadia. Not sailing around

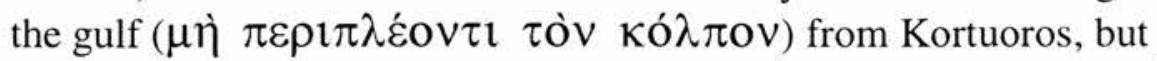

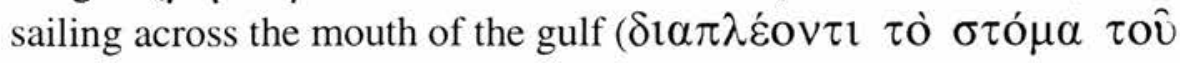


кó $\lambda \pi \mathrm{O}$ ) eastwards to Hermonassa....' (Menip.Perg.Perip.9r20-27: comp.10r21-9, 13r4ff.).

Returning again to Str.Geog.8.5.1 (p.161f. above), we can also note that the distance given to Korykos/Kimaros, the northwest point of Crete, is for the 'shortest voyage'

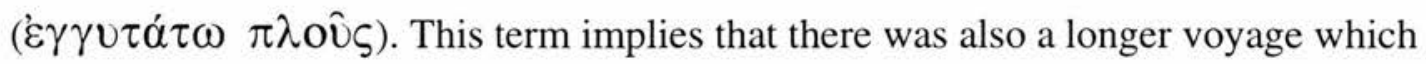
could be taken between the same two points, and this longer voyage will have been that which took in en route Kythera, details of which Strabo includes immediately before giving the distance from Tainaron to Korykos, and which indeed he elsewhere describes as lying on that particular route (Str.Geog.10.4.5). Here again we have evidence that sailors crossing the open sea preferred both to leave and to return to land at promontories, so as to minimise the distances involved, but would consider making slight detours to take in islands as stopping-off points, thereby again decreasing the distance between landfalls (compare above, p.151ff.).

This role of headlands in particular, as milestones, turning points, and departure points when sailing across the open seas on standard sailing routes, explains why two apparently unrelated points lying on completely different parts of the Mediterranean coasts (see fig.59) can be said to 'lie opposite' one another, as in this example:

'One of the cities [of Karpathos] was called Nisyros...It lies opposite ( $\kappa \varepsilon i \tau \alpha 1 . . . \kappa \alpha \tau \dot{\alpha})$ Leuke Akte in Libya, which is about one thousand stadia distant from Alexandria and about four thousand from Karpathos.' (Str.Geog.10.5.17)

This description of the relative positions of Nisyros and Leuke Akte can only be explained by their use as points between which sailors crossed from Greece to Africa, and back. The sense in which they are 'opposite' one another may be compared with that in which the headlands of two promontories forming the mouth of an irregularly shaped gulf may also appear to be opposite one another to coastal sailors, if not to travellers by land (see p.144, where ' $\alpha \pi \varepsilon v \alpha \nu \tau$ íov' in used). Similarly, Melita and Gaudos (Malta and Gozo) are said to lie 'off' or 'in front of' Pachynos, the southeasterly cape of Sicily, at a distance of eighty-eight miles (Str.Geog.6.2.11: 


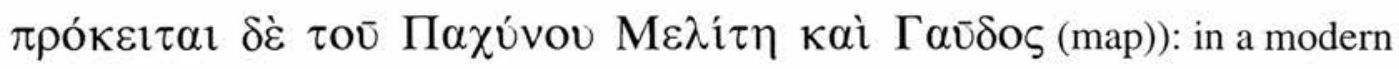
geographical context, islands lying nearly ninety miles southwestwards of a cape which extends southeastwards would hardly be said to be 'in front of' or even 'off' that cape; the statement is best understood as indicating that ships sailing from the north to these islands would leave the coast of Sicily from the vicinity of Pachynos ${ }^{398}$.

\section{COASTAL NAVIGATION.}

\section{Headlands, islands, and other topographical features as coastal landmarks.}

The navigational equipment available to ancient Greek sailors was limited to the sounding lead and line (p.229). This was useful only in a strictly local context, allowing the crew to judge the depth of water they were in, and so to estimate the distance between ship and shore. To determine the ship's position in a wider sense, mariners had to rely solely upon information they could gather without the use of instruments, and here visible landmarks were of the utmost importance ${ }^{399}$. Spotting these landmarks was a responsibility not simply left to the crew collectively, but allocated to the proreus ( $\pi \rho \omega \rho \varepsilon v ́ \varsigma$ ) or prorates ( $\pi \rho \omega \rho \alpha \dot{\tau}\rceil \varsigma$ ), the look-out stationed at the prow of the ship, who was also responsible for spotting dangerous rocks and other obstructions appearing in the path of the ship (see p.71, where the quotation of Philos.Imag.2.15 also refers to this aspect of the proreus' duties). Sophocles describes the prorates who is 'to keep a look-out for the path [ $\pi$ ópov] to Troy of the sons of Atreus, ${ }^{400}$.

This description is interesting, because clearly the surface of the sea itself could neither delineate a $\pi$ ó $\rho \varsigma_{\zeta}$, nor help the crew to deduce their position and direction. Sun, stars, winds, and other signs may have helped sailors to calculate the direction in which they were sailing (see below, pp.185ff.), but could hardly be said to delineate or mark a $\pi$ ó $\rho \varsigma_{\zeta}$, and it must be assumed that the lookout is searching instead, or also, for coastal landmarks which confirm that the ship is on the proper course, and inform him of how far along the route the ship has come. For long journeys a succession of 
many such landmarks would have been required in order for the crew continually to maintain their desired course and deduce their exact position. What features on the coast, then, provided these recognisable landmarks, upon which those sailing within sight of the coast relied?

Strabo certainly clearly describes the features by means of which he recognised a given part of the coast, and so determined his position. In the first of the following passages, he describes how points ( $\tau$ ó $\pi \mathrm{O} \boldsymbol{\imath})$ on the coast lie in a certain order ( $\tau \alpha \dot{\xi} \backslash \zeta)$; in the second and third he gives details of that order:

'It is difficult, in naming so many places, most of them insignificant and situated in the interior, to avoid error in every case in the matter of their order. The seaboard, however, has a certain advantage with regard to this: the places there are better known; and, too, the sea more readily suggests the order of places.' (Str.Geog.9.2.21)

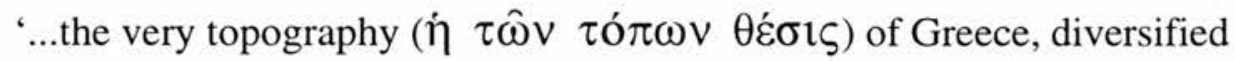
as it is by many gulfs, many capes, and, what are the most significant, large peninsulas that follow one another in succession...' (Str.Geog.8.1.3)

'Opposite Kanastron [Kanastraion], a cape of Pallene, is Derrhis, a headland near Kophos Limen; and these two mark off the limits of the Toronaean Gulf. And towards the east, again, lies the cape of Athos, which marks off the Singitic Gulf. And so the gulfs of the Aegean Sea lie in order, though at some distance from one another, towards the north as follows: the Maliac, the Pagasitic, the Thermaic, the Toronaean, the Singitic, the Strymonic. The capes are, first, Poseidion, the one between the Maliac and the Pagasitic; secondly, the next one towards the north, Sepias; then the one on Pallene, Kanastron; then Derrhis; then come Nymphaion, on Athos on the Singitic Gulf, and Akrathos, the cape that is on the Strymonic Gulf...' (Str.Geog.7.fr.32)

This ordering of the coastline into a progression of headlands separating successive gulfs has already been discussed in relation to the manner in which ships plotted their course on a periplous (above, p.144f.). Yet it can also be seen that that the regular progression of promontories and headlands provided a series of landmarks by means of which Greek coasts could be divided into a number of distinct stretches, specifically 
the gulfs lying between the successive promontories. Recognition of a prominent headland thus allowed a mariner to ascertain the general area of the coast in which he found himself, and he could then go on to look out for the next prominent landmark on his route, or to identify local features of the coast in greater detail, as Strabo does when he arrives at a major headland, names the gulf which that headland gives access to and also the headland enclosing it on the opposite side of its mouth, and then goes on to describe in detail the coastal features of the gulf in question ${ }^{401}$.

Headlands and promontories were well suited to this role. They occur frequently along the Greek coasts (and along the north coast of the Mediterranean generally), and, being particularly significant points on both coastal and open-sea sailing routes, would in any case have been seen in passing by seafarers. Moreover, because promontories by their very nature extend out to sea farther than any other points on the coast, and often rise to great heights, owing to their origins in faulting (see p.17f.), their headlands and peaks are the first points to appear over the horizon when approaching land from the open $\mathrm{sea}^{402}$. Many can be seen from fifty miles away, some for considerably greater distances (for examples, see above, p.128f., n.350), especially during the typically clear weather of the Mediterranean summer (for which see p.48f.). Even when poor light or fog obscures all other details and features of the coast, the silhouettes of promontories, running out to headlands and falling away to the sea, tend to remain clearly discernible (fig.60; for coastal fog, see p.61). Once mariners were so far from the coast that it had receded below the horizon, such valuable landmarks by no means disappeared, for the peaks and headlands of the mainland were simply replaced by islands. Scattered throughout the Aegean, and also to the south (Crete, Kythera) and to the west (the Ionian islands) of mainland Greece, and having similar geological origins to the promontories of the mainland (p.28ff.), many of these islands were equally high, and so were visible from equally far away (again. see p.128f. and n.350) $)^{403}$. The highly distinctive forms and silhouettes of individual promontories, headlands, and islands facilitated their recognition by mariners in ancient times ${ }^{404}$, and continues to do so in the modern era, silhouettes of promontories still being used to establish a ship's position relative to the coasts of Greece ${ }^{405}$. 
The names of some landmarks were taken from the animals and objects that sailors were reminded of by their shapes, two unmistakable examples being the promontories of Kynosoura on Salamis, 'the dog's tail' (fig.28), and Drepanon in Achaia, 'the sickle'. There are many other well-known examples ${ }^{406}$ (fig.61). Such names helped to impress the image of the outline of a landmark, and its location, on the memories of sailors, and other names clearly reflect other characteristics of landmarks which made them particularly conspicuous and distinctive. Here the most important class are those which are named from their colour, and of these most allude to the white hue of the chalks, limestones, and other calciferous rocks which predominate in Greece ${ }^{407}$, and which were particularly reflective in the summer sun (the basic colour terms used in such names, $\lambda \varepsilon \cup \kappa o ́ \varsigma$ and ớp̧̣ó $\zeta$, both indicate this shining clarity as well as white hue). The white cliffs of Cape Helle(s) still help sailors to distinguish the north from the south side of the entrance to the Hellespont ${ }^{408}$, and the widespread equivalent use of white coasts as landmarks in antiquity is revealed by their nomenclature.

Thus both the island of Leukas and its southerly promontory Leukatas (figs.20, 21) were named after their white ( $\lambda \varepsilon \cup \kappa o ́ \varsigma$ ) cliffs (Str.Geog.10.2.8), the value of which as a landmark is recognised in an epigram in which a sailor appeals to 'Phoebos, who dwells on the sheer height of Leukas, visible from afar to sailors.' (Anth.Pal.6.251). Other landmarks named after their white colour and seen on coasting voyages are commonly mentioned by Strabo and other geographers. Hence, sailing east (or more accurately, south) from Rhegion one passed the promontory Leukopetra ("white rock': Str.Geog.6.1.7). Sailing to Euboia from Sounion, one came first to Leuke Akte ('white headland': Str.Geog.9.1.22), and headlands of the same name stood on the Thracian shores of the Propontis (Hdt.7.25, Str.Geog.7.fr.55, Scylax Perip.68), and on the north coast of Libya (Str.Geog.10.5.17, 17.1.14). The same term is used as a description, rather than the name, of the landmark Orestes makes for when reaching the northern shores of the Black Sea during his voyage to Tauris (Eur.I.T.436; whiteness possibly derived from the droppings of the local sea-birds also mentioned in this passage, rather than from the natural colour of the rock). Also in the Black Sea, 500 stadia beyond the mouth of the Tyras (mod. Dneister), was the island simply 
called Leuke ('white': Str.Geog.7.3.16, Scylax Perip.69), and another Leuke island was found south of eastern Crete (Pliny.H.N.4.12). Leukosia was the name of an island off the west coast of Italy (Str.Geog.6.1.6), and Leuka that of a promontory on the southern tip of the heel of Italy, one of the first landfalls for mariners sailing across from Greece ${ }^{409}$. Near Phokaia in Asia Minor was the promontory and harbour of 'Leukai' (Pliny.H.N.5.31, Scylax Perip.81). Tenedos was also known as Leukophrys

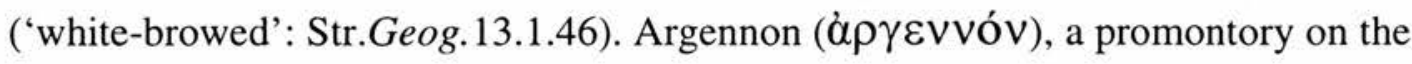
coast of Asia Minor opposite Chios (Str.Geog.14.1.33), is simply an Aeolic form of

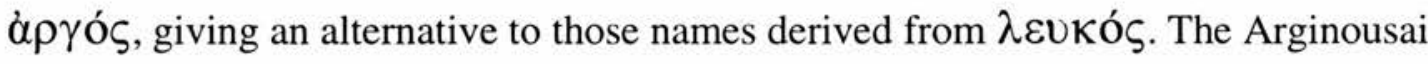

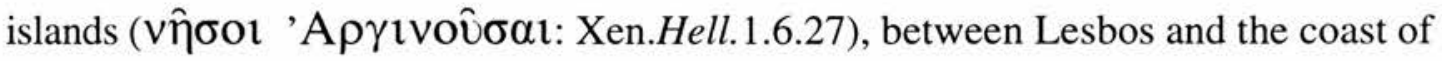
Asia Minor, provide another variant.

A dark or black hue ( $\mu \varepsilon \dot{\lambda} \lambda \alpha \varsigma, \mu \varepsilon \lambda \alpha v$ ó $)$ was also fairly commonly referred to in nomenclature. Promontories called Melaina were known in Chios (Str.Geog.14.1.35) and on the coast opposite, below Mt. Mimas (Str.Geog.14.1.33), and again just west of the river Rhebas on the Black Sea's southern coast (Per.Pont.Eux. $8 \mathrm{r} 43^{410}$, Menip.Perg.Perip. 5703ff., Ap.Rhod.Arg. 2.651). Similarly, Melanos promontory stood in the Propontis, near Kyzikos and Priapos (Str.Geog.12.8.11) ${ }^{411}$. Black Corcyra was named after its dense covering of trees, rather than the colouring of its rock $^{412}$ (compare Etna's 'dark-leafed peaks' (Pind.P.1.29: $\mu \varepsilon \lambda \alpha \mu \varphi u ́ \lambda \lambda o 1$

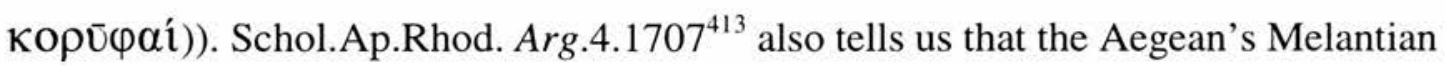
rocks, somewhere west of Ikaria (Str.Geog.14.1.13), where Apollo shone a beacon for the Argonauts (Ap.Rhod.Arg.4.1707), stood near Thera and were named after their black hue.

Situated between the headlands of Melaina and Argennon on the coast of Asia Minor

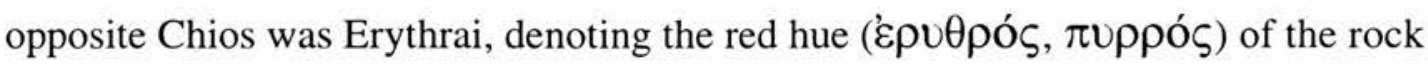
there ${ }^{414}$. Likewise named after their red colour were the promontories of Erythraion on the southeast coast of Crete, and Pyrrha ${ }^{415}$ in Achaia Phthiotis (similarly, Pyrrha was also the name of a promontory on the Bay of Adramyttion: cf. Str.Geog.13.1.51). Erythrinoi, a Paphlagonian town on the shores of the Black Sea, passed by Jason 
(Ap.Rhod.Arg.2.941), was named after the colour of the rocks on which the town stood (Str.Geog.11.3.10). At the entrance to the Bosporos stood the Cyaneae, the

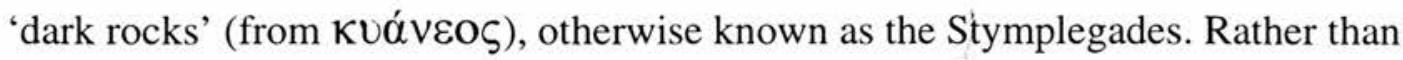
describing its appearance, the name of Prote (from $\pi \rho \hat{\omega} \tau$ os: the 'first' or the 'beginning'), an island off the southwest coast of the Peloponnese, refers directly to this island's function as the first landmark, and indeed the first sight of land and the first possible landfall, for ships approaching Messenia from the open seas to the west (above, p.154) ${ }^{416}$.

Thus the names of these landmarks reflected distinguishing features or characteristics by which they and their locations might be recognised. Given the profusion of such landmarks on the Greek coasts, and the tendency for land always to be visible when at sea in Greek waters, especially the Aegean (above, p.128f.), landmarks were always available to facilitate orientation and navigation - in Cary's view 'Navigation in the Aegean is thus reduced to the simplicity of a ferry service. ${ }^{417}$. When approaching a coast from the open sea, sailors could calculate their position and the direction in which they were sailing as soon as land came into view, because, as we have seen (above, pp.145-54), ships sailing landwards from the open seas commonly headed for prominent offshore islands or headlands, and these were exactly the sorts of topographical features which also functioned as navigational landmarks.

One further category in the nomenclature of prominent landmarks consists of the names of those localities, most often headlands, upon which altars, temples or more developed shrines had been constructed. Such names simply record the name of the deity worshipped, as at Artemision in northern Euboia. By far the most common such name 'Poseidonion'/'Poseideion'/'Poseidion', reflects the many temples and altars set up to the principal god of the sea at points on the coast which were of significance to mariners $^{418}$ (fig.1). At such points, not only the natural topography, but also the shrines themselves functioned as landmarks; such artificial, or incidental, landmarks are the investigated further in the following section. 


\section{Artificial and incidental coastal landmarks.}

In the Argonautica, Apollonius of Rhodes describes whole series of coastal landmarks which were seen by the Argonauts, and which could have been used by any mariners to establish their position and to chart their progress along the coast ${ }^{419}$. These landmarks consist not only of prominent mountain peaks, headlands, and islands, but also man-made features such as tombs:

'And the Sepian headland sank away, and Skiathos appeared in the sea, and far off appeared Peiresiai and the $\mathrm{calm}^{420}$ shore of Magnesia on the mainland and the tomb of Dolops; here then in the evening, as the wind blew against them, they put to land, and paying honour to him at nightfall burnt sheep as victims, while the sea was tossed by the swell: and for two days they lingered on the shore, but on the third day they put forth the ship, spreading on high the broad sail.' (Ap.Rhod.Arg.1.582-90)

The Greek term used for these tombs, $\sigma \hat{\eta} \mu \alpha$, literally denotes a 'sign', and it is clear that, from a very early date, the Greeks believed these tombs to have been set up at specific points on the coast so as to be seen by mariners out to sea:

'....the long-haired Achaians may give him burial, and heap up for him a barrow by the wide Hellespont. And someone shall some day say even of men that are yet to be, as he sails in his many benched ship over the winedark sea: 'This is a barrow of a man that died in olden days, whom on a time in the midst of his prowess glorious Hektor slew.' So shall some man say, and my glory shall never die.' (Hom.Il.7.85-91)

'And over them [the bones of Achilles and Patroclus] we heaped up a huge and flawless tomb, we the mighty host of Argive spearmen, on a

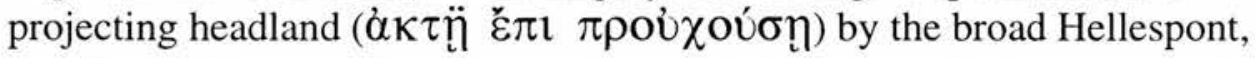
that it might be seen from far over the sea both by men that now are and that shall be born hereafter.' (Hom.Od.24.80-4)

“ "So bury me [Elpenor] there with all my arms, such as they are, and raise a mound for me on the shore of the grey sea in memory of an unlucky man, to mark the spot for future voyagers. Do this for me, and on the barrow plant the oar I used to pull when I was alive and on the benches with my mates."......We gave him solemn burial where the headland runs furthest out to sea.' (Hom.Od.11.71-8, 12.8f.: Elpenor's barrow was held to be in the territory of the Latini (ps-Scylax.Perip.8)) 
Whether the Bronze Age erectors of these tombs did choose their sites with a view to visibility from the sea is irrelevant here. It is more important to realise the implications of these later beliefs and statements regarding the tombs, i.e. that Greek sailors did actually see them from the sea, associate them with figures from the heroic past, and use them as landmarks just as they used prominent natural features of the coast. Moreover, in historical times, the Greeks continued, or revived, the practice of erecting tombs at significant points on the coast, where it was expressly intended that they would be seen by sailors:

'At the Grand Harbour of the Piraeus, a sort of elbow juts out from the headland of Alkimos, and when you have rounded this elbow, on the inner side where the sea is calm, there is a large foundation of masonry and the altar-like structure upon this is the tomb of Themistocles. Diodorus imagines that the comic Plato bears him out in the following passage: Fair lies thy tomb for it will speak to merchants everywhere; it will behold the seamen sailing out and in, and mark the contests of the ships.' (Diodorus the Periegete, in Plut.Them.32)

'I, Philainis, celebrated among men, have been laid to rest here, by extreme old age. Thou silly sailor, as thou roundest the cape, make no sport and mockery of me; insult me not....' (Anth.Pal.7.345)

'Thence 90 stadia to the monument of Satyros, which consists of a mound thrown up on a certain cape in memory of one of the illustrious potentates of the Bosporos.' (Str.Geog.11.2.7)

Although small when viewed from out to sea, tombs had distinct outlines, and were clearly visible as landmarks on an otherwise clear skyline ${ }^{421}$ (figs.62, 63). Their use as landmarks is demonstrated in passages such as that from the Argonautica quoted above (p.172: see also Ap.Rhod.Arg.2.659f., 833-6, 841-4, 911-7), and is explicitly alluded to by Strabo and Euripides, with reference to Kynossema:

'..this entrance is called the beginning of the Hellespont. And here is the cape called the Kynos-sema; though some call it Hekabe's sema, and in fact her tomb is pointed out after one has doubled the cape.' (Str.Geog. 13.1.28) 


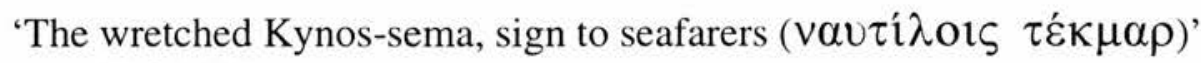
(Eur.Hek.1273.)

The development of mythological associations and traditions in connection with these tombs may, intentionally or unintentionally, have helped sailors to distinguish and remember particular tombs more clearly, just as names reflecting the colour or shape of headlands and cliffs helped sailors to identify natural landmarks (see above, p. $168 \mathrm{ff}.)^{422}$.

Tombs were not the only structures that were used as landmarks. Periploi and other accounts of sailing voyages often specifically describe coastal temples and towers as having been erected at sites from where they would be clearly visible from the $\operatorname{sea}^{423}$ (figs.62, 63):

'....to the sons of Tyndareus [the Dioscuri] will I raise a lofty temple on the Acherousian height, which all sailors shall mark far across the sea and shall reverence.' (Ap.Rhod.Arg.2.806ff.)

'And likewise the extremity of the isle [Pharos] is a rock, which is washed all round by the sea and has upon it a tower...with many stories...This was an offering by Sostratos of Knidos, a friend of the kings, for the safety of mariners, as the inscription says: for since the coast was harbourless and low on either side, and also had reefs and shallows, those who were sailing from the open sea thither needed some lofty and conspicuous sign to enable them to direct their course aright to the entrance of the harbour.' (Str.Geog.17.1.6)

'Then come Rhoiteion, a city situated on a hill, and, adjacent to Rhoiteion, a low-lying shore on which are a tomb and a temple of Aias.'

(Str.Geog.13.1.30)

'On the right, as one sails towards the city [of Samos], is the Poseidonion, a promontory with which Mt. Mykale forms the seven stade strait; and it has a temple of Poseidon.....After the Samian Strait, near Mt. Mykale....first on the seaboard is the Panionion, lying three stades above the sea, where the Panionia, a common festival of the Ionians, are held, and where sacrifices are performed in honour of Helikonian Poseidon.' (Str.Geog.14.1.14, 20; fig.64) ${ }^{424}$. 
In the second of these passages, the tower of Pharos acts not only as a marker of the dangerous shoals and rocks which had to be avoided while entering the harbour of Alexandria, but also as a sign to help sailors reach that harbour from the open sea, i.e. it compensated for the lack of prominent natural landmarks near Alexandria. Similarly, the third passage describes a temple on a low-lying shore, rather than on a height from which it could have been seen from further out to sea. Such temples or towers marked points on the coast which were, on the one hand, extremely important in navigation (as points headed for, or points at which courses were changed), but which also, being low-lying, would easily have been missed by mariners had they not been so marked. More recently, the same function was given to the last remaining column from the temple of Hera on Samos, which was left standing by later quarriers stripping the ancient sanctuary in order to provide a landmark for ships approaching this low-lying and featureless coastal plain. The use of a single column for this purpose underlines just how prominently visible whole buildings could be from some distance out to sea $^{425}$.

Most coastal temples, towers, and tombs, however, stood either upon high and often cliffy headlands, or on the coasts overlooking straits. Many such structures were probably erected at these places simply in order to attract the attention of the maximum number of passing ships, as these most often approached the coast at headlands and in straits (cf. above, e.g. pp.85, 93, 145, 147ff., 154f.). Nevertheless, temples, tombs, and towers in such locations clearly had, or developed, a navigational function. It is unlikely, however, that, like the monuments erected on low-lying shores, they helped sailors establish what part of the coast they were approaching, as this basic function was served by the prominent natural features of the coast upon which these structures stood ${ }^{426}$. So what function did these coastal structures serve in navigation? 


\section{Coastal landmarks and inshore navigation.}

The key to the navigational function of coastal towers, tombs, and temples located on headlands and along straits lies in the fact that such locations were not only areas which attracted large amounts of shipping, but were also areas of considerable danger and environmental complexity, where extreme caution and complicated navigational procedures were often called for (see pp.67-94, and below). In such dangerous and, in the case of straits, constricted waters, highly visible and distinctive fixed points on shore, such as temples, tombs, and towers, could play a vital role in enabling pilots to ascertain the exact position of their craft, and thus also both to avoid falling foul of hidden dangers, and to make specific and important manoeuvres at the correct time and place.

Some such tombs, temples and towers might simply remind sailors of the dangers presented by the physical environment in the area, and this is particularly the case with structures erected in commemoration of, or otherwise connected with, the death of a sailor nearby ${ }^{427}$, or indeed his survival of a life-threatening situation ${ }^{428}$. Thus Propertius, lamenting the death of the youth Paetus in a storm off Pharos at Alexandria, describes how the youth's tomb, on the shore nearby, will be taken as a reminder of the dangers of the seas nearby, personified as Poseidon:

'Whenever a sailor passes by Paetus' tomb, let him say "You [Poseidon] can cause fear even to the brave.", (Propert.El.3.7.28f.)

Moreover, this 'warning' function is explicitly expressed in an inscription on a tower on Cape Pyrgos in Thasos (fig.65), quite possibly itself the cenotaph of a drowned sailor:

'I am the memorial of Akeratos, son of Phrasierides. I stand on the extremity of the harbour as a saviour [ $\sigma \omega \tau \eta \dot{\rho} 10 \mathrm{v}]$ of ships and sailors. so, farewell!' (I.G.XII, 8, add. 683: for additional references, see n.423)

This inscription suggests a more specific or active role for the tower - rather than simply warning sailors away from a danger area which they had no reason to approach 
and was best avoided, it claims to 'save' or 'deliver' them from the dangers facing r. ships whenever they entered of left the harbour ${ }^{429}$ : this raises the possibility that the tower somehow functioned as a reference point for ships. The tower may have facilitated a safe passage between harbour and open sea by helping sailors to keep to a specific line of approach, where a safe channel was known to $\operatorname{lie}^{430}$. Despite the inscription, however, it is impossible in this case, and in most others, to prove that specific temples, tombs, and towers were used as leading marks or fixed points in inshore pilotage.

However, the position of many such structures strongly suggests such a function, especially where two monuments could be seen simultaneously, allowing sailors to judge their exact position more accurately. Thus both of the low headlands on either side of the strait of Rhion, at the entrance to the Corinthian Gulf, held a temple of Poseidon: the forts which superseded them were still being used in sailing directions for the strait this century. So too, the two shrines of Poseidon on opposite sides of the Samian strait (Str.Geog.14.1.12ff., ), a stretch of water only seven stades wide separating Samos from Asia Minor, appear ideally placed to act as navigational markers - on the southern, mainland shore, the Panionion stood on a low hill marking and overlooking the eastern entrance to the strait, while on the opposite, Samian shore, the temple of Poseidon stood just inside the western entrance to the strait, on a headland (the 'Poseidonion') visible from beyond the strait and fronted by the offshore island which presented the only physical obstacle to passing ships ${ }^{431}$ (fig.64). Mariners, by marking their position relative to such fixed points on the shore, could calculate their position in the strait, and thus know when best to change direction or make other manoeuvres in order keep to channels of a safe depth, and to avoid any hidden rocks or other dangers ${ }^{432}$.

One passage from Strabo provides explicit testimony as to exactly how such landmarks could facilitate complicated navigational procedures in difficult and dangerous environments. He describes the best strategy for crossing between the 
opposite shores of the Hellespont at the narrows between Abydos and Sestos, without falling foul of the strong and eddying current:

'Sestos lies farther in towards the Propontis, farther up the stream that flows out of the Propontis. It is therefore easier to cross over from Sestos, first coasting ( $\pi \alpha \rho \alpha \lambda \varepsilon \xi \alpha \dot{\mu} \varepsilon \varepsilon v 1)$ a short distance to the Tower of Hero and then letting the ships make the passage across by the help of the current. But those who cross over from Abydos must first follow the coast ( $\pi \alpha \rho \alpha \lambda \varepsilon \kappa \tau \varepsilon \dot{\varepsilon} \mathrm{v} \dot{\varepsilon} \sigma \tau \mathrm{ìv})$ in the opposite direction about eight stadia to a tower opposite Sestos, and then sail across obliquely and thus not have to meet the full force of the current.' (Str.Geog.13.1.22)

Thus it is clear that man-made monuments and structures such as temples, towers, and tombs which stood on the coast (but very often had been built with no intentional navigational function in mind) were employed by ancient mariners as general landmarks (particularly on low-lying shores), and also to facilitate precise navigation in coastal waters. A third function of these structures, again shared with headlands and straits, was that of distance marker or milestone.

We saw earlier (pp.161-6) that ancient Greek sailors calculated the distances of long voyages by mentally breaking down the route into a series of legs between major headlands, straits, harbours, and other features of coastal topography, the distances between which were commonly known. The following passages illustrate how temples, tombs, and towers situated at significant points on sailing routes were also often included amongst those coastal milestones:

'This city [Herakleia] is around 1500 stadia from the Chalkedonian temple $^{433}$ and 500 stadia from the Sangarios river.' (Str.Geog.12.3.2)

'[Sinope] is 3500 stadia distant from the [Chalkedonian] hieron, 2000 stadia from Herakleia, and 700 from Cape Karambis.' (Str.Geog.12.3.11)

'The length of this coast, I mean on a straight voyage from Rhoiteion to Sigeion, and the monument of Achilles [at the southern end of the Hellespont], is 60 stadia.' (Str.Geog.13.1.31) 
'Euboia, from the sanctuary of Zeus at Kenaion to the sanctuary of

Poseidon at Geraistos, runs for 1350 stadia' (ps.-Scylax.Perip.58)

\section{NAVIGATION OUT OF SIGHT OF THE COAST.}

\section{Navigation of coastal waters in fog or at night.}

Sailing at night was not an uncommon practice (see below, pp.226-30), and ships also had to cope with seriously reduced visibility when they encountered fog (for which see p.61). While ships would endeavour to approach coastal waters only in conditions of good visibility (below, p.228ff.), this was not always practicable. Inevitably, sailors occasionally had to navigate inshore waters, or even land or set sail from the coast, in conditions of low or zero visibility, as when, in 428B.C., Peloponnesian triremes ravaging Corcyra attempted to escape a larger Athenian fleet:

'...toward night a signal was flashed to them that sixty Athenian ships were approaching from Leukas....The Peloponnesians accordingly set sail that very night for home, going with all speed and keeping close to the shore ( $\pi \alpha \rho \grave{\alpha} \tau \eta \dot{v} \gamma \eta \bar{v})$; and hauling their ships across the Leukadian isthmus, in order to avoid being seen, as they would be if they sailed around [the island of Leukas], they got away.' (Thuc.3.80.2, 81.1)

Later, when discussing the manoeuvres and counter-manoeuvres of the Peloponnesian and Athenian fleets in the region of the Hellespont during the summer of 411B.C., Thucydides describes (8.101.3) how the Peloponnesian fleet, by setting sail from the

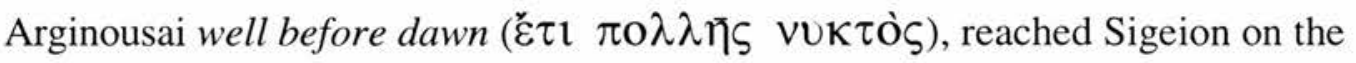
evening of the same day, and he continues:

'But the Athenians who were at Sestos with eighteen ships....realised that the Peloponnesians were entering the straits. So that same night, making what speed they could, and keeping close to the shore (í $\pi \circ \mu \varepsilon i \xi \alpha \nu \tau \varepsilon \zeta$ ) of the [Thracian] Chersonesos, they sailed towards Elaious, wishing to get by the enemy's ships and out into the open water.' (Thuc.8.102.1) ${ }^{434}$ 
In such difficult situations, the only piece of navigational equipment known to ancient Greek sailors, the sounding lead and line (p.229, and above, p.166), proved a particularly valuable instrument, for it provided a means by which the depth of water and the nature of the sea floor could be tested. The information thus gathered could be used to estimate both the distance from ship to shore and the type of coast likely to be encountered, as when the crew of the ship taking St. Paul to Rome, having been lost for two weeks after being blown off course in a storm off Crete, realised one night that they were approaching an apparently rocky coast (see p.117ff., where the passage, Acts 27.18-45, is quoted and discussed, and fig.55). By studying the material dredged up from the sea floor by the sounding lead, sailors in familiar coastal waters might also, despite the darkness, distinguish the safe channels which ran along the coast or led into a harbour from the shoals and rocky patches where the ship might run aground ${ }^{435}$. On the other hand, sailors who were lost or in unfamiliar waters, such as those taking St. Paul to Rome, had to await daybreak before identifying safe passages and anchorages (again, see p.117ff.).

It is clear, however, that the sounding lead was not the only means by which ancient Greek sailors could judge their position in relation to a coast which was hidden by fog or the dark of night. Thus in the passage from the Acts of the Apostles just referred to, the crew of the ship put down a sounding lead because they had already, despite the

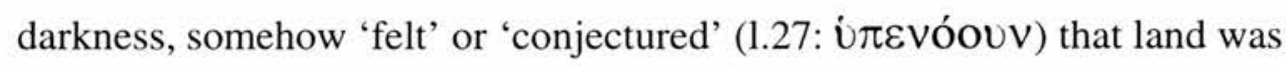
approaching. This was clearly a potentially lifesaving ability, especially for mariners who were lost or in unfamiliar waters, and it is unfortunate that we are not in this instance informed of the means by which the crew thus foresaw the approaching coast. Strategies here may have involved sounds, smells, and, in foggy or moonlit conditions, any visible sign in the waters around the ship, that might suggest that land was near.

Thus in certain areas, especially along indented and gently shelving coasts, discerning but disorientated sailors might have calculated the direction, if not the distance, towards land by observing the direction in which coastal currents in the area were 
running, or to the time of day and the direction from which diurnal breezes were blowing ${ }^{436}$. In conditions of low, but not zero visibility (fog or strong moonlight), the presence of a cliffbound coast nearby might be inferred from the sight of reflected wave patterns, running in a direction contrary to that of the main mass of waves, (for wave reflection, occurring only against certain types of coast, see p.39). Likewise, colour changes in the water could also be significant, with lighter hues generally being indicative of shallowing water ${ }^{437}$. The sound of waves breaking against the shore ${ }^{438}$, and even the sound or smell of sheep or other animals can also be taken as clear indications of a nearby landfall. Vell.Pat.1.4.1 even records the tradition that Chalkidian colonists headed for Italy were led to the site of Cumae by 'the sound at night of a bronze instrument like that which is beaten at the rites of Ceres'. Although there is little evidence for such navigational practices in ancient Greece (for evidence for the use of birds, see below, p.192), such interpretation of winds, currents, waves, and smells is known from other low-technology seafaring cultures, and is entirely in line with other navigational and seafaring strategies, also based upon a close observation of natural and physical surroundings, which we have already seen to be firmly attested in ancient Greek seafaring ${ }^{439}$. Otherwise sailors unaware that they were approaching a coast, or unable to avoid doing so, could only rely upon divine providence:

'Thither we sailed in, and some god guided us through the murky night; for there was no light to see, but a mist lay deep about the ships and the moon showed no light from heaven, but was shut in by clouds. Then no man's eyes beheld that island, nor did we see the long waves rolling on the beach, until we ran our well-benched ships on shore.' (Hom.Od.9.1428)

'In the night-time arose the mischief from the cruel surge...... Ourselves, however, and our ship, its hull unshattered, some power, divine not human, preserved by stealth or intercession, laying hand upon its helm;

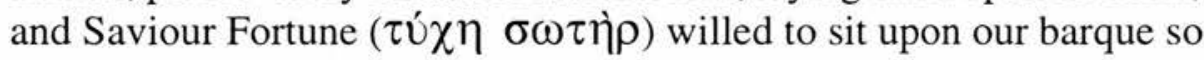
that it should neither take in the swelling surf at anchorage nor drive upon a rock-bound coast.' (Aesch.Agam.653, 661-6) 
On the other hand, crews who, despite poor visibility, were well aware of their position in relation to the coast, and sought either to come ashore, or alternatively to leave harbour for the open sea, could facilitate their difficult manoeuvres by igniting artificial lights on the ship, by which they could identify the entrance to or exit from an anchorage:

'All through the night they kindle flaming brands:

Yea, and methinks they will not wait the morn,

But, burning torches $(\pi \nu \rho \sigma \alpha)$ on the fair-benched ships,

In homeward flight will get them from this land.' (Eur.Rhes.95-8)

\section{Beacons.}

In addition to providing light in and around a ship through the use of torches, the tactic of countering poor visibility with artificial light was also widely employed in the form of beacons and other onshore lights. When exactly beacons came to be set up specifically as a navigational aid for mariners is a matter of debate ${ }^{440}$, complicated by the fact that it is not always clear whether references are specifically to beacon fires of one sort or another (not necessarily designed for navigational use), or rather to other types of fires which were visible to sailors by chance. While $\Phi \rho \cup \kappa \tau$ ó $\varsigma$ and $\pi \cup \rho \sigma o ́ \varsigma$ are the terms most often used to denote beacon fires, and other fires are often simply termed $\tau \grave{\alpha} \pi u \rho \grave{\alpha}$, the use of these terms is not so standardised that the purpose of the fire being referred to is always clear.

In addition to being used as navigational aids and leading marks for sailors, beacons were also used for various purposes related to war - to relay the news of the fall of a $\operatorname{city}^{441}$, to warn others of approaching enemies ${ }^{442}$, to indicate an attack and call for reinforcements ${ }^{443}$, or to indicate that city walls had been breached and to initiate a new phase of an attack ${ }^{444}$. Such beacons, if visible, would provide a general indication of the presence of land when seen by mariners sailing at night, as would any other fires lit to provide heat or light for those spending the night out of doors ${ }^{445}$. 
Of far greater significance, however, were beacons which were intentionally lit, not simply to indicate the presence of land to those sailing at night, but to provide them with leading marks which enabled them to recognise an exact point on the coast, and so either to take precautions to avoid dangers, or to enter a harbour safely. When such beacons came into being is again not entirely clear. Certainly the construction of the Pharos at Alexandria ushered in a period in which many other harbours came to be given lighthouses ${ }^{446}$, but prior to this, simpler beacons, not supported by sizeable structures, had been used to guide ships safely into harbours for some time. Hard evidence for such harbour beacons, unfortunately, is slight ${ }^{447}$, but includes some remains in the Piraeus, near the probable site of the tomb of Themistocles, dating from the later fifth century B.C. ${ }^{448}$. Literary evidence can take us little further back than this, and in fact there is no specific mention of harbour lights at all before or during the fifth century $\mathrm{BC}$ We do have references from this period to the myths concerning Nauplius' wrecking of the Greek fleet returning from Troy. While there is apparently no mention of Nauplius in the Nostoi of Agias (see Proclus' Chrestomathy), and other fifth century writers connect Nauplius only with the creation of beacon signals for the army (Soph.fr.432.6), Euripides preserves the tradition that Nauplius caused the wreck of the Greek fleet by lighting false beacon fires at Kaphereus, at the north end of the south-east extremity of Euboia, and the phrasing of his first reference to Nauplius seems to imply that the story, and so also the use of navigational beacons, was already well-known:

'Why should I tell of the shipwrecks ${ }^{449}$ in the Aegean, and of the Euboian beacons of Nauplius...' (Eur.Hel.766f.)

'Lighting the blazing beacons on sea-swept Euboia, a lone seafarer killing many Greeks, dashing them on the Kapherean rocks and the headlands of the Aegean by the light of his treacherous star.' (Eur.Hel.1126-31)

Although it is not explicitly stated here, it is clear that by lighting the beacons on Kaphereus, Nauplius was held to have made the returning Greeks assume that a safe haven was to be found there, so that they sailed straight towards the light, and so into 
the rocky and cliffbound coast ${ }^{450}$. Possibly (as Ap.Bibl.Ep.6.7) the Greeks were understood to have assumed that the beacons had been lit by some fellow sailors who had already been cast ashore alive at a safe haven, but it is also possible that they were imagined as having been already looking out for a harbour's beacon light to land at, and that they mistook Nauplius' beacon for the real one. If so, the identity of the real harbour and its beacon would most likely be Geraistos, which was the only harbour in this part of Euboia, and was home to the sanctuary of Poseidon at which Nestor and his contingent had already put into during their return, in order to give thanks for having completed the Aegean crossing in safety ${ }^{451}$. In any case, these passages from the Helen show that leading beacon lights had, by the fifth century BC at the latest, come into common use in helping to guide ships safely into port during the night or in fog.

Other types of fixed beacons were also used to mark important points on the coast where ships might have to change course, avoid a submerged rock or reef, or otherwise make careful manoeuvres. These most likely would have stood at places where towers, tombs, and temples provided the same function by day. The idea that all coastal towers were lighthouses or beacon towers has rightly been firmly rejected ${ }^{452}$, but there is evidence that some such sites may have had associated beacons. Thus there appears to have been a fire-beacon of some sort at Kynossema, the tomb standing on the headland of the same name at the entrance to the Hellespont, which functioned as a navigational marker for sailors (see above, p.173f.) ${ }^{453}$. Philostratos the Elder also describes a beacon by a temple at the entrance to the Bosporos from the Black Sea, where the narrowness of the strait, the force of the current, and the presence of the Cyaneae rocks made careful navigation and pilotage, especially at night, extremely important. He may be describing the temple of the Chalkedonians, on the Asiatic side, or that of the Byzantines on the European shore opposite, the two temples standing as landmarks for seamen just as Kynossema did at the entrance to the Hellespont ${ }^{454}$ : 
'You see the temple yonder, the columns that surround it, and the beacon light at the entrance which is hung up to warn from danger the ships that sail out from the Euxine.' (Philos.Imag.1.12.27-31)

It is notable that sailors would have to have had a good knowledge, oral or written, of different beacons and their locations, for disaster would be caused by confusing those which marked safe harbours with those which marked dangerous coasts such as the one described by Philostratos above. Possibly harbour beacons were in some way distinguishable from others by their appearance, but the likelihood of confusion can be inferred both from the confusion apparently often occurring in the use of military beacon signals (see n.442), and from the fact that lights used on the boats of night fishermen were at times mistaken for beacon lights by other ships ${ }^{455}$.

\section{Navigation on the open seas.}

The methods ancient Greek sailors used to calculate their direction of travel and the distances they had covered were far from accurate. For directions they relied mainly upon the position of the sun by day ${ }^{456}$, and of the stars by night ${ }^{457}$, neither method being highly accurate when judged by eye alone.

Thus, to take directions according to the position of the sun, it is also necessary to take into account the time of day (according to which the sun will lie in a certain direction, e.g. due south at mid-day), which sailors, lacking clocks of any sort, could only do by estimation ${ }^{458}$. Likewise, while the generally clear skies of the ancient sailing season facilitated navigation by observation of the stars (and equally of the sun $)^{113}$, exact directions could not be ascertained through observation even of a perfectly clear night sky. All stars appear to rotate around the celestial pole, in the north of the sky, as the night progresses, so that again the time of day (or, rather, night) has to be taken into account in order to ascertain the exact direction in which any star or constellation lies. Judging directions by this method was complicated by the fact that the stars rise and follow their set paths across the sky four minutes earlier every day, while for long-distance sailors the situation was complicated slightly further still by the fact that the part of the sky visible to an observer changes with 
latitude, so that the position of individual stars relative to the horizon also changes, and a few stars in the north of the sky were only visible to those sailing in the northern Mediterranean, while some in the south of the sky were visible only to those in the southern Mediterranean ${ }^{460}$.

The closer stars are to the celestial pole, the less they change position as they rotate around the pole. Moreover, whereas stars far away from the celestial pole rotate in such wide circles that they appear to rise and later disappear over the horizon in the course of the night, stars near the celestial pole always remain visible in the sky. Thus the Greeks looked to stars near the celestial pole for a reliable indication of northerly direction, just as modern navigators refer to Polaris. Early Greek navigators principally made reference to the Great $\mathrm{Bear}^{461}$ :

'Gladly then did goodly Odysseus spread his sail to the breeze; and he sat and guided his raft skilfully with the steering-oar, nor did sleep fall upon his eyelids, as he watched the Pleiades, and late-setting Bootes and the Bear, which men also call the Wain, which ever circles where it is and watches Orion, and alone has no part in the baths of ocean. For this star Kalypso, the beautiful goddess, had bidden him to keep on the left hand as he sailed over the sea [as this would ensure he kept progressing eastwards].' (Hom.Od.5.269-77)

However, the Great Bear, a broad constellation which lies some distance from the celestial pole, was a far from perfect indicator of northerly direction. A more accurate indicator was to be found in Kochab, a member of the Little Bear constellation which stood, in Homer's day, only eight degrees from the celestial pole, and so appeared to the naked eye to maintain a constant position ${ }^{462}$. However, it was not until around the time of Eudoxus, in the first half of the fourth century BC, that knowledge of the Little Bear as a better indicator of north was learnt from the Phoenicians ${ }^{463}$ - in the passage quoted above, Homer is apparently even unaware of the Little Bear's existence, citing the Great Bear as the only constellation which remains constantly visible in the night $\mathrm{sky}^{464}$. 
These points exemplify the inaccuracy which was endemic in ancient Greek sailors' attempts to navigate by the sun and stars without the help of any measuring instruments or equipment. General directions could certainly be ascertained with some accuracy, especially by more experienced mariners, but not to such a degree that the exact point, or even area of coast at which a ship would arrive after crossing a wide expanse of open sea, out of sight of land, could be predicted. Another technique commonly used to ascertain the direction in which a ship was travelling, reference to familiar winds, was no more accurate, but could be employed when skies were overcast $^{465}$.

Most of the winds which blew as a result of the annual meteorological cycle in the eastern Mediterranean were regular enough in their direction and other characteristics to be readily identified and distinguished from each other (see pp.48-52): that winds with certain characteristics could be reliably associated with given directions is implicit both in the development of progressively more detailed wind roses, and also

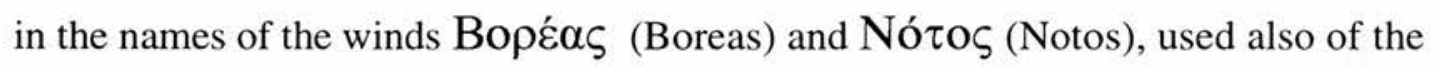
'compass points' from which those winds blew, respectively north and south ${ }^{466}$. The name Nó $\tau$ os, moreover, is also related to various terms used to describe characteristic features of the wind - its fog, rain, and briny, sticky humidity (for which, see pp.52, 63), as well as its direction. Thus the adjective vo $\tau \varepsilon \rho o ́ \varsigma$, verbs vo $\tau \varepsilon \dot{\varepsilon} \omega$

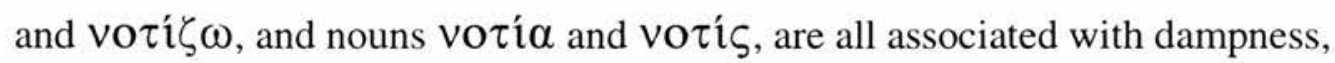
moisture, rain and sweat, while vó $\tau 10 \zeta$ can indicate either a moist or rainy aspect or a southerly aspect. Such close relationships between terms which describe features of weather, the winds that are associated with those weather features, and the direction from which those winds come, suggest the direction from which a wind was blowing could be identified relatively easily by its 'feel', its notable characteristics (see also p.248f.).

The importance of being able to identify winds in this way becomes clear when we recognise the role of winds in ancient sailing directions. Evidence here comes from the periploi (sailing manuals) which, as well as giving descriptions of the significant 
features along coasts, also give details of sailing routes between ports and promontories around the Mediterranean coasts. The information given in such route descriptions tends to consist simply of the distance between the two points (and/or how long the trip should take - the two were in a sense synonymous: on distance measurements see below), and the wind with which the journey should be made, which mariners would therefore have to be able to identify ${ }^{467}$. Those mariners who started such sailing voyages with the wind blowing in a suitable direction, but then found the wind changing direction, did not simply have to adjust the ship's rigging and steering gear to compensate for the change in wind direction, but also first had to ascertain the new direction in which the wind was blowing. Even for experienced mariners who were very adept at first getting, and then periodically readjusting their bearings simply by reference to the wind, it is fair to assume that, after a number of such changes in wind direction over the period of a day or more on the open sea, it would difficult to know how constant the ship's direction of travel had been, and so also to know exactly how far from the intended destination the ship would be when it eventually reached foreign shores.

Predicting when, and where, a ship would reach the foreign shores aimed for was one of the most difficult aspects of open-sea navigation, but also one of the most important (see below, pp.189ff., 228f.). Techniques for measuring both the length of an open-sea sailing route, and how far along such a route a ship had progressed were far from exact, and again involved no accurate instruments of measurement ${ }^{468}$. Distances for sea journeys, especially on long overseas routes ${ }^{469}$, were often given in terms of a number of days' sailing. Various authorities, ancient and modern, and seldom agreeing, have estimated how many stadia a ship could cover in a day, but the meaninglessness of such figures has been illustrated by Casson, who points out that how far a ship could travel in a day was principally dependent upon how strong the wind was, and upon whether it was blowing with the direction of travel or against $\mathrm{it}^{470}$ : a holkas attempting to sail against the wind would be lucky to get anywhere in a day (see p.243). Journey distances given in terms of so many days' sailing were at best vague estimates for the 'average' sailing ship with a suitable following wind (in 
the periploi, the winds required for particular journeys are sometimes added as qualifiers to the number of days' sailing required). Sailors following a route described in a periplous clearly could in no way assume that they would arrive at their destination after exactly the number of days indicated in the description.

Even where journey distances were given as a certain number of stadia, these figures were not arrived at by direct measurement, but could only be calculated on the basis of the estimated speed of a ship (which, as we have seen, was not particularly reliable) and the amount of time it took to complete a given journey. Experience might enable sailors to estimate the speed of a ship, and the distance it was covering, with greater accuracy, especially when in sight of the coast, where reference could be made to known landmarks and the scale of the coastal landscape ${ }^{471}$. Even if absolute figures could not be calculated, experienced crew members could also make accurate estimates of how weather (especially wind) and sea conditions were affecting the relative speed of their ship, although such estimates would again generally be less accurate when sailing on the open seas, out of sight of the coast. A ship's speed might also have been measured according to how long it took to pass an object of known length, such as a piece of rope, or how long a small object took to pass from bow to $\operatorname{stern}^{472}$. This would give a more accurate estimate of the ship's speed, but again, without proper means to measure time, figures were never wholly precise $\mathrm{s}^{473}$, so that there were often wide discrepancies in the figures given by different authorities for the same journeys:

'The voyage from Salmonion [a headland in eastern Crete] to Egypt takes four days and nights, though some say three. Some state that this is a voyage of 5000 stadia, but others still less...' (Str.Geog.10.4.5)

'The sea-passage ( $\delta \dot{i} \alpha \rho \alpha)$ from Rhodes to Alexandria is, with the north wind, approximately 4000 stadia, while the coasting voyage ( $\pi \varepsilon \rho i \operatorname{in}(\mathrm{o} \varsigma)$ is double that distance. Eratosthenes says that this is merely the assumption made by navigators in regard to the length of the sea-passage, some saying it is 4000 stadia, others not hesitating to say it is 
even 5000 stadia, but that he himself, by means of the shadow-catching sun-dial, has discovered it to be 3750 stadia.' (Str.Geog.2.5.24)

'According to the Chorographer, the distances from Brundisium as far as Garganon amount to 165 miles, whereas according to Artemidorus they amount to more; and thence to Ancona 254 miles according to the former, whereas according to Artemidorus the distance.....is 1250 stadia, a much shorter distance.....And they do not agree with the commonly accepted distance along the Illyrian coastline, from the Keraunian Mountains to the recess of the Adriatic........However, every writer does not agree with every other, particularly about the distances, as I often say ${ }^{474}$.' (Str.Geog.6.3.10)

Even when sailors did have as accurate a knowledge as possible of the distances involved in an impending journey, they could still not predict when they would reach the port of destination without facing the problem of assessing the rate at which they covered that distance in the course of the journey. As described above, this could only be judged by eye, according to the crew's knowledge and experience of their ship, and of how their relative speed and performance had been affected by sea and weather conditions. Furthermore, they would have to take into account not only the ship's average speed during the journey, but also the degree to which it had been sailed on a straight course towards the destination (i.e. with a good following wind), as opposed to having been forced to deviate from the straight course. Such deviations occurred through being blown unavoidably off course by storm winds, through drifting with the current during a calm, through tacking to and fro in order to capitalise on winds which were forwards of the beam, or through the ship's tendency to be displaced sideways when sailing forwards by utilising winds not directly from the rear, but from one side (for thus sailing with the wind 'on' or 'aft of the beam', and for tacking, see n.577). Even experienced sailors would find it difficult to assess these deviations from the direct route to the destination well enough to accurately maintain and adjust their estimates of their changing position as the journey progressed ${ }^{475}$.

It was because of such inaccuracies in long-distance route-planning and navigation that sailors found it very important to be able to recognise a coast they approached from the open sea by its profile, and particularly by the profiles of distinctive 
landmarks such as headlands and islands ${ }^{476}$. Sailors reaching the end of long-distance open-sea routes were keen to reach land during daylight for this reason, and also because, during the night, an approaching coast might not be spotted in time to avert disaster (p.227ff.). However, timing the arrival at foreign shores in this way was extremely difficult for sailors who, as we have just seen, were often not exactly certain of the distance and direction in which they had travelled, and so were likewise unsure of how much further away the foreign shore was ${ }^{477}$. It was important, therefore, for navigators whose calculations suggested that they might be coming to the end of their open-sea crossing relatively soon, to find any possible means of ascertaining the direction and rough distance towards the coast they were aiming for. In particular, it was a matter of urgency for any sailors caught on the open seas in dangerous weather to be able to judge the direction of the nearest island or coast where shelter and safety from the elements might be found (see above, pp.128, 133f.).

There were a number of strategies, based upon an intimate knowledge and observation of aspects of the sea and sky, to which sailors could resort in order to establish their position in relation to coasts which were not yet in sight. Some of these involved identifying the area of the sea in which the ship was then sailing, while others enabled sailors to infer the presence and position of islands and/or coasts which were not yet near enough to be visible to the naked eye.

Some ways of identifying waters as being coastal when the coast itself is obscured by fog or darkness have already been discussed (above, p.179ff.). When far from the coast, a good knowledge of the seas generally, combined with close observation of the waters a ship was passing through, might still allow sailors to calculate their general position. One method was to observe the set of the current, which flowed in different directions in different parts of the Mediterranean Sea, and in different parts of the local seas around Greece. It has been noted, for instance, that currents in the Mediterranean Basin, and in the deep recesses found along its northern shores (including the Aegean and Adriatic Seas) circulate in an anticlockwise motion, and weaken notably the further they are from the coast (p.41f.). The crew of a ship which 
had become lost as a result of storm winds in, say, the Adriatic, might then have sought to ascertain whether the Greek or the Italian shore was nearest by observing the direction of the current - if it flowed northwards, it would indicate that the Greek coast lay nearer, if southwards, the Italian. The regularity of currents in the Mediterranean, and locally around Greece, would generally have made it easier for mariners to associate particular currents with particular areas of sea (see p.233f.), and so would also have facilitated this method of ascertaining a ship's position. The refraction of waves around islands (which sends waves travelling off in a direction different from that of the main, unrefracted, mass of waves in the sea) may also have given visual clues as to the direction of land still below the horizon, or otherwise hidden from view. Such techniques are employed by other low-technology seafaring cultures $^{478}$.

Observation of the location and movements of animal life may also have provided sailors with indications of which area of sea they were in. The areas in which certain marine species generally remained indefinitely, because currents made the water nutrient rich there, or for some other reason, and also the habitual feeding grounds of seabirds, would become known to experienced mariners, in particular fishermen, and would form features on their mental map of the seas. Such knowledge was an important aid to navigation in situations where more explicit landmarks or signs were unavailable $\mathrm{e}^{479}$. Whether observation of the movements of migratory fish such as anchovies, pilchards, tunny and mackerel, which journey annually from the Atlantic or the central Mediterranean to their spawning grounds in the Black Sea and the Aegean and back again, could also have provided sailors with clues as to their location when they found themselves lost or otherwise unable to establish their precise position, is less clear ${ }^{480}$.

Turning to methods of ascertaining the direction and proximity of coasts and islands not yet visible, animals again had a role to play. Here birds were of most interest, to the extent that the observation both of species which nest on the coast and feed out to sea, and of migratory species which fly to and fro across the Mediterranean each year, 
could inform the knowledgeable sailor of the direction of the nearest landfall. Thus in the early morning, seabirds, leaving their nesting sites on rocky promontories and offshore islands and travelling to their feeding grounds, may show the direction of the land from which they came, as they also do when returning home at dusk ${ }^{481}$. Migratory birds tend as a matter of course to follow long peninsulas and chains of islands as far as possible before heading out to sea, and when returning to land, in order to simplify navigation and to find the shortest sea crossings possible ${ }^{482}$. Pliny (H.N.10.30), for example, noted that cranes cross the Black Sea by the 'strait' between capes Karambis and Kriou Metopon ${ }^{483}$. Distant islands and promontories could, moreover, be seen from far further away by birds than by mariners because of the birds' greater elevation, so that, on the open sea, the flight paths of migratory birds, which were easily spotted because of the tendency of even normally solitary birds to flock together during migration in order to simplify navigation ${ }^{484}$, also indicated the direction of the nearest landfall ${ }^{485}$. Vell.Pat.1.4.1 records that Chalkidian colonists were arrived at the site of Cumae by following a pigeon (Latin 'columba'), probably the rock pigeon, o'tvá $\zeta$ or $\pi \dot{\varepsilon} \lambda \varepsilon 1 \alpha^{486}$. A more developed practice was to carry birds aboard ship until the crew felt that land was near, and then to release them, in the knowledge that the birds would fly directly towards the nearest land ${ }^{487}$.

As sea birds will return to land when the sea becomes too rough to feed ${ }^{488}$, and as the annual bird migrations coincided with the changeable and often stormy weather of spring and autumn (for which see p.48f.), these bird signs were particularly valuable to sailors surprised by a sudden or unforeseen deterioration in weather conditions. Pomp.Mela.1.110 describes how a sailor caught in a storm on the Black Sea managed to find land again by following a swan.

A second method of inferring the position of coasts and islands still hidden below the horizon involved observation of the clouds, rather than the birds, in the sky. During the main summer sailing season, skies in the Mediterranean are very often clear (p.48f.). When clouds do develop, they are almost always orographic (i.e. formed when warm and humid air blowing off the sea is forced upwards into colder altitudes 
when crossing peninsulas and islands (see fig.49), although they may also be formed where intense diurnal heating (associated only with land surfaces) produces strong convectional air currents (see pp.62-5) Thus isolated patches of cloud in summer skies can be taken to indicate the presence and direction of a landfall ${ }^{489}$. Orographic cloud, which can rise up thousands of feet, may be seen from the greatest distances, but the considerable elevation of any cloud will render it visible to mariners as distances far greater than those at which the land beneath becomes visible to them. Similarly, plumes of smoke rising into the sky may also be readily interpreted as indicating the presence of land. This is a common feature of traditional navigational practices ${ }^{490}$, and there is an instance of such interpretation of rising smoke in the Odyssey:

'But Odysseus, in his longing to see were it but the smoke leaping up

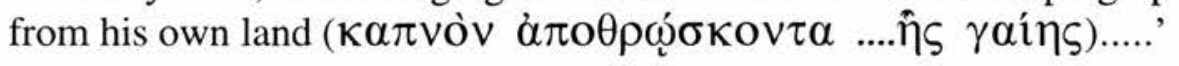
(Hom.Od.1.57f.) 


\section{THE ROLE OF THE PHYSICAL ENVIRONMENT IN ANCIENT GREEK SEAFARING.}

\section{The maritime functions of specific features of coastal topography.}

A survey of the importance of coastal topography in ancient Greek seafaring shows that nearly all distinct types of coastal feature were of considerable practical significance in ancient seafaring.

Some types of feature were significant only for the danger they posed to mariners. Thus coasts running along major NW-SE geological fault lines for long distances, as, for example, at Magnesia (Thessaly), Euboia, and Malea, tended to have steep and rocky, shores (pp.71f., 77ff., fig.51), often cliffbound (p.121ff.), where strong winds, both on- and off-shore, created stormy conditions and made sailing hazardous (pp.78$82,124 \mathrm{ff}$.). Such coasts were often simply avoided altogether, especially where the faulted nature of the shoreline provided few, if any, inlets where shelter was available and ships could be moored or brought ashore (pp.114, 126, 130ff.).

This lack of shelter, which typifies such faulted concordant coasts, was, however, atypical of the Greek coastline as a whole, which is characterised by a high degree of indentation. All types of coastal indentations served important functions, especially in providing shelter and landfall. Thus countless bays, especially those well-protected by neighbouring headlands (pp.98-103, 110-3, figs.47.i, 54), or by offshore islands (p.113-16, fig.56) provided a ready shelter from winds and waves for ships sailing relatively close to the coast of nearly all parts of Greece (p.95f.), other than those faulted areas just discussed. Many such bays had substantial beaches formed partly from sediments washed down by rivers, and partly from material carried along the coast, by longshore drift, and deposited in the more sheltered waters of bays (p.31f.). These beaches allowed ships not only to be moored in bays, but also to be landed and 
dragged upshore, providing a simple alternative to less readily-available man-made harbours (pp.95, 232, fig.68). Natural harbours, formed when the sea eroded narrow gaps through weak points in hard coastal rock, and then hollowed out wide lagoons in the softer rocks behind (p.27f., figs.11, 22, 23), were a form of indentation that provided particularly good shelter, once their often constricted entrances had been navigated (p.97f.).

The other main form of coastal indentation in Greek coasts, the river mouth, also offered shelter from wind and wave to those ships able to navigate their waters (p.102f.). Many river mouths, on the other hand, became heavily silted up, forming shallows where ships might become grounded (p.120f.). Those rivers which were navigable not only in their mouths, but for some distance inland ${ }^{491}$, took on a wider significance, especially where they led towards some important inland site, as, for example, the Alpheios led towards Olympia. Such rivers, offering a cheap alternative to the costlier processes of travel and transportation by land, were not simply convenient resting points for ships proceeding around the coast, but were important elements in navigational topography, towards which ships sailing from overseas countries might be directed, and in respect of which, therefore, sailing distances to and from various ports and other coastal sites were calculated and recorded (p.150f.).

Shelter was also available at some points where deposition had formed protective spits and bars, especially where, as tombolos, these had linked an offshore island to the mainland (pp.117, 120f.). More often, however, deposition produced extensive shallows, where there was no shelter from winds, nor from the breaking waves which rolled shorewards from some distance out to sea, and where there were no landmarks to aid navigation (p.117ff.). In such situations, however, knowledge of local currents and winds, and the contours of the sea bed, allowed experienced mariners to travel safely, and to pass through the channels which might lead seawards to open and deep water, or landwards to lagoons, backwaters, and river mouths where, once entered, the shelter available was all the more effective because of the protection afforded by the deposition features cutting off such areas from the open sea (p.119f.). This is one 
way in which local mariners' intimate knowledge of, and familiarity with, their natural environment was a very important aspect of ancient Greek seafaring; this topic will be discussed more fully below.

Thus both the flat coastal contours produced by faulted cliffs and by deposition processes, and the indentations formed by bays, natural harbours, and river mouths, were, in their own ways, of considerable practical significance in ancient seafaring. However, Greek seafaring and navigation was often characterised by only sporadic, tangential, and short-lived approaches to the coast (pp.142-57), especially on longdistance voyages (pp.145-54), with most time being spent in deeper water. For this reason, the points on the coast which were of most significance to Greek seafarers were not those that were recessed or indented, such as bays and river-mouths, nor those that were essentially flat, such as cliffs and shallows, but those that protruded from the mainland, stretching out into the sea, and standing 'in the way' of passing ships.

Thus it was the promontories (especially the headlands in which they terminated), the offshore islands, and the straits that are formed wherever islands approach the coast (or where two promontories approach each other from opposing directions), that held most significance in the minds of ancient Greek seafarers. Moreover, these topographical features were not only significant in the sense that shipping more regularly approached them than other features of the coast; they took on added significance from the particular dangers to be found within their vicinity, and from the important functions they fulfilled in ancient sailing routes and navigation.

The dangers associated with such prominent coastal features were topographical, oceanographic, and meteorological. Around headlands, reefs and rocks, whether, fully submerged or only awash, pose particular threats (p.68ff.), which tend to be intensified and compounded by the heavy seas (p.72f.) and strengthened, intermingling currents (p.73) typical of such areas. Winds, too, tend to strengthen and to meet around headlands (p.74ff.), with onshore winds increasing the dangers of 
navigation on the exposed flank of the promontory, and lulls, gusts, and squalls likewise complicating sailing conditions on the more sheltered flank (p.76ff.). Similarly, the restricted room for manoeuvre in straits was often further reduced by the presence of rocky outcrops, whether visible or submerged (p.93f.). Navigation in straits was also hampered by currents that were generally stronger than those found in other parts of the sea (pp.85f., 90f.), and in some cases featured eddies or periodic reversals of direction (pp.82ff., 90f.). So too winds funnelling down through straits blow with particular vehemence (p.87f.), while those blowing across straits at sea level do so very turbulently, further complicating navigational procedures (p.91ff.). Another danger commonly encountered at headlands, straits, and offshore islands, stemming at least in part from the navigational significance of such areas, was piracy (pp.139, 157f.).

Nevertheless, for all their navigational hazards, such topographical features featured very prominently in ancient sailing routes. Apart from the initial departure, stops ashore for food and rest, and the final arrival at the destination, many sailing journeys, both coastal (pp.142-5) and overseas (pp.145-52, 154f.), would have consisted solely of a series of relatively straight legs between successive headlands, straits, and offshore islands (and, on overseas routes, mid-sea islands (cf. p.152f.)). 'Hugging the coast', or following the contours of the coast round all its indentations, was generally only practised when ships had a port of call in a particular indentation, or because weather conditions at the mouths of gulfs and other indentations were not compatible with a ship's means of propulsion (pp.135f. (esp. n.362), 142ff., 163f.). It was at headlands, straits, and offshore islands (rather than while sailing between them), that the main changes of direction in the route (i.e. major changes in a ship's overall heading, not temporary changes necessitated by wind conditions, as when tacking) would have been made (p.158ff.). Many of the headlands and islands that had such a fundamental role in ancient sailing routes were easily recognised by the colour of their rock, or by their shape, or by some other distinctive feature (pp.168-71, figs.20, 21, $28,61)$, and were, moreover, the first points of land to appear to mariners as they approached from the open seas (p.166f.). In time, therefore, these became familiar 
landmarks by which sailors established their general position, especially when returning to the coast from the open seas (pp.171, 188-92, 226f.), where navigation was a less precise art (pp.185-93). Sailors also tried to judge distances between such nodal points in their sailing routes as best they could (pp.161-6), and the names they gave these landmarks, and their estimates of the distances between them, were recorded as sailing directions, which began to appear in written form during the sixth century BC (p.161 and n.394), and which must have been recorded and communicated orally for a long time before then.

Mariners, especially those returning from the exposure of the open-seas, also often sought the shelter of headlands (pp.98-101) and of islands, particularly where these, with the mainland, formed a sheltered strait (p.104f., fig.47.i). However, the shelter to be had in the lee of headlands, which regularly featured stormy, changeable and unpredictable weather, or to the lee of often windswept islands, was rarely reliable: dangers came from squalls striking the sea from above after crossing and descending from the relief feature being sheltered behind, from calms, and from winds which veered round to blow onshore, leaving ships embayed and unable to continue their journey (pp.106-10, fig.47.ii). Considerably better quality shelter could be found where the shelter offered by a headland was reinforced by that of an offshore island, or where the coast on the sheltered side of a headland or island featured a sheltered indentation such as a natural harbour (pp.110-6).

The unique maritime significance of different types of feature of coastal topography led in turn to these different types of feature taking on equally varied 'socio-maritime' and terrestrial functions, as outlined in appendix four.

\section{General meteorological and oceanographic considerations.}

Those meteorological and oceanographic phenomena that can be related to specific types of features of coastal topography, and had a bearing upon the navigation of such features of coastal topography, have already been summarised. In addition, there are also more general aspects of meteorology and oceanography which, singly or in 
combination, affected sailing conditions throughout the waters in which the ancient Greeks sailed, and not only in the vicinity of particular types of topographic feature.

In the Mediterranean, the annual climatological cycle falls into two distinct and obvious seasons, a summer with fair and generally constant conditions, and a winter with stormy and changeable conditions. It was this natural division that gave rise to the traditional Graeco-Roman notion of a distinct 'sailing season', during which sailing was expected to be safe, and outside which sailing was deemed to be dangerous (p.221ff.). In practice, however, this distinction was not a hard and fast one: there were, it is true, clear correlations between, on the one hand, the aspects of the climate which had the greatest bearing upon seafaring, and, on the other, the principal climatic differences between summer and winter (e.g. navigation was facilitated by summer's clear skies, and forecasting by its steady conditions, whereas winter saw overcast skies and more sudden changes of weather: see pp.221, 224), but nevertheless, a considerable amount of maritime activity did continue throughout the winter season (pp.223-6). In fact, there were some routes on which winter conditions actually facilitated sailing. These were mainly northerly routes that were difficult to accomplish against the summer Etesians (for difficulties associated with the Etesians, see, for example, pp.95. 99, 104, 106, 129), but were facilitated by the predictable southerlies which are associated with winter, such as the return trip between Egypt and Greece, and the passage through the Hellespont and Bosporos (pp.85ff., 225). Equally, areas where weather conditions were difficult to forecast throughout the year, such as the Adriatic (p.108), were avoided as much in summer as they were in winter (p.114) (thus, we should distinguish between the avoidance of dangerous sailing conditions in particular areas, whatever the time of year, and the avoidance of that time of year at which sea conditions generally might most often become dangerous). Why, then, did the ancients persist in noting a distinction between summer and winter as seasons for sailing and not sailing respectively? It was because the overall weather conditions of summer and of winter were so different, and because the bi-annual transitions between them occurred in such a short space of time, and not because there was a similarly sharp and distinct change in the extent of maritime 
activity between the seasons, nor because winter conditions were wholly and constantly unsuited to seafaring, and summer conditions ideal for it.

Similarly, although Greek mariners often sailed with the coast still within sight, it is far too simplistic to argue that Greek mariners always (or, equally, never) 'hugged the coast', for we have seen that coastal and open-sea routes (to the extent that these are clearly distinguishable: see p.154f.), and the many different types of topographic feature commonly encountered in coastal areas, had both positive and negative aspects (pp.127-142). Being near to the coast could not be equated with safety, and whether any particular coast or topographic feature was approached closely or given a wide berth depended upon various factors, such as the particular route being sailed by a ship in its vicinity, and particularly the sailing (i.e. meteorological and oceanographic) conditions encountered there. There is, however, generally a clear correlation between the distinguishing features of the Greek climate and the distinguishing characteristics of the sailing and navigational techniques employed by the ancient Greeks, and this is particularly true of the overall wind regimes throughout the year, in relation to established sailing routes ${ }^{492}$. Thus the generally direct and open-sea routes followed when sailing in southerly directions evolved in accordance the steadiness of the northerly Etesians (p.222). The coastal and more winding routes generally followed when sailing in northerly directions, on the other hand, evolved not only because coastal topography provided shelter from the Etesians, but also because summer's strongly developed land and sea breezes facilitated northwards travel (p.222f.). Alternatively, as we noted above, the Etesians could be avoided on such routes by taking advantage of one of winter's southerly winds.

Other aspects of sailing also developed in accordance with, and relied upon, the regularity of land and sea breezes in summer. Thus, the whole daily routine of much sailing, particularly the practice of entering harbour early in the morning and returning to harbour in the evening, was based on the diurnal nature of land and sea breezes (pp.110, 223), and on the weakness of the tides, which, had they been stronger, would have confined access to harbours and other areas of shallow water to the 
period of high tide, and would have caused considerable delays to ships approaching or sailing along the coast (pp.132f., 231ff., 244). Similarly, naval tactics that depended upon predictable weather changes (for which see pp.87-90) could not have developed had it not been for the regularity of land and sea breezes.

The other main distinguishing feature of the summer climate, clear skies and good visibility, likewise clearly influenced the development of navigational practices. Navigational techniques relied largely upon visible signals, with particular importance resting on the recognition of headlands and offshore islands from a distance (pp.166$71,190)$, and the visibility of signs in the sky, such as the flight paths of birds (p.192) and the position of the sun and the stars (p.185f.). All these techniques were entirely dependent on bright and clear conditions, as was navigation by smaller terrestrial landmarks such as towers and shrines (pp.172-8). In conditions of poor visibility, sailors could only resort to unreliable techniques, such as establishing directions by reference to wind conditions (on the open sea - see p.186ff.) or sea conditions, and smells and sounds (in coastal waters - see p.180f.). In an area of human activity in which very few technical innovations were ever made, it is a measure of ancient Greek navigators' reliance upon clear skies and good visibility, and the problems they encountered when visibility was seriously reduced (especially in coastal waters - for these problems, and for the resulting principle of approaching coasts only during good visibility, see pp.117f., 180f., 190, 228f.), that two of the very few technical innovations in ancient seafaring, the sounding lead and the beacon, were both extremely important to coastal navigation during fog or night-time (pp.179f., $228 \mathrm{f}$. (sounding lead), pp.182ff. (beacons)).

\section{The living environment.}

In addition to inanimate aspects of the physical environment, such as topography, winds, and currents, living creatures also a role to play in ancient Greek seafaring, though generally a minor one. Not surprisingly, plant life had little role in this maritime activity (but see p.170, on landmarks, and p.267, on weather prediction). Within the animal world, land animals were likewise of little significance (but see 
p.180 on inshore navigation), as were, somewhat more surprisingly, fish and other sea creatures (but see p.191f., on open-sea navigation, and p.254 on weather prediction). It was birds, especially seabirds and migratory birds able to cross large expanses of sea, that were really the only living creatures with a major role in ancient seafaring, and this role pertained weather prediction and navigation. The southwards migration of different bird species marked successive stages in the onset of winter, while, conversely, the northwards migration likewise heralded the return of summer (pp.25667). From day to day, the activities of seabirds gave important clues as to the continuation or otherwise of fair weather (p.252ff.), while the flight paths of both seabirds and migratory birds, and of birds purposefully released from on board ship, were useful navigational pointers for ships out of sight of the coast (p.192f.).

\section{THE PHYSICAL ENVIRONMENT AND HUMAN TECHNOLOGY.}

\section{Interrelationships.}

It has been suggested that the congenial conditions of the Greek summer, and the regular progressions of clearly visible headlands and islands in and around the Greek seas, especially the Aegean, were instrumental in encouraging early, tentative, sea voyages, so that the Aegean environment naturally became a 'major area of innovation in ocean-going boats ${ }^{493}$. In this respect, the beneficial aspects of the physical environment can be seen to have encouraged the development of maritime technology. However, in the period with which the present study is concerned, by which time seafaring had become a commonplace not only throughout the Mediterranean but also in most of the world's oceans, it can be seen that the aspects of seafaring in which developed maritime technology had an important role were complementary to those in relation to which the physical environment was congenial and beneficial. In other words, technological innovation tended not to address navigational tasks or procedures that could be accomplished either by positively utilising the resources of the physical environment, or at least without being prohibitively hindered by the physical environment. Rather, such technological 
innovations as did occur generally facilitated the execution of navigational tasks and procedures which would have been impossible for seafarers relying solely upon their observation, interpretation, and exploitation of their physical environment.

To some extent, this may seem a rather simplistic point - clearly no sea, regardless of how attractive it may be, can be sailed upon before the technical innovation that is the boat. Nevertheless, if sailing practices are examined in closer detail, the premise still appears to hold true, and a clearer picture of the interrelationships between Greek seafarers, their physical environment, and the technology they used, emerges.

Thus the importance of land and sea breezes in facilitating sailing both in northerly directions, against the prevailing Etesians (pp.129, 222f.), and also along, towards, or away from the coast when prevailing atmospheric winds would otherwise have made such manoeuvres dangerous (p.110), is clearly related to the fact that the type of sails used on Greek ships, while capable of propelling ships into the wind, could not do so effectively enough to make tacking a practical means of sailing long distances northwards, or of undertaking complicated coastal manoeuvres with the required degree of safety and accuracy (p.244). Likewise, had land and sea breezes not enabled mariners, despite the limitations of their sails, to sail in the overall direction of their choice (if not by the most direct route), then holkades, which were in any case vulnerable to calms and to weather conditions too violent for the use of sails (p.242f.), and other merchant ships whose small crews and limited numbers of oars effectively maximised the possible sizes of cargoes and of profits, would have been so ineffective for making headway against prevailing atmospheric winds as to be completely impractical, and all merchant ships would have had to have been able to be propelled by oar as well as by sail (see also p.107ff.).

Likewise, in navigation, the lack of technological aids was balanced by exploitation of possibilities afforded by the environment ${ }^{494}$. On the open seas, close observation of the sun, stars, and winds provided an adequate, if not highly accurate, means of navigation (p.185ff.). The shortcomings of such a system, particularly the difficulty of 
measuring distances and of determining exact position (see p.188ff.), were tolerable both because of the existence of techniques for inferring the position of land that was as yet still below the horizon (pp.179ff., 190-3), and also because of the ease with which, once the coast was again in sight, the actual position could be determined by reference to conspicuous physical landmarks (pp.166ff., 190), and the intended position could be reached simply and directly by the grace of land and sea breezes (above).

Thus navigational inaccuracies or mistakes on the open seas could easily be remedied or reversed, but the same was not true in coastal waters, where such imperfect navigation left ships vulnerable to collision with obstacles that could inflict terrible damage, such as submerged or wave-washed rocks and reefs, or even the coast itself. The far greater need for accurate navigation, and the consequently more conspicuous shortcomings of such 'environmental' navigation, when sailing in coastal rather than in open-sea conditions, is reflected in the more developed technology that came to be used in coastal waters. Thus, while it seems that a mechanical device designed to compute position by reference to the stars, which would have been considerably more accurate than navigation on the open seas by eye alone, never came into widespread use by mariners (n.525), a number of technological innovations designed to facilitate safe navigation in coastal waters did clearly become standard features of the equipment used by ancient mariners. Thus the ikria, or raised foredeck, was a standard feature of Greek ships, and made the proreus' job of spotting submerged rocks a far easier one (p.71), while sounding leads brought up information about parts of the sea floor that even the proreus could not see, and were vital for the navigation of shallow coasts where a safe depth of water was only to be found in certain channels and lines of approach. A third innovation, which by its nature related only to coastal waters and the physical obstacles there that might otherwise unavoidably have been fallen foul of, was the beacon: at night, the visual signals from the physical environment, upon which accurate coastal navigation relied by day, disappeared, and so again technology was resorted to when observation and exploitation of the natural environment alone could not adequately facilitate navigation. 
In one sense, the beacon barely rates as a technological innovation at all, as its invention simply involved a new application of a very old and much used tool, namely fire. Moreover, before the invention of beacons, mariners had taken advantage of fires that had either broken out spontaneously or had been lit by the inhabitants of islands or coastal settlements for reasons unrelated to navigation (p.182, n.445). However, beacons were very significant technological devices if only for the high degree of organisation that clearly, despite our lack of information on the matter (p.182, n.440), must have been necessary for their maintenance.

When turning towards the shore, either for temporary shelter or at the end of a journey, mariners again were quite prepared to rely upon areas of shelter provided by the physical environment, rather than those constructed artificially. This was particularly the case in early times, when harbour technology was in its infancy, and was also particularly true of naval fleets on campaign, which might find local harbours either too small or too hostile to accommodate them. Generally, moreover, the speed with which storms or adverse winds often appear in the seas around Greece precluded the possibility of mariners ever relying solely upon man-made harbours, which were extremely costly (in time, resources, and finances) to construct, and so were never so numerous that one was always within easy reach (see p.95ff.). However, it was not only such negative considerations regarding man-made harbours that resulted in their not being relied upon, but also the positive attractions of the natural topography of the coast, which offered a wide variety of places where ships could shelter or be brought ashore (pp.97-105), and so pre-empted any need for any artificial harbour works, except where large maritime communities developed. Even then, the shelter provided by some natural features of coastal topography was of such size and quality that artificial alternatives were late in arriving, and often only took the form of embellishments rather than wholly new constructions (pp.110-7, esp. 112f.). The lack of tides in most areas of the Mediterranean further simplified the process of coming ashore and of setting out to sea again (p.231f.), and of navigating constricted coastal waters (p.132f.). 
There were indeed areas in which technology did develop, to a greater of lesser degree, either through the application of theoretical knowledge to practical problems, such as the design of anchors (p.237f., n.545), and of pumps for removing bilge water (p.239f. n.557), or else through the use of technology previously employed in other areas of activity, such as beacons (see p.182). There remained other areas of seafaring, however, in which the Greeks had neither the scientific knowledge nor the engineering skills necessary to create technological aids, and so had no choice but to accept the limitations imposed upon them by the physical environment.

It is also clear, however, that in some of the latter areas mariners achieved remarkable success in spite of their lack of technology. Critical to this success was a keen knowledge and observation of many aspects of their environment. Thus in weather prediction, mariners found signs in the night sky (pp.247, 250), in cloud formations (p.249f.), in the characteristics of winds and of the ways in which typical weather patterns tended to develop and change over time (pp.248f., 253, 260-4), in the behaviour of birds (pp.252ff., 56-67), of other animals (p.254), and of plants (p.267). The result was a not unsophisticated system of forecasting which, when applied by experienced mariners and constantly updated as new information or weather signs appeared (for the importance of which see pp.155ff., 246, 250ff.), could be quite reliable.

Thus various aspects of the physical environment enabled mariners to adopt navigational practices and strategies that did not require the development and use of innovative technology. Instead of relying upon technology that would overcome or erode the limitations set on their activity by the physical environment, mariners tended, whenever they could, to work within, and to exploit, the navigational possibilities afforded by the physical environment. However, while this may have been a means for mariners to maximise the efficiency of their operations while minimising the financial and technological resources required to carry out those operations, -it is also true that, as a result, maritime practices remained intimately tied to, and shaped by, the limitations imposed by the physical environment. 
Thus in weather prediction, while it was possible to foresee how conditions would develop in a given location over the stretch of a few days, it was far more difficult to predict how they would develop during long-distance voyages of many days' duration, traversing wide expanses of open sea, often between locations of very different topographical and meteorological character. Of course, initial predictions could be revised and updated as weather systems developed and as new areas were reached (pp.156f., 250f.)., but this would be of little help, for example, to a mariner who, as he reached the middle of an open-sea crossing, realised that a spell of extremely stormy weather was about to set in.

Such dependence on the physical environment, and such ties to the limitations imposed by that environment, had a particularly strong influence on two aspects of seafaring - the timing of journeys, and the routes followed: while the overall regularity and predictability of the daily and annual cycles of winds and weather in Greece made it relatively easy to plan the route and timing of a sea journey so as to minimise the risk of running into foul weather or difficult sailing conditions (pp.221ff., 243f.), the underlying necessity, given the Greeks' lack of technology for overcoming many problematic aspects of the physical environment, of avoiding many routes and times only restricted mariners 'freedom of movement'.

Thus, because ships could not sail very closely into the wind, areas where the prevailing atmospheric winds dominated over land and sea breezes were very difficult to navigate when a ship was headed towards the wind. Such areas were particularly dangerous if currents flowed in the same direction as the prevailing wind, especially if it blew towards a high, straight, lee shore, where diurnal breezes tend to be less well developed, so that ships might helplessly be blown onto it. Thus in the Aegean, winds and currents from the direction of the Hellespont advanced upon the northeast coasts of Thessaly, Euboia, and Malea, all of which were therefore given a wide berth by mariners whenever possible (pp.71f., 78-82, 122-6). Likewise, in the Adriatic, the currents flowing down the eastern shores of Italy from the north were regularly bolstered by the violent Bora, which could blow ships from any point of the Adriatic 
onto the lee shore of Italy, and caused difficulties for ships anywhere in the Adriatic (pp.80,114, 122, 125). The only way to sail such routes safely was to do so at a time when such dangerous winds could be expected to be absent. Often this was not a simple matter, though. Katabatic winds, for example, tend to spring up with little warning, and those as strong as the Bora may do so at almost any time of the day or year (pp.51, 108, 114). Meanwhile, in the Aegean, while there are indeed long periods of the year when the Etesians do not blow, other, equally violent, northerlies, such as those connected with the passage of depressions, could be commonly encountered, and posed just as great a threat (p.114f.). The result was that at some times of the year, only specific routes could be sailed. Thus the Greece-Egypt route was one of the only routes for which suitable weather conditions could generally be expected in winter (p.225). In summer, on the other hand, the routes taking advantage of the shelter to be had in the lee of the promontories and offshore islands of the east and the west coasts of the Aegean were the only means for sailing ships to reach the northern extremities of that sea against the Etesians (pp.93, 99f. 104). Likewise, some routes could only be sailed, without danger or serious difficulties and delays, at certain specific times either of the year or, where there were strongly developed diurnal breezes to be taken advantage of, of the day. One such route was that from the Aegean to the Black Sea via the Hellespont and Bosporos, which was best attempted either during the night, when the land breeze blew up the straits, or in spring, when the westerly Zephyros, or the southerlies and southwesterlies associated with passing depressions, could be used to propel ships up the straits against the forceful currents (pp.85f., 225). Holkades, in particular, were restricted to seasons and routes for which weather conditions were generally settled and favourable (p.243f.). Oared ships, being less dependent on the winds, particularly land and sea breezes, had more freedom to follow the direction of their choice, but being generally less seaworthy than sailing ships, they, too, had to be careful to avoid dangerous weather whenever possible. Moreover, because their large crews had to come ashore regularly for food and rest, oared ships were also subject to limitations, and preferred coastal routes to those over the open seas (pp.135f., 240f.). 
The lack of technology relating to navigation also imposed significant restrictions on the timing and routes of journeys, particularly because mariners, when crossing open seas, had no accurate way of measuring exactly how far, and in what mean direction, they had travelled (pp.185-90), and because generally, whether on the open sea (pp.190-3) or in coastal waters (pp.166-78) their navigation relied upon visual information. These factors, at least as much as those relating to the difficulties of weather prediction, were a disincentive to sailing at times when visibility was poor - in the dark of night (p.228), under the generally overcast skies of winter (p.224), or even during fog (pp.179, 228) or rain (n.558). Even if it was relatively safe to spend several days and nights sailing over the open seas, the inaccuracies of navigation meant that sailors could never be sure at what point and at what time they would arrive on the coast they were headed for, and so they had to be particularly vigilant, and only approach coastal areas from the open sea during daylight (pp.179, 190, 228f.; for non-visual navigation, see p.180f.). Again (see above, p.205f.), it may be noted that what little navigational technology the Greeks did have generally related to coastal navigation (the sounding lead, beacons: see p.118f., 179f., 182ff.), and this was particularly important to those who had no choice but to sail in coastal waters at night, despite the hostile environment (for these, see pp.179, 225f., 230) ${ }^{494 a}$.

Another situation in which the practice of coastal navigation by visible landmarks caused difficulties for mariners, and in which, consequently, navigational technology again developed a more important role, was when ships journeyed along low coasts, which were most commonly found in areas subject to heavy deposition of sand and other sediments, such as the west coast of the Peloponnese (pp.117-21, 131 and n.358, figs.18, 33). Navigation in such areas was not only more difficult because of the lack of visible landmarks, but also because of the danger of running aground on the shallows which typify depositional coasts (p.117f.), because of the narrowness of the channels leading to any harbourages protected by those shallows (p.119f.); shelter was generally hard to find in such areas, however, and even anchors might have difficulty in taking a hold in the soft sandy sea bed (see pp.117f., 237f.). Furthermore, areas of extensive shallows were among the few kinds of place where tidal 
fluctuations tended to be pronounced, causing further navigational complications (see p.232f.). The sounding lead was vitally important in such coastal areas (p.117f.), and the lack of visible landmarks was partially compensated by a further type of artificial 'technology', in the form of the temples, tombs, and towers erected on low shores, particularly on headlands and at the entrances to harbours. These were all used both as landmarks and as leading marks (see p.173ff. and n.425).

Thus, given the state of ancient navigational technology, the physical environment imposed limitations on the times at which, and the routes by which, sea journeys could be safely accomplished. Evidence of these limitations may also be found in the activities of pirates, who, as a result of the restricted timings and routes used by mariners, knew where best to station themselves in order to intercept commercial shipping (see pp.139, 157f.).

\section{Knowledge of the local environment.}

Because ancient Greek seafaring was thus both restricted by the limitations imposed by the physical environment, and also dependent upon the possibilities and resources afforded by that environment, an intimate knowledge and understanding of the physical environment became any seafarer's most important tool. The value of such knowledge in ancient seafaring can be most clearly illustrated by reference to the problems encountered by mariners when they arrived not simply in unknown waters, but in waters where the physical environment itself differed in one or more important respects from their native waters.

Thus, as has already been discussed (p.232f.), the Argonauts were supposed to have encountered enormous difficulties, which they felt helpless to overcome, in the Gulf of Syrtis, where the confusion caused by tides stronger than those found almost anywhere else in the Mediterranean was increased by the extensive shallows which are another problematic feature of that gulf. Similarly, for those mariners who occasionally attempted to pass through the Straits of Gibraltar, the strong tides and currents, the high seas, and the increased cloud cover encountered in the Atlantic 
were strong disincentives (p.231ff. and n.532). The ancient Greeks' maritime technology developed within, and so was most compatible with, the Mediterranean environment (pp.237, 243ff.). Moreover, mariners' familiarity with that environment made vital skills such as weather forecasting far better informed and more reliable than when mariners found themselves in an unfamiliar environment (see p.248). Just as mariners in unfamiliar environments made up for their lack of local knowledge by enlisting native inhabitants as pilots (see below), so they compensated for their inability to interpret the different and often unfamiliar weather signs by seeking the advice of those who lived locally. Theophrastos states the basic principle:

'Wherefore, good heed must be taken to the local conditions of the region
in which one is placed. It is indeed always possible to find such an
observer, and the signs learnt from such persons are the most
trustworthy.' (Theophr.Signs.3)

Similarly, by illustrating the problems encountered by non-Greek mariners when sailing in Greek waters, it can be shown that the success of the Greeks in navigating their native seas was due less to the safety and congeniality of the local marine environment than to Greek mariners' deep familiarity with, and understanding of, that environment.

Thus, in their invasions of Greece during the early fifth century BC, the Persians suffered a number of serious setbacks at sea as a direct result of their unfamiliarity with the physical environment. Despite the fact that Darius had earlier sent out a reconnaissance party which must have encountered the various northerlies which prevail at nearly all times of the year, the Persian fleet advancing along the north coast of the Aegean in $490 \mathrm{BC}$ made the mistake of following the coast around the northeast coast of the Athos peninsula in the Chalkidike: when the northerly Boreas struck up, the Persian ships were helpless to avoid being cast against the rocky shore of the promontory, and the Persian fleet was seriously weakened (p.77f.). The following year, Darius took the alternative route through the Cyclades (Hdt.6.95), but the use of Hippias, the son of Peisistratos, as a guide for the Persian fleet headed for 
Marathon (Hdt.6.102, 107), must at least partly have been motivated by the Persians' continuing lack of familiarity with Aegean geography ${ }^{495}$.

Xerxes signalled his equally poor understanding of the Aegean environment when, in $480 \mathrm{BC}$, he attempted to avoid the disaster that had earlier struck Darius solely by digging a canal through the base of the Athos peninsula, as if Athos were in some way a uniquely stormy point in the Aegean, and that, once passed, the rest of the route would be free from danger. Rather than being unique, however, Athos is typical, as most promontories in the north and west Aegean stretch southeastwards, and so present a long northeastwards-facing rockbound flank against which the prevailing northerly and northeasterly winds strike at full force off the sea. Thus, when storms broke off the northeast coasts first of Magnesia and then of Euboia, Xerxes' own fleet met much the same fate as that of Darius had (pp.71, 78, 125f.).

In the same area, as the Persian fleet advanced towards Artemision, more casualties were suffered when ships fell foul of 'the Ant', a low reef in the channel between Skiathos and Magnesia. Even after they had thus discovered the presence of the hazard, the Persians still had to enlist the help of a local Greek from Skyros to relocate it, in order to mark its position with a stele (p.94). The Persians also availed themselves of local knowledge in order to navigate the Euboian Sound, where, apparently, the winding channels nevertheless so confused them that they put Salganeus, their Greek pilot, to death ${ }^{496}$. On the return journey, if Herodotos is to be believed, Xerxes again courted disaster from northerly winds in the northern Aegean, conditions which Greek mariners knew to avoid (p.114f.).

In such situations, whichever fleet had the greater familiarity with the local environment often did not simply hope that its less well-informed adversary would encounter difficulties, but actively employed any strategy it could to maximise those difficulties. Thus it should not be assumed that, during the Persian invasions, Artemision was chosen as the point at which the Greek fleet would position its defence simply because this was the best choice in terms of providing support and 
security for the land forces at Thermopylai. Rather, it was imperative for the Greeks to fight within the confines of a strait, as they also did later in the campaign at Salamis $^{497}$, and, more importantly still, such a position denied the Persian fleet access to the Euboian Sound, where the protection from wind afforded by the heights of Euboia and the size of bays such as Aulis, would have provided even a fleet as large as the Persians' with ample shelter. By holding Artemision, the Greeks forced the Persian fleet to remain in an area where local topography made navigation and routefinding particularly problematic for the foreign invaders (see p.94 and n.272 above for discussion of these aspects of the Euboian Sound), and where the Persians had no choice but to moor off a coast where they were hopelessly vulnerable to the prevailing northerly winds, which in due course took their toll. Herodotos does not actually state that this was a part of Greek strategy, but he suggests as much in the speech he places in the mouth of Artabanus, warning Xerxes of the difficulty of finding harbours large enough to shelter his fleet in the Aegean (Hdt.7.49: see pp.20f., 96), and in his accounts of the Delphic oracle's advice to the Greeks to pray to the winds (Hdt.7.178), and of the Athenians' invocations to Boreas, which were apparently motivated to some extent by their realisation of the Persian fleet's vulnerability to such northerly winds (Hdt.7.189).

Even in battles between rival Greek forces, one side's superior knowledge of the local environment was an advantage that often proved decisive. Thus, while Themistocles chose to fight the Persians in the strait of Salamis, at a time of day when conditions would be most detrimental to the Persian fleet (p.89f.), Phormio similarly chose the site and time of his battles at the entrance to the Corinthian Gulf in $427 \mathrm{BC}$ in such a way as to maximise his fleet's advantage over the less well trained crews of the opposing Peloponnesian fleet (p.87ff.): Thucydides stresses the difficulties that the Peloponnesian crews encountered in dealing with the rough waters raised by the diurnal breezes there (Thuc.2.84), and later mentions how some of the Peloponnesian crews, being unfamiliar with the local waters, ran aground in the shallows (Thuc. 2.91.4) ${ }^{498}$. 
Similarly, katabatic winds blowing from the high land of Asia Minor down onto the straits separating that land mass from offshore islands of the eastern Aegean proved decisive factors in two naval battles: an Athenian fleet attacking Chian triremes in the Chian strait in $427 \mathrm{BC}$, and a Mithridatic fleet attacking Rhodes in $88 \mathrm{BC}$, both failed to predict, or to cope with, the onset of such winds, and their adversaries, having a better understanding of local wind conditions, quickly took advantage of the resulting confusion and so repulsed the attacks (see p.91f.). So too Diodorus Siculus (13.39f.) states that the Athenian defeat of a Peloponnesian fleet in the narrowest part of the Hellespont, between Sestos and Abydos, in 411 BC was largely the result of the greater experience of the Athenian helmsmen, who were better able to cope with the strengthened current there ${ }^{499}$. In the Adriatic, where Greek mariners tended to find the topography and sailing conditions dangerous and confusing (pp.80, 114, 132, nn.242, $325)$, the local Illyrians exploited their greater familiarity with the topography and weather conditions, and so became successful pirates (n.368).

Just as local knowledge could be a decisive factor in naval battles, so too it was one of the mariner's greatest weapons in his battle with the elements. Navigation in particular relied heavily upon mariners' ability to recognise both natural and artificial landmarks, and to know their relative positions (pp.146, 166-78, 184). The importance of such knowledge is reflected both by the fact that the crew member responsible for spotting such landmarks, the proreus, was second in rank only to the helmsman (kubernetes) (p.166), and also by the considerable evidence that mariners adopted various strategies to enable them to remember the appearance, identity, and location of different landmarks more easily (pp.168-91, n.422). Local knowledge was particularly important in the navigation of the approaches to harbours and anchorages, because of the danger of grounding on rocks and reefs (see, for example, p.70f.

(Paus.2.29.6 on the dangers Aigina's offshore rocks and reefs posed to non-Aiginetan mariners)), or on shallows (p.119f.). Even the sounding lead was a far more effective tool in the hands of mariners whose local knowledge of the contours and composition of the sea floor allowed them to interpret the information provided by the sounding lead far more effectively (p.179f., n.435). 
Local knowledge was also important, say, when dangerous weather conditions developed, and mariners had to know where shelter could be found most easily and quickly. Moreover, a strongly developed knowledge of all aspects of the local environment could help mariners to avoid being caught in such dangerous weather conditions in the first place; despite the lack of forecasting technology, mariners familiar with local weather conditions (not only with the different winds, but with particular cloud formations and typical patterns and cycles of weather - see pp.24852), and with the weather-related activity of local seabirds (p.246ff.) and other animals (p.254), could often predict weather patterns for the near future well enough to avoid embarking upon journeys along routes upon which they were likely to fall foul of the weather. In particular, information derived from local knowledge of the environment in which a journey was to take place would form the basis upon which mariners decided whether to follow a more direct 'open sea' route, or a longer, but potentially faster and safer, 'coastal' route (see pp.127-139). Here it should be remembered that routes were essentially defined and characterised not by some rigid or conceptual distinction between 'coastal' and open sea' sailing, but by the various navigational strategies open to ancient mariners in the Mediterranean environment. Which of these strategies were employed on a given voyage depended upon a mariner's prior knowledge, and ongoing observation, of the local environment, according to which he would attempt to foresee the sailing conditions and weather conditions that he was likely to encounter, and so decide on the best way of sailing from his home port to his final destination (pp.139-42). The contrast between 'coastal' and 'open sea' routes appears even more artificial in the light of the practice of sailing across the mouths of gulfs of any size (see pp.154-61), and also of the relatively common practice of changing the planned route as weather and sailing conditions were observed to change during the course of a voyage (see pp.156f., 250f.). Such local knowledge and observation of the environment was especially important during periods of the year when weather conditions were particularly changeable (see pp.254-67). 
Thus mariners who found themselves in areas or conditions that were highly unfamiliar to them were seriously disadvantaged. As a counter this, sailing directions and other information was transmitted orally among mariners, and, from the sixth century BC or earlier, recorded in written form as periploi (pp.161, 187, n.394). Even more useful to mariners in such unfamiliar surroundings were local pilots

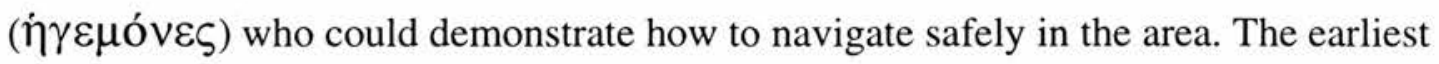
literary mention of such pilots, Hom.Od.10.487-51 $5^{500}$, describes clearly the anxiety mariners felt about entering unknown waters without a local guide: when Kirke advises Odysseus that, before he can reach Ithaka, he must travel to Hades (Od.10.487-495), Odysseus is horrified, and wonders who will be able to guide him to Hades, given that no-one has previously sailed there (Od.10.496-502). Kirke,

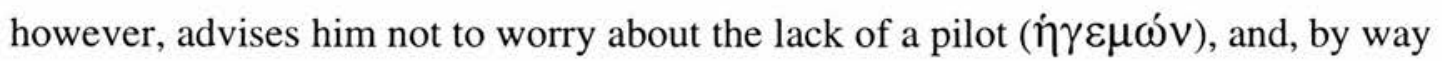
of an alternative, describes to him the wind with which he can sail to Hades, and the landmarks by reference to which he can be sure to follow the right route (Od.10.503515). Such information, it may be noted, is typical of the sailing directions used throughout antiquity (see pp.145, 167ff. (landmarks), 186f. (winds)). Another early tradition emphasising the importance of pilots is the story of the colonisation of Kyrene from Thera. When instructed to found a colony in Libya, 'they neglected to obey the oracle, seeing that they knew not where Libya was, and feared to send a colony out to an uncertain goal' (Hdt.4.150). The colony was eventually sent out only after the Theraeans had encountered the Cretan Korobios, "who told them that he had once been driven out of his course by winds to Libya, to an island there called Platea. This man they hired to come with them to Thera; thence but a few men were first sent on shipboard to spy out the land, who, being guided by Korobios to the aforesaid island Platea...sailed back with all speed to Thera to bring news of the island' (Hdt.4.151).

Darius' and Xerxes' employment of local Greeks, in order to help them navigate the highly indented and unfamiliar coasts of Greece, has already been discussed ${ }^{501}$. The Argonauts, likewise sailing on a journey into relatively unknown lands, were also held to have made use of local knowledge whenever possible: Phineus describes the 
landmarks and the dangers along the whole route from the Propontis to Kolchis (Ap.Rhod.Arg.2.317-407; compare Kirke's directions to Odysseus at Hom.Od.12.37ff.), and before reaching Kolchis, the Argonauts meet the sons of Phrixus, who then act as their guides for the last part of the outward journey (Ap.Rhod.Arg.2.1192-5). Later, the Argonauts became stranded in the Tritonian Lake, and after searching aimlessly for a route out, they summon Triton (Ap.Rhod.Arg.4.1537-53), whose reply again emphasises the helplessness of those sailing in unknown waters, and the consequent value of the intimate knowledge of local inhabitants:

'...But if you are searching for a passage through this sea, as often is the need of men passing through a strange land, I will declare it. For my sire Poseidon has made me to be well versed in this sea.'

(Ap.Rhod.Arg.4.1556-9; compare Hdt.4.179, quoted at p.119)

So too in the historical period, Greeks made use of local pilots in Africa and other areas of the Mediterranean that they rarely visited, and which were markedly different from Greece ${ }^{502}$. Thus when Peloponnesian ships headed for Sicily during the Peloponnesian War were blown off course to Libya, they used Kyrenaian pilots to guide them along the African coast to Neapolis, from where they crossed to Sicily (see Thuc.7.50, quoted at p.145). Similarly, when, during a voyage from Alexandria westwards along the coast of Africa, the ship carrying Bishop Synesius became grounded on a coastal reef (see p.138f.), local knowledge, first in the form of advice, then in actual pilotage, was again required in order to bring the ship to a safe anchorage:

'Now when day appeared, a man in rustic garb signalled and pointed out which were the places of danger, and those that we might approach in safety. Finally he came out to us...took over the tiller....and brought her to anchor in a delightful little harbour, Azarium.' (Synesius Letters.4)

Pilotage services were no doubt eventually organised at Mediterranean ports with difficult entrances, as they were in other waters to which the Greeks sailed: in the following passage, the rocky and current-washed headlands enclosing the Indian port 
of Barygaza are reminiscent of those of the Mediterranean (see above, pp.69-73), and were dangerously awkward to navigate, except for those who regularly worked in the waters nearby (compare Pol.4.39ff. on the use of pilots in the Maiotis (quoted above, p.120)):

'The voyage...from Barbarikon to the promontory near Astakapra across from Barygaza called Papike is 3000 stades....The gulf which leads to Barygaza, since it is narrow, is hard for vessels coming from seaward to manage......For on the right hand side, at the very mouth of the gulf, there extends a rough and rock strewn reef called Herone.....on the left hand side is the promontory called Papike; mooring here is difficult because of the current around it.....For this reason local fishermen in the king's service come out with crews and long ships....to meet vessels and guide them up to Barygaza.' (Per.Maris.Eryth.41-44 (1C AD))

Thus it can be seen that, in nearly every aspect of ancient Greek seafaring, the physical environment had an important role. By its very nature, the environment restricted and limited the extent to which mariners were free to travel the seas, and often presented seafarers with very difficult or dangerous conditions. Yet, and possibly even because the activities of seafarers were thus so affected, even governed, by the environment, it was also the environment, and mariners' familiarity with it, that was most often the key to overcoming the dangers and difficulties that seafarers so commonly faced. Similarly, it was specifically by exploiting the environment that mariners, within the limitations set upon them by the environment and by the maritime technology of the time, achieved the great success and diversity of activity which characterises ancient Greek seafaring. In navigation, in seeking secure shelter, in finding ways to sail towards regions from which prevailing winds blew, in planning both local and long-distance routes, in weather forecasting, in naval battles, and in many other activities, the successful methods or strategies developed by the Greeks were nearly always based upon an extensive knowledge and exploitation of their physical environment.

I hope, in this thesis, to have shown how the activities of ancient seafarers were generally strongly conditioned by the topography, meteorology, and oceanography of 
the seas and coasts around which they sailed. Few specific geographical areas or historical events have been given the attention that they might individually merit elsewhere, but this was inevitable given the nature of the thesis. However, I hope that, by establishing the wide-ranging significance of the environment in ancient seafaring, this thesis may facilitate future studies of the historical geography of specific areas, and likewise of the significance of the physical environment in specific historical events.

Indeed it is quite natural for me to see the thesis having such a role, for that was the original aim of this line of research. A study of the significance, to seafarers, of the typical topographical features of the Greek coasts, was originally envisaged simply as one approach to ascertaining the possible significance of the siting of coastal sanctuaries of Poseidon. At that stage, I anticipated that the headlands, straits, harbour entrances, and other coastal sites at which sanctuaries of Poseidon and other deities were situated would prove to have been areas of some difficulty and, indeed, danger for mariners. This indeed proved to be the case. However, I did not anticipate the degree to which headlands and other features of coastal topography were of great, and beneficial, significance to mariners, especially in facilitating navigation. Similarly, while it was clear from the outset that there were many other ways in which the physical environment generally made life difficult for mariners, I did not foresee drawing together so many other ways in which mariners, rather than relying heavily upon maritime technology, instead relied upon their detailed understanding and careful interpretation of a great variety of aspects of their physical environment. The combination of rationalism, superstition, and religion which informs Greek seafarers' understanding of their environment seems, to me, to be characteristic of an outlook upon the world shared by ancient Greeks generally, as does the concerted effort mariners undertook to integrate such an interpretation of their environment into their daily lives. It is this near fascination with the physical environment, and the desire to understand its nature, not simply for the sake of knowledge but as a means of ascertaining the best way for men to conduct their activities within that environment, that, for me, leaves the most abiding impression. 


\section{APPENDIX ONE: Sailing seasons, winter sailing, and night sailing.}

\section{The sailing season.}

In ancient seafaring, wintertime and night-time were the most commonly avoided periods, for obvious reasons. The stark meteorological contrasts between the summer and the winter seasons in the eastern Mediterranean (for which see p.48ff.) led to the summer generally being equated with the sailing season, and the winter generally with dangerous conditions during which sea voyages were not recommended ${ }^{503}$.

While, even during the summer months, all parts of the Mediterranean were at times subject to very strong winds and stormy conditions, the degree to which the daily and annual cycles of winds and weather were regular and predictable, especially during summer (pp.48ff., $52 \mathrm{ff}$.), made it relatively easy to plan the route and timing of a sea journey so as to minimise the risk of running into foul weather or difficult sailing conditions. Thus Strabo comments on sailing conditions and winds in the Mediterranean, with particular reference to the seas between Italy and Iberia ${ }^{504}$ :

'For the sea routes all pass through a zone of fair weather, particularly if the sailor keeps to the high seas; and this fact is advantageous to the merchant freighters. And further, the winds on the high seas are regular.... Poseidonius says that he observed a peculiar circumstance on his return voyage from Iberia, namely that the east winds on that sea.......blew at a fixed time each year.' (Str.Geog.3.2.5)

Every bit as regular as these easterly winds were the Aegean's northerly or northeasterly winds, the Etesians, which blew steadily during the summer months (p.49f., fig.41) ${ }^{505}$. Generally accompanied by clear skies and fair conditions, the Etesians could be relied upon by even the most cautious of sailors ${ }^{506}$ :

'Fifty days after the solstice, when the season of wearisome heat has come to an end, is the right time for men to go sailing, Then you will not wreck your ship, nor will the sea destroy the sailors, unless Poseidon the Earthshaker be set upon it, or Zeus the king of the deathless gods, wish to slay them; for the issues of good and evil alike are with them. At that time the winds are steady, and the sea is harmless. Then trust in the winds without care, and haul your swift ship down to the sea and put all the 
freight on board. But make all haste you can to return home again and do not wait till the time of the new wine and autumn rain and oncoming storms with the fierce gales of Notos who accompanies the heavy autumn rain of Zeus and stirs up the sea and makes the deep dangerous.'

(Hes.W\&D.663-677)

The 'steady' winds are of course the northerly Etesians, here contrasted with the southerly Notos. Hesiod is right to regard the advent of Notos as both heralding the end of summer and also being a wise time to cease seafaring, because these southerly winds generally only appear in conjunction with depressions crossing the Mediterranean, often bringing heavy cloud, rain, and storms with them (see pp.48f., 50f.). Thus the summer months, when the Etesians held sway, comprised the sailing season proper in the Mediterranean, and this is essentially true of the whole of the ancient period; although its opening tended gradually to be pushed further and further back into spring, and its close later and later into autumn, as ship design, knowledge of weather conditions and navigation techniques slowly improved ${ }^{507}$, sailing in the Mediterranean in ancient times was, whenever practicable, timed to avoid those times when stormy depressions were most likely arrive from the Atlantic or from southern Europe.

During the summer months, however, when the Etesians were blowing, sailing, particularly towards the south or the west (i.e. with a steady following wind), was generally a simple affair, and even in Homer's time, trips from Crete to Egypt and from Phoenicia to Libya were seen as standard routes ${ }^{508}$. Sailing to the north or the east, against the prevailing wind, was less straightforward ${ }^{509}$, but the strong land and sea breezes which developed strongly and at predictable times in coastal areas (pp.526) could be used to make headway ${ }^{510}$, especially in areas where shelter from the Etesians could be found in the lee of promontories or islands. Thus one important route ran up the west coast of Asia Minor, where land and sea breezes blew strongly through the deep bays lying between the long east-west oriented promontories which typify that coast (p.21), and where those promontories, along with the many nearby islands of the eastern Aegean, also provided shelter from the Etesians ${ }^{511}$. Similarly the sound separating Euboia from mainland Greece (fig.47) was an important corridor for 
north-bound shipping in the Aegean during the summer months, as was noted by Theophrastos ${ }^{512}$.

Land and sea breezes also facilitated leaving harbour at night or in the early morning, and returning to land in the evening, in areas where the Etesians would otherwise have made such access to harbours difficult or dangerous (see p.109f.). The combination of the Etesians with steady and regular land and sea breezes, then, provided congenial sailing conditions for ancient Greek sailors in the summer months. One further way in which navigation was facilitated by the steady summer conditions of the Mediterranean was that clear skies could be depended upon, leaving coastal landmarks unobscured, and sun (or stars) always in sight as an aid to navigation and reckoning the time of day ${ }^{513}$.

\section{Winter sailing.}

While the sailing season proper was held to end with the arrival of winter and the appearance of the first depressions from the west, it is clear that the seas around Greece were far from devoid of shipping from that point of the year until summer conditions reasserted themselves around the following May. Rather, sailing continued, but was approached with considerably more caution and even trepidation once summer conditions had weakened to such an extent that more stormy conditions might be expected to develop at any time. The heightened anxiety of those still sailing the seas as winter began to arrive is clearly described, for example, by Bishop Synesius, and by Theocritus ${ }^{514}$ :

'It was the thirteenth day of the waning moon and a great danger was now impending, I mean the conjunction of certain constellations and those well known chance events which no-one, they say, ever confronted at sea with impunity. So at the very moment we should have stayed in harbour we so far forgot ourselves as to run out again to sea. The storm opened....' (Synesius Letters 4)

'Fair voyage to Mytilene shall Ageanax have when the Kids stand in the evening sky, and the south wind speeds the wet waves, and when Orion stays his feet on the wet ocean, if....the halkyons shall lay to rest the waves and the deep, the south wind and the east that stirs the seaweed in 
the lowest depths, the halkyons, birds most dear to the green Nereids and to them whose prey is from the sea. Ageanax seeks passage to Mytilene; may all things favour him, and fair weather attend him to his haven.'

(Theoc.Id.7.52-62)

Elsewhere Theocritus gives a vivid description of a ship caught in a winter storm at night:

'....the two brothers born in Lakonia to Thestius' daughter, who succour... ships which, defying the constellations that set and rise into the heavens, encounter grievous tempests - blasts that raise a huge wave from astern, or from ahead, or from where they will, and cast it into the hold, and breach the bulwarks on either side. And with the sail hangs all the tackle, torn and in disarray, and as the night comes on with heavy storms of rain, the wide sea roars beneath the blows of the blasts, and of the iron hail. Yet even so from the very depths do ye recover ships with their crews that thought to die. And forthwith the winds are stilled and an oily calm lies on the deep. The clouds disperse this way and that; the Bears are seen again, and between the Asses the dim Crib betokening that all is fair for voyaging.' (Theoc.Id.22.4-22 (parts))

Here, at the end of the passage, Theocritus picks up on another potentially serious disincentive to winter sailing, in addition to the danger of shipwreck in stormy conditions: this was the greatly increased degree of cloud cover generally seen, which obscured coastal landmarks and the sun (or, as here, the stars at night), making navigation a far more difficult task ${ }^{515}$. Another problem was that winds tend to change direction far more often and with far less warning in winter than in summer: this made weather prediction more difficult, and obliged sailors to find routes which would be safe and practical even if winds changed direction, and to find sheltering places protected from all, or at least most, likely wind directions (see p.106ff.).

The increased danger of sea travel in this season is reflected in the terms of Athenian maritime loans in the fifth century BC, in one of which it was stated that interest was to be paid:

'at a rate of two hundred and twenty-five drachma on the thousand; but if they should sail out from the Pontos to Hieron after the rising of Arcturus 
[mid-Sept.] at three hundred on the thousand, on the security of three thousand jars of Mende wine....' (Dem.35.10)

Here the higher rate of interest to be paid after the rising of Arcturus (one of the astronomical events which signified the end of the sailing season: see below, p.247) reflects the greater risk taken by the creditor in funding a venture so late in the year. Nevertheless evidence such as this also bears witness to the fact that a significant amount of sailing did take place on the Greek seas during the winter months. Similarly, Aratos' warning (Phaen.300ff.) to sailors that from November onwards they should not trust the night and should put to shore at evening also seems to imply that sailing by day at this time of year was still considered relatively safe and was commonly undertaken during the winter months.

One safe winter sailing route ran between Greece and Egypt, exploiting the strong northerlies sweeping across the Mediterranean from the high continental interiors of Europe and Asia Minor on the southbound leg, and the southerly Sirocco on the return, northbound, leg. In their absence, land and sea breezes along the eastern shores of the Mediterranean could be relied upon ${ }^{516}$. The evidence normally cited for this winter route is Dem.56.30, where it is stated that mercantile voyages to Egypt from Rhodes continued uninterrupted throughout winter, but earlier evidence for this winter route is contained in Pind.I.2.39-42, where Xenocrates of Akragas is described as sailing as far as the River Phasis in the Black Sea during summers, and as far as the Nile in winters. Using the southerly winds of spring and autumn to ease passage through the Hellespont, Bosporos, and other northwards passages (see p.85f.) was another incentive to sailing outside of the sailing season proper.

Moreover, merchant shippers clearly were not the only ones who were inclined at times to think that the potential advantages of continuing to sail after the end of the sailing season outweighed the risks: for tactical reasons fleets might be prepared (or forced) to endure hardship and even risk catastrophe by staying out on active service after the end of the sailing season proper (e.g. Dem.50.22ff. (quoted on p.96), where the trireme is also forced to stay out at sea overnight), or even by setting off on 
campaign in midwinter (Thuc.8.39). The Spartans stranded on Sphakteria during the Peloponnesian War were expected specifically to await the bad weather of winter before attempting to escape from the island by ship (Thuc.4.27.1). Likewise, fishing for certain marine species clearly continued throughout the winter months, especially for the valuable murex, which provided purple dye but could only be harvested in autumn and winter ${ }^{517}$. Sophocles possibly best summarises the ancient attitude towards winter sailing - a formidable challenge which is nevertheless taken up by formidable sailors:

'Many things are formidable, and none more formidable than man! He crosses the gray sea beneath [Notos,] the winter wind, passing beneath the surges that surround him...' (Soph.Ant.332-7)

\section{Night sailing}

As with winter sailing, night sailing also had a bad reputation - witness the objections of Odysseus' crew when he suggests a night voyage, and the fear displayed by the Argonauts as they sailed through the night, attempting to reach Greece from Crete:

'It is from the night that fierce winds are born, wreckers of ships. How could one escape utter destruction, if haply there should suddenly come a blast of Notos or of the blustering West wind [Zephyros], which oftenest wreck ships in despite of the sovereign gods?' (Hom.Od.12.286-90)

'But after, as they sped over the wide Cretan sea, night scared them, that night which they call the Pall of Darkness; the stars pierced not that fatal night nor the beams of the moon, but black chaos descended from heaven, or haply some other darkness came, rising from the nethermost depths. And the heroes knew not whether they drifted in Hades or on the waters; but they committed their return to the sea, in helpless doubt whither it was bearing them. But Jason raised his hands and cried to Phoebos with mighty voice, calling on him to save them; and the tears ran down in his distress.... And quickly, O son of Leto, swift to hear, did you come down from heaven to the Melantian rocks, which lie there in the sea. Then darting upon one of the twin peaks, you raised aloft in your right hand your golden bow, and the bow flashed a dazzling beam all around. And to their sight appeared a small island of the Sporades, over against the tiny isle Hippuris, and there they cast anchor and stayed.'

(Ap.Rhod.Arg.4.1696-1720) 
However it would be wrong to state categorically that night sailing was avoided unless absolutely necessary. In fact, if we discount instances involving triremes and other galleys, which, whenever possible, had to come ashore overnight to properly feed and rest the crew, and to replenish supplies of food and, particularly, of water (see p.241), night sailing in itself is rarely described in such negative terms as in the passages from the Odyssey and the Argonautica just referred to. Indeed the Odyssey itself is the source of various examples of overnight sea journeys, some of which last for not just one night, but for as many as five, six, or even nine consecutive nights ${ }^{518}$. In the historical period, all long-distance voyages across the open seas, principally by merchant ships but also occasionally by galleys ${ }^{519}$, to Africa, Italy, Sicily, and elsewhere, must have entailed overnight sailing as a matter of course. Thus, for example, Dem.32.5f. describes the death of Hegestratos when, during the night, he jumps overboard from a ship which had left Syracuse and was already 'two or three days sail from land'. Throughout the archaic and classical periods such commercial voyages must have been undertaken with great regularity during the summer months, and even during winter in the case of long-distance routes which could be sailed yearround (for winter voyages to Egypt, for example, see above, p.225).

Generally, however, night sailing during winter was avoided (but see, for example, Theoc.Id.22.4-22 (p.224 above), Dem.50.22f. (pp.96, 225): as noted above (p.225) Aratos (Phaen.300ff.) recommends that from November onwards sailors should not trust the night and should put to shore at evening; this implies that during the more settled conditions of summer, night sailing was considered relatively safe, and was commonly undertaken. Rouge has also illustrated the routine nature of night sailing by reference to 'the topos of the pilot guiding his ship by the stars and ensuring a safe crossing while everyone else was asleep ${ }^{520}$. Ancient historians have long noted that the Greeks navigated by the stars ${ }^{521}$, a practice which also implies considerable experience of night-time sailing (see p.185f.).

Navigation by the stars, however, was only possible under clear skies ${ }^{522}$. We have already noted (p.224) that the difficulty of navigation under the cloudier skies 
associated with the winter climate acted as a disincentive to sailing during this season, and particularly to night sailing, when coastal landmarks other than beacons were also obscured (for beacons, see p.182ff.): we may note that the dismay of the Argonauts in Ap.Rhod.Arg.4.1696-1720 (above, p.226), is due specifically to the obscuring of the stars and moon, and that salvation comes in the form of a beacon provided by Apollo.

Whenever the night sky remained clear, however, sailing in the dark seems not to have been precluded because of any difficulty in navigating over long distances ${ }^{523}$. Rather, the main disincentive appears to have been that in the darkness, particularly in the absence even of moonlight, it was far more difficult to spot local signs of danger far enough in advance to be able to take effective evasive action. Thus, in Hom.Od.12.286-90 (quoted above, p.226:), the crew's main complaint relates not to navigation, but to the danger that they may be taken unawares by squalling winds, the approach of which, during daylight, would have been visible by the white crests and the wave patterns produced by the wind's striking the surface of the sea (for which see fig.47.ii) ${ }^{524}$. Similarly other hazards, such as rocks, reefs, and sandbanks were harder to spot; during another night voyage episode (Hom.Od.9.142-8, quoted above, p.181), the combination of darkness, cloud cover, and fog (for fog formation at night see p.61) lead to the crew failing even to notice the sizeable island they are approaching.

As such obstacles and dangers, including squalls, are generally associated with coastal waters (cf. pp.24, 28ff., 31f., 58ff., 63ff., 129f.), and as, in darkness, the coast itself is an obstacle that can be unintentionally struck (p.179ff.) it is probably fair to say that night sailing was far more commonly and safely undertaken on open-sea voyages than on coastwise journeys. This would also accord with the literary evidence available for night-time sailing, which refers primarily (but far from exclusively: see p.179, and below, p.229f.) to long-distance overseas routes. Coastal stretches on such routes would still have been completed by day: the ship and its crew would aim to set sail and depart from the coast during daylight, pass one or more nights on the open seas, and then make landfall near the port of destination again during daylight. Thus, in an 
episode of the Peloponnesian War, during which a force of Peloponnesian troops headed for Sicily had been blown off course to Libya, the route and timing of the crossing from the north coast of Africa to Sicily most favoured by local mariners was such that ships left the African coast in daylight, were on the open sea during the whole of the night, and reached the Sicilian coast in the light of the following day:

'Bad weather had carried them to Libya. The people of Kyrene had given them two triremes with pilots and...they had gone along the coast to Neapolis..... from which there is the most direct crossing to Sicily, a voyage of only two days and a night.' (Thuc.7.50)

Lacking any navigational instruments apart from the sounding lead ( $\beta$ o $\lambda \hat{i} \zeta$, $\kappa \alpha \tau \alpha \pi \varepsilon(\pi \Uparrow \eta \tau \eta \rho i \eta)^{525}$, it was especially important that ancient Greek ships making landfall after having traversed a wide stretch of sea did so during daylight hours, so that the precise point on the foreign shore at which landfall had been made could be ascertained, and so that crews could be aware of any dangerous coastal or off-shore features in the vicinity ${ }^{526}$. Even for ships which had been blown off course by bad weather and were lost at sea, reaching the coast during daylight was still never a matter left to chance: the crew of the ship taking Paul to Rome somehow realised that land was approaching even though it was night-time, and they had not been taking any soundings (Acts of the Apostles 27.27f: the passage is quoted on p.117; for possible ways in which the sailors might have foreseen the approaching land, see p.180f.). Fearing being cast against a rocky shore, the sailors let out anchors (Acts 27.29ff) and wait for morning, when we are specifically told (Acts 27.39) that the crew immediately try both to recognise the coastline, and to identify a point at which they might come ashore safely.

While night sailing might most safely have been accomplished on the open seas, clearly it was not uncommonly also undertaken in coastal waters, especially for strategic reasons. Thus one common traditional fishing technique, used to catch a variety of species, demanded the fishermen work at night, when they would use lights carried aboard their boats to attract the fish in the surrounding waters ${ }^{527}$. Fishing for 
tunny was sometimes carried out at night without even the aid of a light (cf. Hdt.1.62, Opp.Hal.4.640): tunny were apparently attracted to the full moon (Arist.H.A. 599b16f.), and so approached the surface waters, presumably in the same way that other fish did so in response to the firelights carried in the fishermen's' boats.

Triremes also occasionally had to stay at sea in coastal waters through the night, when unable to land due to either the hostility of the local inhabitants, or the nature of the shore itself (see Dem.50.22f., quoted on p.96), or in order to escape enemy ships in the area, or to gain some tactical advantage against them (pp.87ff., 179). Naval or mercantile craft might also have put out to sea in darkness in order to exploit sometimes advantageous aspects of night-time conditions, such as land breezes (see p.109f.). In fact, scholars such as Zimmern have argued that a great deal of sailing took place at night specifically because of the advantages that the land breeze offerred $^{528}$. Zimmern based his arguments on passages such as Hom.Od.2.388, 4.786, where first Telemachos and then Penelope's suitors leave Ithaka after sunset. However, these passages do not specifically refer to the land breeze, and other motives for night sailing may be understood here, such as secrecy; Neumann is also correct to note that the phrase 'after sunset' is not necessarily reconcilable with the land breeze, which actually sets in around three hours after sunset ${ }^{529}$. Nevertheless, Neumann demonstrates the existence of the practice, at least in the third century AD, through reference to Heliodorus of Emesa's Ethiopian Story 4.16, where a Phoenician merchant clearly states that 'the night time is the most advantageous for sailing, because vessels are then sped on their way by land breezes which raise no great swell. $^{, 530}$. 
APPENDIX TWO: The seaworthiness of ancient Greek ships, in the context of the Mediterranean environment.

This appendix sets the subject matter of the main chapters into a wider context. While the main topics addressed here strictly do not fall within the scope of the main thesis, their discussion will facilitate a better understanding of the specific problems which faced ancient Greek seafarers, and of the solutions that were found to those problems.

Firstly the Mediterranean maritime environment is discussed, comparing general aspects of that sea's oceanography and meteorology with equivalent aspects of the world's oceans. Then, after a brief overview of common ancient Greek attitudes to the sea and to seafaring, we shall go on to discuss those technical aspects of ancient Greek ships which relate specifically to their performance, seaworthiness and durability, rather than solely to construction techniques and design. These discussions will also address some relevant background issues and contextual points which may have gone unaddressed in the main text.

\section{The Mediterranean as a seafaring environment.}

In studying the dangers and problems inherent in seafaring and navigation in ancient Greece, it is important first to emphasise that there are various ways in which the Mediterranean Sea, and particularly the Aegean Sea, are relatively conducive to rudimentary seafaring and navigation ${ }^{531}$. As an enclosed sea, all but cut off from the open oceans, conditions are far calmer in the Mediterranean than they are beyond the Strait of Gibraltar, through which ancient Greek sailors long dreaded to pass, fearing the unknown and far more dangerous conditions of the Atlantic Ocean. Pindar thus describes 'the trackless sea beyond the Pillars of Herakles, which that hero and god set up as far-famed witnesses of the furthest limit of voyaging. ${ }^{532}$.

In this respect, one of the most significant aspects of the Mediterranean's isolation is that its tides and currents are relatively weak. Tidal fluctuations are insignificant except in shallow bays and gulfs, and in some restricted straits (p.47, fig.39). In such 
bays and straits, and in most oceanic areas (note Caes.G.W.3.13, quoted below, p.237), harbours (especially natural harbours) often had to be entered or left at high tide, as, at other times, the depth of water was not sufficient to allow ships to pass safely over rocks and shallows at the entrance. In most parts of the Mediterranean, however, the near constant sea level meant that entering and leaving harbour was not only safer ${ }^{533}$, but also did not have to be timed to coincide with the high tide, leaving ancient Greek mariners free to simplify sailing to and from the coast by exploiting land and sea breezes (on which see pp.109f.).

Similarly, the relatively common practice of bringing ships ashore simply by beaching them, and securing them by pulling them above the high water mark ${ }^{534}$, was also clearly a far easier and less accident prone procedure where there was no tidal fluctuation: where tides ran high, beaching, especially during low tide, would have entailed pulling the ship far up the beach, to avoid it being dislodged and set adrift during high tide $^{535}$.

The relative ease of coming ashore in a tideless sea is best illustrated by literary episodes describing Greek sailors' entry into strongly tidal areas, as when the Argonauts are blown uncontrollably into the extensive shallows of the Gulf of Syrtis on the north coast of Africa (Ap.Rhod.Arg. 4.1240ff.) ${ }^{536}$. Here Apollonius illustrates not only the particular problems that tides present, but also the fact that Greek seafarers were unfamiliar with strong tides, and that their traditional techniques for landing at and departing from the coast neither took account of tidal fluctuations, nor were practicable in areas where strong tides occurred. The most telling aspect of the account is the reaction of Ancaeus to the Argo becoming stranded at the high water mark; as helmsman of the ship, he would normally be expected to be the crew member most able to resolve such problems:

'Here accordingly the flood tide - for this tide often retreats from the land and bursts back again over the beach coming on with a rush and a roar thrust them suddenly on to the innermost shore, and but little of the keel was left in the water....And among them Ancaeus, the helmsman, in despair at their evil case, spoke with grieving heart: "Verily we are 
undone by a terrible doom; there is no escape from ruin; we must suffer the cruellest woes, having fallen on this desolation, even though breezes should blow from the land; for as I gaze far around, on every side do I behold a sea of shoals, and masses of water, fretted line upon line, run over the hoary sand. And miserably long ago would our sacred ship have been shattered far from the shore; but the tide itself bore her high on to the land from the deep sea. But now the tide rushes back to the sea, and only the foam, whereon no ship can sail, rolls around us, just covering the land. Wherefore I deem that all hope of our voyage and of our return is cut off. Let someone else show his skill; let him sit at the helm - the man that is eager for our deliverance. But Zeus has no will to fulfil our day of return after all our toils."

Thus he spake with tears, and all of them that had knowledge of ships agreed thereto.' (Ap.Rhod.Arg. 4.1240-1244, 1259-1278 (my italics))

Far from taking control of the situation, the helmsman Ancaeus is at a loss as regards how to resolve the crisis. The tide has receded, so that the ship cannot simply be pushed back into the water and sailed out to the open sea using the land breeze, the traditional method used by most Greek sailors on an everyday basis, and the only way Ancaeus knows of getting the Argo back to sea. Moreover, the receding tide means that the Argo, if taken back out to sea, would no longer be able to avoid the dangers which threatened to shatter her as she entered the gulf, and which she previously avoided because the high tide 'bore her high' as she entered. Ancaeus is even depicted as being unaware that the high tide would return in a matter of hours, at which point the Argo might be easily refloated. Few of the Argonauts were inexperienced and unskilled sailors, yet 'all of them that had knowledge of ships' share Ancaeus' despair; their problem, as envisioned by Apollonius, is that, despite their experience, Greek sailors rarely had either reason or opportunity to become familiar with the difficulties of sailing in strongly tidal areas, especially in earlier times, when the Mediterranean was less well known ${ }^{537}$.

Similarly, open-water currents in the Mediterranean are generally far weaker than in the freely circulating oceans; only in certain straits, and occasionally off headlands, do they ever becoming so strong as to pose dangers or difficulties for sailors ${ }^{538}$. Moreover, the regularity of currents in the Mediterranean (p.39ff., figs.39, 40), and 
the absence of tidal fluctuations, would have led to their local characteristics becoming highly familiar to experienced professional sailors, and would also have made it easier for mariners to forecast the sea conditions they were likely to encounter on any journey.

While the Mediterranean may become extremely rough and stormy at times, the sea's relative isolation leaves it free from waves of the massive proportions found in the open oceans. While strong winds, which are necessary for the formation of large waves, are common at nearly all times of year in the seas around Greece (pp.48-52), the long stretches of open water, which are also a necessary condition for the development of large waves (p.33), are far less in evidence. Not only is the Mediterranean a far smaller body of water than any of the world's oceans, it is also characterised, especially in the north, by long peninsulas and large numbers of islands, nowhere more so than around Greece (pp.18ff., 28ff.). These act as barriers preventing the development of really large waves, and even affect the direction and force of winds passing over them (pp.57-60). Thus Mediterranean waves contrast with those of the open oceans, where the combination of extremely violent winds and open stretches of water thousands of miles in length can produce waves towering up to fifty feet high (note Caes.G.W.3.13, quoted below, p.237) ${ }^{539}$.

Some general aspects of the Mediterranean's climate and winds were also beneficent to ancient sailors. While all parts of the Mediterranean are subject to very strong winds and stormy conditions at times, the regularity of the daily and annual cycles of winds and weather, especially in summer (pp.48f., 52-6), made it relatively easy to plan the route and timing of a sea journey so as to minimise the risk of running into foul weather or difficult sailing conditions ${ }^{540}$. In particular, the land and sea breezes which had such an important role in ancient Greek seafaring (pp.109f., 129, 141, 222f., n.510) do not develop so strongly around the open oceans, where the colder waters, the less indented coastlines, the far fewer islands, and the less temperate climate all tended to reduce the strength and reach of such winds. The same promontories and islands partially responsible for the strongly developed land and sea 
breezes in the Mediterranean also provided many sheltered areas in their lee, where ships could escape bad weather, while clear summer skies added to their visibility, making them ideal landmarks for sailors ${ }^{541}$.

\section{Ancient Greek attitudes towards seafaring.}

The various aspects of the Mediterranean's physical environment that were far less severe than conditions in the open ocean environment might lead us to assume that, for the ancient Greeks, seafaring was relatively trouble-free, with navigation a far simpler affair, and seafaring far less dangerous, than was the case for other, oceangoing, peoples. However, such a conclusion would be contradicted both by the growing number of ancient shipwrecks discovered by underwater archaeologists ${ }^{542}$, and also by the testimonia of the ancient Greeks themselves. Surviving Greek literature contains a much evidence that the sea was held to be a place of enormous danger, and that seafaring professions had a bad reputation not only as a result of social prejudice, but also because of the disasters which could so easily befall the sailor and his relatives.

Thus even during the meagre fifty days which Hesiod admits as being a safe period for sailing (Hes.W\&D.663-677, quoted above, p.221f.), almost guaranteed to be free from meteorological dangers, this land-loving Boiotian still fears the sudden, unexpected disaster which might be attributed to an act of the ambivalent gods: 'Trust in the winds without care' he continues, as if to suggest that even under the best of conditions the sailor must still trust the sea, the winds, and the gods, rather than himself, to bring him safely home. Solon, too, characterises the sailor as one who lives with the threat of death or disaster always present:

'If a man is needy and the works of poverty oppress him, he decides that he will assuredly win great wealth. Different men spend their efforts in different directions. One wanders over the sea, abundant in fish, striving to bring profit back in ships, not grudging his life [my italics], when he is borne along by the boisterous winds.' (Solon fr.12.41-6) 
The idea, hinted at here, that men only took to a sailing profession out of need, if there was no alternative employment to be found on land, is a common one, and is often used by Strabo to explain the importance of trade or of other maritime professions in the economies of certain islands and coastal regions ${ }^{543}$, including Aigina:

'Ephorus says that silver was first coined in Aigina by Pheidon; for the island, he adds, became a merchant centre, since on account of the poverty of the soil, the people employed themselves at sea as merchants.' (Str.Geog.8.6.16)

Equally, seafaring professions were gladly given up, either as soon as less dangerous opportunities arose,:

'I, men of the jury, have by now been for a long time engaged in foreign trade, and up to a certain time risked the sea in my own person; it is not quite seven years since I gave up voyaging and, having a moderate capital, I try to put it to work by making loans on adventures overseas.'

(Dem.33.44)

or when one was ready to retire:

'O king of the sea and lord of the land, I, Krantas, dedicate to you this my ship, no longer immerged in the sea - my ship, bird blown by the wandering winds, in which I, poor wretch, often thought I was being driven to Hades. Now, having renounced them all, fear, hope, sea, storms, I plant my steps confidently on dry land.' (Anth.Pal.6.70)

Thus it is clear that seafaring was perceived by the ancient Greeks as a very dangerous activity, despite the relatively congenial aspects of their seafaring environment which were highlighted earlier in this appendix. In order to explain why seafaring was perceived to be so dangerous, it is necessary to look not only in much closer detail at the physical environment of seafaring (see particularly ch.2), but also at the equipment and technology available to seafarers within that environment, principally their ships. 


\section{The seaworthiness of ancient Greek ships.}

In the first place, it is clear that the more demanding maritime environment of the Atlantic resulted in the development of far more durable ships than those which were designed for Mediterranean conditions:

'They [the Veneti] construct their hulls with somewhat flatter bottoms than our craft to make it easier to go through the shallow depths of low tide and over shoals; the prows and the sterns are rather high to handle the size of the waves when the sea is stormy; the ships are made throughout of oak to withstand any amount of violence and hard treatment. Beams are of timbers a foot square made fast with iron nails an inch thick, and anchors are held by iron chains instead of ropes. Their sails are of hide or of softened leather instead of canvas, possibly because they have no flax or do not know how to use it, but more likely because they think that canvas will not stand up to the storms of the ocean and the violence of the winds and will not drive such heavy ships efficiently.' (Caes.G.W.3.13)

As Casson has noted ${ }^{544}$, ancient Greek ships, like most Mediterranean ships of the time, were far less durable than those of the inhabitants of northern Europe, which were designed to withstand the much fiercer conditions of the North Sea. Not only were Greek ships not designed or able to cope with conditions in the North Sea; they clearly often found difficulty in coping with the calmer conditions of the Mediterranean environment. Some of the shortcomings of ancient Greek ships in this respect are related to the designs and purposes of particular types of ship, particularly in the case of warships, which were intended to be weapons as well as sailing vessels. However, other problems affected all ancient Greek ships, and such problems were primarily associated with ship-building techniques, and specifically with the materials used.

Thus few, if any, Greek ships featured the oak, the thick beams and iron nails, the leather sails, or the metal anchor chains which were incorporated into the robust ships of the Veneti. Anchors on Greek ships, made of stone in the Homeric period, later of lead, bronze or iron, were instead secured by ropes ${ }^{545}$. Even metal anchors with arms, once they had been introduced, had a tendency to drag rather than to take a firm hold in stormy conditions, and sailors had to be careful to check that they were securely 
moored $^{546}$. The earlier stone anchors, without any arms, must have been even less reliable, and the added weight of metal chains, had they been used in place of ropes to secure the anchors, might have helped to alleviate such problems. Vital wooden components of Greek ships were made from materials neither strong enough nor thick enough to prevent disaster striking in fierce storms: thus Synesius, on his voyage westwards from Alexandria (Letters 4), saw the yardarm of the ship shatter during a storm (comp. Anth.Pal.6.245: a yardarm snapped by Boreas), while a thunderstorm causes the death of Odysseus' helmsman when the whole mast breaks and falls into the ship (Hom.Od.2.411ff.) ${ }^{547}$. Sails made from pieces of canvas stitched together, while strong enough to propel Greek ships at a reasonable rate, were never as strong as leather sails, and again, instances of sails and tackle being torn to shreds by violent winds are common in Greek literature ${ }^{548}$. Once sails had begun to rip, it was very hard to prevent further damage while the winds continued unabated:

\section{'...Tossed in despair, fear-dazed,}

Men could not grasp the oar, nor reef the sail

About the yard arm, howsoever fain,

Ere the winds rent it, could not with the sheets

Trim the torn canvas, buffetted so were they

By ruining blasts...' (Quintus Smyrnaeus, Fall of Troy 14.497-501)

To protect the sails and the mast, diligent helmsmen paid careful attention to the state of the winds, and knew when to brail in more and more of the sail so that progressively less of its surface area was exposed to the full force of a strengthening gale. In desperate circumstances, the whole sailyard could be lowered, either partially, or right to the level of the deck ${ }^{549}$. Another part of all ships' equipment which may not have performed very well, either through being too fragile or through having poor manoeuvrability, was the steering gear ${ }^{550}$.

Another problem associated with ancient Greek ships was that waves regularly cast water right inside the hull. As we saw above, the ships of the Veneti had high prows and sterns, to help them cope with the larger waves of the North Sea. Despite the fact that waves in the Mediterranean do not tend to become as large as those of the open 
oceans (above, p.234), they clearly became high enough at times to spill over the gunwales of ancient Greek ships. This affected galleys - triaconters, penteconters, biremes, and triremes - worst, as these ships intentionally sat particularly low in the water $^{551}$, but affected all ships to some extent, especially those lacking decks. Ships with no katastroma $(\kappa \alpha \tau \alpha \dot{\sigma} \sigma \rho \omega \mu \alpha)$, or overall deck, were by no means uncommon, and indeed were the norm before the fifth century B.C. ${ }^{552}$, and any time waves rose high enough to rise over the gunwales of such a ship, large amounts of water were likely to end up in its hull. For oared galleys the problem was both more of an inconvenience, as water pouring over the sides of the ship would interfere with the rowers, and also more complicated: not only were these ships, being lower, more vulnerable to waves spilling over their gunwales, they could also let water in through the oarports of the lowest tier of rowers, the thalamites or thalamioi, as these oarports sat only around eighteen inches above the water line $\mathrm{e}^{553}$. To prevent water from getting into the ship, the lower oarports were fitted with leather sleeves, and sidescreens, which could be made of wicker, canvas, hair, or leather, were fitted above the gunwales ${ }^{554}$. These measures, being adopted continuously from Homeric times onwards ${ }^{555}$, were presumably thought to be generally adequate, as the problem was also partially alleviated by the fact that warships tended never to fight, although not necessarily never to cruise, in rough waters ${ }^{556}$. Before pumps were invented, water ending up in the hull of a ship had to be bailed out:

'This wave in turn comes (like ?) the previous one, and it will give us much trouble to bale out when it enters the ship's.....Let us strengthen (the ship's sides) as quickly as possible, and let us race into a secure harbour...' (Alcaeus A6.1-8) ${ }^{557}$

Here Alcaeus also seems to suggest that the ship's defences against waves are inadequate, and in need of strengthening. The fact that Chabrias fitted out the triremes under his control with extra protection (Polyaenus 3.11.13) suggests even more clearly that the side-screens were not completely effective, particularly, we may surmise, in windy conditions, when the height of the waves increased (see p.33). Still more water could end up in the holds of ships lacking full decks when rough weather 
was accompanied by rain. The combined wind, waves, and rain of a storm could wreak enormous damage on an undecked Archaic ship:

'ships which....encounter grievous tempests - blasts that raise a huge wave from astern, or from ahead, or where they will, and cast it into the hold, and breach the bulwarks on either side. And with the sail hangs all the tackle, torn and in disarray, and as the night comes on with heavy storms of rain, the wide sea roars beneath the blows of the blasts of the iron hail.....' (Theoc.Id.22.4ff.) ${ }^{558}$

Such were the problems that afflicted all types of Greek ship alike when rough conditions were encountered at sea. In addition to these problems, particular aspects of the various different types of ship employed by the ancient Greeks caused difficulties for seafarers in the Aegean and in the Mediterranean generally.

\section{Oared warships.}

Early galleys ${ }^{559}$, from which triremes were later developed, held twenty rowers, or thirty (triaconters), and eventually fifty (penteconters). One of the main advantages of this type of craft was that, powered by oar rather than by sail, its speed and direction were less tied to those of the prevailing winds than was the case for sailing ships ${ }^{560}$. However, while this advantage grew proportionately with the growing numbers of rowers incorporated into such vessels, the lengthening of the ship, entailed by the increased number of oars, detracted from its seaworthiness: Casson estimates that a penteconter would have measured ninety feet in length (compared with the forty feet of a twenty-oared galley), while Carpenter sets the figure at over one hundred feet ${ }^{561}$. While the length of galleys thus increased, their width did not, so that relative to their length and to their weight, they became increasingly narrow and therefore more fragile. This, added to the complications of building and operating ships of such length, meant that penteconters were not particularly seaworthy, especially in heavy $\operatorname{seas}^{562}$. The successors of the penteconter managed to accommodate even more rowers without significantly increasing the length of the ship. This was achieved by arranging the oars in tiers, two in the case of the bireme, then three with the advent of the trireme ${ }^{563}$. The new triremes, which were probably invented in the first half of the 
seventh century BC, and had become the standard warship in use by the end of the sixth century B.C. ${ }^{564}$, were thus much more powerful than their predecessors.

However they were little safer. Essentially the trireme was developed as an instrument of war, and thus in its design military capabilities overshadowed seaworthiness ${ }^{565}$. In practice, moreover, the trireme it was subjected to greater stress and strain than any other type of ship, and its crew faced particular difficulties.

Thus it was extremely difficult, even with trained oarsmen, to keep all of a trireme's one hundred and seventy oars working properly and to a unified beat, and the full complement of rowers was rarely used outside battle. While the trireme was equipped with a sail for cruising, this was of no use in choppy seas raised by adverse winds, and in such conditions, the trireme, even when rowed, could get into real difficulty ${ }^{566}$. Moreover the large crew needed to man all the oars also meant that conditions in triremes were extremely cramped, and for this reason alone it was important for the trireme to come ashore every night if possible, so that meals could be cooked and the crew could be properly rested. Long journeys away from the coast were therefore difficult, and there was little space in the trireme for the storage of vital provisions' especially when extra hoplites or cavalry were being carried ${ }^{567}$. Lying at anchor at night was not only inconvenient, it was also relatively dangerous, especially for a whole fleet as opposed to a single ship, as triremes' anchors were not particularly heavy, and the ships themselves were liable to drift ${ }^{568}$. Its shallow draft made the trireme suitable for beaching ${ }^{569}$, but could cause serious problems, even capsizal, if it became unbalanced due to rough seas or an uneven distribution of weight within the ship $^{570}$. Constant hauling ashore, along with participation in battles in which the principal means of incapacitating an enemy ship was to ram directly into it, put an enormous strain on the structure of the trireme, and to help prolong the life of the ship ropes known as hypozomata (í $\pi \hat{\zeta} \zeta \omega \mu \alpha \tau \alpha$ ) were stretched tightly between the bow and the stern of the trireme. These helped to hold the hull of the ship together and to prevent elements working loose, and were not simply there to protect the trireme in case of an extreme accident or some unusually severe handling: ancient sources make it clear that the hypozomata were there to protect the ship from the strain of everyday 
sailing, and that triremes not fitted with hypozomata were regarded as unfit to be sent out on campaign, or even to be put on the active list in Athens ${ }^{571}$. Another problem routinely associated with triremes, and galleys in general, was their propensity to leak water through the hull, even when protected with pitch. This made the ships slow and heavy, and to counteract the problem triremes had to be hauled ashore and allowed to dry out whenever possible ${ }^{572}$. Lightness was fundamentally important to the tactical qualities of the trireme, to the extent that the wood used for all but a few vital parts of the trireme was chosen for its lightness, rather for its resistance to decay, which was the main factor in choosing wood for merchant ships ${ }^{573}$.

\section{Merchant ships.}

Merchant ships, while lacking many of the drawbacks of triremes and other ships designed for military purposes, had their own shortcomings. In contrast to penteconters and triremes, merchant ships had small crews and were designed to have the maximum of storage space, for cargo but also for provisions. This had obvious advantages, particularly in facilitating long voyages across the open seas ${ }^{574}$, but also meant that the ships were far heavier than galleys and had larger drafts. This in turn meant that they were to some extent less suited to navigating in coastal waters, being harder to beach, and more at risk of coming to grief on submerged rocks in shoal water. These problems were exacerbated when merchant ships were heavily laden with cargo, or even overloaded, at which times there was also far more danger in sailing in rough waters: merchant ships may have indeed been far more seaworthy than military ships, but for fully laden ships, stormy weather could often only be endured by jettisoning large amounts of cargo. This was such an accepted practice in bad weather that the value of cargo lost in such circumstances did not have to be repaid to creditors by debtors according to the conditions of Athenian maritime loans ${ }^{575}$. Merchant ships could also get into serious trouble at times when they could not rely on their sails, i.e. in very rough weather, or when winds were blowing in an unfavourable direction, or when there was a calm. In such circumstances, the small size of the crew became a handicap rather than an advantage, as the ship's ability to reach more favourable waters depended upon the ability of the crew to row the ship 
out of the danger area, assuming it was equipped with oars in the first place.

As much commercial shipping restricted itself to sailing long established trade routes along which the prevailing winds were known to be favourable, a fair proportion of ancient merchant ships relied solely upon their sails for propulsion, and had no oars at all, apart from the steering oar. Such a ship, known as a holkas (ó $\lambda \kappa \alpha ́ \zeta$, derived from $\check{\varepsilon} \lambda \kappa \omega$, 'to tow'), had to be towed by oar-powered ships in any situation in which their sails were rendered useless, i.e. in a dead calm, or when winds and currents were set against them, or when navigating in a restricted space such as a harbour. Towing was fine when, for example, there were triremes on hand to help Athenian grain ships overcome the winds and currents of the Bosporos to reach the Black Sea, or to facilitate their passage through the Aegean against northerly winds (Dem.Orat.50.22ff.) or even when the ship's small launch ( $\lambda \dot{\varepsilon} \mu \beta 0 \varsigma$ ) could be used to tow a holkas short distances from harbour or mooring out to open water where sails could be hoisted. However, holkades were clearly helpless when caught in conditions which were too rough to allow use of the ship's launch, if there were no friendly oarpowered ships to tow the holkas out of danger ${ }^{576}$. For holkades, then, it must have been imperative to avoid seasons and areas where conditions were bad, unknown, or unpredictable. It was perhaps the holkas, more than any other type of ship, which depended on the ideal sailing conditions, which, in the words of Philostratos the Elder (Imag.2.17), were 'neither roused and turbulent, nor yet flat and calm, but a sea fit for sailing, as if it were alive and breathing.'

\section{Conclusions.}

It is clear, then, that the ships used by the ancient Greeks were not of such quality that mariners could sail the Mediterranean at will, free from danger and without navigational complications. Indeed, it should not be expected to have been otherwise. We have seen that there were various shortcomings, some of which were characteristic of all ships, others which were particular to specific types of vessel. However, these shortcomings have to be seen in the context of general Mediterranean environment, which was examined in the earlier part of this appendix. There we saw 
that many aspects of the Mediterranean were advantageous to mariners, and in such advantageous conditions, especially during the summer when the Etesians were blowing steadily and predictably, ancient Greek ships probably encountered few problems, assuming that their captains and crews were familiar with the seas and coasts around which they were navigating.

Indeed, the existence of some of these advantageous factors in the Mediterranean environment may help to explain why Greek and other Mediterranean ships in ancient times never developed in such a way as to lose some of what would, in another environment, have been seen as design faults or imperfections. Thus the fact that, having a poorly developed system of sails, many Greek ships could not sail very closely into the wind ${ }^{577}$ might have become a serious problem for ships regularly having to head north in seas where the strength and endurance of the northerly Etesians were so renowned (e.g. Athenian grain ships; see also p.86, on Dem.4.31, 8.14); however, diurnal land and sea breezes, which are also very conspicuous in the Mediterranean (pp.52-6, n.510), provided a means, if a relatively slow one, by which northwards progress could be made and the influence of the Etesians on sailing schedules could be reduced (see pp.85f., 129), thereby also reducing the incentive to develop a better system of sails ${ }^{578}$. Similarly, Greek sailors may never have come to rely so heavily upon being able to beach their ships had there not in the first place been such a wealth of conveniently shelving beaches to be found in the sheltered bays around the indented Greek coastline (fig.68), nor a lack of tides, which otherwise would have complicated not only this method of coming ashore, but also entering and leaving harbours (above, p.231ff.). It was mainly only in areas of particularly unwelcoming topography, or during extreme weather conditions, that the shortcomings of ancient ships became apparent, and then often glaringly so. The following passages illustrate this, contrasting the care and efficiency normally associated with the ships and their crews with the disaster which could nevertheless strike when an unexpected situation was encountered. In the first passage, Demosthenes denies blame for the failure of Athenian opposition to Philip, which he had earlier instigated: 
'As if a shipowner, who had done everything in his power for a prosperous voyage, who had equipped his craft with every appliance he could think of to ensure her safety, should encounter a great storm, and then, because his tackle was overstrained or even shattered, should be accused of the crime of shipwreck! "But", he might say, "I was not at the helm" - nor was I in command of the army - "and I could not control fortune, but fortune controls all.".' (Dem.18.194)

Although the question of personal responsibility is rather differently interpreted by Xenophon in this second passage, his opinion of the vulnerability of ships when caught in unexpectedly bad weather is very similar to Demosthenes':

'Do you notice how the bow officer is angry with those in the bow, and the helmsman is angry with those in the stern for a mere nod, when there is a storm and high sea? For in such a crisis even small mistakes are enough to cause complete disaster.' (Xen.Anab.5.8.20)

Greek ships, we might say, were made for good sailing conditions, and did not perform too well when those conditions deteriorated. Their vulnerability to sudden changes in weather conditions must be one of the main reasons why seafaring commonly had, as has been discussed above (p.235f.), such a bad reputation. So to the seaworthiness of ships had an important effect on the practicalities of sailing: in the opinion of Tim Severin, who has reconstructed, and sailed in, the types of ship that might have been used by Odysseus and by Jason, "the early navigator guided his course less by the map, the stars, or even the landmarks than by the sailing conditions for which his ship was designed or capable." ${ }^{579}$. 


\section{APPENDIX THREE: Weather prediction.}

It was shown in appendix one that it was by no means uncommon for ancient Greek sailors to continue voyaging both during winter and during the night. This does not mean that Greek sailors were reckless, nor that there was less danger involved in sailing at these times than in daylight during the summer months. Rather, it means that it is too much of a generalisation to say that sailing during the summer and in daytime was 'safe' but that conditions during wintertime and at night were 'too dangerous' for seafaring: no mariner decides whether or not to set out to sea simply on the grounds of what time of year it is and what time of day it is. Clearly, nights can be calm as well as stormy, and winters often feature lulls in generally bad weather, just as conditions can quickly deteriorate and disasters can happen at sea even during the day or during the summer months, especially when the Etesians blow so hard as to become a danger to shipping ${ }^{580}$.

It was important, therefore, for the mariner to be able in some way to forecast weather conditions and associated sailing conditions. Before each individual journey, no matter when it was undertaken or how long it was to last, (but particularly for long journeys, during which weather conditions were more likely to change, and landfall could not be made in a hurry in the event that conditions did deteriorate badly), sailors had to attempt to predict how the weather was likely to behave while they were at sea:

'From land one should look ahead for (a fair) voyage if one can and has the skill' (Alcaeus 249.7f. (= Lobel \& Page (1955) L1.7f.))

As a journey progressed, seafarers would constantly reassess and update their appraisal of the changing weather (see below): this is made clear in the terms of the maritime loan quoted earlier (p.224f.), the phrasing of which suggests that the crew had yet to decide whether or not, and if so for how long, they would continue with 
their mercantile voyage after the accepted date for the end of the sailing season had passed.

Of course, weather prediction was a much simpler affair during the stable and less changeable conditions of summer (for which see p.48ff.), whilst during winter, or if a night voyage was being contemplated, a sailor might have been much more likely to come to the conclusion that conditions were too dangerous; but he might, for example, observe that winter did not seem to have arrived as early as it had done in previous years, and so risk a last journey that year; or at sundown he might look at the sky and see nothing that suggested conditions were going to deteriorate overnight, and so feel safe venturing out on the sea in the darkness. To investigate this subject further, we must address questions concerning the methods and criteria used by ancient Greek sailors to forecast the weather.

\section{Weather prediction and the physical environment.}

The most general type of forecast could be made by reference to the time of year, a practice we have already noted (p.221f.), and which resulted in the establishment of commonly accepted limits to the 'sailing season'. Summer and winter could be taken to start and end at set dates in particular months, but as the calendars used by the ancient Greeks were not fully synchronised with the solar year, a better measure of the precise time of year and season could be, and, in seafaring, generally was found by reference to the solstices and equinoxes (e.g. Hes. $W \& D .564 \mathrm{ff}$., and 663f. (quoted above, p.221f.)) and to the stars, more precisely to the various risings and settings of certain stars and constellations, particularly the Pleiades, Arcturus, Orion, and the Kids $^{581}$. However, such astronomical phenomena also vary slightly with latitude and over the years ${ }^{582}$, and so they too were not entirely accurate indicators of the precise time of year. In any case, these slight inaccuracies and variations are insignificant when compared with the great differences noticeable in the weather which occurs on the same date in different years ${ }^{583}$ : predicting weather simply by reference to the date, the season, and astronomical events gives a rough indication of the likelihood of encountering fair or stormy weather conditions at that time of year, but nothing more; 
any more accurate prediction regarding weather conditions can only be made by taking into account actual meteorological conditions observed in a particular area a particular time. Thus Aratos advises:

'Thou canst always add the signs of the passing season, comparing whether at rising or at setting of a star the day dawns such as the calendar would herald.' (Arat.Phaen.1145-8, comp. 752-777)

The most direct way to forecast weather conditions for the near future was to use one's past experience of local weather and climate to judge how present weather conditions might develop. Here we encounter (again) a very significant aspect of ancient seafaring and navigation, the importance of, and advantages which can be gained from having, an intimate knowledge of the oceanographic and meteorological character of the seas in which one sailed; such knowledge made sailing considerably safer for the ancient sailor, and left him in a position far favourable to that of the mariner sailing in 'uncharted waters'. In the present context, knowledge and observation of local conditions gave the mariner many clues as to the best and the safest times to sail. These clues came from a wide variety of aspects of the natural environment about him ${ }^{584}$. The types of observation made by ancient seafarers in order to predict impending weather conditions are recorded in works such as Theophrastos' On Weather Signs, Aristotle's Meteorologica, Aratos’ Phaenomena and the lost Phaenomena of Eudoxus, on which Aratos' work was based: many of the ideas and information contained in these works came from mariners, and others whose occupations involved the weather, who had doubtless been using such techniques for centuries $^{585}$.

One obvious way to predict weather conditions was to assess the winds. The ancient Greeks had a strongly developed familiarity with, and impression of, the nature of the different winds they regularly encountered, which extended to anthropomorphic, mythological, and divine characterisation. Such characterisation reflected the Greeks' experience of the different winds, and the wind from any given direction was associated with particular types of weather ${ }^{586}$. More importantly in terms of weather 
forecasting, there were also set opinions, developed through experience and detailed observation, as to how particular winds tended to develop through time, and regarding the weather conditions that would develop once another wind had died down. These opinions show, if not an understanding, a deep familiarity with important aspects of climate and weather in the eastern Mediterranean, such as the cycle of winds in a depression, and the different characteristics (humidity, temperature, etc.) of winds from different directions. Such observations tend to be well founded, but, in the form we now have them (in the works of Theophrastos, Aratos, etc.), are often stated as unconditional observations when actually they relate either to weather conditions which were to be found in Greece during only a part of the year, or to winds which were to be found only in certain parts of Greece ${ }^{587}$. Such oversights are understandable in literary works of this nature, composed from both the author's first hand observations and also the testimony of other observers from different localities, but we should not assume that such over-generalising assumptions were likewise made individually by those with a professional interest in the weather, including sailors, whose observations were thus gathered together. In any case, despite these oversights, it seems clear from sources such as this that the Greeks had a clear and well-defined familiarity with the winds and the weather patterns by which they were typically affected. Such a strong familiarity with not just particular winds, but with protracted patterns of weather, would have been invaluable to mariners attempting to foresee the weather conditions they would encounter during a long sea-journey.

In addition to those concerning the wind, predictions could also be made about the possibility of rain and storm, according to the state of the sky. One of the most commonly read signs was the presence or absence of orographic cloud on high mountain tops, visible to sailors for miles around (p.193 with n.489 and fig.49). Orographic cloud, being a precursor of most of the rainfall which affects Greece (cf. p.62ff), was a particularly useful indicator of future rainfall, and equally the absence of cloud on some mountains which were typically associated with orographic rain was rightly taken as a sign of fair weather: 
'For wherever the clouds run into an obstacle and stop, rain is generated.' (Theophr.Vent.5)

'When winds blow with difficulty against steep mountains, there clouds are more likely to form, where the wind cannot push them further. When they have been formed and are subject to pressure, they break.'

(Arist.Probl.26.7)

'When clouds settle down on the tops of the mountains, the weather will be stormy; but if the tops become clear, it will be fine.' (Pl.H.N.18.356)

Orographic cloud that developed a cumulonimbus form was correctly taken as a sign that not only rain could be expected, but a full-blown thunderstorm (see pp.59, 63f., with n.205) ${ }^{588}$. Distant lightning flashes and thunder claps were also rightly taken as indicating the direction from which foul weather might come ${ }^{589}$. Other types of cloud were likewise understood to be symptomatic of the development of particular weather conditions $^{590}$, and winds blowing, not from a particular compass direction, but from a large expanse of open sea, were rightly understood to be the most likely to bring rain (Arist.Probl.26.24, 56, Theophr.Vent.4). For the mariner too far from land to spot orographic cloud, there were other signs of growing humidity in the atmosphere which portended rain or stormy winds in the near future, such as a southerly wind accompanied by fog (for the rain-producing properties of which, see pp.52, 59, 63) ${ }^{591}$. By observing the degree to which the sun or moon became obscured when clouds passed over them, sailors gauged the density and thickness of those clouds, and so forecast the conditions they might be expected to bring ${ }^{592}$. Such weather signs were harder to discern during the night, especially around the turn of the months, when the moon was small and shed little light ${ }^{593}$; some clues could be found in the clarity of the moon ${ }^{594}$ and of the starry sky, particularly, it seems, in the area around what was called the Asses' Manger (or the Crib)in the constellation of Cancer ${ }^{595}$, but nevertheless, the last moments of daylight were especially keenly observed for signs of the weather to be expected during the night ahead, as were the first moments of daylight for signs of weather expected during the day ahead ${ }^{596}$. 
Weather signs such as these would have been readily learned by mariners through experience, observation and oral tradition. Such knowledge would clearly have helped ancient sailors to plan their voyages more thoroughly and to reduce the chance of their encountering dangerous or adverse weather conditions over the coming days. A good example of just how valuable a detailed knowledge of weather patterns could prove to be is given in the following passage, where the confusion and misplaced consternation of the passengers puts the forecasting skills and navigational experience of the professional sailors into clear relief:

'All at once he veered about as though some new idea had possessed him, and went for the open water, struggling as best he might against a contrary sea. Presently a fresh south wind springs up and carries us along, and soon we are out of sight of land and have come into the track of the double-masted freighters, whose business does not lie with our Libya; they are sailing in quite another course. Again we made common cause of complaint, and our grievance now is that we have been forced away too far from the shore.... "What do we want of the open sea? Let us rather make for Pentapolis, hugging the shore, for then, if indeed we have to face one of those uncertainties which, as you admit, are unfortunately only too frequent on the deep, we shall at least be able to take refuge in some neighbouring harbour.".....and what is more a gale commenced to blow from the north ...with great difficulty however we headed her in. Then Amaratus thunders out, "See what it is to be master of the art of navigation! I had long foreseen this storm, and that is why I sought the open. I can tack in now, since our sea room allows us to add to the length of our tack. But such a course as the one I have taken would not have been possible had we hugged the shore, for in that case the ship would have been dashed on the coast." Well, we were perforce satisfied with his explanation so long as daylight lasted and dangers were not imminent.....' (Synesius, Letters 4)

The steersman Amaratus had clearly here anticipated the onset of a strong northerly wind, which indeed might spring up on the tail of a southerly wind during the weeks when depressions first start to cross the Mediterranean in autumn (see pp.49f., 107), during which time of year Synesius, later in the letter, confirms the voyage to have taken place. A northerly gale would threaten to drive any ship sailing along the southern shores of the Mediterranean onto the African coast ${ }^{597}$, as we have already seen happen to the Argo (see pp.80f., 232f.). The ship carrying Synesius survives not 
because of the reaction of the crew to the onset of the wind, but because the wind had been anticipated early enough to give Amaratus enough time to quit the coast and to sail out into safer waters while more favourable winds lasted. This passage underlines the importance to ancient sailors of not only trying to predict the weather conditions they would meet on an impending voyage, but also of continually updating that prediction as the voyage progressed and as new 'weather signs' appeared. Apparently Pindar believed that sailors' ability to forecast wind conditions for their voyages in advance, and to continually revise their forecasts during the voyage, and thus avoid dangerous storms, gave them considerably more than just a few hours' notice of impending bad weather:

'But mariners wise knew well of a blast that is bound to blow on the third day after, nor do they suffer loss through greed of gain...' (Pind.N.7.17f.)

Such deep familiarity with the weather patterns typical of summer and of winter conditions was invaluable to sailors contemplating voyages during either of those two seasons. However, weather patterns are never standard to such an extent that significant variations do not occur, and watching the weather alone could not guarantee sailors their safety. As well as advising mariners to look for meteorological signs that give more precise warnings of changes in the weather than astronomical events (Arat.Phaen.752-777, 1145-8, see above, p.247f.), Aratos also recommends comparing a variety of types of weather sign:

'Make light of none of these warnings. Good rule is it to look for sign confirming sign. When two point the same way, forecast with hope; when three, with confidence... Study all the signs together throughout the year and never shall thy forecast of the weather be a random guess.' (Arat. Phaen.1142ff., 1153f. $)^{598}$

\section{The role of birds in weather prediction.}

The main source for alternative weather signs, which could be compared with those gained from watching the weather itself, was the behaviour of animals, particularly, for mariners, birds: 
PEI ' '....To the seer ye shall tell when 'tis lucky and well for a merchant to sail o'er the seas,

So that never a skipper again shall be lost. CHOR. What 'never'? Explain

if you please.

PEI Are they seeking to know when a voyage to go? The birds shall give answers to guide them.

Now stick to the land, there's a tempest at hand! Now sail! and good luck (Aristoph.Birds.594-7) ${ }^{599}$ shall betide them.

Seabirds and migratory species were of particular importance to mariners in this respect because their behaviour is distinctly influenced by weather conditions, and could be easily observed from land, before a voyage commenced, or equally well from on board ship during a voyage. Birds are particularly sensitive to the atmospheric changes that occur as weather conditions develop, and for this reason their weatherrelated behaviour, if properly interpreted, can provide important information regarding the impending weather ${ }^{600}$ :

'Nor is it surprising that aquatic birds and birds in general perceive signs of coming changes of atmosphere.' (Pliny.H.N.18.88)

'....In all these matters men fall behind: they only know these changes when they occur.' (Ael.On Animals 7.8)

While migratory birds were visible only during the spring and autumn transitions between summer and winter, seabirds could be observed all year round, and so gave seafarers clues as to whether any unseasonable weather was imminent, whether stormy weather in summer, or fair weather in winter: 'as for a skipper the cry of a marine bird or the passing of a wisp of yellow cloud betokens wind and a rising sea, so for a mind expert in divination...' (Plut.Mor.581F-582A). The behaviour of sea birds is connected to developments in the weather insofar as rough conditions may inhibit the birds' ability to fly or to rest on the sea properly ${ }^{601}$, prevent them from feeding ${ }^{602}$,or cause them physical damage or even death ${ }^{603}$. Thus many birds will flee from approaching foul weather, while others will give up trying to feed and return to land when conditions become too rough ${ }^{604}$, and the sight of large flocks of seabirds 
flying from sea to land was rightly taken by Greek mariners as a sign of impending gales or storms ${ }^{605}$.

'If birds appear in great numbers and they are white [i.e. gulls], it is a certain indication that there will be heavy storms....And when birds come speeding in to land from the sea, this is evidence of stormy weather.... When birds of the sea and lake come in to land, they know that there will be a heavy storm...' (Ael.On Animals 7.7)

Individual species of bird which are particularly prone to thus fleeing before the weather, such as the heron, shearwater, and gulls ${ }^{606}$, were taken as especially noteworthy indicators of deteriorating weather ${ }^{607}$.

\section{Other animals in weather prediction.}

The appearance or behaviour of some marine animals was also taken to warn that storms or gales would soon appear. Thus Theophrastos predicts storms according to the behaviour of dolphins moving into coastal waters, of cuttlefish (whose behaviour when storms are imminent is not clearly described), and even of jelly-fish appearing in large numbers ${ }^{608}$.

\section{Weather prediction during the winter-summer and summer-winter transitions.}

Rather different problems arose during periods of the year when it was difficult to predict whether summer or winter conditions, or indeed either, would prevail. The Greek climate has two main seasons, winter and summer, and the 'autumn' and 'spring' months are essentially short periods of transition between these two seasons, marking the end and the beginning of the main summer sailing season respectively (p.48f.). The changeable weather that characterised these two transitional periods was naturally the most difficult to predict:

'The winds which come when Orion rises and sets are of no fixed character because during transitions all phenomena are very uncertain. Orion rises at the beginning of autumn and sets at the beginning of winter, with the result that, because it does not coincide with a single season (the end of one, the beginning of the other), the winds are necessarily unstable and uncertain, partaking of the nature of both seasons. And so the star is called 'difficult' when rising and setting because of the unsettled character 
of the season. The winds then are bound to be turbulent and irregular.'

(Thephr.Vent.55: compare Arist.Probl.26.13)

Sailors keen to take advantage of fair conditions as soon as these arrived in the spring were, even more than usual, in need of a more accurate indicator of coming weather than fixed calendar dates and the timing of astronomical events, which, as we noted above, were unreliable at best. From references in surviving literature, it is clear that sailors looked for the advent of Zephyros, the west wind, as a sign that the winter storms had, temporarily at least, abated, and that there would follow a period of calm during which seafaring would be relatively safe $\mathrm{e}^{609}$ :

'Snow during summers is a sweet drink for a parched man, and to feel the Zephyr of spring is sweet to sailors come out of the storm of winter....' (Anth.Pal.5.169.1ff. (attr. Asclepiades, C3 BC))

'Would you like, my boy, to have us discourse about these islands just as if from a ship, as though we were sailing in and out among them in the spring-time when Zephyros makes the sea glad by breathing his own breeze upon it? But you must be willing to forget the land and to accept this as the sea, not roused and turbulent, nor yet flat and calm, but a sea fit for sailing, as it were alive and breathing...' (Philos.Imag.2.17)

The Greek winter, and the depressions associated with it, are typified by alternating cold and fierce northerly winds, the ancient Boreas, and warmer wetter southerlies, the ancient Lips, both of which were strengthened by the great differences in atmospheric pressure between the air over the Mediterranean and that over the continental land masses to the north and south (see pp.48f., 50ff.). Westerly winds would appear in spring when high pressure developed over the Mediterranean, either during a break in the sequence of depressions moving eastwards from the Atlantic, or once those depressions had started to take a more northerly course, over continental Europe, as high pressure also began to build up over the Azores and to break down over Europe (for these changing meteorological conditions in spring see p.49).

Ancient Greek seafarers were therefore by and large right to see the appearance of milder westerlies as a signal that fairer conditions could be expected for the immediate 
future, even if it could not quite be taken for granted that no more depressions would take the more southerly route across the Mediterranean. Later in the year, the first tell-tale signs of depressions, such as frontal cloud and southerly winds (p.48), provided clear and unmistakable evidence that the stable conditions of summer were

giving way to winter weather. Thus sailors had the means to predict the beginning and the end of the winter and summer seasons in meteorological terms, and to a limited extent to predict the patterns of weather that would be encountered during both of those seasons.

\section{The role of migratory birds in predicting seasonal transitions.}

Again, though, as at other times of the year, if not more so, accurate predictions of how spring and autumn weather would develop at any particular time were generally easier to make when observations of the weather itself were complemented by other types of weather sign. Of particular importance here, again, was bird behaviour, specifically the migration of birds, for these bi-annual migrations (between summer breeding grounds and more southerly wintering quarters) took place during, and indeed in response to, the changing weather conditions during the transitions between winter and summer and vice versa, as was noted by Aristotle ${ }^{610}$.

As migration (especially over the sea, where there is no opportunity to rest) is extremely taxing and regularly involves many fatalities ${ }^{611}$, migrating birds seek to improve their chances of survival and success by setting off under the optimum weather conditions. Thus, as navigation is reckoned at least partially according to the sun and stars, and as wind conditions have a marked effect upon the time and energy used in flight, birds tend only to begin their migrations when clear skies and following winds are not only present but also likely to continue for as much of the journey over the sea as can be foreseen ${ }^{612}$.

Thus in general, the appearance of flocks of migrating birds gave notice that fair weather conditions could be expected for the immediate future. More specifically, migration tends to continue at a steady pace as long as spring or autumn weather is 
generally fair, but during prolonged periods of unfavourable weather, migration tends to be delayed, so that when a short spell of fair weather next occurs, vast numbers of birds may be seen all taking advantage of what may be a short-lived opportunity to embark upon their migration during favourable conditions ${ }^{613}$. Thus, the appearance of unusually large numbers of migrating birds in the sky could be taken as a sign of fair weather returning for the immediate future, while the absence of such birds in a period of the year when they might be expected to be seen signalled that abnormally poor weather conditions were to continue.

This system of weather forecasting was further refined in accurdance with the ancient Greeks' knowledge of the different times at which different species of birds began their migrations, according to their breeding habits, feeding habits, ability to endure harsh weather on the ground and in the sky, and the distance covered during migration ${ }^{614}$. Thus Aristotle remarks on the order in which different species migrate:

'It is always the weaker ones that are the first to make the move at either extreme, for example...the quails before the cranes: the former move in Boedromion [September/October], the latter in Maimakterion [November/December].' (Arist.H.A.597a21-24)

Thus by taking into account those species of birds which had already migrated, those which were in the process of doing so, and those which had not yet begun, ancient sailors could gain a fairly detailed impression of how advanced the transition from summer to winter, or from winter to summer, was ${ }^{615}$. From as early as Hesiod's time, it was the emigration of the crane that was believed to coincide most closely with the point in autumn after which wintry weather conditions, unsuitable for seafaring, were likely to appear; likewise, the reappearance of the swallow was believed to mark that point in the arrival of summer when conditions again became fair enough for voyaging:

'Mark, when you hear the voice of the crane who cries year by year from the clouds above, for she gives the signal for ploughing and shows the season of rainy winter....The shrilly wailing daughter of Pandion, the 
swallow, appears to men when spring is just beginning.' (Hes.W\&D.448$51,568 f.)^{616}$

For this reason, and as a case study in ancient weather prediction, lore attached to the cranes' migration in autumn, and to the swallows' in spring, will now be discussed more thoroughly.

\section{The end of summer and the autumn migration of cranes.}

The typical Mediterranean summer's clear skies and northerly winds blowing across the sea from southern Europe to northern Africa, are particularly beneficial to birds migrating southwards, as well as to seafarers. On the contrary, winter's depressions, with their associated cloud cover, precipitation, and southerly winds, hinder southerly bird migrations as well as discouraging seafaring. Aristotle notes that the northerly wind is a more favourable wind than the southerly in this respect, thereby displaying his understanding not only of the fact that the autumn migrations were significant weather signs, but also of the reasons why they should be so:

'When the quails have landed, if it is good weather or a north wind they pair off and are quiet, but if it is a south wind they are in difficulties through not being good fliers; for the wind is wet and heavy.' (Arist.H.A.597b9-13)

While some species, for this reason, migrate southwards before the onset of the first winter depression, and so before the end of the ancient summer sailing season, others, including cranes, wait longer, eventually leaving during a spell of relatively high pressure and fair weather between passing depressions, or, failing that, during the northerly winds and generally clear skies which are to be found after the passage of the cold fronts of depressions (for which see pp.49, 51f.) ${ }^{617}$. We have already quoted (above, p.257) a passage in which Aristotle notes that cranes migrate later than other birds; a few lines later (Arist.H.A.597a32-b1) he also notes that cranes may even fly into the wind when they migrate, i.e. against the southerly winds of a depression. However, the ancient Greeks were aware that cranes, like other bird species, 
preferred if possible to initiate their migrations when it was likely that fair winds and clear skies would aid them for the initial stages of their journey:

'When cranes takes flight and do not come back it is a sign of fair weather: for they do not do so until they see a clear sky before them as they fly.' (Theophr.Signs 52)

'Many instances of intelligence seem to occur among the cranes too. For they migrate a long way, and fly to a great height in order to survey the distance, and if they see clouds and bad weather (' $\chi \varepsilon 1 \mu \varepsilon \dot{\varepsilon} \rho \alpha^{\prime}$ - more accurately translated as 'wintry weather') they fly down and stay quiet.' (Arist.H.A.614b18-22)

'In summer they remain in their country, but in mid-autumn they leave for Egypt, Libya, and Ethiopia, appearing to know the map of the earth, the disposition of the winds, and the variation of the seasons.....Having waited for a fair and favouring wind from behind, and using it as an escort to speed them forward, they then form their order of flight into an acuteangled triangle, in order that as they encounter the air they may cleave it with the least difficulty, and so hold on their way.' (Ael.On Animals 3.13)

Migrating cranes, then, could be taken as a sign that weather conditions were for the moment fair enough for seafaring, but also that winter weather would return soon, so that they were also forewarners of the end of the summer sailing season:

'When to Libya the crane flies clanging again, it is time for the seed to be sown, and the skipper may hang up his rudder a while, and sleep after all his exertions.' (Aristoph.Birds 710f.)

Conversely, weather in which even cranes would not fly was weather which should also be avoided by seafarers:

'If a pilot observes on the high seas a flock of cranes turning and flying back, he realises that they have refrained from advancing further owing to the assault of a contrary wind. And taught, as you might say, by the birds, he sails home again and preserves his vessel. So the pilot's art, being a lesson and a discipline first acquired by these birds, has been handed on to mankind.' (Ael.On Animals 3.14) 
'Cranes flying in to land from the sea indicate to the intelligent man that a violent storm is threatening. But if the same birds are flying tranquilly, that is a promise of fine weather and a calm atmosphere; and if they make no sound they are reminding those who have experience that it will be fairly calm. And if they (fly in from the sea?) uttering their cries and confusing their order in their agitation, there again they are threatening a heavy storm.' (Ael.On Animals 7.7)

It was also important to note the manner of their departure, for as noted above (p.256f.), if winter was late in coming, and the favourable weather conditions of summer deteriorated only slowly, the birds tended to leave with little urgency, doing so individually or in small groups, at a slow but steady pace. If, however, winter arrived early and summer conditions were about to deteriorate rapidly, then the cranes reacted by leaving with far more urgency and in large flocks, all keen to start the migration before adverse conditions set in:

'In seasonable flight of thronging cranes rejoices the seasonable farmer: in untimely flight the untimely ploughman, For ever so the winters follow the cranes: early winters, when their flight is early, and in flocks: when they fly late and not in flocks, but over a longer period in small bands, the later farming benefits by the delay of winter.' (Arat.Phaen.1075-81)

'If cranes fly early and in flocks, it will be an early winter; if they fly late and for a long time, it will be a late winter; and if they wheel as they fly, it indicates stormy weather.' (Theophr.Signs 38)

In the second of these passages, Theophrastos finds one more aspect of the cranes' migration which can be used to help forecast weather: their manner of flight. Like all soaring birds, cranes are adept at rising on up-currents of air to reach a high altitude, from which they can see far and fly for long distances by gliding on a gradual descent ${ }^{618}$. It is when rising on such up-currents of air that cranes and other birds display the wheeling motion referred to here by Theophrastos, and also elsewhere by Aratos in the same context ${ }^{619}$.This is a method of flying which involves far less expenditure of energy than is the case when flying by simply flapping the wings, especially when gaining altitude ${ }^{620}$. Accordingly, when winds are not favourable, but instead are turbulent, or blowing in an adverse direction, it is more effective for cranes 
to seek out thermals and other up-currents of air on which to gain height relatively effortlessly, so as to reach a point where winds may be less turbulent, and from which it can make progress by gliding rather than by beating its wings. Thus Theophrastos is right to associate cranes wheeling upwards with rougher weather, particularly with obscured skies and turbulent winds. This is particularly true of the immediate vicinity of spots where cranes are seen wheeling upwards, for the up-draughts on which they do so are themselves often associated with rough conditions: currents of air which are rising, for whatever reason, may produce cloud if they reach a level where water vapour starts to condense into droplets (p.61ff.), while orographic up-currents, formed when an air stream is forced to rise to cross a relief barrier, produce turbulent eddies and squally conditions in the lee of the barrier, and can result in rain (p.59). This is especially true of islands and rocky outcrops in the sea (p.59f.), and as the upcurrents found in the lee of islands are often exploited by migrating birds ${ }^{621}$, it is quite feasible that wheeling cranes were taken by mariners to signify areas of the sea where dangerously turbulent wind conditions were to be expected, and so avoided. As such turbulent up-currents may be found in an area so far to the lee of the island causing the original disruption of the airstream that from that area the island itself, having dropped below the horizon, cannot be seen (p.58f.), wheeling cranes might appear to sailors as the only available clue to the presence of such turbulent winds.

However, cranes are also large and strong enough not to have to rely on such upcurrents of air, and in fairer conditions they prefer instead to make long direct flights in which they maintain their speed and altitude by making much more energetic use of their wings, in the manner of non-soaring birds ${ }^{622}$. The advantage of this latter method is that, given reasonable wind conditions (i.e. winds not so strongly adverse that the rate at which the bird advances against it is prohibitively slow in relation to the amount of energy it is forced to expend), the crane will make far faster horizontal progress than if it spends a considerable time simply gaining height on up-currents ${ }^{623}$, and also it will, by thus completing the journey in a shorter time, minimise the risk of running into foul weather. Clear skies, associated with northerly but not with southerly winds (p.48f.), also reduce the need to gain altitude for navigational 
purposes. Thus when wind conditions are favourable, i.e. calm or running steadily from the north, the crane may attempt direct flight without pausing to gain height, and this aspect of the relationship between cranes' manner of flight and weather conditions is also remarked upon by Aratos:

'Cranes, too, before a gentle calm, will wing their way onward in one track, all in a company, and in fair weather will be borne in no disordered flight.' (Arat.Phaen.1010ff.)

\section{The end of winter, swallows' spring migration, and the 'bird winds'.}

Some months later, the reappearance of swallows was taken as a sign of the return of spring and the re-opening of the sailing season (Hes.W\&D.448-51, 568f., 674-82, Anth.Pal.10.2.1ff., Aristoph.Birds 714, Ael.On Animals 1.52). However, in contrast to the abundant evidence for the detailed weather lore attached to the cranes' autumn migration, there are very few references in ancient literature to weather lore pertaining to the timing and manner of the swallows' spring migration from Africa to Greece. In fact, it is not just the references to such weather lore that are lacking, but rather the weather lore itself, apart from the general observation already cited, that their appearance heralded the return of spring and the start of the sailing season. The main reason for this is quite clearly that many Greeks, most famously Aristotle (H.A.600a10), thought that swallows hibernated in Greece over winter, rather than migrating to Africa ${ }^{624}$. However, it is surprising that the migration of the swallows was not known of through simple observation of the returning migrants, especially as their re-appearance was both interspersed with that of many bird species that were known to migrate, and also was specifically, if casually, associated with the advent of certain 'springtime' winds: the Greeks apparently thought that that the appearance of the swallows and of these winds were contemporaneous only by chance; in fact, the return of the swallows from Africa in spring was facilitated by the advent of these winds.

The winds in question were known, fittingly, as the ò $\rho v \imath \theta$ í $\alpha \iota$ $\alpha v \varepsilon \mu o \imath$, or 'bird winds' (for the even more specific 'swallow wind', see below, p.266). If we try to 
characterise these winds by reference to the descriptions of them given in ancient Greek literature, the result is neither clear nor very convincing. A number of authors state that they are northerlies (P.Hib.27.59 $9^{625}$, Arist.De Mundo395a4, Met.362a2331), while others describe them as cold and strong winds (Hipp.Epid.7.105 (quoted below, n.628), Democ.14.3, 7), which in winter again suggests northerly winds such as Boreas. Aristotle gives the most detailed descriptions of the bird winds, but, while the shorter of the passages (De Mundo 395a4: 'The so-called Ornithian winds, which occur in spring, are a northerly type of wind.') is quite unequivocal, the longer passage is rather confused:

\begin{abstract}
'Similarly after the winter solstice the Bird winds blow. These are feeble Etesian winds, blowing later and with less force than the Etesian winds proper. They do not begin to blow till the seventieth day after the solstice, because the sun is then farther off and so has less power....So they blow intermittently until the Etesian winds rise again at the summer solstice; for from then onwards the wind tends to blow almost continuously.'

(Aristotle, Met.362a23-31)
\end{abstract}

This description of winds which last from seventy days after the winter solstice until the summer solstice, i.e. for around sixteen weeks, is clearly at odds with the more general opinion that the bird winds were a far shorter-lived phenomenon - Democritus $(14.3,7)^{626}$ and Pliny (H.N.2.47, quoted below, p.266) for example, while agreeing almost exactly with Aristotle on the date at which the bird winds start, asserted that they lasted for only nine days. In fact, Aristotle's description could equally well describe those northerly winds known as the 'forerunners' ( $\pi \rho \circ \delta \rho o ́ \mu o 1)$, which were said to blow as weak northerlies until the Etesians proper set in full strength after the summer solstice (Arist.Met.361b24, Prob.26.12). Aristotle's assertion that the bird winds were northerly is accepted by Tozer ${ }^{627}$, but questioned by Lee, who argues i) that an ancient commentator (Alex.99.11) identifies the bird winds of Met.362a23-31 with the southerly winds mentioned at Met.362a14, and ii) that the association of the winds with migrant birds returning in spring suggests that they were indeed southerly winds ${ }^{628}$. Arguing that Aristotle likened the bird winds to the Etesians for reasons other than their direction, Lee concludes that the bird winds were 
in fact southerly, despite De Mundo 395a4. However, there are also good reasons for questioning Aristotle's assertion that the bird winds were southerlies ${ }^{629}$. Another possibility is that there is some confusion here between the spring bird winds and the autumn winds on which birds migrated south, which were indeed northerlies (see above, p.258f.): Aristotle's capacity to confuse elements of the spring migration with those of the autumn migration is indeed seen elsewhere, at H.A.597b9-13 (quoted on p.258), where, in a discussion of how quails migrate south in autumn, he refers to how they 'pair off' ( $\sigma \cup v \delta \cup \alpha ́ \zeta o v \tau \alpha i$; i.e. as breeding couples) in fair weather: breeding, of course, occurs only after returning to Greece on the spring migration, not while stopping off on the autumn journey south. So, were the birds winds in fact southerlies, or from another direction altogether?

Birds, as we have seen (above, p.256ff.), look for optimum conditions, in terms of clear skies and wind direction, in which to undertake their migrations. Typical winter conditions, with strings of deep depressions crossing from west to east, may bring southerly winds that would suit spring migrants returning north, but they also bring obscured skies, precipitation, and stormy conditions, and so are unsuitable for migrating birds at any time of year. Typical summer conditions, on the other hand, do bring clear skies, but also constant and forceful northerlies, the Etesians, blowing all the way from Europe to Africa. These are ideal for birds migrating south in autumn, but wholly impractical for those migrating back to Greece from Africa in the spring. Neither those conditions typical of summer, nor those typical of winter, then, are well suited to spring migrants seeking a combination of clear skies and winds that will not impede their progress ${ }^{630}$. However, there is a springtime transitional period between winter and summer, when winter conditions have started to ease, but summer conditions have not yet settled in. During this period, in the absence of depressions, anticyclonic ridges of high pressure periodically develop over the Mediterranean, bringing clear skies and light winds which, over Greece, blow as westerlies (p.49), and have tentatively been identified with Zephyros, the light west wind said by the ancient Greeks to usher in spring (see above, p.254f. and n.609). Such conditions are ideally suited to birds keen to migrate northwards to their breeding grounds ${ }^{631}$. 
Moreover, the period of the year during which these conditions develop is also compatible with the birds' opposing instincts to return as early as possible, so as to be able to breed, and to delay the return until warmer weather (and so also insect food) could be found even at the northern end of the migration route. Thus the time of the winter-summer transition, which mariners were keen to forecast (above, p.254), was also a natural time for birds to undertake their northwards migration.

It is possible then, that the westerly winds associated with springtime anticyclonic ridges over the Mediterranean can be identified both with the west wind Zephyros, which was taken as a sign of spring and of the arrival of safe seafaring conditions (above p.254f.), and with the bird winds on which swallows (and some other birds) returned to Greece, also marking the advent of spring. Here it is significant that Oppian records a tradition in which the appearance both of the swallow and of Zephyros are linked together as signs of spring: if the bird winds and Zephyros were different winds, then this tradition would make little sense ${ }^{632}$ :

'...the mother swallow, the bird that first heralds the Zephyros of spring.' (Opp.Hal.3.244)

Other larger and stronger birds, being able to cope with more windy and wintry conditions, and so not having to rely as heavily as the swallow upon anticyclonic weather, tended to return to Greece, and so mark the advent of spring, rather earlier in the year than the swallow (e.g. the kite, for whose connection with spring, and with springtime concerns other (and apparently commencing earlier in the year) than seafaring, see the reference to Aristoph.Birds $713 \mathrm{ff}$. in n.615 above). However, it was not until the swallows returned that it was thought safe to return to the sea, and this surely must be the case precisely because swallows' migration occurred under exactly those typical springtime weather conditions which were held to provide the first opportunity for seafaring. Thus, in the following passage, written in the third century $\mathrm{BC}$ by Leonidas of Tarentum, the advent of the swallow and of Zephyros are not only connected, but are both cited as signals of the opening of the sailing season, thereby 
also providing the type of cross-referencing of weather signals recommended by

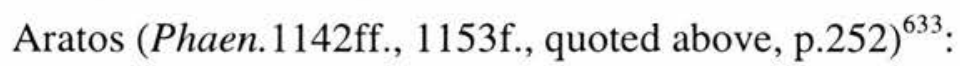

'It is the season for sailing; already the chattering swallow has come, and the pleasant Zephyr, and the meadows bloom, and the sea with its boiling waves lashed by the rough winds has sunk to silence. Weigh the anchors and loose the hawsers, mariner, and sail with every stitch of canvas set. This, O man, I, Priapos, the god of the harbour, bid thee do that thou mayst sail for all types of merchandise.' (Anth.Pal.10.1)

Such association of the swallows' return with the spring advent of Zephyros, both signalling the opening of the sailing season, further strengthens the argument for equating the bird winds with the westerly Zephyros. Pliny makes the connection even more strongly:

'Accordingly the spring opens the seas to voyagers; at its beginning the West winds soften the wintry heaven, when the sun occupies the 25th degree of Aquarius; the date of this is the 8th February....Certain persons give the name Chelidonias to the West wind on the 19th February, owing to the appearance of the swallow, but some call it Ornithias, from the arrival of the birds on the 71st day after the shortest day, when it blows for nine days.' (Pliny.H.N.2.47)

It is not clear here whether Pliny is saying that Chelidonias, the 'swallow wind', is an alternative name for the 'bird wind', for both seem to apply to Zephyros ${ }^{634}$, but on different dates, the bird winds apparently coming later than the swallow winds (an order hard to credit, given the late arrival of swallows in comparison with that of other birds ${ }^{635}$ ). It may be, again, that Pliny is recording details from two separate traditions, each of which stem from the same original observation of the contemporaneity of the advent of these westerly winds in spring and the return of swallows and other birds from their winter homes. In any case, Pliny clearly states that Zephyros and the bird winds are one and the same, and that swallows and other birds return from Africa during the period in which it blows.

Notwithstanding any confusion over the identity of the bird winds, it is clear that the seasonal migrations of birds, both in autumn and in spring, were of great value to the 
mariner in his attempts to forecast seasonal changes in the weather. Such animal behaviour, being directly related to the annual changing of the seasons, provided a more reliable indicator than solar and astronomical signs. Solar and astronomical signs merely indicate the date of the solar or calendar year, according to which certain weather conditions would be expected to prevail, but by additionally paying close attention to changes in actual weather conditions, and to such bird behaviour as was directly related to changes in the weather, seafarers effectively extended the limits of the sailing season (or, to put it another way, forecast periods of good sailing conditions that fell outwith the theoretical limits of the sailing season as defined according to astronomical events), according to how early signs of spring weather conditions started to appear, and to how late signs of summer weather conditions persisted, in any given year ${ }^{636}$.

\section{Plants as signals of changing seasons.}

Even plant life could be seen to give clues as to the state of the weather. The annual growth cycle of plants, like the timing of bird migrations, is tied to the annual climatological cycle, and so different stages in a plant's growth marked different stages of the year's weather. Again, different plant species respond to changes in the seasons earlier than others, just as different species of bird migrate earlier than others, so particular events in the growth cycle of particular plants could be taken as indicators of weather suitable (or unsuitable) for sailing in, in the same way that the migrations of particular species of bird were. Thus many references to Zephyros' and swallows' role in marking the start of the sailing season also cite the reappearance of meadow flowers, and Hesiod reckoned weather conditions to have improved enough for sailing when the fig tree had come into leaf ${ }^{637}$ :

'Another time for men to go sailing is in spring when a man first sees leaves on the topmost shoot of a fig tree as large as the foot-print that a crow makes; then the sea is passable, and this is the spring sailing time.' (Hes.W\&D.678-82) 


\section{APPENDIX FOUR: Terrestrial and 'socio-maritime' functions of features of coastal topography.}

This appendix includes material relating to the significance of headlands, islands, and other topographic features which, while bearing directly upon maritime affairs, does not actually pertain specifically to the processes of navigation and of sailing techniques. This material is not only significant in its own right, but also reflects (and indeed is directly related to) the truly maritime and 'navigational' significance of different features of coastal topography.

\section{Coastal settlements and natural indentations.}

The role of indentations as places of shelter is most clearly reflected in settlement patterns, especially in earlier Greek history, when artificial harbour works were as yet in their infancy, and settlements, not by chance, often developed close to naturally sheltered indentations in the coast (pp.95f., 110-6). Thus, for example, the site of the early Greek community of Emborio on Chios, and the success of the town's harbour attracting not only locally-produced votives, but also dedications from diverse parts of the eastern Mediterranean, have been linked to the location of the natural harbour there, ideally placed as a sheltering point for any ships having difficulty sailing either north, through the often problematic Chian strait to the island's asty, or south towards the open and exposed waters of the Aegean (p.97 and n.281, fig.11, map). Where indentations were well protected against prevailing winds, and also offered easy access inland, as on the east-west faulted west coast of Asia Minor, settlements were perhaps particularly likely to develop (p.123).

\section{Religious associations of headlands, islands, and straits.}

The far more developed terrestrial and 'socio-maritime' roles that headlands, offshore islands, and straits, in comparison with other features of the coastline, assumed, can also be related to their greater navigational significance. As we have seen (pp.171, 175, fig.1), a high proportion of coastal sanctuaries are situated either on headlands, on offshore islands, or along the shores of straits, and this is related to the 
navigational significance of these areas not only directly, through the use of such shrines as leading marks and reference points in coastal pilotage (pp.175-8), but also indirectly, through seafarers' recourse to religion as an expression of their fears, hopes and general concerns when sailing in these areas of particular danger and navigational importance (n.430). The correlation between the points at which mariners resorted to religious activity and the points which they found to be dangerous or otherwise important in navigation, or both, can be seen in the following passage of the first century $\mathrm{AD}$, which apparently relates to a voyage westwards from the eastern end of the Corinthian Gulf:

Blest god of the harbour, accompany with gentle breeze the departing sails of Archelaus through the undisturbed water as far as the open sea, and thou who rulest over the extreme point of the beach, save him on his voyage as far as the Pythian shrine. From thence, if all we singers are dear to Phoebus, I will sail trusting in the fair Zephyros.' (Anth.Pal.10.17)

We have seen (pp.142f., 145-52) that voyages can be 'broken down' into an initial stretch from the point of departure from land to the first headland of the coast at which a change of direction was to be made, followed by a series of stretches between successive headlands and offshore islands, until, on a long-distance voyage, the ship headed out to the open sea from a suitable headland or offshore island. The significant coastal features on such journeys were the initial point of departure and particularly the headlands, but also the offshore islands, at which the ship most closely approached the shore, where dangerous or at any rate changing sailing conditions (i.e. winds, currents) might be met (pp.67-78), and where changes in direction were made (p.158ff.). These are exactly the points at which the author of this epigram describes changes in the nature of the journey and inserts appeals to different gods. Thus the sailor looks to the harbour god to protect him through the 'undisturbed water' of the sheltered coastal zone, as far as the sheltering headland in which the coastal indentation holding the harbour terminates. At this point, where the shelter provided by the headland is lost, and stronger winds and waves are encountered, the ship has reached the 'open sea', and the god with a shrine on this headland is appealed to for protection as far as the next shrine on the (coastal) route, the 'Pythian shrine'. Beyond 
this point, the ship will trust in 'fair Zephyros'. This detail, describing how the ship's bearing is no longer set according to visible coastal landmarks, but simply by sailing with a particular wind, is indicative of the transition from coastal sailing to open-sea sailing. On striking out over the open sea, where there will be no more shrines at which religious protection can be sought, the sailor relies upon the good will of Phoebus, the god of the coastal shrine from which the ship headed out to sea, and Zephyros, the wind/god that will carry him across the seas. Thus it can be seen that religious activity focuses on the most significant points of the journey - the harbour of departure, the headland where the ship meets less sheltered conditions and sets a bearing for a point further along the coast, and the coastal shrine from which the ship heads out onto the open seas.

Furthermore, the siting of sanctuaries, tombs, and other memorials on headlands and offshore islands, and along the shores of straits, is a direct reflection of the increased concentration of maritime traffic at those points, for such monuments were intentionally placed to be seen by the greatest possible numbers of passers-by (p.172f. and nn.423, 425), and it was doubtless this intentional visibility that led to their being used as landmarks and milestones (pp.175, 178, 183f.). Another interesting aspect of those sanctuaries located at points of the coast which had considerable navigational significance is that a higher proportion of these functioned as the centres of amphictyonies than is the case for sanctuaries generally (fig.1). The most famous such sanctuary was that of Apollo at Delos, a central point on Aegean sea routes, and the centre of the Delian League. Others were the sanctuary of Hera at Cape Lakinion, on the southern 'heel' of Italy (for the navigational significance of which, see p.153f., and n.387), which held a festival of all Italian Greeks, the sanctuary of Poseidon on a headland near Samikon on the west coast of the Peloponnese, which was the centre of the Triphylian league, the sanctuary of Poseidon on Kalauria, an island at the southwestern end of the Saronic Gulf, which was the centre of the Kalaurian League, and the Panionion, on the slopes of the peninsula of Mykale, overlooking the eastern entrance to the Samian strait, which was dedicated to Poseidon, and was the central meeting place of the Panionian League ${ }^{638}$. The siting of these amphictyonies reflects 
not only the basic religious associations of such locations, and the geographically and socio-politically isolated aspect of many promontories and islands, but also the greater accessibility of such sites, from various seaward directions; in such ostensibly nonhierarchical organisations, drawing members from a wide catchment area, this freedom and equality of access to the administrative and religious centre was significant in both symbolic and practical terms.

Similarly, the visibility and accessibility of headlands led to their being commonly the sites of trophies erected after naval victories in the waters nearby, for trophies, as memorials to the victors' prowess, were designed to be seen by as many passers-by as possible. Just as the fact that headlands are the parts of the coast that protrude furthest into the open seas led to them being the points of land to and from which open-sea crossings were made (pp.145-9), so, too, headlands were chosen as trophy sites because they would most often have been the points of land closest to, and most readily reached from, the sites of naval battles. Trophies were also often erected as dedications in sanctuaries, and here again, if chosen on the grounds of proximity to the site of the battle, rather than reputation (i.e. the number of visitors who would see the trophy), such sanctuaries were likely to be situated headlands (or islands, or overlooking straits). As such sanctuary sites were in any case generally connected with maritime activity in the area (see above), the gods worshipped there were likely to be fitting recipients for dedications related to naval battles.

Thus, in the aftermath of both of Phormio's encounters with his Peloponnesian enemies in the Corinthian Gulf in 427B.C. (for the battles, see p.87ff.), trophies were set up in sanctuaries situated on nearby headlands, as well as at Delphi. After the first encounter, fought outside of the strait at Rhion, the victorious Athenians

'sailed away to Molykreion; then they set up a trophy on Rhion, dedicated a [captured Peloponnesian] ship to Poseidon [i.e. at his temple on the headland of Molykrian Rhion there], and returned to Naupaktos.'

(Thuc.2.84.4) 
In the second encounter, the Peloponnesians sailed through the Rhion strait, prompting the Athenian fleet lying at Molykreion to sail out, whereupon the Peloponnesians attacked, defeating roughly half of the Athenian fleet, the other half escaping to Naupaktos and 'riding at anchor off the temple of Apollo' (Thuc.2.91.1). Taking advantage of a confused and disorganised Peloponnesian advance, the eleven Athenian ships charged out from their mooring place by the temple, and emerged victorious from the ensuing encounter. Both sides therefore claimed at least partial victory, and accordingly the Athenians 'set up a trophy at the place from which they had set out and won the victory' (Thuc.2.92.4), while the Peloponnesians 'also set up, in token of victory, a trophy.....and the ships which they had taken they dedicated on the Achaian Rhion by the side of the trophy' (Thuc.2.92.5) ${ }^{639}$.

\section{The military and naval significance of headlands, offshore islands, and straits.}

Many naval battles actually took place just off headlands, or within straits, especially when a fleet being attacked had a chance of determining the site of the battle. Straits were often the choice because the restricted room for movement there effectively minimised an enemy's advantage of superior manoeuvrability or numbers (see p.90ff. and n.263). Otherwise, a combination of topographic, oceanographic and meteorological factors created difficult or even dangerous sailing conditions around many headlands and straits, and thus it was at such sites that defending fleets could best exploit their own knowledge, and their enemy's relative inexperience, of their local seas and weather. Thus Phormio's choice of site for his battles in 429 BC allowed him to exploit his numerical superiority and his crews' greater ability to deal with rough sea conditions ${ }^{640}$. So too, during the Peloponnesian War, difficult sailing conditions in the Chian strait turned victory into disaster for Athenian triremes attacking local warships, and, in 88B.C., the Rhodian fleet defeated that of Mithridates by taking exploiting the navigational difficulties experienced by Mithridates' ships while crossing the strait between Rhodes and the mainland of Asia Minor (p.91f.). 
In the case of seaborne attacks on coastal areas, we again find that, because they are both navigationally and strategically important points, and also are easily approached from the open sea, headlands, offshore islands, and straits are typically the topographic features most readily and heavily targeted. This is stated as a general principle by pseudo-Xenophon in his discussion of the advantages of Athenian seapower:

'In addition to this, every mainland has either a projecting headland, or an offshore island, or a narrow strait, where it is possible for those who control the sea to put in and harm those who dwell there.' (ps-Xen.

Ath.Pol.2.13)

An example of the application of this principle can clearly be seen in Athenian naval attacks upon the Peloponnese during the Peloponnesian War. Many fleets were at that time sent round the Peloponnese to attack areas of coast under Spartan control, and to establish fortified areas from which further raids could be made. Whether simple raids were made, or long-term fortifications established, headlands and off-shore islands tended to be the points at which these operations were directed. This was partly because, by land, such areas were easiest to defend against Spartan forces, but equally important were the facts that such points on the coast were the most easily reached and defended from the sea, subsequently were the most easy sites to resupply and reinforce from the sea, and also were the best points from which to control the seas roundabout.

Thus in $431 \mathrm{BC}$ an Athenian fleet, headed significantly for Corcyra, coasted around the Peloponnese pillaging and making depredations at various points (Thuc.2.25). Thucydides names only Methone, a town on one of the extreme headlands of the Akritas peninsula in southwest Messenia, and the town of Pheia on the Ichthys headland in Elis. In the same year the Athenians expelled the Aiginetans from their island, on the grounds that they were to blame for the outbreak of war, and 'besides, Aigina lay close to the Peloponnese, and it was clearly a safer policy to send colonists of their own to occupy it.' (Thuc.2.27). Later in the year, the Athenians also fortified and garrisoned Atalante, 'the island which lies off Opuntian Lokris and had hitherto 
been unoccupied. Their object was to prevent pirates from sailing from Opous and the other ports of Lokris and ravaging Euboia.' (Thuc.2.32).

The following year (430 BC), the Spartans equipped the fleet which was eventually defeated by Phormio in the Corinthian Gulf. One of the original reasons for forming the fleet was 'to make themselves masters of Zakynthos and Kephallenia also; after that the Athenians would no longer be able to sail round the Peloponnese in the same way as before.' (On the navigational, and therefore also strategic, importance of the Ionian islands generally, see p.153f. and nn.384, 386, 387)

In $425 \mathrm{BC}$ the Athenians despatched forty ships to Sicily, permitting Demosthenes, one of the strategoi in command of the fleet 'to use the forty ships at his discretion in operations about the Peloponnese' (Thuc.4.2.4). When the fleet was forced to shelter from bad weather at Pylos, the only good harbour on this part of the coast ${ }^{641}$ (fig.56.iii), Demosthenes stressed the defensive advantages of the place and the value of fortifying it, but 'the other generals said there were many unoccupied headlands in the Peloponnese, which he could seize if he wished to put the city to expense.

Demosthenes, however, thought that this place had advantages over any other; not only was there a harbour close by....' (Thuc.4.3). Here again we can see not only the practice of targeting particular strategic headlands and offshore islands, but also, in the other generals' reservations, the general principle of targeting headlands and offshore islands (the generals' reservations concern the cost of such operations, but implicitly recognise their tactical value). Note also that the Spartans originally placed hoplites on Sphakteria because 'they were afraid that the Athenians would use it as a base for carrying on the war against them.' (Thuc.4.8.6). When an Athenian fleet arrives and finds Sphakteria inaccessible, it turns instead towards another offshore island in the region, Prote (Thuc.4.8.6; for this island, see n.416).

During the same year, a second Athenian fleet attacked Solygeia, on the Corinthian coast of the Saronic Gulf (Thuc.4.41-4). Afterwards, the fleet raided several other places on the Peloponnesian coast of the Saronic Gulf, but made its only permanent 
incursion at the promontory of Methana, which was fortified and garrisoned as a base from which the Argolic peninsula could subsequently be raided. (Thuc.4.45.2). The following year (424 BC), the Athenians sent sixty ships against Kythera, took the island, and then proceeded to raid nearby parts of the coast of mainland Lakonia from the island (Thuc.4.53-6).

In $419 \mathrm{BC}$, Alcibiades attempted to fortify the headland of Achaian Rhion (Thuc.5.52), which, given the pro-Athenian status of Molykrian Rhion across the strait (for which see Thuc.2.83ff.), would have given the Athenians complete control of the entrance to the Corinthian Gulf.

Finally, in 413 BC, thirty ships under Charicles, aided by fifty-five headed for Sicily under Demosthenes, sailed round the Peloponnese (Thuc.7.20), attacking Epidauros Limera and then

'landing on the coast of Lakonia opposite Kythera, where the sanctuary of Apollo is, they ravaged portions of the land and fortified a place shaped like an isthmus, in order that the helots of the Lakedaimonians might desert thither and that at the same time marauders might make it, as they had made Pylos, a base for their operations.' (Thuc.7.26).

Overall, the evidence from Thucydides reveals a general pattern whereby Athenian fleets were prepared to make short raids against almost any type of area on the Peloponnesian coast, but only made concerted attacks, and attempted to establish permanent operational bases, wherever there were isolated headlands (Methone, Pheia, Pylos, Methana, and on the Malea promontory) or offshore islands (Aigina, Atalante, Sphakteria, Kythera). It is important to realise that such sites were chosen not simply because the Athenians, having effective control of the seas, were more able to defend them, but also because of their navigational accessibility and significance.

Just as headlands and offshore islands were the points at which the Athenians established bases in Peloponnesian territory, and again by reason of their strategic and navigational importance, so headlands and offshore islands were most often the 
features of coastal topography fortified by home states in order to protect their shipping and their coastline from enemy attack (see p.158 and n.390). Just as headlands and offshore islands are visible from far out to sea, and so make excellent landmarks (p.167ff.), so too viewers from such points can gain far-reaching and panoramic views of the seas roundabout (see Hom.Il.2.791-4, quoted in n.431).

\section{The role of headlands in fishing.}

The panoramic views available from headlands led not only to their being used as lookout points against enemy fleets and pirates, but also as watch stations for fish, particularly for tunny. Tunny, during their annual migrations, made for particular bays and shoals, and it was in such places that they could be harvested most easily and in the greatest numbers. However tunny hunts were large-scale operations which had to be properly timed and co-ordinated; for this purpose, watching stations were established on local headlands, from where the approach of the tunny shoals could best be tracked, and the movements of the fishermen could be best directed ${ }^{642}$.

\section{The role of headlands and offshore islands in colonisation.}

Whereas many indigenous Greek coastal settlements were located next to indentations that offered good natural harbourage (above, p.268), colonies were far more likely to be situated on offshore islands or headlands. As in the case of the bases established in the Peloponnese by the Athenians during the Peloponnesian War (above), the choice of site was no doubt heavily influenced by the fact that headlands and offshore islands are most easily defended against local inhabitants ${ }^{643}$. However, headlands and offshore islands were also chosen because they tended to be the points to and from which overseas sailing routes led, with other parts of foreign coasts being reached after an additional coasting voyage from the headland or island at which landfall from the open sea was first made (pp.145-52). This can be seen in the early colonisation of Corcyra, the island that controlled the 'coastal route' to Italy, by the Corinthians, and in many of the colonies later established in Italy and Sicily, especially those around the Straits of Messina, beyond which mariners had either to pass through the Straits, which were easily controlled by local powers, or around the potentially hostile coast of Sicily. By 
choosing such sites, colonists could ensure both that they had only to sail relatively direct routes in order to return to the metropolis, and also that they could do so, or indeed sail for any other overseas destination, without having to pass along stretches of coastline controlled by neighbouring colonies or by natives. 
1. Further, Murray (1987) p.139 argues assertively that the physical environment, especially winds and coastal topography, is the key to understanding episodes in all aspects of human activity on the seas and in coastal areas in ancient Grecce.

2. For the archaeological evidence for this general lack of development in maritime technology, see Parker (1992) pp.23-26. Of course various techniques of ship construction were used in different areas of the Mediterranean, and various types of ship were used at different times, but there were few radical developments in the technology used to design, build and sail these ships. Developments in ship design and technology are described and accounted for in app.2. The other major area of technological innovation was in the development of artificial harbour works, for which see $\mathrm{p} .95 \mathrm{ff}$. and n.278f.

3. In many cases, these later authors have proved valuable because they contain references to ideas and knowledge not available to earlier authors. While Homer, for example, displays a detailed knowledge of many aspects of the marine environment and of sailing practices (as will become clear to the reader as the thesis progresses), there are also areas which he either was ignorant of or chose not to refer to. Many centuries later, both Apollonius of Rhodes and Quintus of Smyrna sought to rekindle the style of Homeric epic, but contemporary and modern audiences alike tended to see their works as poor imitations of Homer, rather than independent works of some quality (see $O C D$ sv. Apollonius (1) Rhodius, Quintus Smyrnaeus). However, while researching the present thesis, the author found that many of the aspects of the marine environment and of sailing practices not mentioned by Homer are in fact referred to by Apollonius or by Quintus, often in similes which, therefore, resemble Homeric similes in style, but not in content. Marine erosion, for example, is described in detail by Quintus (Fall of Troy 9.374-384, see p.24), as is mariners' use of land breezes to clear land at dawn by Apollonius (Arg.1.1273ff., 4.1223f., see p.109f.), but neither of these subjects are ever treated in Homer. For these reasons, then, material from later authors has proved very important for the purposes of this thesis, and this importance underlines the fact that authors such as Apollonius and Quintus not only had the literary knowledge and skill to recreate the style of Homeric epic, but also had a scientific and cultural knowledge that was of equal breadth to, and independent of, that of Homer. For other aspects of the marine environment and of seafaring mentioned by Apollonius or Quintus but not by Homer, see Fall of Troy 2.216ff. (p.33) 11.226-232 (p.35) and Arg.1.922-8 (p.73), 925-935 (p.86), 1159ff. (p.55), 2.360ff. (p.57), 728-32 (p.39).

4. McCaslin (1980) p.88: "Climate and weather: In the opinion of most scholars, these two factors have not significantly changed since the Late Bronze Age." In n.1 he cites Rouge (1966b) p.39 as the most emphatic proponent of this opinion. Earlier, both Semple and Meigs had reached similar conclusions (Semple (1932) p.100, Meigs (1961) p.374), on the evidence that ancient crop types persisted alongside more recent introductions and tillage methods and traditional dates of the agricultural year remained very similar to those recorded by Hesiod and other ancient authors. See also the comments of Cary (1949) p.3. For examples of studies drawing on modern wind data to evaluate aspects of seafaring in the ancient world, and for further expressions of opinions on the likelihood of climate and wind change since ancient times, see Murray (1987) p.139f.

5. Murray (1987) p.156: see also Murray (1995) pp.33, 37f., and the similar comments of Mantzourani and Theodorou (1991) p.46f. on the lack of climatic change since $900 \mathrm{BC}$. So too the opinion of Bintliff (1977) p.51, and the more developed arguments of Bintliff (1982) p.152, e.g. 'Careful study of literary sources gives strong evidence for a climate during this era [700-200 BC] comparable to that of the present day.'.

6. Murray (1987) p.140 and nn.11, 18, Coutant and Eichenlaub (1975) pp.xxiv - xxvii. See also Neumann and Metaxas (1979) p.185f., who make the same point, and also cite arguments that the 
Etesians would have been slightly more strongly developed during a cooler climatic period. Again, however, this would make no significant difference in terms of this thesis.

7. Pryor (1988) p.12f. Mantzourani and Theodorou (1991) p.46f., in their study of maritime cultural and trade routes between Crete and Cyprus during the Bronze Age, also emphasise the absence of significant changes in the oceanography of the Mediterranean since ancient times, and the validity of modern meteorological and oceanographic data for the interpretation of ancient history.

8. For ancient references to Onougnathos as a headland, rather than the island it is now, see Paus. 3.23.1, Str.Geog.8.5.1.

9 Pirazzoli et al. (1994) 206, Papageorgiou et al. (1993) 279f., Bintliff (1977) pp.9, 24.

10. See Cary (1949) pp.163 (the Maeander), 295 (the Vardar). Hammond (1968) p.22 also argues that deposition in the sheltered bay of Marathon in Attica, and that of Pylos in Messenia, has advanced the shoreline in both of those areas.

11. Mantzourani and Theodorou (1991) p.47 similarly note that apart from erosion, isostatic and tectonic changes, modern coastlines are very similar to those of antiquity.

12. See, for example, Stiros (1995) p.21 on the coastline at the tip of the Perachora peninsula.

13. It will be noted that ancient wrecks are not here included amongst the main sources of evidence. Where relevant to, or illustrative of, the maritime significance of particular features of the physical environment, some rediscovered ancient wrecks have been alluded to, principally in the notes.

However, I have not attempted to make more of the considerable number of ancient wreck sites in Greek and other Mediterranean waters (Parker (1992) p.6 puts the number of wrecks recorded by the Greek Department of Underwater Antiquities at 1000, although only a very small proportion of these have been published), for to cite wrecks whenever and wherever they may individually be deemed to provide supporting evidence for the maritime significance of a particular geographical area or topographical feature could only be justified by undertaking some form of statistical analysis of the geographical and topographical positions of all known wrecks in the areas covered by this thesis.

Such analysis, unfortunately, could not hope to provide constructive or reliable information for our purposes, because of a number of factors which mean that the wrecks rediscovered in recent times, numerous though they are, are not a representative sample of the far larger total number of ships which were wrecked in the Mediterranean in antiquity. Thus diving, the principal technique by which ancient wrecks are found, is only very practical and effective in relatively shallow and coastal waters, so that the relatively small number of wrecks found in very deep water (for which see Parker (1992) p.5, table 1) does not imply that relatively few ships sank in deep water in antiquity.

Similarly, just as, in the Mediterranean as a whole, disproportionately large numbers of wrecks have been discovered wherever amateur diving has been most popular (Parker (1992) p.6), so too the fact that roughly half of the wrecks discovered in the Aegean lie off the coasts of the Dodekanese islands, and in the straits separating those islands from the southwest coast of Asia Minor (see Parker (1992) map 13), may relate as much to the strong recent historical tradition of sponge diving in that area than to any idea that such a large proportion of ancient maritime traffic passed through this admittedly important area, or that this area was so much more prone to cause shipwrecks than other areas of the Aegean. Thus Frost (1963) passim. demonstrates the importance of knowledge gathered by sponge divers concerning ancient wrecks, and notes (p.14) that 'The Bodrum divers have an unsurpassed knowledge of their coastal waters, and in Karia [i.e. in the divers' local waters], where a long history of piracy is combined with natural hazards, there are many ancient wrecks.' See further the comments of Frost (1982) p.272, Frost (1993) p.449, and, for examples of wrecks found by Dodekanese sponge divers, Parker (1992) p.57f. \#50, p.453 \#1238.

It may also be argued that in areas where shipwrecks were particularly likely to occur because of local physical conditions (strong currents, storm waves, rocky coasts, etc.), those physical conditions 
will also tend to destroy or disperse the remains of wrecks in the area. Similarly, where less harsh physical conditions (such as sandy or sedimental coasts and sea floors, weak currents, and sheltered waters) led to fewer shipwrecks, those few shipwrecks that happened to occur would be more likely to survive in a better state of preservation because of the physical conditions of the area in which the shipwrecks occurred. Thus the numbers of wrecks rediscovered in sheltered, relatively safe, areas may be disproportionately high: compare the comments of Frost (1963) p.3 on the surprising frequency with which stone anchors are found in some types of sea floor topography, and the infrequency characteristic of others. For these reasons I believe that the validity of any statistical analysis of wreck sites would be questionable, and I have therefore not attempted to assess either the danger presented by different topographical features, or the sailing routes used by the ancient Greeks, through the evidence provided by wrecks.

14. Semple (1932) pp.584, 587, Tozer (1873) pp.66, 72, Cary (1949) p.46, Walker (1962) p.7.

15. Cary (1949) p.39f., Walker (1962) p.336.

16. Walker (1962) p.3, Cary (1949) p.1, Bintliff (1977) p.5, Melentis (1977) p.266ff.

17. Walker (1962) p.335.

18. Bintliff (1977) pp.6-9.

19. See Str.Geog.1.3.4f., discussing the views of Eratosthenes, Strato, Xanthus the Lydian and other earlier geographers.

20. Walker (1962) p.406, Pinar-Erdem and Ilhan (1977) p.308.

21. Walker (1962) p.7, Cary (1949) p.40, Bintliff (1977) p.7, Mantzourani and Theodorou (1991) p.46, Melentis (1977) p.267, Renfrew and Wagstaff (1982) p.74.

22. Cf. Str.Geog.2.1.40, 4.8, quoting earlier authorities.

23. Walker (1962) p.335f., Bintliff (1977) p.6f., Melentis (1977) p.266ff.

24. See further Bintliff (1977) p.9 and Walker (1962) p.335 on the geology of the southern Peloponnese.

25. Or, less commonly, NW, as in the case of Keraunia on the coast of Epeiros, for which see pp.75, $100,151,155,191$.

26. For such 'Pacific' coasts, named after the area where they are most commonly found, see Horrocks (1981) p.144f.

27. East coast of the Parnon range - Mediterranean Pilot IV p.93, New Pilot p.211f., Cary (1949) pp.81, 89f; Epeiros - Cary (1949) pp.45, 57, Hammond (1967) p.8f.; Thessaly - New Pilot p.223, Cary (1949) pp.45, 63; Euboia - Mediterranean Pilot IV p.237f., Cary (1949) p.73.

28. Xerxes repeatedly failed to heed warnings: Hdt.7.10f., 35f., 46-50.

29. Pinar-Erdem and Ilhan (1977) p.308, Walker (1962) p.406..

30. Walker (1962) p.3, Cary (1949) p.40f.

31. See, for example, Walker (1962) p.345f., on the eastern coasts of the Adriatic.

32. Beckinsdale (1956) p.193 summarises of the process. 
33. See Beckinsdale (1956) p.181, 188ff., Horrocks (1981) p.8ff.

34. See Beckinsdale (1956) p.180f., Trenhaile (1987) pp.269, 271f., Horrocks (1981) p.8ff.

35. Beckinsdale (1956) pp.295ff., Horrocks (1981) p.151.

36. For other occurrences of $\dot{\alpha} \lambda \hat{\jmath} \xi \alpha \nu \tau \mathrm{O}$ see IG 91.878 and Anth.Pal.7.404.

37. Beckinsdale (1956) p.297, Trenhaile (1987) pp.266, $267 \mathrm{ff}$.

38. Horrocks p.151, and cf. n.21 above.

39. Beckinsdale (1956) p.295, Trenhaile (1987) pp.12f., 17, 23, 272, 275.

40. Trenhaile (1987) p.269f.

41. See Hdt.8.15 and How and Wells (1912) loc. cit.

42. Trenhaile (1987) p.271ff., Beckinsdale (1956) p.297. Ap.Rhod.Arg.2.568f., quoted above, p.28, describes of a typical series of such caves.

43. Trenhaile (1987) p.273.

44. See Frisk (1970) and Boisacq (1950) s.v. $\sigma\rceil \rho \alpha \gamma \xi$. Also Arist.H.A.548a24; Pl.Phaedo110a.

45. Trenhaile (1987) p.274ff., Beckinsdale (1956) p.297, Horrocks (1981) p.151.

46. Trenhaile (1987) p.276f.

47. Trenhaile (1987) p.177f., Walker (1962) p.335.

48. Trenhaile (1987) p.187, Beckinsdale (1956) p.311.

49. Samothrace - Cary (1949) p.98, Walker (1962) p.333; Leukas - Mediterranean Pilot III p.160; Euboia - Cary (1949) p.73, Mediterranean Pilot IV pp.237f., 241; Thessaly - Cary (1949) p.63, New Pilot p.223; Hellespont - Mediterranean Pilot IV p.479; Samos - Mediterranean Pilot IV p.379; Southern and western Peloponnese, Ionian islands, west coast of central Greece - Mediterranean Pilot III pp.1, 8, 63, 66, Mediterranean Pilot IV pp.72, 93, New Pilot pp.207ff., 211f. Depth of the Ionian Sea - Mediterranean Pilot III p.8, Walker (1962) p.6.

50. Mediterranean Pilot III p.8.

51. Beckinsdale (1956) pp.147, 297, Trenhaile (1987) p.178, Horrocks (1981) p.141.

52. Cary (1949) p.8, Walker (1962) pp.368 (Crete), 369 (Epeiros and Akarnania).

53. Beckinsdale (1956) p.296, Trenhaile (1987) p.187, Horrocks (1981) p.142.

54. For a clearer description of the rocky shelf running out in front of a cliffy coastline, see Ap.Rhod.Arg.2.728-32, quoted below, p.29.

55. Beckinsdale (1956) p.297, Trenhaile (1987) p.176, Horrocks (1981) p.141f.

56. Beckinsdale (1956) p.312. 
57. Trenhaile (1987) p.266.

58. Beckinsdale (1956) p.297f., Horrocks (1981) p.151.

59. Beckinsdale (1956) p.311.

60. Walker (1962) p.333, Melentis (1977) p.267.

61. Walker (1962) p.345, Beckinsdale (1956) p.306.

62. The name of the island has been derived from ' $1 \theta 0$ s, 'straight, steep': see Tozer (1873) p.51.

63. Beckinsdale (1956) p.306.

64. Bintliff (1977) p.6.

65. Melentis (1977) p.271ff., Renfrew and Wagstaff (1982) p.74ff. See also Mediterranean Pilot IV p.169.

66. At least three points in Chian strait are particularly notable for such offshore rocks or shallow reefs: on the coast of Asia Minor at Kumuthi point (Mediterranean Pilot IV p.405) and Cape Bianco, ancient Argennon (Mediterranean Pilot IV p.391), and on Chios at Cape Ayia Helena, opposite Argennon (Mediterranean Pilot IV p.399, Hunt (1940-5) p.49). For other dangers in the strait see Mediterranean Pilot IV, pp.391f., 398-407.

67. Cf. Cary (1949) pp. 59 (the Achelous), 64f. (the Spercheios), 295 (Vardar (Axios)), 163 (the Maeander, for which see also Walker (1962) p.406).

68. Cf. Str.Geog.1.2.23, 30, and Heubeck, West, and Hainsworth (1988) for similar explanations in other ancient authors, and for objections to these explanations; Hdt.2.5 also clearly describes the deposition on the sea floor of sediments washed down by the Nile.

69. Beckinsdale (1956) p.299f.

70. Walker (1962) p.365.

71. Cary (1949) p.86.

72. Beckinsdale (1956) p.302.

73. Tombolos - see King (1972) p.502. For the accuracy of Strabo's statement that the Akte peninsula of the Piraeus was originally an island, see Garland (1987) p.7.

74. I.e. all of these are islands which have become linked to the mainland through deposition, apart from Leukas, where the cutting of the tombolo has turned a nominal 'headland' into a true island.

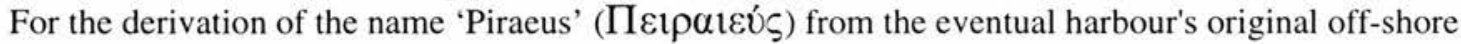
position cf. Payne (1940) p.1. For fuller descriptions of the deposition features Strabo mentions here cf. also: Leukas - Str.Geog.10.2.8, Thuc.3.81.1, Cary (1949) p.59, Semple (1932) p.600, Hornblower (1991) p.476; Mytilene - Str.Geog.13.2.2, Cary (1949) p.99; Echinades - Hdt.2.10.

75. For Kenaion and the Lichades islands, see Mediterranean Pilot $I V$ p.232. For Drepanon, the other headlands of Achaia, and the term taeniai (from $\tau$ 'ív $\omega$, 'to stretch'), see Tozer (1873) p.71, Smith (1854-7) p.13, s.v. Achaia. 
77. Compare Il.2.394f., 4.422f., 9.4ff., 11.304-9, 13.795ff., 14.394ff., 15.624ff., Od.13.96ff.

78. Horrocks (1981) p.137.

79. For the process of refraction see King (1972) p.96, Bigelow and Edmondson (1947) p.56, Horrocks (1981) p.138, Beckinsdale (1956) p.147, Bryant (1991) p.60.

80. King (1972) pp.91, 94, Bigelow and Edmondson (1947) pp.100, 160.

81. King (1972) p.93, Bigelow and Edmondson (1947) p.108f.

82. Bigelow and Edmondson (1947) pp.63, 121.

83. Bigelow and Edmondson (1947) p.99f.

84. Heubeck, West, and Hainsworth (1988) p.284, re. Hom.Od.5.393.

85. Bigelow and Edmondson (1947) p.58, King (1972) p.95.

86. Bigelow and Edmondson (1947) p.127.

87. Bigelow and Edmondson (1947) pp.127 (on-shore winds), 128 (on-shore currents), 130 (offshore winds), Bryant (1991) p.64 (opposing currents heighten waves). Arist.Met.338a notes that larger waves tend to break sooner than smaller waves.

88. Bigelow and Edmondson (1947) p.56.

89. Bryant (1991) p.60, King (1972) p.96, Bigelow and Edmondson (1947) p.159. The Greeks' use

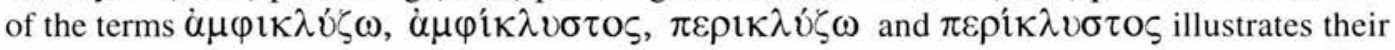
awareness that waves break particularly heavily, and from all sides, around headlands. While not surprisingly used primarily of islands, which are surrounded by the sea (e.g. Aesch.Pers.596, 880, HHAp.181, Str.Geog.16.2.13, Thuc.6.3, Soph.Tr.780, Dicaearchus110), these terms are also occasionally used to describe specific coastal features, almost always headlands (e.g. Bacc.Ep.15.1322, Soph.Tr.752, Str.Geog.17.1.6f.), although Str.Geog.11.4.2 describes a cliff. Theophr.Vent.33 describes the immense waves that break against the headland of Phaistos on the south coast of Cyprus, even when no wind was apparent. Though not deduced by Theophrastos, this phenomenon was also due to the way waves refract around an indented coastline: see Coutant and Eichenlaub (1975) p.79.

90. King (1972) p.97.

91. King (1972) p.96, Bigelow and Edmondson (1947) p.157ff.

92. See Bigelow and Edmondson (1947) p.165f.

93. Bigelow and Edmondson (1947) p.108f., Beckinsdale (1956) p.295.

94. Beckinsdale (1956) p.147.

95. King (1972) p.95.

96. Bigelow and Edmondson (1947) p.163. 
97. Walker (1962) p.11, Beckinsdale (1956) p.133.

98. Walker (1962) p.10, Couper (1989) p.52.

99. Walker (1962) p.11, Beckinsdale (1956) p.136. For an explanation of the two-way currents in sea straits, see Defant (1961) vol.1, p.513ff.

100. Couper (1989) p.45, Walker (1962) p.11, Mantzourani and Theodorou (1991) p.50.

101. Mediterranean Pilot IV, p.15f.

102. Mediterranean Pilot III, p.23.

103. Walker (1962) p.13, Couper (1989) p.52.

104. For the generation and properties of deep-sea and near-coast currents see King (1972) p.120f.

105. See above, p.31f., and Beckinsdale (1956) p.300ff.

106. King (1972) p.121.

107. See above, p.41, and Tozer (1873) p.62.

108. For other examples, see Str.Geog.7.fr.56(57), 8.2.2f., 10.5.13.

109. For examples, see Mediterranean Pilot III, pp.63 (Cape Matapan (anc. Tainaron)) and 159 (Cape Ducato (anc. Leukatas)), also Mediterranean Pilot IV, p.395 (Cape Mastiko, Chios).

110. New Pilot p.231.

111. $70.6 \%$ of the $115400 \mathrm{~m}^{3}$ lost though evaporation every second, as opposed to $3.2 \%$ through the Hellespont: Walker (1962) p.10, Horrocks (1981) p.355f. For the rate of evaporation, see above, p.39f.

112. Walker (1962) pp.7, $406 \mathrm{ff}$.

113. Fluctuations in the upper current: Carpenter (1948) pp.2, 5, Walker (1962) p.408, Semple (1932) p.65f., Defant (1961) vol.1, p.523.

114. For the Coriolis force, see Beckinsdale (1956) p.25f., Bryant (1991) pp.15f., 276 (s.v. 'Coriolis Force'), Couper (1989) p.45, and for its effect in the Bosporos, Defant (1961) vol.1, p.514f. with fig. 236. Note also the northwards moving surface currents marked B, C, and D in the diagram of currents flowing through the Bosporos in Marsigli (1978) p.35, noted also by Carpenter (1948) p.2.

115. Mediterranean Pilot IV, p.15f.

116. Formation and movement of nearshore currents: see above, p.31f.; Nearshore drift along the coast of Euboia: Mediterranean Pilot IV, p.241; Strength of current in the Doro channel: New Pilot p.169.

117. On this passage of Polybius, see also Marsigli (1978) p.34, and compare the figures given for the speed of the Bosporos current above, p.44.

118. Mediterranean Pilot IV, p.382.

119. Mediterranean Pilot IV, p.400f., Hunt (1940-5) p.48. 
120. Straits of Messina: Defant (1961) vol.1, p.533f., vol.2, p.395ff., Pryor (1988) pp.13ff., 92, Walker (1962) p.5, Cary (1949) p.28. Euripos: Defant (1961) vol.2, p.189ff., Cary (1949) p.28, Tozer (1873) p.237f. For sources demonstrating the ancients' common familiarity with the refluent currents of the Euripos, see, for example, Aesch.Agam.191ff., Eur.I.T.6ff. For a discussion of ancient sources mentioning the Straits of Messina, see p.84.

121. Bigelow and Edmondson (1947) p.55, Cary and Warmington (1929) p.10, 20, Casson (1971) p.273, Mantzourani and Theodorou (1991) p.47, Myres (1911) p.55, Pryor (1988) p.12, Semple (1932) p.583, Walker p.13.

122. In general see Defant (1961) vol.2, pp.388-395, Walker (1962) p.13, Cary (1949) p.26f.; also Defant (1961) vol.2, p.399 on the Adriatic, n.107 above and Semple (1932) p.583 on the Euripos and Straits of Messina, and Mediterranean Pilot III, p.95 on the Gulf of Corinth. For specific examples of deposition features resulting from the lack of tides in the Mediterranean, see King (1972) pp.519, 527.

123. Walker (1962) pp.19, 24, Barry (1968) p.207, Beckinsdale (1956) p.72, Pryor (1988) pp.18, 20.

124. Walker (1962) p.24, Semple (1932) p.90, Mediterranean Pilot IV, p.14. See Manual p.394 s.v. 'Continental Polar Air' for the connection between the clear skies of the Mediterranean summer and the northerly winds from continental Europe: "In summer $c P$ air arrives from the heated continent. Passing over the cooler sea it becomes stabilised and being relatively dry it is not likely to give rise to sea fog. It gives the fine weather characteristic of the eastern Mediterranean in summer.".

125. Walker (1962) p.25, Beckinsdale (1956) pp.73, 124, Barry (1968) p.206, Braudel (1975) p.233, Pryor (1988) p.17.

126. Walker (1962) p.12f., Semple (1932) p.87.

127. Walker (1962) p.20, Beckinsdale (1956) pp.88, 111.

128. Beckinsdale (1956) p.74, Horrocks (1981) p.219.

129. Walker (1962) p.21f.

130. Beckinsdale (1956) pp.74, 95, Semple (1932) p.579f. Met. Office (1967) pp.30, 127f. describes the passage of ridges of high pressure during the intervals between successive depressions.

131 Walker (1962) pp.19ff., 24, Barry (1968) p.207, Beckinsdale (1956) p.72. The ancient Greeks' familiarity with the Etesians is well-attested. Apollonius of Rhodes, for example, recognises their ubiquitous nature in the Aegean during the summer months when he describes them as winds 'which by the command of Zeus blow over every land equally.' (Ap.Rhod.Arg.2.498). For their annual occurrence, see n.505.

132. Walker (1962) p.24, Manual p.213. For the channelling of winds by prominent relief features, see below, pp.57, 60 .

133. The Etesians' unremitting and often stormy nature: New Pilot, pp.168, 211, 249 and Mediterranean Pilot $I V$, p.11. On the basis that it has been argued that the climate in ancient times was slightly cooler and wetter, and that, in recent history, relatively cool and wet years have seen particularly strong Etesian winds, Neumann and Metaxas (1979) p.185f. postulate that the Etesians may have been to some extent even more strongly developed than they are in the modern era.

134. High pressure associated with land masses, low pressure with warmer and lower-lying sea basins: Walker (1962) p.124f., Beckinsdale (1956) p.124, Semple (1932) p.87. 
135. Walker (1962) pp.21, 28, Semple (1932) p.87, Manual p.339ff.

136. Walker (1962) p.397.

137. Beckinsdale (1956) p.74, Horrocks (1981) p.220, Walker (1962) pp.18, 23, Manual p.211.

138. Semple (1932) p.601, Mediterranean Pilot III, p.13.

139. Horrocks (1981) p.220, Walker (1962) p.23, Cary (1949) p.4, Manual, p.211.

140. Walker (1962) p.19, Barry (1968) pp.166, 206f., Horrocks (1981) p.220f.

141. New Pilot, p.179, Manual, p.211, Braudel (1975) p.233.

142. Walker (1962) p.23.

143. Walker (1962) pp.23, 336, Taylor (1971) p.19f., Pryor (1988) p.19. Cf. Hes.W\&D.504ff.

144. Beckinsdale (1956) pp.74, 95, 107, Barry (1968) p.207f., Horrocks (1981) p.219, Manual, p.211. For the ancient name, cf. Str.Geog.12.3.27: '..he (Homer) mentions Libya and the Lips, the wind that blows from the western parts of Libya.'

145. Walker (1962) p.336f., Manual, p.211. For the greater frequency and force of the Sirocco in the spring and early summer, see Manual, p.213 (sv. 'Khamsin'), Beckinsdale (1956) pp.74, 95, Barry (1968) p.207, Walker (1962) p.24.

146. Beckinsdale (1956) p.74, Mediterranean Pilot IV, p.301, Manual, p.211. Theophr.Signs.20, 36 describes the Sirocco as a hot wind bringing rain and heavy cloud. Hdt.2.25 characterises Notos and Lips as moisture-carrying winds.

147. Adriatic - Walker (1962) p.23f.; Rhodes and Asia Minor - Mediterranean Pilot IV, p.301; Aegean - cf. Anth.Pal.7.653: 'At the setting of the Hyades the fierce Sirocco rose and destroyed Epierides in the Aegean Sea, himself, his ship and crew...'. For the Sirocco reaching northwards to the Bosporos, see Marsigli (1978) p.37, and for the problems it can cause ships sailing along the north coast of the Aegean, How and Wells (1912) vol.2, p.136 on Hdt.7.24.

148. Manual, p.208.

149. Barry (1968) p.37f, Beckinsdale (1956) p.47f., Horrocks (1981) p.162f.

150. Barry (1968) p.108, Manual, pp.190f., 208.

151. Mediterranean Pilot III, p.168, IV pp.12f., 133, New Pilot, p.168f. The ancient Greeks were clearly familiar with the regular daily cycle of these winds. See, for example, Plut.Them.14f. on the sea breeze (discussed at p.90), and Ap.Rhod.Arg.1.1273ff., 4.1223f. on the land breeze (discussed at p.109f.). Arg.1.1273ff seems to imply a combination of land breeze and mountain breeze, for which see immediately below in the main text. For the views of Aristotle and Theophrastos, see below in the main text. A good discussion of the shortcomings of their arguments, from the point of view of a modern meteorologist, is in Neumann (1973) passim.

152. Mediterranean Pilot III, pp.13, 168, IV p.12f., Manual p.208, Beckinsdale (1956) p.75.

153. Sea breezes stronger than land breezes: Barry (1968) p.108, Mediterranean Pilot IV, p.12f., Manual, p.208. Barry (1968) p. 108 gives typical speeds of $4-7$ metres per second $(=10-15 \mathrm{mph})$ for sea breezes, only c. 2 metres per second $(=c .5 \mathrm{mph})$ for land breezes. However, these do not relate 
specifically to conditions in Greece: Manual p.208 gives force 4-5 on the Beaufort scale ( $=$ c. $15-30$ $\mathrm{mph})$ as an upper limit for Mediterranean sea breezes.

Range of land breezes: Mediterranean Pilot III, p.13, Manual p.208. The Manual does not distinguish between the ranges of land breezes and those of sea breezes, giving 10-15 miles (16$24 \mathrm{~km}$ ) as the limit of both. Under normal conditions, however, the sea breeze has a greater range than the land breeze because of its greater initial strength and speed. Thus while Mediterranean Pilot III p.13 gives land breezes a range of up to 20 miles (32km) out to sea, Barry (1968) p.108 estimates that sea breezes may penetrate up to $50 \mathrm{~km}$ inland.

Land breezes strengthened by mountain winds: Mediterranean Pilot III p.13, Mediterranean Pilot IV p.168f., Barry (1968) p.108.

154. For Aristotle's and Theophrastos' familiarity with, but misunderstanding of, land and sea breezes, see Coutant and Eichenlaub (1975) pp.xlii-xliii, and p.77 on Theophr.Vent.28.

155. Beckinsdale (1956) p.100.

156. Barry (1968) p.105, Horrocks (1981) p.220, Manual p.208f.

157. Cf. Barry (1968) p.105 and fig.III.6.

158. See above, p. 53 and nn.151, 153. Note also Mediterranean Pilot IV, p.12f. on the strength of diurnal breezes in the Gulfs of Argos, Smyrna, and Thessalonike (anc. Thermaic Gulf), from each of which a valley leads into the mountainous interior.

159. Bora and Livas as katabatic: Walker (1962) pp.23, 337, Horrocks (1981) p.220. Katabatic winds on all seas near mountainous coasts, by day as well as by night: Manual p.209.

160. For more literary evidence of the Greeks' familiarity with this and other characteristics of such katabatic winds, see p.114f., p.248f. and n.586.

161. Semple (1932) p.581f.

162. Manual, p.182.

163. Beckinsdale (1956) p.347. See also Mediterranean Pilot IV, pp.108, 152, 192, 379, and Cary (1949) p.108f. for the association of dangerous squalls with winds descending down lee slopes of high land (after initial vertical displacement).

164. Manual pp.146, 187, Beckinsdale (1956) p.347. The slowing of a wind as it approaches ground level is a gradual one, and the degree by which it is slowed is dependent upon the ground relief. Thus winds tend to flow with greater speed over the flat surface of the sea than over the rougher relief of land masses.

165. Manual p.183.

166. Manual p.146.

167. Manual p.182.

168. Air stability depends on the environmental or atmospheric lapse rate of the temperature of the atmosphere, and the adiabatic lapse rate of the temperature of any air pocket which is forced to rise through the atmosphere, as when vertically displaced by an obstacle. The lapse rate describes the general decrease of air temperature with altitude, while the adiabatic lapse rate describes the rate at which temperature falls in a rising air pocket. (This adiabatic cooling results from the falling 
pressure in a pocket of air as it rises. Equally, air descending to lower levels of the atmosphere, where air pressure is higher, tends to be adiabatically heated.) If the atmospheric lapse rate is higher than the adiabatic lapse rate of an air pocket rising through it, then the air is unstable: the rising air pocket becomes increasingly hotter and less dense than the air around it, and consequently continues to rise after the obstacle which initiated its ascent has been passed. If the atmospheric lapse rate is lower than the adiabatic lapse rate of an air pocket rising through it, then the air is stable: the rising air pocket becomes increasingly cooler and denser than the air around it, and consequently falls back to its original level once an obstacle has been passed. If the atmospheric lapse rate equals the adiabatic lapse rate, then the rising air pocket will come to rest at the level of the obstacle it has passed over.

Various factors can affect stability. The diurnal heating of the earth's surface and the lower levels of the atmosphere during the day causes a corresponding increase in the lapse rate in the lower levels of the atmosphere. Also, air saturated with water vapour has a lower adiabatic lapse rate than dry air, because, as the air rises, some water vapour condenses, releasing heat to the air, thus slowing its adiabatic lapse rate. The greater the initial temperature of saturated air, the more condensation occurs as it rises, and thus the lower is the adiabatic lapse rate of that air. Thus the hotter and more saturated a rising pocket of air is, the less stable it will be. For turbulence, and the different factors which affect it, see Manual pp.183ff. (esp.), 146f., 148, 151, 152f. Also Barry (1968) p.105.

169. For squalls typically blowing down from high coasts, see Mediterranean Pilot III, p.63, and IV, pp.13, 73.

170. Horrocks (1981) p.222 \& fig.13.16, Beckinsdale (1956) p.347, Barry (1968) pp.105, 107. New

Pilot p.249 describes squalls extending for miles to the lee of Ikaria.

171. See below, p.62f., on 'orographic rain'.

172. Horrocks (1981) p.230, Mediterranean Pilot IV, p.81, Manual p.277.

173. Mediterranean Pilot III, pp.13, 65, New Pilot, p.231.

174. See Manual p.183. For the frequency and intensity of squalls around the Greek coasts and islands, see: Mediterranean Pilot IV, p.13 (Aegean generally); III p.13 (East coast of Leukas); III p.63 and $I V$ p.81 (Malea peninsula); $I V$ p.73 (Tainaron peninsula); $I V$ p. 108 (Hydra/Dokos); $I V$ p. 192 (Tenos); $I V$ pp.379, 382 (Samos); $I V$ p.396 (Chios). For their increased frequency during the summer Etesians, see New Pilot p.231, Mediterranean Pilot III p.63, IV pp.81f., 379, 382. For the unpredictability of squalls, see Mediterranean Pilot III p.63, IV pp.81, 108, 121, 152, New Pilot p.194. Ancient authors such as Homer were also aware of the intensity and unpredictability of squalls, which were emphasised in similes, e.g. Hom.Il.11.296ff., 747, 12.252f., 20.51

175. See Mediterranean Pilot IV pp.81 (Malea), 108 (Dokos), New Pilot p.406 (Kara Burnu peninsula (ancient Melaina) opposite Chios), Semple (1932) pp.75 (Rhion), 618 (Lekton promontory)

176. Barry (1968) p.207, Semple (1932) p.616, Beckinsdale (1956) p.347, Mediterranean Pilot IV, p.194. Note also Aristotle's comments on the formation of eddies in winds passing from wide open spaces through narrow gaps: Arist.Met.370b17ff.

177. For direction changes in winds funnelled through the long bays of the Aegean coasts, see Mediterranean Pilot IV, p.12.

178. For the purposes of this thesis, fog and mist are identical. While the thesis endeavours only to use the term 'fog', the term 'mist' may appear in, or in reference to, quotations of sources not translated by myself. Where the term 'mist' does thus appear, it should be understood to be synonymous with 'fog'. 
179. For the process by which air cools as it ascends, as a result of decreasing pressure, see above, n.168, and Beckinsdale (1956) p.50, Horrocks (1981) p.187. The amount of water air can absorb before reaching the dew point rises proportionately with air temperature - see n. 168 above, and Horrocks (1981) p.185.

180. Beckinsdale (1956) pp.50, 105, Horrocks (1981) pp.187, 195, Manual p.279.

181. Long before Aristotle, Hesiod and others also knew that the source of rain was moisture rising from ground level up through the atmosphere: see West (1978) p.297 on Hes.W\&D.550-3. Similarly, Xenophanes (c. 570-475 BC) correctly held that moisture is drawn up from the sea, forms clouds, and eventually rain (Dicks (1970) p.47).

182. Beckinsdale (1956) p.55.

183. Night fog rises after sunrise, forming stratus cloud: Manual p.234.

184. Beckinsdale (1956) p.52, Horrocks (1981) p.227.

185. Beckinsdale (1956) p.52.

186. Horrocks (1981) p.189f.

187. For diurnal heating see above, p.52ff. For the relation of diurnal heating to atmospheric stability and air temperature at ground level, see above, n.168.

188. Horrocks (1981) p.227.

189. Walker (1962) p.31, Manual p.277.

190. Horrocks (1981) p.227, Manual p.262.

191. See above, pp.48f., 50f. for the annual cycle of depressions crossing Greece, also Walker (1962) p.12f.

192. Walker (1962) p.22, compare Manual p.278.

193. Walker (1962) p.12f.

194. Walker (1962) p.22, Barry (1968) p.206, Manual p.393f. sv. 'Continental Arctic Air'.

195. See above, p. 58 and n. 168 .

196. Walker (1962) p.28.

197. Horrocks (1981) p.206, Manual p.262f.

198. Barry (1968) p.93, Beckinsdale (1956) p.52f.

199. Walker (1962) p.22.

200. See above, p.50f., also Hammond (1967) p.17 (on the high rainfall on the coast of Epeiros in northwest Greece), Walker (1962) pp.12f., 22, 337, 397, 400, Beckinsdale (1956) p.73, Cary (1949) p.4, Barry (1968) p.206.

201. Walker (1962) p.22, Manual p.276. 
203. Walker (1962) pp.337 (Sirocco), 364 (Etesians).

204. Manual p.277.

205. Archilochus quoted in Theophr.Signs.45; the Sirocco - Signs.20, 35; clouds over Euboia Signs.22. See also Theophr.Signs.21, 24, 34, 43, 51, all of which concern the presence or absence of cloud over or around mountains as indicators of the likelihood of ensuing rain. See also Theophr.Vent.5, Arist.Probl.26.7, Pl.H.N.18.82, etc. discussed at p.249f. below.

206. Walker (1962) p.30.

207. For these conditions as the main factors in the development of thunderstorms, see Beckinsdale (1956) p.108, Barry (1968) p.93, Horrocks (1981) p.229, Manual p.276.

208. For stable and unstable winds, and their differing behaviours when crossing barriers, see above, pp.58ff., esp. n.168.

209. Rapid condensation in rising air currents in Greece: Manual p.151f.

210. Beckinsdale (1956) pp.50ff., 105, Horrocks (1981) p.190f.

211. Beckinsdale (1956) p.56, Manual p.279.

212. Beckinsdale (1956) p.108, Barry (1968) p.93.

213. Beckinsdale (1956) p.56, Manual p.279. For the possibility that Greeks as early as Hesiod knew that moisture rising through the atmosphere from ground level led eventually to thunderstorms, see West (1978) p.297 on Hes.W\&D.550-3.

214. Beckinsdale (1956) p.56, Walker (1962) p.22, Manual p.279.

215. Beckinsdale (1956) p.53, Horrocks (1981) p.227, Manual p.263.

216. Walker (1962) p.28, Manual p.263.

217. Beckinsdale (1956) p.50, Horrocks (1981) pp.190, 195 f.

218. As will be apparent from both the quotations from ancient sources and the general discussions found in this and the following chapter. For discussion of these terrestrial and 'socio-maritime' functions of headlands, see app.4.

219. See, for a general example, Cic.Ad.Att.5.9.1f.: 'I reached Actium on 14th of June after feasting like an alderman both at Corcyra and the Sybota islands, thanks to your gifts......From Actium I preferred to travel by land, in view of the wretched passage we had and the danger of rounding Leukatas.' Generally heightened danger around headlands: Braudel (1975) p.109, Rouge (1981) p.18f., Semple (1932) pp.616, 629, Taylor (1971) p.31f, Tozer (1873) pp.63, $76 f$.

220. Note also the following passage from Synesius Letters 4: '...there was never a moment when this fellow allowed us to be free from fear of the uttermost danger. As soon as he had rounded the cape with the temple of Poseidon, he made straight for Taposiris [a town near Alexandria], with all sails spread, to all seeming bent on confronting Skylla, over whom we were all wont to shudder in our boyhood when doing our school exercises. This manoeuvre we detected only just as the vessel was nearing the reefs, and we all raised so mighty a cry that he perforce gave up his attempt to do 
battle with the rocks.' For the etymology of Skylla from $\sigma \kappa v \dot{\nu} \lambda \lambda \varepsilon \mathrm{v}$, 'to rend', see Liddell and Scott s.v. $\sum \kappa \dot{\lambda} \lambda \lambda \alpha$, Tozer (1873) p.77.

221. For this Skyllaion, and its position, see Frost (1980a) p.186ff. For the story of the drowning of Skylla, see Paus.2.34.7, Str.Geog.8.6.12f., Ap.Bibl.3.15.8.

222. Tozer (1873) p.77 states that Skylla "represented the dangers of navigation, and was supposed to have her abode on promontories.", referring to Preller, Griechische Mythologie, i. 483. Similarly, Semple (1932) p.622 characterises Skylla as a malign deity who 'represented the terrors of dangerous headlands'.

223. The proreus was the subordinate of the steersman (Xen.Oec.8.14, Arist.Pol.1253b29), and had command over those crew members stationed in the bow of the ship (Xen.Anab.5.8.20). As bow officer, prorates, he is contrasted with the stern officer, prumnetes, presumably reflecting the complementary duties of steersman and lookout, each overseeing the crew members in their end of the ship. The proreus was usually, if not always, a promoted oarsman, and could be further promoted to become a helmsman (prumnetes, kubernetes) - see Aristoph.Eq.541-4, noted by Morrison and Williams (1968) pp.266, 277 n.82, and Rouge (1981) p.89. Rouge (1981) p.158f. states that the proreus automatically took control of the ship if anything happened to the kubernetes (steersman).

224. A raised ikria, later known as the selma (Morrison and Williams (1968) p.132f.) stood both at the stern of the ship for the helmsman ('poop') and at the bows for the proreus ('fo'c'sle'): see Morrison and Williams (1968) p.47f. For an Archaic vase-painting depicting the proreus on look-out in the raised foredeck, see Morrison and Williams (1968) p.98 \& pl.15a. For the foredeck as the best vantage point for a lookout, cf. also Hom.Od.12.229ff.: 'I went to the foredeck of the ship, whence I deemed that Skylla of the rock would first be seen.' The proreus was to be found even in the smallest crews: see the bronze image, dedicated at the sanctuary of Poseidon at Isthmia, depicting a small boat crewed by two rowers, a helmsman, and the proreus: Broneer (1959) p.328 \#8: IM2090 and fig.5. For the other 'lookout' duties of the proreus, see p.166, and n.524.

225. See How and Wells (1912) vol.2, pp.214f., 238f., on Hdt.7.188, 8.13; for the disaster at Ipnoi, see below, p.78. Various possibilities for the exact locations of the sites named in descriptions of the disaster off the coast of Thessaly, particularly Cape Sepias, were put forward during the nineteenth and the early twentieth centuries. The main rival interpretations were those of Wace (Wace (1906) passim) and Tarn (Tarn (1908) pp.210-216), but Pritchett's re-assessment (Pritchett (1963),

favouring Wace), based upon topographic fieldwork and archaeological evidence discovered by Wace after 1906, may be taken as conclusive, identifying Cape Sepias with modern Cape Pori (near which a tombstone of a native of Sepias was found - Pritchett (1963) p.4) and Ipnoi with a series of marine caves, resembling rural ovens (hence the name), in the cliffs slightly further north, near the modern village of Keramidhi (Pritchett (1963) p.1f. and pl.2, fig.2); compare fig.7, and note also Thyrides ('the windows'), the name of the cliffy coast pocked with marine caves on the west face of Tainaron in southern Lakonia (Str.Geog.8.5.1). The cape now known as Sepias further south, by Cape St. George, need not be the site of ancient Sepias, for the ancient and modern names appear to have been derived independently and for different reasons: ancient Sepias might have taken its name either from the cuttlefish $(\sigma \eta \pi i \alpha$ : either because the cape may have been thought to resemble a cuttlefish in some way, or because the animals may have been commonly found in the area: Compare Ichthys (which Hornblower (1991) p.281 interprets as “'Fish'-shaped”), and (possibly) Chelontas, promontories on the west coast of the Peloponnese. ), or from the hue of the ink extracted from the cuttlefish (also $\sigma \eta \pi i ́ \alpha$ ), which the rock may have appeared to share. As schol.ad.Pind.N.3.35 preserves the story that during Peleus' pursuit of his bride, Thetis leapt into the sea from C. Sepias and there turned into a cuttlefish, it would seem most likely that the name of the cape was connected with the fish found in the area (i.e. the Thetis myth provided the aetiology either for the presence of cuttlefish in the area, or possibly for the name of the cape itself), rather than with the colour of the cape. Modern Sepias, on the other hand, presumably does take its name from its colour, which is so distinctive that the cape is used as a landmark - see Mediterranean Pilot IV p.256, quoted in n.414. 
For other examples of coastal rocks named after their distinctive colours and used as landmarks in ancient times, see p.169ff.

226. $\kappa \alpha \theta 0$ $\pi \varepsilon \rho \theta \varepsilon$, translated in this version as 'to the north', could also indicate 'to seaward' (Mooney (1912) p.127). That, in this case, it indeed does have this latter meaning is clear, as only this interpretation is geographically accurate.

227. For these and other similar names of headlands, see Tozer (1873) p.76f; also directly below in the main text and n.230.

228. For details of the many promontories known as Zephyrion, see Smith (1854-7) vol.2, p.1337. The derivation of a place name from the direction of the local prevailing wind can be seen in the entry on Zephyrios Limen in Menip.Perg.Perip.9r29f.: 'It [Aristias island] has a harbour sheltered from the winds from the west. From Aristias island to the region of Zephyrion [the next point on the coast]...'. Aristias island is an alternative name for the 'Isle of Ares' visited by the Argonauts (Ap.Rhod.Arg.2.1030ff.). Ps-Scylax.Perip.71, which gives an equivalent geographical description to that of Menip.Perg.Perip.9r29f., calls the islands the Isle of Ares, thus showing that the two names referred to the same island.

229. Although Xenophon does not name the winds he has in mind, we may suggest the northeasterly Etesians, which predominate in the Aegean eastwards and northwards of Attica, and the southwesterly sea breeze, which in summer prevails in the Saronic Gulf, south and west of Attica. See Mediterranean Pilot IV, pp.133, 168.

230. For the exact location of the ancient Cheimerion, see Hammond (1945) p.28. For the west coast of Greece as particularly stormy and rainy, see p.63f. Ancient names such as Plemmyrion, Araxos, Zephyrion, Keraunia, and Cheimerion may be compared with some modern names of capes which are just as expressive, illustrating both the bad weather and also the danger to be found there; thus, C. Fear (Florida, USA), C. Foulweather (Oregon, USA), C. Trepidation (Australia), the Cape of Good Hope (S. Africa), and Cape Wrath (Scotland).

231. Semple (1932) p.215, on Hdt.9.114; Semple (1932) p.618, and Cary (1949) p.98f. also describe how many ships failed to round Cape Sigeion, opposite the Thracian Chersonesos at the entrance to the Hellespont, due to the combination of strong winds and currents from the north. See also Semple's comments on the Salmonion promontory at the eastern extremity of Crete: Semple (1932) p.630. Compare Pryor (1988) p.97ff. on the navigation of the Asia Minor coast in medieval times.

232. Warnings to give headlands a wide berth in order to avoid rocks, currents, squalls, etc. abound in the Mediterranean Pilot, e.g. Mediterranean Pilot IV pp.121 (Aigina, quoted above, p.70), 125 (rocks and shoals off Cape Zoster on the southern shores of Attica), 150 (winds and currents off the northern promontory of Keos), 256f. (rocks, shoals, and currents between Cape Sepias and the nearest capes of Skiathos). Another example of the winds and offshore islands around a headland causing shipwreck can be found in Anth.Pal.7.738 (the Salamis promontory of Cyprus).

Anth.Pal.7.397 cites the northerly Boreas as causing the shipwreck of a mariner against the Mykale promontory near Samos.

\section{How and Wells (1912) vol.2, p.80.}

234. For the various winds striking these promontories, see also Semple (1932) pp.623, 629 (Khamsin/Sirocco, Bora), Mediterranean Pilot IV pp.73, 81, Wace and Hasluck (1907-8) p.174, and Cary (1949) p.83 (squalls), Mediterranean Pilot IV pp.82, $91 \mathrm{f}$ (meeting of northeasterly and northwesterly winds at Malea) and Mediterranean Pilot III p.65, IV p.70 (land and sea breezes).

235. Compare New Pilot p.179: 'The Bora.....is less formidable from its violence than the sudden and rapid impetuosity and the furious gusts with which it rushes from the defiles of the mountains and 
the several outlets formed by the islands; so that vessels are in danger of in a short time being blown from thence upon the coast of Italy, or of losing their masts, in consequence of the great swell of the sea, occasioned by so violent a wind.'

\section{6. $S I G^{3}$ III 1229.}

237. This is Jebb's interpretation of three mutilated verses. See Jebb (1905) pp.263, $461 \mathrm{ff}$.

238. Compare Anth.Pal.7.275 and, for the south coast of the Peloponnese generally, Anth.Pal.7.498.

239. Compare New Pilot p.210.

240. Thus Pryor (1988) p. 13 comments upon the Straits of Messina, between Italy and Sicily: "The straits themselves, however, were probably the most difficult passage anywhere in the Mediterranean except for the Bosphorus [Bosporos], Dardanelles [Hellespont], and Negropont [Euripos]." Thus all four of Pryor's most difficult passages are straits.

241. The current around Crete, having traversed the Mediterranean from west to east and returned along the south coast of Asia Minor, tends to run at around 2 knots (Pryor (1988) p.13). In the Aegean it generally runs slightly faster, being strengthened by the outflow from the Hellespont. See also p.231f.

242. Another problem associated with straits, involving currents only indirectly, occurs in areas which are generally stormy, or where two large bodies of water meet. Thus Myres notes the increased choppiness of the waves at the entrance to the Adriatic, where southwards-moving waves raised by the strong northerly winds in the gulf (see p.50f.) meet the current and waves of the Ionian sea to the south. For similar problems associated with waves at the entrance to the Corinthian Gulf, see below, p.87f.

243. Hammond (1945) p.36 and n.33, quoting an unspecified edition of the Mediterranean Pilot III, p.132.

244. See p.46f. and the references in n.120, esp. Pryor (1988) pp.13ff, 92.

245. A current of six knots: Pryor (1988) p.13. For the dangers of the current and other aspects of the Straits of Gibraltar, see Braudel (1975) p.117.

246. Carpenter (1948) p.3ff. On the speed attainable by triremes, and its performance against headwinds (but not against adverse currents) see below, n.560.

247. For the northeasterly Etesians strengthening currents in these straits, see Mediterranean Pilot IV, pp.168, 194, New Pilot, p.249, Cary and Warmington (1929) p.25, Semple (1932) p.215, Labaree (1957) p.29ff.

248. During lulls in the Etesians, it may have been possible to take advantage of an afternoon sea breeze blowing from the Aegean towards its northern shores, and thus up the Hellespont strait, or of the northwards breeze which is said to blow up the strait at night during the summer (Cary and Warmington (1929) p.26f.).

249. Casson (1959) p.77 and Cary and Warmington (1929) p.27 suggest that spring southwesterlies (i.e. the Sirocco) were key elements in opening up the passage to the Black Sea. Cary (1949) p.46 does not mention the southwesterlies, but agrees that passage to the Black Sea had to be made in springtime, before the Etesians became established. Labaree (1957) pp.29-33 uses modern wind and current data to show that southerly winds strong enough to take a sailing ship through the Bosporos in a matter of hours usually blew on at least five days a month during the height of summer, and on more than ten days a month earlier in the year. Use of westerly winds to pass through the Bosporos, 
not previously discussed by modern authors, is clearly described in Anth.Pal.10.7: 'Stranger, I, Priapos, was set up on this sea-beaten rock to guard the Thracian strait, by the sailors, whom I had often rushed to help when they called upon me, bringing from astern the sweet Zephyr....'. For the westerly winds of spring, see p.49, and for the greater frequency of southerly winds in spring than at other times of the year, see p.52 and n.145.

250. Carpenter (1948) p.9f.

251. Rate of current - p.45f., n.116. For the speed at which triremes could be rowed, see n.560.

252. Cf. pp.57, 60, and Pryor (1988) p.13, Semple (1932) p.599f.

253. Delays at the entrance to the Hellespont - n.231 above. For delays caused to shipping trying to pass northeastwards through the Doro channel, see Mediterranean Pilot IV, pp.152, 194. The current in the Mykoni channel, separating Mykonos from Tenos, is usually weaker than in the Doro channel, the Steno channel (separating Tenos and Andros), or even in the very wide channel between Mykonos and Ikaria to the east (Mediterranean Pilot III, p.15f.).

254. Phormio's deliberate calculation is accepted by Cary (1949) p.46 n.4, Casson (1959) p.103f., Neumann and Metaxas (1979) passim, and is favoured by Hornblower (1991) p.365, but in her study of Thucydides, Hunter is of the opinion that Phormio simply took advantage of the confusion which resulted in the Peloponnesian fleet once the wind had started to blow, and that Thucydides, for his own purposes, revised the actual events to show Phormio as having taken account of the tactical advantage that he might gain from the wind when planning his strategy before the battle: 'what were in reality Phormion's responses to the Peloponnesian defensive strategy and to their confusion, especially after the wind began to blow, the historian converted to purposes which correctly anticipate what were in fact only probabilities...' (Hunter (1973) p.45). In support of this view she argues that Phormio was not able to choose the time of his attack, that it was merely luck that the start of the engagement coincided with the onset of the wind, and that the whole idea of Phormio using a wind in this way may simply have been a fictional duplication of Themistocles' similar tactic at Salamis (Hunter (1973) p.45, n.2).

Now while it is impossible to prove that Thucydides did not rewrite events in this way, Hunter's supporting arguments do not provide firm evidence that he did, and there is nothing in the text describing Phormio's reaction to the attempted night-crossing by the Peloponnesians that is at all implausible: Phormio, like any sailor, would have been very familiar with land and sea breezes, and having been stationed at Naupaktos for some time, could have been far more certain of exactly when the breeze would blow from the Corinthian Gulf than Hunter suggests. Moreover, Thucydides does not state how much time elapsed between the Peloponnesians attempting to cross the Gulf and the onset of the wind, and rather than the two events having coincided by luck, as Hunter argues, Phormio may well have taken advantage of the fact that the Peloponnesian fleet was clearly content to hold a defensive formation (this detail of Thucydides' account can hardly be doubted, unless the whole account of the battle, and of the Peloponnesians' understandable desire to avoid a battle (see below), is rejected) by holding off his actual attack until the wind arose. This is in fact exactly what Thucydides explicitly says: see Thuc.2.83.5-84.3, quoted above, p.89, especially 'they kept sailing round the Peloponnesian fleet....but orders had been given by Phormio not to attack until the signal.....As for the attack, he thought that was in his power whenever he chose.'. Again, if Themistocles had used similar tactics at Salamis, (rather than Themistocles' tactic being a fictional duplication of Phormio's actual tactic, as Gomme (1956a) p.219 suggests: see $\mathrm{n} .264$ below)) then it is hard to believe that Phormio would not have heard of its success, and being the capable naval commander that he clearly was, we should not be surprised if Phormio sought to emulate Themistocles' tactic if and when a suitable opportunity arose. The fact that Phormio was heavily outnumbered only makes it more likely that he would be keen to exploit any possible tactical advantages to the full. So, while it may well have been by chance that Phormio was able to exploit the breeze, in the sense that he had little control over the timing of the Peloponnesians' attempted crossing, at which time he had no choice but to force an engagement, it is not unreasonable to 
assume that when it was clear that the engagement was imminent, Phormio, as an imaginative and opportunistic commander, looked for any ways in which the exact time and place of the battle could be exploited, as he might do before any battle.

It is even possible that Phormio may indeed, contra Hunter, have been able, to some extent, to determine the time of battle. Here there are two important facts to note. Firstly, Phormio's ships were faster (Gomme (1956a) p.217, Morrison and Coates (1986) p.69), and therefore he had some degree of control in the initial tactical manoeuvring on the day before the battle. Secondly, Phormio was well aware that most of the Peloponnesian ships were carrying troops headed for Stratos in Akarnania, where they were keen to reinforce their allies before an attack upon the town, and had little interest in fighting a major engagement at sea. The Peloponnesians, then, understandably kept coasting ever further west along the southern shores of the Corinthian Gulf, hoping that at some stage (probably at Rhion, or possibly Chalkis, if this was still in Athenian hands - see Gomme loc. cit.) Phormio would stop tailing them, at which point they could make a crossing unchallenged (Thuc.2.83.3). If they were to do this, then they had to disembark somewhere west of Molykreian Rhion (see Gomme (1956a) p.217f. for the possible landing points). Given the Peloponnesians' need to reach Stratos as soon as possible, Phormio knew that the longer he kept tailing the Peloponnesians, and the longer they remained on the south coast, the more desperate they would become to make the crossing. Likewise, as the north and south coasts diverge very rapidly west of Rhion (where they are only seven stades apart according to Thuc.2.86.3; Neumann and Metaxas (1979) p.182 give $1.67 \mathrm{~km}$; see Frazer (1898) vol.4, p.157 for the distances given by other sources), Phormio also knew that the further west the Peloponnesians sailed, the longer and more difficult their crossing would be, especially as they were relatively inexperienced sailors. A third factor which increased the urgency of crossing was simply to rest and feed the crews and their passengers: even on triremes that were not carrying large numbers of troops over and above the crew, there was little space for provisions, or even for the crew to relax (see p.241). Conditions would have been even worse on troop-carriers, which held an extra thirty hoplites in addition to the normal ten marines (Morrison and Coates (1986) pp.156f, 225f.).

Thus once he had successfully prevented a crossing on the day before the battle (it is unclear whether the text of Thuc.2.83.3 describes just the attempted crossing which ended in battle (as in the translation of Morrison and Coates (1986) p.70, or also an earlier attempted crossing in the light of the previous day, which was aborted when the Peloponnesians declined to stand and face Phormio's advance, as may be indicated in the translations of Smith (1919) and Rhodes (1988), and certainly is in the careful translation of Rusten (1989) p.227), Phormio may well have been fairly confident that the Peloponnesian fleet would attempt the crossing either during the night, when he could exploit the land breeze, or the next morning, when he could exploit the sea breeze. That he expected an attempt at night may well be indicated by the fact that he spotted the Peloponnesians' move so quickly when it came, even though they were some kilometres away and shrouded by darkness: presumably he had lookouts on watch for any signs of movement from the Peloponnesians. Neumann and Metaxas (1979) approach the question somewhat differently. For discussion of their arguments, see below, n.259.

255. Neumann and Metaxas (1979) p.184, presumably following Thuc.2.83.3.

256. Mediterranean Pilot III, pp.23, 94.

257. The winds are commented upon by Curtius (1851) pp.403f, $420 \mathrm{n} .2$, and Leake (1830) vol.3, p.207f., the currents in the strait by Frazer (1898) vol.4, p.156f.

258. For the mountains fringing the Corinthian Gulf, and the winds blowing off them, see New Pilot p.203, Mediterranean Pilot III, p.11. For the merging of land and sea breezes with mountain and valley breezes, see p. $55 \mathrm{f}$.

259. For the automatic acceptance of the morning wind exploited by Phormio as the land breeze, see Cary (1949) p.46, Meigs (1961) p.375. Neumann and Metaxas (1979), on the other hand, identify 
the wind exploited by Phormio as the Etesians. Rather than working solely from the text of Thucydides, they attempt to reconcile his account with modern wind data for the area. This is undoubtedly a preferable methodological approach, but unfortunately there are no detailed modern wind data for the waters in which the battle took place, and the authors have instead to use wind data for Patras, on the coast of the Peloponnese south of the battle site. They conclude that the wind in question was not the land breeze, but the northeasterly Etesians, which, in Patras at this time of year, appear to strike up at around 7.30 a.m., c.2 hours after sunrise, and blow notably more strongly than winds earlier in the day (Neumann and Metaxas (1979) p.185ff., Table 1 and fig.2.). The

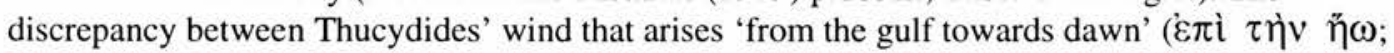
dawn occurring c.5.30 a.m. in this area at this time of year) and the Etesians which blow from the northeast from c.7.30 a.m. is dealt with by the recommendation that 'we should not take the specification 'from the Gulf' seriously' (Neumann and Metaxas (1979) p.186), and by 'supposing that the historian's story need not be accurate down to the smallest detail' and assuming 'that his description is not necessarily accurate as far as details of 'precise' direction and time of rise of speed of the wind go.' (Neumann and Metaxas (1979) p.187). The authors argue that, because winds are slowed less by friction over the sea than they are over land, the northeasterly winds might arise somewhat earlier, c.7.00 a.m., over the waters of the Corinthian Gulf, where the battle took place. They then attempt to account for the time elapsing between the Peloponnesian fleet's night-time departure from the Peloponnesian coast, in an attempt to reach the coast of Akarnania, and the start of the battle when the northeasterly winds rise around 7.00 a.m.: Phormio, it is argued, only spotted the Peloponnesian fleet at dawn, c.5.30 a.m., and then took upwards of an hour to travel eight kilometres of water and reach the Peloponnesian fleet; after this, it is suggested that more time elapsed as the poorly-trained Peloponnesian fleet first took up its defensive circular formation, and then the Athenian fleet completed at least one circumsailing of the Peloponnesian fleet. Neumann and Metaxas conclude that 'All in all, when all of the aforementioned factors are considered, the beginning of the Athenian attack, i.e. the time when the wind arose, could not have been earlier than something like one and a half hours after dawn.', i.e. around 7.00 a.m.

However, there are problems with this reconstruction, not least because it requires us to suppose not simply that 'the historian's story need not be accurate down to the smallest detail', but that it must be inaccurate to a very significant extent. Thucydides' account states that 'finally when, during the night, they [the Peloponnesian fleet] had tried to slip their moorings and get away but had been detected, under these circumstances they were forced to fight in the middle of the channel (Thuc.2.83.3).... 'The Peloponnesians drew up their ships in as large a circle as they could (Thuc. 2.83.5).....As for the Athenians, drawn up in single column they kept sailing round the Peloponnesian fleet in a circle (Thuc.2.84.1). There is no suggestion here that the Athenians did not spot the Peloponnesian fleet until dawn, nor that the Peloponnesians waited until the Athenians arrived to take up their defensive position. Rather, given more than an hour before the Athenians reached them, either they could have avoided battle by retreating to the Peloponnesian shore, or they could have continued forwards in an attempt to reach the Akarnanian shore opposite before being caught by the Athenians. Even if we assume that they did remain in the same position, it is completely unrealistic to suppose that they did not use the intervening time to take up their defensive position, or, if indeed they did not, that the Athenians, having arrived, would politely have waited for them to complete their formation before initiating their attack - under these circumstances an immediate attack upon such a disorganised enemy would have been far more advantageous then waiting for the enemy to assume formation, and then waiting even longer for a wind to arise which would cause that formation to become disorganised again. In fact, the text of Thucydides suggests that the Athenians spotted the Peloponnesian fleet during the night, and sailed out to meet them at some point mid-channel, by which time the Peloponnesians had already taken up their defensive position. Thus Neumann and Metaxas' attempt to account for the time between 5.30 a.m. and 7.00 a.m. seems inadequate, and therefore acceptance of their argument that the battle started c.7.00-7.30 a.m. requires us not only to reject Thucydides' statement that the wind arises 'towards dawn', but to reject his whole account of the timing of events, including the attempted night-crossing by the Peloponnesians. Such a night-crossing would clearly be timed so that it could be completed under darkness, as this is the whole point of the manoeuvre: it would be senseless to start the crossing at 
such a time that by dawn the fleet was only half-way across the channel, in clear view of the Athenians, and too far from either shore to avoid an encounter. Thus, at whatever point the attempted crossing was detected, there must have been enough time for the Athenian fleet on the Akarnanian coast to reach the Peloponnesian fleet before dawn, given that there was clearly enough time for the Peloponnesian fleet, had it remained undetected, to cover the same distance and reach the Akarnanian shore before dawn. Thus the two fleets came together before dawn, by which time the Peloponnesian fleet would already have taken up formation, so that the only way we can accept Neumann and Metaxas' identification of the wind as one arising at around 7.00-7.30 a.m. is if we assume that the Athenian fleet remained circling the Peloponnesian from dawn until this time (i.e. for around two hours), and that Thucydides was misinformed about the time the wind arose.

If we assume that the wind in question did arise just before or around dawn, then analysis of the wind data used by Neumann and Metaxas still proves informative. Neumann and Metaxas (1979) p. 186 table 1 indeed shows northeasterly winds arising very strongly from c.7 a.m., but also that the winds they replace, which would blow throughout the period of dawn, can be identified as night land breezes. Thus between the hours of 2 a.m. and 7 a.m., the most frequently occurring wind is from the southeast, i.e. blowing directly offshore, as we would expect of a land breeze. The next most frequent wind during this time of the day blows from ENE, i.e. from the direction of the Corinthian Gulf, and this presumably indicates the land breezes blowing into the Corinthian Gulf and being funnelled out through the strait at Rhion, and spreading out over the seas and coastlands to the west. Neumann and Metaxas (1979) p.186 Fig.2 also stresses the marked rise in wind speed that occurs with the arrival of the northeasterly winds c.7 a.m. While the earlier land breezes at Patras are indeed not nearly as strong as the later northeasterlies, we would expect the land breeze coming from the Corinthian Gulf to be far stronger, as it is funnelled through the strait at Rhion and spills out over the waters immediately to the west, than it would be after reaching as far southwest as Patras, crossing over the coastlands there, and contending with the local southeasterly land breeze there. Moreover, Thucydides does not state that the wind in question is particularly strong, merely that it arises, and its main significance is more its effect on the sea in the waters west of the Rhion strait, which depends more upon the direction of the wind (blowing through the strait) rather than its speed. The time of year during which the battle occurred, in late July or early August (Neumann and Metaxas (1979) p.183), is in any case precisely that time of year at which land and sea breezes are most strongly developed. Moreover, the morning land breeze has its counterpart in the afternoon sea breeze, but the Etesians have no such counterpart that can be identified with the wind blowing into the Gulf also reported by Curtius and Leake. For these reasons, I maintain that the wind exploited by Phormio was the land breeze, but it should be noted that this breeze blowing out of the Gulf has been extensively reported and recorded, from ancient down to modern times (see Neumann and Metaxas (1979) p.185), and, whether land breeze, Etesians, or some other wind, it was clearly a real meteorological phenomenon readily exploitable by a commander such as Phormio.

260. Mediterranean Pilot III, p.95.

261. Gomme (1956a) p.217.

262. Rusten (1989) pp.226, 234, Morrison and Coates (1986) p.73f.

263. Hdt.8.10.1; 8.60, Morrison and Coates (1986) p.53, Morrison and Williams (1968) pp.134-40. Thus the Greeks chose to face the Persian invasion at Thermopylai on land, and in the Euboian Sound at sea: both the pass at Thermopylai and the strait of Euboia are restricted passages where smaller forces can successfully hold off far larger forces. For Salamis see the main text, and Morrison (1974) p.26.

The tactic continued to be used against numerically and tactically superior enemies: during the Peloponnesian War, the Syracusan fleet and its Peloponnesian allies preferred to fight inside the large harbour of Syracuse (for which see fig.56.i), to remove the tactical advantages the faster and more manoeuvrable Athenian fleet might otherwise have had - see Thuc.7.67 on Gylippos' reasons for choosing the site, and the comments of Casson (1959) p.105f., Morrison and Williams (1968) 
pp.314-320, Morrison (1974) p.23. Again, Thuc.2.13.3f. informs us that the Peloponnesian ships at Pylos refused to sail out of the broad harbour behind Sphakteria to meet the Athenian fleet in the open sea, as the Athenians would have preferred.

264. Gomme (1956a) p.219 n.1 suggests that Plutarch's statement, which is not supported by Aeschylus or Herodotos, is an example of a supposedly common error, 'the duplication of an action for another occasion', ascribing to Themistocles the imaginative tactics of Phormio. Frost (1980b) p.154f. agrees. Hunter (1973) p. 45 \& n. 2 conversely suggests that Phormio is accredited with the talents and tactics displayed by Themistocles at Salamis. However, if we follow Hunter in assuming that Themistocles did exploit the sea breeze at Salamis, and that this was well known (e.g. by sources used by Plutarch long after the event, and, according to Hunter's argument, by Thucydides), then it is more than likely that Phormio (and many other naval commanders, especially Athenians) would also have known of the episode, and would consider using similar tactics where they seemed advisable and workable (see n.254 above). In fact the tactic might have become more common than we hear of, given its apparent success against more cumbersome and less experienced fleets (see Gomme's comments on Thuc.2.84.2 - Gomme (1956a) p.219).

Still less likely seems the possibility that Themistocles was wrongly said to have made use of tactics first used by Phormio fifty years later. If that were so, then the commentator who first made the claim on behalf of Themistocles (if not Plutarch, one of his sources) would have to have done so after the nature of Phormio's tactics had become common knowledge, fifty years after the battle of Salamis. Even then it could not simply be claimed that Themistocles used the same tactics as Phormio did later, for there are two important differences between the two accounts. Firstly, Phormio makes use of the land breeze at dawn to cause confusion amongst inexperienced oarsmen, while Themistocles uses the sea breeze around mid-morning to cause confusion amongst ships which were higher than his. In effect, the commentator, on hearing of Phormio's tactics, would have had to have known that, although the Persian crews at Salamis were, if anything, more experienced than the Greeks rather than less, their ships were rather taller, and that this greater height might have caused the Persian ships problems if Themistocles had used not the land breeze, which blows offshore at night, but the sea breeze, which blows onshore during the day. The differences between the two accounts are so significant that considerable knowledge of the structures of Greek and of Persian warships during the Salamis campaign, of the nature of diurnal breezes around the Greek coasts, and of the effect these breezes could have upon different types of warship, would have been necessary, along with a fair deal of imagination, to create this false if brilliant account of Themistocles' tactics at Salamis. Indeed it would seem far more likely that Themistocles, who had all of this information and knowledge to hand on the day, would have independently realised the possibilities of exploiting the sea breeze in this way than that an anonymous historical commentator did fifty years after the event, merely by extrapolating from Phormio's rather different tactics. Frost's statement that 'it is impossible to predict weather with any degree of certainty anywhere in the Aegean' (Frost (1980b) p.154f.) is clearly an exaggeration, and is contradicted by Mediterranean Pilot $I V$ p.12f, where the specific times at which the land and sea breezes commence and cease blowing in the gulfs of the Aegean are discussed (for western Greece, compare Mediterranean Pilot III, p.168 on the 'very regular' times at which land and sea breezes blow around the coasts of Leukas). Again, the importance of sailors' knowledge and understanding of local weather patterns and conditions should not be underestimated.

Frost's argument concerning the effects the sea breeze would have had on the ships of the Persians and on those of the Greeks is less well informed and less reliable than that of Morrison and Coates (1986) p.157, who argue that Plutarch exaggerated the differences between the Persian and the Greek ships at Salamis to make his point. As evidence that the Greek and Persian ships were so alike as to be difficult to tell apart, they cite Hdt.7.194.1-3, where some Persian ships arriving late, and trying to locate the Persian fleet which had anchored at Aphetai inside the Gulf of Pagasai, mistake the Greek fleet at Artemision for their own, and are thus captured. However, by these commentators' own admission, this mistake was made in the evening light, and it should be emphasised that the Greeks have no problem recognising that the approaching ships are Persian and not Greek. The Persians' mistake may be explained by the fact that 207 of the Persian fleet of one thousand ships were in fact 'fast ships' of the Greek type (Morrison and Coates (1986) p.49), so that the latecomers might easily 
mistake the Greek ships for the similar fast ships in their own mother fleet, whereas the Greeks, having no tall transport ships, easily recognised the approaching ships as Persian.

Finally there is Lenschau's argument, reported by Gomme (1956a) p.219 n.1, that the sea breeze would not spring up until 11a.m., whereas the battle of Salamis was stated by Herodotos (8.83) and Aeschylus to have commenced at dawn. However, it may be that manoeuvres began at dawn, but the battle proper did not. Herodotos makes no mention of the Persians' initial progress up the strait, and speaks of the Greeks backing water as the Persians approach, until they too charge and a general melee follows, which the Persians lose mainly because 'the Greeks fought orderly and in array, but the foreigners were by now disordered and did nought of set purpose' (Hdt.8.86). Rather than being motivated by fear, the Greeks' initial decision to back water was presumably a tactical one, to draw the Persians further and further into the narrows of the strait, and possibly also to spin out as much time as possible before the onset of the sea breeze, which may begin around 10am. in the Saronic Gulf (Mediterranean Pilot IV pp.12f; cf. also pp.133, 168f for the strength and southwesterly direction of the sea breeze in the Saronic Gulf), rather then the $11 \mathrm{am}$. suggested by Lenschau. That the backing water manoeuvre did take some considerable time is suggested by the tale related by Herodotos (8.84) that a vision of a woman was seen crying 'What madness is this? How long will you still be backing water? [my italics]' The tale may reflect confusion amongst crews who were not aware of the reasons for, and tactical advantages of, the manoeuvre. Shaw (1993) p.99 notes the use of the tactic of backing water in other historical battles, for example by the Athenians retreating to Corcyra in 427B.C. (Thuc.3.77f.), and by the Rhodian fleet when facing that of Mithridates in 87B.C. (App.Mith.Wars.12.24f.). The fact that, in the latter encounter, a Rhodian fleet, faced by a far larger number of enemy ships, backed water for between one hour and a whole day (Appian does not state when the encounter began, but informs us that the Rhodians kept backing water until the onset of darkness), shows that the Greeks might equally have backed water for a considerable time when facing the Persian fleet's advance on the morning of the battle of Salamis.

Hammond (1956) p.39 argues that the speed with which the battle commences and unfolds was accelerated in Aeschylus' account for dramatic purposes, and that in fact the Persian fleet would have taken two and a half hours to deploy and reach battle positions (Hammond (1956) p.51). There would then have followed the period during which the Greeks backed water, so that all in all over three hours might easily have passed between dawn and the commencement of the battle, by which time the arrival of the sea breeze might have been imminent. Plutarch may have correctly recorded a detail of the battle which Herodotos and Aeschylus failed to simply because he used one or more of the many other contemporary or near-contemporary accounts of the battle which had been written (for which see Hammond (1956) p.39).

265. For wind conditions on the Aegean coast of Asia Minor, see Mediterranean Pilot IV, p.13.

266. Variable currents in the strait of Samos - Mediterranean Pilot IV, p.382 (normally three or four knots eastward, sometimes westward); for reversals of the current in the strait of Chios, see p.46 and n.119 above; see also Mediterranean Pilot IV, p.323 for the variable currents around Nisyros and the surrounding islands, p.395 for the current off the south end of Chios.

267. Hunt (1940-45) p.48, see also Mediterranean Pilot IV, p.400f.

268. Mediterranean Pilot IV, p.399.

269. Wachsmuth (1967) p.396f. has interesting comments upon the mythological etymology of Mimas, as well as of other capes and islands named after Titans and other uncivilised figures - e.g. Geraistos, Tainaron (from Tainaros), Kalauria (from Kalauros), the Skironian rocks and cliffs (from Skiron), etc. Such names apparently allude to those held responsible for the awkward or dangerous winds and currents found in those areas, and preserve the memory of the worship of pre-Olympian figures at these points. 
271. See Mediterranean Pilot IV, pp.108f., 115 (Argolic peninsula), 379, 382 (Samian strait). Ancient wrecks found off the Argolic peninsula, in the Dokos strait (Parker (1992) p.1 and p.162 \#362) and in the strait between Hydra and Spetses (AR 1981/2 p.15, Parker (1992) p.163, \#363) testify to the dangers of these straits in antiquity.

272. Aulis repeatedly used as a gathering place for fleets sailing to the northeast Aegean:

Hollinshead (1979) p.25. Euboian sound used as a route to the northern Aegean - Cary (1949) p.73f, Semple (1932) p.600f., Tozer (1873) p.237, none of whom mention Theophr.Vent.28, where the blocking of the Etesians by the high land of Euboia is specifically linked to ships sailing northwards through this channel - see Coutant and Eichenlaub (1975) p.77; squalls falling from the heights of the mainland and of Euboia - Mediterranean Pilot IV p.228. The tortuous nature of the winding passage through the Euboian Sound is illustrated by the execution of the Boiotian pilot Salganeus because Megabates, the commander of the Persian fleet, had, on approaching the Euripos from Artemision, become convinced that he was being led into a dead end rather than through a channel that led directly to Attica (Str.Geog.1.1.17, 9.2.9).

273. Specifically, classical wrecks have been found at Ay. Ioanni Tholou Bay ( $A R$ 1984-5 p.57, Parker (1992) p.47 \#19-20), Komi headland (AR 1954 p.23, Parker (1992) p.228, \#552, Garnett and Boardman (1961) pp.104f.), and Ay. Stephanos island at the southern end of Delphinion Bay (Garnett and Boardman (1961) p.106f.).

274. For the multitude of dangers in the Skiathos channel, see Mediterranean Pilot IV, p.256ff. The Ant, now known as Lephtari rock, is there described as 'the crown of a rocky shoal about half a cable $[100 \mathrm{~m}$.] in extent.....It can generally be seen by keeping a good look out, as it is just awash, though at times, when the sea is smooth, it may not be detected until close to it with a little swell only, it has been observed that the sea did not break.'.

275. The remains of this pillar, or its base, may only have disappeared quite recently: Mediterranean Pilot IV p.256 mentions that hewn stones from an ancient 'building' were plainly visible there.

276. New Pilot p.231.

277. For the 'harbour' (a river mouth), the sandy coast, and the archaeological remains at Amnisos, near Knossos and Iraklion in Crete, see Princeton s.v. 'Karteros'. Amnisos "is barely a real harbour at all, certainly not a safe anchorage." (Rutherford (1992) p.163); it is important here to distinguish between the secure harbour, where ships may happily be moored for long periods in complete safety, and the far less secure but relatively sheltered areas of coastal water, such as the Amnisos river mouth here, to which mariners may resort in times of severe weather, simply in order to avoid being shipwrecked or being blown far off course. Frost (1972) p.97 raises the idea of 'proto-harbours', made by artificially building up natural breakwaters such as offshore rocks and reefs. The only incidence of such harbourworks I know of are at Aigina, in the so-called 'Thieves Harbour' immediately to the north of the main harbour of the ancient town, from which it is separated by the promontory holding the temple of Apollo. I visited this site in August 1993, and the remains of cut stones can clearly be seen, inserted into and filling out the breaks in the natural reefs protecting the bay. However, no date has been established for these remains, and they are not necessarily earlier than the first Greek examples of completely artificial moles and breakwaters.

278. Quay and breakwater on Delos: Blackman (1982) p.93, Casson (1971) p.362. Similar moles constructed elsewhere in the seventh century BC: Lehmann-Hartleben (1923) pp.50-65. At Zagora, on the other hand, the late tenth century to late eighth century community on Andros, despite being 'in constant contact with the continental Greece, the other islands, and more especially with Euboia', and eventually falling 'under the influence of the Euboians as a port of call on their way to the east Aegean' (Cambitoglou (1981) pp.20,111) had no harbour works, but relied on the sheltered sandy coves to either side of the headland that the town was built on (fig.52). Likewise at Emborio on 
Chios, the eighth to sixth century town, while 'perhaps an important port' (Boardman (1967) p.249), never constructed any permanent harbour facilities; the ships which brought considerable amounts of imported goods to the town found sufficient shelter in the natural harbour there, with its pebble beach flanked by two rocky headlands (described further below, p.97 and n.281). Moreover, according to Thucydides (1.93.3; see below, p.112), work did not start upon providing the natural harbours of the Piraeus with artificial port facilities, naval or commercial, until Themistocles' archonship in 493B.C., a full hundred years after Athens had started her long history of substantial naval activity with the attack on Sigeion. Prior to the fifth century, the main Athenian port had been the wholly undeveloped beach of Phaleron Bay (Garland (1987) pp.11, 13, 15, Cary (1949) p.77), which was still the main anchorage for the Athenian navy in 490B.C., at the time of the Battle of Marathon (Hdt.6.116). Hornblower (1991) p.139f. suggests that Piraeus had not been developed before this date because 'use of Piraeus was unthinkable as long as Salamis opposite was in hostile, specifically Megarian, hands.'. On the harbours of Piraeus, see further below, p.111ff.

The idea that artificial harbour facilities had only just started to appear when the Odyssey was written is supported by the fact that the author of that work clearly knew of such technological developments, yet chose not to retroject them into the Heroic Age. I am indebted to Mr. J.G. Howie for this observation.

279. Polycrates' harbour works the first such attested in Greece: Blackman (1982) p.93, and Picard (1988) p.388, where a description is given of the then recently discovered archaic harbour of Thasos, constructed at the end of the sixth century BC or the start of the fifth century BC, and so the earliest known artificial Greek harbour after Polycrates'. See also Picard (1989) p.499ff. Artificial harbours became far more common in the fifth century BC - Starr (1989) p.21.

280. See also Morrison and Williams (1968) pp.135, 204, and 310f. for the preference for beaching rather than lying at anchor.

281. See the descriptions of the harbour, and the shelter provided by its flanking headlands, in Boardman (1967) p.xi, and Hunt (1940-5) p.48. Hunt (1940-5) p.49 suggests that mariners may instead have sheltered at Kalamoti, slightly north of Emborio, as this is the last point that can generally be reached when northerly winds make it impossible to beat up the strait. However there is no evidence of ancient activity at Kalamoti, and Boardman (1967) p.1 makes the alternative point that 'Emborio offers the first good harbour to seafarers from the south entering the channel between Chios and the mainland of Asia Minor.' (my italics). For the imported dedications at the Harbour Sanctuary, see Boardman (1967) p.64.

282. Leake (1835) vol.3, p.119. For the fact that $\kappa \omega \varphi$ ò here signifies 'calm', rather than any other possible interpretation, see below, n. 321 .

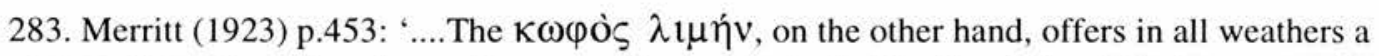
comparative calm. The entrance is narrow, flanked on both sides by cliffs which rise perpendicularly from the water, and within the entrance the bay opens out, about a mile deep and a mile across. The hills gradually slope down and give place to the sand beaches toward the east [i.e. at the innermost point of this west-facing bay].'. For the typical features of the natural harbour, see p.27f.

284. Emborio - Hunt (1940-5) p.48. Perachora - Payne (1940) p.15, Blackman (1966) p.192, Morgan (1989), p.132. Blackman's notes on the geological history of the area (p.193f. and n.4) are now superseded by Stiros (1995); local changes in relative sea level mean that a map of the harbour would not accurately illustrate the harbour as it was in antiquity. The dangers generally presented by the narrow entrances to natural harbours are also illustrated in the classical and Hellenistic wrecks discovered in the mouth of the natural harbour of Serce Limani (Parker (1992) p.399 \#1071, p.400 \#1073), while two other wrecks found within the harbour (Parker (1992) p.399f, \#s 1070, 1072) show that, even once safely entered, such natural harbours could not always guarantee protection from sudden changes of weather. 
285. Shelter sought behind headlands - Cary (1949) pp.46, 56, Cary and Warmington (1929) pp.5, 10, Pryor (1988) p.21, Semple (1932) p.584.

286. The significance of $\pi \alpha \rho \alpha \pi \lambda \dot{\eta} \xi$ in this context, suggested by Heubeck, West, and Hainsworth (1988) p.285, was brought to my attention by Mr. J.G. Howie.

287. For references see p. 75, n. 231 above. Alternatively ships could shelter behind Tenedos or Lesbos: for sheltering behind islands, see below, p.104ff. Even inside the Hellespont, ships occasionally sheltered behind headlands - see Carpenter (1948) p.2.

288. Perachora, for which cf. p. 98 and n. 284 above, is a good example: the promontory of Perachora is rocky, cliffbound at most points, and lies 'in a notoriously difficult area of the [Corinthian] Gulf, with irregular and fierce crosswinds and currents' (Morgan (1989) p.132). Such foul conditions led ships regularly to seek shelter behind the headland, at the sanctuary of Hera which stands in a small natural harbour. As the harbour was itself too small for all but the smallest ships to enter, the many ships which stopped there, and presumably made most of the (imported) dedications at the sanctuary, must have done so simply for the shelter from winds and waves afforded by the headland, and not for any other advantageous aspect of the coast here, which was not welcoming.

289. Cary (1949) p.98 stresses the shelter from the Etesians available on this route. In medieval times, ships heading north towards the Hellespont were also attracted to this route by the northwardsrunning current (Pryor (1988) p.15), and the same was presumably the case in ancient times.

Elsewhere in the Aegean, of course, the currents ran southwestwards from the Hellespont (cf. p.41).

290. Sounion: shelter in Legrena Bay for ships unable to round the headland against northeasterly winds and currents - Paus.1.1.1, Mediterranean Pilot IV p.124, Dinsmoor (1970) p.5, Tataki (1983) p.22; Semple (1932) p.613 notes the exposure of Legrena Bay to winds from the Saronic Gulf, as does Frazer's commentary on Paus.1.1.1 (Frazer (1898) vol.2 p.1f.), where reference is also made to the alternative inlet providing shelter on the northeast side of the headland, for which see also Dinsmoor (1970) p.5. For the southerly and westerly winds to which Legrena Bay is exposed, and the resulting embayment of the theoric ship there, see below, p.108f. For an example of the use of the bay for shelter, see Xen.Hell.5.1.23: 'Proceeding also to Sounion, he [Teleutias, the commander of a Spartan fleet] took a number of transport vessels, some laden with corn and some with merchandise.'. On the shelter from prevailing winds provided by promontories on the west coast of the Aegean, cf. also Hdt.7.193, where the Persian fleet, having been caught out by onshore winds against the exposed east coast of the Magnesian peninsula, finds shelter behind the same peninsula, in the Gulf of Pagasai.

291. Sailing conditions around the northern end of Keos are discussed in Mediterranean Pilot IV p.150. For the harbour and the port, see Princeton s.v. Keos.

292. Discussed by Morrison and Williams (1968) p.184f. and by Kenny (1947) passim.

293. For the prevalence, and violence, of the sea breeze in the Gulf of Argos see Mediterranean Pilot. IV p.12f. Cary (1949) p.88 and Bintliff (1977) pp.310, 350 comment upon the sheltered position of Nauplia behind Palamidhi. For the Kalaurian Amphictyony, see Snodgrass (1971) p.402, Harland (1925) passim, and Kelly (1966) passim.

294. Rusten (1989) p.131 discusses the distinction between the town of Pheia and the territory of that town, which Thucydides also simply calls 'Pheia'. For the lack of other good harbours on this stretch of the Greek coast see also Cary (1949) p.85f, and below, pp.117, 273 (the area to the south), and figs.18, 33.ii.

295. For the importance of Naupaktos to the Aitolians, see Woodhouse (1897) pp.47, 337. 
296. Semple (1932) p.75 notes that Naupaktos lies in the wind shadow of the Molykreian Rhion promontory. For an image of the ships which moored in this sheltered spot, we might recall the holkas lying at anchor in the open waters between Molykreian Rhion and Naupaktos, around which the Athenians under Phormio turned impending defeat in their second battle in the Corinthian Gulf into victory - see Thuc.2.91. The general lack of good harbours along the faulted, steep, and rocky coastline of the Corinthian Gulf is described by Mediterranean Pilot III p.11, Cary (1949) p.68, and Papageorgiou et al. (1993) p.275.

297. For a historical example of the use of this headland and river mouth as shelter for a fleet, see Xen.Anab.6.2.2: 'And coasting along they came to the city of Herakleia.....and they came to anchor alongside the Acherousian Chersonesos'. Pliny.N.H.6.1 also calls the river mouth 'Sonautes' (Mooney (1912) p.195 on Ap.Rhod.Arg.743-51), suggesting that this river mouth protected by a promontory was regularly used as a sheltered retreat by sailors caught in dangerous winds.

By coincidence, there was a second river Acheron which had its outflow adjacent to a headland, and this too was used for shelter by ships in an otherwise harbourless region subject to onshore winds: -...the river Acheron runs through Thesprotia and empties into the lake, to which it gives its name. There is also a river Thyamis, which separates Thesprotia and Kestrine, and between these rivers rises the promontory of Cheimerion. It was at this point of the mainland that the Corinthians cast anchor and made camp.' (Thuc.1.46.4f.). For the topography of this region, see Hammond (1945) p.28.

298. See, for example, Cary (1949) pp.46, 56, Cary and Warmington (1929) pp.5, 10, Pryor (1988) p.24, Semple (1932) p.580, Tozer (1873) p.66.

299. For the modern continuation of the practice, see the directions advising sailors to take advantage of the shelter available in the lee of Chios (Mediterranean Pilot IV p.194) and Rhodes (Mediterranean Pilot IV p.301).

300. Cary (1949) p.90.

301. For the danger caused to sailing ships in the Aegean by squalls see Mediterranean Pilot IV p.13. The similes of the Iliad provide ample evidence of the violence of the squalls which descend onto the Aegean Sea, and of the fear which they aroused; see for example Hom.Il.11.296ff., 13.795ff. (for the latter, see p.59). In such passages the interpretation of the Greek as describing squalls rests less on the precise meaning of words such as $\dot{\alpha} \hat{\varepsilon} \lambda \lambda \eta \eta$ (Hom.Il.11.296ff.) and $\lambda \alpha \hat{\imath} \lambda \alpha \psi$

(Hom.Il.13.795ff.) as on the accurate description of the nature and effects of the winds. Thus in

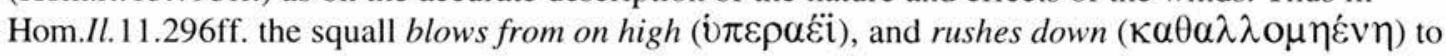

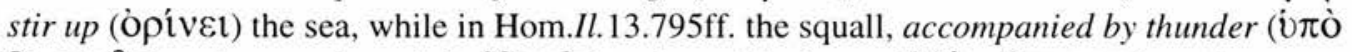
$\beta \rho 0 v \tau \hat{\eta} \varsigma)$ rushes earthwards $(\pi \dot{\varepsilon} \delta \mathrm{ov} \delta \varepsilon)$, mixes with the sea ( $\dot{\alpha} \lambda \hat{\mathrm{i}} \mu \mathrm{i} \sigma \gamma \varepsilon \tau \alpha \mathrm{l})$, and creates seething

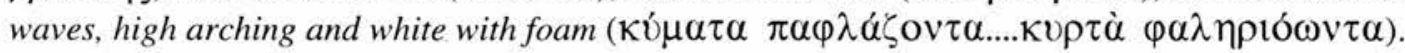
See the commentaries of Leaf (1888) vol.1 p.487 on Hom.Il.11.296ff., and of Leaf (1888) vol.2, p.50 and Janko (1992) p.142 on Hom.Il.13.795ff. For the characteristics and effects of squalls see pp.5760 .

302. Squalls are also produced on the (northerly) coasts where the initial vertical displacement of the wind occurs, especially where these coasts are high and cliffy (below, p.125f.), as, for example, on the east coast of Malea (see Mediterranean Pilot IV, p.73). See Anth.Pal.7.699, on the difficulty of finding sheltered anchorage anywhere around the coasts of Ikaria, and compare New Pilot, p.249, where the island is called 'Nicaria'.

303. Semple (1932) p.624.

304. Squalls noted by Pryor (1988) p.95. 
305. For squalls in the bay of Karystos, see also Mediterranean Pilot IV p.152.

306. Mediterranean Pilot III p.65, IV pp.73, 81f., Cary (1949) p.45, Semple (1932) p.629.

307. Rowing ships out of harbour into an area of favourable breezes: Morrison and Williams (1968) pp.62f., 202f., 310f., with nn.7 (p.64), 17 (p.65), and 66-70 (p.218f.), where references are given to clear examples in ancient texts.

308. Morrison and Williams (1968) p.311 record instances where unfavourable winds prevent even triremes from putting to sea.

309. For discussion of this passage, and of the difficulties of getting ships into open water through on-shore winds generally, see Morrison and Williams (1968) p.201f.

\section{Mediterranean Pilot IV p.13.}

311. Compare Pryor (1988) p.87.

312. For example, see the difficulties that land and sea breezes cause to the enemies of Phormio during the Peloponnesian War, and to those of Themistocles at Salamis, above, pp.87-90. For the strength of the sea breeze in the gulfs of Argos and Smyrna, see Mediterranean Pilot IV p.13, and in the Saronic Gulf - n.229 above.

313. A delay in the ship's progress seems necessary to explain why some of the passengers on the ship decided to return to Athens by land from Sounion, and how they then arrived back in Athens before the theoric ship.

\section{Mediterranean Pilot IV p.133.}

315. Theophr.Vent.32, verified by Coutant and Eichenlaub (1975) p.79, Mediterranean Pilot IV p.152.

316. In Arg.1.1273ff. the Argo sets sail from the vicinity of Kios in the deep Kianos Gulf in the eastern Propontis, while in Arg.4.1223f. the ship departs from Drepane, commonly associated with the historical island of Corcyra: land and sea breezes would be strongly developed in both of these areas. For the association between bays and sea breezes, see pp.53, 55. Compare Arg.1.519-23 (p.36 above; the Argo similarly setting sail from the Gulf of Pagasai), and Arg.2.1228ff. (leaving the Isle of Ares, off the southeast shores of the Black Sea).

317. Scheria, the land of the Phaeacians, is of course often identified with Corcyra (the Corcyraeans themselves made the identification: Thuc.1.25.4; for the relationship between the two, see Howie (1989) passim.), where there is also such a 'double' harbour, formed by a protrusive headland (see fig.24.i). Cary (1949) p.59f. calls this the 'anvil' type of harbour. Ps-Scylax Perip. 30 claims three harbours for Corcyra.

318. Paus.2.34.9: 'After it [Bouporthmos], the mainland is skirted by a crescent-shaped beach; and after the beach there is a spit of land up to a sanctuary of Poseidon, beginning at the sea on the east and extending westwards [i.e. running eastwards out from the coast]. It possesses harbours...Here the Hermionians had their former city.' The author has twice visited the site, and agrees with Frazer (1989) vol.3, p.293 concerning the ancient town's lack of fertile territory or land access, and the quality of the harbours and the excellent shelter provided by nearby islands and capes. McAllister (1969) p.169 also states the promontory 'protects the harbour'.

319. Garland (1987) p.18 notes that larger cargo vessels could not ride at anchor in Phaleron Bay. 
320. Mounychia harbour used exclusively for naval purposes - Garland (1987) p.160. So too Zea Garland (1987) p.154, where the excellent shelter available in Zea harbour is also noted.

321. The name 'Calm Harbour' occurs at Xen.Hell.2.4.31 and nowhere else. For its location, see Garland (1987) p.151, and especially Day (1927) p.443f.. That $\kappa \omega \varphi \grave{\varsigma} \varsigma$ here, and in the case of the identically named harbour near Torone (above, p.97), denotes 'calm' rather than 'false' or 'unserviceable' is clearly established by Day (1927) p.442f. See also Hornblower (1996) p.425f.

Also named in accordance with its excellent sheltering properties was the harbour called Panormos, or 'safe in all winds/conditions'. Panormos, the harbour of the town of Orikos, was a sheltered lagoon, entered via a narrow channel which connected it to the deep bay of Orikos, which in turn was protected by the promontory of Keraunia on the coast of Epeiros: see Str.Geog.7.5.8 and Hammond (1967) p.472f. For another 'Panormos', see Paus.7.22.7, quoted on p.145.

322. Compare Cary (1949) p.77f., and Garland (1987) p.7f.: the development of the Piraeus, hand in hand with that of the Athenian navy, "owed everything to the unrivalled protection which its three landlocked harbours afforded to Athens' naval arm.”.

323. For islands protecting the south coast of the Argolic peninsula from southerly winds, see also Frost (1977) pp.234, 237 on the island of Soupia, which provided sheltered anchorage for the ships of the ancient inhabitants of Phourkari on the mainland opposite, and still does for modern boats.

324. Cf. Blackman and Branigan (1975) p.24: Kaloi Limenes, 'though far from completely safe, is the safest haven on this stretch of coast.... The bay is well protected from the sudden north winds and offers good anchorage except from the southeasterly winds of winter.... Offshore islands, Nisis Ayios Pavlos and Megalonisi, provide partial protection from the southwest.'. Exposure to SE winds,

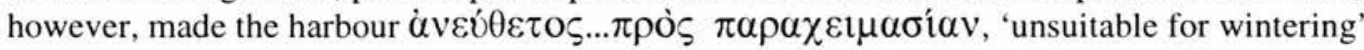
(Acts.27.12, quoted above, p.104f.). For illustrations of the site, see Blackman and Branigan (1975) p. 18 , fig. 1 , and plates $6 \mathrm{~d}, 7 \mathrm{c}, 7 \mathrm{~d}$.

325. Glover (1932) p.23, Cary (1949) p.45, Cary and Warmington (1929) p.24, Myres (1911) p.58f., Semple (1932) p.601. For the problems encountered when ships did sail in the Adriatic, see pp.80, 132; the storms which wreck both the Cretan founders of Hyria (Hdt.7.170), and, later, Darius' reconnaissance party (Hdt.3.138) off the coast of Iapygia in Italy are most likely to have been caused by the northeasterly Bora blowing across the Adriatic from the mountains of Dalmatia.

Anth.Pal.7.498 testifies to the fierce winds and waves also to be found in the Ionian Sea, which lay directly south of the Adriatic and so experienced the same winds.

326. Compare Anth.Pal.7.303 (Thracian Boreas), 502 (Strymonian).

327. For the funnelling of winds, see pp.57, 60. For winds in the Doro channel, see pp.87, 99. See also the comments of Fraenkel (1950) vol.2, p.116 on the violence of northerly winds around Euboia, and references to them in Aeschylus' Agamemnon.

328. Semple (1932) p.581f., Coutant and Eichenlaub (1975) p.70.

329. Ps.-Scylax Perip.68, Picard (1988) p.388f., Picard (1989) p.499f., Wynne-Thomas (1978) p.45, Archontidou-Argyri, Simossi, and Empereur (1989) p.58.

330. Presumably a common practice, as the terms of a fifth-century BC Thasian law concerning the importation of wine suggests - see IG XII, Suppl. 347, II, Pleket (1964) p.9, Puoilloux (1954) pp.45, $130 \mathrm{ff}$.

331. Cary (1949) p.98, Wynne-Thomas (1978) p.44f. 
332. Note that the Athenian ships guarding Sphakteria during the Peloponnesian War moored all around the island, except when there was an onshore wind, in which case no ships would moor to seaward of the island (Thuc.4.23.2, 26.7).

333. Cary (1949) p.86, Walker (1962) p.365. For the Anigros river and the sands and marshes of the Triphylian and Messenian coasts, cf. Str.Geog.8.3.14f., Paus.5.6.3.. Thuc.2.25.4 characterises this area as being $\dot{\varepsilon} \nu \dot{\alpha} \lambda \iota \mu \dot{\varepsilon} \nu \omega \chi \omega \rho i \omega$, 'in a harbourless region'. See also n.425.

334. For the inconvenience and danger associated with extensive coastal shallows, see Beckinsdale (1956) p.311f., Bigelow and Edmondson (1947) p.135f., Taylor (1971) p.3f. Note also

Xen.Anab.7.5.12f. on the coast near Salmydessos, on the south coast of the Black Sea, 60 miles west of the Bosporos, one of the most feared areas of coastal shallows: 'Here many vessels sailing to the Pontos run aground and are wrecked, for there are shoals that extend far and wide..... ( $\tau \dot{\varepsilon} v \alpha \gamma o \zeta$

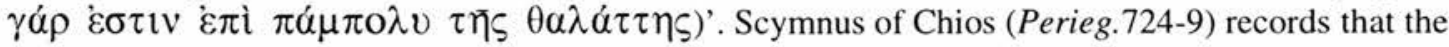
shoals around Salmydessos stretch out for 700 stadia, and were utterly harbourless and difficult to

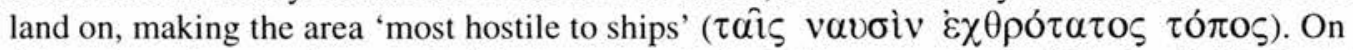
Salmydessos' reputation as a 'wicked step-mother' of ships, see also Archilochos fr.79a.3 with the commentary of Campbell (1967) p.158, Aesch.Pr.B.726f. with the commentary of Griffith (1983) p.218. See also, especially for the organised recovery of valuable goods from these wrecked ships, Stronk (1986) passim.

335. Evidence that ships often dropped anchor in such areas comes from the many anchors discovered on the sea bed - see Frost (1993) p.449. For how closely ships could sail into the wind, see p. 243 and n.577, and for the tendency of even anchored ships to drift, see pp.235f., 240 and nn.546, 568 .

336. For various attempts to identify the 'Tritonian lake' with actual features of the North African coast, see How and Wells (1912) vol.1 p.359, on Hdt.4.178, and Weld-Blundell (1895-6) p.114ff. Some part of the Syrtis seems most likely: Jason was indeed blown to Syrtis, and from there he reached the Tritonian lake in later versions of the story (Ap.Rhod.Arg.4.1240ff.), when the northern African coast was better known to the Greeks. The difficulty of equating the Tritonian lake with any modern body of water is stressed by Braswell (1988) p.90, on Pind.P.4.20f.

The precise naval meaning of diekplous is discussed by Morrison and Williams (1968) p.137f., Morrison (1974) pp.22-6, and Morrison and Coates (1986) p.43, who argue that the fleet carrying out the diekplous formed into line ahead (i.e. single file) and attempted to pass through a single gap between two adjacent ships of the enemy fleet. Lazenby (1987), supported by Holladay (1988) p.149ff., emphasises clear difficulties with this interpretation (principally (p.170) that the immobilisation of any one of the leading ships would make it impossible for the rest of the fleet approaching from behind to complete the manoeuvre), and argues instead that the attacking fleet also formed into line abreast, with each ship trying to pass through the gap between the two enemy ships directly in front of it. Shaw (1993) p.102f. suggests that the diekplous was carried out by individual ships, wherever gaps appeared in the enemy line in front of them, once opposing fleets had made contact with each other. Whichever interpretation one accepts, the action of passing through the narrow channels between adjacent ships is clearly comparable to that of passing through open water channels between islands, sand banks, and other features of shallow waters and river mouths.

337. Str.Geog.1.3.18, 10.2.19, Hdt.2.10, Paus.8.24.5, Thuc.2.102.2-5, Gomme (1956a) p.249.

338. Scylax Perip.35, Str.Geog.1.3.8, 10.2.8, Lehmann-Hartleben (1923) pp.263-7, Cary (1949) p.59, Semple (1932) p.599f., Murray (1987) p.162 n.1.

339. Str.Geog.1.3.19, 13.2.2, Scylax Perip.79, Cary (1949) p.99. 
340. Either the tombolo was eroded between Strabo's visit and that of Pausanias, or else it was so narrow and marshy or sandy that it could reasonably be seen either as an island or as a promontory. The island of Minoa is now not only connected to but assimilated into the mainland: the topography of ancient Nisaia and Minoa, and its relation to the present topography of the area, is discussed by Frazer (1898) vol.2, p.539-42 (on Paus.1.44.5), Gomme (1956a) p.334ff. (on Thuc.3.51), Hornblower (1991) p.442, and Casson (1912-13) passim. For the similar history of Kyzikos in the Propontis, at times a headland and at others an island, see Mooney (1912) p.127f. on Ap.Rhod.Arg.1.936ff.

341. Beckinsdale (1956) p.311f. characterises the fault coastline as the poorest in harbours of any type of coast.

342. One nautical league $=c .3 .46$ miles. Thus the harbourless coast described here extends for at least forty-five miles. The northeast coast of Euboia, described in the second passage, is far longer: even the southeasterly portion of it which is described here, trending 'in a westerly and then northerly direction', runs to over fifty miles.

343. Evidence that adverse winds often forced ships to drop anchor in such cliffy or rocky areas, in water shallow enough for their anchors to contact the sea bed, is provided by the many anchors that have been discovered on the sea bed in such areas - see Frost (1993) p.449. For the degree to which ships could sail into the wind, see p.243 and n.577. For the tendency of ships to drift, even when anchors had been dropped, see pp.235f., 240, and nn.546, 568 .

\section{Compare Pryor (1988) pp.95, 97f.}

345. For the problems that these onshore prevailing winds caused to ships trying to shelter off the west coast of the Peloponnese, see Thuc.4.23.2, 26.7, on the Athenian triremes guarding Sphakteria: 'at night their [the Athenians'] whole fleet lay at anchor on all sides of it [Sphakteria], except to seaward when there was a wind....They [helots bringing food into Sphakteria] found it easier to elude the guard of triremes when the breeze was from the sea, since then it was impossible for the ships to lie at their moorings off the island...'. For the lack of harbours along the west coast of the Peloponnese, see also pp.101, 117, 273.

346. Cary (1949) pp.45f., 73f., Rouge (1981) p.18, Tozer (1873) p.237.

347. See, for example, Braudel (1975) p.104f., Casson (1959) p.38, Ormorod (1924) p.15f., Rose (1933) p.31, Semple (1932) p.584f., Starr (1989) p.21. Note also the more sceptical comments of Gomme (1933) p.16f.

348. Braudel (1975) p.106.

349. As well as it greater size, the Atlantic also features generally worse seafaring conditions than the Mediterranean: see below, pp. 230-4, $236 f$.

350. Islands and coasts, particularly promontories, visible from fifty miles away - Cary and Warmington (1929) p.10, Cary (1949) p.46f., Semple (1932) p.587, Severin (1954) p.14f. Cary (1949), Semple (1932), and Severin (1954) loc.cit. note that Athos (in the Chalkidike) and Samothrace were visible at up to one hundred miles. Taylor (1971) p.63 makes the same observation regarding Mt. Ida in Crete. Severin (1954) p.15 has a short discussion of the degree of deterioration in visibility of landmarks due to pollution since ancient times.

351. No point in the Aegean over forty miles from land - Semple (1932) p.587. Corcyra only fortyfive miles distant from Italy - Cary (1949) p.60. Italian and Greek shores visible simultaneously Myres (1896) p.617. Opposite shores of the Black Sea visible simultaneously on a direct crossing between Cape Karambis in the south and Cape Kriou Metopon in the north - Str.Geog.7.4.3, quoted below, p.147 (cf. also n.374). 
352. And even then, coasts and islands were similarly in evidence in many other areas of the Mediterranean - cf. Braudel (1975) p.106.

353. Taylor (1971) p.63.

354. Starr (1989) p.21 gives the ability to run ashore to escape storms as the main reason why ancient Greek ships 'tended to hug the coast'.

355. Cary and Warmington (1929) p.10, Pryor (1988) pp.15, 90, 92, 98, Rouge (1966b) p.34f., Rouge (1981) p.17.

356. Calms commonest in summer: see Arist.Met.361b23f. with Murray (1987) p.150.

357. Rouge (1981) p.18f. briefly discusses the types of coast which are unsuitable for navigation, and Taylor (1971) likewise notes the main physical dangers which threaten ships sailing close to the shore. For detailed discussion, see above (ch.2).

358. The north African coast was particularly dangerous because the perils of a low shore with few landmarks were combined with those of a lee shore onto which strong prevailing winds relentlessly blew. See below, p.174f. and n.425, for the navigational difficulties of low coasts (esp.

Str.Geog.17.1.6 on Alexandria), and, for the dangers of strong northerly Etesians blowing onshore, see p.232f., on Ap.Rhod.Arg.4.1240-1244, 1259-1278; for the combined danger, see p.118f., on Hdt.4.179, quoted there, and also Pryor (1988) p.22f.

359. Compare McGrail (1983) p.314f. for the importance, to early mariners crossing the English Channel, of paying due attention to the state of the tide when sailing to, from, or anywhere near the coast.

360. Passages referring to calms often stress how no wind is as dangerous as too much wind for sailors. See Anth.Pal.7.293, also Philostr.Imag.2.17: '...not roused and turbulent, nor yet flat and calm, but a sea fit for sailing.' The difficulty of rowing out of a calm is described in Hom.Il.7.4ff.: 'And as a god giveth to longing seamen a fair wind when they have grown weary of beating the sea with polished oars of fir, and with weariness are their limbs foredone...'. Homer, describing Menelaos' difficult return from Troy, also refers to the danger of running out of supplies when becalmed: 'There the gods held me twenty days, nor did the sea-winds ever show their breath, they that serve to waft ships over the broad back of the sea. And now would all of our corn have been spent, and likewise the strength of the men, except...' (Hom.Od.4.360-4). Plut.Mor.303CD stresses the danger of running out of water during a calm, and refers not only to warships but also to merchant ships, which carried greater supplies; compare Anth.Pal.7.293, and see also Aesch.Agam.565f.

361. Cf. Braudel (1975) p.106.

362. Thus Casson (1971) p. $280 \mathrm{n} .43$ discusses how varying wind and sea conditions governed the route and manner by which a twenty-oared galley carrying Cicero down the west coast of Italy (ad.Att. 16.6.1) would have sailed: a calm meant that the crew rowed along their preferred route (i.e. the direct, open-sea route); moderate winds allowed them to sail along this same route; very strong winds, however, forced the crew to follow the contours of the coast, rowing near to the shore. For examples of long-distance journeys accomplished by triremes and penteconters, see n.519.

363. Morrison and Coates (1986) pp.132, $161 \mathrm{f}$.

364. Taylor (1971) p.64 briefly discusses the influence of the type of ship and cargo upon the choice of route. Hdt.8.118 (quoted above, p.114f.), in which people are cast overboard to ensure the survival of a ship and the rest of its passengers, should clearly not be taken as evidence of normal, or even of 
exceptional practice. See also Thuc.1.10.4 on the danger of carrying passengers across the open sea in undecked ships (for ships with no overall deck, see p.238f.).

365. Even some Athenian grain traders carried out their business in this way. Thus in Dem.34 and 35, merchants sail from Athens to Mende, where they pick up wine, and then on to the Black Sea, where they sell the wine and buy grain, which they then take back to Athens. Mende lay on the standard sailing route between Athens and the Hellespont, so the Athenian traders were not sailing out of their way. Compare Braudel (1975) p.107.

366. Taylor (1971) p.63f. thus distinguishes between experienced and skilled merchant officers and trireme 'captains unaccustomed to the sea'.

367. Polyaenus 3.11.13, Morrison and Williams (1968) p.282. See also below, p.238f.

368. Ormorod (1924) pp.19, 23, 25f., Rouge (1981) p.18f. Note also that Theophrastos' 'Cowardly Man' (Char.25) mistakes headlands for pirate ships, which might also be taken to indicate that pirates operated mainly on the coast, and typically from headlands. The maze of longitudinal islands off the Illyrian coast was one of the most famous pirate haunts (Walker (1962) p.7).

369. Braudel (1975) p.107.

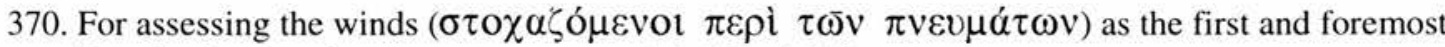
consideration in planning a sea voyage, see Aristides 2.148.

371. П $\alpha \rho \mu \varepsilon^{\prime} \beta \varepsilon \tau 0$ indicates that the fleet, as it sailed across the mouth of the gulf, 'left on one side' the towns of the gulf - Herodotos is not contradicting himself by saying that the fleet did enter the gulf, to pick up the reinforcements. These reinforcements, unlike those from the Singitic Gulf mentioned previously, and those from the west coast of Pallene mentioned later, included ships as well as men, and presumably made their own way out of the gulf, to be received by the Persian fleet. How and Wells (1912) vol.2, p.172 suggest they were picked up by a detachment of the Persian fleet which did enter the gulf, but nothing in the text specifically suggests this.

372. See Casson (1971) p.280, n.43, where the author, discussing Cicero's journey from Pompeii to Vibo, correctly emphasises both the amount of time that could be saved by sailing directly across the mouths, rather than along the shores of bays.

373. Note that the name of Cape Farewell (in Greenland) suggests a similar role for some headlands in the modern era.

374. The passage between Karambis and Kriou Metopon is also described as being the shortest crossing of the Black Sea by Menip.Perg.Perip.5902f. Ps-Scymn.ad.Nic.reg.998ff. describes Kriou Metopon as 'a high mountain dropping steeply into the sea, involving a journey of a day and a night from Karambis'. Compare Per.Pont.Eux.8v25ff. and Scymn.Perieg.825ff., 953-7, where essentially the same information is given. These passages clearly indicate that the strait between Karambis and Kriou Metopon was used as a regular sailing route.

375. For other examples, see also Paus.3.23.1 (Kythera, Onougnathos), Str.Geog.10.2.19 (Dolicha, Araxos), 14.1.12ff. (Samos, Mykale, and, Sounion), 14.2.19 (Kos, Nisyros). Wachsmuth also characterises ancient sailing as a progression of voyages between headlands - see Wachsmuth (1967) p.394f.

376. For Tainaron as a port of departure to destinations even further afield than Crete, see Plut.Cleomenes.22.5 (Cratesicleia, the mother of Cleomenes, sails from Tainaron when headed for Egypt as a hostage of Ptolemy) and 38.4 (the wife of one Panteus 'made all speed to Tainaron, and there embarked on a ship bound for Egypt.') Cf. also Thuc.7.19 (above, p.80: troop-carrying 
merchant ships set sail from Tainaron for Sicily), and Str.Geog.8.5.1 (below, p.161f.: the sailing route from Tainaron to a headland in Kyrenaia). Compare Diod.Sic.17.108, 111, 18.9, 21, 20.104 where mercenaries gather at, and wait to be picked up for service abroad from, Tainaron. The wellknown fact that sailing routes followed the coast to such prominent headlands before striking out across the open sea, and made landfall at such headlands when arriving from foreign lands, meant that, by gathering in this otherwise almost uninhabited corner of Lakonia rather than in a major port town, mercenaries could avoid causing consternation among the local population and authorities while still being able to come into contact with a great deal of international maritime traffic. For the site of the harbour, the sanctuary of Poseidon, and the Hellenistic settlement, see fig.57.

377. For the location of these towns on the west coast of the Peloponnese, see Zachos (1984) and Themelis (1968) passim.

378.Note also Tozer (1873) p.73: "But the most important influence which the promontories exercised on the Greeks was their bringing them into connection with foreign peoples."

379. Strabo here clearly thinks it surprising and unusual enough to be worth explaining (cf. 'and yet' - $\delta \dot{\varepsilon} \kappa \alpha \grave{i}$ ) that the longer route was also the more popular, presumably because most readers would expect the shorter route between headlands to be the more popular: thus elsewhere (Geog.6.3.7) he states that those sailing across westwards from Greece make for Brundisium specifically because this is the 'more direct route' ( $\varepsilon \dot{v} \theta 0$ $\pi \lambda$ ot $\alpha \mu \bar{\alpha} \lambda \lambda \hat{\nu} v)$.

380. See Jeffrey (1976) p.50 for the strength of interest in the Olympic festival displayed by colonies in Sicily, Italy, and elsewhere.

381. That Ichthys, with the harbour of Pheia on its northern side, was an important landmark, or even stopping point, on the sea route to Olympia, is supported by a passage of Strabo in which the distance and geographical relationship between the two are given: 'Off Pheia lie a little island and a harbour, from which the nearest distance from the sea to Olympia is 120 stadia. Then comes another cape, Icthys...Then comes the mouth of the Alpheios.' (Str.Geog.8.3.12). For the harbour of Pheia, see p.101. Xenophon's description of Iphicrates' journey from Athens around the Peloponnese to Corcyra in 373B.C., also gives important evidence regarding the position of Ichthys in relation to the Alpheios, as a place of possible shelter, and as a point on long-distance sea-routes, where landfall was made from the open-sea, or equally from where ships headed out to the open sea: 'Then, after reaching Elis and sailing past the mouth of the Alpheios, he anchored beneath the promontory called Ichthys. From there he put to sea on the following day for Kephallenia...' (Xen.Hell.6.2.31). Further evidence that the headland of Ichthys, and the harbour of Pheia sheltered by it, were important points on sailing routes to Italy and Sicily comes from Thuc.7.31.1: 'At this time Demosthenes....was on his way to Corcyra [en route to Sicily]; at Pheia in Elis he found lying at anchor a merchant-ship in which the Corinthian hoplites were about to be carried across to Sicily.'.

382. See also the case of the Oinoussai islands in the strait separating Chios from Asia Minor, as reported in Hdt.1.165.1. The asty of Chios, lying on the east coast of the island, controlled traffic through the strait, beyond which was the west coast of Asia Minor, to which trade routes came from the east. Thus Chios town was a considerable emporion, and when the Phokaians asked to be allowed to settle on the Oinoussai islands, the Chians refused, fearing that these small islands, lying actually within the strait, and marginally closer than Chios town to the coast of Asia Minor, would become the more important emporion.

383. For the importance of Lakonian trade with the west, see Gomme's note on this passage: Gomme (1956b) p.508. Note that the Spartan fleet that sailed to Sicily in 413 BC set out from Tainaron (Thuc.7.19), and ships returning to Lakonia from the west would no doubt have made landfall either here or further inside the Lakonian Gulf, at Gythion, both of which sites could be reached sooner than Kythera. Tainaron is also mentioned as a place of departure for ships sailing to Egypt and other places in Africa, but mainly where large fleets, rather than single ships, are concerned (see n.376), 
and it should be emphasised that this more westerly headland seems rarely if ever to have been preferred to Kythera as the destination of ships coming from Africa. The role of Tainaron as a place of departure for fleets no doubt relies upon the fact that there was a sizeable sheltered bay there, where ships could safely gather, with harbour facilities for embarking passengers, and a sanctuary of Poseidon for religious observations (fig.57). Kythera was of no use here, for Spartan fleets and their crews and passengers clearly had to embark upon their voyage from the Lakonian mainland, and Malea could offer no such sheltered bays. Hornblower (1996) p.70 cites very early evidence for Kythera as a landing place for merchants from Egypt.

384. For the problems associated with seafaring around the west coast of Greece, see pp.31f., 101, 117. For Corcyra and Zakynthos as 'connecting links' between Greece and Italy, see Cary (1949) p.59f. Compare Braudel (1975) vol.1, p.126f., on the importance of Corcyra in the medieval period. Murray (1987) p.162 nn.1 and 2 notes both the difficulty of navigation on the northwest coast of mainland Greece and the strategic importance of Corcyra. Similarly, Hammond (1967) p.36 sees the plentiful shelter and harbourage available in and around the Ionian islands as a factor detracting from the influence of the coast of Epeiros, which was less well-suited to shipping.

\section{See Str.Geog.7.7.5, Cary (1949) p.60.}

386. Thuc.1.44.3 also states, as part of the Athenians' reflections on the Corcyra issue, that the island was 'admirably situated for a paraplous to Italy and Sicily'. See also Thuc.6.30.1, 34.4ff., 7.33.4, and Xen.Hell.6.2.4, 9, in all of which the importance of Corcyra for triremes, rather than merchant ships, headed for Sicily is again expressly stated. The passages from Thucydides, especially 6.34.4ff., also stress the importance of Cape Iapygia on the Italian side of the crossing, and the fact that minimising the distance of the open-sea crossing was of great importance to the crews of triremes. Thus note the terms in which Arrian describes one of the future conquests that Alexander had supposedly planned: 'to make for Sicily and the Iapygian promontory, as he was already rather disturbed that Rome's fame was advancing to a great height.' (Arr.Anab.7.1.3). Xen.Hell.6.2.2f. also bears witness to Athenian interest in Zakynthos, presumably for its importance to sea routes to Italy and Sicily, as well as for its role as an offshore base from which to threaten the Peloponnese. For the general strategic significance of Corcyra, see Wilson (1987) passim., esp. pp.121f., 127f. on control of the seas in the area, and above, nn.381, 384 .

387. Morrison and Coates (1986) p.101f. argue from Thuc.6.33f. that the direct $385 \mathrm{~km}$. crossing from Corcyra to Kroton (on Cape Lakinion), which has shorter than the crossing from Leukas, was 'clearly beyond the capacity of a trieres'. However, for the successful completion of longer journeys than this by triremes, see n.519. For Cape Lakinion (now Cape Colonna) as a standard landmark or landfall on the crossing from Greece to Italy, see the remarks concerning shipwrecks in the vicinity in Pensabene (1978) p.105: '...Cape Colonna, apparently a place which ships coming from the east had to pass in order to go into the Tyrrhenian Sea.' This view echoes the comments of Dunbabin (1948) pp.182, 194 n.1. Dunbabin (1948) p.194f. also largely corresponds to the comments made here regarding sea routes to Sicily.

388. See also Page's interpretation of Sappho fr.17 (= A17 in Lobel and Page (1955) p.15), where, in a variant of the events of Hom.Od.3.150ff., Menelaos, together with Agamemnon, calls upon Zeus, Hera, and Dionysos (rather than 'the god' only, as in Homer) on Lesbos, in order to complete their journey: Page (1955) pp.59-62. A Lesbian sanctuary of Zeus, Hera and Dionysos is also mentioned in Alcaeus G1 (\#129 in Lobel and Page (1955) p.177f., and in Page (1955) p.176f.), where it is described as being $\varepsilon \tilde{\delta} \delta \varepsilon 1 \lambda \mathrm{OV}$, a term which indicates that which is conspicuous, particularly from the sea. On the basis of the information contained within these fragments, and field work carried out in Lesbos, Quinn identified the site of the sanctuary as Cape Phokas, a promontory with a natural harbour, flanked by a generally cliffy coastline, on the south coast of Lesbos (Quinn (1961)). Views from the site of the sanctuary take in the coast of Asia Minor, Chios, and Psara (anc. Psyria) (Quinn (1961) p.392). Thus the promontory on which the sanctuary stood, with its harbour, was an ideal stopping point for ships having reached Lesbos and deciding which route to follow next - whichever 
route was taken, it was from this point that the coastline of Lesbos would be abandoned for the open sea, with the next landmark on the journey already in site.

389. The harbour at Geraistos was large enough to shelter the fleet of Agesilaos headed for Ephesos in 396 BC (Xen.Hell.3.4.4, Plut.Agesilaos.6.4), and later the Roman fleet operating in the Aegean in 200 BC (Livy.31.45.10). For the position of Geraistos and the sanctuary of Poseidon there, see below, n.418. For Geraistos as a stopping point on journeys between southern Greece and the northwest Aegean, see also Arr.Anab.2.1.2 (quoted below, p.158), and Thuc.3.3.4 (discussed in n.509). The fact that Philip II 'seized the shipping at Geraistos and levied untold sums' (Dem.4.34) suggests again that Geraistos was an important stopping point for merchant ships on long-distance journeys, including (given the context of this passage) Athenian grain ships returning from the Black Sea. In fact, these are explicitly stated to have stopped at Geraistos at Xen.Hell.5.4.61: ' ...the Athenians were quite blocked up; their corn ships had come as far as Geraistos, but from thence they could not venture to sail, as the Lacedaimonian fleet was hovering about Aigina, Keos, and Andros.'.

390. Ormorod (1924) pp.19-26, without exploring the reasons why. See especially p.23f. (islands at the mouths of gulfs) and p.25f. (promontories).

391. Ormorod (1924) pp.20, 26.

392. For similar attempts to control shipping by guarding headlands and offshore islands, compare, for example, the fortification of Sounion (Thuc.8.4, Dinsmoor (1970) p.29f.), of Skyllaion near the Straits of Messina (Str.Geog.6.1.5, quoted above, p.111), of Achaian Rhion (Thuc.5.52), and of Kythera (Thuc.4.53, quoted above, p.152). Semple (1932) p.584ff. has a general discussion such fortified look-out points. Note also the importance attached to Corcyra, which commanded the 'coastal' route to Italy and Sicily (Thuc.1.36.2, quoted above, p.153).

393. The role of headlands in particular as turning points, as well as landmarks, has been discussed briefly by Severin (1954) p.16, and Tozer (1873) p.72f. Burnett (1994) p.160 states that Kynossema, a headland on the Hellespont, 'marked a point where a ship's course had to be changed'. Hammond likewise deduces that at Cape Cheimerion, on the Thesprotian coast opposite Corcyra, 'a navigator evidently changed course' (Hammond (1967) p.475), and that Thucydides' description of the area (Thuc.1.46.4f.) 'is clearly that of the mariner, who changes course at Cape Varlam [Cheimerion] where the Corfu [Corcyra] channel is lost to sight and Port Splantza comes into view' (Hammond (1945) p.28). For headlands as the points at which whole new sections of coast become visible to mariners, see immediately below in the main text.

394. Our earliest extant manual, the Periplous of pseudo-Scylax, dates from the fourth century BC, or else was constructed from manuals dating from that time (see Der Kleine Pauly vol.5, s.v. Skylax, Bunbury (1959) vol.1, p.404f.). However, the original Scylax of Caryanda wrote in the sixth century BC (Hdt.4.44), and How and Wells were also of the opinion that some of the distances given for voyages by Herodotos, himself writing in the fifth century BC, were taken from earlier seamen's periploi - See Hdt.4.85ff., esp.86.1, and How and Wells (1912) loc. cit. (vol.1, p.331ff.), where their conclusions can hardly be doubted, given the amount and nature of the information supplied by Herodotos. Similarly, Hammond argues convincingly that Thucydides took some of his topographical descriptions from sailing manuals - see Hammond (1967) p.471ff. (also, with less discussion, Hammond (1945) p.28). Hekataios certainly wrote a geographical treatise on the coasts and islands of the Mediterranean in the late sixth century BC, and Myres (1896) p.610 links the formulation of sailing directions to the spread of colonisation and commerce, a plausible suggestion which could take the date of the earliest manuals back further still: how long such sailing directions remained a purely oral tradition is of course open to question. Tozer (1873) p.73 briefly notes the 'milestone' function of headlands.

395. See, for example, Str.Geog.6.2.1 (quoted above, p.151), 8.2.1 (quoted above, p.143.), and 6.3.10 and 10.4.5 (both quoted below, p.189). There are many other passages where Strabo specifically attributes a distance given in his text to a particular geographer whose works he has consulted. His 
most explicit comments concerning his reliance upon early geographers for these distances between different points on the Mediterranean coasts come at Str.Geog.2.1.7f., 2.4.3, 6.3.10, and 7.7.4. Here and elsewhere it becomes apparent that Strabo took such information, directly or indirectly, from the works of Artemidorus (late 1C BC), Dicaearchus (late $4 \mathrm{C} \mathrm{BC}$ ), Eratosthenes (3C BC), Hipparchus ( $2 \mathrm{C} \mathrm{BC}$ ), Megasthenes (4C BC), Patrocles (late $4 \mathrm{C} \mathrm{BC}$ ), Polybius ( $2 \mathrm{C} \mathrm{BC}$ ), and an author referred to (Geog.6.3.10) only as 'the Chorographer'.

396. The fact that it is generally only headlands to which distances are given for overseas journeys, while the distances to ports, straits, and other features are given for coastal journeys, is further evidence that open sea crossings generally took the form of direct passages between prominent headlands on either side of the sea being crossed.

In addition to the examples quoted here, there are many more. For a selection dealing with Greek (including Sicilian and southern Italian) promontories and islands, see the following (page numbers indicate where a passage has been quoted in the main text: Str.Geog.5.2.6, 6.1.5, 11, 6.2 .1 (p.151), 6.3 .5 (p.149f.), 8 (p.150), 7.4.3 (p.147), 7.7.5, 7.fr.51, 8.2.1 (p.143), 9.5.13, 10.2.15 (p.147), 18, 19 , 10.4 .5 (p.189), 10.5 .1 (p.153), 18, 12.3 .2 (p.178), 11 (p.178), 13.1.31 (p.178), 51, 13.2.1, 13.3.5 (p.144), 14.1.35, 14.2.19, 14.5.3 (p.147). Also Paus.3.23.1, 7.22 .7 (p.145).

397. For examples, see Str.Geog.8.2.1, quoted above, p.143, and 8.3.33.

398. Compare Dicaearchus 130: Where the various Cyclades islands, which obviously cover a wide area, are said to be see 'lying off Geraistos'. The passage is also recorded, probably correctly, as Dionysios son of Calliphon's Description of Greece 130. The manuscripts in question, and their authorship, are discussed in Diller (1952) pp.28f., 100. For the position of Geraistos, see n.418 below.

\section{Compare Braudel (1975) p.106.}

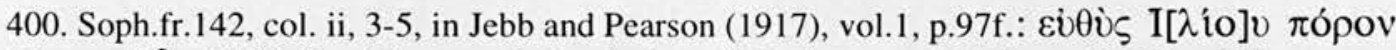
'A $\tau \rho \varepsilon[\delta \delta \hat{\alpha} \nu$ 'i] $] \delta \varepsilon \sigma \theta \alpha t$. The translation is that of Morrison and Williams (1968) p.195.

401. For examples see Str.Geog.8.4.4ff. and 8.5.1ff., on the Messenian Gulf, bounded by Akritas and Tainaron, and the Lakonian Gulf, bounded by Tainaron and Malea. For the practice of making for a prominent landmark on the coast, and then coasting along the shore from there to one's destination, see Rouge (1981) p.22, Tozer (1873) p.72, and compare Severin (1954) p.3. On the importance of headlands and of the peaks of islands and promontories as landmarks for mariners sailing along the coast and for those approaching the coast from the open sea, especially in an age before the invention of artificial navigational devices, compare McGrail (1983) p.314f. ('Inbound Pilotage'). McGrail (1991) p.86 ('Detecting new lands', 'Pilotage and navigation techniques') points out the importance of clear landmarks in early sea voyages, distinguishing the simple pilotage which is possible in such conditions from the more complicated navigation which is required in the absence of such landmarks, or in poorer visibility. Simple voyages between opposite sides of a channel or between the islands of an archipelago can thus be made by inexperienced mariners before the development of proper navigation techniques. Severin (1954) p.14 discusses the importance of such landmarks to Greek sailors of the Bronze Age/Heroic Age. Taylor (1971) pp.3, 63, also stresses the importance of coastal landmarks to the Greeks of the Iron Age, and quotes Odysseus: " 'My home is under the clear skies of Ithaka, our landmark is the wooded peak of windswept Neriton' '. The passage is Hom.Od.9.21f., and although Odysseus does not actually state that Neriton functions as a landmark, this is implied by the adjective $\alpha \rho \imath \pi \rho \varepsilon \pi \dot{\varepsilon} \varsigma$.

402. For the nearest point of land also being the first to appear to mariners approaching from the open sea, see Hom.Od.7.279f.: 'and on the eighteenth day appeared the shadowy hills of the land of the Phaeacians [Scheria], at the point where it lay nearest to him (ö $\theta 1 \tau^{\prime} \not{\alpha} \gamma \chi 1 \sigma \tau o v \pi \dot{\varepsilon} \lambda \varepsilon v$

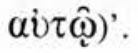


403. See also Bintliff (1977) p.8, Braudel (1975) p.106, Cary and Warmington (1929), p.10ff, Pryor (1988) pp.12, 21, Semple (1932) pp.584ff., 587, 616, Wachsmuth (1967) p.394f.. Cary (1949) p.45ff. and Cary and Warmington (1929) p.12 stress the particular wealth of such landmarks in the Aegean, and, along with Semple (1932) p.584, the heightened visibility produced by clear summer skies, for which see also above, p.48f. In winter, clear skies are less common (pp.48f., 50ff.), and thus the landmarks are less visible, and cannot be seen from as far away as is possible in summer (p.222): for the effects of atmospheric conditions on the distances at which coastal features appear on the horizon, see McGrail (1991) p.86, table 1; For the distances at which such landmarks can typically be seen in the seas around Greece, and the effects of modern pollution, see above, nn. 350, 351. See also Edlund (1987) p.49 on the significance of promontories in Magna Graecia: 'There is no reason to doubt the close connection between the promontories and the needs of the seafarers to find landmarks as well as protection in bad weather.'. On the religious aspects of recognising (and putting in to) headlands, see Wachsmuth (1967) p.406.

404. For example, Burnett (1994) p.159 describes Kynossema, on the shores of the Hellespont, as having been 'easily recognised by the curious shape of the headland'.

405. See, for example, Mediterranean Pilot III, p.63, where the silhouette of the promontory of Tainaron, as seen at a distance of twenty miles, is illustrated. See also below, p.169 and n.408, on the modern use of distinctively coloured cliffs to aid navigation.

406. There are other, less well known, examples of promontories called Kynosoura and Drepanon listed in Smith (1854-7). The Kynosoura promontory forming the northern end of Marathon bay on the east coast of Attica is similarly shaped to that on Salamis, both having the long, narrow, winding shape reminiscent of a dog's tail. These and similar types of names are collected and discussed by Curtius (1861) p.143ff., and Tozer (1873) pp.77ff., 368ff. Kriou Metopon ('Ram's Forehead'), the name of headlands in Crete (Str.Geog.10.4.2,5) and Paphlagonia (Str.Geog.7.4.3) may be added to the examples given there. Sometimes rocky outcrops and other topographical dangers were similarly named after their resemblance to animals, as in the case of the 'Ass' and the 'Ant', discussed above, p.94. For discussion of 'Sepias', 'Ichthys', and 'Chelontas'. see above, n.225.

407. See above, p.21. Compare McGrail's comments on the significance of the colour of different parts of the coast to early seafarers crossing the English Channel: McGrail (1983) p.314, 'Inbound Pilotage'.

408. Mediterranean Pilot IV, p.479f.

409. Edlund (1987) p.48.

410. The Periplus Ponti Euxini is an anonymous work composed by combining the information given in three earlier sailing manuals, the Periplous of Menippus of Pergamon, Arrian's Epistle to Hadrian containing a Periplus of the Euxine Sea, and an anonymous periegesis addressed to King Nicomedes, now attributed to pseudo-Scymnus. There are also details taken from the periplous of pseudo-Scylax: see Diller (1952) pp.102ff., 107. Note also that both of these capes were still called the Black Cape at least as late as the early years of this century, the Chian example being called 'Kara-Burnu' (Mediterranean Pilot IV, p.396ff.) and the Black Sea example being called 'KaraBurun' (Mooney (1912) p.174).

411. Again, some, though not all of these examples are discussed by Curtius (1861) p.143ff., and Tozer (1873) pp.78, 368.

412. Smith (1854-7) vol.1, p.672.

413. Noted by Mooney (1912) p.396. 
414. Tozer (1873) p.367. On the red rock of Erythrai see Smith (1854-7) vol.1, p.852 sv. ERYTHRAE. Note also that, in another example of the continuation of this practice in modern times, the Mediterranean Pilot $I V$ p. 256 advises that (the modern, rather the ancient) Cape Sepias may be recognised by its 'very dark colour; the next point to the north being reddish, these two points form an excellent mark for vessels coming from the north to distinguish Skiathos channel from Skopelos channel...': the name of the cape presumably derives from this dark colour, which is rendered 'sepia' $\left(\sigma \eta \pi^{\prime} \mid \alpha\right)$ in Greek - see above, n.225 for this, and for the distinction between the ancient and the modern capes bearing this name.

\section{Tozer (1873) p.367.}

416. Tozer (1873) p.68, Curtius (1852) p.183. Scylax Perip. 46 provides evidence that there was a harbour available on Prote for ships approaching from the open sea and seeking shelter and/or rest. Moreover, Thuc.4.13.2f. describes how the west coast of the Peloponnese was so lacking in good harbours (cf. also Thuc.2.23, 25 (quoted above, p.101), 4.8.6 (quoted above, p.116), 27.1; also above, n.294) that ships on coastal routes that were unable to shelter at Pylos had no choice but to make for Prote: 'Meanwhile, the Athenian fleet from Zakynthos arrived....But they saw that both the mainland and the island were full of hoplites, and that the Lacedaimonian ships were in the harbour and not intending to come out; they therefore, being at a loss where to anchor, sailed for the present to Prote, an uninhabited island not far from Pylos, and bivouacked there.'

In a similar vein, Luce (1976) p.157 n.4 also derives the name 'Asteris' (Hom.Od.4.846, Str.Geog.1.3.18) from the star-like appearance of brightly gleaming sunlit limestone rock.

\section{Cary (1949) p.47.}

418. The form of such a name depends upon the author in which the name appears, rather than upon

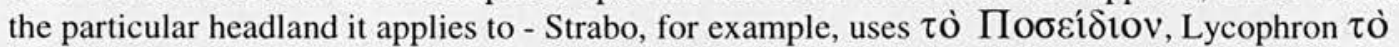

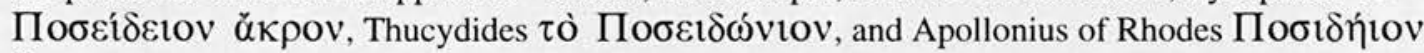

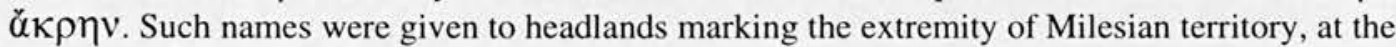
north end of the Gulf of Iasos (Str.Geog.14.1.2, 3; 2.1, 22, Lycophron.Alex.722, von Gerkan (1915) passim); on both Chios and Samos, where the straits between those islands and the coast of Asia Minor are narrowest (Str.Geog.14.1.14 (Samos), 33, 35 (Chios)); forming the western extremity of the mouth of the Pagasitic Gulf (Str.Geog.7.fr.32); at the western point of the Pallene peninsula, near Mende in the Chalkidike (fig.53; Thuc.4.129, Vokotopoulou (1989) - (1992)); at the northern extremity of the Kianos Gulf in the eastern Propontis (Ap.Rhod.Arg.1.1279); near Onchesmos in Thesprotia, marking the northern end of the Corcyra channel (Str.Geog.7.7.5, Hammond (1967) p.474); near Samikon, in the western Peloponnese (fig.18; Str.Geog.8.3.13, 20); in the harbour of Alexandria (Str.Geog.17.1.9); in Lukania in Italy (Lycophron.Alex.722); on the south coast of the Black Sea east of Herakleia (Menip.Perg.Perip.5720f.); on the coast of Cilicia, west of Cyprus (Stad.Mar.Magn.175); and in the Arabian Gulf (Str.Geog.16.4.18). For a further example, of Ptolemaic date, in the Persian Gulf, see Smith (1854-7) vol.2 s.v. 'Posidium'.

Many more temples of Poseidon stood on otherwise-named headlands, most of which were extremely significant on ancient sailing routes: at Hermione (Paus.2.34.9ff., McAllister (1969)), on the headlands of Elis generally (Str.Geog.8.3.12), at Tainaron (fig.57; Paus.3.25.4, Str.Geog, 8.5.1, psScylax.Perip.47, Waterhouse and Hope-Simpson (1961) p.123f., Cummer (1978)), at Geraistos (Str.Geog.10.1.7, ps-Scylax.Perip.58; on the exact site, see Choremis (1974) with Jacobsen and Smith (1968) p.184), at Sounion (Paus.1.1.1, ps-Scylax.Perip.57, Dinsmoor (1970), Tataki (1983)), at Achaian Rhion (Str.Geog.8.2.3), at Molykreian Rhion (Pliny.H.N.4.6), and at the entrance to the Bosporos (Pind.P.4.203-9, Athen.12.536ab). For a shrine of Poseidon on the promontory of Malea in Lakonia, see the list of headland sanctuaries of Poseidon in Eur.Cyc.292-5.

Other sanctuaries of Poseidon stood on points of maritime significance other than headlands, as at Isthmia, and on the heights of Kalauria, at the southwestern extremity of the Saronic Gulf 
(Str.Geog.8.6.14, Paus.2.33.3, Wide and Kjellberg (1895) passim.), on the southwest coast of Tenos, where ships sheltered when unable to pass northwards through the Mykoni and Steno channels on either side of the island (Str.Geog.10.5.11, Etienne and Braun (1986)), at the entrance to the Black Sea from the Bosporos (Athen.12.536ab), and at the Panionion on the southern, Asiatic, shores of the Samian strait (Str.Geog.14.1.20).

419. Severin (1954) p.15. The passage he discusses is Ap.Rhod.Arg.1.580-608, on the route from the Tisaean headland in the Pagasitic Gulf to the isle of Lemnos in the northeast Aegean. For other examples, see Arg.2.648-59, 911f., 930-45 on the voyage eastwards from the Bosporos, along the southern shores of the Black Sea to Sinope.

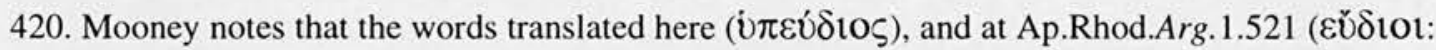
quoted at p.45) as 'calm' should in fact be taken to mean 'clear(ly visible)' (Mooney (1912) pp.106, 102 respectively). This strengthens the impression that Apollonius is here emphasising the role of such prominent coastal features as landmarks.

421. The tomb of Themistocles: there is doubt concerning whether or not Themistocles' body was actually exhumed from his grave in Magnesia and re-buried at the Piraeus. However, if not, it seems that he was given a cenotaph there. Although there are a number of sites in the Piraeus which might be identified with Themistocles' tomb/cenotaph, it is most likely to have stood on the westernmost tip of the Akte peninsula, where the remains of a tomb or cenotaph and a single column are still to be seen. Whether or not Themistocles lies here, Plut.Them.32 ( $=F G r H 372 \mathrm{~F} 35)$ seems clearly to refer to a real monument which stood at the entrance to the harbour and was indeed used as a reference point and landmark by sailors. The other main literary source for what was taken to be the tomb of Themistocles in ancient times, Paus.1.1.2, also supports identification with the monument on the Akte peninsula. For the evidence and arguments, see Garland (1987) pp.147f., 216, and Wallace (1972) passim., esp. pp.451, 460f.

Concerning the siting and visibility of other tombs, I noted, during a visit in the summer of 1996, that the mound which was erected over the tomb of the hero of Lefkandi in Euboia would have stood exactly on the skyline when observed from the Euboian sound below, thus giving a clearly visible silhouette to sailors passing through this busy sailing route. The emphasis on barrows being visible to passing ships may be compared with the common practice of erecting prominent tombs along the roadsides leading away from city gates: both types of burial are sited so as to be noticed not only by the local population but also by arriving foreigners and by passers by. For the importance of the Bronze Age and Homeric tomb's role in prolonging and broadcasting the memory of the deceased, see also Mylonas (1948) p.65: 'Obviously the $\tau \hat{\nu} \mu \beta 0 \zeta$ had nothing to do with the condition of the "psyche," but its sole purpose was to proclaim the $\kappa \lambda \varepsilon \dot{\delta} \zeta$ of the departed.'. For lack of burial and subsequent obscurity as one of the worst aspects of death by drowning see Hom.Od.1.234-43, 5.30612 , 24.287-96.

Sailors may also have traditionally been buried near the sea. The episode in the Odyssey in which the shade of the oarsman Elpenor successfully persuades Odysseus to bury his body in a mound on a headland, with his oar planted on top (Hom.Od.11.71-8, 12.8f., quoted above, p.172), may reflect a common practice - compare Anth.Pal.7.264, 266f., 276f., 279, 287: for oars depicted on a sailors tomb, see Anth.Pal.7.279; for another example of the placing of the actual oar on the top of a sailor's tomb, see Anth.Pal.7.505; Teiresias' instructions to Odysseus to plant his oar in the ground in a place where men have no knowledge of the sea, in order to make atonement with Poseidon and to avoid a death at sea (Hom.Od.11.121ff., 23.267-284), seems also to suggest that the planting of the oar signifies the end of a life at sea. Whereas, amongst the non-seafaring population, only persons of considerable status appear to have been buried in mounds, coastal or otherwise, Elpenor is a common and rather un-heroic figure. The consequences of not receiving burial as a result of drowning at sea were dreaded by ancient mariners (see Hom.Od.1.234f., Eur.Hek.26-54, Synesius Letters 4, Propert.El.3.7), and this is reflected in the curses Elpenor's shade threatens to bring down upon his former master Odysseus if he does not provide a burial. Burial on the nearest point of the coast to 
waters in which death occurred, rather than in the homeland, was presumably the norm for sailors who died far from home - see Anth.Pal.7.282, and the mythological and historical examples listed in n. 427 below. Where corpses were irretrievably lost at sea, cenotaphs were apparently often constructed in place of tombs - see Anth.Pal.7.271-5, 285, 291f., 374, 395, 397, 500, 591f., 652-4 and Young (1951) p.132.

422. Compare the remarks of Fenton (1993) p.44f.: 'Individual features of landscape are vivified in stories linked to religious, historical or supernatural events, and the topography is thus embedded in a local mythology....They [maritime communities] have generated their own customs and mythologies, which have spilled out to encompass the restricted region of the sea over which the people fish or traffic. That part of the sea is known intimately by marks of various kinds, it is divided into subregions named for their associations, and frequently invested with spiritual potencies.

Orientation at sea is by direct recognition of what has been learned and recounted, seen and recognised, on countless occasions before.'. For some such mythological associations, see note 427 below.

423. Towers: the remains of great numbers of towers survive in the islands and mainland of Greece (see, for example, Young (1951) p.144ff. (general catalogue), Young (1956) p.52ff. (Siphnos), AR 1992/3 p.42f. (Levkas), Osborne (1986) passim (Thasos), McLeod (1960) 316ff. (Salamis). Their functions varied, particularly according to their location (Young (1951) p.130ff, Osborne (1986)), and even in the case of those erected on or above the coast, it is clear from their precise position that many can have had no navigational function. However, the inscription on the tower (of Akeratos) at Cape Pyrgos in Thasos (I.G.XII, 8, add. 683, Baker-Penoyre and Tod (1909), pp.95ff., no.9, and p.250, Young (1951) p.132, Osborne (1986) p.169) demonstrates that such towers could be used as navigational aids and/or markers of danger in inshore waters (for a translation of the inscription, and discussion of its significance, see below, p.176; for the tower, see fig.65). Many towers built in similar locations on headlands, such as those at Phanari (fig.66), Babouras and Akrotiri, all also in Thasos, probably had similar functions (Osborne (1986) p.169). The more recent discovery of four (or possibly five) round towers constructed on top of the harbour walls of the classical port of Thasos town (not discussed by Osborne (1981); see Picard (1988) p.388, Picard (1989) p.499ff., Archontidou-Argyri, Simossi, and Empereur (1989) p.57f.) reinforces the navigational function that such towers had, especially on this island. Another good example is the square tower at Kastri in Levkas (AR 1992/3 p.43), which, along with other towers on the island which proved to be less suitable for navigational purposes, I visited in the summer of 1996. At Kastri, the tower, situated on the apex of a rocky headland falling southwards towards the sea (fig.67), has panoramic views across all of the southerly approaches to Levkas by sea, and commands the bays along the south coast of the island, and so might, in its original state, have been an important landmark for those approaching the island from the south.

Temples: again there are a great many temples situated on the coasts of Greece, far from all of which catered exclusively, or even predominantly, for mariners. However, of those coastal temples not situated in harbours, the vast majority stood on headlands or along straits (see, for examples, fig.1). In the case of many temples, especially those whose patron deities had clear maritime associations, such a location does in all likelihood reflect the greater volume of sea traffic and the heightened concerns of mariners in these areas. Thus Schachter (1992) p.48 notes that 'Poseidon [who has the greatest number of shrines on headlands - see p.170 and n.418 above], as his sanctuaries suggest...controlled passages at critical points on land and sea...'. Again, however, this does nothing to prove that any of these temples were consciously used as markers of danger or as navigational aids, but generally their locations would give these temples the potential to fulfil such functions. It is interesting to note that modern lighthouses often stand on the sites of earlier temples (e.g. the temple of Poseidon on Cape Posidhi at Mende: see Vokotopoulou (1989) p.416ff., and below, n.425) and tombs (e.g. the Tomb of Protesilaos on Cape Helles at the entrance to the Hellespont: see Mediterranean Pilot IV p.480). Similarly, modern military outposts on headlands once the site of ancient temples, as, again, at Posidhi in the Chalkidike, and Cape Ayia Helena on Chios (both of which held temples of Poseidon), exploit the good lines of sight to and from such sites. The fullest discussion of the sacred associations of headlands and promontories is Wachsmuth (1967) p.397ff., 
while Semple (1932) pp.613-634 contains brief information on many of the 175 templed promontories she counted, and discusses the religious and geographical reasons why so many temples and tombs were located at such sites. See also Taylor (1971) pp.32, 62f.

\section{See also, for further examples, Str.Geog.3.1.9, 3.5.5, 7.3.16, 8.3.20.}

425. For the column left standing at the Heraion on Samos, see Kyrieleis (1993) p.125f., and compare the single column standing by the 'tomb of Themistocles' in the Piraeus: Wallace (1972) pp.451ff., $460 \mathrm{ff}$., and pl.111a (cf. also n.421 above). In addition to the Pharos and Rhoiteion examples discussed here, we may note other low-lying coasts where temples stood - at the narrow entrance to the Corinthian Gulf, Strabo (Geog.8.2.3) describes Rhion as 'a low-lying cape $(\dot{\alpha} \lambda ı \tau \varepsilon v \eta \dot{\zeta} \varsigma \alpha \check{\alpha} \rho \alpha)$,...it lies between Patrai and Aigion, and possesses a temple of Poseidon'. Frazer describes a 'perfectly flat cape' here (Frazer (1898) vol.4, p.156). The temple clearly would have made the cape far easier to identify, and, along with its counterpart on the north side of the channel (Pliny.H.N.4.6), may also have been used as a valuable leading mark or point of reference by ships navigating this difficult channel - see below, p.176f. and n.431, and, for the difficulties of navigating the channel, above, p.87f.

Near Mende in the Chalkidike was another low-lying cape upon which stood a series of temples dedicated to Poseidon, recently rediscovered (see Vokotopoulou (1989) p.416ff., (1990) pp.399-410, (1991) pp.303-311, and (1992) pp.443-7; see also n.418 above). The site is illustrated in fig.53. The coast is composed almost entirely of loose shingle and reaches no particular height for some distance inland, making the cape particularly difficult to distinguish from seaward (see Mediterranean Pilot $I V$ p. 269 and the illustrations there). A modern lighthouse stands nearby (see $\mathrm{n} .423$ above), and like it the temple of Poseidon probably acted as a landmark for ships approaching or sailing past this headland: Thucydides describes how in $423 \mathrm{BC}$ the Athenian force under Nicias, advancing against the insurgent Mende, sailed out from Potidaia and put in at the temple of Poseidon, from there advancing on foot (Thuc.4.129). In the Decree of Themistocles (SEG 18 (1962) \#153 line 40ff.), the hundred ships sent on a sortie to Euboia are similarly directed 'to the Euboian Artemision' ('ย $\pi \dot{\mathrm{l}} \tau \dot{\mathrm{o}}$

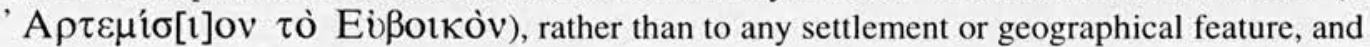
Thuc.7.26 records how an Athenian fleet 'landed in Lakonia, opposite Kythera [i.e. on Malea], where the temple of Apollo stands'.

There is also the case of the temple of Poseidon at Samikon on the west coast of the Peloponnese (again, see n.418 above). Samikon stood on a steep ridge falling westwards into the sea (the remains are best described by Bisbee (1937)), bordered to the north and south by lagoons and mud-flats, for which see figs.18, 33). According to Strabo (Geog. 8.3.20), the town itself could not be seen from the sea. By my observations, made during a visit to the site in the summer of 1996, this would have been true of ships approaching from the west (Italy, Sicily) or from the south (the Aegean)), but not from the coastal waters to the north, from where the town would have been clearly visible (see fig. 33, a view northwards from the remains of the town)- ships may however have avoided this area of deposition and shallow waters because of the dangers of running aground (see above, pp.31f., 101, 117). Immediately to the south of the mountain ridge upon which Samikon stood (the ridge seen in fig.18) was a mooring place which could be used by those putting in at Samikon, but from where the town could not be seen. Next to it stood the temple of Poseidon (Str.Geog.8.3.17, 20), which again would have served admirably as a landmark to draw ships towards a mooring place which may otherwise have been all but indistinguishable on such a flat and low-lying coastline.

Even where such shrines on low-lying capes held no temple, but only an altar, this did not preclude the shrine having a landmark function: in the case of the Milesian Poseidonion, for example, the monumental altar, first erected in the first half of the sixth century, stood upon a small precinct, which itself stood upon high foundations, leaving the whole structure rising up to a height of over $5 \mathrm{~m}$., making it a clearly visible landmark - see von Gerkan (1915) p.465f. and Taf.24. 
See also Strabo on the difficulty of navigating the mouth of the Rhone, near Massilia, because of the flatness of the coastlands there, which meant that 'in foul weather you cannot clearly discern the land even when quite close'. The Massiliotes counteracted this by erecting towers and a temple of Ephesian Artemis as landmarks - see Str.Geog.4.1.8, and the comments of Taylor (1971) p.62f. It is also worth mentioning the tomb of Lichas, said (Aesch.fr.17 (30)) to have stood on Cape Kenaion, the northwest point of Euboia, at the northern end of the Euboian Sound. Here the Lichades islands, stretching out from the cape in a long thin line, are, like the cape, very low-lying, and consequently difficult to make out clearly from aboard ship (see fig.34). Thus, the tomb may again have been taken by mariners as a warning of nearby danger.

\section{Above, pp.166-71. Note, however, the nomenclature of $\sigma \kappa o ́ \pi \varepsilon \lambda o ́ v . . . . K o \lambda \omega ́ v\rceil \varsigma$}

(Ap.Rhod.Arg.2.650), near the outlet of the River Rhebas on the south shores of the Black Sea. This name might indicate a headland identified or recognised not by its shape or colour, but by the burial mound which stood upon it.

427. For tombs situated on headlands or along straits which were identified with the burial places of mythological or historical figures who had died in the seas nearby, see Hom.Od.3.278 (Phrontis, steersman of Menelaos, clusively said to have been killed by the 'dart of Apollo' at Sounion), Str.Geog.9.2.9 (Salganeus, pilot of the Persian fleet from Artemision through the Euboian Sound, put to death just north of the Euripos for leading the Persians into what they took to be a blind alley of the sea. See also Str.Geog.1.1.17 where this case is again referred to, and the similar case of Pelorus, who attempted to guide the Carthaginians through the Straits of Messina, where is Cape Pelorias), Paus.3.22.10 (Kinados, as Phrontis, a steersman of Menelaos, buried on Cape Onougnathos in southeast Lakonia), and 9.11.3 (Ikaros, drowned when his ship, equipped with sails designed by his father Daedalos, capsized, his body being washed ashore on Ikaria). Note also the burial of Tiphys, the steersman of the Argo, on the Acherousian headland where he had died from illness (Ap.Rhod.Arg.2.851ff.). On the west coast of Italy, Cape Palinuri, Cape Miseno, and the promontory of Gaeta all take their name from sailing companions of Aeneas who were said to have died in the vicinity and so been buried on prominent points of the coast nearby (Semple (1932) p.620). For the practice of burying drowned sailors at the nearest point on the coast to where they had died, see n.421. If these tombs were intended to be seen as warnings that life-threatening storms were to be found in the area, then sepulchral epigrams warning sailors not to risk their lives by sailing out to sea after mooring their ship to such a tomb (eg.Anth.Pal.7.264, 266 (compare other warnings: Anth.Pal.7.269,272)) can be seen as merely verbalising the danger warning contained implicitly in the tomb itself.

428. Sailors followed general Greek practice in making vows of dedication to divine powers in return for their help in surviving desperate situations. Often such dedications took the form of statues (e.g. those attributed to Herostratos (Athen.15.676ab), Daedalos (Paus.9.11.14), and Arion of Methymna (Hdt.1.23, Plut.Mor.160C-D, Paus.3.25), or personal items (cf. Anth.Pal.6.164, 166, 245), or parts of the ship (e.g. Agamemnon was said to have dedicated his rudder - see Callim.Hymn to Artemis 228f.). In some cases, however, temples were said to have been dedicated, e.g. the temple of Apollo Epibaterios at Troizen, by Diomedes (Paus.2.32.2), a temple of Athena by the Argonauts on their safe return to Greece (Paus.3.24.7), and the temple of Artemis Diktynna in Crete, in thanksgiving for the survival of Britomartis (schol.Aristoph.Frogs.1356). Eurylochos also vowed to erect a temple of Helios if he returned home safely (Hom.Od.12.346).

429. For the various dangers often encountered when entering and leaving ancient Greek harbours, see pp.106f., 109f., 229ff., and the remarks of Semple (1932) p.624.

430. These functions were clearly also combined in the coastal shrines of gods and heroes, which both marked dangerous areas, and also ensured the safety of mariners in such dangerous areas not only by providing them with fixed reference points or leading marks to aid their navigation, but also by accommodating the divinities to whom sailors could appeal for protection. Compare Rouge (1981) p.198. For the appeal or offering to the deities of coastal shrines by sailors in passing ships see 
Wachsmuth (1967) pp.397ff., esp. 406. Many 'harbour shrines' were located on the headlands flanking harbours (as is made clear, for example, in Soph.fr.371, translated by Jebb and Pearson (1917) vol.II, p.43.; for specific examples of such shrines, see Semple (1932) p.622ff., esp. p.626), as was the monument of Akeratos (fig.65) referred to in the text above, while others stood at the extremities of the moles forming the harbours (compare the tomb of Themistocles in this position (p.173 and n.421 above). These also had a double-edged protective function, religious and navigational, as is noted by Edlund (1987) p.48 in regard to the temples of Magna Graecia: "The distribution of promontory sanctuaries follows two main principles. One is that of the harbour sanctuary which helps to protect sailors and which assures them safe entry into the harbour. The other is linked to the trade routes which determined the voyages taken by sailors in good and bad weather throughout history." (There then follow examples of temples which stood upon the headlands which were the first landfalls for sailors approaching Italy from Greece).

431. For such shrines placed at the entrances of long straits that ran between islands and the mainland, see also n.418 above, on the Thesprotian Poseidonion, situated on the mainland coast at the northern entrance to the Corcyra channel, another very important shipping route.

For the temples of Poseidon and navigational hazards at the Rhion strait, see above, nn.418, 425. On the use of the later castles on either side of the strait by navigators this century, see Mediterranean Pilot III p.96f. (and compare Mediterranean Pilot III p.49). For similar directions for navigating the Samian strait by referring to the relative position of local headlands, see New Pilot p.247. Two marble towers, probably dating from Hellenistic times, lying opposite one another across the Samian Strait, may also have had a navigational function. This seems all the more likely in view of the fact that a boatshed stood next to the tower on the Asia Minor side of the strait, which may have functioned as a lighthouse (or as a ferry signal/terminal). The foundations of both towers remain: see Shipley (1987) pp.265f., 267. Two towers facing each other across the narrow strait separating Salamis from Megara may have had a comparable navigational function; for the towers see McLeod (1969) p.316ff.

Comparative evidence for such navigation with reference to tombs, towers, and temples, may be found in the use of prehistoric tumuli of similar dimensions and siting as navigational aids by modern sailors in coastal waters off Sweden: see McGrail (1983) p.314f., where it is also suggested that barrows along the coast of the English Channel might have been used as landmarks and navigational aids by early cross-channel sailors. See also the comments of Severin (1954) p.16f. on coastal tombs in Greece as memorials and navigation markers. There is a related use of burial mounds as look-outs and vantage points - see Hom.Il.2.791-4: 'Polites, son of Priam, who was wont to sit as a sentinel of the Trojans....on the topmost part of the barrow of aged Aesyetes, awaiting until the Achaians should sally forth from their ships.'.

432. Compare McGrail (1983) p.315. See also the comments of Burnett (1994) on the dangers of rounding Kynossema, the need to change direction here, and the importance of having clearly visible landmarks to give warning of danger and ensure safety when sailing into or out of the Hellespont. For the tomb on Kynossema, see also the passages quoted above, p.173f.

I developed a clearer impression of the kinds of ways in which such structures might be used to ensure a safe approach to a harbour in August 1993, when I had the opportunity to observe the remains of the temple of Apollo in Aigina town from the sea, while approaching the harbour on a ferry from Piraeus (fig.63).

On first approaching from the northeast, the temple and the promontory on which it stands remained hidden behind the next promontory to the north, which is the westernmost point of Aigina. The ferry then passed east of, and very close to, the small islands to the north of Aigina, but then took a very wide berth taken when heading in a southwesterly direction and rounding the northwest point of Aigina, behind which the temple of Apollo was hidden (For the danger of offshore rocks and reefs around Aigina, see p.70). As we passed this point, the moment at which we changed to a southeasterly course, to run directly and safely to the pier in the harbour, was exactly that moment 
when the temple of Apollo appeared from behind the promontory we were in the process of passing. Of course this large modern car ferry has a far deeper draft, and so has to steer far further out from the coast, than the smaller ships of ancient times, but the appearance of the temple at the precise moment at which we changed course to follow a safe submarine channel leading to the harbour highlighted one clear way in which temples could have been used in ancient navigation, especially as temples were so commonly to be found on the headlands at the extremities of harbours. The temple also had a clear view down the west coast of the island, and through the strait separating Aigina from Moni islet, and would thus also have been conspicuous from these southerly approaches to the town, and just as valuable a landmark for ships approaching from that direction.

433. See also Str.Geog.11.2.7, quoted on p.173 above. The 'Chalkedonian hieron/temple', a sanctuary of Zeus Ourios, was an extremely important landmark and milestone. Standing on a headland on the Asiatic coast at the entrance to the Bosporos from the Black Sea, it marked the transition between the two bodies of water (see Menip.Perg. in Steph.Byz. sv. X $\alpha \lambda \kappa \eta \delta \omega v)$ ). It often appears in sailing directions where distances from different Black Sea ports to the entrance to the Bosporos are given: in addition to the examples from Strabo quoted here, see Menip.Perg.Perip.5604, 5622 (periplous of the Black Sea starts from the temple of Zeus Ourios), 5704f. (distance to the Rhebas river), 5717f. (distance to Herakleia), 6001f.(distance to Sinope), 6020 (distance to Amisos).

434. See also the night-time coastal manoeuvres of Phormio's Athenian fleet and his Peloponnesian enemies at the entrance to the Corinthian Gulf: Thuc.2.81-4 (discussed above, p.87ff.). Hdt.8.9 also describes how the Greeks stationed at Artemision reacted to the news that a detachment of the Persian fleet was sailing round Euboia, in order to outmanoeuvre them, by planning to wait until midnight, and then to engage the enemy detachment. At Thuc.1.48, the Corinthian and Corcyraean fleets both set sail well before dawn to gain tactical advantages prior to battle, and the Athenian fleet attacking Solygeia in $425 \mathrm{BC}$ sails in by night to escape observation (Thuc.4.42f.). See further Morrison and Coates (1986) pp.67, 70-85 on these and other naval battles in which triremes sailed in coastal waters by night for tactical reasons. See also Thuc.4.31f., where the Athenian triremes at Pylos put to sea and land on Sphakteria during the night, surprising the Spartan hoplites there, who had thought the ships were simply sailing to their usual watch station (i.e. there is a routine of night sailing here).

435. See Rouge (1981) p.22f., Taylor (1971) p.29f., and compare McGrail (1983) p.315, Severin (1954) p.10, and especially Fenton (1993) p.50: 'Sounding alerts him [the pilot] to possible danger, certainly, but it is most effective when it extends and completes his understanding of his whole predicament. If the bottom of a bay or channel is known beforehand...it may be possible to infer position from a test of depth and ground.'.

436. For inshore currents running along the coast as a result of longshore drift, see above, pp.31, $41 \mathrm{f}$. For the direction of prevailing currents around the coasts of Greece and other areas, see p.40f. For diurnal breezes blowing alternately landwards and seawards across coastal waters in a daily cycle, see above, pp.52-7. Arabian navigators' use of land and sea breezes in this way, as a sign of approaching land, is noted by Fenton (1993) p.51.

437. Reflected wave patterns: see McGrail (1983) p.315, McGrail (1991) p.86, and Fenton (1993) p.53f. for the similar techniques for inferring the position of land, by noting the presence and direction of swells or smooth waters, used by British and Portuguese navigators in the 16th to 18th centuries $\mathrm{AD}$ Note also the related, and more complicated, technique of judging the direction of distant islands by the refracted wave patterns they cause: see below, p.191.

Water colours: an example of such use of water colour to identify deeper and shallower waters comes in Ap.Rhod.Arg.4.1573ff., where Triton gives the Argonauts direction for leaving the shallows of the Tritonian lake: 'That is the outlet to the sea, where the deep water lies unmoved and dark; on each side roll white breakers with shining crests; and the way between for your passage out is narrow.'. 
Although there is little other evidence for the interpretation of water colour in this way, it is notable

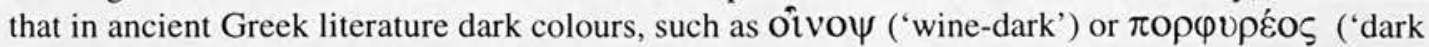
(purple)') tend to be used to describe large expanses of sea being crossed by sailors on long-distance journeys or arriving from the open sea. Note, however, that Howell (1955) p.86 prefers to interpret oivo $\psi$ as referring to the 'foaming' of wine and of the sea, rather than to their colour: there is little, if any, evidence to suggest which interpretation is the more accurate. MÉ $\lambda \alpha \varsigma$ or $\mu \varepsilon \lambda \alpha \nu$ ó (black) tends only to be used of the open sea in stormy weather, especially when the sea is darkened by overcast stormclouds (e.g. Hom.Il.7.58; see also Hom.Od.12.373ff., where the appearance of a dark cloud above Odysseus' ship causes the sea beneath the ship to darken). Terms indicating lighter colours, such as $\gamma \lambda \alpha v \kappa \eta ் ~ o r ~ \chi \alpha \rho o \pi \delta ́ \varsigma$ (green, blue), on the other hand, tend to be used mainly in connection with calm, sheltering, shallows and coastal waters, as in Anth.Pal.5.209.1f., 6.33.1ff., Soph. fr.371 (in Jebb and Pearson (1917) vol.II, p.43), and Theoc.Id.11.42f., as translated by Gow (1952) vol.1, p.89.

Similarly, members of the Odyssey flotilla, whom I met in the village of Vlicho in Levkas during the summer of 1996, informed me that a dark water colour indicated depth, except where darkness was clearly caused by sediment, as in the nearby Levkas channel, in which case depositional shallows are indicated. In shallow water, green and blue light will be reflected off the sea bed, making the water appear lighter, unless the water is obscured by sediment. Conversely, in deep water, far less sunlight penetrates as deep as the sea bed; what little that does is blue, and only some of this is reflected all the way back to the surface of the water, which therefore appears darker (see Met. Office (1967) pp.267-70 for the degree to which light penetrates waters of differing depths: thus the use of $\mu \dot{\varepsilon} \lambda \alpha \varsigma$ (see Heubeck, West, and Hainsworth (1988) p. 216 on Hom.Od.4.358f.). For the greener hue of shallow waters, as opposed to the darker blue of deeper waters, see figs. $6,10,11,52$. The nearest we get to evidence for such practices in ancient Greece is Per.Maris.Eryth.26, and relates to weather prediction as much as to navigation: 'The harbour, exposed to the sea, is dangerous at certain times, since the place lies open to the north wind. A local sign of approaching storm is the greater disturbance in the depth of the sea and a change of colour.' See also the reference to water colour below, n.439, and in McGrail (1991) p. 86, Severin (1954) p.8, and at Fenton (1993) p.53, where is a record that the lightening hue of water was specifically, and correctly, taken note of by Portuguese navigators as an indication of shoaling water - the colour is even called a 'shoal-like hue'. Compare the 'paler water' that, on the eve of his discovery of New Zealand in 1769, Captain Cook took as the definitive sign that land was approaching.

438. Although not cited specifically as a signal of approaching land, the roar of the sea against the shore is often referred to. According to Homer (Il.4.425), waves breaking heavily against the coast

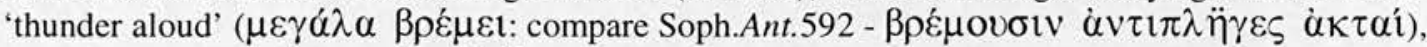
and Odysseus heard 'the boom [ $\delta 0 \ddot{0} \pi \mathrm{O} \zeta]$ of the sea against the reefs' as he approached the coast of Scheria (Hom.Od.5.401). Oppian describes shores (Hal.1.383) and rocks (Hal.5.652) as 'farsounding' ( $\pi \mathrm{o} \lambda \nu \rho \rho \alpha \dot{\theta} \theta \bar{\alpha} \gamma \mathrm{\zeta})$, while Quintus Smyrnaeus describes headlands 'howling from all quarters' (Fall of Troy1.318ff.). Similarly, 'moaning promontories', along with 'loud noises on the beach' generally, are taken as weather signs by Theophrastos (Signs.29), who presumably would expect sailors also to notice such noises.

439. See McGrail (1983) p.315, McGrail (1991) p.86f., Severin (1954) p.8, Taylor (1971) p.36, Fenton (1993) passim, especially pp.45ff., 50f., Hornell (1946) passim., especially p.143ff. Taylor (1971) p.85 and Fenton (1993) p.51, both quote the following Buddhist passage recommending the pilot's understanding of his environment: 'He knows the course of the stars and can always orient himself; he knows the value of signs, both regular, accidental, and normal, of good and bad weather; he distinguishes the regions of the ocean by the fish, the colour of the water, the nature of the bottom, the birds, the mountain, and other indications.'.

440. Taylor (1971) p.62f. ignores the problem of dates, while Rouge (1981) p.22 is non-committal. Ormorod (1924) p.43f. believes beacons to have been organised from Homeric times onwards, but bases his conclusions entirely upon medieval evidence, and limits his discussion to the use of beacons 
to give warning of approaching pirates. Burnett (1994) p.159 postulates the organisation and use of beacon fires by early grain merchants sailing into and out of the Hellespont, but again, while this may well have been the case, there is no substantive evidence. Her suggestion (Burnett (1994) p.159 n.44) that such shore-to-ship beacons are known from Hom.Il.19.375-9 is untenable - $\tau$ ó $\tau \varepsilon$

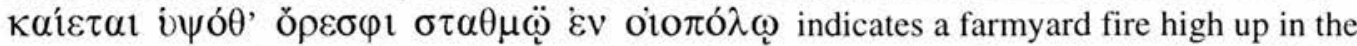
mountains, not a beacon fire on the coast. Likewise the suggestion (loc. cit.) that Hom.Od.10.28ff.

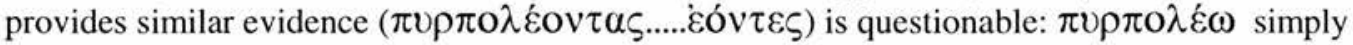
denotes lighting or tending any fire, and while this does not preclude a beacon fire (Heubeck and Hoekstra (1989) p.45 rather ambiguously gives 'watch-fire'), it is rarely, if ever, used in this sense elsewhere. Indeed, if this passage does refer to a beacon, it constitutes the only evidence we have, scant as it is, for how navigational beacons were organised and maintained during all of Greek antiquity.

This unfortunate lack of evidence relates to nearly all aspects of ancient Greek beacons, and must be emphasised. Where beacons were lit in front of temples (for an example, see Philos.Imag.1.12.27-31, quoted below, p.184) their organisation, administration, and financing was presumably worked into that of the sanctuary and its cult as a whole. Likewise, beacons lit at the entrances to harbours and ports (for which see below, p.182f. and nn.446-8) were presumably administered by those officials in charge of the running of the ports as a whole. However, there is no evidence for this, nor for who financed and organised any beacons lit upon isolated and uninhabited parts of the coast. Similarly, we do not know if beacons were lit every night for the whole of the night, or only at certain times, nor whether a beacons 'message' was a simple continuous light or some form of code with commonly-accepted meanings. For examples of the interpretation and misinterpretation of beacon signals, see below, nn. $442,444$.

\section{Aesch.Agam.8ff., 281-312, Hdt.9.3.}

442. Hdt.7.179, Thuc.8.101f. The message relayed in Thuc.2.93.4-94.1 (also described in Diod.Sic.12.49) was taken to mean this, but wrongly so. The tower from which these beacon messages were sent may have been found: see Princeton s.v. 'Salamis', McLeod (1960) passim. Beacon messages in this age could be easily misinterpreted, especially if enemies lit decoy beacons: see also Thuc.3.22.7ff. For such beacons in a purely naval context, see Xen.Hell.6.2.34.

\section{Hom.Il.18.207-14, Thuc.2.93.4-94.1 (compare Diod.Sic.12.49), 3.22.8, Xen.Anab.7.8.15.}

444. Little Iliad fr.11 (=schol.ad.Lycoph.344), Thuc.4.111f. Other messages may of course have been relayed without being recorded in extant sources, but before improvements made to the 'science' by Achilles Tacticus and others, the signalling system was limited in the amount of detailed information that could be relayed (see Pol.10.42-7, esp.43), and apparently easily misunderstood (see n.442 above).

445. See Hom.Il.19.375-9 (fires from a mountain steading), Od.10.28ff. (probably shepherds or similar, rather than beacons intentionally lit to be seen by mariners - see n. 440 above), Thuc.8.101f (the fires lit by trireme crews spending the night ashore).

\section{Herodian 4.2.8.}

447. For arguments postulating the existence of such beacons as far back as Homeric times, see n. 440 above.

448. Burnett (1994) p.159 n.44, without further references.

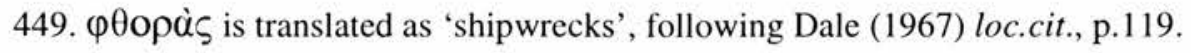


450. Dale (1967) p.139 also comes to this conclusion. That this is correct is made explicit by later accounts - see schol.ad.Eur.Orestes 432, Ap.Bibl.2.1.5, Bibl.Ep.6.7, 11, Anth.Pal.7.289. For the inhospitable coast and sea conditions in the region of Kaphereus and southern Euboia generally, see pp.20, 23, 45f., 71f., 86f., 122-6. Historical wreckers carried out the same ploys, luring ships to their destruction on rocky coasts by means of false beacons, and then plundering the cargoes. Nauplius himself is characterised as such a professional wrecker in Ap.Bibl.2.1.5. On Nauplius as the progenitor of the wrecking tradition, see Rouge (1966a) p.1468f.

451. Hom.Od.3.177f. For the position of Geraistos on the southeast coast of Euboia, see above, nn. 398, 418 .

452. See, for example, Young (1951) p.132, Osborne (1986) p.169. Also Taylor (1971) p.62f.

453. See Burnett (1994) p.159, Gomme, Andrewes, and Dover (1981) p.349, on Thuc.8.102.1.

454. For the Bosporos strait, the Cyaneae, and the two temples, of the Byzantines and of the Chalkedonians, overlooking them and marking the entrance to the Black Sea, see Hdt.4.85ff., with How and Wells (1912) loc. cit. (vol.1, p.331ff.), Str.Geog.7.6.21-6, and Pol.4.39, with Walbank (1957) loc. cit. (p.488f.). For the temples as landmarks and 'milestones' for sailors, see above, p.178, n.433.

455. This information comes from a Rhodian law of the first century AD banning such ship-borne lights: see Radcliffe (1921) p.179. Aesch.Agam.590ff. also seems to imply that beacons were generally regarded as untrustworthy. For an example of the way in which different messages could be relayed effectively by different, pre-arranged, signals, see Xen.Hell.6.2.34.

456. Taylor (1971) pp.3, 63, Cary and Warmington (1929) p.6

457. Casson (1959) p.38, Rouge (1981) p.22, Taylor (1971) pp.3, 40, 63.

458. Cf. McGrail (1991) p.86, Severin (1954) p.12, Rouge (1981) p.22. One technique for measuring how long sun or stars had been up was to measure their altitude against the mast or rigging of the ship - see Taylor (1971) p.48. For the Greeks' lack of instruments for measuring time, see n.473 below.

459. Semple (1932) p.582, Pryor (1988) p.12, Cary and Warmington (1929) p.6, Taylor (1971) p.64. For the clear skies of the sailing season cf. pp.48, 219, 221, 226. Homer was clearly familiar with many significant stars and constellations (see Bunbury (1959) vol.1 p.34f., Dicks (1970) pp.30f., 33f.), as was Hesiod (Dicks (1970) p.34f.), whose Astronomia displays a developed knowledge of the stars.

460. Difficulty of making accurate astronomical observations by eye alone, and of making accurate calculations - Dicks (1970) pp.9f., 35. Stars rise and follow course across sky earlier each day Taylor (1971) p.13, Dicks (1970) p.12; Visible stars change with latitude - Taylor (1971) p.40, Bunbury (1959) vol.1, p.396, Dicks (1970) p.35.

461. Circumpolar stars always visible, but others rise and set over horizon - Dicks (1970) p.11. The Great Bear the first such constellation noted - Dicks (1970) p.31. The discovery of the constellation and its navigational function were attributed to Nauplius, the legendary early sailor (schol.ad.Arat.Phaen.27). For the practice of referring to the celestial pole and nearby stars for basic directions and orientation, see McGrail (1991) p.86, Severin (1954) p.12.

462. Taylor (1971) p.12.

463. Thompson (1929) p.28f. simply states that the Greeks referred to the Great Bear, the Tyrians to the Little Bear. Cary and Warmington (1929) p.208 n.16 argue ignorance of the Little Bear until the 
time of Pytheas, but Taylor (1971) p.43 cites evidence for the earlier date. See generally also Taylor (1971) pp.8f., 40f. For the different distances at which these stars stood from the celestial pole in ancient and in modern times, see Dicks (1970) pp.15f., 31.

464. Taylor (1971) p.9 on Hom.Od.5.269-77, quoted immediately above in the main text.

465. Ascertaining direction of sailing by prevailing winds: Rouge (1981) p.22, Cary and Warmington (1929) p.6, Taylor (1971) p.52ff., 63, Severin (1954) p.8.

466. McGrail (1991) p.87 stresses the importance of the regularity and steadiness of winds forming part of an annual meteorological cycle in such navigation. Taylor (1971) p.14f. discusses how the 'feel' of a wind and the weather it brings can indicate the direction from which it blows, and makes the point about Notos and Boreas cited in the main text here. Murray (1987) pp.144f., 147 and $\mathrm{nn} .23,27$ emphasises sailor's ability to identify winds in this way, and that, for the Greeks, direction was no more important than any other characteristic when identifying winds. Fenton (1993) p.48f. echoes these comments, and asserts that orientation according to winds was universal amongst seafaring peoples before the invention of the compass. Rouge (1981) p.17 also comments on mariners knowledge of the sea and particularly of the winds. On the characteristics of the winds found most commonly on the seas around Greece, see Taylor (1971) loc.cit. (general descriptions), and above, pp.49f. (Etesians), 50ff. (the Adriatic Bora and related winds in the Aegean such as the Hellespontias and the Thraskias, 52 (the Lips, now known as the Sirocco), 262-5 (Zephyros). Bunbury (1959) vol.1, p.36f. and Dicks (1970) p.32 discuss Homer's (and later Greeks') use of expressions derived from the names of winds to designate directions and compass points.

The wind roses devised by the ancient Greeks had from between four and twelve points (discussions in Cary and Warmington (1929) p.6, Fenton (1993) p.48f., and esp. Taylor (1971) pp.15f., 53ff.). Sailors apparently preferred an eight-point wind rose (Taylor (1971) p.55), as did many others (Semple (1932) p.93), this being a compromise between the reliability of the simple four-point rose and the greater detail but lesser accuracy of the twelve point roses (see Pliny H.N.2.46). However, it is questionable whether mariners would have used such formal and geometrically schematic systems to assess winds at all, given that these take no account of local variations in wind conditions, such as are produced, for example, by topographic obstacles (for which see pp.57-60).

467. See, for example, Str.Geog.2.5.24, quoted below, p.189. For a number of other examples, with some discussion, see Taylor (1971) pp.50-5, esp. p.52f.

468. Cary and Warmington (1929) p.5ff. note the Greeks' lack of instruments for measuring time, distance, and bearings.

469. See Taylor (1971) p.51; an example can be seen in Str.Geog.10.4.5, quoted below, p.189. The point is also made by Bunbury (1959) vol.1, p.392f., where is also a discussion of the inevitable inaccuracies involved in such estimations of ship speeds, distance of a day's sailing, and route distances.

470. Casson (1951) p.136f., Casson (1971) p.281-96, where many ancient passages citing the duration of particular voyages are discussed, and where the importance of wind direction is emphasised in the separate discussion of voyages made with the wind and voyages made against the wind; the differences in the two resulting sets of figures clearly illustrate the relevance of this approach. There are clearly also other important factors here, in addition to wind speed and direction: the type of ship (for the main differences, especially between oared ships and sailing ships, see pp.238-41; also Taylor's note (Taylor (1971) p.51) on ancient figures for a day's rowing as opposed to a day's sail); the possible need to drop anchor or come ashore for stops during the day (for which see n.567); whether or not the ship continued sailing through the night (for night sailing and/or stoppages, see pp.224-8, 239). Sheltering from storms, and also waiting for calms to end, could also add considerably to journey times: on calms, see above, p.134f., and below, p.240f. 


\section{McGrail (1991) p.87.}

473. On the handicap of not having accurate devices for measuring time, see Cary and Warmington (1929) p.5, Rouge (1981) p.22, McGrail (1991) p.87; cf. also above, p.185. Figures given for the distances of particular journeys not only vary widely from one ancient geographer to the next (this in itself is proof of their general inaccuracy), they also tend to be far from the true figure, as ascertained using modern techniques. Thus Fehling (1989) p.237 notes that the distances Herodotos gives for the north-south and east-west journeys across the Black Sea (Hdt.4.85.2) are overestimated by roughly $60 \%$ and $100 \%$ respectively.

474. Eg. Str.Geog.2.1.7f., 2.4.2ff. See also above, p.161f. and the references discussed in nn.395, 396.

475. Taylor (1971) p.52 speaks of crews taking pride in 'knowing the 'feel' of their ship and of how much head she was making.' . Cary and Warmington (1929), after giving (p.4) the seemingly arbitrary figure of 500 stadia as the 'expected' distance covered by a ship on an average summer's day, go on to discuss (p.5) the 'rough and ready' methods used to assess the speed of ships, and give typical examples of the erroneous estimates made of distances at sea in ancient times. See also Cary and Warmington (1929) p.6f. for similar inexactitude in ancient navigation and orientation, at sea and on land, and the comments of Rouge (1981) p.21 on the mutability of sailing routes and the difference between the speed and the duration of a crossing. Rouge (1981) p.22, Fenton (1993) p.48f., and particularly McGrail (1983) p.314 have brief but interesting comments on how ancient sailors used their 'mental chart' (McGrail loc.cit.), or 'sensory map' (Fenton loc.cit.), to maintain their bearings when out of sight of the coast. See also the reflections of Severin (1954) p.13f. on coping with the inaccuracies of navigation out of sight of the coast and without the aid of a compass.

476. See above, pp.147ff., 151ff., 166-71. Taylor (1971) p.63 and Rouge (1981) p.22f. also emphasises the link between the inaccuracy of open-sea navigational techniques and the importance of having easily recognisable landmarks on returning to the coast. Compare Severin (1954) pp.3, 13f., and esp. p.17: "there were neither accurate means of measurement nor any certainty about the vessel's ability to follow the optimum course or even make its landfall.".

477. For strategies adopted to avoid approaching the shore at night, and to navigate in coastal waters at night when necessary, see above, pp.179-84.

478. For mariners' ability to judge the set of a current by eye alone, see Fenton (1993) p.47f., and, for the interpretation of refracted wave patterns, Fenton (1993) p.46 on the Marshall Islands: 'When a swell encounters an island obstacle, part is reflected upon itself and part is refracted, producing a pattern of intersecting waves radiating from the island. In any part of the surrounding sea, it is at least formally possible to analyse the local wave patterns and deduce the direction of the island. The Marshallese are able to interpret these disturbances - by visual inspection, the feel of the canoe's motion and the sound of the waves against the hull - with sufficient accuracy to locate islands well below the horizon.'.

479. Compare the comments of Severin (1954) p.12f., on orientation according to the feeding grounds of whales in the northern Atlantic.

480. These species tend to follow standard routes during their migrations: as with the timing of the migrations, there is some variation in routes from year to year, but only to a limited degree: see Gallant (1985) p.27. The size and importance of the catches available from such mass movements of fish meant that sailors, especially fishermen, became very familiar with these migrations: passages such as Str.Geog.7.6.2 and Arist.HA.570a26-571b2, esp.571a12-22 (for other ancient references, see Bintliff (1977) pp.120,240f.) make it very clear that the ancient Greeks had a well developed 
knowledge of the timing and routes of the migrations, and of the whole annual life cycles, of different species, particularly those of tunny, the species most commercially exploitable. While there is some disagreement about the degree of regularity in the timing and routes of fish migration amongst classical scholars, scientific studies are quite unambiguous: "Migrating fish follow clearly defined routes within the area occupied by a particular stock and the movements are regular. This is well known to fishermen who profit by their knowledge....The feeding, wintering and spawning areas occupies [sic] by a stock are usually stable over a period of at least several decades. The fish return to places formerly occupied: in other words they home. (Harden Jones, Greer Walker, and Arnold (1978) p.187, 'Regularity', 'Homing')".

It is notable that most fishing practices in ancient Greece took place in coastal waters (Bintliff (1977) pp.8, 117f., 122, 244, Gallant (1985) p.12), where little could be learned that would help mariners lost on the open sea. However in deep water some line fishing did take place (Bintliff (1977) p.217f., Gallant (1985) p.15), and Gallant's assertion that ancient fishing boats were incapable of making voyages across the open seas (Gallant (1985) p.12) seems untenable: fishing boats are often described in literature as sailing relatively long distances away from the coast, as in the Contest of Homer and Hesiod 1.260ff., where Hesiod's murderers attempt to escape by taking a fishing boat from the

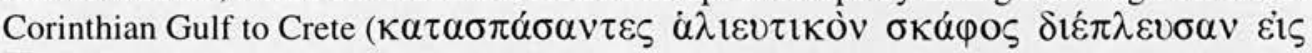
K $\rho \tilde{\tau} \eta v)$. Moreover, while much fishing was coastal, it was far from always local: Bintliff (1977) pp.115, 118-122, 241f., supported by Renfrew and Wagstaff (1982) p.33, and echoing the comments of Cary and Warmington (1929) pp.19, 27, and Rose (1933) p.9, has advanced the theory that much of the exploration (and eventual colonisation) of the Aegean and was initially carried out by fishermen following migratory species of fish, to do which their boats must have been reliably seaworthy. This theory has subsequently been developed by Van Andel and Runnels (1988), and supported by Parker (1992) p.1. While some migration routes, particularly those of tunny, were also largely coastal (Bintliff (1977) p.567 n.22), species such as anchovies and pilchards migrate between coastal areas in summer and the deep open sea in winter: the migration routes of these species, moreover, tend to be the most consistent (Gallant (1985) p.27), and so in these cases we clearly have a situation in which fishermen were sailing deep water in the knowledge that certain species of fish were to be found in particular areas according to the time of year. It is interesting to note that Bintliff (1977) p. 217 points out that tunny, because of their phosphorescence, are most easily spotted in dark and/or rainy conditions, i.e. just the sort of conditions in which 'standard' navigational techniques, by sun, stars, and landmarks, are impractical, and less common techniques must be resorted to.

While there is little explicit evidence for navigation according to seafarers' knowledge of fishing grounds and fish behaviour, there is not only evidence that Greek seafarers had such knowledge, but also a great deal of evidence of such practices in other low-technology seafaring cultures: see the comments above, p.181 and esp. n.439. On identifying waters according to sightings of fish in those waters, see also Fenton (1993) p.45f., 51.

481. McGrail (1983) p.314, Severin (1954) pp.8, 12, Hornell (1946) p.146f., for the practice in other low-technology seafaring cultures. For the deep familiarity of ancient Greek sailors with local species of seabirds, see Pollard (1977), esp. pp.14, 19, 73. The description of the island of Ares in Ap.Rhod.Arg.2.1030ff. clearly illustrates familiarity with the tendency of seabirds to colonise offshore islands where food sources are near to hand, and predators few. The hostility of the birds in this passage is a reflection of the natural tendency to protect nesting sites. Cf. also p.169 above, on the 'white headland' of Eur.I.T.436.

482. Elkins (1983) p.124, Clarke (1912) p.197. Such use of coastal landmarks is of particular importance to birds crossing large bodies of water, where there are few landmarks, and where birds therefore tend to scatter and drift more so than they do over land - see Alerstam (1975) p.494. For specific islands resorted to by migratory birds, see n.485 below, and the comment of Vaughan (1960) p.87: 'Kythera....forms a stepping stone between the most southeasterly point of the Peloponnese (8 miles) and the northeasterly tip of Crete, so that it might be expected to provide excellent opportunities for watching migration'. Some ornithologists, on the other hand, prefer the theory of 
'broad front' migration (see n.631): sufficient evidence to prove or disprove either theory is not available, mainly because of the difficulties of tracking large numbers of birds over wide areas of sea, but the use of landmarks in navigation, and of islands as resting points, during migration, is well established.

483. Reference from Thompson (1936) p.68f., sv. $\gamma \hat{\varepsilon} \rho \alpha v o \varsigma$. For the passage between Karambis and Kriou Metopon as the shortest possible north-south crossing of the Black Sea, see Str.Geog.7.4.3 quoted above, p.147f.

484. Elkins (1983) p.113; compare n.610. For the importance of flocking in making birds not only more visible to seafarers, but also more reliable indicators of land, see Fenton (1993) p.52, where the point is made that 'Bird behaviour is generally complex and not always predictable; birds may wander, or become lost, or sicken and die'. Following this point, extracts from Columbus' record of his journey to the West Indies in 1492 show that on September 30, 'Four tropic birds came to the ship, which is a great indication of land, since so many birds of one kind being together is a sign that they are not straying or lost.'. Even these birds, though, were a false alarm, and 'it was only, in fact, the definite, unchanging line of flight of the massive flock of birds seen on 7 October that moved him to change course...'.

485. Comp. McGrail (1991) p.86, 1987 279f., Hornell (1946) pp.142-8. The name of Porto Quaglio (Port of the Quails), now Porto Kaio, at the southern tip of the Tainaron promontory, illustrates the fact that migrating birds, here quails moving between Greece and Egypt, tend to make for the nearest landfall (promontories) after crossing open water (Semple (1932) p.622). Likewise islands have an important role: in ancient times Delos derived its alternative name Ortygia from the quails (ǒ $\rho \tau \nu \xi)$ which rested there during their migrations (Pollard (1977) p.62). Ortygia was also the name of other islands (e.g. Hom.Od.5.123), including that upon which Syracuse was originally founded (fig.56.i). $\mathrm{X} \varepsilon \lambda \iota \delta$ óvi $\alpha 1$, 'The Swallows' was the name of a headland (now known as Cape Gelidonya) and two offshore islands on the south coast of Asia Minor (ps-Scylax.Perip.83), again presumably because of the area's association with migrating swallows.

For the Greeks' knowledge of the difficulties quails and other birds encountered in making such long migrations, see p. $255 \mathrm{ff}$. Soaring birds such as cranes are particularly likely to follow promontories and islands in order to minimise the distance of sea-crossings, because their manner of flight is made difficult over open expanses of water, but made easier by features such as islands and promontories, which provide thermals and orographic uplift: see Elkins (1983) pp.39, 163, and, for the rising air currents around such coastal features, above, pp.57-61. For ancient literary reports of Greek seafarers observing birds as a navigational strategy, especially as indicators of the direction of landfall, see Wachsmuth (1967) p.189ff.

486. The passage is noted by Wachsmuth (1967) p.190. Despite Velleius' more general term columba, I have made the identification with the rock pigeon because of this bird's tendency to inhabit rocky coasts - for this, and for similar traditions, see Thompson (1936) pp.210, 226. Note also, however, that the domestic dove $\pi \varepsilon \rho 1 \sigma \tau \varepsilon \rho \alpha ́$ was used as a homing pigeon, and was carried on ships in the Persian fleet at the time of the disaster at Mt. Athos in 490B.C. - see Thompson (1936) p.242, Wachsmuth (1967) p. 190.

487. Wachsmuth (1967) p.190. The dove set up on a ship's mast by Achilles as a target in an archery competition (Hom.Il.23.850-9), and that released by the Argonauts before passing through the Cyaneae (Ap.Rhod.Arg.2.328, 557ff.; comp. Hom.Od.12.62) may both be understood to have been available for such uses because they were in any case carried aboard for navigational purposes.

488. See p.250ff., where both ancient and modern references are given to the return of seabirds to land as signs of worsening weather. 
489. Comp. McGrail (1991) p.86, Severin (1954) p.12, Fenton (1993) p.54f. The earliest mention of orographic cloud in sailing directions occurs in Kirke's narration of the route that Odysseus will have to follow when he leaves her abode (Hom.Od.12.37ff.). In this passage, the description of Skylla and Charybdis begins: 'On the other part there are two rocks, whereof the one reaches with sharp peak to the wide heaven, and a dark cloud encompasses it; this never streams away, and there is no clear air about the peak neither in summer nor in harvest tide.' (Hom.Od.12.73-6).

490. McGrail (1991) p.86. Similarly, for navigation according to bird signs by other low-technology seafaring peoples, see the citations in nn.439, 481 above, and especially Fenton (1993) p.51ff.

491. Such rivers were relatively few, especially during the summer sailing season, when river-beds were at their driest. See Cary (1949) p.47.

492.In addition to what follows in the main text here, note also Murray (1987) p.139: "In addition the winds determined both coastal and offshore sailing routes, defined navigational hazards, and at times, affected the outcome of naval battles.....So stated simply, understanding a coastal area's wind regime (its recurring annual wind patterns) could be an important factor in helping to reconstruct and evaluate the record of human activity along that coast.' and n.3: 'The overall wind patters or 'wind regime' of an area combine with the topographical features of its coast (such as capes, submerged rocks, shoals, offshore islands, and harbourless lee shores) to determine the routes habitually used and areas to be avoided in coastal navigation.' .

493. Bintliff (1977) p.121, citing Casson (1971) as a source, without any further reference. See also the remarks of Bintliff (1977) p.8, and Walker (1962) p.13.

494. Compare the comments of Severin (1954) p.17, on how the unreliability of maritime technology forced sailors to assume an attitude of pragmatism in their seafaring, and particularly their navigation.

494a. It should be noted that the lack of accurate navigational devices, and the resulting errors made when calculating ships' positions, were not fully overcome until the invention, in the eighteenth century, of the chronometer, a device which records local time and the time at the original port of departure, thereby enabling sailors to calculate their longitude. Although accurate calculation of longitude was particularly important for the ocean-going ships of the eighteenth century, with the chronometer being designed as an answer to this specific problem, the lack of accurate time- and speed-measuring instruments was a problem which caused severe difficulties for ancient Greek and more recent mariners alike. Thus even in the early eighteenth century, disasters in which many lives were lost as a result of striking coasts unexpectedly at night continued to happen - see Sobel (1995) pp.6f., 12. The danger and uncertainty facing any mariner sailing out of sight of the coast, and unable to measure time and speed accurately, is well described by Sobel (1995) pp.4-20. Here (Sobel (1995) p.16) may be found the following observation by Samuel Pepys, which also touches upon sailors recourse to religion when in situations of particular danger (for which see also below, pp.26871, and above, n.430): 'It is most plain, from the confusion all these people are in, how to make good their reckonings, even each man's with itself, and the nonsensical arguments they would make use of to do it, and disorder they are in about it, that it is by God's Almighty Providence and great chance, and the wideness of the sea, that there are not a great many more misfortunes and ill chances in navigation than there are.'.

495. On Darius' route through the Cyclades, see Hammond (1968) p.43ff., and, for the importance of the local knowledge of Hippias in first choosing the bay of Marathon as the Persians' landing place in Attica, and then in reaching Marathon from Eretria, see Hammond (1968) p.44. The choice of Marathon was important not only because of the plain's apparent advantages as a battle site, but also because of the shelter provided from northerly winds by the headland Kynosoura (Hammond (1968) pp.41, 44), and the bay of Marathon's capacity to shelter such a large fleet (Hammond (1968) p.42). For the difficulty the Persians encountered in finding suitable harbours, and the sufferings northerly 
winds in the Aegean caused for them during their invasions of Greece, see below in the main text, p. $212 \mathrm{f}$., and the references given there to other parts of this thesis.

496. Str.Geog.1.1.17, 9.2.9. In the first of these passages, Strabo mentions this episode, and the wreckage of so much of the Persian fleet by storms, as examples illustrating of the importance of having geographical knowledge of the locality in which a planned enterprise is to take place.

497. For the choice of Artemision because of its proximity to Thermopylai and the narrowness of the sea passage there, see Hdt.7.175ff. For the desire to fight within the confines of a strait, see also p.89f. and n.263.

498. Morrison and Coates (1986) p.71 and Hornblower (1991) p.364f. stress the tactical advantages gained by Phormio through his use of his 'superior knowledge of local weather conditions'.

499. Noted by Neumann and Metaxas (1979) p.187.

500. Taylor (1971) p.60ff. Another episode from Homer is Od.5.276f., where Odysseus attempts to return to Ithaka from the Isle of Kalypso after having been instructed by the goddess how to navigate homewards according to the night sky.

501. Likewise, the Persians' army also made use of guides to lead them through Greece - see, for example, Hdt.7.128, 130.

502. Note also that Herodotos (8.132) claims (see the objections of How and Wells (1912) loc.cit.) that when, after their victory at Salamis, the Greek fleet was entreated by Ionian (Chian) envoys to sail to Ionia, they agreed only to sail as far as Delos because 'they feared all that lay beyond, having no knowledge of those parts....'. Eventually the fleet sailed to Samos, but only after securing the accompaniment of the Samian Hegesistratos (Hdt.9.90ff., 96).

503. The duration and dates of the sailing season in the ancient Mediterranean are well known and have been fairly thoroughly discussed: see Rouge (1981) p.15, Casson (1959) p.39, Casson (1971) pp.270-273, Semple (1932) p.579f., Pryor (1988) p.87ff., Braudel (1975) p.263. Gow (1952), on Theoc.Id.7.53f., 57, 13.25ff., Ep.25.5, is particularly good on the astronomical events which sailors used to time the changes of seasons by. For further discussion of methods used by the ancient Greeks to observe the passing of the seasons, and the transitions between them, see below, p. $253 \mathrm{ff}$.

504. These easterly winds between the Balearic islands and Gibraltar are the equivalent of the Etesians in that they are the prevailing winds of the summer sailing season: see Casson (1971) p.272.

505. The close association of the Etesians with the summer sailing season is strengthened by the etymological interpretation of ' $\varepsilon \tau \eta ் \sigma \iota \alpha$ ' as 'winds blowing at stated times of the year ( $\check{\tau} \tau \varsigma$ ), as in Mooney (1912) p.182, on Ap.Rhod.Arg.2.498.

506. Note that Snider interprets Hes. $W \& D .663 \mathrm{ff}$. as meaning that the best time to go sailing is during the period starting fifty days after the solstice, and ending at the time of the grape harvest and the new vintage, i.e. in September (Snider (1978) p.129f.). However, even if these lines may formally be interpreted in this way, the argument that the fifty days after the summer solstice were seen as a dangerous time to go seafaring because of the strength of the Etesians at that time (Snider (1978) p.132) is unsustainable in the light of the ample evidence in ancient literature that attests to the importance of the Etesians in facilitating ancient travel by sea (for which see below in the main text). Not the least of this evidence is the scholiast on Hes.W\&D.663ff., who, as Snider points out (Snider (1978) p.133), stresses that the season of the Etesians, in July and August, is the best time to sail. 
507. Gradual extension of the sailing season: Rouge (1981) p.15f, Pryor (1988) p.87f. Compare Hesiod's season (W\&D.609-90) with the far longer one described by Vegetius in the late fourth century AD (Epit.Rei.Milit.4.39).

508. Bunbury (1959) vol.1, p.72, citing Hom.Od.5.293, 14.246.

509. It is important to note, however, that the Etesians do not blow constantly throughout the summer season. Just as calms and southerly or westerly winds (Sirocco, Zephyros) occasionally developed in, and were used to sail northwards through, the Hellespont and Bosporos (see p.85f.), so too the Etesians in the Aegean sometimes give way to southerly or westerly winds which facilitate sailing directly northwards or eastwards across the Aegean, and remove the need to follow coastal routes. Thus in Thuc.3.3, a single holkas appears to have traversed the Aegean from southwest to northeast significantly more quickly than a fleet of forty triremes: on hearing on the Mytilenean revolt (428B.C.), the Athenians 'suddenly despatched forty ships [triremes] which happened to be ready for a cruise around the Peloponnese (Thuc.3.3.2).' The ships set off (Thuc.3.3.4), but they take longer to complete the journey than 'a man who crossed over from Athens to Euboia, went thence by land to Geraistos, and, chancing ( $\varepsilon \pi \imath \tau v \chi \omega \mathrm{v})$ there upon a merchantman [holkas] that was putting to sea, took ship and on the third day after reaching Athens reached Mytilene. (Thuc.3.3.5)'. The triremes arrived 'not long afterwards (oi $\pi \circ \lambda \dot{v}$ i $\sigma \tau \varepsilon \rho \circ v)$ ' (Thuc.3.4.1). As the triremes had an initial start, and would have gained a further lead while the pro-Mytilenaean messenger travelled to and through Euboia, it follows that the holkas must have travelled much faster than the triremes to reach Lesbos first, presumably helped by a strong southerly or westerly wind. The text of Thucydides here does not indicate that it was particularly uncommon for merchant ships thus to cross the Aegean. For the frequency of southerly winds during summer in the Aegean, see p.8579 and n.249.

510. Land and sea breezes strongly developed, and facilitate sailing to, from, and along the coast Cary (1949) p.46, Cary and Warmington (1929) p.10, McCaslin (1980) p.89f. \& n.5, Mediterranean Pilot IV pp.12f., 168f., Pryor (1988) pp.12, 15, 90, 92f., 98, Roberts (1995) p.313, Rouge (1966b) p.34f., Rouge (1981) p.17, Semple (1932) p.582.

\section{Cary (1949) p.98, Pryor (1988) p.98.}

512. Theophr.Vent.28, with Coutant and Eichenlaub (1975) p.77. This use of the Euboian Sound is also noted by Cary (1949) p.73, Semple (1932) p.600f.

513. Regular winds and climate add to safety and simplicity of navigation: Braudel (1975) p.106, Cary (1949) p.46, Cary and Warmington (1929) pp.5f, 12, McGrail (1991) p.86f., Semple (1932) p.87, 93, Taylor (1971) p.63f., Tozer (1873) p.64. The significance of clear summer skies is noted by Cary and Warmington (1929) p.6 and Pryor (1988) p.12. See also above, p.185.

514. The movements and conjunctions of certain constellations are mentioned in the three passages quoted here to signify that winter had arrived: for the significance attributed to the movements of the constellations in relation to weather patterns and the changing of the seasons, see pp.246f., 254. For the navigational significance of the Bears, see p.179f., and for 'the dim Crib betokening all that is fair for voyaging', see p.250 and n.595, where it is referred to as the Asses' Manger. For the dangers of winter sailing, and the willingness of merchants to risk those dangers, see also Theoc.Ep.25:

'Mortal, be sparing of thy life and sail not the sea out of season; brief, as it is, is the life of man. Hapless Cleonicos, from Hollow Syria, thou was eager to reach for Thasos, trafficking Cleonicos, and as thou wast voyaging at the very setting of the Pleiades, with the Pleiades themselves thou didst sink beneath the waves.'. For the role attributed to halkyons (kingfishers) in winter weather, see n.580.

515. Casson (1971) p.271f. and Pryor (1988) p. 87 remark on the lack of clear skies as a disincentive to winter sailing, as does McCaslin (1980) p.89f. for the LBA. 
516. This route depended not only on particular winds, but also on the circular (anticlockwise) circulation of currents in the eastern Mediterranean, which permitted a southwards sailing with the currents of the western part of this circulation system, and a northwards return journey with the currents in the eastern arm of the circulation system. The possible routes can be clearly seen in Mantzourani and Theodorou (1991) p.49, fig.8, showing the circulation of currents in the eastern Mediterranean. The winds on which the return journey from Egypt to Greece was made are discussed most fully in Murray (1995) p.41f. Rouge (1981) p.146, conversely, argues that these trips were 'fast easy connections, thanks to the working of the winds out of the west in that maritime area, making crossings in both directions possible by sailing with the wind on the quarters.' (my italics). However he does not identify these 'winds out of the west', and they appear unknown to other authors discussing this route. One other positive aspect of winter sailing was that, while storm winds were common, at least the opposite problem of calms was absent. For calms as a summer phenomenon, see Arist.Met.361b23f. and Murray (1987) p.150. For the problems they caused, see pp.129f., 134f.

517. Casson (1971) p. 270 n. 3 provides further references to winter sailing, particularly naval. Meigs (1961) p.373 notes the strategic importance, and consequent common occurrence, of winter sailing during the Peloponnesian War. For winter fishing, see Bintliff (1977) pp.217f., 350, 539ff. Murex only available in autumn and winter - Zimmern (1931) p.35.

518. Cf. Hom.Od.2.434, 4.270-7, 10.28ff., 13.70-95, 14.252-8, 15.292-300, 15.471-84, 16.366ff. Some (though not all) of these journeys are admittedly made by 'legendary' seafarers such as the Phoenicians (15.471-84) and Phaeacians (13.70-95), or across geographically vague expanses of sea, while others are made at night for secrecy, e.g. Telemachos' departure from Ithaka (2.434). However, the adverse reaction of the crew at Od.12.286-90 may be seen as a narrative device necessary in order to bring Odysseus and his crew to the isle of Helios, where by tradition they had eaten the cattle of Helios, and the voicing of fears regarding the danger of the sea might also be taken as a literary strategem to remind the audience of the coming sea disaster (when the crew are wrecked as punishment for their sacrilege), so heightening the 'suspense' of the story. Indeed the crew's negative response here could have been included as a 'twist', whereby, by initially refusing to risk shipwreck during the night, the sailors only set in chain a series of events (landing on the isle of Helios, not being able to leave, and so eating the cattle) which will lead to their certain shipwreck. In any case, none of the other night sailing episodes in the Odyssey causes any anxiety amongst the crew. The trip from Crete to Egypt, involving four consecutive nights on the open sea, is entirely relaxed and free from danger: '....we embarked and set sail from broad Crete, with Boreas blowing fresh and fair, and ran on easily as if down stream. No harm came to any of my ships, but unscathed and free from disease we sat, and the wind and the helmsman guided the ships. On the fifth day we came to fair-flowing Aegyptos....' (Hom.Od.14.252-8). So too the Argonautica has a number of episodes in which night sailing features as a routine practice, not specifically associated with particular dangers, e.g. Ap.Rhod.Arg.2.727f.: '...during the night the wind ceased and at dawn they gladly reached the haven of the Acherousian headland.'.

519. Pentekonters journey between Thera and Kyrene - Hdt.4.156f.; two hundred Athenian triremes sail from Cyprus to Egypt, clearly not along the hostile Phoenician coast - Thuc.1.104.2; and a further fifty follow directly from Athens and the Aegean - Thuc.1.110.4. Peloponnesian triremes travel direct from Leukas to Taras in southern Italy - Thuc.6.104. Even on short coasting voyages, triremes might readily set sail during the night for tactical advantage - see p.179.

520. Rouge (1981) pp.14, 23.

521. Bunbury (1959) vol.1, p.63f., Taylor (1971) pp.3, 8f., 12f., 40, 63, Severin (1954) p.15f, Casson (1959) p.38, Rouge (1981) p.22, Pryor (1988) p.12, Semple (1932) p.582, Cary and Warmington (1929) p.6.

522. Thus Pearson (Jebb and Pearson (1917) vol.1, p.100), discussing references to night sailing in Soph.fr.143, writes 'It is a mistake to suppose that the Greeks did not sail by night, seeing that the 
use of the stars for the purpose of navigation was attributed to Palamedes ([Soph.] fr.432). But if the sky was clouded it was necessary to lay to, and the sailor's dread of night became proverbial.'

523. See Morrison and Coates (1986) p.67, for example, on night-time manoeuvres by triremes.

524.During a visit to Levkas in the summer of 1996, the leaders of the Odyssey flotilla described to me how, every afternoon, squally katabatic winds fall from the high land of the island down to its west coast and out over the sea. Sailors apparently predict the arrival and advance of these winds simply by observing the progress of the 'white horses' raised on the surface of the sea as it is struck by the wind. This is presumably also how the proreus spotted oncoming winds, a duty referred to in

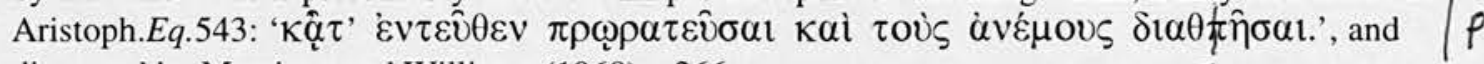
discussed by Morrison and Williams (1968) p. 266.

525. Muckelroy (1978) p.120, Taylor (1971) p.35, McGrail (1991) p.86, Morrison and Williams (1968) p.135. The evidence for the sounding lead comes from classical wreck sites (Muckelroy (1978) p.120) and from Hdt.2.5.2. Claims that, in the fifth century BC, Anaximander invented the gnomon, by which latitudes could be calculated, (e.g. Bunbury (1959) vol.1, p.122) have been refuted by Dicks (1966) passim., Dicks (1970) p.45, and in any case, this instrument seems never to have been used in practice by seafarers (Cary and Warmington (1929) p.5f.). Likewise Thales' formula for calculating a ship's position using geometry (Casson (1959) p.77) is unlikely ever to have been widely adopted by sailors. While known, the magnetic properties or iron (PI.Ion 535f.) and of the lodestone (Cole (1984) p.30) were not exploited in the form of the compass (Cary and Warmington (1929) p.6). The astronomical 'computer' of c.80B.C., found on the Antikythera wreck (Parker (1992) p.56), would presumably have been used as a navigational device by the ship's crew, but such devices must have been extremely complicated, time-consuming, and expensive to produce, and, as time progressed, would have had to have been readjusted to take into account the changing appearance of the night sky (thus the date of $80 \mathrm{BC}$ was determined by establishing the date at which the position of the stars would have been compatible with the settings of the computer). Because of this, and because of the lack of other evidence for their use, there is little reason to think that such instruments were anything more than novelties, or that they ever came into general use in antiquity, especially during the earlier Greek period.

526. Compare McGrail (1983) p.314, who stresses the importance of making landfall either during daylight or during bright moonlight.

527. For night fishermen, see Anth.Pal.6.11, and for the flints used to ignite the fires required for this technique of fishing, see Anth.Pal.6.5, 28. Techniques for fishing at night are discussed by Mair (1928) pp. xxix, xlvii-xlviii; see also Radcliffe (1921) pp. 99, 179, Bintliff (1977) p.217.

528. Zimmern (1931) p.39.

529. Neumann (1973) p.6 and n.24.

530. Neumann (1973) p.7.

531. Many of these aspects of the Mediterranean in relation to seafaring, summarily mentioned here, are individually and more fully discussed elsewhere in the thesis. Where this is the case, the following notes make reference firstly to modern works which briefly mention these aspects of the Mediterranean, and secondly to other sections of this thesis where discussion of these points is developed, and where references to more detailed discussions in other modern studies may be given.

532. Pind.N.3.20ff. Cf. also Pind.O.3.43ff., I.4.11f., N.4.69f., and Hdt.4.152ff., where Colaeus of Samos does pass through the Strait, and accordingly becomes the first Greek to reach Tartessos; however, it is a strong easterly wind, rather than the will or desire of Colaeus, that takes the ship through the Strait, and 'divine providence' $(\theta \varepsilon i \eta n ~ \pi o \mu \pi \hat{n} \chi \rho \varepsilon \omega \mu \varepsilon v o 1)$, rather than the skill and 
experience of the crew, that brings it safely to Tartessos. On the difficulties of navigating the Strait of Gibraltar, which persisted into the late Middle Ages, see Braudel (1975) p.117, Pryor (1988) p.13, Wachsmuth (1967) p.229f. Ps.-Scylax Perip. 1 notes the high tides and open seas to be found beyond the Pillars of Hercules (ie. Gibraltar). Bunbury (1959) vol.1, p.398 and n.2 points out that Aristotle's opinion (Met.354a22f.), shared by many other Greeks, that the sea beyond the Pillars of Hercules was little troubled by winds (he says the sea there is shallow and calm), only shows "how little it [the Atlantic] was known to Greek mariners.".

533. Clearly, however, entering many Mediterranean harbours remained difficult and dangerous, not only in the case of natural harbours, with their typically narrow entrances (see p.98 and n.284), but also at some more open-mouthed harbours, as can be inferred, for example, from a ship wrecked upon a reef at the entrance to the harbour at Areopolis in the southern Peloponnese (Parker (1992) p.59 \#54).

534. See, for example, Ap.Rhod.Arg.2.750, Hdt.7.59, Hes.W\&D.624ff., HHAp.487f., Hom.Od.9.546; Morrison and Williams (1968) pp.62f. (\& n.1), 65, 204, 311.

535. If the assertion that ships were normally unloaded before being hauled up on land is correct (Rouge (1981) p.14), then the inconvenience of landing at low tide would have been even greater, as not only the ship but also its contents would have had to be carried up to the high tide mark.

536. The 'geographical side' of this episode in the Argonauts' travels is discussed by Weld-Blundell (1895-6) p.114ff., where the point is also made that onshore northerly winds, such as those which blew the Argonauts southwards to Africa, would further increase the strength of the tide in the Gulf of Syrtis, and thus cause even greater problems for ancient Greek mariners unfamiliar with such tides.

537. For the comparable advantages and relative simplicity of sailing along coasts in the tideless Mediterranean, rather than landing on them, see p.132f.

538. Weakness of Mediterranean currents, strengthened at straits and headlands - Cary and Warmington (1929) p.10, Casson (1971) p.273, Myres (1911) p.55, Semple (1932) p.582. See also above, pp.39-47, 73, 79f., 83-7, 99ff.

539. Large waves absent from Mediterranean - Pryor (1988) p.12. Ocean waves reach up to 50' Bigelow and Edmondson (1947) p.23f., Beckinsdale (1956) p. 146.

540. Regular seasonal winds and climate add to safety and simplicity of navigation: Cary and Warmington (1929) pp.5f, 12, McGrail (1991) p.87, Pryor (1988) p.12, Semple (1932) p.87, 93, Tozer (1873) p.64.

541. High coastline and islands serve as landmarks, especially given clear Mediterranean atmosphere: Bintliff (1977) p.8, Braudel (1975) p.106, Cary (1949) p.46, Cary and Warmington (1929) p.10, 12, McGrail (1991) p.86, Pryor (1988) pp.12, 21, Semple (1932) pp.582, 584, 587, 616, Severin (1954) p.14f., Taylor (1971) p.63f. See also above, pp.127f., 166-71.

Landfall/shelter easily found, in bays or in lee of promontories and islands: Cary (1949) pp.46, 56, Cary and Warmington (1929) p.10, Pryor (1988) pp.21, 24, Semple (1932) pp. 580, 584, Tozer (1873) p.66. See also above, pp.97-101, 103ff., 110-6, 128.

542. Over one thousand in Greek waters alone, according to Parker (1992) p.6: see also above, n.13.

543. For examples where the inhabitants took to fishing rather than to commerce see Str.Geog.6.1.1 (Elea in Lukania), 14.2.21 (Iasos), Heraclides Creticos 1.23f. (Anthedon in Boiotia). 
545. Ropes - Morrison and Williams (1968) pp.245, 295, 301. For anchor chains only replacing ropes in the first century BC, see Frost (1963) p.16ff., amended to the first century AD in Frost (1982) p.270. Frost's argument that iron anchors cannot have been introduced until the replacement of anchor ropes by chains in the first century BC or AD (Frost (1963) and (1982) loc.cit.), combined with the discovery of iron anchors which actually date from the third century BC (see below), may indicate that chains were in fact introduced at this earlier date, although none have yet been reported.

Anchors made from stone - Morrison and Williams (1968) pp.56f., 62f., McCaslin (1980) p.54f.; or bronze - Pind.P.4.24f., with, as yet, no archaeological verification; or iron - Morrison and Williams (1968) p.302, McCaslin (1980) p.54f.; or lead - McCaslin (1980) p.56.

The latest-known Greek stone anchor stock comes from a classical wreck off Majorca, dated to 360340 BC: see Parker (1992) p.393, \#1058. Stone anchors were also found on the wreck of another fourth century BC Greek ship, at Taranto (Tarentum/Taras) in Italy (Nibbi 1993) p.15).The discovery, in the harbour of Zea in the Piraeus, of examples of a type of stone anchor then unparalleled at any wreck sites (now classified with those from Taranto just mentioned, and another from Volos (Frost (1993) p.454 and fig.5), suggests that classical triremes were equipped with stone anchors (no sunken trireme has yet been discovered): Frost (1963) pp.6, 12, Nibbi (1993) p.15, Frost (1993) p.454ff. and fig.4. McCaslin (1980) p.54ff. takes the introduction of metal anchors with arms back to the sixth century BC on the basis of the appearance of the term $\alpha \gamma \kappa v \rho \alpha$ in literature, alongside the earlier $\varepsilon \dot{v} v \alpha \iota$ and $\lambda \hat{i} \theta 0 \zeta$. Frost (1963) p.13 agrees that $\ddot{\alpha} \gamma \kappa \nu \rho \alpha$ denotes a 'hooked' anchor with arms, although not necessarily a metal one - thus stone examples dated to the sixth century BC, one inscribed with the name of Sostratos, presumably he of Hdt.4.152, have been found at Tarquinia, Italy (Frost (1982) p.268.

Frost dated the earliest known lead anchor stocks to the second century BC (Frost (1963) p.16), but later agreed with the opinion of Gianfrotta (1977) that stone anchors survive into the fourth century BC an so overlap with the introduction of lead-stocked anchors (Frost (1982) p.269. Rouge (1981) p. 65 dates the introduction of the iron anchor to the second century BC Earlier examples have been discovered more recently: Parker (1992) p.29 cites the archaeological evidence for the appearance of iron and lead anchors in wrecks from the third century BC onwards, and Frost (1982) p.270 refers to, but does not specify, archaeological and inscriptional evidence for the arrival of lead stocks early in the fourth century BC. Stone anchors in any case do appear to have continued in use for some time after the introduction of metal anchors (Frost (1963) p.15, Nibbi (1993) p.15, Frost (1982) and Gianfrotta (1977) cited above).

546. Rouge (1981) pp.66, 88; see, for examples, Aesch.Supp.764-772, Alcaeus Z 2 12ff. (\#326, p. 265 in Lobel and Page, and in Page (1955) p.185ff.). For an explanation of how the upwards pull of a rope, rather than the horizontal pull of a heavier chain, can lead to drifting, see Frost (1963) p.16f., Frost (1982) p.264f.

547. Compare Aesch.Eum.555ff., 564. The yard-arm, which was lashed to the upper portion of the mast and had the sail suspended from it, was particularly vulnerable if lifts (ropes tied from the top of the mast to the ends of the yard-arm, to stop the yard-arm from bending under pressure) were not used, as was the case on all Greek warships and possibly also some or all commercial shipping - see Emanuele (1977) p.181ff. For the probable function of various other ropes attached to the sailyard, see Rouge (1981) p.58f., and especially Morrison and Williams (1968) p.299ff.

548. See, for example, Hom.Od.9.67f., Theoc.Id.22.4-22 (quoted on p.224 above), and Quintus Smyrnaeus, Fall of Troy 14.497-501, quoted immediately below in the main text. Also Alcaeus Z 2 $12 \mathrm{ff}$. (\#326 in Lobel and Page (1955) p.265, and in Page (1955) p.185ff.), where the 'feet' ( $\pi$ ó $\delta \varsigma \zeta)$ are ropes normally used to control the lower corners of the sail - see Morrison and Williams (1968) 
p.56. For the fact that sails were made not from single pieces of cloth but from a number of smaller pieces stitched together, see Morrison and Williams (1968) p.54.

549. Sails - e.g. Soph.Elec.335, see also Morrison and Williams (1968) pp.64, 202f., 312; Sailyard Morrison and Williams (1968) p. 294, Casson (1971) p. 275.

550. Cf. Morrison and Williams (1968) pp.53, 195, 291f., 312, Rouge (1981) p.61ff., Cary and Warmington (1929) p.4f., Casson (1971) pp.224-8, Morrison (1984) p.221ff.. Lehmann (1978) attempts to resolve the question of whether the steering oar was moved laterally or rotated, deciding upon the former, while Rouge (1981) loc.cit. proposes a historical development through a variety of types of rudder, which he sees as being responsive and efficient. Morrison, on the other hand, describes the ancient Greek steering oar as a 'comparably weak form of rudder', but admits that the 'degree of efficiency [of the steering oar] is difficult to assess theoretically' (Morrison (1984) p.221f.). Morrison and Coates (1986) p.175f. favour the rotating steering oar, but again stress the difficulty of assessing its performance and efficiency without proper sea-trials. Note also that Thurneysson found a simple reconstruction of the ancient steering oar to be efficient in tests (Thurneysson (1979) p.3).

551. Casson (1959) p.36f.

552. Morrison and Williams (1968) pp.15f., 51, 64, 131, 161f., Casson (1959) p.84.

553. Morrison and Williams (1968) p.169.

554. Morrison and Williams (1968) pp.55, 64, 169, 302, Morrison and Coates (1986) p.169f., Casson (1959) p.37, Rouge (1981) p.87. Note, however, that in sea trials, leakage through the oarports of the reconstructed trireme Olympias was 'trivial', despite the ship encountering waves of up to one metre in height (Coates and Morrison (1993) p.134f.).

555. Odysseus' craft, on which he sailed from Kalypso's isle, was fitted with wicker side screens see Hom.Od.5.256ff.

556. Cary (1949) p.56, Morrison and Williams (1968) p.285, quoting Vitruvius 4.43.

557. Alcaeus A6.1-8 = \#6 in Lobel and Page (1955) p.116ff., and in Page (1955) p.182f. For bilgewater covering the masthold, see also Alcaeus Z 2 (\#326 in Lobel and Page (1955) p.265, and Page (1955) p.185ff.) Pumps were probably a late innovation, and even then did not feature in every ship the earliest known definite example dates from the late second century BC (Parker (1992) p.28), but possible pumps have also been found on a wreck of c.300-270 BC discovered at Serce Limani on the coast of Asia Minor opposite Rhodes (Parker (1992) p.399, \#1071), and on the classical Greek ship wrecked off Majorca c.360-340 BC (Parker (1992) p.393, \#1058). The Kyrenia wreck, though not equipped with a pump, was at one stage fitted with a sump, by means of which the ship, which was presumably leaking more and more water as it grew older, could be bailed more efficiently (Steffy (1985) p.95, Parker (1992) p.232, \#563).

558. See also the commentary of Gow (1952) vol.2, p.386 (with further references), especially on Theoc.Id.22.14. Rainy weather could prevent a fleet from setting sail (Xen.Hell.1.6.28); one reason for this was that visibility at sea was significantly reduced during rainy conditions (Xen.Hell.1.1.16).

559. The invention of the pentekontor has been dated to the Mycenaean Age (Williams (1958) passim., argued less forcefully in Morrison and Williams (1968) p.8, Morrison and Coates (1986) p.25), and that of two-level ships to the (later) eighth century (Williams (1958) passim., Morrison and Williams (1968) p.39f., Morrison and Coates (1986) p.32f.).

560. Carpenter (1948) p.7f. Morrison and Coates (1986) pp.103-6 calculated, from literary evidence, an all-out speed of seven or eight knots, later revised by Coates and Morrison (1993) p.135 to 7 or 8 
knots as an average speed, with short sprints of up to 9.5 knots possible. In early sea trials, the reconstructed trireme Olympias reached a speed of six knots, and Morrison believed it could achieve nine (Morrison (1988) p.175; compare the comments of Starr (1989) p.23), and, indeed, a sprint speed of almost 9 knots was eventually achieved in sea trials (Coates and Morrison (1993) p.138, Gifford (1993) p.100, Shaw (1993) p.43). Thuc.3.49.4, however, clearly indicates that contrary winds were a significant impediment to a trireme's progress. Against an increasing headwind, the Olympias took eight hours to reach the Corinth Canal (from an unspecified starting point, and therefore at an unspecified real or relative speed), and, over a period of seventy minutes, made 3 knots headway against a wind gusting up to 25 knots and waves up to $1 \mathrm{~m}$. high (Coates and Morrison (1993) p.139). However, at the end of this seventy minutes, the crew was exhausted (Shaw (1993) p.109).

\section{Casson (1959) p.37, Carpenter (1948) p.7.}

562. Casson (1959) pp.85, 102, Morrison and Coates (1986) p.196ff., Rouge (1981) p.83, Starr (1989) p.22.

563. Or, alternatively, the length of the ship could be reduced without also reducing the number of rowers: see Morrison and Coates (1986) pp.32-5.

564. A late eighth century date is proposed, on the assumption that the ships built by Ameinocles of Corinth (Thuc.1.13) were triremes, by Morrison (1979) passim., esp. p.62. Lloyd opts for a midseventh century date on the basis of the same evidence under a revised chronology (Lloyd (1972) p.277, Lloyd (1975) pp.53, 56). Morrison and Williams (1968) pp.129f., 158ff., arguing that Thuc.1.13 may not refer to triremes, and Morrison and Coates (1986) p.39f., then accepting the revised chronology of Lloyd, both opt for a mid-seventh century date. Rouge (1981) p.84 prefers to date the appearance of the trireme to the end of the seventh century BC

565. Compare the comments of Rouge (1981) pp.85, 88, Starr (1989) p.23, Gomme (1933) p.17ff., Morrison and Coates (1986) p.36

566. For the operational problems associated with having so many oars on a ship the size of a trireme, and the common practice of using only some of the oarsmen at any one time, see Morrison and Coates (1986) p.96, and Morrison and Williams (1968) pp.285, 309f., with references including Thuc.2.84.3, on Phormio in the Corinthian Gulf, for which see p.87ff. Casson (1971) p.279f. also stresses the difficulty of achieving a unified beat, the importance of training, and the fact that the trireme was rarely rowed by the whole crew at once, except during battle. For the tactical advantages to be had by trireme crews who were better trained than their adversaries, see again above, p. $87 \mathrm{ff}$., on Thuc. 2.84, and for the practical difficulties of, and strategies for, co-ordinating the rowers of the reconstructed trireme Olympias, see Shaw (1993) pp.50-57, Rankov (1994) pp.141-5.

567. Stated most clearly by Morrison and Coates (1986) p.95. Merchant ships, on the other hand, had the space to carry plentiful provisions for their relatively small crews: evidence from the Kyrenia wreck, where plates, bowls, saucers, and wooden spoons were all found in sets of four, shows that this ship had a crew of four (Parker (1992) p.232, \#563); the crews of most merchant ships probably numbered between four and six (Parker (1992) p.29). These supplies were supplemented by fishing (Steffy (1985) p.72, Parker (1992) p.29), and merchant ships were also often equipped with cooking facilities (Rouge (1981) p.40f., Casson (1974) p.154, Parker (1992) p.29). However these conditions were certainly not shared by the crews of triremes. It is true that, like later Aegean oarsmen (see Braudel (1975) p.241) ancient Greek rowers may have survived on a very frugal diet (see, for example, Thuc.3.49, where the crew keep rowing overnight, eating bread soaked with wine and oil while at the oar - but this is in extraordinary circumstances), but vast amounts of water would have been required by a full complement of rowers working all day in hot summer conditions. This point is made by Cary and Warmington (1929) p.7, Gomme (1933) p.18, Severin (1954) p.14, and Rouge (1981) p.88, and is supported by the sea trials of the reconstructed trireme Olympias: when rowing hard in hot weather, each oarsman required one litre of water every hour (Coates and Morrison 
(1993) p.138, Shaw (1993) p.108, Rankov (1994) p.138). Furthermore, Xenephon tells us that the crews of the triremes under the command of Iphicrates in 373B.C. had a noonday as well as an evening meal, and came ashore for both (even in hostile territory: also compare Thuc.8.101.2-3), at which times collecting water was another important duty (Xen.Hell.6.2.28ff.). Stops during the day as well as at night were in fact the norm for triremes - see Morrison and Williams (1968) p.311, Morrison and Coates (1986) ch.6 passim., Casson (1959) p.102. One of the difficulties the Athenians faced in their blockade of Pylos/Sphakteria was said to be that 'since there was no anchorage for the ships, the crews would take their food on land by turns, while the rest of the fleet lay at anchor out at sea.' (Thuc.4.26.3).

Triremes sometimes carried up to seventy-two hoplites or, with a depleted crew, thirty cavalry, so reducing space on board even further - Morrison and Williams (1968) p.248. Nevertheless triremes, singly and in fleets, did occasionally make long open-sea journeys (examples are listed above, n.519), and Thuc.7.50 even records a fleet of troop-carrying Peloponnesian triremes being blown off course to Libya while sailing from the Peloponnese to Sicily; of course, this long detour was involuntary, but the ships, their crews, and their human cargo did apparently all survive and eventually reach Sicily (cf. above, pp.145, 228f.).

568. Rouge (1981) p.88.

$569.1 \mathrm{~m}$. according to Rouge's estimate (1981) p. 85 ; only $0.85 \mathrm{~m}$. according to the better-informed calculations of Shaw (1993) p.89. For the practice and practicalities of hauling triremes up slipways and beaches, see Shaw (1993) pp.87-90.

570. For the view of the trireme as an excellent weapon but a poor ship, and the importance of coming ashore every day due to cramped conditions, see Rouge (1981) p.88, Gomme (1933) pp.1619, Cary (1949) p.56, Casson (1959) p.37f, Starr (1989) p.22f., Morrison and Williams (1968) p.265, Taylor (1971) p.64, Rose (1933) p.31.

571. For the stress put upon a trireme by hauling it ashore, see Shaw (1993) p.89. For hypozomata see Morrison and Williams (1968) pp.294-298, Morrison and Coates (1986) pp.170ff., 197-200, 220f., Morrison (1988) p.173f. The most recent reconstruction of how these ropes were fitted inside the hulls of triremes is Shaw (1993) pp.58-68. Literary sources showing that hypozomata were essential for triremes on even routine active service are listed in the notes to Morrison and Williams (1968) pp.295, 297.

572. Morrison and Williams (1968), pp.135, 280 with references, Rouge (1981) p.88, Severin (1954) p.14. Leaking in many merchant ships was counteracted, from the fourth century BC (or earlier) onwards, by sheathing the hull in lead or copper. The earliest known sheathing (lead, c.360-340 BC) comes from the classical Greek wreck discovered off Majorca (Parker (1992) p.393, \#1058).

Athen.5.207b refers to the practice, in a description of one of the enormous wheat transports built by Hieron II of Syracuse in the second century BC: 'fixed to the timbers was a sheath of leaden tiles, under which were strips of linen canvas covered with pitch.'. Archaeological remains tally well with this description: see Casson (1959) pp.195, 197, 217, Casson (1971) p.214ff. On the Kyrenia wreck (c.310 BC), agave leaves were used in place of canvas, and the sheathing was not original, but added to counteract severe damage to the hull's timbers (Steffy (1985) pp.72, 83f., 95-9). Such protection was unsuitable for triremes, however, not only because such sheathing was incompatible with regular beaching, but also because of the added weight involved, as triremes were deliberately designed, for reasons of manoeuvrability, to be a light as possible. On the practice of sheathing, see Parker (1992) p.27, Morrison and Coates (1986) p.187.

573. Theophr.Enq.Pl.5.7.1ff. See the discussion of Morrison and Coates (1986) p.180ff.

574. Gomme (1933) p.17. See n.567 above. 
575. Dem.35.11. On the legal aspects, see Chowdharay-Best (1976) p.86. There are various other literary references to such jettisoning in order to survive a storm at sea. Not only cargo was jettisoned: see Meijer and van Nijf (1992) \#217, p.169 (= Acts of the Apostles 27.18-45), quoted above, p.117, where the ship's gear is also ditched; and Hdt.8.118, quoted above, p.114, where Persian nobles are said to have leapt overboard to lighten the ship on which Xerxes was returning to Asia Minor. See also the metaphoric image in Aesch.Agam.1005-13. Compare the report in Severin (1954) p.10, where, in the China Sea, all of a sailing ship's heavy material, including six anchors and the main mast, are jettisoned. Careful arrangement of cargoes composed of different goods of differing weights and densities was practised, and helped ships to maintain their buoyancy (Parker (1992) p.28), while at least some crews added ballast to one or other side of the hull in order to properly balance their ships (Parker (1992) p.232\#563).

576. Merchant ships more seaworthy than triremes and other military vessels - Rouge (1981) p.145; and are difficult to beach - Morrison and Williams (1968) p. 244 with references (lead sheathing (for which see $\mathrm{n} .572$ above), where applied, would also not have coped with beaching: that on the Kyrenia wreck was only $1 \mathrm{~mm}$. thick (Steffy (1985) p.83f.)); holkades lack oars and often have to be towed by triremes or the ship's lembos - Morrison and Williams (1968) p.244f. (citing Dem.50.22, Thuc.6.44.1, 7.23.2, 7.50.1f.), Rouge (1981) pp.47, 158. Parker does not cite evidence for his statement that 'Classical ships apparently did not have boats which could tow them in a calm' (Parker (1992) p.27). Presumably he is arguing from their absence from wreck sites, but this cannot be taken as proof that they did not exist - immediately before this statement he notes that few masts and no oars have been found on any wreck sites! Many may in any case be absent from wreck sites because they were used to escape from a sinking ship. Literary evidence, such as that already referred to in this note, clearly attests such lemboi. See also Tipps (1985) p.447, on the towing of Roman horse transports against the prevailing winds off Sicily during an encounter with a Carthaginian fleet in 256B.C. (Pol.1.25-28).

577. The Kyrenia wreck is thought to have been able to sail 'amazingly close to the wind', and the reconstructed Kyrenia II also performed well with the wind approaching the quarters (Parker (1992) p.232 \#563): both terms denote sailing nearly at right angles to the wind direction. By bracing the sail around, so that it was no longer at right angles to the ship's keel, but pointed fore and aft, ancient ships were made to sail with the wind on the beam (i.e. at right angles to the direction the ship was pointed in), or even slightly forward of it, in which case they would be sailing at about $80^{\circ}$ into the wind (Rice Holmes (1909) passim., Casson (1950) p.45, Casson (1971) p.274, Morrison and Williams (1968) p.312, Hodge (1975) p.157). The procedure is described by Aristotle (Arist.Mech.7.851b6). A shallow draft led to a tendency to drift sideways: in sea trials, the reconstructed trireme Olympias, when it managed to sail $60^{\circ}$ into the wind, made $7-10 \%$ leeway (Coates and Morrison (1993) p.138, Shaw (1993) p.109), leeway being the ratio of sidewards drift to forwards motion. By tacking (sailing a zig-zagging route, with the wind first on one side of the ship, then on the other), ships could make continuous progress against the wind (Casson (1951) p.137f.), even if at a prohibitively slow rate for the completion of long-distance voyages in a reasonable time thus the reliance upon land and sea breezes, by which more direct and effective progress could be made (Roberts (1995) p.312f.). Another disincentive to sailing into the wind was the relative danger of the technique: important actions had to be taken in order to prevent the ship from capsizing, or turning to conform to the wind's direction (to luff) - the part of the sail turned to the rear of the mast was brailed up, so that most of the surface area of the sail was forward of the mast. This helped to stabilise the ship, as did working the steering oar to maintain the desired course, while having the crew, and sometimes any passengers, lean into the wind prevented the ship from capsizing, as on modern yachts. See Casson (1971) p.273ff., Morrison and Williams (1968) p.312f., Murray (1995) p.39, Rouge (1981) pp.21f., 51, Tilly (1994) passim, Roberts (1995) passim. Another innovation which could aid sailing with the wind on the beam was the foresail, hoisted on a second mast at the front of some merchant ships (Rouge (1981) p.55, Basch (1983) p.413), and also on some galleys, including triremes (Casson (1980) passim., Basch (1983) p.413f.): these foresails, being positioned directly in front of, and often being narrower than, the main sail, did little to increase the propulsive power of the ship when winds blew from astern, as the foresail sat in the 'wind shadow' of the main sail; they would, then, only have functioned well when the wind was on the quarters (blowing from 
one side), and then would have been of considerable use in sailing into the wind and making other difficult manoeuvres - see Basch (1982) p.355, Basch (1983) p.413.

578. Roberts (1995) p.312f. cites the use of land and sea breezes as an important alternative to sailing to windward when returning to the home port.

\section{Severin (1954) p.2 (compare loc.cit. p.17).}

580. That the winter weather was not constantly fierce and stormy, but regularly featured calm periods and lulls is suggested by the persistent credence given by the ancient Greeks' to the 'Halcyon

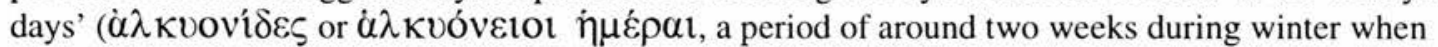
the halcyons were supposed to calm the seas so that they could nest upon the waves), despite the fact that there is no zoological truth to the tradition whatsoever. The fact that different traditions place the period of the 'halcyon days' anywhere from around the winter solstice (Arist.H.A.542b4) to late February (Democritus 14.3, 7, in calendars attributed to Geminus and Ptolemy - see Diels (1952) p.143f. and Freeman (1948) p.95), shows only that such periods of calm could occur at any time through the winter months. Full references to ancient beliefs concerning the halcyon (kingfisher), along with an assertion of their falsehood, and a possible explanation for the origins of these traditions, can be found in Thompson (1936) p.48ff. In meteorological terms, calms in winter can be expected during the breaks between the depressions which cross the Mediterranean in winter (see above, pp.48f., 50). For a clear example of the propensity for stormy weather to appear in summer, and calm weather in winter, see Cic.ad.Att.7.2.1, where, as late as Nov.24, Cicero finds that his crossing from Epeiros to Brundisium is attended by 'the fairest of breezes', despite knowing from experience (ad.Att.5.9.1f .) that the same area of the Adriatic can be rough and dangerous even in summer.

That nights were regularly calm enough even for small vessels to put out to sea is implied by, amongst other evidence, those fishing techniques specifically designed to be carried out individually by fishermen at night (see n.527). Voyaging by day in summer, when the Etesians were at full strength, could be especially difficult for oared ships - cf. Arat.Phaen.152-5, and above, n.560. Similarly, cf. Mediterranean Pilot III, p.94 where summer conditions in the Gulf of Corinth are described: nights are generally calm, while during the day winds are variable, occasionally blowing strongly enough to raise high seas. A similar situation is seen in Hdt 7.188, where a calm night is followed by the development of terrible storms during daylight: 'they lay eight ships deep, their prows pointing seaward. So it was with them for that night; but at dawn, after clear and calm weather, the sea began to boil, and there brake upon them a great storm and a strong east wind, that which the people of that country call the Hellespontian.'. This, of course, is only one isolated example, but it is enough to show the fallacy of assuming that sea and weather conditions at night will be worse than those encountered during daylight, and that ships accordingly sailed only by day.

581. Measurement of time and the seasons the chief aim of Greek astronomy - Dicks (1970) pp.26-9, 34f., 37f. A good explanation of how the ancient Greeks timed the seasons according to the movements of stars and constellations is in Taylor (1971) p.13f., to which the reader is directed, and because of which no more detailed treatment is included here. See also Dicks (1970) p.36f. The different classes of stellar risings and settings are described and explained by Dicks (1970) p.12ff. For ancient sources which make mention of these astronomical phenomena with reference to sailing seasons, see Hes.W\&D.564ff., 618ff., and esp. Theoc.Id.7.53f, 13.25ff., Ep.25.5 (cf. above, p.224f. and n.514) with Gow's commentary (Gow (1952) vol.2, pp. 145f., 237, 548), wherein will be found many more references to relevant ancient sources. For further passages describing seafarers caught in winter weather just as the constellations signified the end of the sailing season, see also Dem.35.10, quoted above, p.225f., and Anth.Pal.7.272f., 392, 395, 495, 502f., 534, 539, 653. The rain, and the northerly and southerly winds mentioned in these epigrams (539 - rain, 495 - Boreas, 502 -

Strymonian, 653 - Lips) can all be equated with the typical winds of a depression, the appearance of which marks the beginning of the winter season - see above, pp.48f., $51 \mathrm{f}$. 
583. The variation in the date that winter weather could set in during any one year led to the rising and setting of various constellations (see above, p.223f. and nn.514, 581), not all of them occurring at the same time, being associated with the end of summer; thus, according to Gow (1952) p.145f., in ancient times the Pleiades set around the same time as Orion begins to set (late October-early November), but the rising of the Kids, also associated with the end of summer, occurred somewhat earlier (late September-early October).

584. In discussing the seafaring and navigation techniques employed by early sailors lacking any scientific instruments, McGrail emphasises the importance of comparing actual local conditions with those normally expected for that time of year (McGrail (1983) p.314), and gives a summary of the various aspects of the natural environment which may be of use in weather forecasting (McGrail (1991) p.87; Severin (1954) p.11 stresses the importance of being familiar with local weather patterns and sequences.

585. Thus in the introduction to his work, Theophrastos writes:

'The signs of rain, wind, storm and fair weather we have described so far as was attainable, partly from our own observation, partly from the information of persons of credit ( $\pi \alpha \rho$ ' $\dot{\varepsilon} \varepsilon \dot{\varepsilon} \rho \omega \nu$ oij $\dot{\alpha} \delta$ okí $\mu \omega \nu \lambda \alpha \beta \delta \delta \tau \varepsilon \zeta)$....Wherefore good heed must be taken to the local conditions of the region in which one is placed. It is indeed always possible to find such an observer, and the signs learnt from such persons are the most trustworthy.' (Theophr.Signs 1, 3)

In passages where Theophrastos is discussing weather signs which are visible specifically from the sea (e.g. (especially) Theophr.Signs 29, 31, 36), we must assume that unless Theophrastos is, as seems unlikely, arguing from his own experience, he has gained his information from seafarers, who would be the only people in the right position to make observations which were worthy of credit in this context. Explicit evidence that Theophrastos used mariners' proverbs in his work comes from Theophr.Vent. 5 - for this passage, and Aristotle's and Theophrastos' reliance upon farmers and sailors, see Murray (1987) p.150 and n.32, Murray (1995) p.36 and n.5. See also the comments of Murray (1987) p.156 and p.164, n.16 on the reliability of wind observations by Aristotle and Theophrastos.

Evidence that at least some of this lore was of considerable age can be seen in passages where a far older authority is quoted by way of confirmation: thus, for example,

'If a cloud stands upright on a mountain peak, it indicates storm; whence Archilochus' lines "Mark you, Glaukos; deep ocean is now stirred up with waves, and about the heights of the Gyrai there rises a cloud erect, the sign of storm.".' (Theophr.Signs 45)

See also Dunbar (1995) p.397f. on the antiquity of weatherlore traditions, e.g. "we should expect this awareness of a connection between bird-behaviour and weather-change to be well established in the folklore of a farming and sailing people like the Greeks long before it is recorded in their literature, in Theophrastos' On Weather Signs (28) and Aratos' Phaenomena (913ff.).'.

586. The characteristics of the major winds are given in Taylor (1971) p.14f., where the point is made that the different winds encountered in the seas around Greece had such recognisable characteristics that mariners took their bearings according to the 'feel' of the wind, from which they could tell the direction from which it was blowing. See the discussion of winds in navigation above, p.186f. Murray (1987) p.147 notes that "For the ancients, a wind's name was just as descriptive of its physical characteristics as is was of its direction (and perhaps more so).". Compare Taylor (1971) p.63, Cary and Warmington (1929) p.6. Arist.Probl.26.17 even discusses the distinctive smell of the south wind Notos. 
587. Thus Theophrastos relates (Signs 29) that 'the north wind (Boreas) has less force as it ceases to blow, the south wind (Notos) as it begins.'. This is certainly true of the winds associated with the passage of first the warm front (bringing southerly winds), and then the cold front (bringing northerly winds) of a depression (see above, p.50ff.), although it should be noted that depressions only affect Greece during the winter season, and that northerlies in particular are not always associated with depressions (e.g. the Etesians) - cf. Coutant and Eichenlaub (1975) p.xxxiii on Theophr.Vent.5. Theophrastos also states (Signs 35) that winds from the northern quarter are those most likely to appear on top of other winds (and compare Arist.Met.364b3ff., Probl.26.47), but that when winds 'die down of their own accord, they change to the next winds on the figure, reckoning from left to right, according to the course of the sun.' (we must imagine a windrose illustrating the text here: Theophrastos means that each wind is followed by that blowing from the next compass point round the windrose, in a clockwise direction). Here again we are dealing primarily with winter conditions, when the contrast of cold polar air over Europe and warmer air over the Mediterranean can indeed induce sudden and forceful blasts of northerlies such as the Bora and the Livas across the Adriatic and the Aegean, appearing indeed 'on top of other winds'; see above, p.107f. All other winds tend to be related to passing depressions, in which winds start from the south, with the warm front, and then veer round through west to the northerlies associated with the cold front. Thus a depression passing over Greece results in just such a series of changes of wind direction as Theophrastos describes with reference to his windrose. That Theophrastos and Aristotle were indeed describing the passage of a depression is clear from the proverb quoted at Arist.Probl.26.46: 'Why is it said that 'if the south wind [Notos] summons the north wind [Boreas], winter is upon is.'?' (for depressions being characteristic only of winter, see p.48f.). Compare the very similar comments in Theophr.Vent.9, 52, and the comments of Coutant and Eichenlaub (1975) p.xxxiii, and p.68 on the proverb in Vent.5. Likewise, Theophrastos (Signs $35 f$.) correctly notes the moisture carried by southerly winds, and the fierce nature and clear skies associated with northerly, particularly northwesterly winds. Aristotle, meanwhile, notes that, southerly winds bring rain generally at the end of the period during which they blow (Probl.26.19), that they also increase in strength the longer they blow, in contrast to northerly winds (Probl.26.39, 41,45), that the degree of cloud cover increases with the strength of the south wind (Probl.26.20,38). For the meteorological accuracy of these statements (again when related to climatic conditions at specific times of the year, i.e. depressions), see above, pp.49-52, and Elkins (1983) p.24f. Where a wind's name was originally derived from that of the country lying in the direction from which the wind blew (e.g. the Thraskias, Hellespontias), confusion could arise in that such names indicated different directions according to the locality of the observer: see Taylor (1971) p.15.

588. Cf. Theophr.Signs 20, 22, 24, 34, and 43 (orographic cloud and rainfall); 51 (fair weather if orographic cloud absent from certain mountains); 45 (orographic cloud and storm, containing the passage of Archilochus quoted in n.585 above). In the latter passage, the description of 'erect' or 'upright' cloud over a mountain or island accurately indicates the cumulonimbus type.

During a visit to Aigina in August 1993, local fishermen confirmed that they share Theophrastos' belief (Signs 24) that cloud over the peak of Aigina signified coming rain.

589. Theophr.Signs 21, 32f; Arat.Phaen.924ff.

590. See, for example, Theophr.Signs 31, 43, 45, 51; Arat.Phaen.988ff., 1112-20.

591. Theophr.Signs 57; Arat.Phaen.938ff.

592. Theophr.Signs 22; Arat.Phaen.832f.

593. Arat.Phaen.1148-52.

594. Theophr.Signs 12, 27, 39, 51; Arat.Phaen.778-818. 
595. Theophr.Signs 23, 43, 51; Arat.Phaen.892-908, 994. On the Asses' Manger, see also Theoc.Id. 22.21 with the commentary of Gow (1952).

596. See, for example, Theophr.Signs 10f., 26, 38, 50; Arat.Phaen.819-831, 845ff.

597. On the dangers to ships sailing the Mediterranean of being swept onto the north coast of Africa during northerly gales, see Pryor (1988) p.21f., Rouge (1981) p.18.

598. See also Dunbar (1995) p.449ff., where it is pointed out that Hesiod cites both star-movements and bird- (and other animal-) movements as signals for the advent of new stages of the agricultural (and indeed sailing) year. A good example is Hes.W\&D.568f. - see the commentary of West (1978) p.300.

599. See Dunbar (1995) p.397f. on this passage, and particularly on folklore and the question of how dependent or independent mariners and others were upon seers for such interpretation of bird behaviour. Wachsmuth (1967) p.191 makes the point that the two methods of using birds to forecast weather, by observing the natural world, and through superstitious divination, go hand in hand. See also Pollard (1977) p.14.

600. Sensors in the ears of swallows which register changes in atmospheric pressure and so warn the birds of developments in weather conditions are described in Incredible Journeys: A Swallow's Journey (BBC 1, 8.00pm, Thursday 9 Jan., 1997). See also Wachsmuth (1967) p.191, .

601. Elkins (1983) pp.191f, 201.

602. Elkins (1983) p.191f.

603. Elkins (1983) pp.186f., 188.

604. Elkins (1983) pp.109f., 191, 193f., 198, 201.

605. See also Theophr.Signs 40, 47, Arat.Phaen.1024f. Wachsmuth (1967) p.191 discusses the role of seabirds in general in weather prediction.

606. Heron - Elkins (1983) p.183ff.; Shearwater - Elkins (1983) pp.193f., 200; Gulls - Elkins (1983) pp.196, 201.

607. Shearwaters - Ael.On Animals 7.7; herons - Theophr.Signs 28, Arat.Phaen.913ff.; gulls Theophr.Signs 47, Ael.On Animals 7.7.

608. Theophr.Signs 19, 40. Compare PlinyH.N.18.85, 87. Jelly-fish, which have little control over their own movement, are at the mercy of sea currents, and unusually large congregations of them are produced by unusually strong currents. As fluctuations in the strength of currents are produced by variations in the strength of wind, it follows that the appearance of large numbers of jelly-fish in one place was indeed a likely indicator very strong winds blowing from the direction from which the jelly-fish had arrived. However, generally the credibility of weather signs citing the behaviour of marine animals is far harder to verify than those citing bird behaviour.

609. See also Anth.Pal.10.15, attributed to Paulus Silentiarius (fl. 6th century AD). Despite the late date, the epigram states even more clearly the connection between Zephyros and the start of the sailing season: "Now the heart entrancing spring in all the beauty of her meadows opens the closed folds of her bosom to the Zephyrs; now the ship slides down the wooden rollers, pulled from the beach into the deep. Go forth fearlessly, ye sailors, your sails strutting with the wind...'. As the west wind of spring, Zephyros was seen as the safest of winds (Anth.Pal.7.668), but this wind must be distinguished from the north-west wind, also called Zephyros, which was associated with storms and 
squalls, and not restricted to the spring months - see Bunbury (1959) vol.1, p.36 and n.8, and Tozer (1873) p.143f. Thus Theophrastos, as well as using the name Zephyros to denote a specific wind (Theophr.Vent.38, 40,41), uses $\tau \dot{\alpha} \zeta \varepsilon \varphi v ́ \rho 1 \alpha$ of the different westerly winds in general (Theophr.Vent.47). In Homer, Pindar, and Aristotle, Zephyros is generally a stormy wind, while in Bacchylides it is calm (this information comes from an unpublished lecture on Zephyros given by a fellow Classics postgraduate, Sian Phillips, at Edinburgh University in March 1997).

On the basis of Theophr.Vent.38 ('The Zephyros is the mildest of the winds; it blows in the afternoon toward land and it is cool; during the year, it blows in two seasons only, spring and autumn.': compare Arist.Probl.26.52), Murray (1987) p.147 has identified the spring Zephyros as the sea breeze, which indeed blows towards land in the afternoon, and is relatively cool. The strength of the sea breeze in summer is why, in Murray's opinion, Theophrastos did not include summer as one of the seasons in which this 'mildest of the winds' blows. However, Coutant and Eichenlaub (1975) p.xxviii cite modern wind data to show that westerly winds are indeed far more common in spring and autumn than at other times of the year, and elsewhere Theophrastos characterises Zephyros as a wind that blows not from the sea generally, but from the Atlantic (Vent.41ff.), and which blows from the land in localities where the coast faces east rather than west (Vent.45). These remarks clearly describe a wind that results from general atmospheric conditions over the Mediterranean, rather than a local breeze that blows in relation to the configuration of the coast. Moreover, if we identify the spring Zephyros that marked the start of the sailing season as the sea breeze, we immediately run into problems: such onshore winds were in fact the least suited to embarking upon sea voyages, especially the sea breeze, which blows only in the afternoon and evening; the sea breeze was generally used to return to land at the end of the day, while it was the land breeze, blowing offshore in the early morning, that was used to set sail from the coast (for these aspects of land and sea breezes, see p.109f., 222f.). If Murray is right (and it must be admitted that Theophrastos does seem to describe diurnal breezes when describing Zephyros, as when discussing the times of day the wind arises), then we must distinguish the Zephyros of Theophr.Vent.38 from the Zephyros which elsewhere is described as specifically a springtime wind which both marked the start of the sailing season, and was used by birds returning from Africa (see below, pp.262-6: a sea breeze, blowing only in the vicinity of the coast, is no use to birds crossing the whole width of the Mediterranean Sea). This Zephyros may best be identified as the mild westerlies which blow when weak ridges of high pressure develop over the Mediterranean in springtime (p.49), bringing the clear skies that were also so important to ancient seafarers (see pp.221, 224f., 227f., 234f.). Thus Theophrastos describes Zephyros as a wind which blows principally in spring, 'while the sun is beginning to control' (Vent. 38, 40). Theophrastos may indeed have confused Zephyros with sea breezes, as these, while not blowing exclusively from the southwest, are most notable when blowing from that direction, because then they counteract the prevailing Etesians (cf. Vent.31), whereas sea breezes blowing from the northeast merge into and so merely reinforce the Etesians, and do not appear as distinct winds.

610. Arist.H.A.596b30-597a3, 597a27ff.. Many species of birds which spend much of their lives in Greece, including quail, swallows, geese, cuckoos, blackbirds and other thrushes, and turtle doves, migrate southwards in autumn, and spend the winter in Africa. Other species, such as cranes, storks, and kites, though not living in Greece even semi-permanently, pass through the country during their migrations between more northerly countries, where they spend the summer, and warmer areas to the south, where they spend the winter. Full references to the ancient literature concerning the migration of these birds, along with information regarding the survival of these species in modern Greece, may be found in Thompson (1936) pp.71f. (Cranes), 119f. (Kites), 149 (Thrushes), 152 (Cuckoos), 174 (Blackbirds), 216 (Quails), 222f. (Storks), 290 (Turtle-doves), $317 \mathrm{ff}$. (Swallows), 326 (Geese). See also Dunbar (1995) pp.449-455 on the migrations of cranes, kites, and swallows. Migrating birds were also convenient weather signs because they were easy to spot, as even normally solitary species prefer to fly in flocks, for navigational purposes (Elkins (1983) p.113); see also above, p.192f.

611. Elkins (1983) pp.112, 137f.,143, $187 f$.

612. Elkins (1983) pp.113f., 116, 123. 
614. For examples of the various factors which cause some bird species to migrate earlier than others, see Clarke (1912) p.178, Elkins (1983) pp. 111f, 114f, 118f., $125 \mathrm{f}$.

615. For an example of the spring immigration of different species marking different phases in the winter-summer transition, see Aristoph.Birds 713ff., where the advent of the kite (that is, the black kite - see the comments of Dunbar (1995) p.454, loc. cit.) marks the time for sheep shearing to begin, but it is not until later, when the swallow arrives, that people change their winter clothes for summer garb.

616. Refer also to $W \& D 674-82$, where Hesiod explicitly states his opinion that the changes of weather, which were heralded by the departure of the crane and by the arrival of the swallow, did indeed mark respectively the last and the first opportunities for safe seafaring in the year. For a full list of ancient references to the arrival of the swallow as a sign of spring, see Thompson (1936) p.317ff.; to the departure of the crane as a sign of winter, see Thompson (1936) pp.71f., 74. For the arrival of the swallow as a signal to resume seafaring, see also Anth.Pal.10.2.1ff: 'It is the season for the ship to travel tearing through the waves; no longer does the sea toss, furrowed by dreadful fret. Already the swallow is building her round houses under the roof, and the tender leaves of the meadows smile. Therefore, ye sailors, coil your wet hawsers and drag the anchors from their nests in the harbour. Haul up your well-woven sails...

617. Compare the behaviour and tactics of birds migrating south from Britain during autumn in very similar prevailing weather conditions, described by Elkins (1983) pp. 113-6, 123f.

618. For ancient references to the high altitude at which cranes fly, see Thompson (1936) p.70f. Note that many soaring birds prefer to follow land routes on their migrations, because thermals are more common over land, and because land routes are generally less taxing than sea routes (see above, p.256). Cranes, however, are prepared to cross bodies of water, generally taking the shortest possible crossings, as do most birds (see p.192f., but note the alternative theory of 'broad front' migration (nn.482, 631)), but also exploiting the thermals found over islands (cf. n.622). That the ancient Greeks were familiar with these migratory habits of cranes is shown by Eur.Hel.479ff., which mentions cranes migrating to Libya via the river Eurotas in Lakonia: from the Eurotas estuary, the Taygetos peninsula stretches away to Tainaron, which, being the most southerly point in Europe after Gibraltar, is a particularly important point for migratory birds seeking to minimise the distance they have to travel over the sea: Porto Kaio, near Tainaron, is named after the quails which stop there during their migrations - see further n.485.

619. Arat.Phaen.1028-1032. See Elkins (1983) p.168, fig.33.

620. Elkins (1983) pp.35ff., 164f., 168.

\section{Elkins (1983) p.41.}

622. Alerstam (1975) p.494, where the assertion that thermals and, therefore, soaring, only ever occur over land does not take into account the use, by birds crossing the sea, of thermals over and around islands, for which see immediately above in the main text, and nn.618, 621 .

623. Elkins (1983) p.164f. See also Alerstam (1975) p.489ff. for the slower rate of progress of cranes following land routes, as opposed to those following sea routes, due to the greater incidence, and use, of thermals over land surfaces.

624. Ignorance of the swallows' migration was maintained in spite of the fact that swallows were renowned for their far travels, and known to reside in Egypt: see the references to swallow 
'migration' in Thompson (1936) p.317f. For the supposed hibernation of the swallow, see Thompson (1936) p.318.

625. See Grenfell and Hunt (1906) p.146.

626. Quoted in Geminus' Calendar (Democ. 14.3) and by Ptolemaeus (Democ. 14.7). See Diels (1952) vol.2, p.143f., Freeman (1948) p.95f.

\section{Tozer (1873) p.64.}

628. See the note to Arist.Met.362a23ff. in Lee (1952) p.178. One possible explanation for the identification of the bird winds as northerlies by some authors, is that very often migratory birds are most conspicuous, not when flying at altitude with their preferred winds, but when forced to land and take shelter from bad weather, particularly from strong headwinds (De Lucca (1969) p.328, Moreau (1961) p.377; Moreau specifically witnessed migrant swallows taking shelter aboard the ship on which he was travelling across the Mediterranean (in April) when northerly winds appeared (Moreau (1938) p.19); compare p.253f. above, on the equivalent actions of seabirds). For spring migrants headed north, such winds would be northerly winds. At this time of year northerly winds blowing off the rear of a depression passing north of Greece, over continental Europe (for such winds at this time of year, see pp.49, 50f.), draw cold continental polar air down from the north, and appear in Greece as katabatic winds such as the Thraskias and the Bora. Thus we may have a situation where birds migrated back to Greece on light westerly winds and sunny clear skies, and then appeared en masse when the westerly winds were interrupted by sharp, icy northerly blasts: Hippocrates' description of the bird winds suggests such a change in weather conditions: 'The bird winds are strong and cold; and sometimes snowy conditions can develop from fine weather' (Hipp.Epid.7.105, my italics). These northerlies are particularly associated with the coastlands of Thrace, Macedon, and Thessaly, onto which they descend violently from the mountains of the interior (above, pp.52, 56). This may explain why it is mainly writers who wrote and gathered information in northern Greece (e.g.

Aristotle, and Democritus as recorded by Geminus and Ptolemaeus) that describe the bird winds as northerlies.

629. Lee's identification of the bird winds of Met.362a23-31 with the southerly winds mentioned at Met.362a14, is followed by Murray (1987) p.148, again despite De Mundo 395a4. While Murray sees De Mundo $395 \mathrm{a} 4$ as 'further indication (if such were needed) that these winds are defined by too many vague and conflicting observations to be included in this study' (Murray (1987) n.31), it is also his opinion (Murray $(1987)$ pp. 148, 158) that Aristotle described the bird winds as southerlies in order that his evidence should accord with his theoretical anemology, whereby every northerly wind should have a corresponding southerly. Indeed, in the present study, further discussion of the bird winds is only justified by the attempt to identify them by reference to the strategies and weather by which spring migrants return to Greece, rather than solely to the confused ancient sources. Coutant and Eichenlaub (1975) p.xxviii argue that Aristotle confused the ornithian winds with the southerly leukonotoi, and that the bird winds were in fact moist northerlies blowing in February and March, but they do not cite the evidence upon which these arguments are based.

\section{Compare Elkins (1983) p.149.}

631. Elkins (1983) p.126. Birds returning to Greece from the south would find it no less difficult to do so through westerly winds then through southerly winds, as long as the wind was moderate, and skies were clear (Elkins (1983) p.150). Moreover, it is possible that many of the swallows returning to Greece in spring did so, and still do so, not directly from the south, but from a point further west along the north coast of Africa, from where westerly winds would be even more useful on migration.

Unfortunately there are no specific studies on the routes and weather typical of the spring migration of swallows over the eastern Mediterranean (e.g. see Moreau (1953) p.355f.), and very few on those of other birds' spring migrations over the Mediterranean, especially around the area of Greece. However, different evidence, when collected together, does suggest that swallows may return to 
Greece from the southwest, and not only from the south: those swallows wintering south of the Sahara (some winter in Egypt - see n.624 above) prefer to avoid the potentially fatal heat and drought of that desert on their spring migration, and instead skirt along its western fringes, so that the Mediterranean crossing starts from the western end of the north coast of Africa (Elkins (1983) p.149).

Swallows returning to Greece from such a point might rest in Sicily or southern Italy en route (see above, p.192f. and nn.482, 485, for migrant birds' tendency to take in islands when following maritime routes), or equally in the Maltese islands, where De Lucca made a study of bird migration (De Lucca (1969)). He found that 'in spring, north and south winds often do not bring any birds at all' (De Lucca (1969) p.326; p.328 has similar comments on northerly winds), which suggests that neither of Aristotle's assertions as to the direction of the bird winds were accurate. Likewise, Moreau observed swallows taking shelter from northerly winds while on their spring migration over the Mediterranean (Moreau (1938) p.19). Concerning westerly winds in particular, De Lucca noted that during their spring migration, 'the Quail and many of the short-winged, and many of the smaller birds' generally appear with NNW to SSW winds (De Lucca (1969) p.322), and that during southwesterly winds, the was a marked increase in the numbers of swallows and other birds (De Lucca (1969) p.327). More important still, he notes the importance to spring migration of anticyclonic conditions, which in Malta (as in Greece) are 'typified by clear skies, good visibility, and westerly winds', and are the only conditions in which quail were found in significant numbers (De Lucca (1969) p.327). Swallows too appeared in large numbers with anticyclonic weather and westerly winds in spring (De Lucca (1969) p.333). In cyclonic (overcast) weather and easterly winds, no migrants at all were seen on successive days, but they reappeared when the weather changed to anticyclonic (De Lucca (1969) p.328), and radar observations showed many birds travelling north during good weather and westerly or northwesterly winds (De Lucca (1969) p.334). Given that, during the autumn migration from Europe to Africa, 'several species reach the Maltese islands from eastern European countries, travelling generally southwest' (De Lucca (1969) p.336), and swallows in numbers 'certainly in six figures' have been seen travelling southwards down the west coast of Greece (Moreau (1960) p.475), we might assume that some of the swallows and other birds seen passing through Malta during their spring migration from Africa back to Europe were headed northeastwards for eastern Europe, where Greece would be the first country encountered (i.e. autumn and spring routes differ only in their direction of travel). This hypothesis is supported by the fact that swallows have been seen crossing the Ionian Sea (i.e. between Greece and Malta) in April (Moreau (1953) p.341).

Nevertheless, migration routes over the Mediterranean have not been sufficiently studied for these suggestions to be stated conclusively. In particular we should note the theories that migrants cross the Mediterranean over a 'broad front' rather than by following specific flight paths (Moreau (1938) p.26ff., Moreau (1953) p.330ff., Bateson and Nisbet (1961) pp. 503, 507, 511: see also above, n.482), and that spring migrants might tend particularly to strike out over the Mediterranean from the area between Algeria and Cyrenaica, where 'the prospects are much more favourable than elsewhere' (Moreau (1961) p.389). However, in any of these circumstances, whatever the routes used, anticyclonic ridges over the Mediterranean clearly provide the most suitable conditions for migrants returning from Africa to Europe, by reason of their clear skies and light westerly winds.

It should also be noted that (despite the assertion made on p.264 above) some migrants may attempt to return to Europe during the passage of winter depressions. In late winter, depressions tend to weaken somewhat, so that the cloud cover normally associated with the southerly and southwesterly winds to the rear of the warm front (for which see pp.48f., 52) becomes broken up. If the cloud breaks enough to give the visibility required for birds' navigation, then birds (especially those returning from the eastern, rather than the western part of the north coast of Africa) may migrate northwards during the southerly winds of depressions (i.e. the Sirocco). Thus whereas De Lucca observed no migrants over Malta during northerly and southerly winds (see above), Stanford noted in Cyrenaica that, while northerlies deterred birds' flight, the southerly and southeasterly Khamsin (Sirocco) brought large influxes of migrants (Stanford (1953) p.322f.). 
632. I.e. the swallow cannot arrive back in Greece while one wind is blowing (the bird wind) and simultaneously be seen as the herald of a different wind (Zephyros). This tradition is represented mainly in Roman authors: Hor.Ep.1.7, 13; Verg.G.4.305ff., but here the Greek origins of the tradition are illustrated.

633. In fact, the Anthologia Palatina has several such clear references to the arrival of the swallow being contemporaneous with that of Zephyros, and both being signals to return to seafaring: see also Anth.Pal.10.4ff., 14, 16.

634. In this passage, Pliny, writing in Latin, does not use the name Zephyros for the west wind, but the Italian (Latin) 'Favonius'. However, a little earlier, in the opening lines of his account of the winds and other meteorological phenomena, he lists the Latin names of the different winds, and gives the direction and the Greek name of each: Favonius blows from the equinoctal sunset (i.e. due west), and is called Zephyros by the Greeks (Pliny.H.N.2.46). It should also be noted that when a ridge of high pressure lies over the Mediterranean, wind and weather conditions are practically identical in Italy and Greece, especially in terms of lack of cloud cover, and of wind direction and strength (note the routine nature of the way he equates Italian and Greek winds in at H.N.2.46.119ff.: only a few local winds, most of them katabatic, do not have names in both languages). Bird migration too unfolds at the essentially same rate in the two peninsulas. Thus even if Pliny is thought of as describing the situation pertaining to Italy, his comments apply equally well to Greece, and we are justified in identifying the west winds he mentions here with the spring Zephyros presently under discussion.

635. Note also that, while the timing of migration does vary from year to year according to weather conditions, the 19th February is generally a rather early date for swallow migration (although Snider (1978) p.131 notes modern records of swallows migrating back to Cyprus by 20th February), and would also have been seen by most as rather early for seafaring. The calendars of Geminus and Ptolemaeus, containing information from Democritus, also have Zephyros blowing for around a month before the bird days/bird winds arrive: the passages are Democ.14.3 (Geminus), 14.7 (Ptolemaeus), in Diels (1952) vol.2, p.143f., and Freeman (1948) p.95f.

636. Thus note that Arist.H.A.597a21-24 gives the time of the cranes' departure as Maimakterion (November/December: quoted above, p.257), while Pliny.H.N.2.47 takes the arrival of the swallow as far back as mid-February (see the preceding two notes). These dates embrace a considerably longer sailing season than that defined by astronomical events: the rising of the Pleiades, for example, taken to mark the start of the sailing season, did not occur until April or May, while the rising of the Kids, one of the signs marking the end of the sailing season, occurs as early as late August; even later signs, such as the setting of the Pleiades and of Orion, commence in late October or early November: see $n .583$ above.

637. For passages citing both Zephyros and spring flowers, see Anth.Pal.10.1 (quoted above, p.265), 2, 4ff., and 15: these epigrams seem to suggest that the advent of Zephyros was held not only to calm the sea, but also to bring out the spring flowers, in which case it is clear that flowering and seafaring should begin at the same time. Note also Theophr.Enq.Pl.7.15.1, where it is said that the 'swallow plant' (celandine) flowers when the 'swallow wind' blows. Again there is a tying up of contemporaneous weather signals, although Theophrastos (loc.cit.) is unsure as to whether there is an intentional connection between the two names and their reference to the swallow: 'the reasons in these cases would seem to be partly in their nature and partly accidental.'. It is possible that this flowering of plants is a response to the sunny clear skies that accompany the spring Zephyros, rather than to Zephyros itself. Snider (1978) p.131 places the appearance of young leaves on fig trees in late March.

638. The Lakinion - Princeton p.470f. s.v. 'Kroton'; Samikon - Str.Geog.8.3.13, 18, 20, Princeton s.v. 'Samikon'; Kalauria - Str.Geog.8.6.14; the Panionion - Str.Geog.8.7.2, 14.2.20. 
Note also that Alcaeus G1 describes the sanctuary of Zeus, Hera, and Dionysos at Cape Phokas on

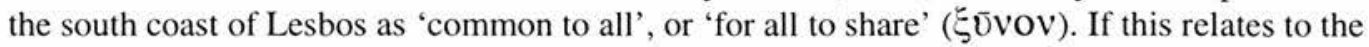
worshippers at the sanctuary, rather than to its deities, than there is at least an allusion to the fact that the sanctuary is in a position which makes it equally accessible (by sea) from all areas of Lesbos - see Quinn (1961) pp.391, 393.

The navigational significance of Isthmia, where the pan-Hellenic festival of Poseidon took place, and where those participating in the cult are referred to by Pindar (N.6.40) as $\dot{\alpha} \mu \varphi 1 \kappa \tau v o ́ v \varepsilon \varsigma$, should also be considered significant here.

639. Thucydides' statement that the second Athenian trophy was set up 'at the place from which they had set out and won the victory' (Thuc.2.92.4) could indicate either the promontory of Molykreian Rhion, where their fleet started the day and where the earlier trophy had been erected in the sanctuary of Poseidon, or the temple of Apollo near Naupaktos, from where the Athenian ships launched their successful attack; in either case the trophy is understood to have been erected in a headland sanctuary. The fact that the ships captured by the Peloponnesians were dedicated (Thuc.2.92.5) by the side of their trophy shows that the trophy must have stood within a hieron, presumably that of Poseidon on the headland of Achaian Rhion. For the temples of Poseidon here, one standing on each of the headlands forming the strait at Rhion, see p.177 and nn.418, 425, 431.

For the dedications made at Delphi, possibly chosen from amongst the four pan-Hellenic sanctuaries because it lay closest to that part of the Corinthian Gulf in which the battles were fought, see Paus.10.11.6, where there is a further reference to sacrifices made to Poseidon and Theseus at Rhion.

For similar trophy dedications, see Diod.Sic.13.40.6, where Thrasybulus erects a trophy on the headland of Kynossema after the victory of his Athenian fleet over their Peloponnesian enemies in the waters of the Hellespont below, and Thuc.1.30, where the Corcyraeans erect a trophy on the headland of Leukimme after their nearby victory over the Corinthians in 435B.C. For the trophy erected at Artemis' sanctuary at Cape Artemision after the Greeks' victory over the Persians there, see Plut.Them.8, Hdt.8.8.

640. Above, p.87ff., Morrison (1974) p.23.

641. Meigs (1961) p.376.

642. For the practice of establishing tunny-watching stations on many headlands, see Opp.Hal.3.630ff., Ael.On Animals.15.5, Aristoph.Hipp.312, Theoc.Id.3.26, and further references given by Mair (1928) pp.398-401. See also discussions in Bintliff (1977) pp.113, 119-22, 241, 595, Gallant (1985) p.22f. A modern parallel to such functions of headlands in ancient Greece may be seen in the name of Cape Lookout in N. Carolina.

643. Cary (1949) p.51. 


\section{ILLUSTRATIONS}

Fig. 1. Sanctuaries mentioned in the text.

Fig. 2. Advancing shorelines around the mouths of the rivers Maeander and Cayster.

Fig. 3. The major geological zones of Greece.

Fig. 4. Fault-related topography.

Fig. 5. Stratification, dip, and jointing in sedimentary rock.

Fig. 6. Erosion features in sedimentary rock on the coast of Corcyra.

Fig. 7. Marine caves in the west coast of the Tainaron peninsula.

Fig. 8. A wave-cut indentation in the west coast of the Tainaron peninsula.

Fig. 9. Wave-cut cliffs on the northeast coast of Euboia.

Fig. 10. Erosion features on the northeast coast of Euboia.

Fig. 11. The natural harbour of Emborio, Chios, from the slopes of Prophetes Ilias to the NE.

Fig. 12. A bay eroded from the coast of the Argolic peninsula, east of Porto Cheli.

Fig. 13. Rocky indentations in the region of the 'Hollows of Euboia'.

Fig. 14. A section of the coast of Melos, composed of heavily eroded stratified rock.

Fig. 15. Faulted cliffs in the region of Thyrides (Cave Grosso), Taygetos peninsula.

Fig.16. Formation of wave-cut cliffs.

Fig. 17. Wave-cut cliffs south of Cape Paraskevi in the northwest Euboian Sound.

Fig. 18. The west coast of the Peloponnese, immediately south of ancient Samikon.

Fig. 19. Undercutting in the rocky coast of Zakynthos.

Fig. 20. The white cliffs of Leukatas, the southerly promontory of Leukas.

Fig. 21. The headland of Leukatas, the southern tip of Leukas.

Fig. 22. The natural harbour at Vathy, Kalymnos.

Fig. 23. The harbours at (i) the Piraeus, (ii) Kophos Limen (Chalkidike), and (iii) Porto Kaio.

Fig. 24. The 'double harbours' of (i) Corcyra and (ii) Sinope.

Fig. 25. The Bay of Kastri, southeast Euboia.

Fig. 26. Cape Gravousa, Thasos.

Fig. 27. Rocky outcrops in the Steno strait, separating Andros from Tenos.

Fig. 28. The site of the battle of Salamis (British Admiralty map 894 (1897)).

Fig. 29. Cape Milianos, near Porto Cheli in the Argolic peninsula.

Fig. 30. Reefs in the Chian strait.

Fig. 31. Longshore drift.

Fig. 32. Waves against an indented coastline.

Fig. 33. Low deposition coasts in the western Peloponnese.

Fig. 34. Cape Kenaion and the Lichades islands, northwest Euboia. 
Fig. 35. Wave refraction in Ay. Andreas Bay (anc. Pheia).

Fig. 36. Deposition features in the Leukas Strait.

Fig. 37. Wave refraction off the coast of Astypalaia.

Fig. 38. The Euripos at Chalkis.

Fig. 39. Surface currents and areas of strong tides in the Mediterranean and Black Seas.

Fig. 40. Currents in the Aegean.

Fig. 41. Prevailing winter and summer winds in the eastern Mediterranean.

Fig. 42. Winter depression tracks.

Fig. 43. Local winds around Greece.

Fig. 44. Land and sea breeze dynamics.

Fig. 45. Vertical displacement of stable air (i), and of unstable air (ii).

Fig. 46. Displacement of wind on passing an island chain.

Fig. 47. The Bays of Karystos (i) and Marmari (ii), southern Euboia.

Fig. 48. Annual rainfall regime in Greece and the Aegean.

Fig. 49. Development of orographic cloud over southern Malea on a typical summer afternoon.

Fig. 50. The routes of the Persian fleets in 492,491 , and 480 BC.

Fig. 51. Malea.

Fig. 52. Zagora, Andros.

Fig. 53. Cape Posidhi, the ancient Poseidonion in the Chalkidike.

Fig. 54. Legrena Bay, seen from the promontory of Sounion to the east.

Fig. 55. Paul's route from Sidon towards Rome.

Fig. 56. Offshore islands sheltering the harbours of (i) Syracuse and of (ii) Thasos, and (iii) the Bay of Pylos.

Fig. 57. The sheltered inlet and the site of the sanctuary of Poseidon at Tainaron, Lakonia.

Fig. 58. Distances and 'milestones' on typical sea routes

Fig. 59. Strabo's measurement of the Mediterranean (Geog.2.4.3), and the 'opposition' of

Nisyros (Karpathos) and Leuke Akte (Geog.10.5.17).

Fig. 60. i. The headlands of northeast Samos at dusk, from the harbour of Vathy.

ii. Headlands on the west coast of the Tainaron peninsula in early morning fog.

Fig. 61. Onougnathos - 'the Ass's Jawbone'.

Fig. 62. The southeast coast of the Peloponnese, between Cape Klemmisi and Limenas Yeraka.

Fig. 63. The temple of Apollo, Aigina.

Fig. 64. Views (i) southeast and (ii) southwest across the Samian Strait to Mykale.

Fig. 65. Monument of Akeratos, Cape Pirgos, Thasos.

Fig. 66. The tower at Cape Phanari, the northeast point of Thasos.

Fig. 67. The tower at Kastri in southern Leukas.

Fig. 68. A pebble beach on the south coast of Samos. 

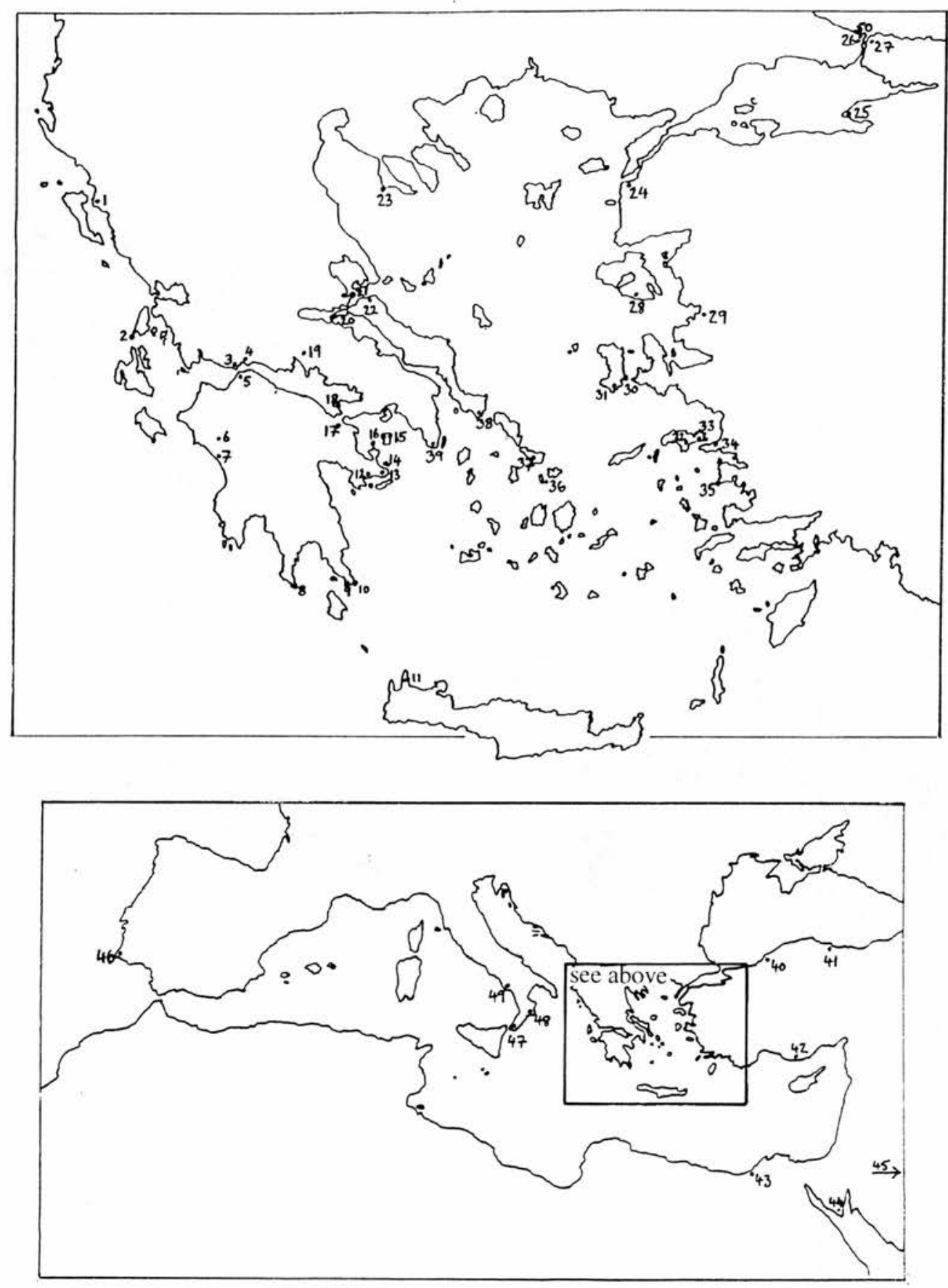

Fig. 1. Sanctuaries mentioned in the text.

For key, see following page. 
Fig. 1. Sanctuaries mentioned in the text.

P: promontory.

S: strait.

I: offshore island.

$\mathrm{H}$ : harbour.

A: amphiktyony centre.

1. Poseidonion, Thesprotia (P).

2. Apollo, Leukatas (P).

3. Poseidon, Molykreian Rhion (P).

4. Apollo, Naupaktos.

5. Poseidon, Rhion (P).

6. Zeus, Olympia.

7. Poseidonion, Samikon (P, A).

8. Poseidon, Tainaron $(\mathrm{P})$.

9. Poseidon, Malea (P).

10. Apollo, Malea (P).

11. Diktynnaion, Crete (P).

12. Poseidon, Hermione (P).

13. Apollo, Troizen.

14. Poseidon, Kalauria (I, A).

15. Aphaia, Aigina (P).

16. Apollo, Aigina (P).

17. Poseidon, Isthmia.

18. Hera, Perachora (P).

19. Apollo, Delphi (A).

20. Zeus, Kenaion (P).

21. Poseidonion, Gulf of Pagasai (P).

22. Artemision, Euboia.

23. Poseidonion, Mende (P, L).
24. Aias, Rhoiteion (L).

25. Poseidonion, Propontis ( $\mathrm{P}$ ).

26. Temple of the Byzantines, Bosporos (S).

27. Zeus Ourios (Temple of the

Chalkedonians), Bosporos (S).

28. Zeus, Hera, and Dionysos, Lesbos (P).

29. Apollo, Grynion (H).

30. Poseidonion, Chios (P).

31. Harbour Sanctuary, Emborio (H).

32. Hera, Samos (L).

33. Poseidonion, Samos (P, S).

34. Panionion, Mykale (S, A).

35. Poseidonion, Miletos $(\mathrm{P})$.

36. Apollo, Delos.

37. Poseidon, Tenos $(\mathrm{H})$.

38. Poseidon, Geraistos $(\mathrm{P}, \mathrm{H})$.

39. Poseidon, Sounion (P).

40. Dioscuri, Acherusia (P).

41. Poseidonion, Black Sea (P).

42. Poseidonion, Cilicia $(\mathrm{P})$.

43. Poseidonion, Alexandria ( $\mathrm{P}, \mathrm{H})$.

44. Poseidonion, Red Sea (P).

45. Poseidonion, Persian Gulf.

46. Sacred Cape (P).

47. Poseidonion, Straits of Messina (P, S).

48. Hera, Lakinion (P).

49. Poseidonion, Lukania (P).

50. Poseidon, Bosporos/Black Sea (S). 


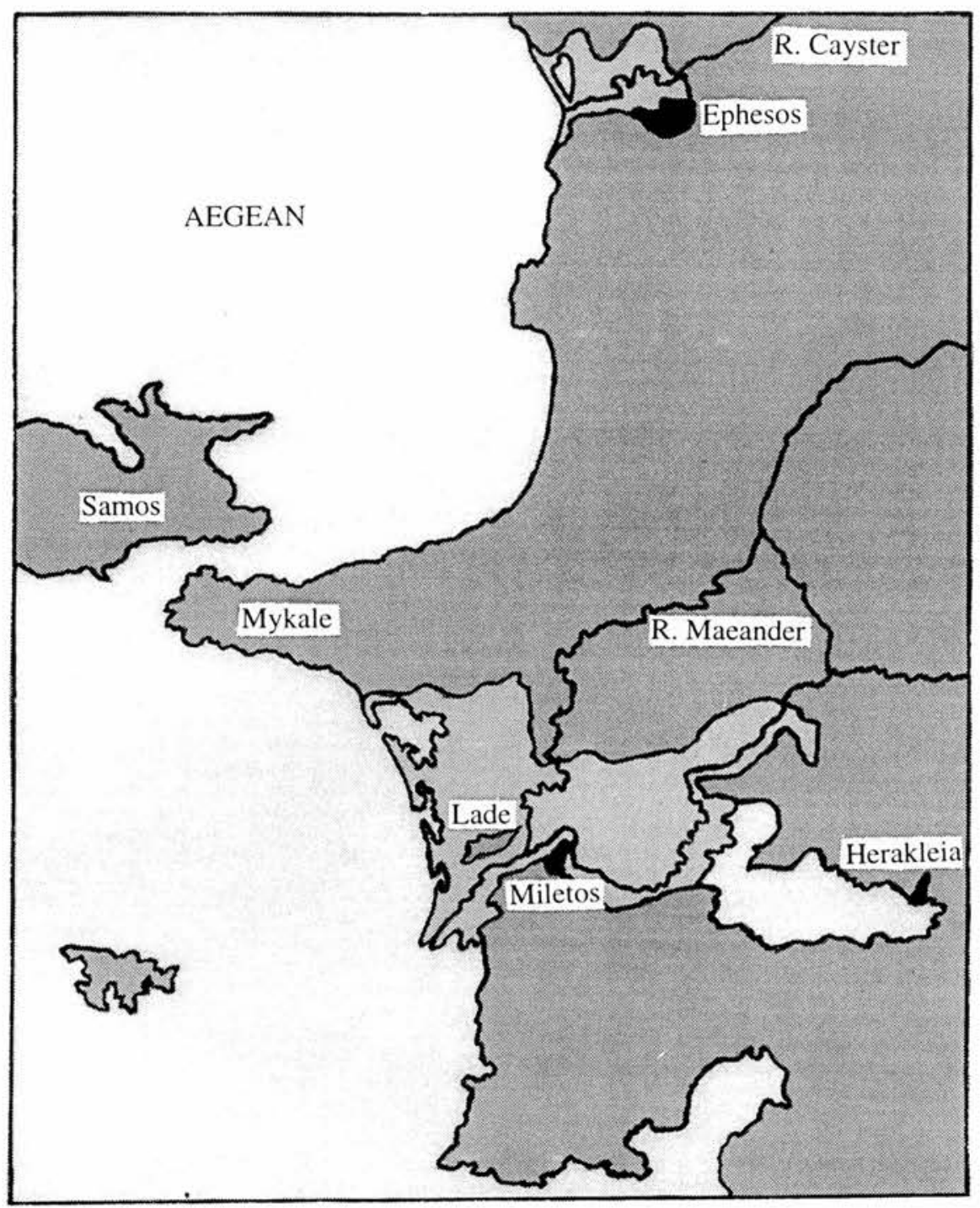

Fig. 2. Advancing shorelines around the mouths of the rivers Maeander and Cayster.

The ancient coastlands, including the island of Lade, are shown in the darker shade; land formed more recently, through deposition, is shown in the lighter shade. Note that not only the island of Lade, but also the once coastal towns of Ephesos, Herakleia, and Miletos, now stand some distance from the sea. 


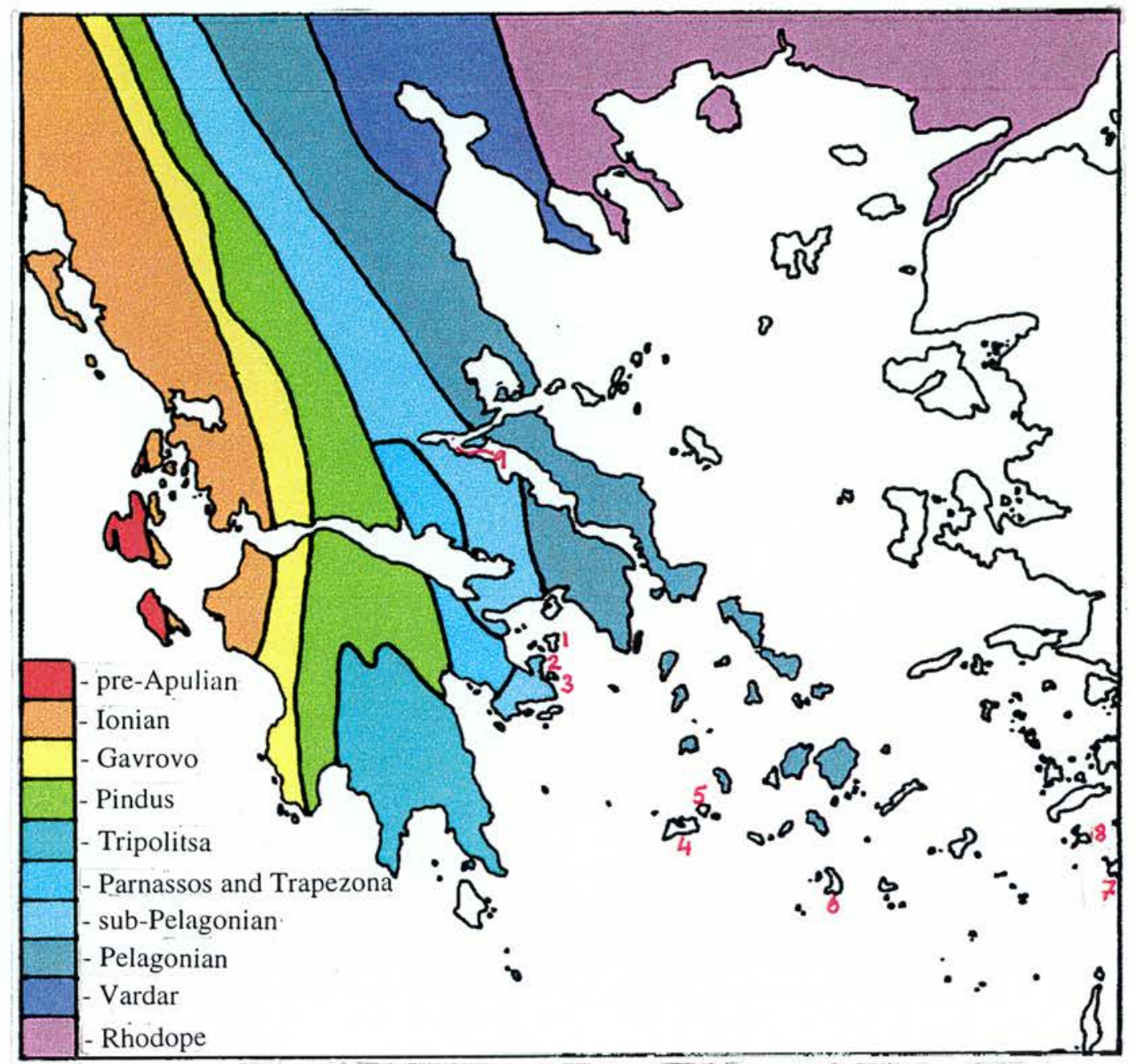

Fig. 3. The major geological zones of Greece.

Note how the geological zones form long belts running from the northwest to the southeast. The zones increase in age from west (left) to east (right). Of particular interest are the island chains of the Cyclades, which stretch away from, and are geologically connected to, the southeastern tips of Attica and Euboia. The red numbers, identified below, indicate islands mentioned in the text as being formed wholly or partially from volcanic material. Note how most of these lie on a line running around the outside edge of the geological block containing the Cyclades: this is a major fault line separating the Cyclades from the geological block to the south, which is known as the Aegean Plate. The southern edge of the Aegean Plate runs south of Rhodes, Karpathos, and Crete, and west of the Peloponnese, and forms the division between the pre-Apulian and Ionian zones of the islands of Zakynthos and Kephallenia.

Volcanic islands: 1 - Aigina; 2 - Methana peninsula; 3 - Kalauria; 4 - Melos; 5 - Kimolos; 6 - Thera; 7 - Telos; 8 - Nisyros; 9 - Lichades. 


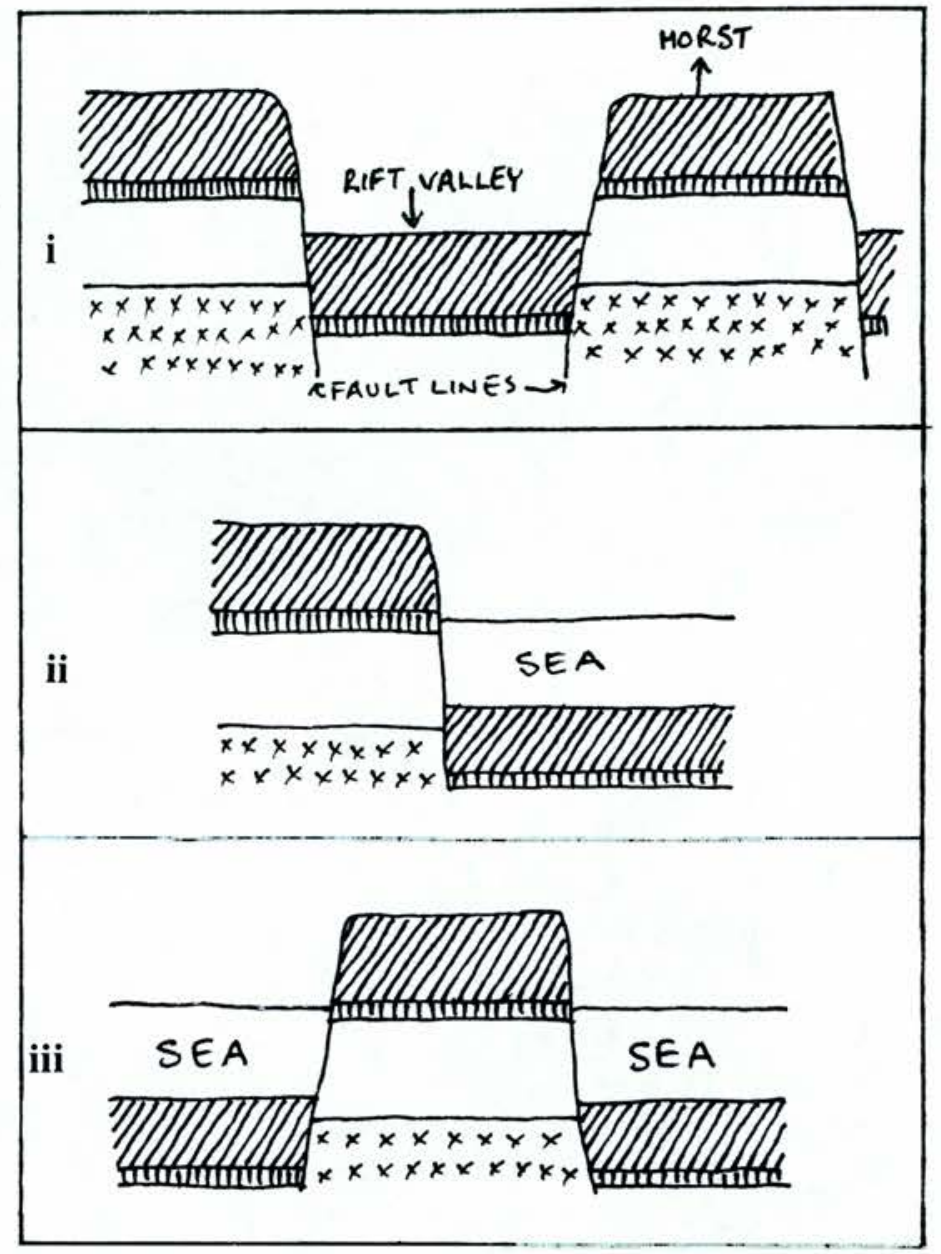

Fig. 4. Fault-related topography.

i : faulting: uplift produces horsts, subsidence produces rift valleys.

ii : submergence: inundation of a simple fault produces faulted cliff coastline.

iii : submergence: inundation either side of a horst produces faulted island.

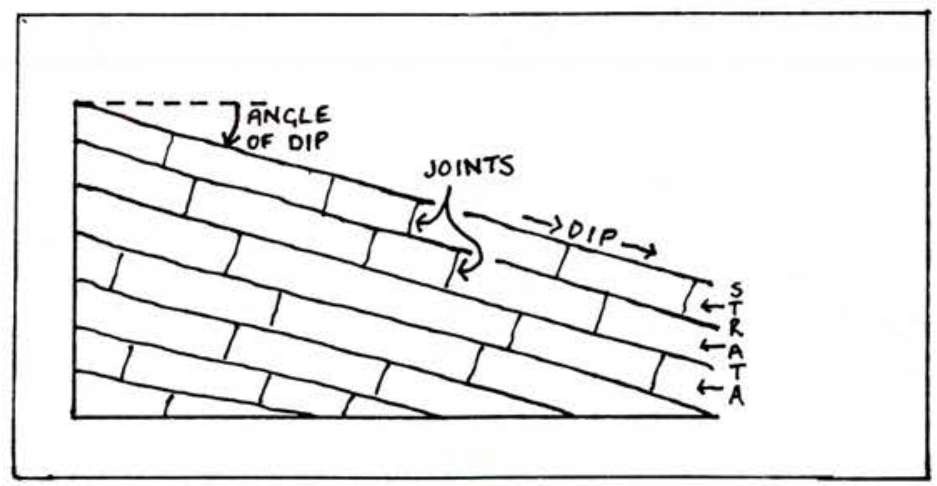

Fig. 5. Stratification, dip, and jointing in sedimentary rock. 


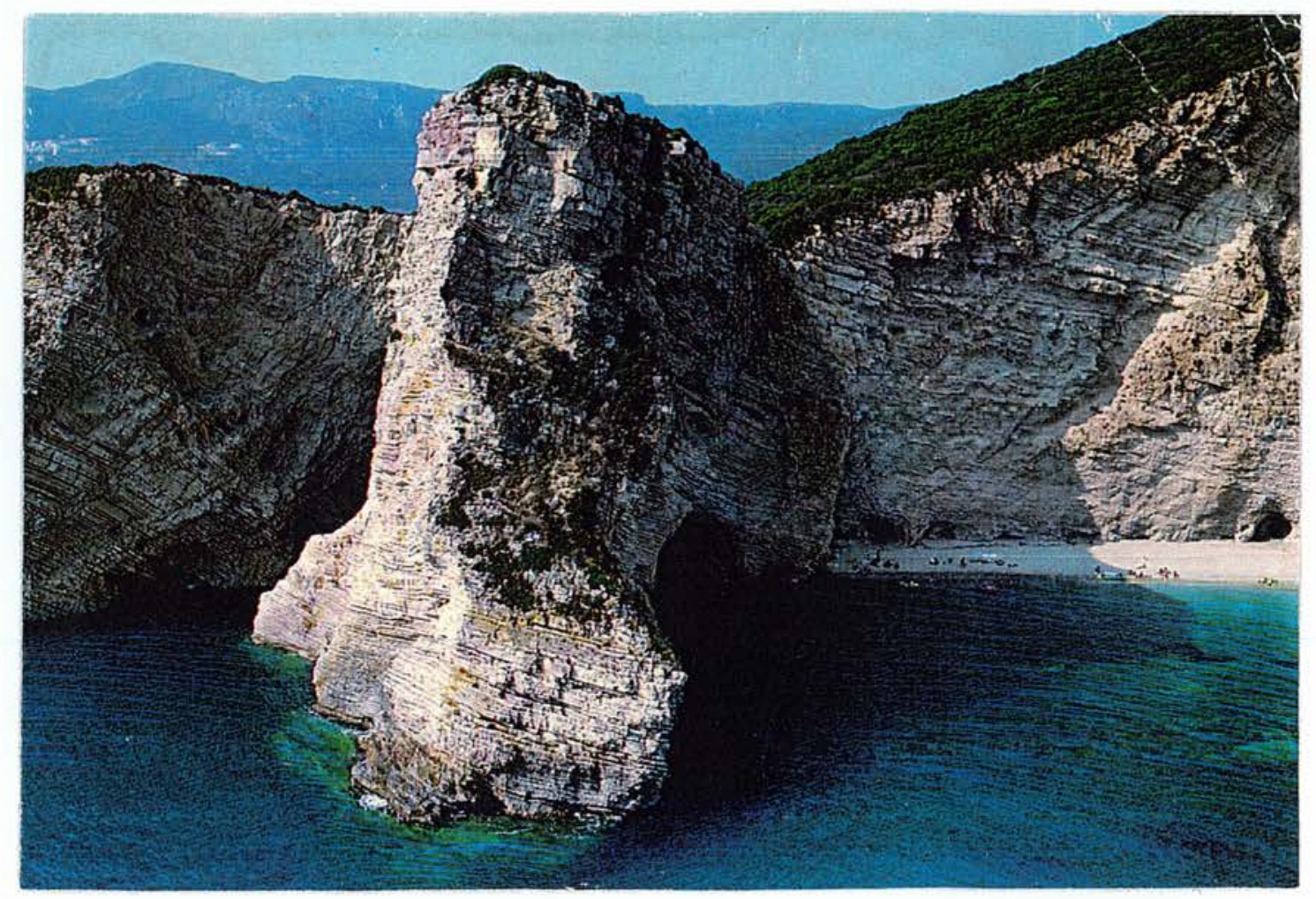

Fig. 6. Erosion features in sedimentary rock on the coast of Corcyra.

The narrow strata of the rock are dipped at a gentle angle. High cliffs have been cut by the waves, and the eroded material has been deposited offshore in the form of a marine bench. Erosion has also produced a number of marine caves, the largest of which has developed into an arch. In the shallowest areas, the water appears distinctly green. 


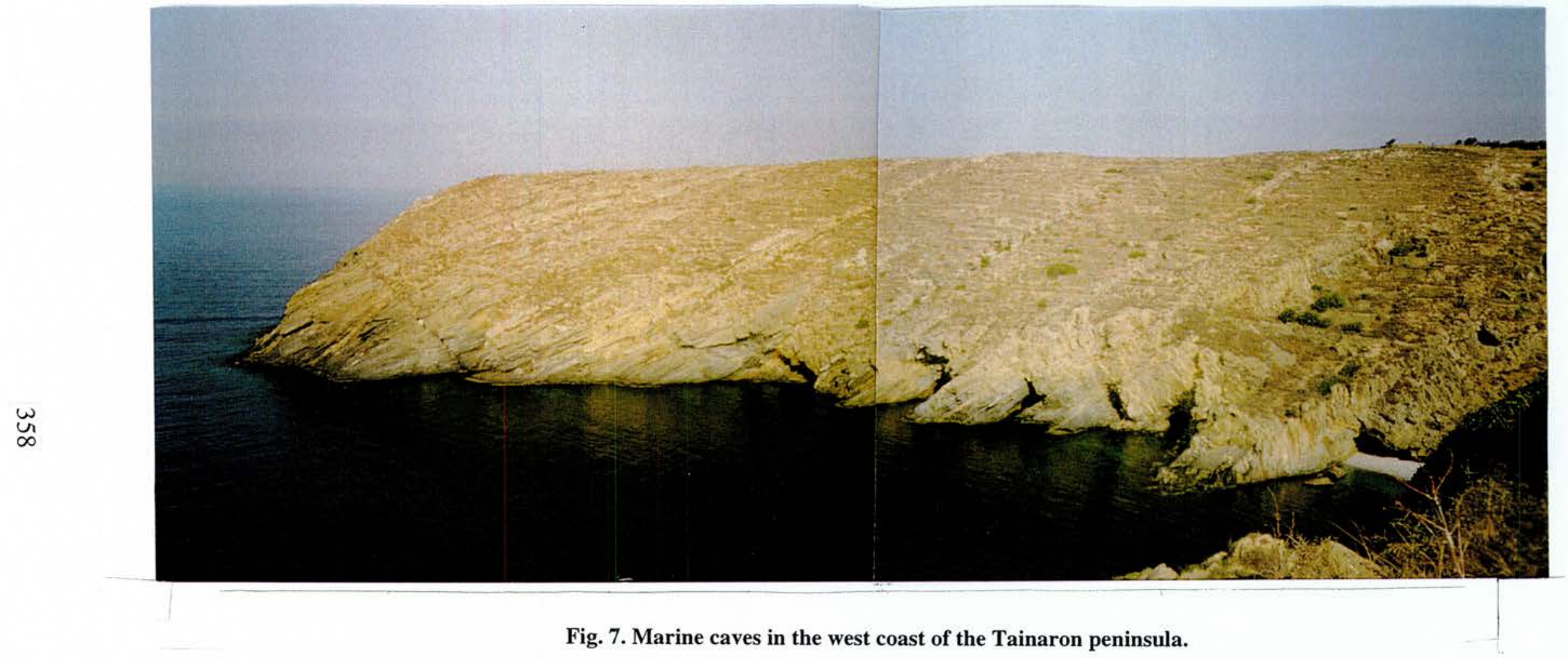

The waves have eroded marine caves at weak points in the stratification; elsewhere low cliffs are being formed. The form of the caves and the incline of the cliffs are related to the angle of dip. 


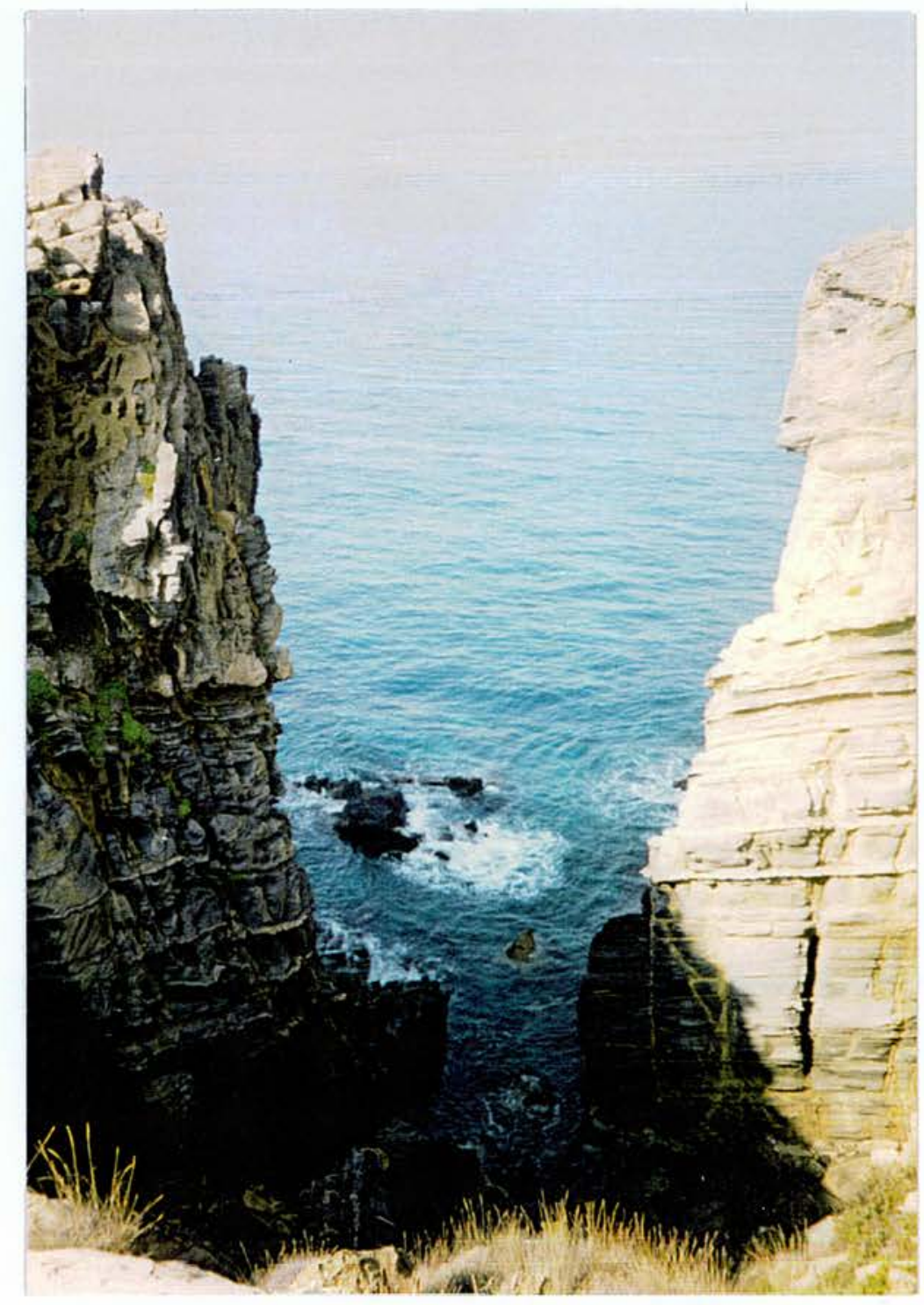

Fig. 8. A wave-cut indentation in the west coast of the Tainaron peninsula.

The rock strata, and the joints aligned at right angles to them, are clearly visible. The steepness of the cliffs is due to the minimal dip of the strata. Here a weak point in the cliff-face has been eroded out, forming a narrow rocky inlet which offers neither shelter nor access to the interior. Note that large rocks eroded from the cliff-face now lie on the short marine bench offshore, causing waves to break over them even during calm seas. 


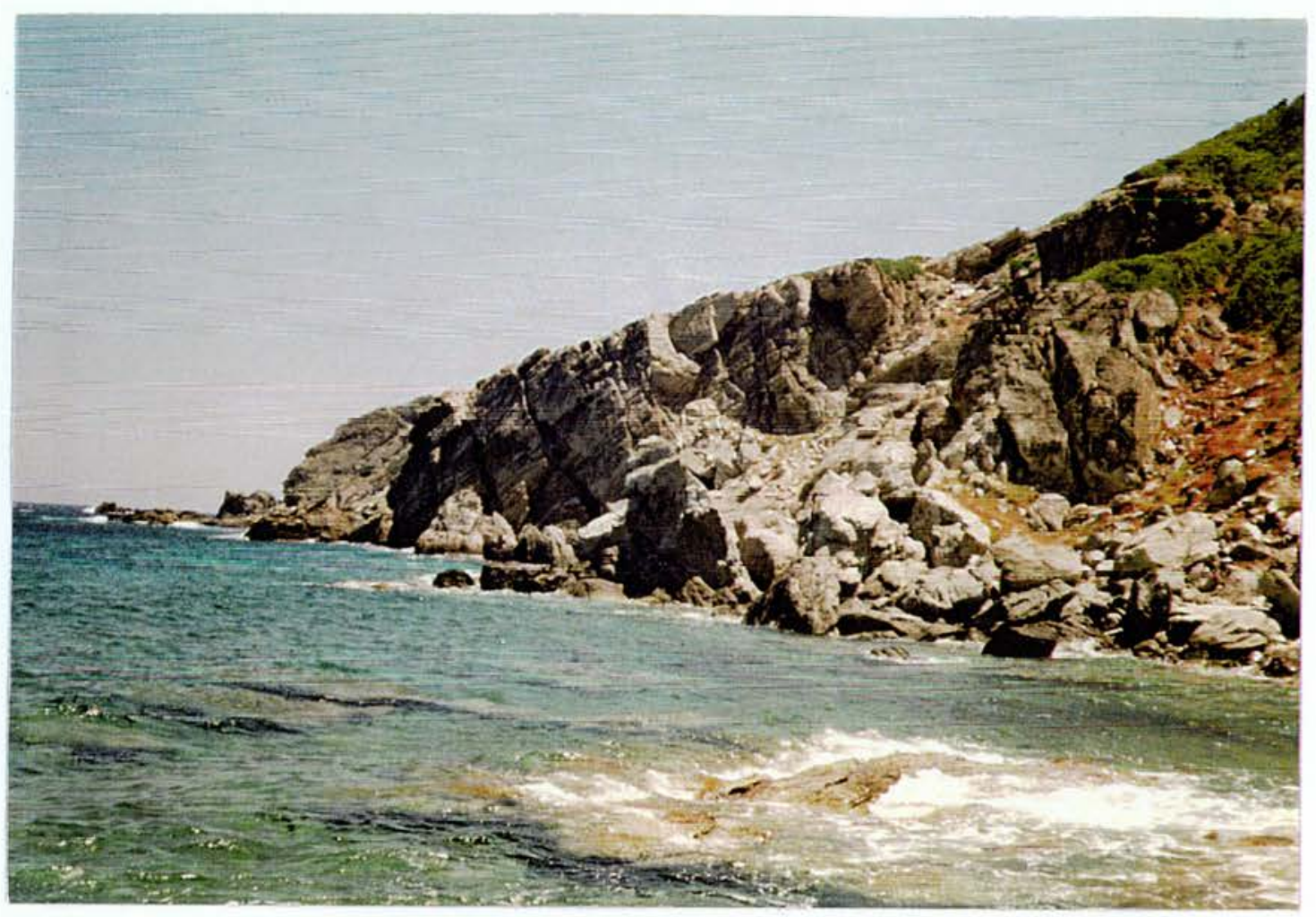

Fig. 9. Wave-cut cliffs on the northeast coast of Euboia.

Large cracks in the cliff face overlooking this small indentation indicate the positions of the joints, which lie at right angles to the rock strata. Note the rocky shelf just below sea level, upon which lies material eroded from the rocky shore, making the indentation dangerous for ships, and so of little use as a place of shelter. 


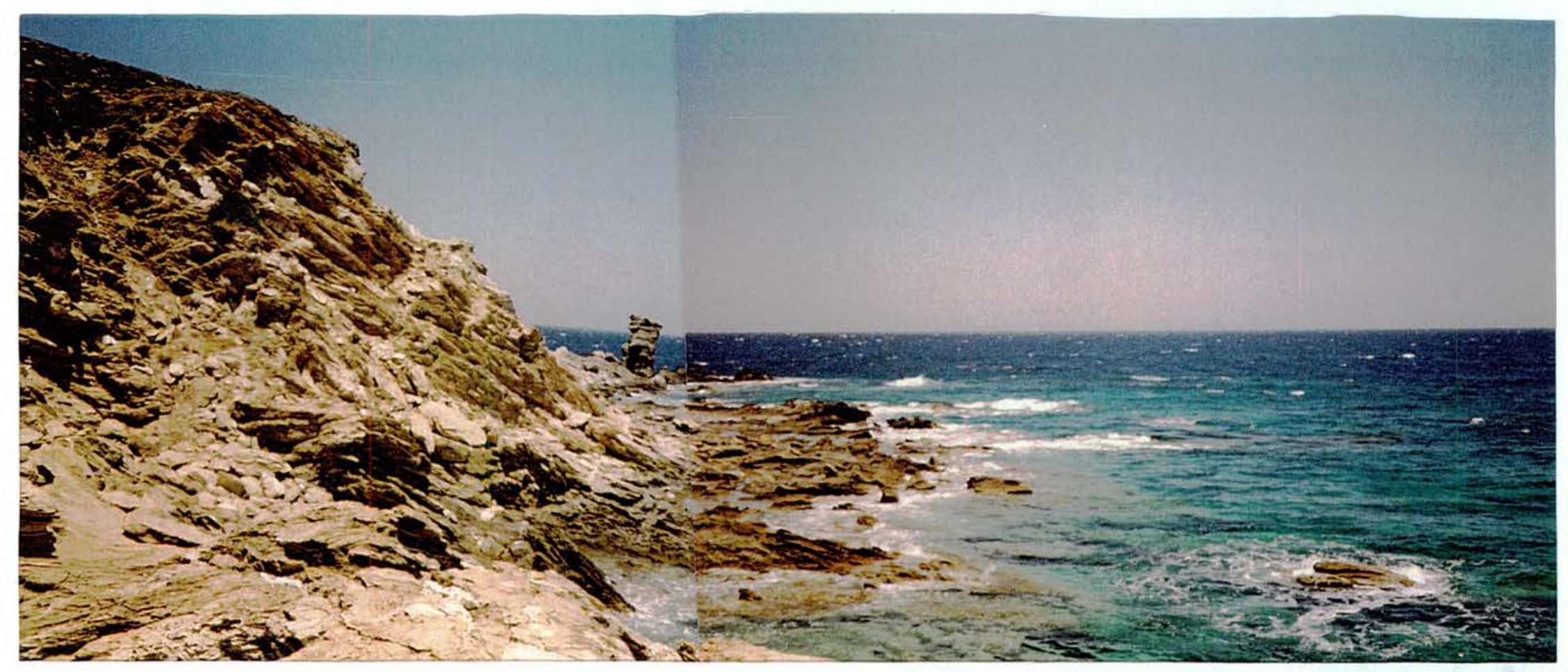

Fig. 10. Erosion features on the northeast coast of Euboia.

The rough cliffs and rocky shelf are the result of the marine erosion of the hill slopes running down to the sea; one section of rock on the shelf has resisted erosion and remains standing in the form of a stack. Note how the incline of the cliffs is related to the angle of dip in the stratified rock, and also that the shallow water covering the rocky shelf appears distinctly light and green in contrast to the darker and bluer colour of the deeper offshore water. 

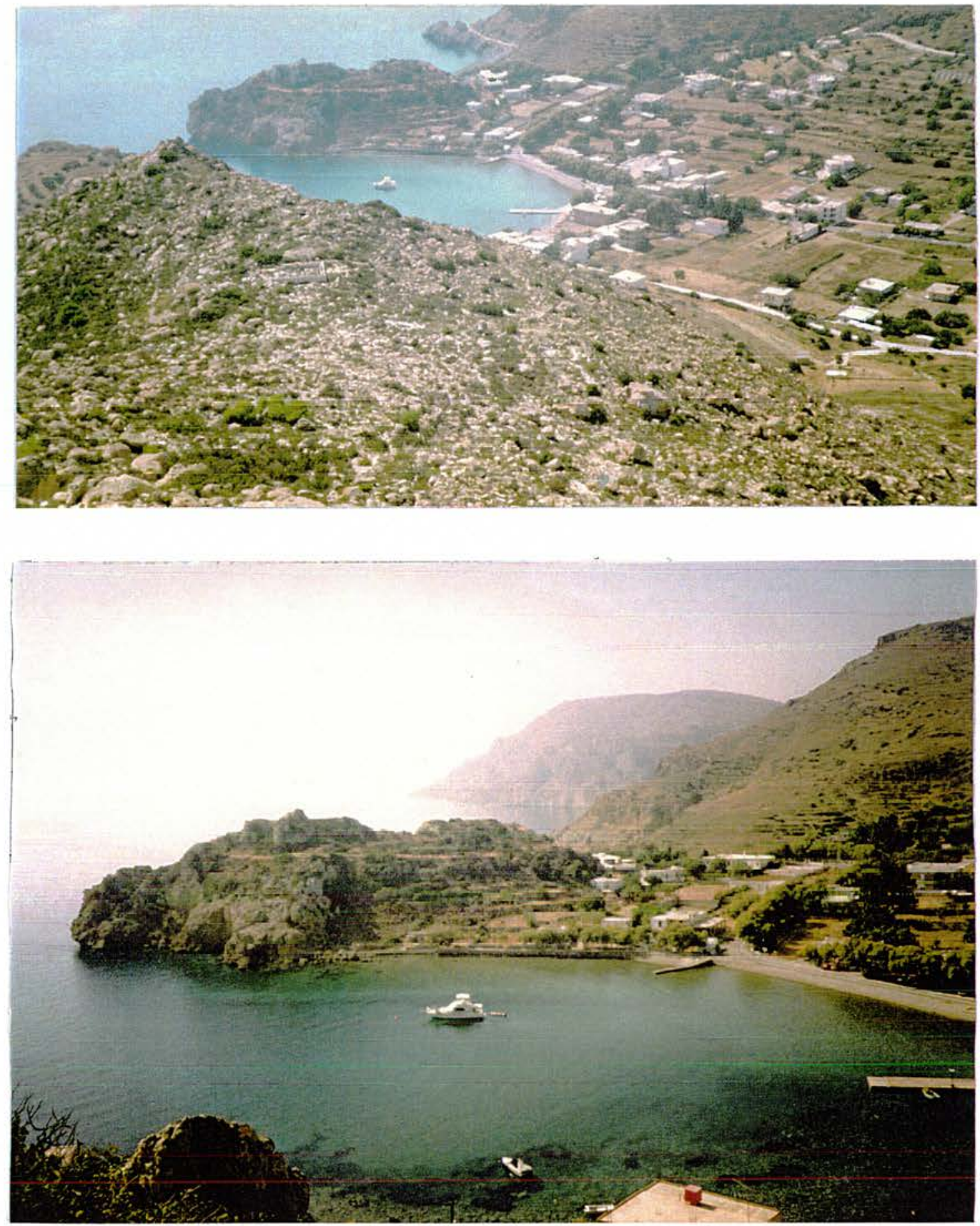

Fig. 11. The natural harbour of Emborio, Chios, from the slopes of Prophetes Ilias to the NE.

The softer rock and earth of the valley has been eroded, forming a bay, while outcrops of harder rock have resisted erosion and so form the headlands flanking, and protecting, the bay. The extremity of the headland seen here has been undercut, a notch having been eroded at sea level by the waves. Note the contrast between the steep slopes at the mouth of the bay and the gentle contours at the head of the bay; these characteristics made the inlet an excellent harbour, with sheltered, shallow water and easy access to the interior. 


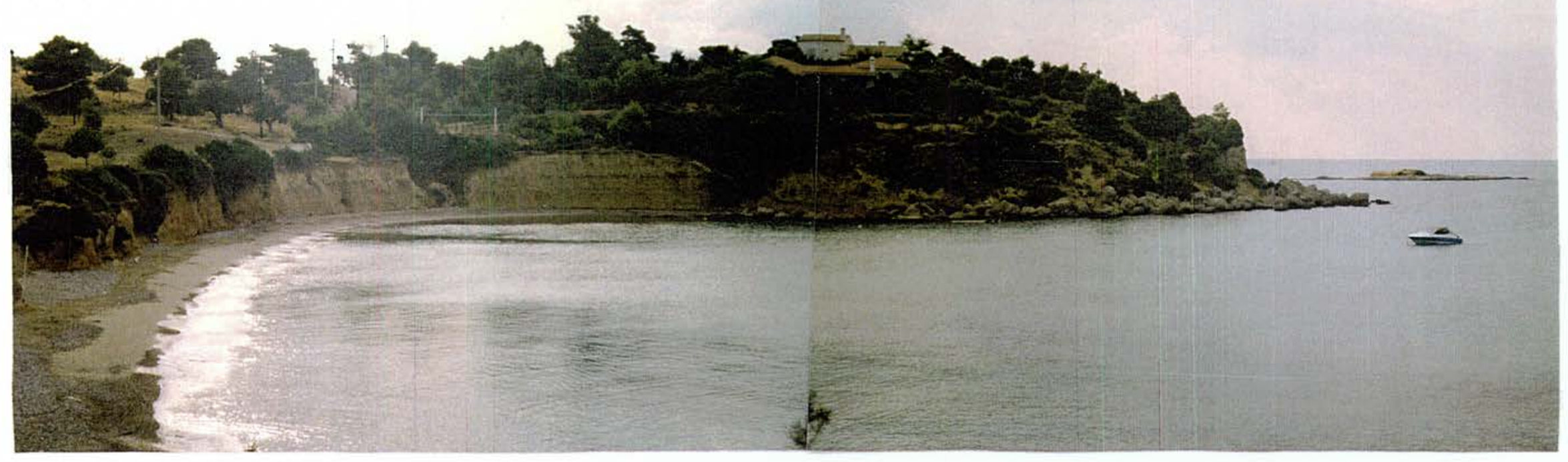

Fig. 12. A bay eroded from the coast of the Argolic peninsula, east of Porto Cheli.

While an outcrop of harder rock, being relatively resistant to erosion, has survived to form a headland, the softer earth and rock nearby has been heavily eroded, forming a bay. Note the loose rocks lying around the extremity of the headland, from which they gradually have been eroded. 

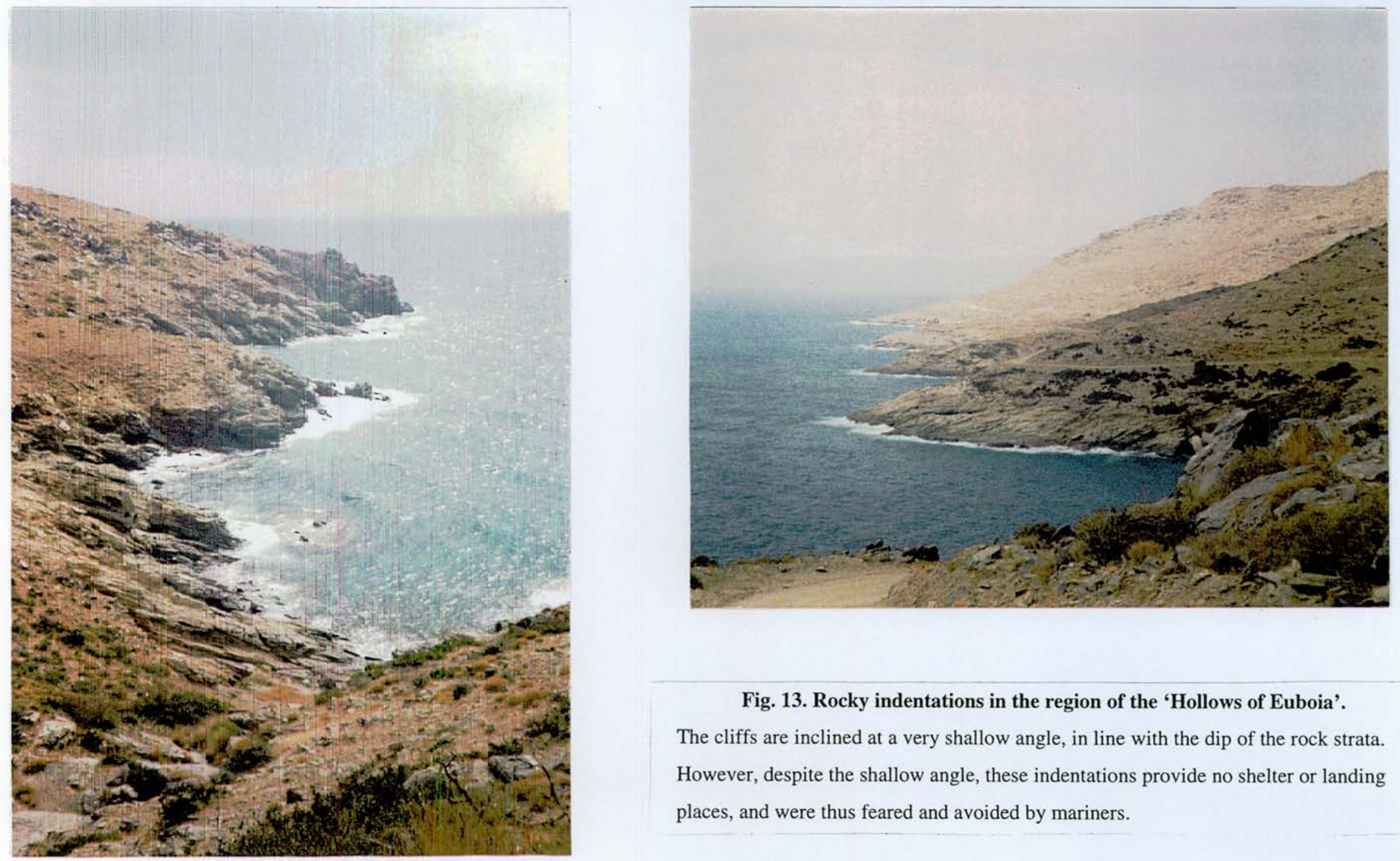

Fig. 13. Rocky indentations in the region of the 'Hollows of Euboia'.

The cliffs are inclined at a very shallow angle, in line with the dip of the rock strata.

However, despite the shallow angle, these indentations provide no shelter or landing places, and were thus feared and avoided by mariners. 


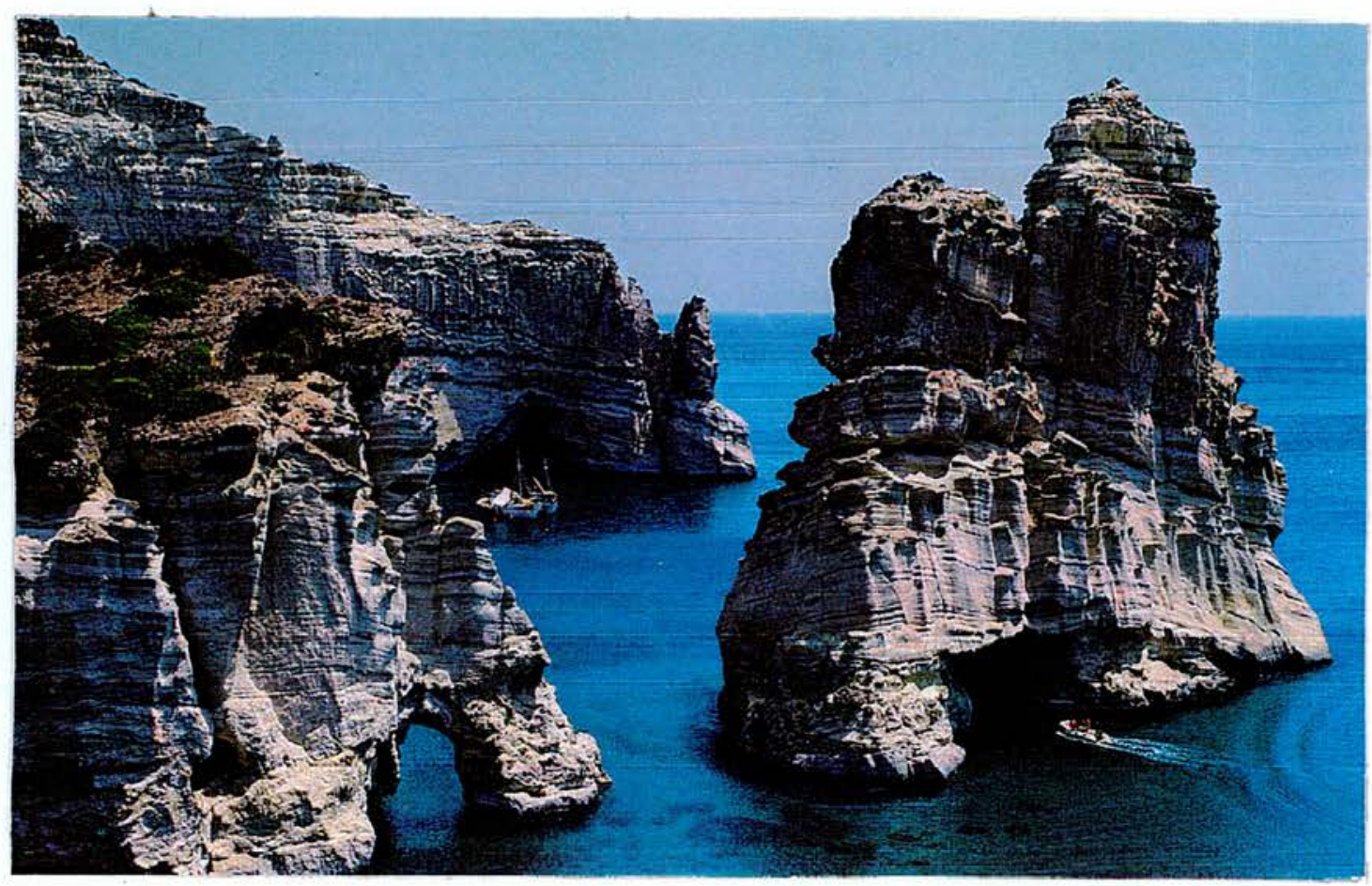

Fig. 14. A section of the coast of Melos, composed of heavily eroded stratified rock. In the foreground, the erosion of joints and other weak points in the rock has resulted in the formation of marine caves, arches, and a large stack. In the background, a pinnacle is in the process of being formed as a joint is gradually eroded. As a result of the almost horizontal dip of the rock strata, the cliffs formed through erosion are nearly vertical, and have rough contours. 

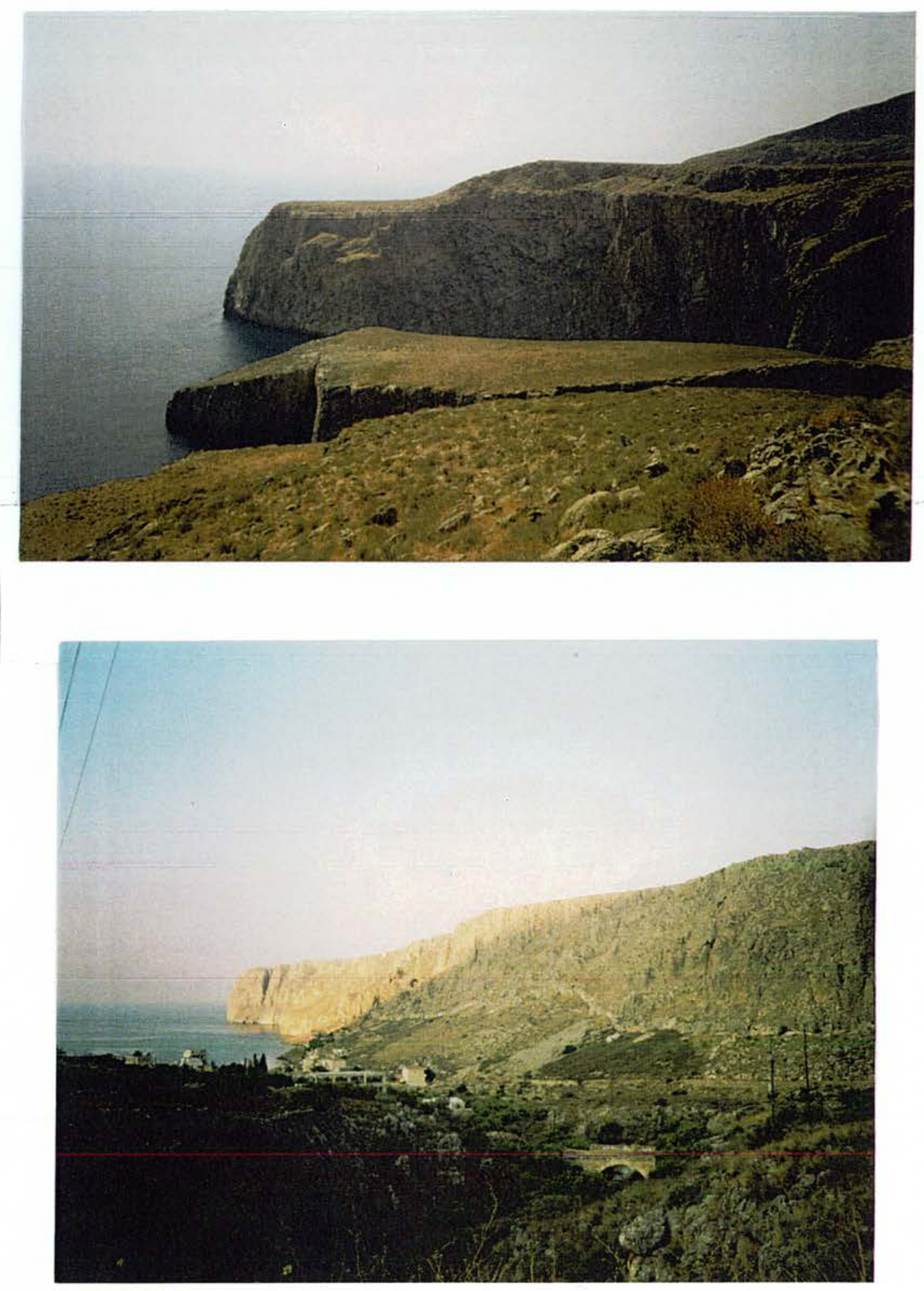

Fig. 15. Faulted cliffs in the region of Thyrides (Cave Grosso), Taygetos peninsula.

That the cliffs are faulted is most clearly demonstrated in the lower picture, where the fault extends across both land and sea. Material eroded from the cliff face piles up at the base of the cliffs, but where the cliffs drop into the sea, they fall away immediately to great depth, so that none of the eroded material remains at, or even near, the surface. 


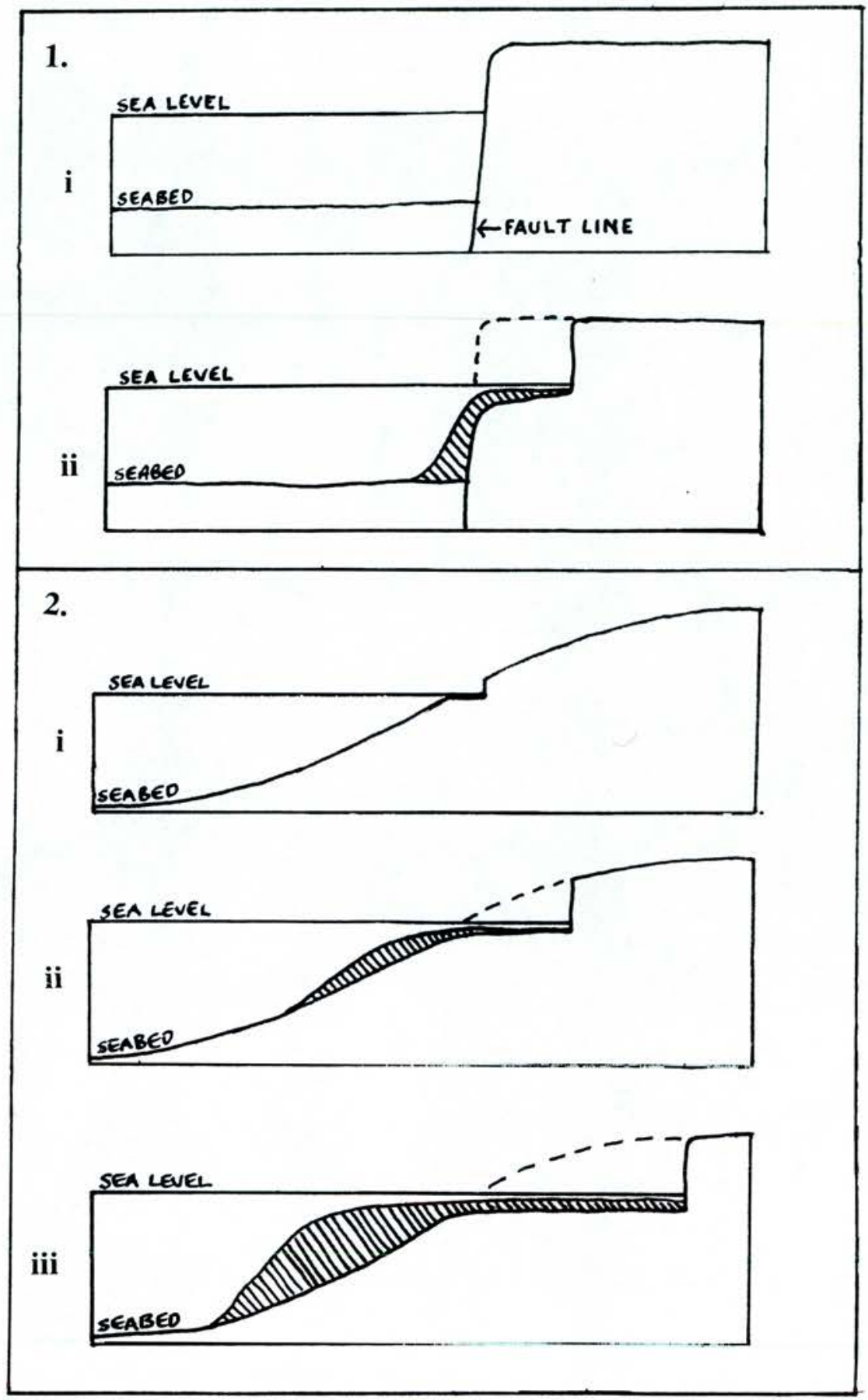

Fig.16. Formation of wave-cut cliffs.

1. Faulted cliff coastline (i) is relatively slowly eroded backwards from sea level up (ii), producing a wave-cut platform, over which material eroded from the cliffs is deposited, forming a marine bench.

2. Submerged coastline is eroded at sea level (i); erosion proceeds relatively rapidly, forming cliffs, in front of which eroded material gradually builds up (ii). As erosion proceeds (iii), a long wave-cut platform strewn with eroded debris develops. 


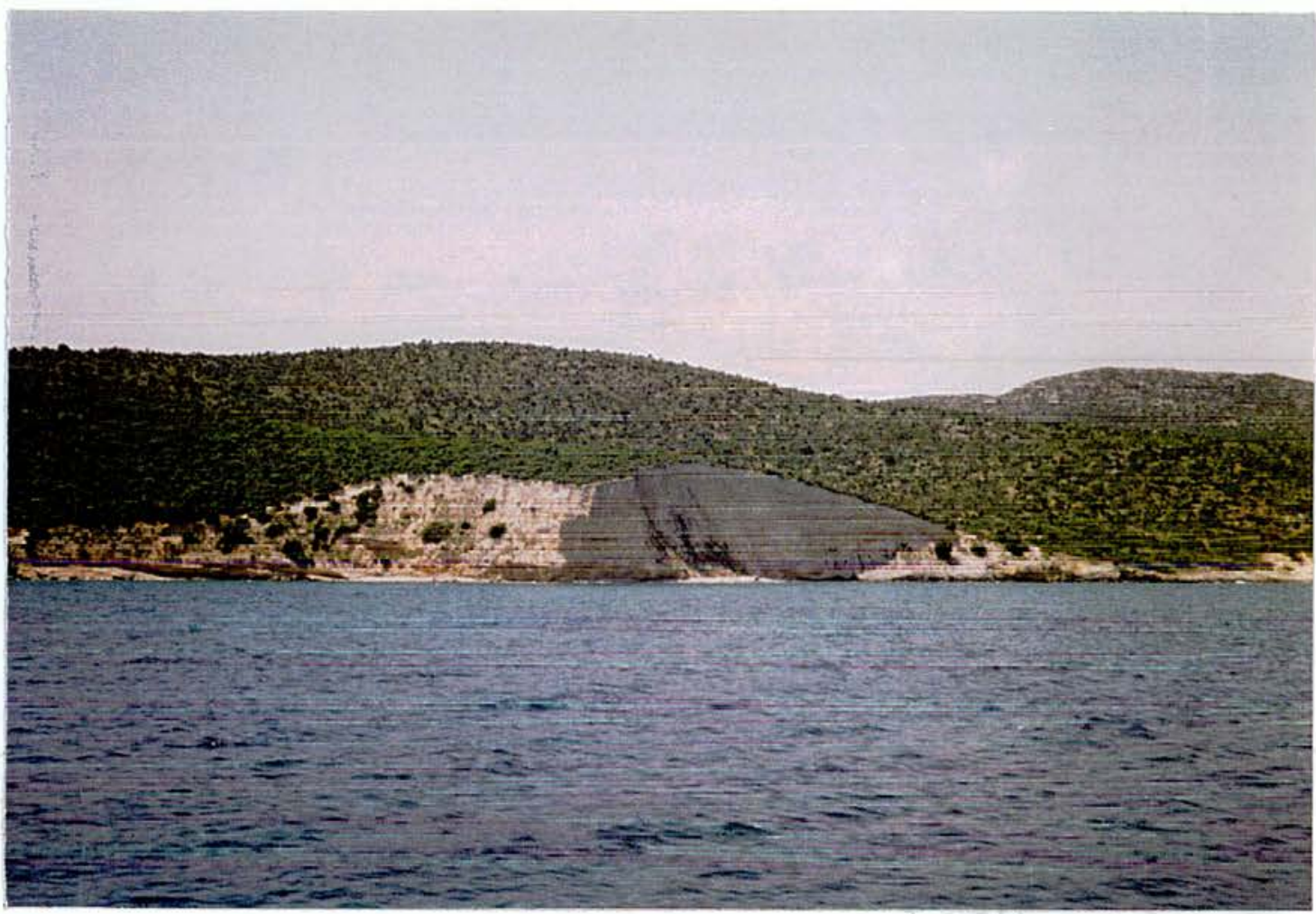

Fig. 17. Wave-cut cliffs south of Cape Paraskevi in the northwest Euboian Sound.

Note how only the more prominent part of the coastal hill-slope, which once would have formed a low headland, has been eroded; the more sheltered and indented area to the right remains relatively unaffected. Some undercutting is visible at the centre of the picture, and also at the left, where a portion of the cliff-face has recently collapsed and now lies in shallow water. 


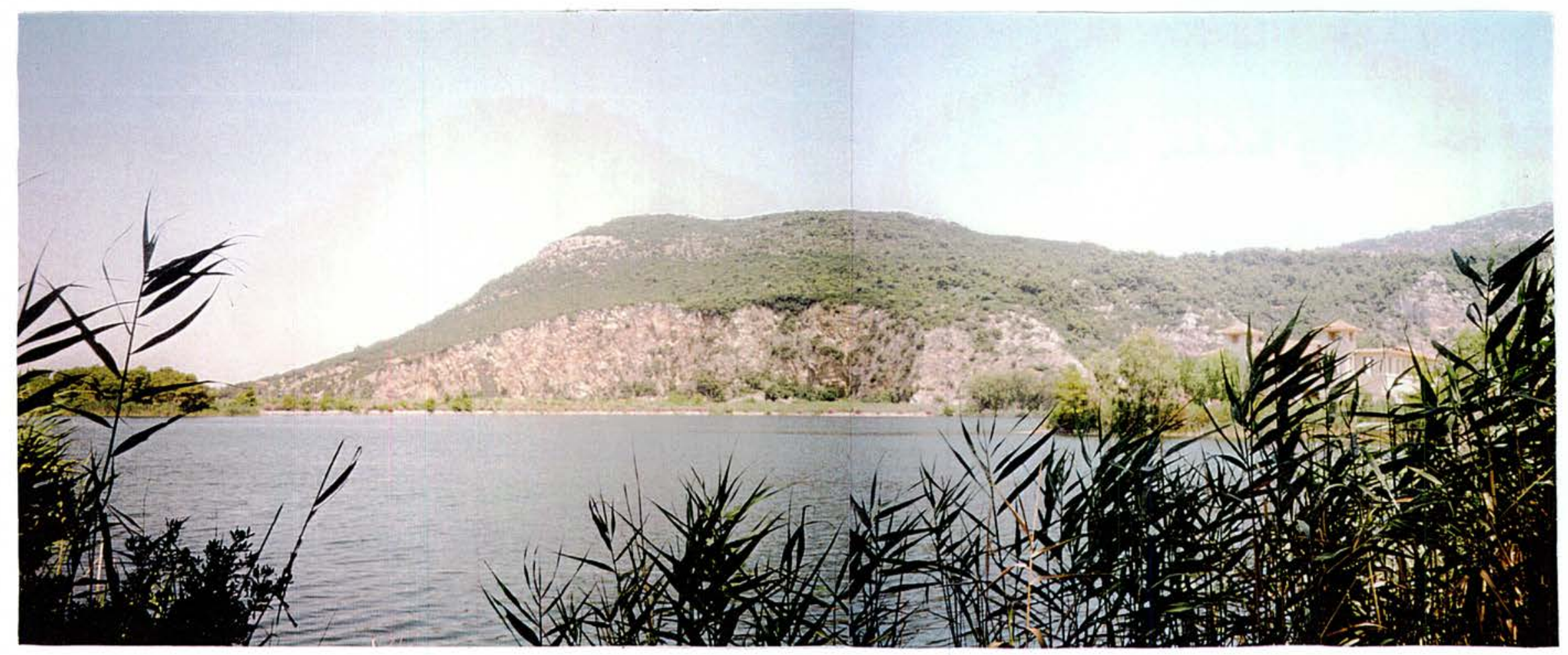

Fig. 18. The west coast of the Peloponnese, immediately south of ancient Samikon.

Samikon stood on the slopes on the far side of this mountain ridge, which is the only high terrain on a coast which is otherwise low and depositional for many miles in both directions. The presence of wave-cut cliffs, the 'Achaiai', show that the ridge was once a promontory washed by the sea; continuous deposition, however, has led to the formation of lagoons (as seen here) and mud flats, which now surround the ridge and cut it off from the sea. Generally shallow, inaccessible, and exposed to the wind, such flat coasts rarely provided good harbourage for ships. Strabo $($ Geog.8.3.13, 20) locates the Triphylians' temple of Poseidon in the vicinity of these cliffs. 


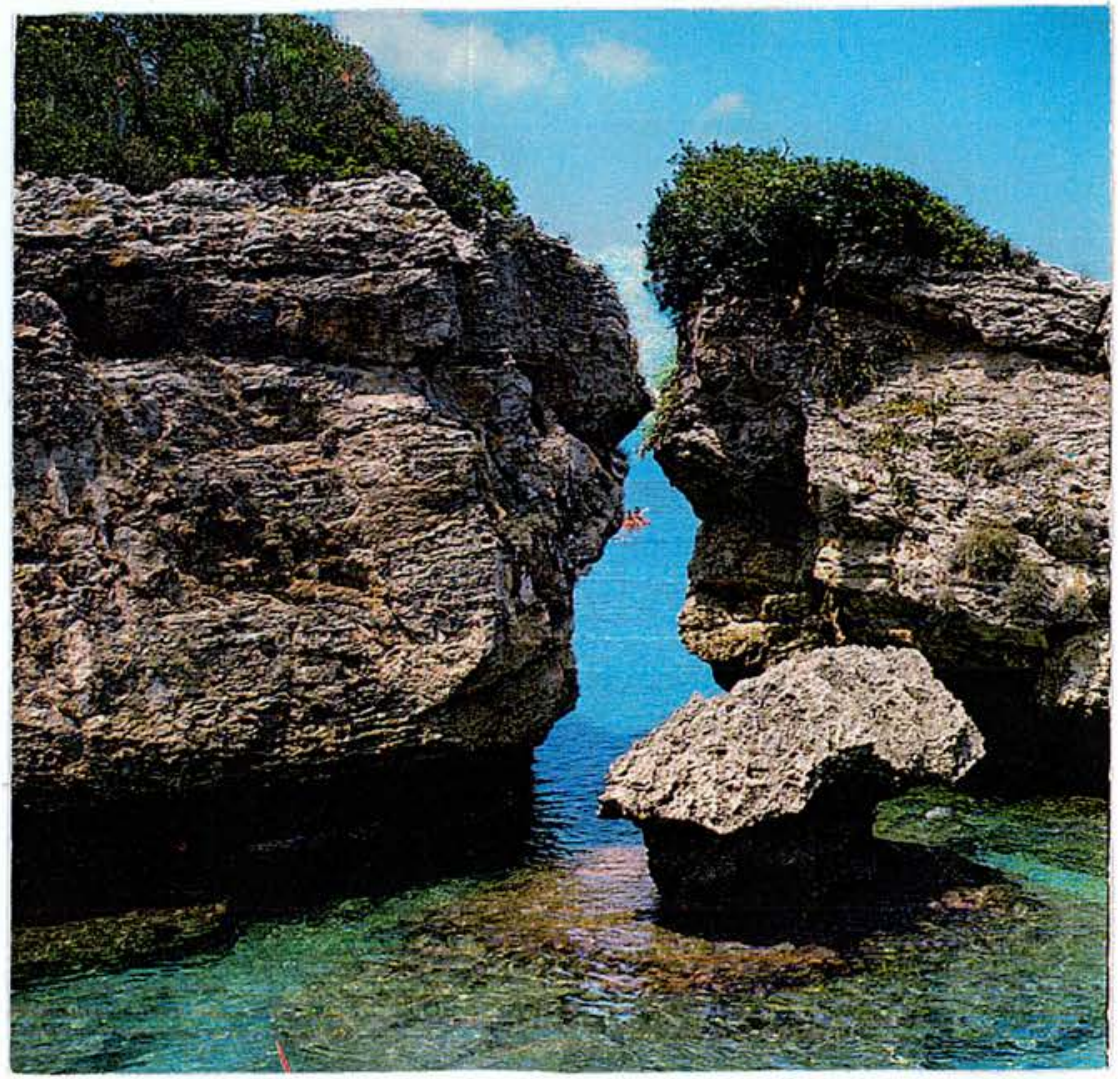

Fig. 19. Undercutting in the rocky coast of Zakynthos.

Note how erosion has the heaviest effect at sea level, where a notch is cut, undermining the rock above and leaving a platform of rock under the surface of the water, where erosion is far less advanced. 


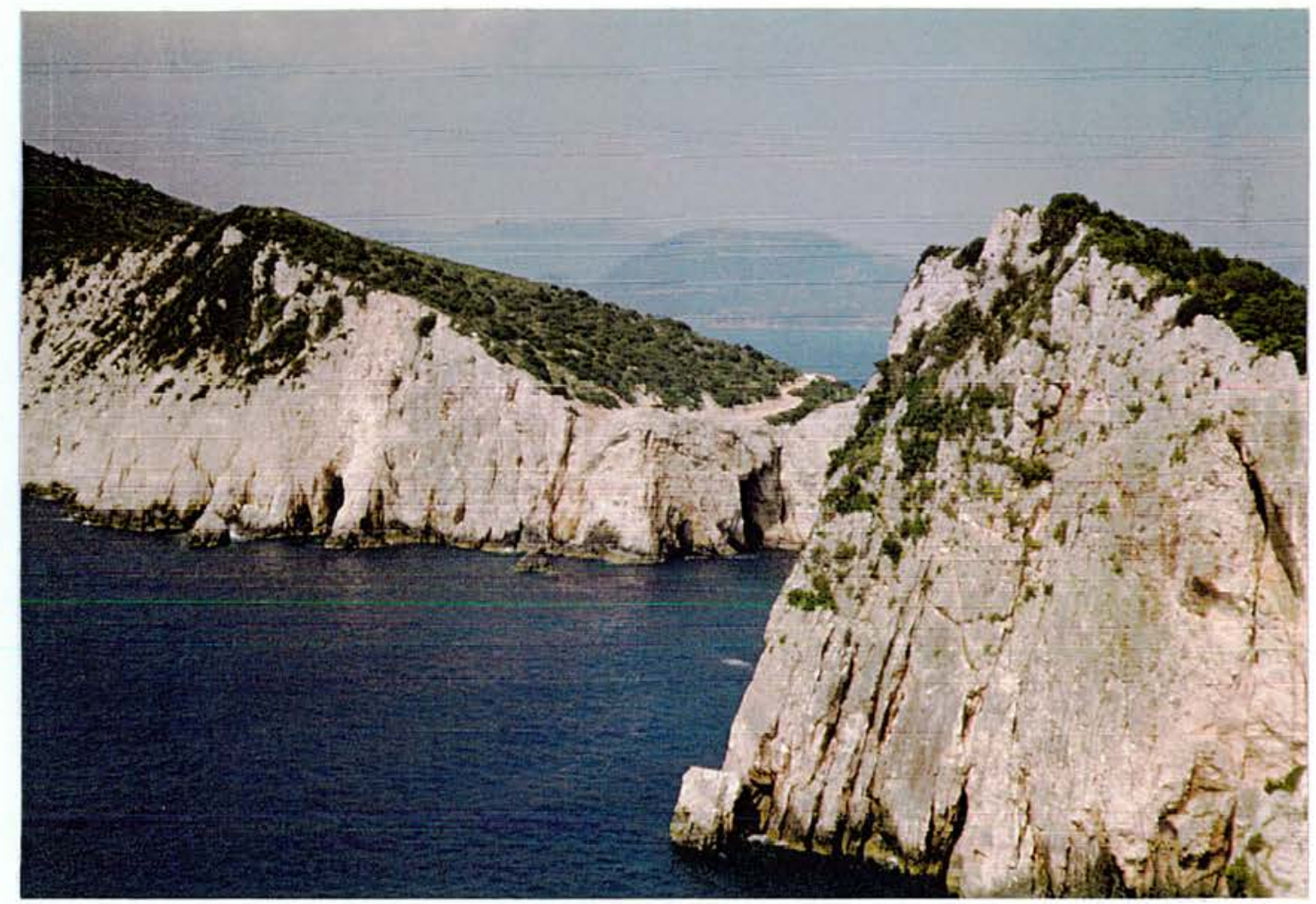

Fig. 20. The white cliffs of Leukatas, the southerly promontory of Leukas.

Erosion is most advanced at the vertical joints, and in some cases marine caves are forming. The height of the faulted cliffs, and their white colour, made them an excellent landmark for sailors approaching from the Adriatic sea. 


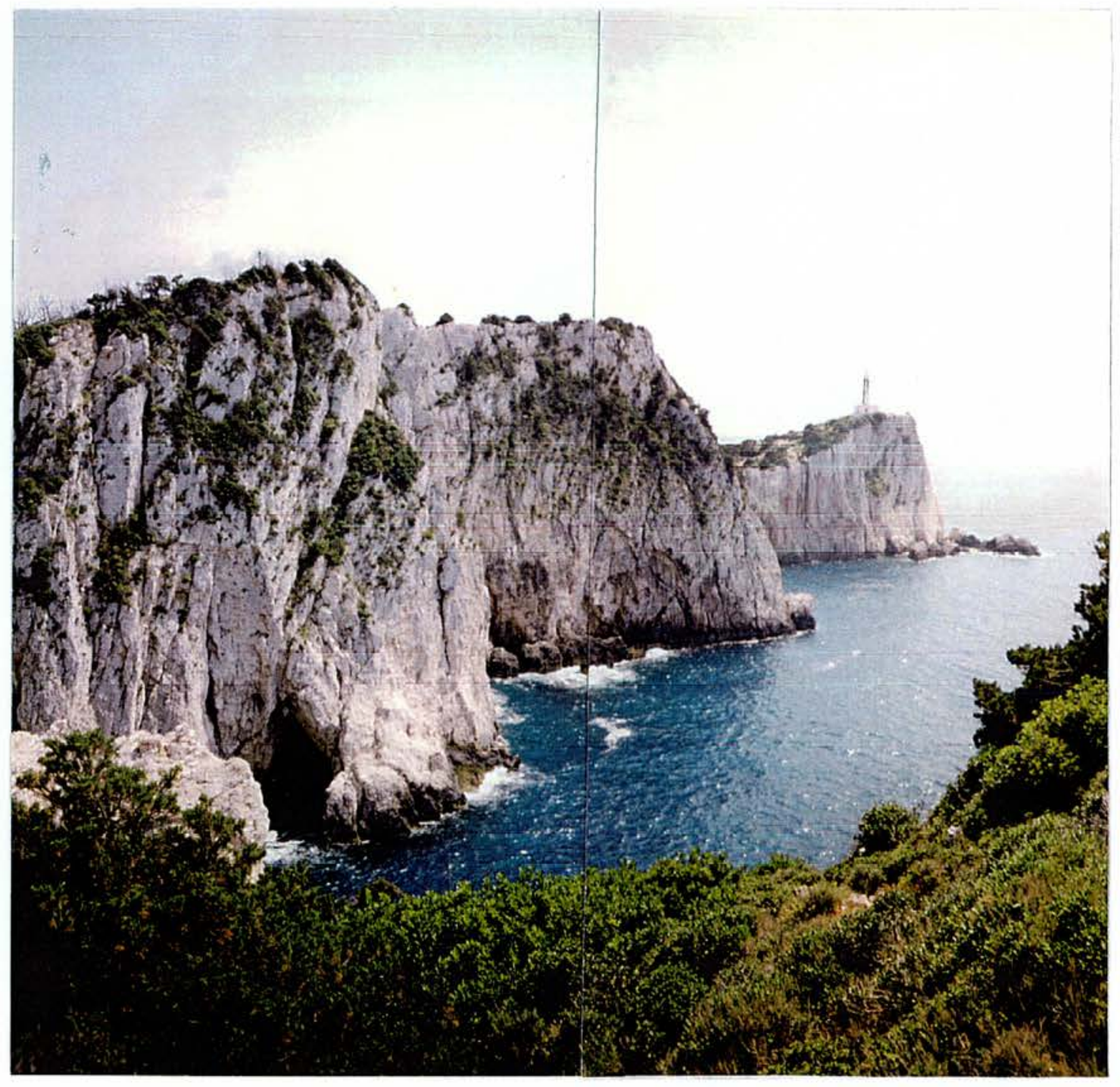

Fig. 21. The headland of Leukatas, the southern tip of Leukas.

The erosion of this faulted promontory has left rocks broken away from the cliff-face lying on a short marine shelf, which drops away into deep water only a short distance from the cliffs. Here stood a temple of Apollo which, along with the bright cliffs themselves, acted as a landmark for sailors. 


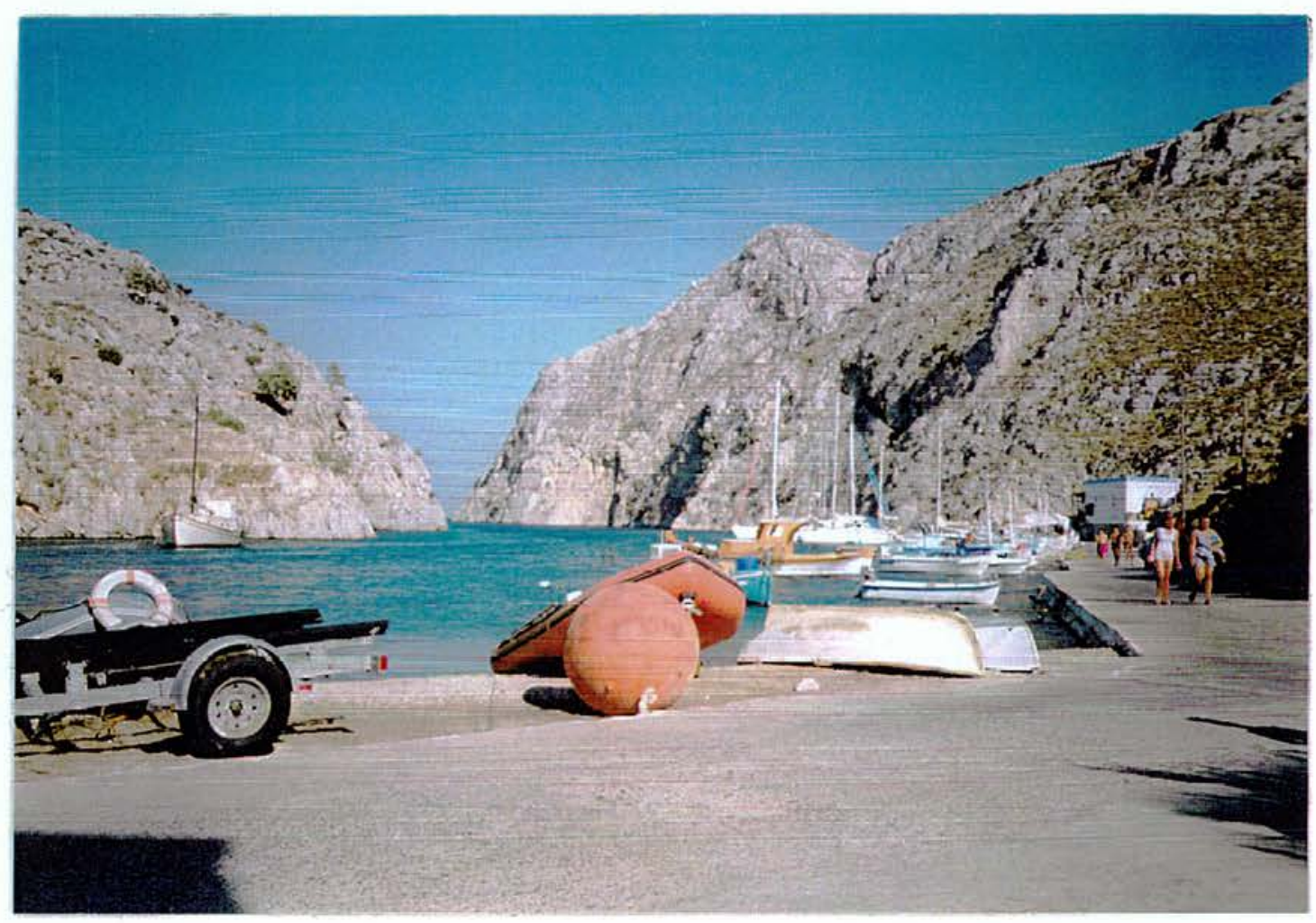

Fig. 22. The natural harbour at Vathy, Kalymnos.

Faulting has produced a deep valley between neighbouring steep mountain ridges: at the coast, the sea has inundated part of the valley, forming a well-sheltered natural harbour. The inlet is protected by high and steep cliffs on either side, but leads to a gentle beach which facilitates landing and gives access to the interior. 
Fig. 23. The harbours at (i) the Piraeus, (ii) Kophos Limen (Chalkidike), and (iii) Porto Kaio.

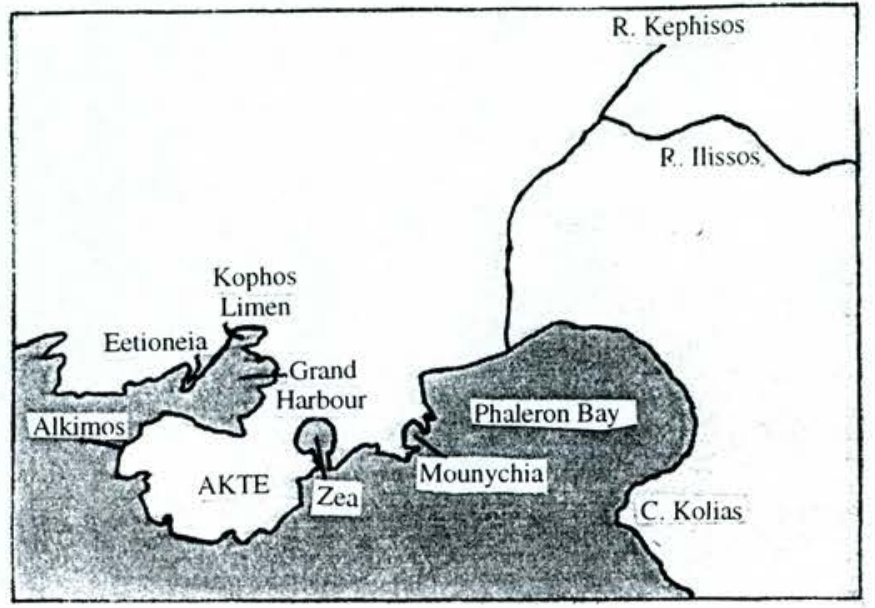

i. The small natural harbours of Zea and Mounychia gave excellent shelter and protection from most winds, including the westerlies to which the Grand Harbour may have been exposed. The Kophos Limen, in a recess of the Grand Harbour, was particularly well protected. Taken together, the three harbours, along with Phaleron bay, could provide shelter from any wind.
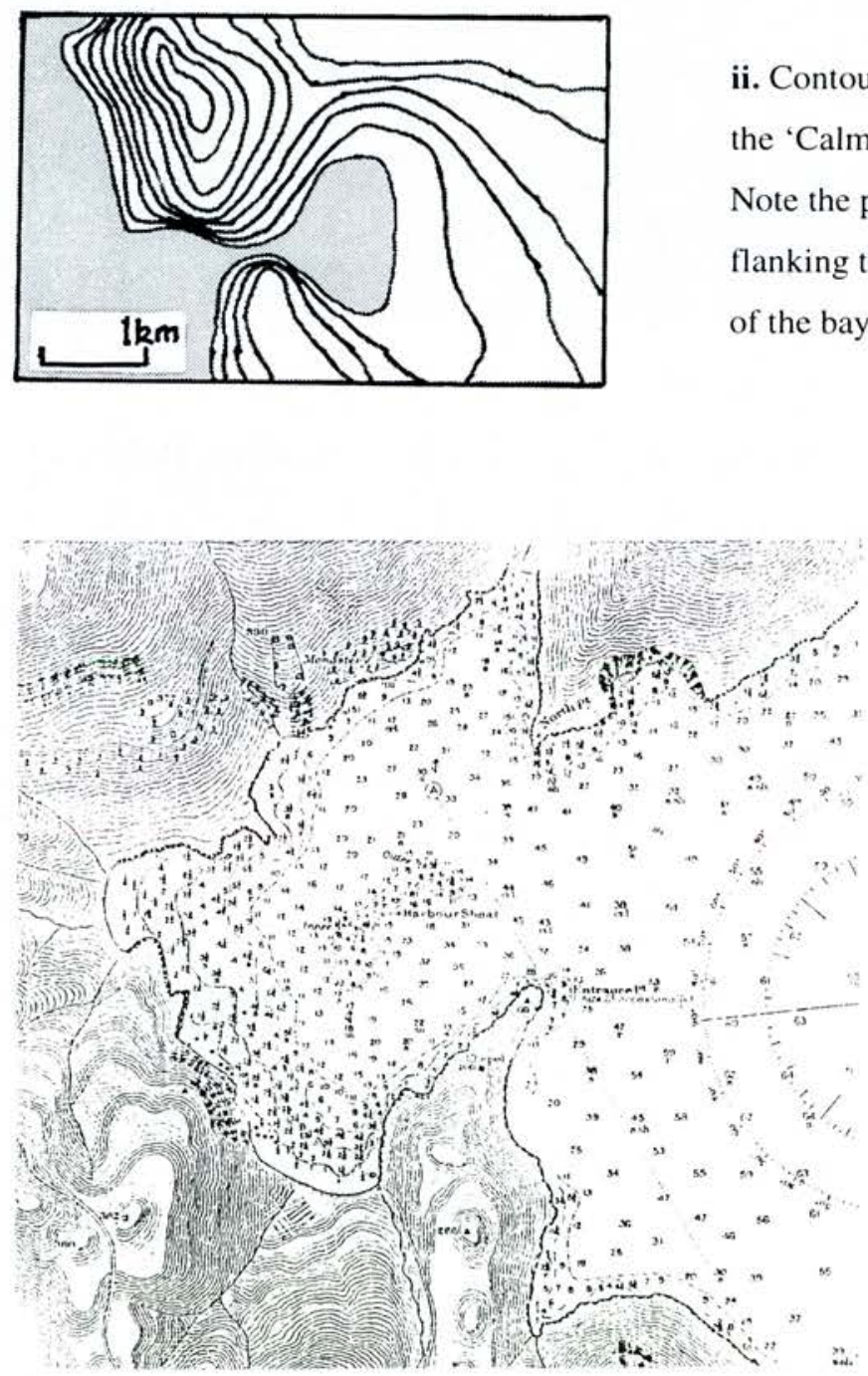

iii. Porto Kaio in the east coast of the Tainaron peninsula (Admiralty chart 3342, (1902)). The rounded bay is protected by two rocky headlands which narrow the entrance from the sea. However, entrance to this well-protected harbour is complicated by the rocky shoal just inside the harbour. 
Fig. 24. The 'double harbours' of (i) Corcyra and (ii) Sinope.

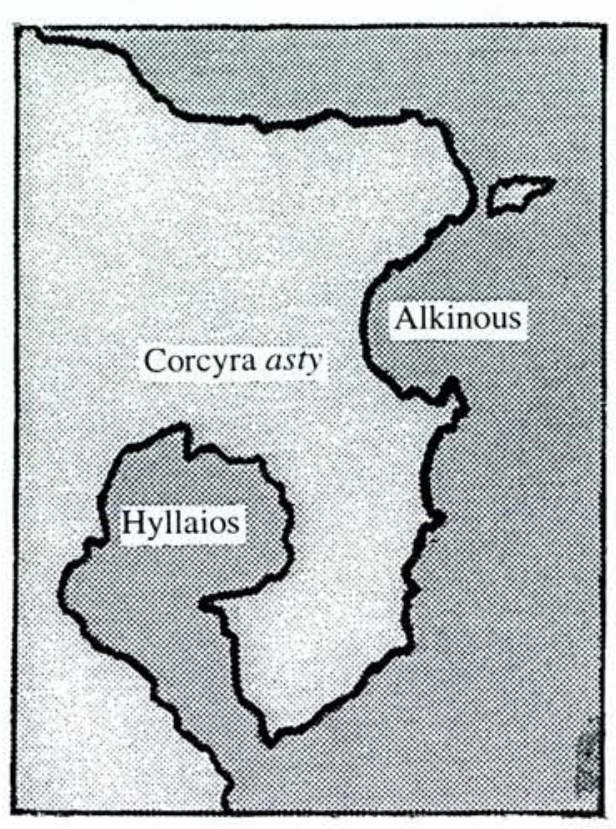

i. On the east coast of Corcyra, in the relatively sheltered waters facing across the channel to the northwest coast of mainland Greece, the harbours of the island's asty were further protected by the promontory on either side of which they lay. The curving shape of the promontory left the more northerly 'harbour of Alkinous' relatively open, while the southerly Hyllaios harbour was very well sheltered, effectively forming a natural harbour. The whole area is reminiscent of Homer's description of the harbours on either side of the city of the Phaeacians, with ships moored on either side of the narrow land passage that runs between them (Hom.Od.6.262-5).

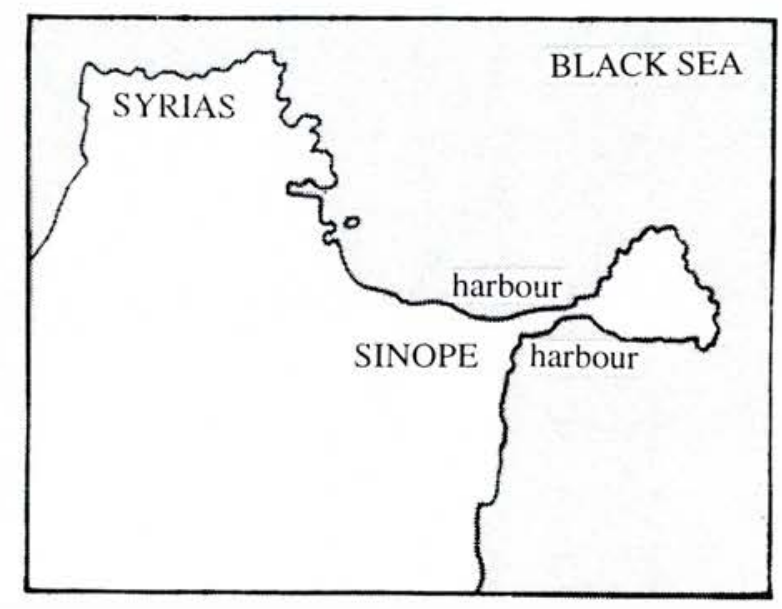

ii. At Sinope a major promontory juts out from the south coast of the Black Sea. On the east flank of this promontory, a narrow neck of land stretches out, connecting the area of the ancient town to a large mass of rock, on either side of which lay the town's harbours. The more northerly harbour lies in a large bay, protected to the west by the main headland of the promontory, and to the east by the headland of Sinope; while it is relatively exposed to the fierce northerlies which rush across the Black Sea and onto its south coast, the more southerly harbour is well sheltered from these by the headland which forms its northern boundary. 


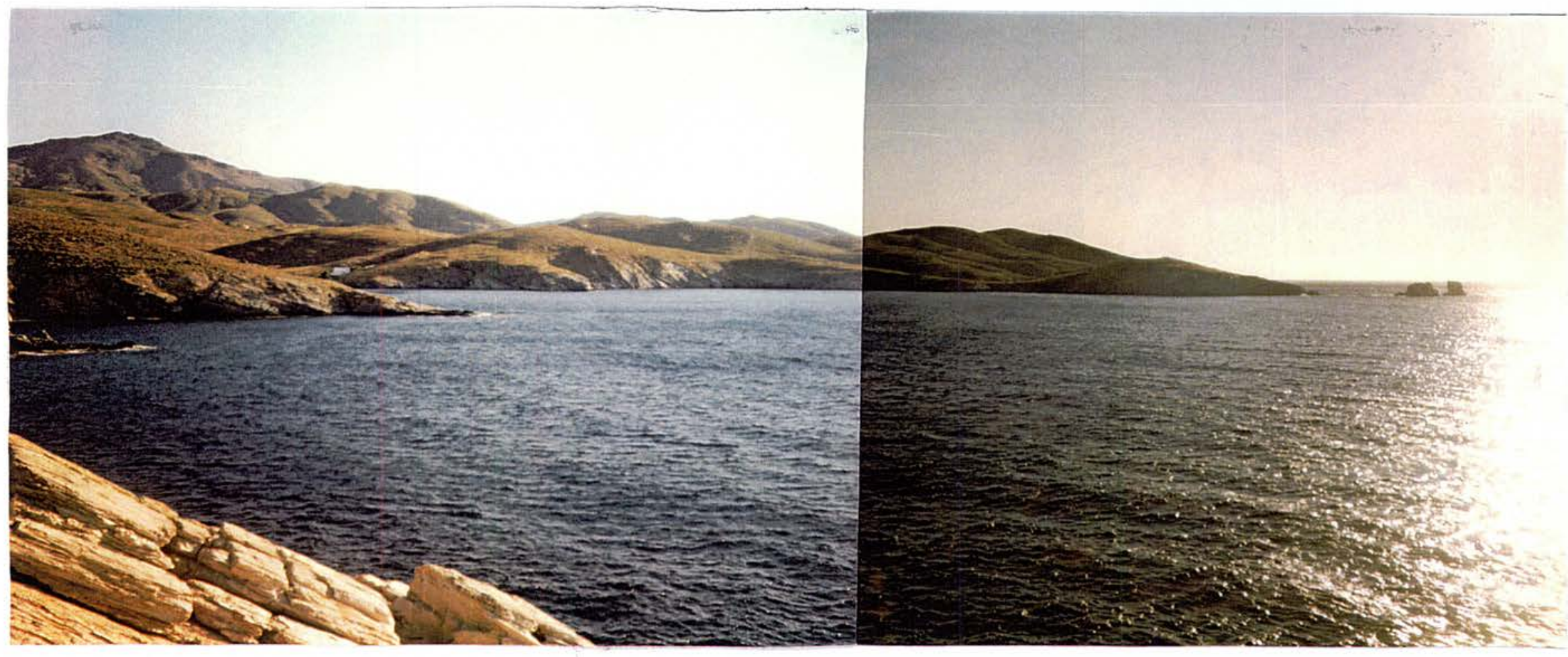

Fig. 25. The Bay of Kastri, southeast Euboia.

Kastri has been identified as ancient Geraistos, site of a sanctuary of Poseidon, and the only well sheltered bay in the region. The coast here was formed along with the Cyclades, when the whole Aegean area was inundated by the sea. The coastal rock has been eroded, gradually forming low cliffs at exposed points; two outcrops of harder rock which were originally part of the headland to the right of the picture remain standing as stacks, while the rest of the headland has been worn back some distance. At the bottom left, note the correlation between the dip of the rock strata and the incline of the low cliffs that have resulted from marine erosion. 


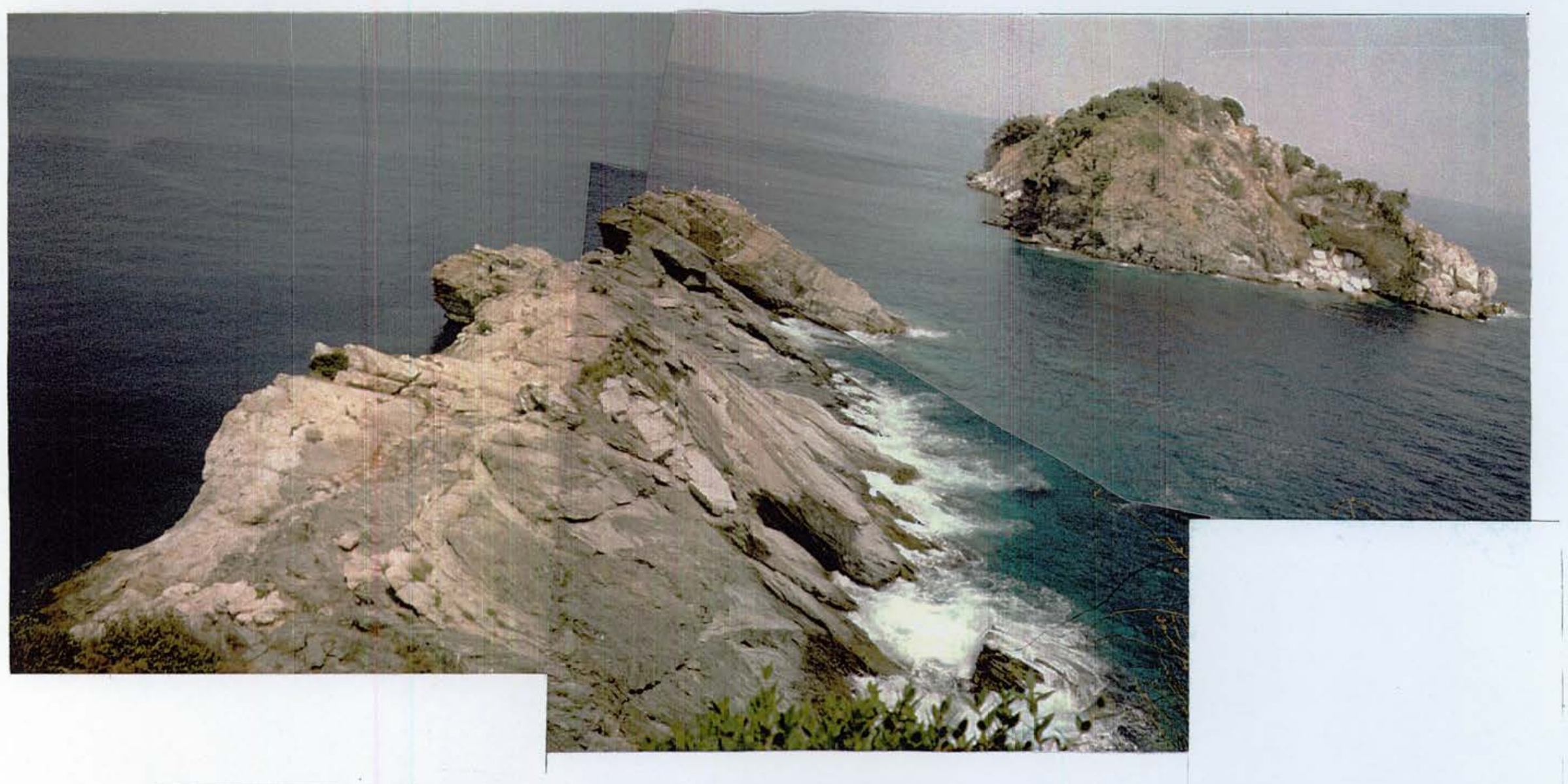

Fig. 26. Cape Gravousa, Thasos.

The rocky island standing off this headlard is typical of indented coasts where sedimentary rock is subject to erosion. Note also how even the smal. waves approaching from the right break forcefully against the exposed side of the promontory, but become totally dissipated as they are refracted arcund the headland, so that nore break against the sheltered side of the promontory. 


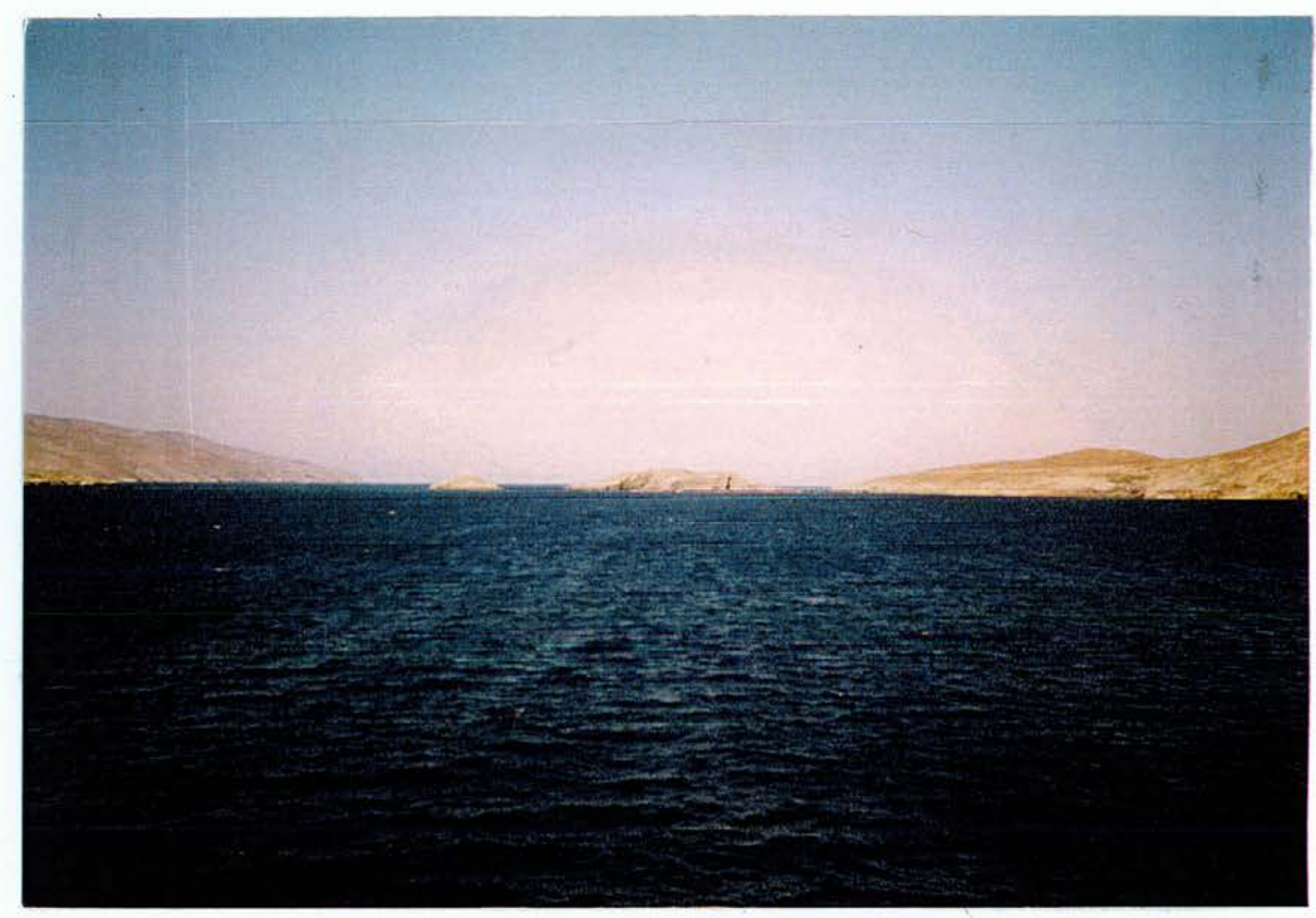

Fig. 27. Rocky outcrops in the Steno strait, separating Andros from Tenos.

The strait was formed when the mountain chains of the Aegean area were inundated by the sea: the mountain peaks remained above water to form the Cyclades, including Andros and Tenos, while some minor rises survived in the form of larger and smaller islets, as seen here. Clearly, the two rocky outcrops complicate the navigation of the relatively narrow strait, especially at night or in fog, when visibility is reduced. 


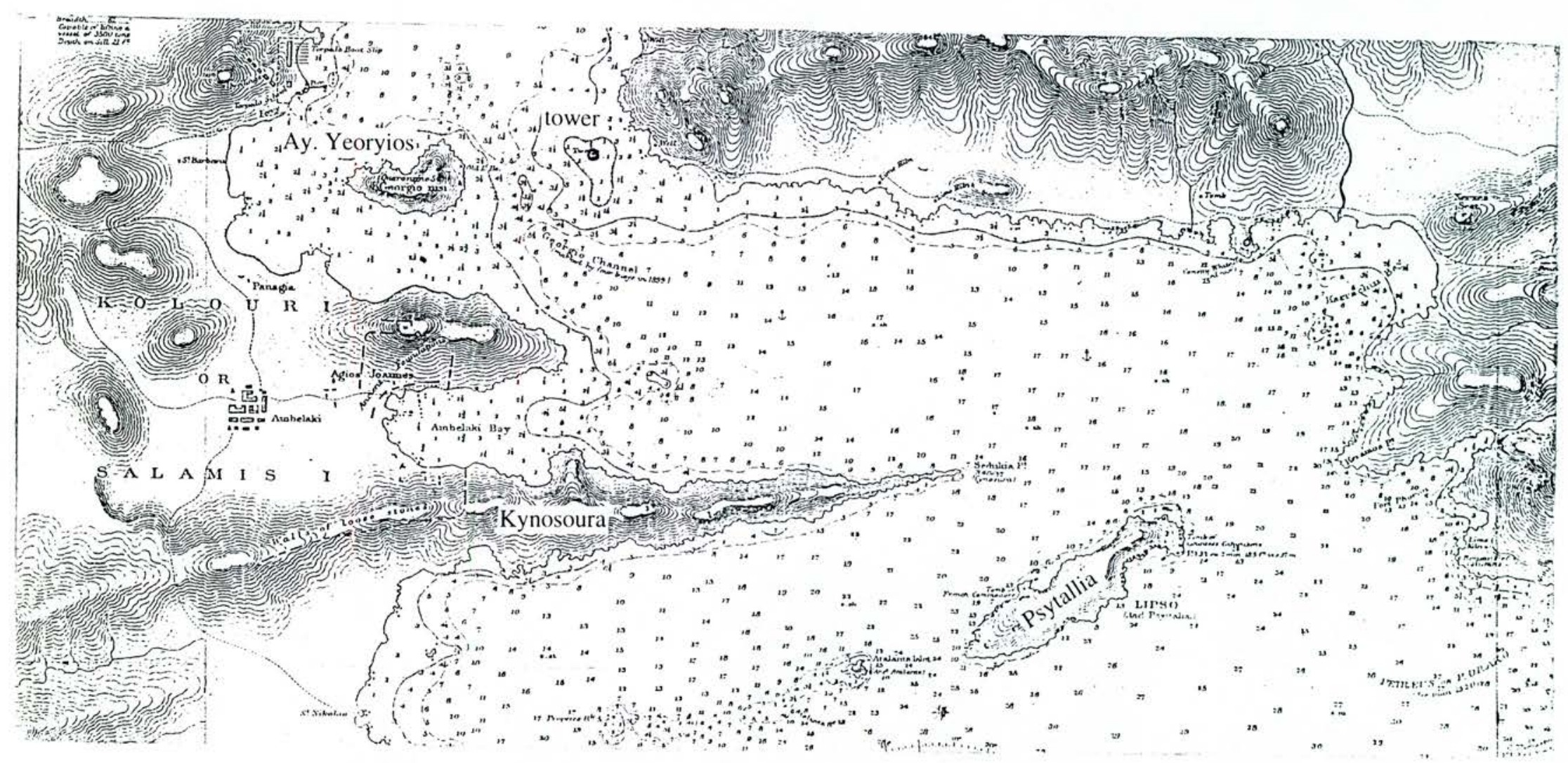

Fig. 28. The site of the battle of Salamis (British Admiralty map 894 (1897)).

Kynosoura, 'the Dog's Tail', is clearly named from its shape and appearance. At the battle of Salamis, the Greeks waited at the narrows, by Ay. Yeoryios island. As the Persian ships entered the increasingly narrow channel from the open waters to the south, they struggled to avoid falling foul of each other, especially when the northerly sea breeze from the Saronic Gulf commenced, and was funnelled up the channel, raising choppy seas. Note the shallows in the narrows of the channel - lower sea levels may mean that the channel was even narrower in antiquity than it appears now, as is suggested by the remains of a tower built upon the shallowly submerged land here. 

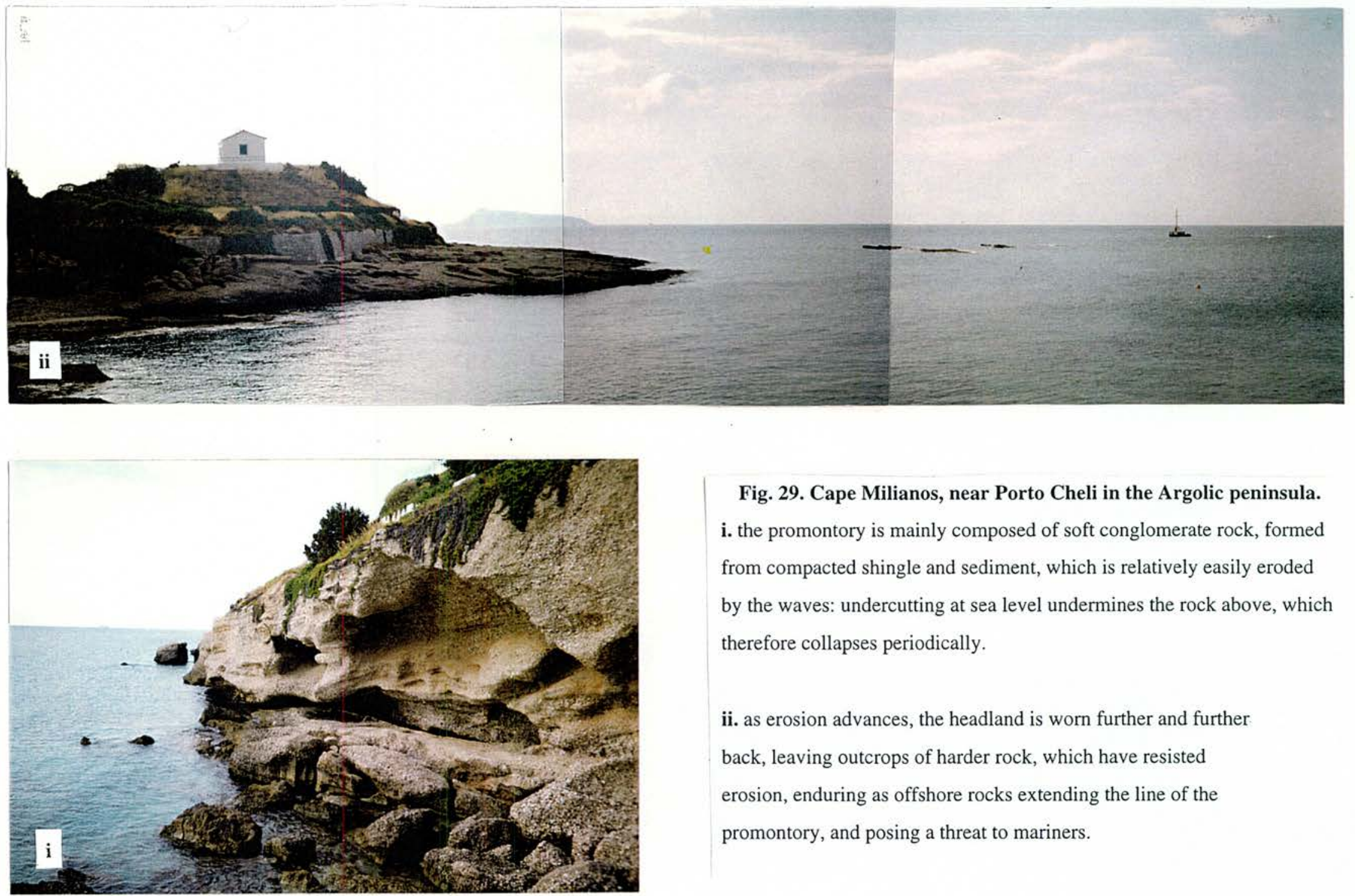

Fig. 29. Cape Milianos, near Porto Cheli in the Argolic peninsula. i. the promontory is mainly composed of soft conglomerate rock, formed from compacted shingle and sediment, which is relatively easily eroded by the waves: undercutting at sea level undermines the rock above, which therefore collapses periodically.

ii. as erosion advances, the headland is worn further and further back, leaving outcrops of harder rock, which have resisted erosion, enduring as offshore rocks extending the line of the promontory, and posing a threat to mariners. 


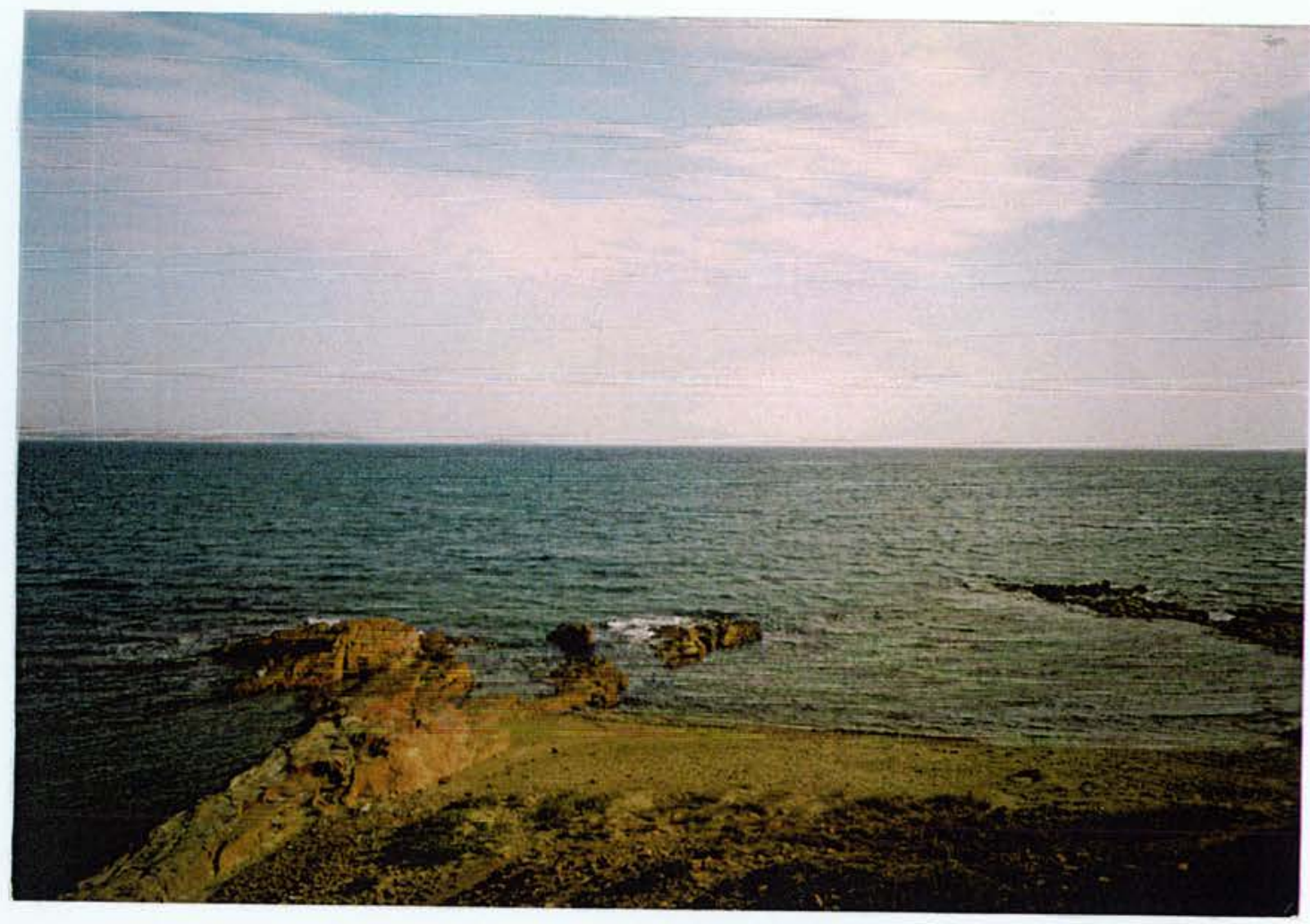

Fig. 30. Reefs in the Chian strait.

Discordant strata of hard rock have resisted erosion and survive in the form of reefs stretching out to sea, while the softer rocks surrounding them have gradually been eroded away. At other points in the strait, which separates the island of Chios from Asia Minor (the coast of which is visible to the left on the horizon) there are far longer reefs, stretching out to sea and rising up to just below sea level, upon which ships might easily become grounded. 


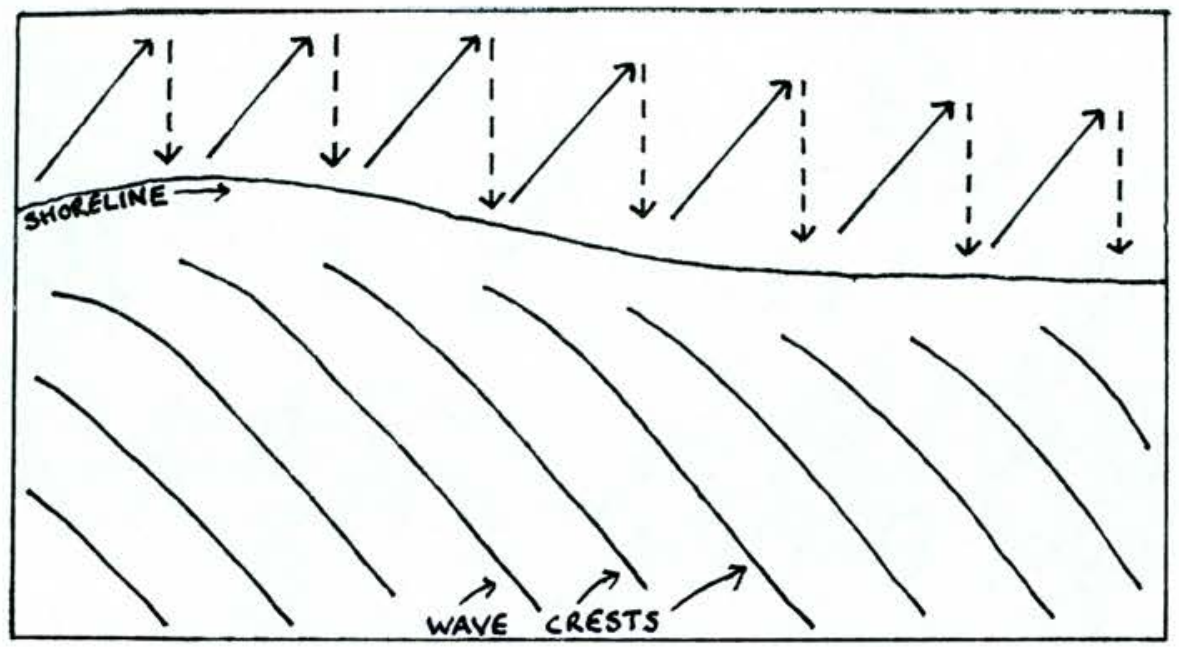

Fig. 31. Longshore drift.

Waves advancing obliquely shoreward (from left to right) strike diagonally up the shore $(\nearrow)$, but retreat directly back down seawards $(\vdots)$. The resulting longshore drift, and transportation of sediments carried in the coastal water, moves from left to right along the shore.

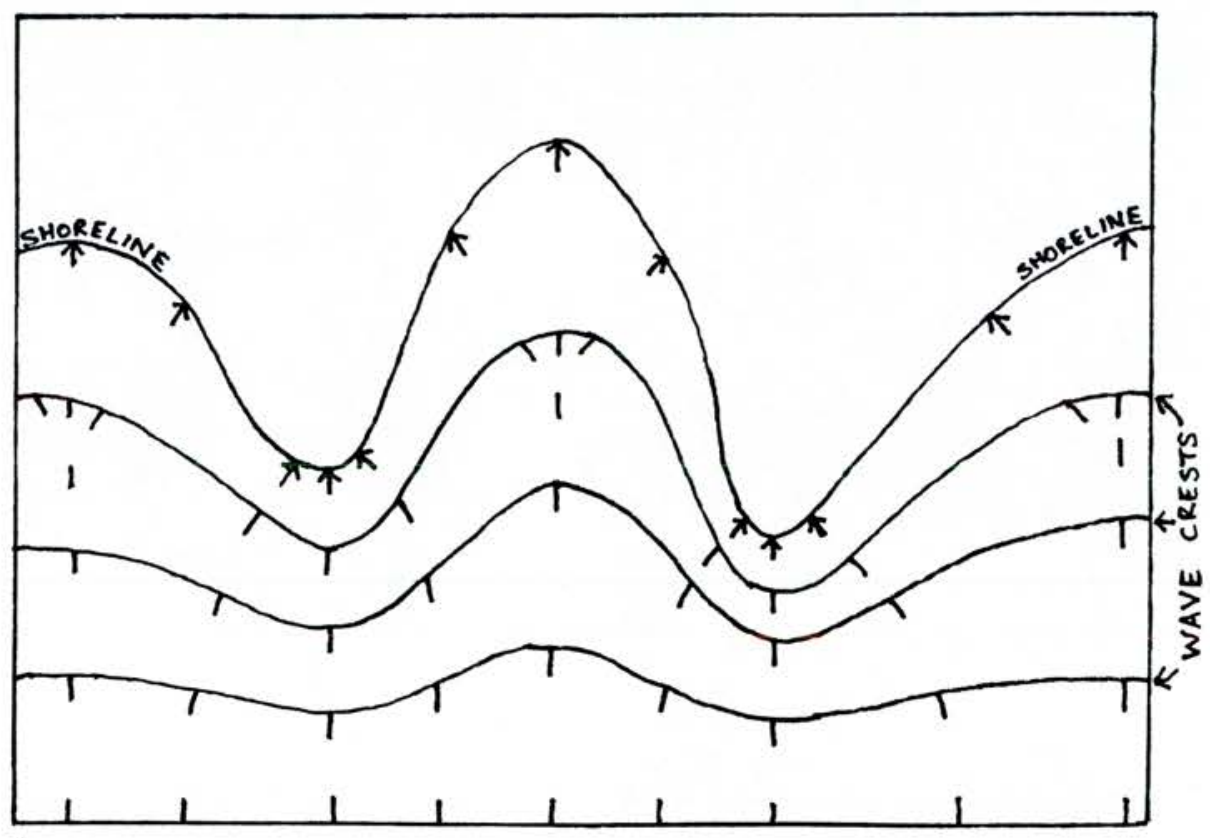

Fig. 32. Waves against an indented coastline.

As the waves reach shallow water, and begin to 'feel' the seabed, they begin to turn towards the nearest parts of the coastline. This causes a large proportion of each wave to break against the headlands; the remaining parts of each wave enter the bays and spread out to cover the curving contours of the coastline. 


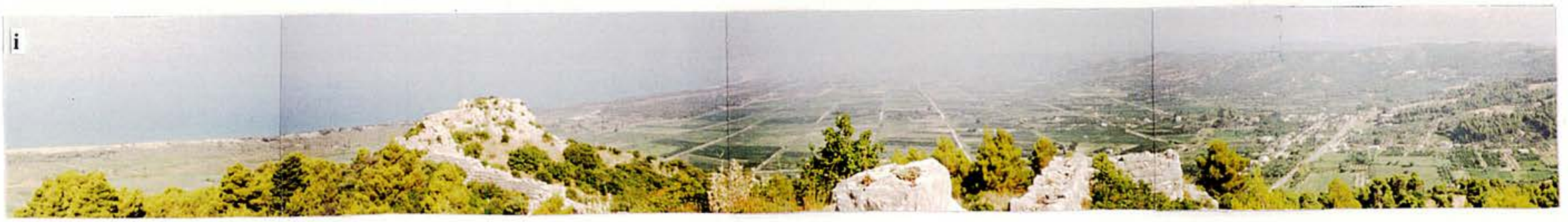

Fig. 33. Low deposition coasts in the western Peloponnese. Samikon lay on an isolated mountain ridge, the low coasts on either side featuring mud flats, lagoons, shallows, and sand banks resulting from deposition. North of Samikon, the lagoons have now been turned into agricultural fields (i), but these, from their low and featureless appearance, are clearly still the result of deposition: originally the coast would have lain at the foothills visible on the extreme right. Graefinghoff's map of 1909 (ii: Dorpfeld (1913) Taf. IV) shows the original lagoons, as well as some of the similar features to the south of Samikon.

Such coastlines were difficult to spot and identify from the open sea, and offered no good anchorage or shelter: thus the ridge of Samikon, and the temple of Poseidon on its sheltered southern flank, would have been an important landmark and source of shelter. The same is true of Ichthys, which marks the northern limit of these deposition coasts.

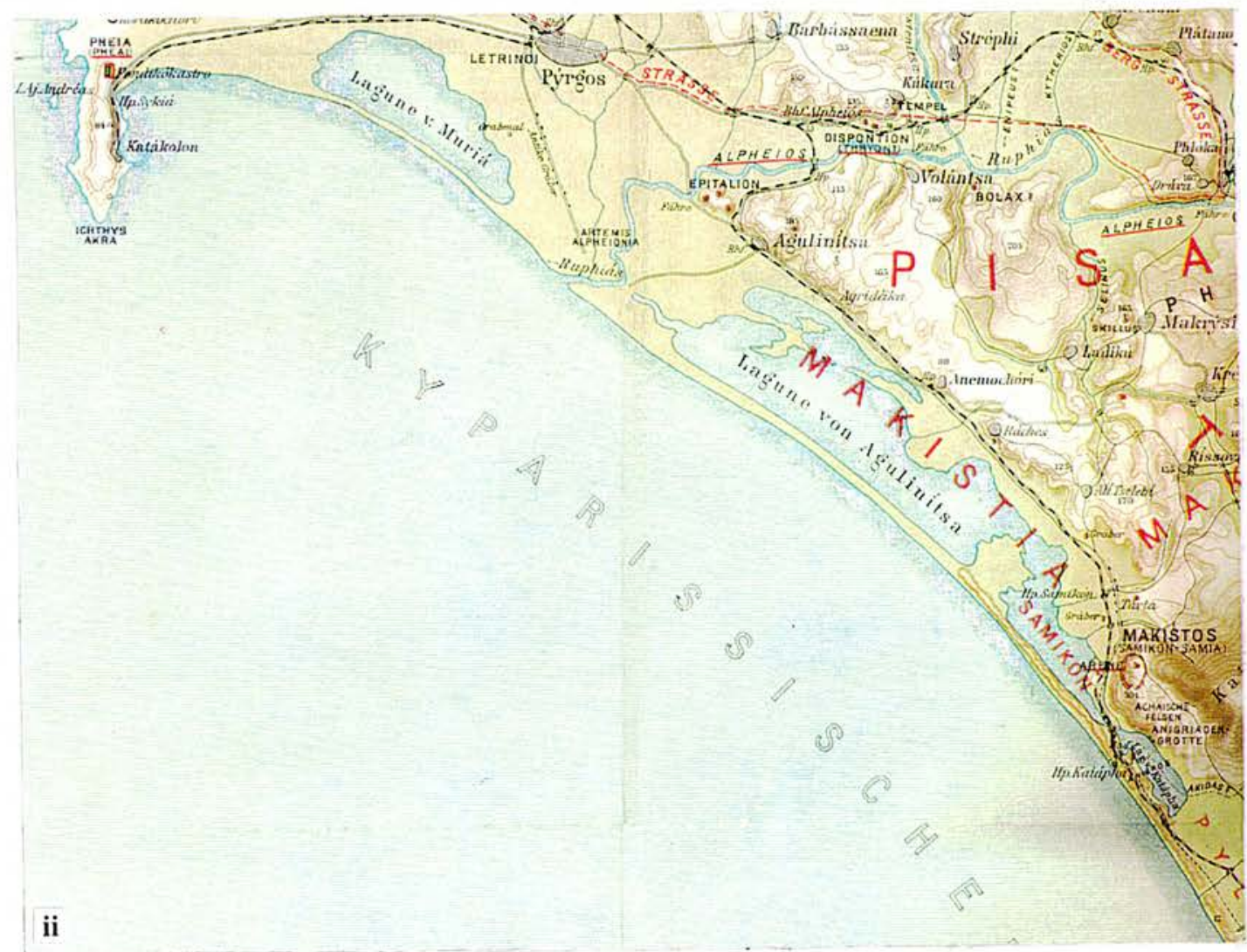




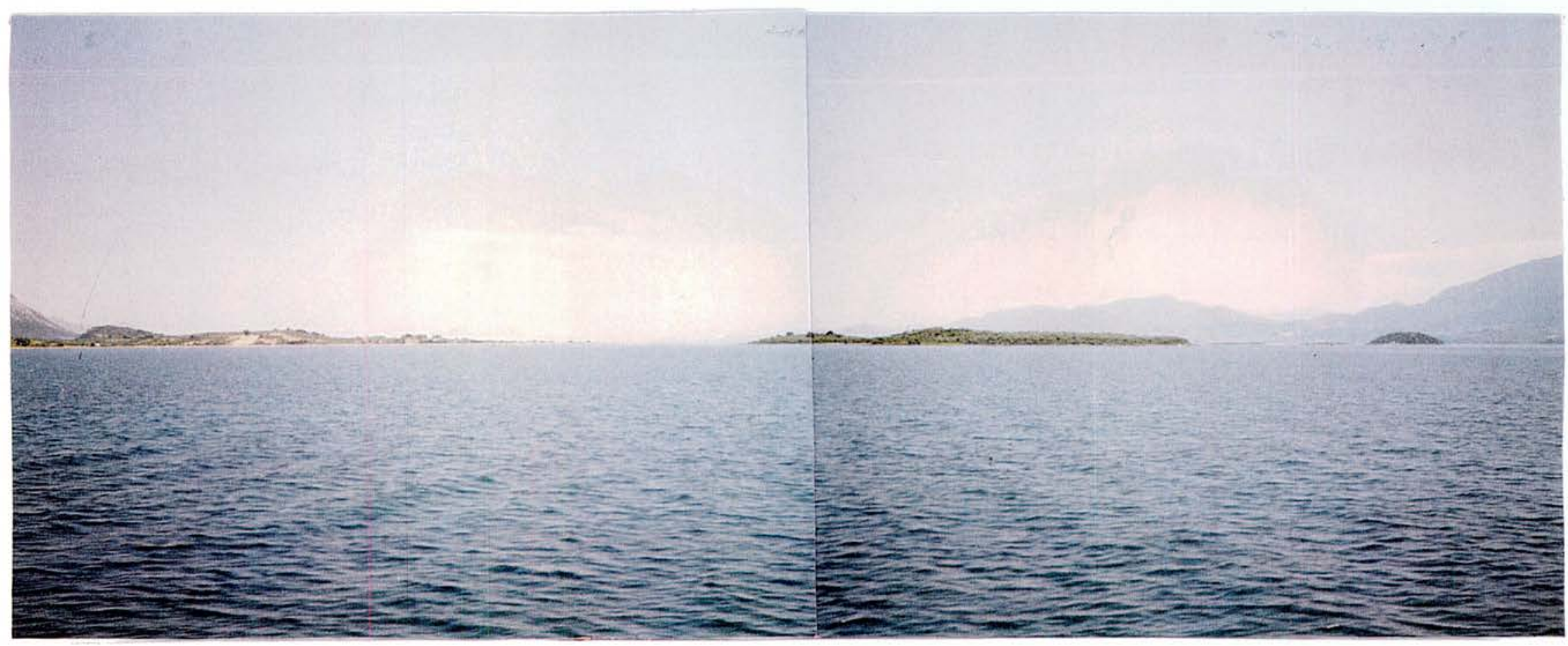

Fig. 34. Cape Kenaion and the Lichades islands, northwest Euboia.

The extremity of Cape Kenaion appears on the left, and two small islets, the Lichades, prolong the line of the promontory. Although having their origins in volcanic activity, both promontory and islands are affected by deposition; then, as now, they would have risen only slightly above sea level, and so would have been hard to spot from afar. The sanctuary of Zeus and the tomb of Lichas, both of which stood on the cape, would thus have constituted important landmarks for sailors in the northern Euboian Sound. 


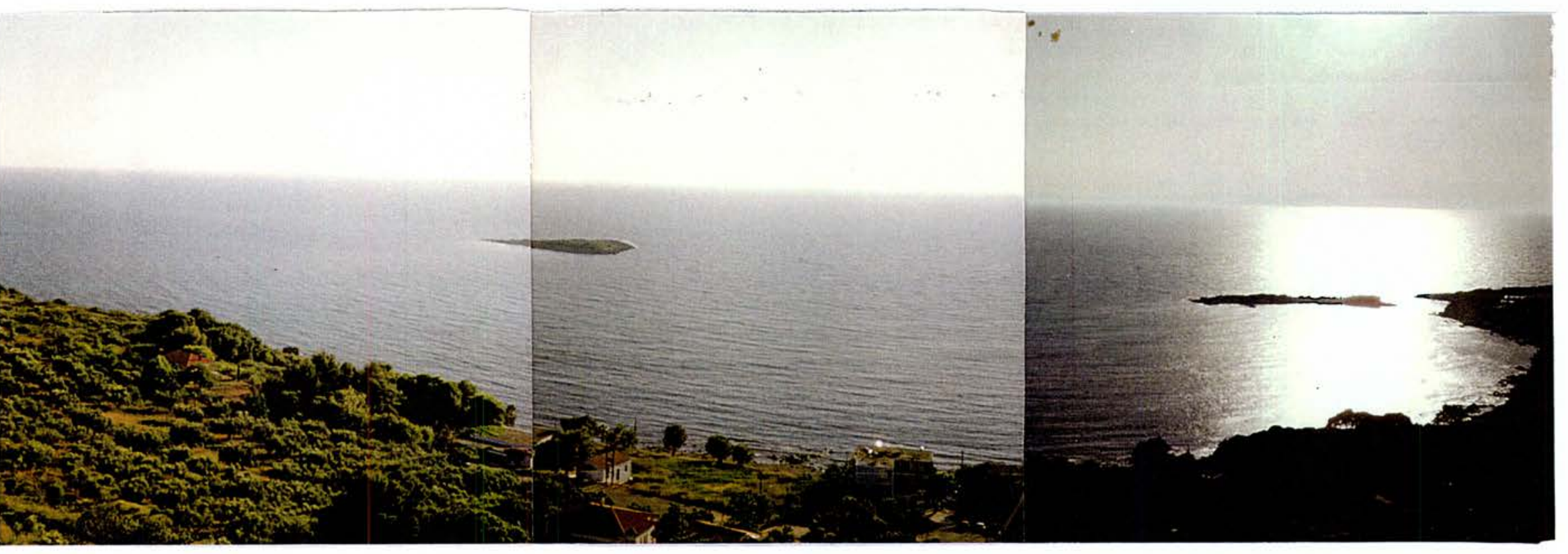

Fig. 35. Wave refraction in Ay. Andreas Bay (anc. Pheia).

Note how the originally straight wave crests are refracted as they advance into the bay, 'bending' to approach all points of the curving shore head-on. The harbour, situated on the flank of the Ichthys promontory, and further protected by an offshore island, was an important place of shelter for ships, especially given the lack of shelter available elsewhere on the west coast of the Peloponnese. 


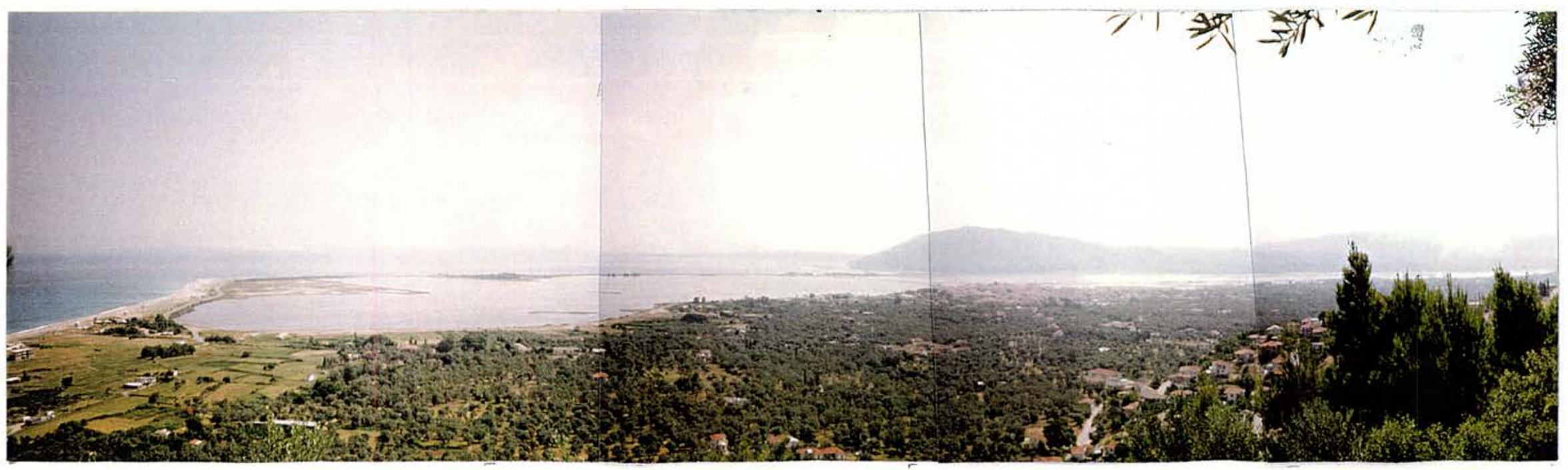

Fig. 36. Deposition features in the Leukas Strait.

The most notable feature here is the great sandy tombolo arching across the northern end of the strait, connecting the island to the mainland. In the strait proper, to the south (right), are extensive mud flats and shallow lagoons. At various times in antiquity, channels were cut through this heavily silted area to allow the passage of ships. The practice continues today. For a good map of the deposition in the whole the strait earlier this century, see Dorpfeld (1927) vol.2, taf.2. 


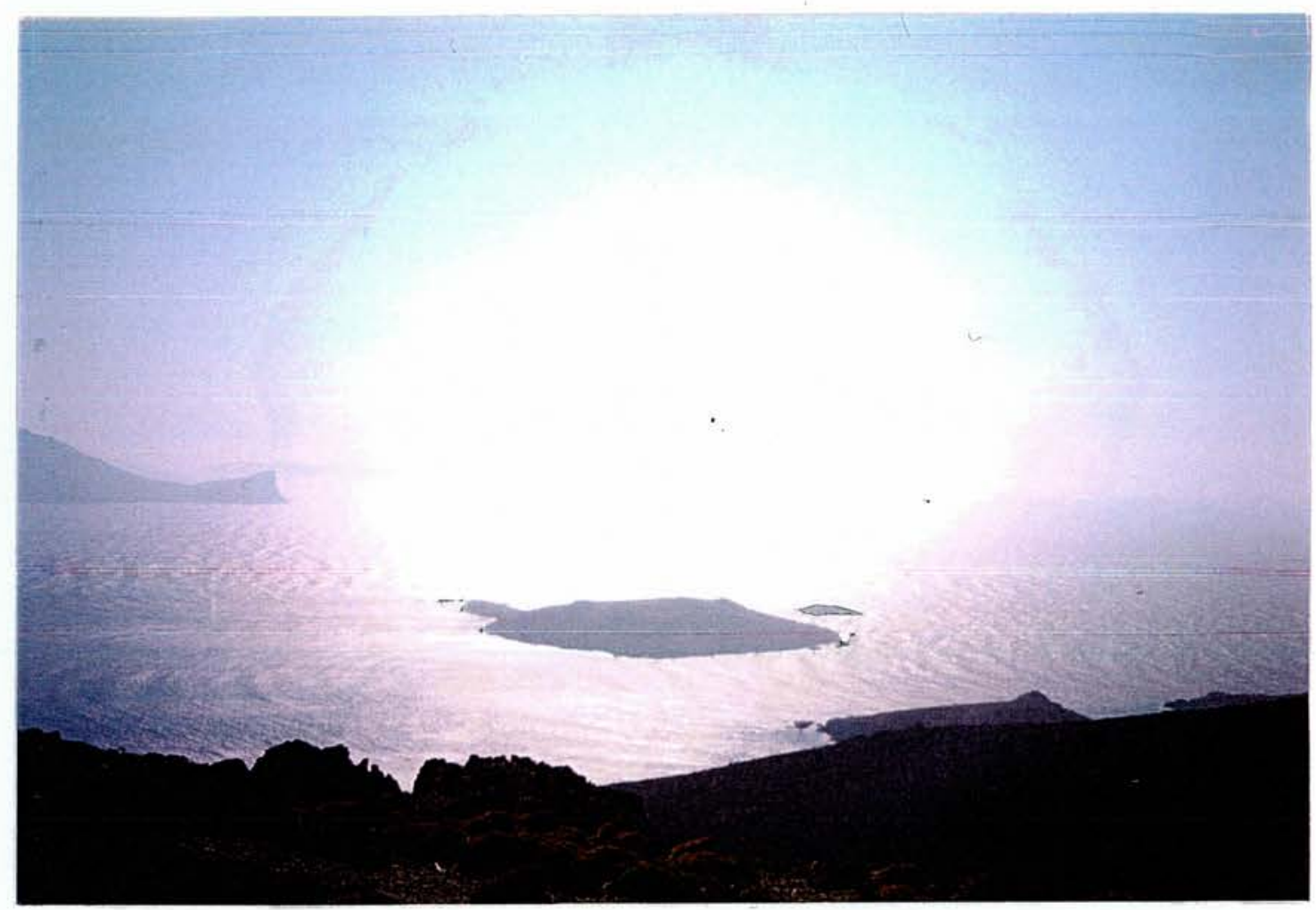

Fig. 37. Wave refraction off the coast of Astypalaia.

Waves proceeding from right to left (north to south) down the west coast of Astypalaia are disrupted upon encountering this small island. While the waves passing beyond the far side of the island appear unaffected, those passing through the narrow strait in the foreground undergo refraction, their crests curving and expanding out to cover the wider area behind the strait and the island. Here the water is notably calmer, because the waves dissipate as they spread out across increasingly longer wave-fronts. 

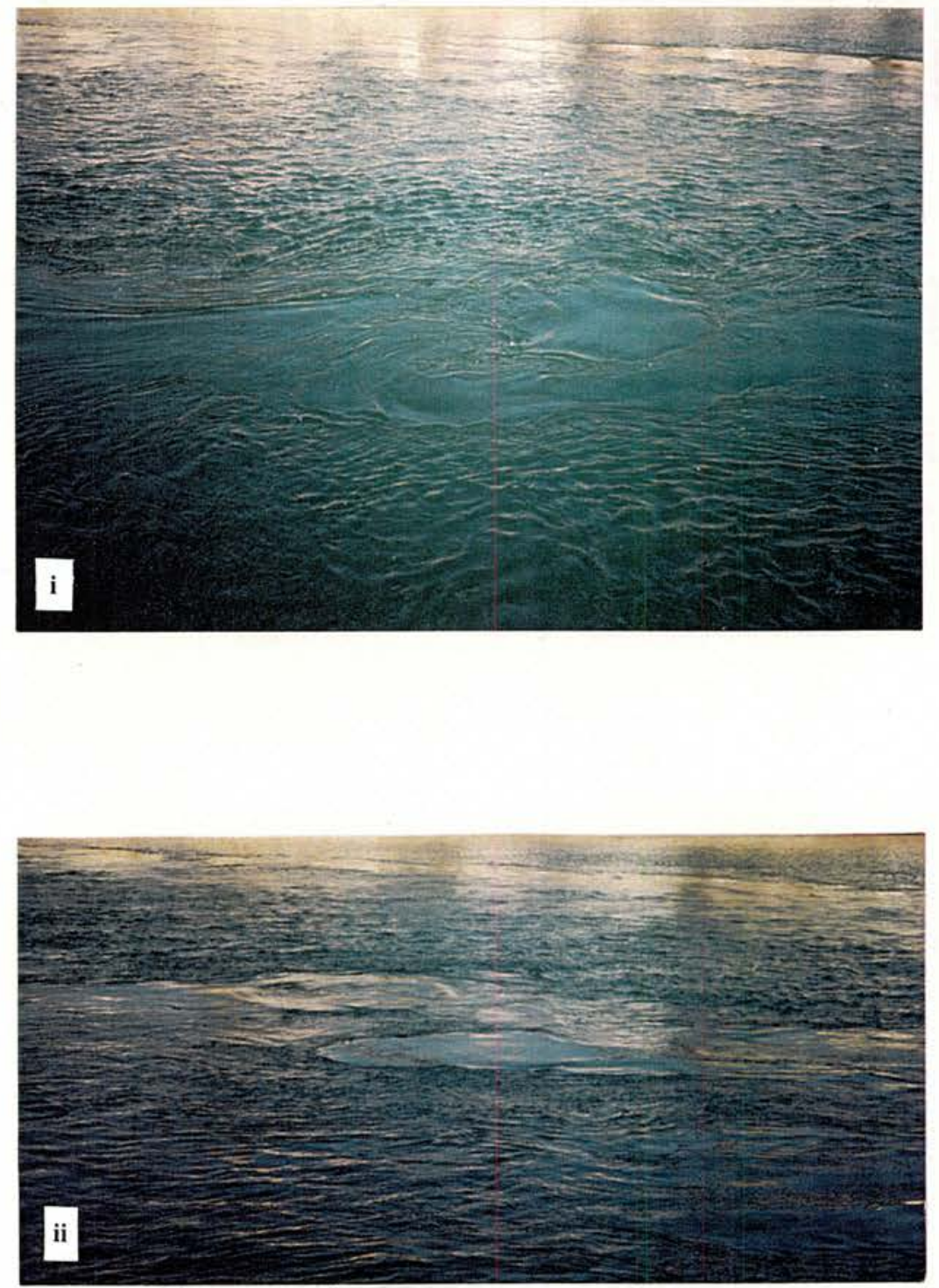

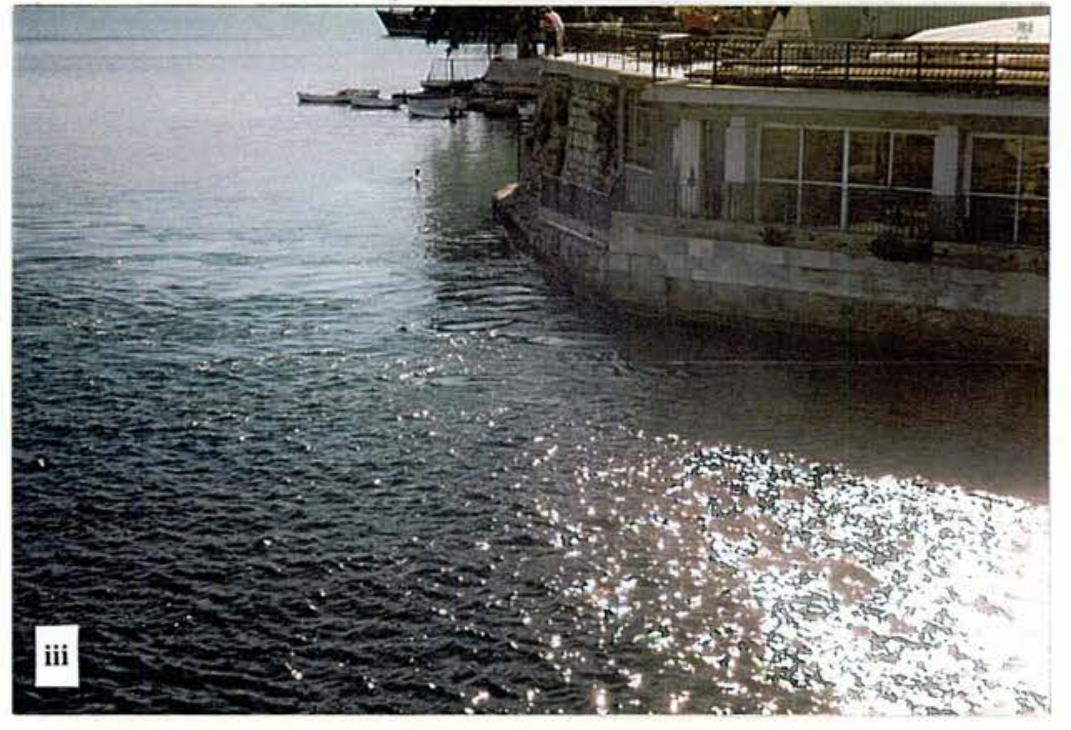

Fig. 38. The Euripos at Chalkis.

In $\mathbf{i}$ and $\mathbf{i i}$ the strength and turbulence of the current in the narrow channel is clear from the patterns formed on the surface of the water, while iii shows shows the contrast with the far calmer waters in the more open area beyond the narrow strait. 


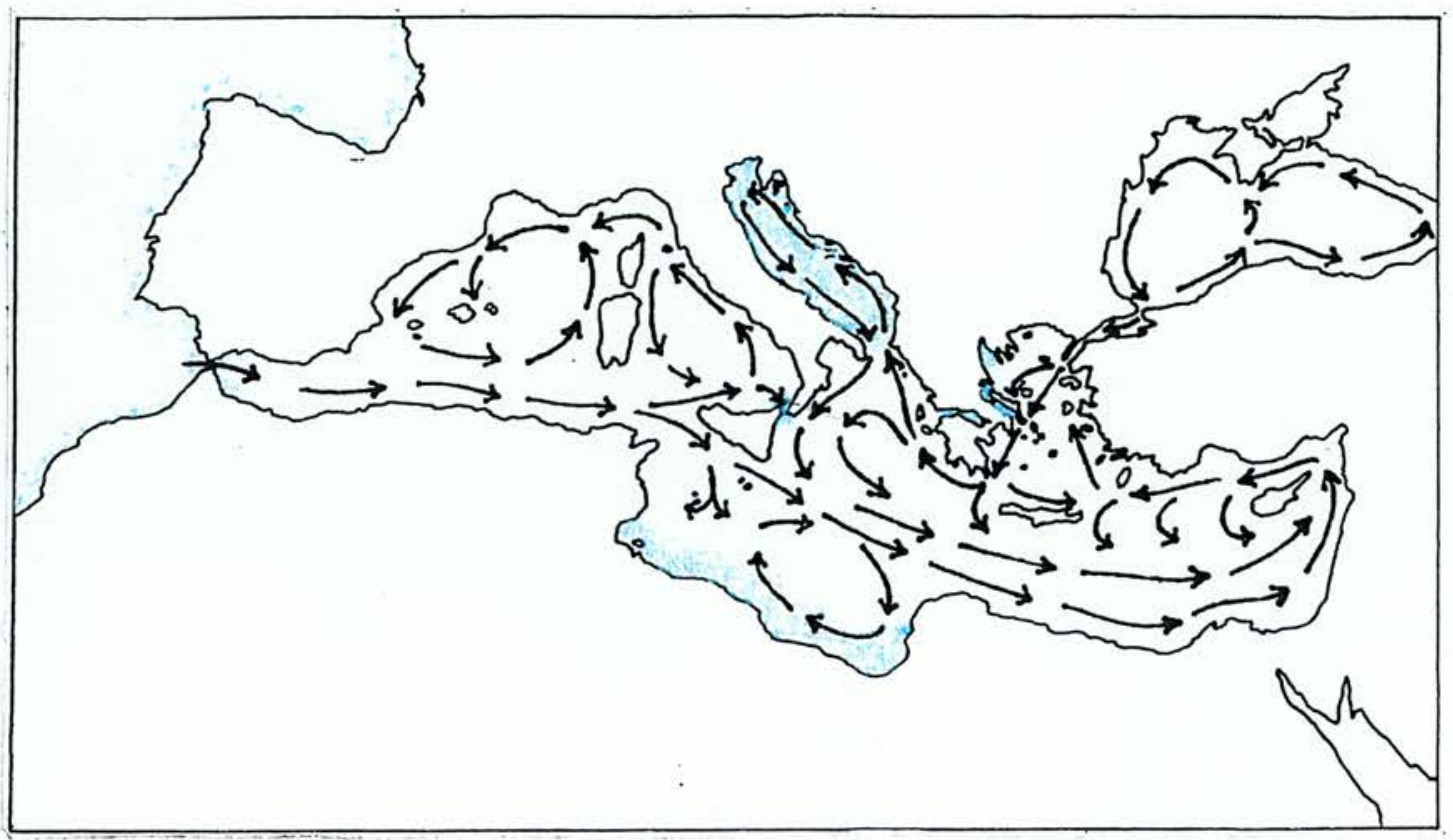

Fig. 39. Surface currents and areas of strong tides in the Mediterranean and Black Seas.

The main surface current entering at Gibraltar passes eastwards along the whole north coast of Africa and then passes northwards up the coast of Palestine and Syria, from where it returns westwards along the south coast of Asia Minor. In the Gulf of Sirtes, the current circulates in a clockwise direction, whereas in the gulfs of the northern Mediterranean, and in the Black Sea, the circulation is anticlockwise. In the Aegean, this anticlockwise circulation is strengthened by the current passing southwestwards out of the Hellespont. Tides in the Mediterranean are generally very weak, but areas where their activity is heightened are highlighted in blue. 


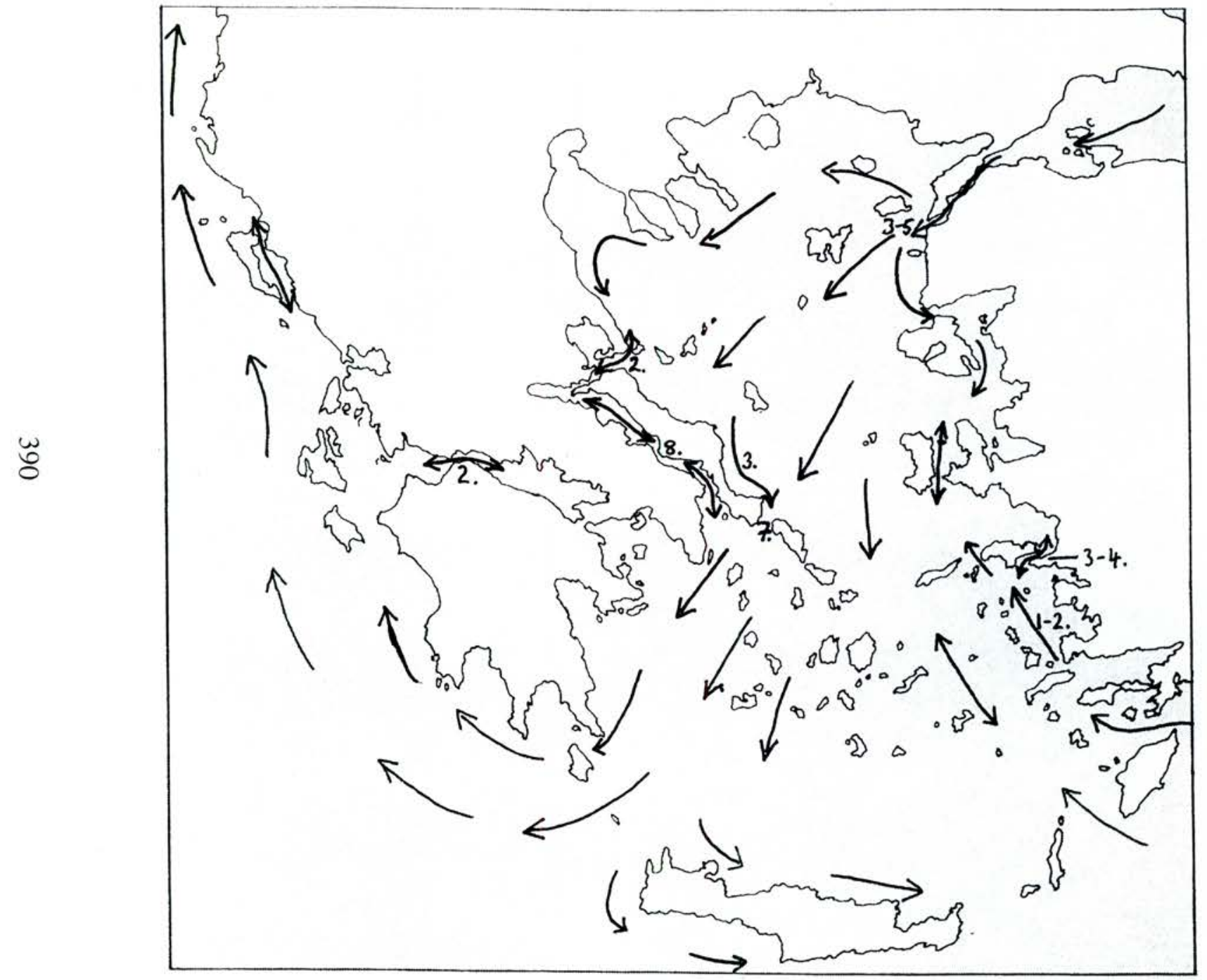

Fig. 40. Currents in the Aegean.

In general terms, the current, boosted by the outflow from the Hellespont, follows the contours of the coast from southern Asia Minor all the way around the Aegean and mainland Greece to Epeiros.

Double headed arrows indicate areas where the direction of flow varies with wind conditions, tidal forces, or both. Numbers indicate typical rates of the current's flow, in knots, at selected points. 


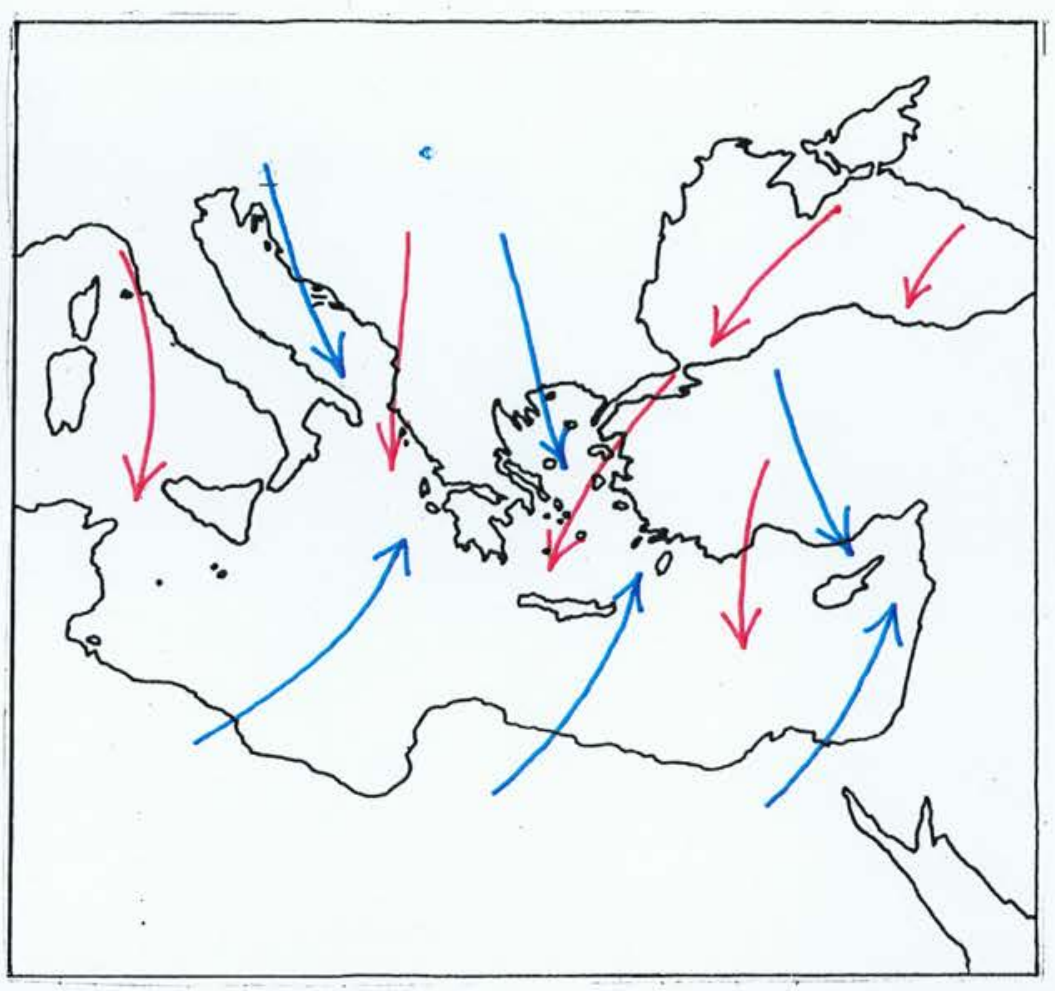

Fig. 41. Prevailing winter and summer winds in the eastern Mediterranean.

Summer winds are northerlies (the Etesians and kindred winds), and are represented by red arrows. Winter winds include both northerlies (Boreas and kindred winds) and southwesterlies (the Sirocco and kindred winds, ancient Lips, Notos), and are represented by blue arrows. 


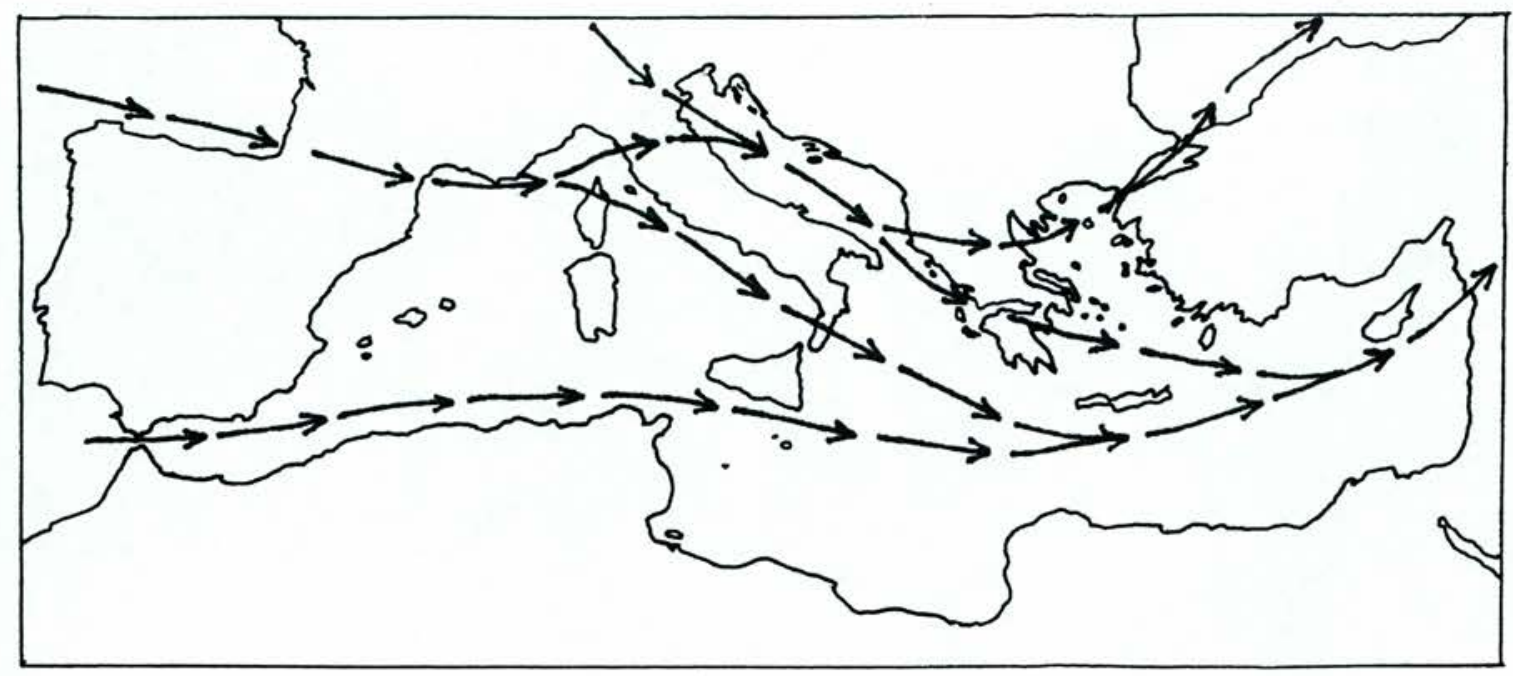

Fig. 42. Winter depression tracks.

The arrows denote the most common paths taken by depressions as they pass over the Mediterranean from west to east. Note the tendency to follow sea surfaces: those land masses that are crossed tend to be relatively narrow. Depressions are particularly attracted to the Adriatic Sea, and may even originate there; from the Adriatic, depressions tend to move southeastwards before crossing peninsular Greece and the Aegean, and then passing either to the north or to the south of Asia Minor. 


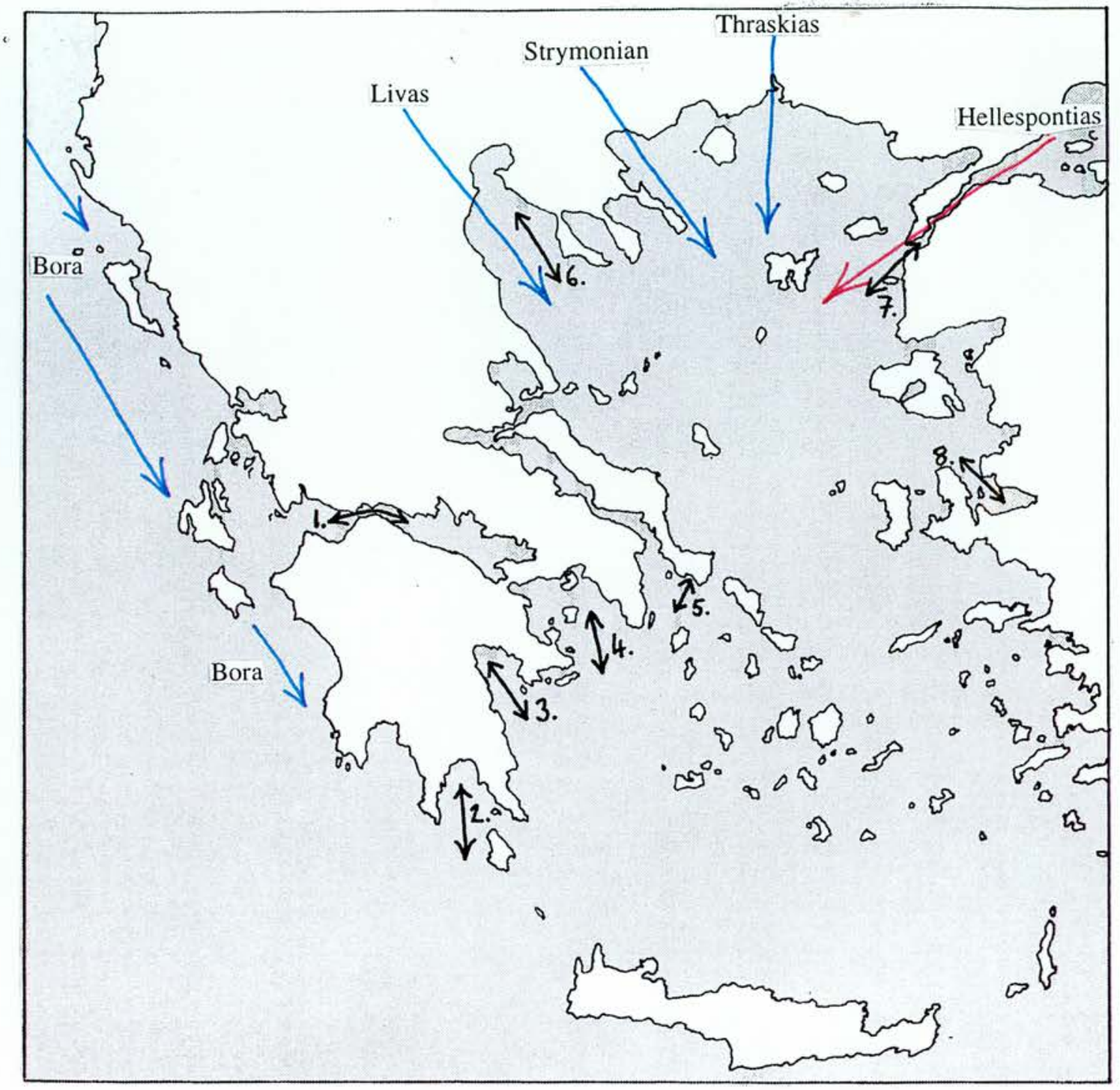

Fig. 43. Local winds around Greece.

The blue arrows all represent katabatic valley winds which blow down forcefully from high mountainous interiors, across coastal plains, and on out the sea.

The red arrow represents Hellespontias, which is generated when prevailing northeasterlies such as the Etesians are funnelled through the long and narrow strait of the Hellespont, becoming especially forceful and turbulent as they do so.

Double-headed black arrows indicate coastal indentations where diurnal land and sea breezes are particularly strong or significant: 1 - Corinthian Gulf. 2 - Lakonian Gulf. 3 - Gulf of Argos. 4 - Saronic Gulf. 5 - Bay of Karystos. 6 - Thermaic Gulf. 7 - Hellespont. 8 - Gulf of Smyrna. 


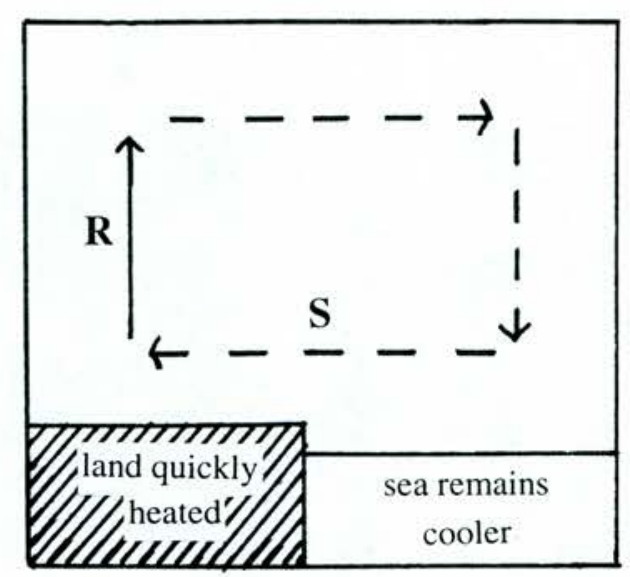

SEA BREEZE (DAYTIME)

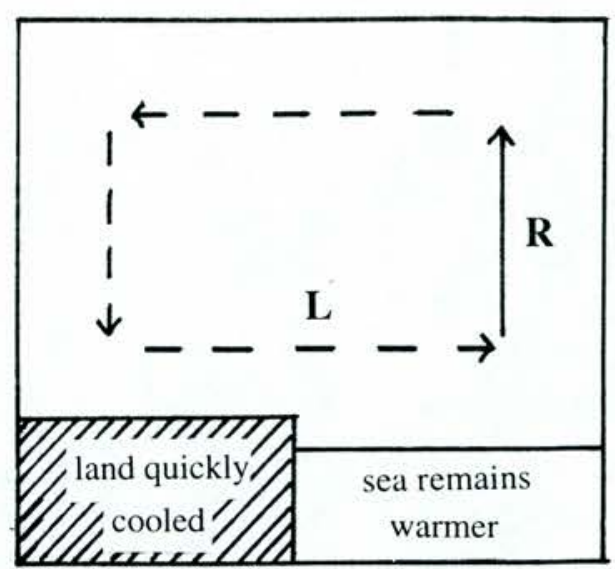

LAND BREEZE (NIGHT)

Fig. 44. Land and sea breeze dynamics.

The air over the hotter surface (i.e. land during daytime, or sea during the night) becomes heated and rising convection currents ('thermals') develop (R). Consequently, atmospheric pressure over the hotter surface

a: rises at high altitudes, inducing a flow of air towards the area over the cooler surface, where air pressure is lower.

b. drops at low altitudes, inducing an inflow of air from the cooler surface, where atmospheric pressure is higher; this flow of air at ground or sea level constitutes the land breeze (L) when blowing from land to sea, and the sea breeze (S) when blowing from sea to land. 


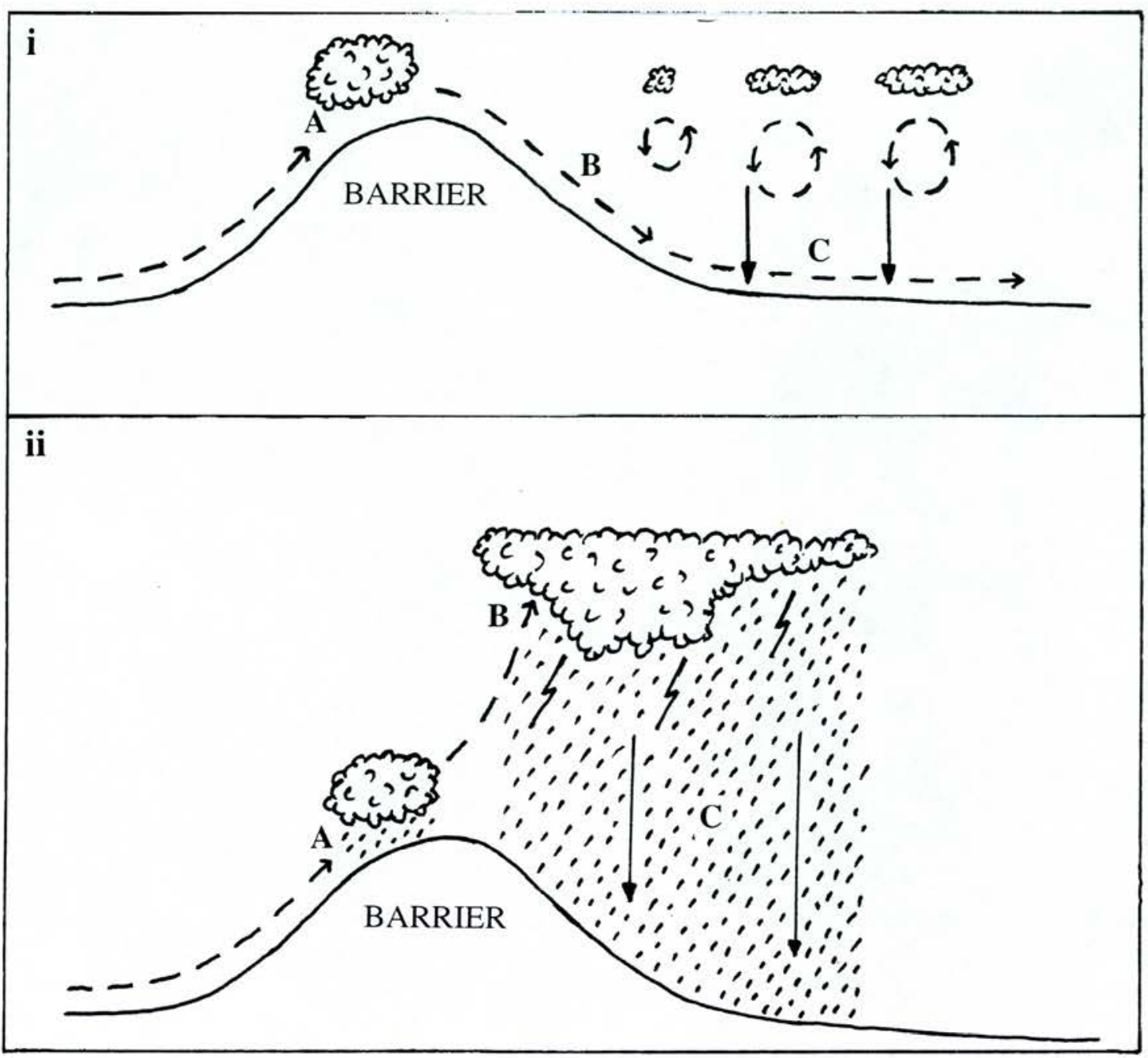

Fig. 45. Vertical displacement of stable air (i), and of unstable air (ii).

i. Stable air rising to pass a barrier may form cloud and even some rain as the air cools and water vapour condenses (A). By the time the stable air reaches the crest of the barrier, its temperature has dropped to a level below that of the surrounding air at this altitude, and it therefore descends over the far side of the barrier (B). This descent is blustery, and can generate eddies higher up in the atmosphere, from which further squalls (solid arrows) may blast downwards (C).

ii. Unstable air, being generally warmer and more humid than stable air, produces more cloud and rain as it rises up in front of the barrier (A). This rainfall produces heat which helps to keep the unstable air warmer than the surrounding air at the crest of the barrier, so that it continues rising, forming cumulonimbus cloud (B). The resulting thunderstorms produce lightning, and throw down copious belts of rain driven by fierce squalls (C). 


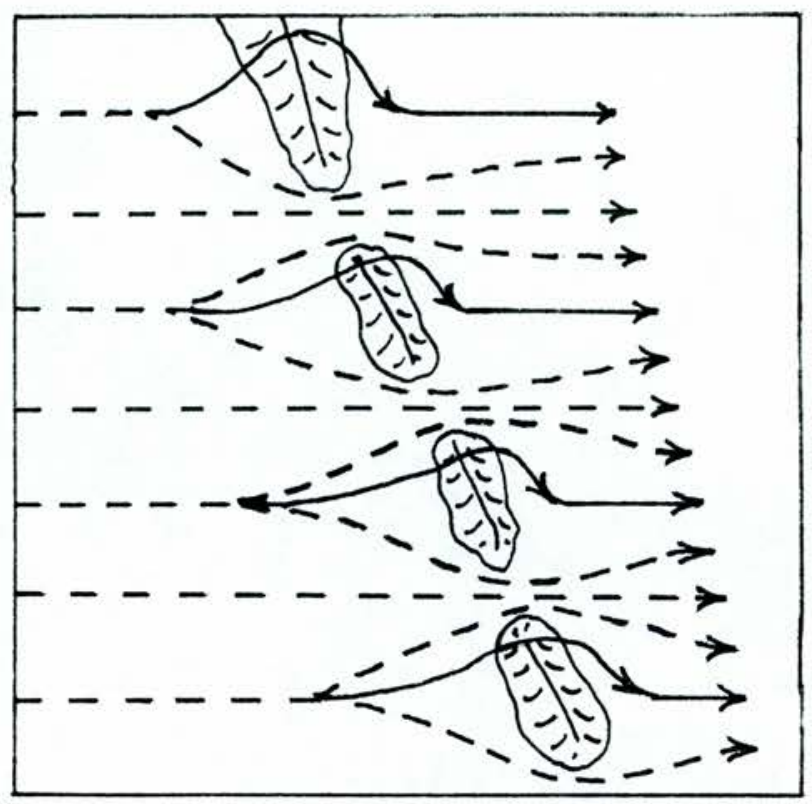

Fig. 46. Displacement of wind on passing an island chain.

Wind approaching from the left undergoes both

a. vertical displacement (solid lines), rising to pass over the crests of promontories and islands, and then descending to their lee, and

b. horizontal displacement (broken lines), veering sideways to pass through the gaps formed by the straits separating the islands with increased force and turbulence. 


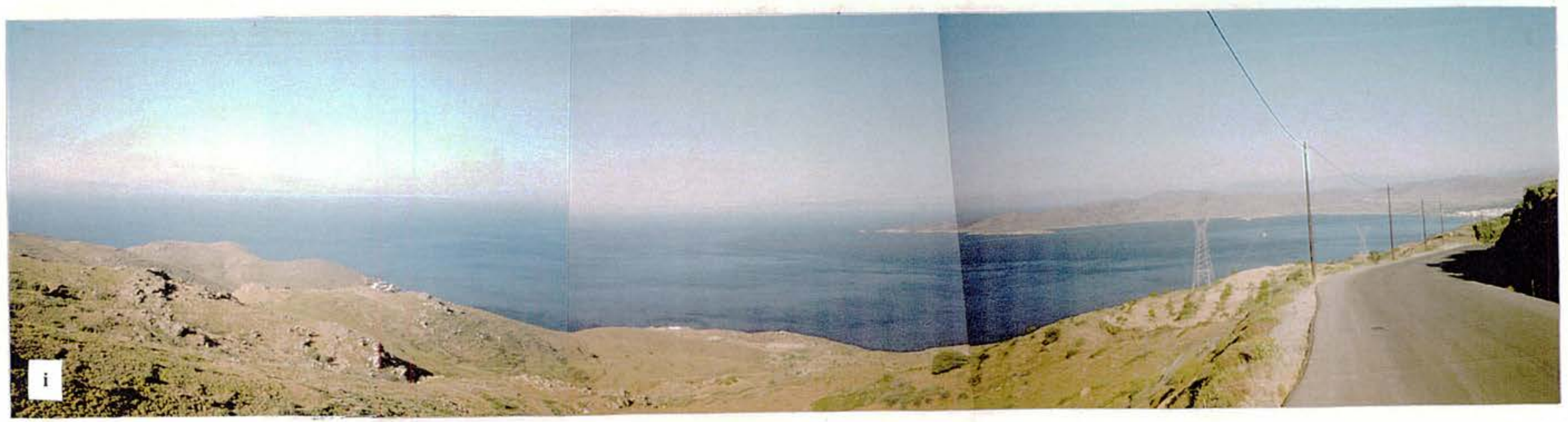

Fig. 47. The Bays of Karystos (i) and Marmari (ii), southern Euboia. The Bay of Karystos, like the whole Euboian Sound, is protected from northerly winds by the heights of Euboia, and often remains calm and sheltered even when northerlies blow strongly onto the northeast coast of the island (i). When northerly winds made passing through the Doro channel separating Euboia from Andros impractical, ships would resort to the bay for shelter, or else travel up the sheltered Euboian Sound. However, sailing conditions could worsen when northerlies appeared over the heights of Euboia in gusts and squalls, striking the water and raising rough seas with characteristic white horses, as in the Bay of Marmari (ii), which adjoins the Bay of Karystos on the northwest.

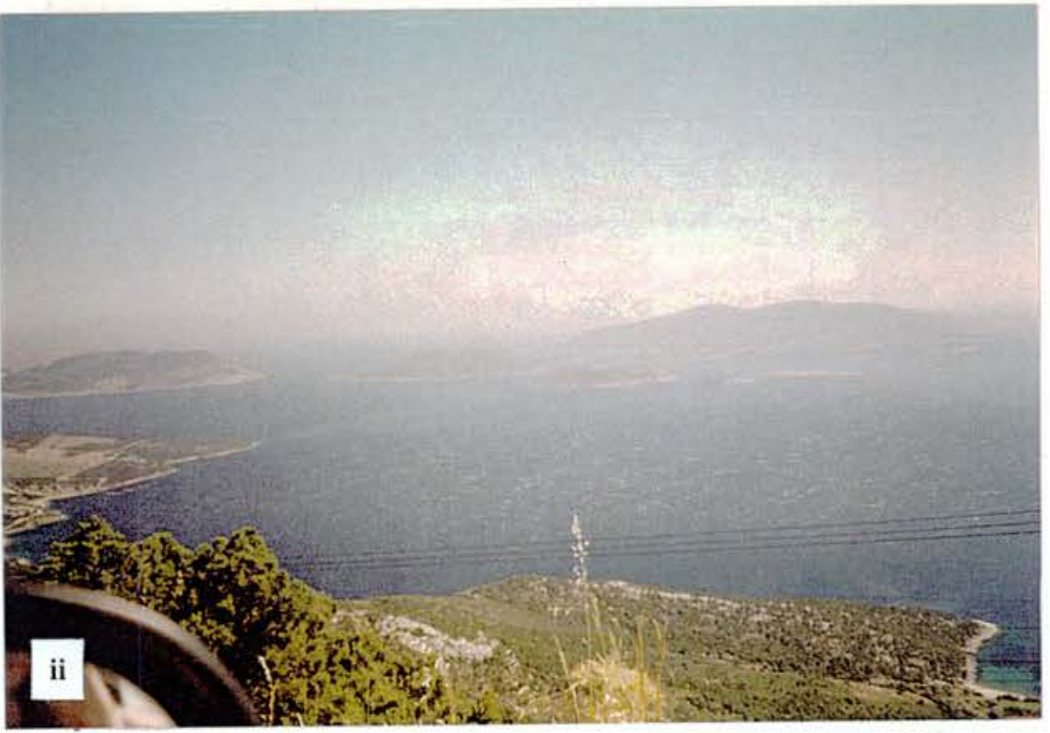




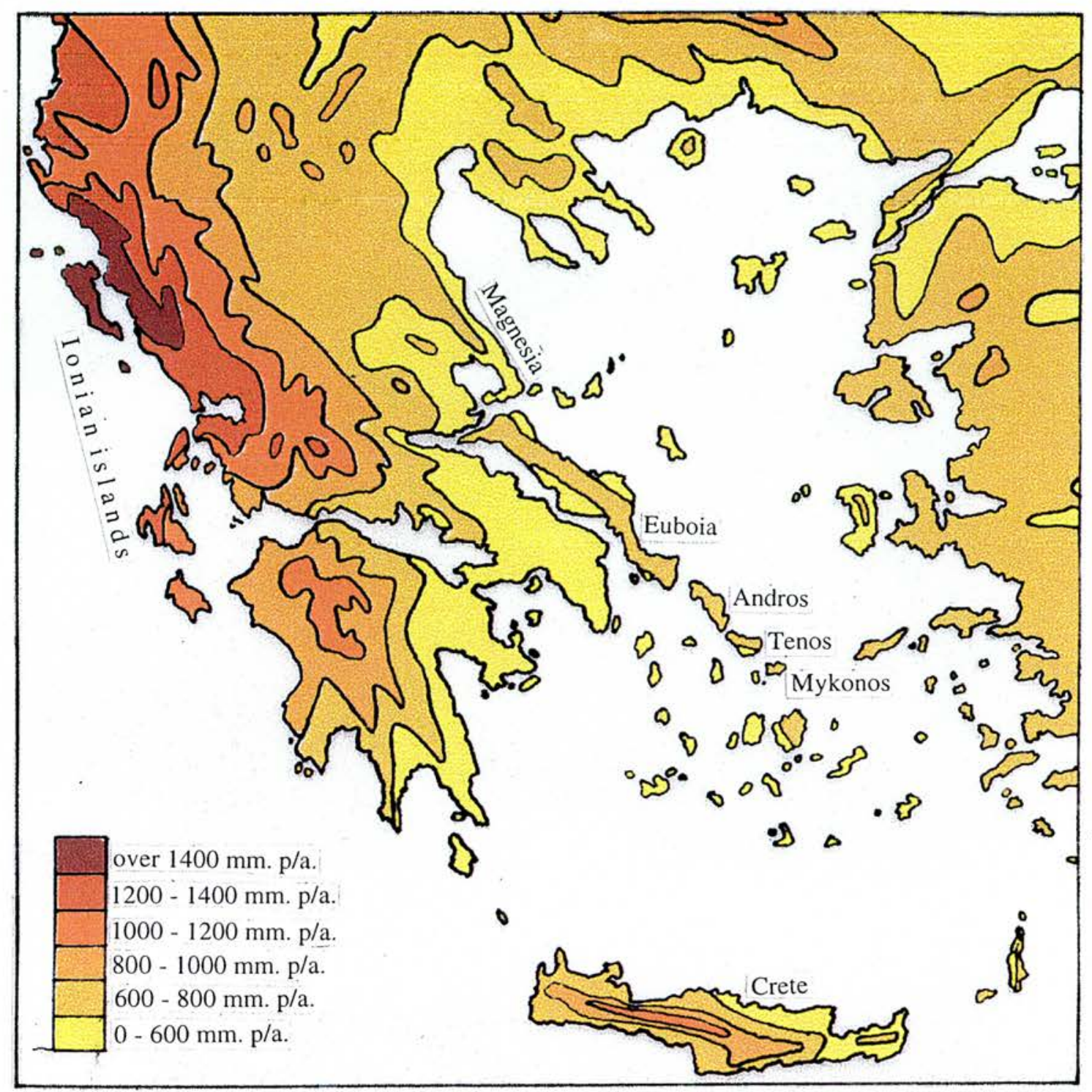

Fig. 48. Annual rainfall regime in Greece and the Aegean.

Note the concentration of rainfall along the Ionian islands and the west coast of Greece, where the high mountains precipitate rain from depressions crossing the Adriatic and Ionian Seas. Similarly, note the higher rainfall found on the high land of Magnesia, and the island chain running from Euboia through Andros and Tenos to Mykonos, all of which the Etesians strike after picking up considerable humidity during their crossing of the Aegean. Similarly the high land of Crete presents a barrier to, and thus recieves rainfall from, both northerly (Etesians, Boreas) and southerly (Lips, Notos) winds. 
For commentary see over, p.400.

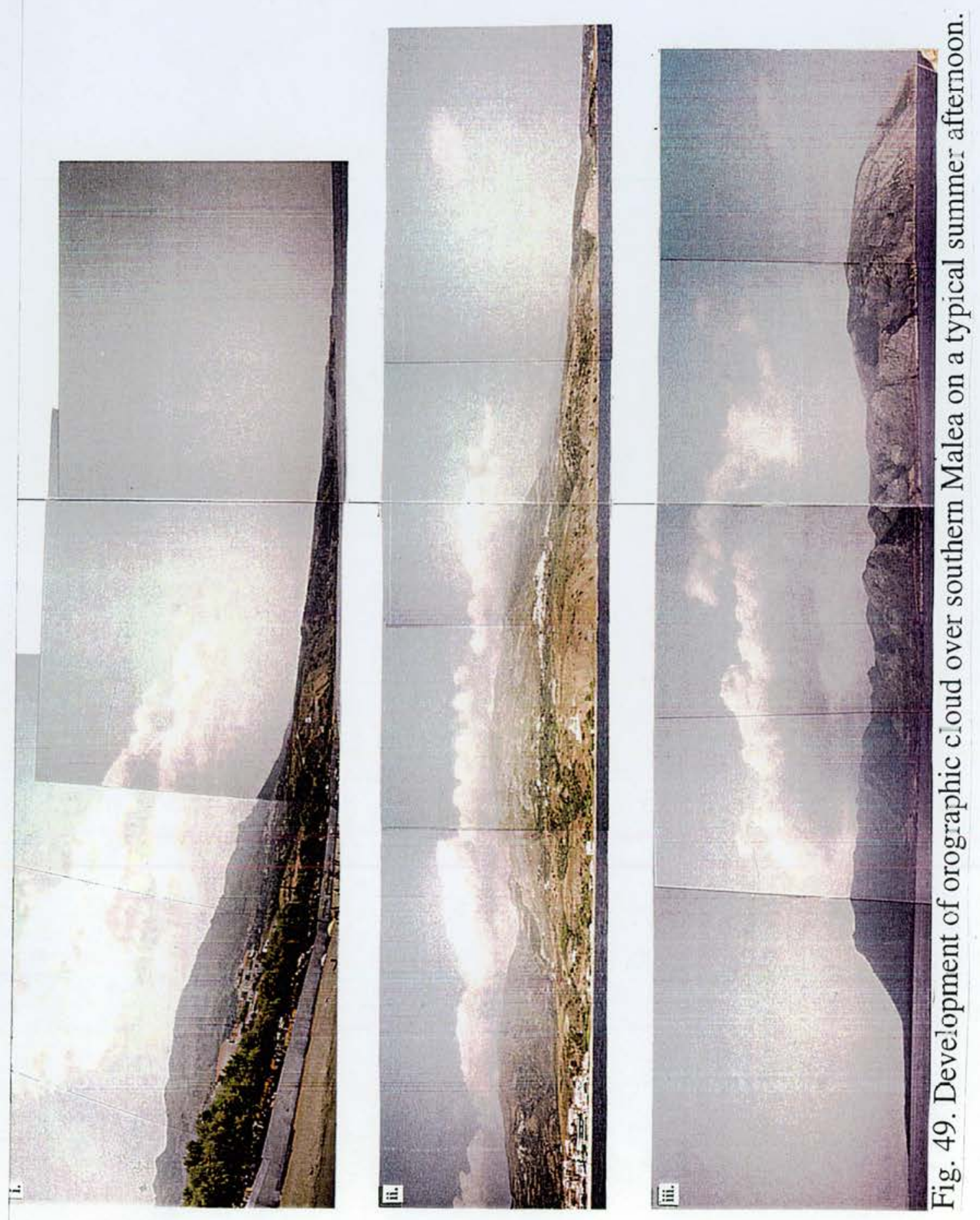




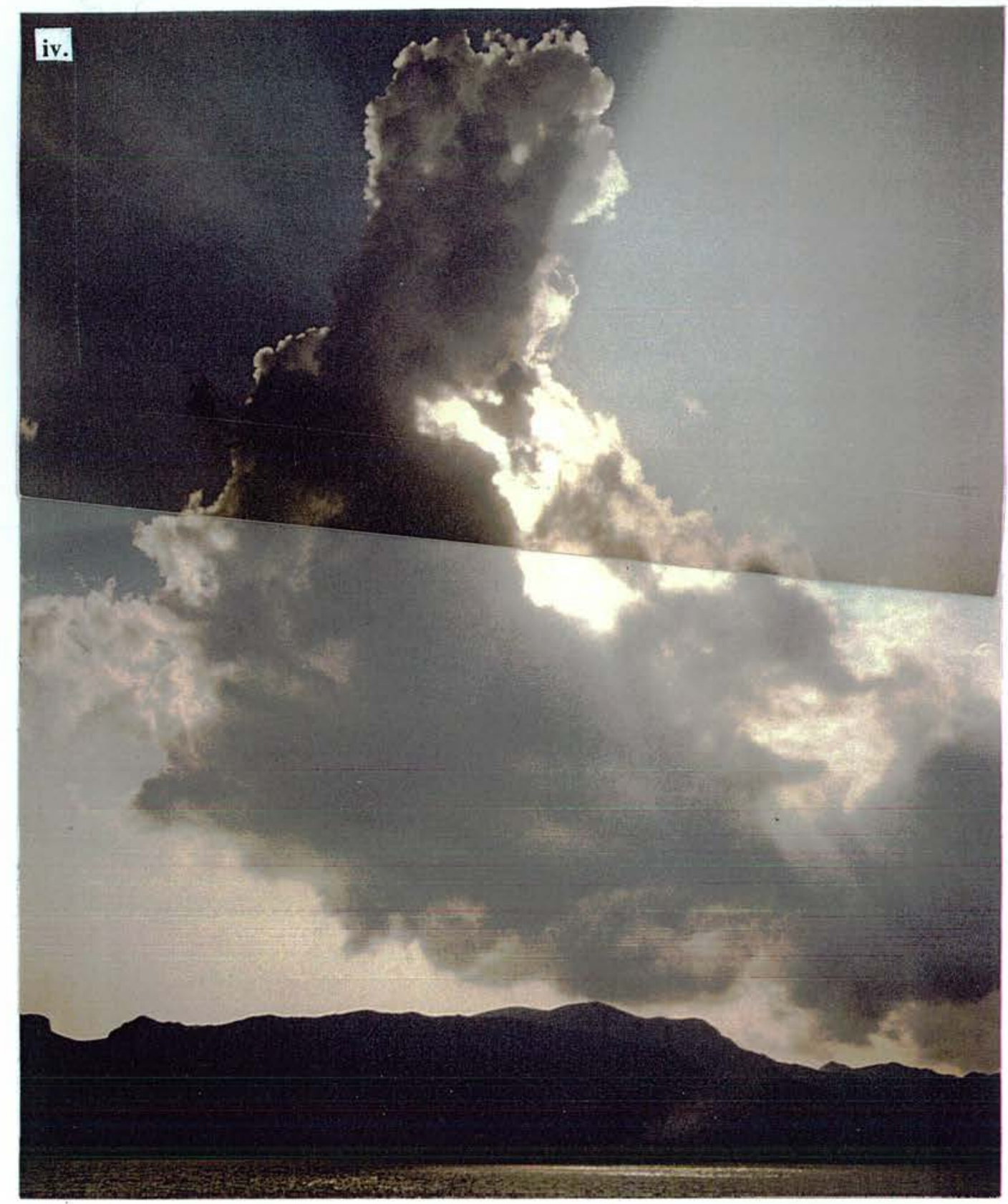

Fig. 49. Development of orographic cloud over southern Malea on a typical summer afternoon.

i. 12 p.m., from the northwest: Cloud begins to form over the highest land, in otherwise clear skies. ii. 4 p.m., from the west: rising heat and humidity lead to the development of cloud across the ridge running down the whole length of the promontory.

iii. 5 p.m., from the south: the view northwards clearly shows that cloud formation begins once the airstream has struck the west (left) coast, and risen over the high land. As the airstream progresses eastwards (to the right), it continues to rise and further cloud develops, indicating unstable air. iv. 5.30 p.m., from the east: cumulus oloud has spread across to the east coast of Malea (pictured here), and is rising rapidly; cumulonimbus may develop, producing rain, squalls, and lightning. Sailors out of sight of the coast knew that such clouds indicated land below, as well as storms. 


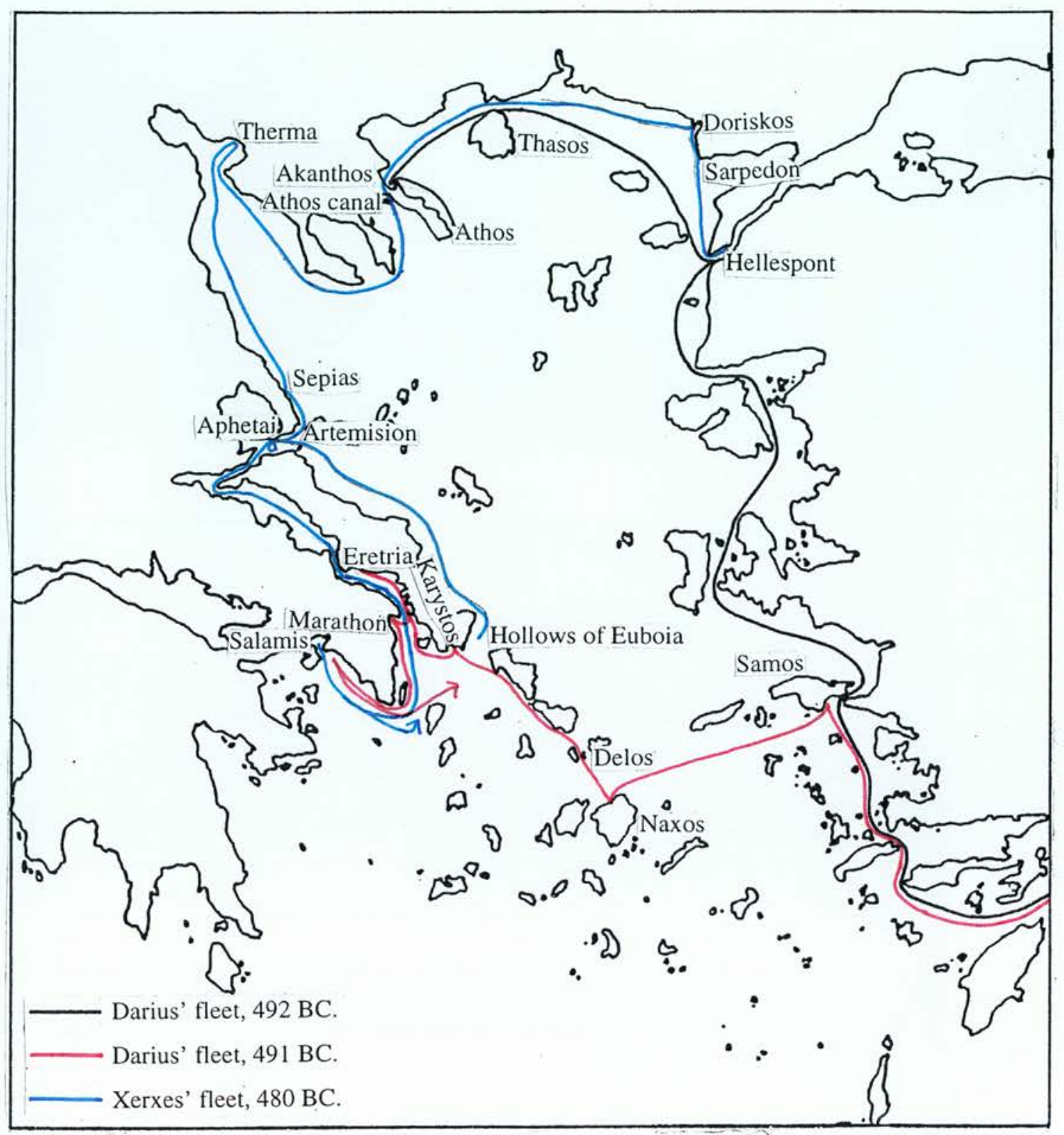

Fig. 50. The routes of the Persian fleets in 492,491 , and $480 \mathrm{BC}$. 


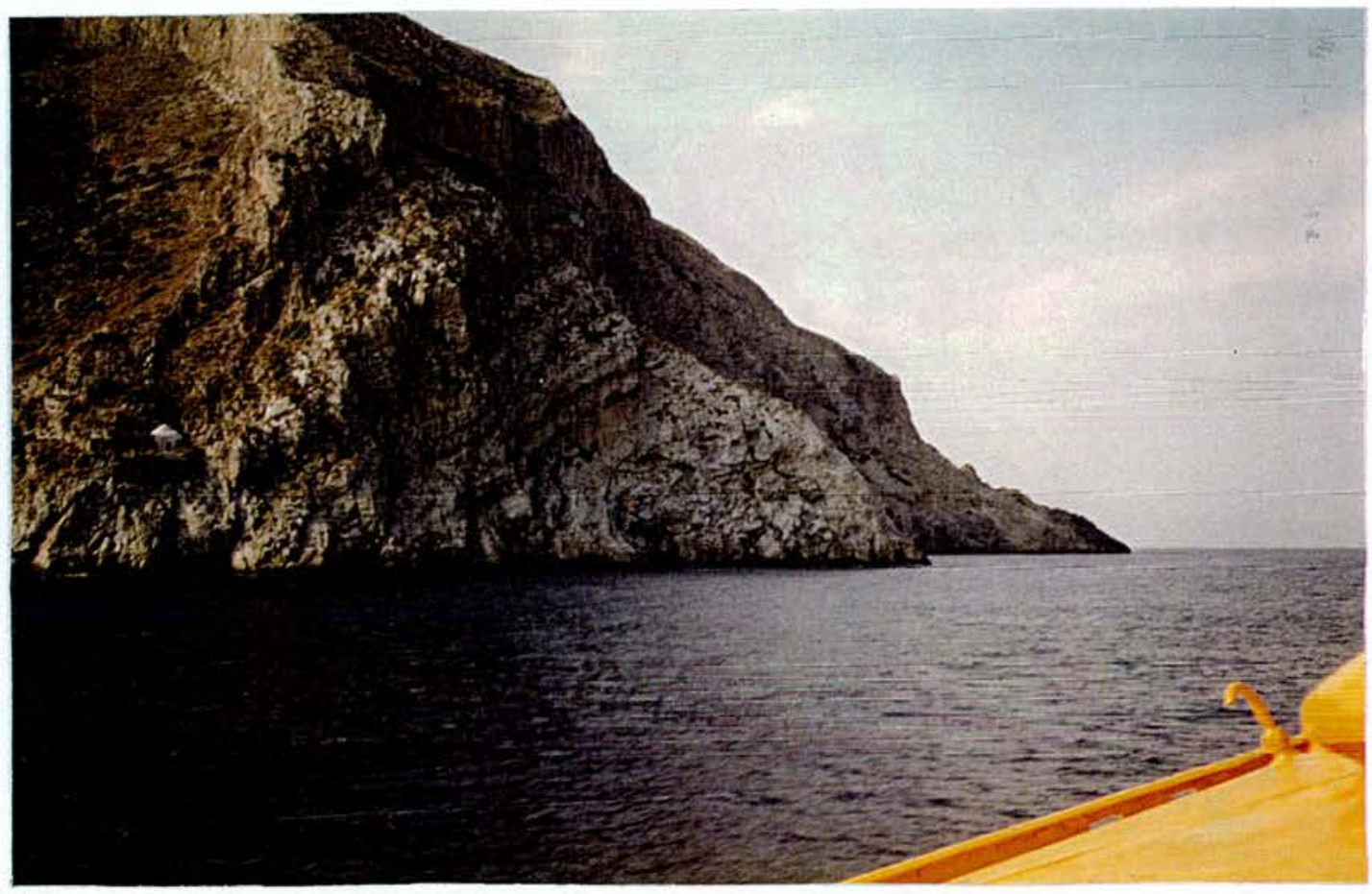

Fig. 51. Malea.

The faulted 'horst' of Parnon reaches its extremity at Cape Malea. Here the steep cliffs falling immediately into deep water offered little opportunity for coming ashore, while the notoriously strong winds and heavy seas often encountered in the area made Malea proverbial for its danger. . 


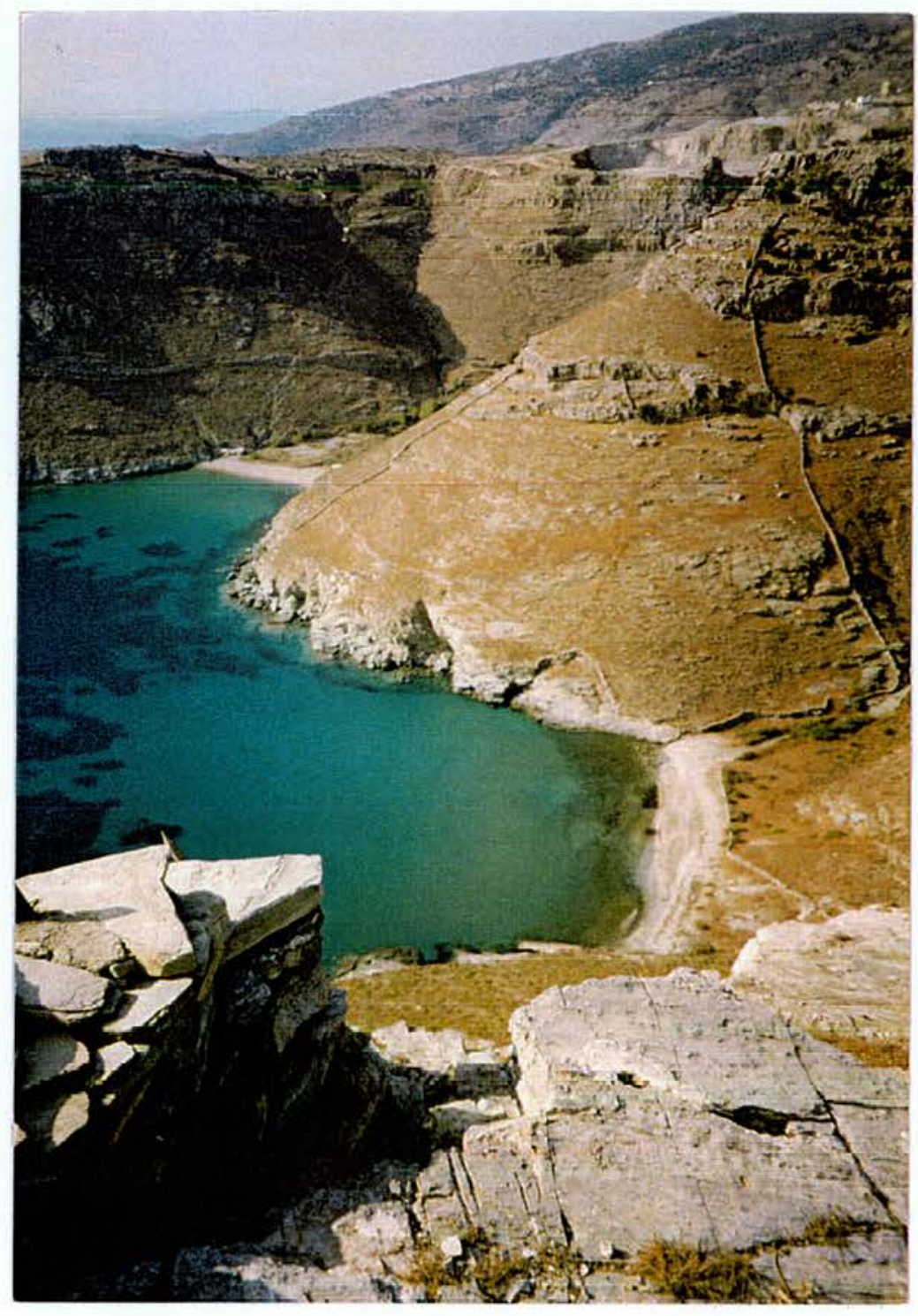

Fig. 52. Zagora, Andros.

This view shows the coast below the promontory upon which the early Greek community of Zagora stood. The community maintained strong contacts with the outside world, and ships owned by local inhabitants, or by those visiting the community, would have sheltered in the undeveloped sandy inlets on either side of promontory. 


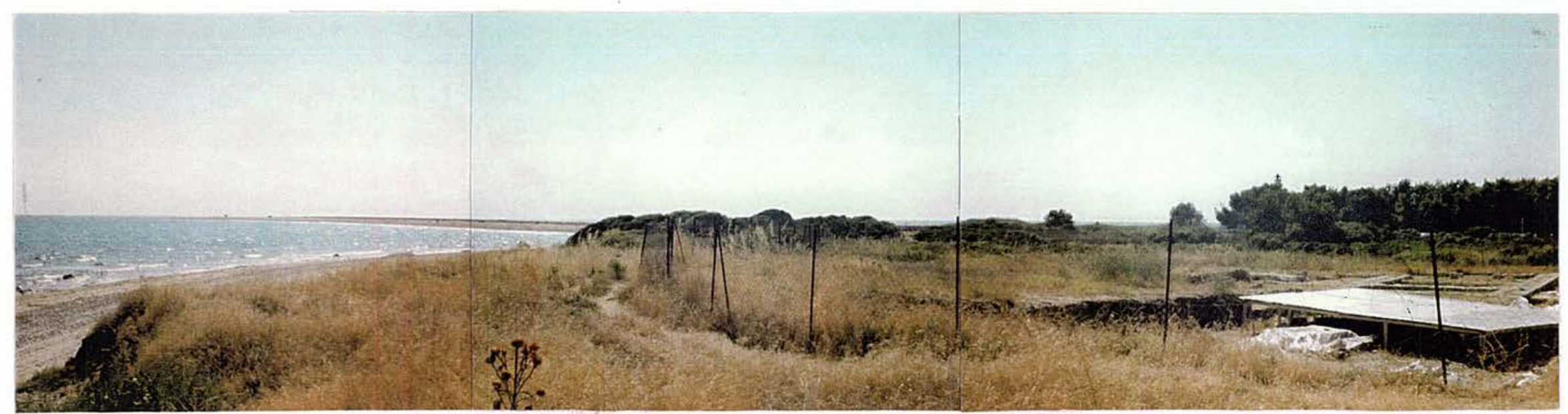

Fig. 53. Cape Posidhi, the ancient Poseidonion in the Chalkidike.

The low promontory, formed through the deposition of sediments and sand, is extremely hard to distinguish from the sea, and was once marked by a temple of Poseidon. The archaeological site to the right of the picture marks the position of this temple. The loosely formed cape is, like most deposition features, subject to changes of shape and position, and thus it may be that, in antiquity, the temple stood closer on, rather than simply near, the promontory. 


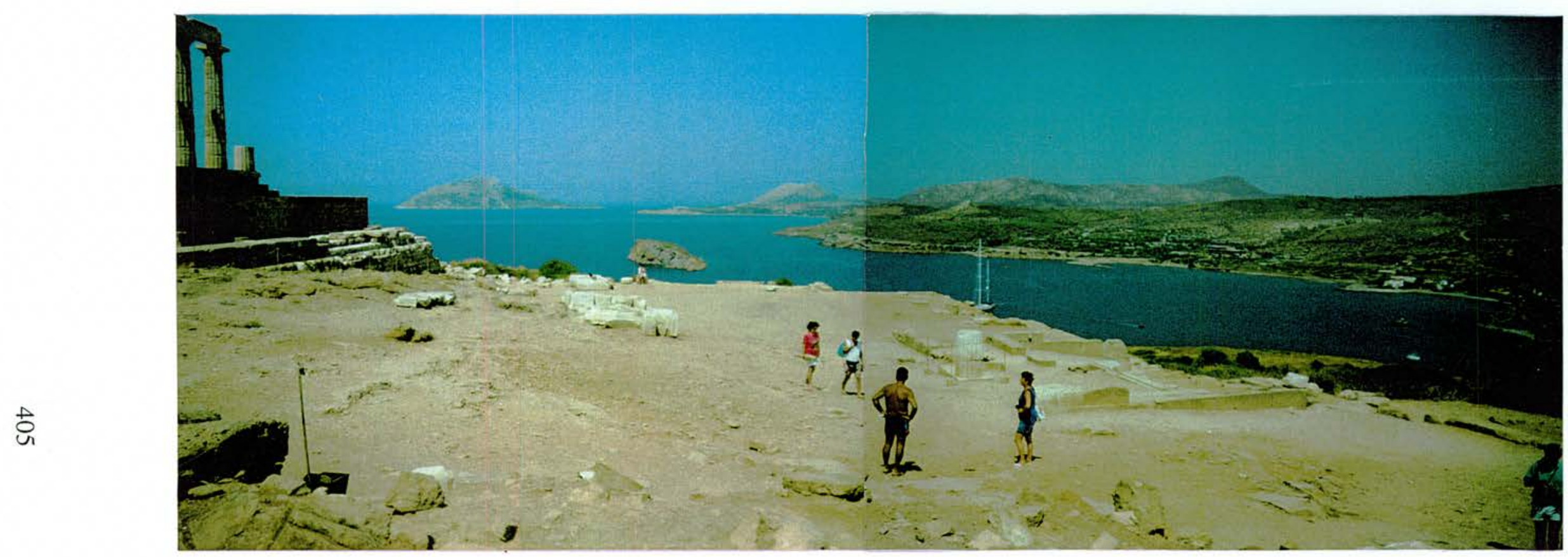

Fig. 54. Legrena Bay, seen from the promontory of Sounion to the east.

Ships unable to round Sounion against the current and strong northerlies such as the Etesians resorted to Legrena Bay, where the promontory of Sounion provided shelter. However, no shelter was available when the strong sea breeze blew landwards from the Saronic Gulf, and ships would then find leaving the bay difficult. 


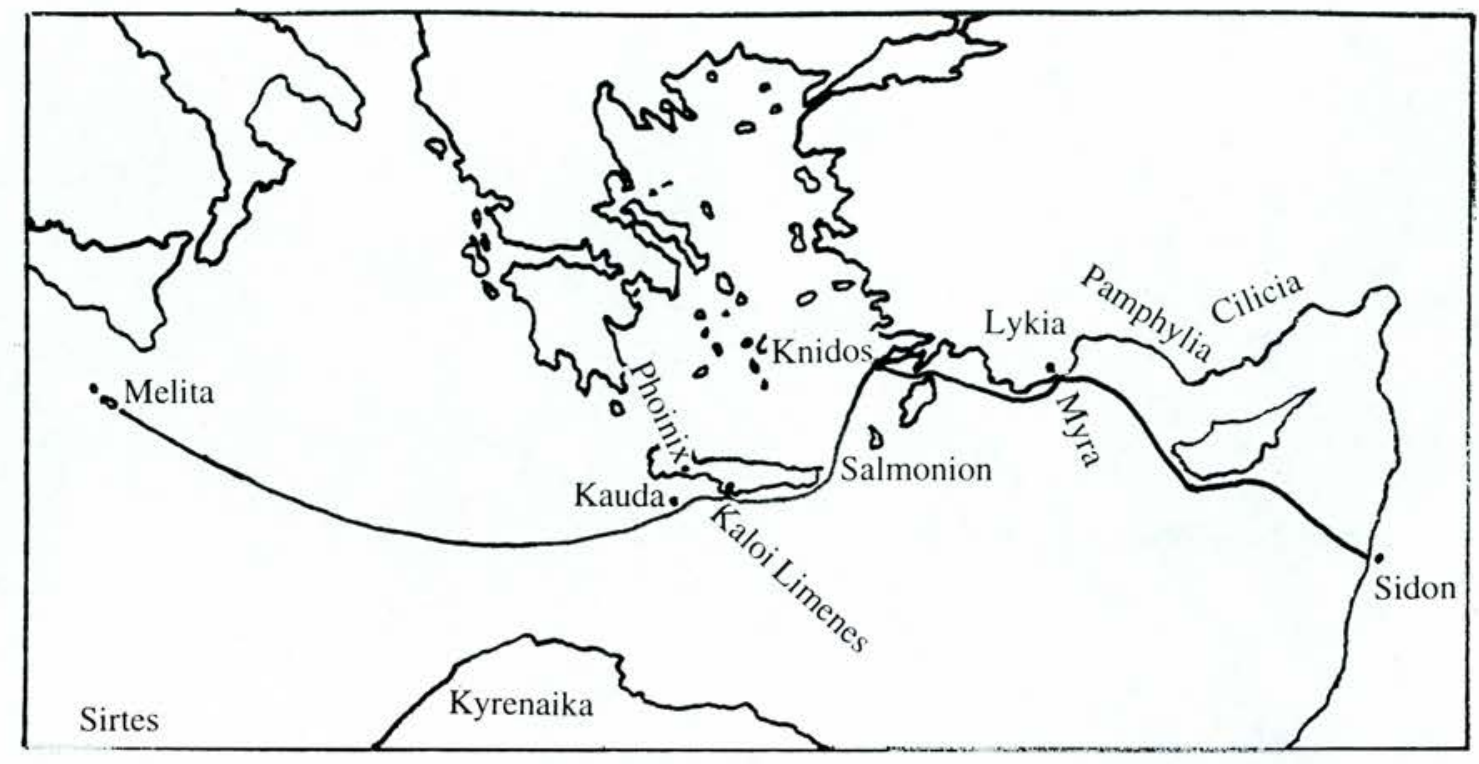

Fig. 55. Paul's route from Sidon towards Rome. 


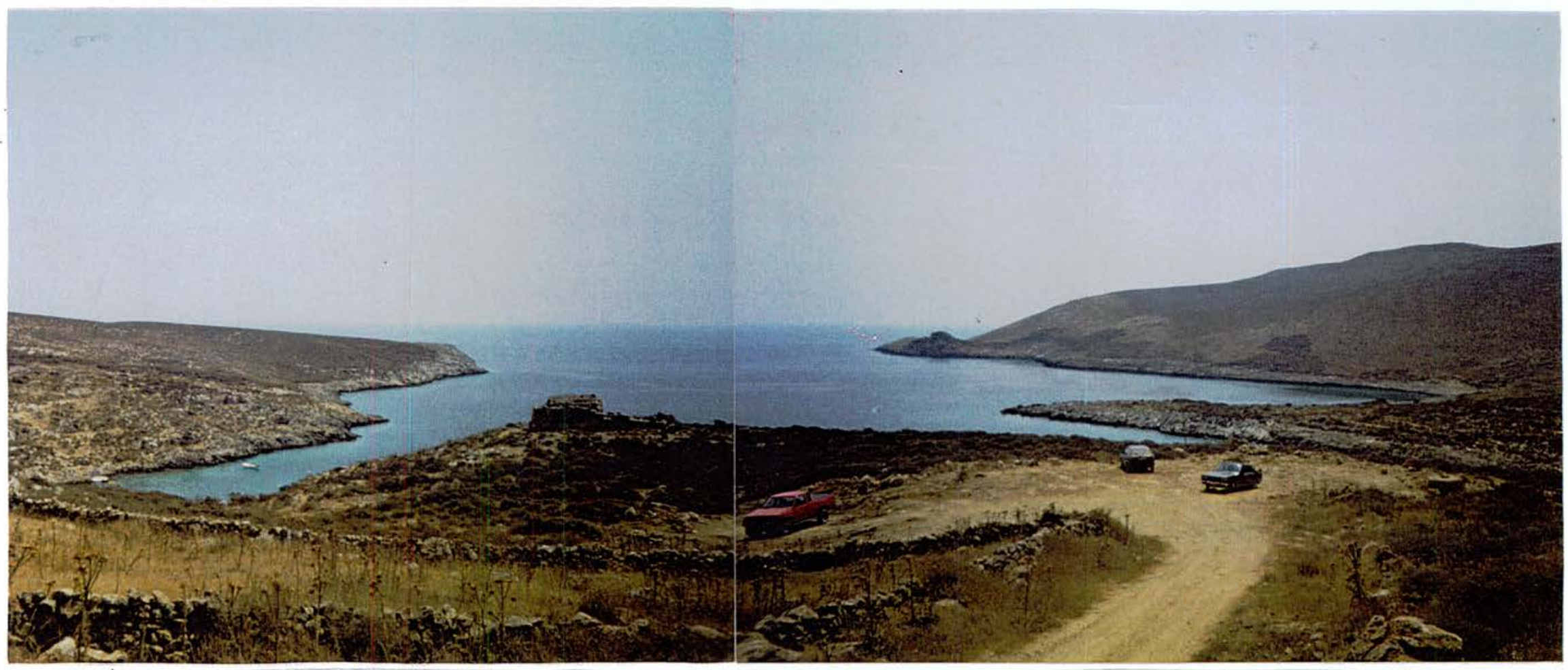

Fig. 57. The sheltered inlet and the site of the sanctuary of Poseidon at Tainaron, Lakonia.

The chapel on the knoll between the two arms of the bay stands on the site of the ancient temple, and incorporates masonry from it. Arion of Methymna was held to have come ashore here when saved from drowning by dolphins; later the inlet was used by the Spartans as a port of departure to overseas destinations. In the Hellenistic period, a settlement grew up here to cater for, amongst others, mercenaries waiting to be hired for service overseas. 


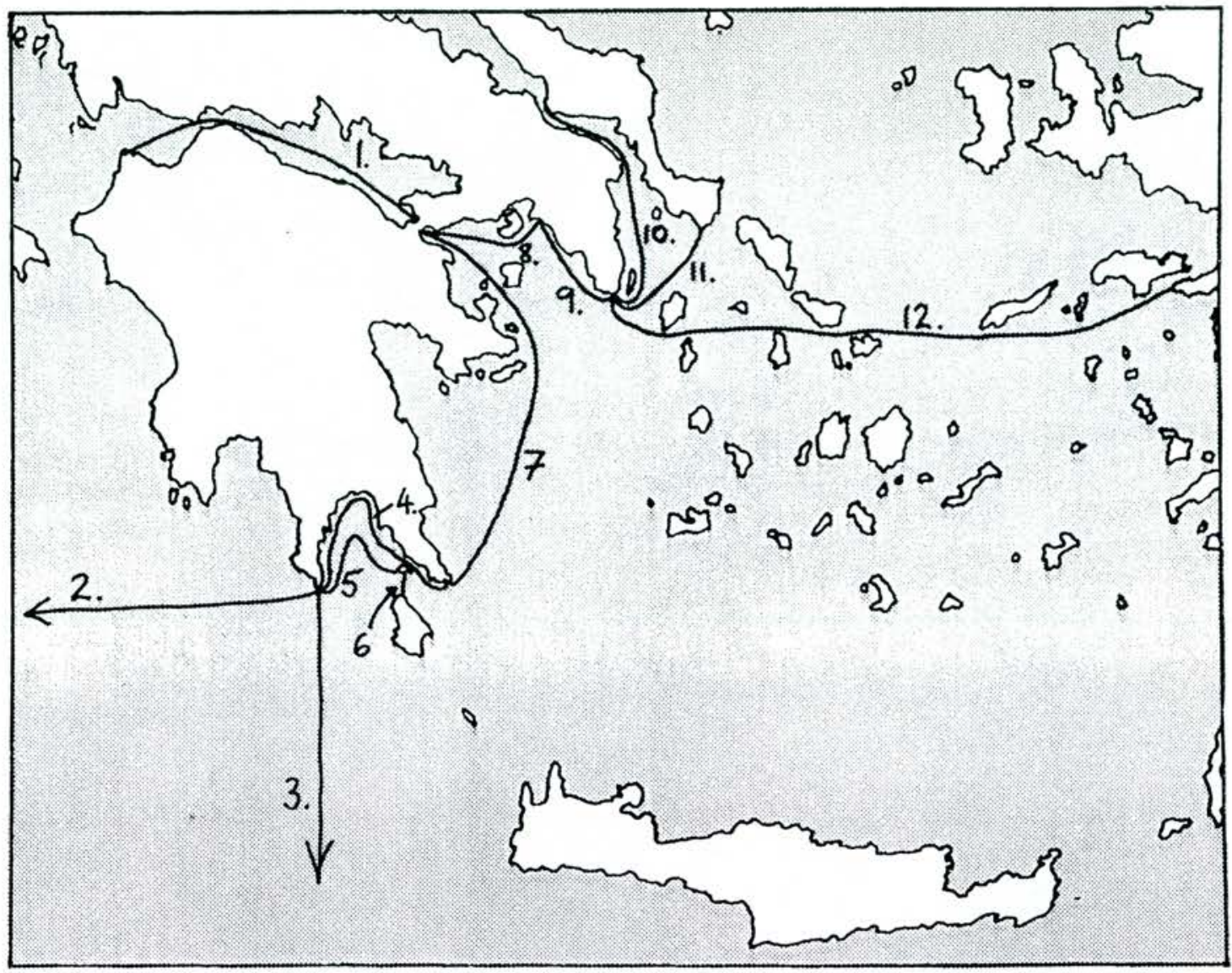

Fig. 58. Distances and 'milestones' on typical sea routes

(Str.Geog. 8.5.1, 6.4, 7.5; 9.1.2, 1.22, 2.8; 14.1.13)

1. Araxos - Isthmus of Corinth: $1030 \mathrm{st}$.

2. Tainaron - Pachynos (Sicily): 4600/4000 st.

3. Tainaron - Phykous $($ Kyrenaia $)=3000 \mathrm{st}$.

4. Tainaron - Malea $=670 \mathrm{st}$.

5. Tainaron - Onougnathos $=520 \mathrm{st}$.

6. Onougnathos - Kythera - 40 st.
7. Malea - Schoinous $=1800$ st.

8. Schoinous - Piraeus $=350 \mathrm{st}$.

9. Piraeus - Sounion - 330 st.

10. Sounion - Euripos $=670 \mathrm{st}$.

11. Sounion - Leuke Akte $=300 \mathrm{st}$.

12. Sounion - Mykale $=1600 \mathrm{st}$. 


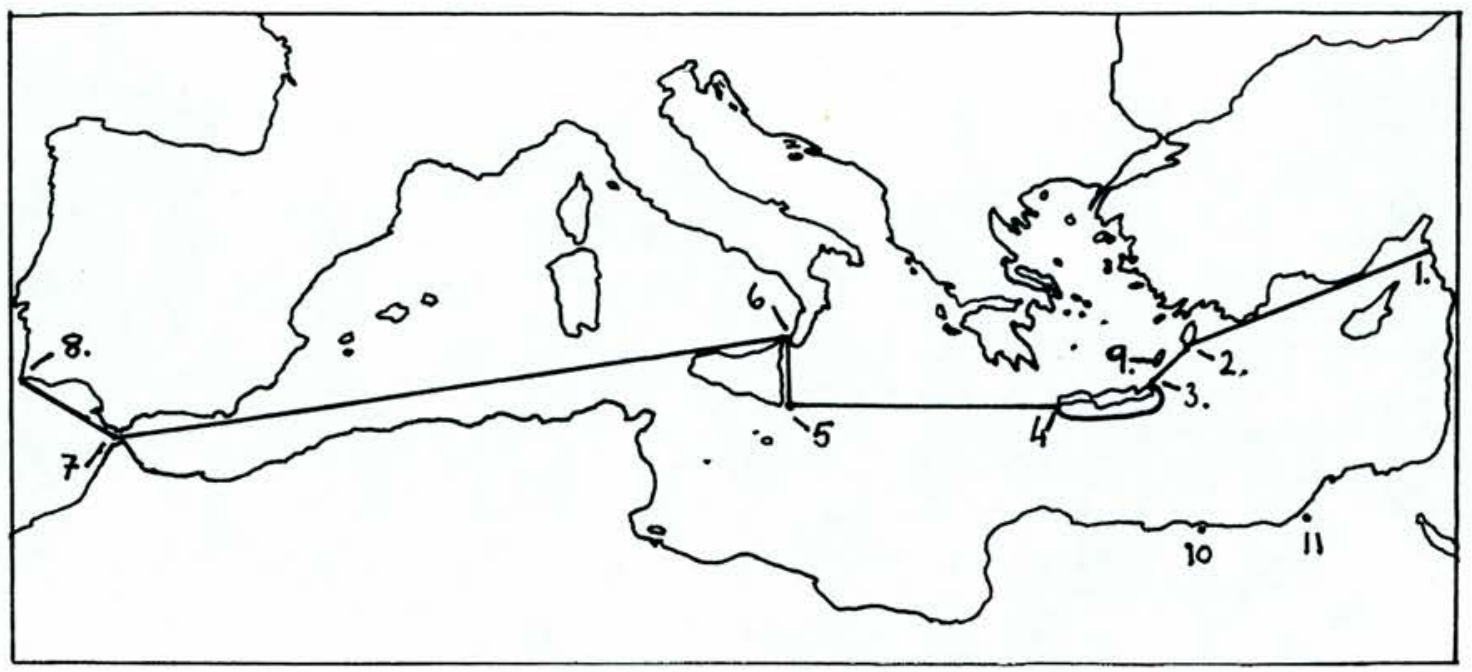

Fig. 59. Strabo's measurement of the Mediterranean (Geog.2.4.3), and the 'opposition' of Nisyros (Karpathos) and Leuke Akte (Geog.10.5.17).

1 - Gulf of Issos. 2 - Rhodes. 3 -Salmonion. 4 - Kriou Metopon. 5 - Pachynos.

6 - Straits of Messina. 7 - Gibraltar. 8 - Sacred Cape. 9 - Nisyros in Karpathos. 10 - Leuke Akte. 11 - Alexandria.

Note that, apart from the starting point at the Gulf of Issos, all the points used in Strabo's measurement of the Mediterranean Sea are either promontories (Salmonion, Kriou Metopon, Pachynos, Sacred Cape), straits (Straits of Messina, Gibraltar), or islands at key points of sailing routes (Rhodes).

The 'opposition' of Nisyros (9) and Leuke Akte (10) appears to relate to their positions on sailing routes between the north and south coasts of the Mediterranean, rather than to any particular geographical relationship between these two points. 

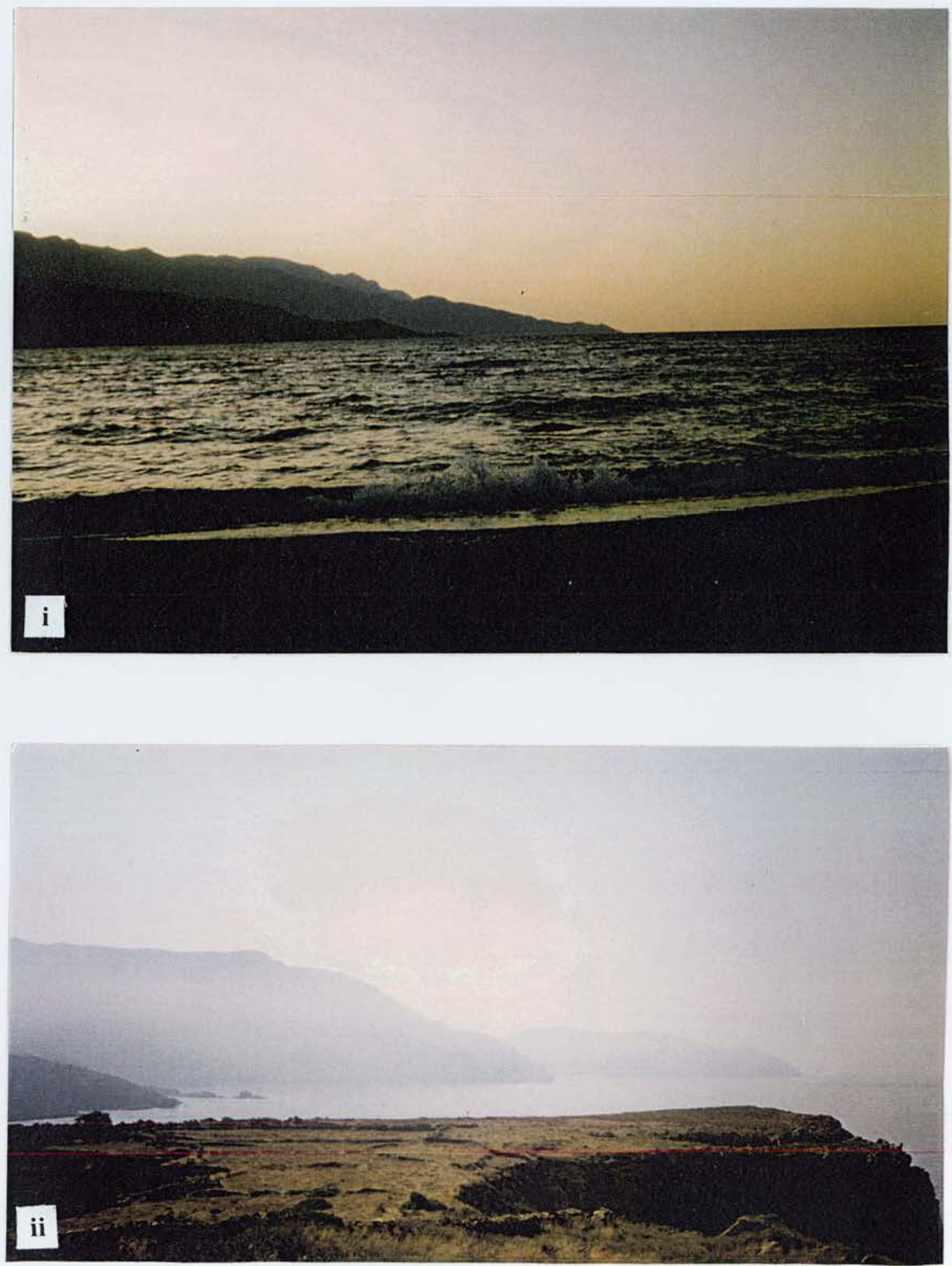

Fig. 60. i. The headlands of northeast Samos at dusk, from the harbour of Vathy.

ii. Headlands on the west coast of the Tainaron peninsula in early morning fog. These images illustrate the degree to which the silhouettes of promontories, running out to their headlands and dropping into the sea, remain clearly visible even in conditions which obscure all other geographical details. 

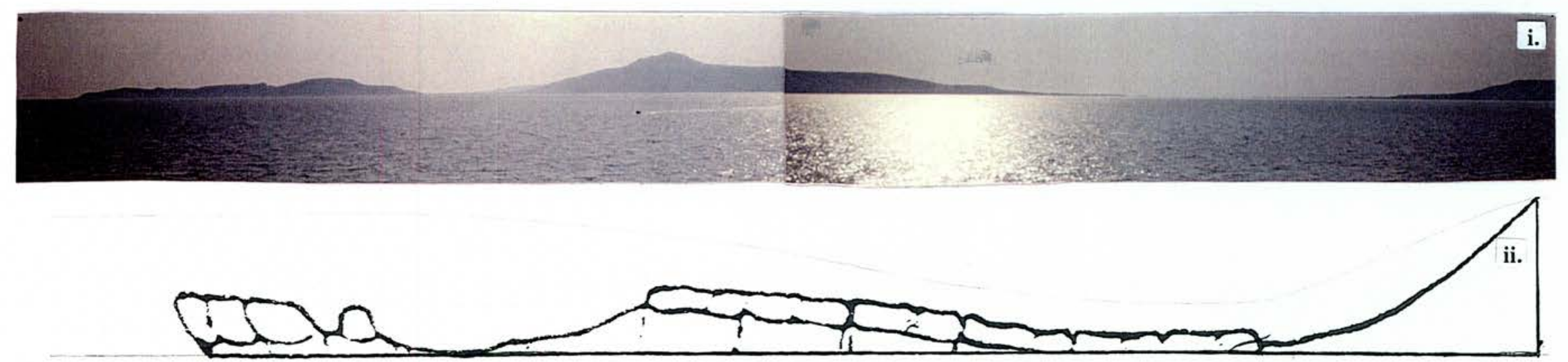

Fig. 61. Onougnathos - 'the Ass's Jawbone'.

i. Onougnathos (mod. Elaphonisos), now an island off the west coast of Malea, was a promontory in antiquity, when relative sea level was lower and the island was connected to the mainland visible on the extreme right.

ii. This illustration of the upper section of the lower jawbone of a horse (the full skull is shown on the right), demonstrates that the promontory was named because, when seen from the seas to the south by mariners navigating around the tip of Malea (i.e. as in the photograph shown above), it clearly resembles an ass's jawbone.

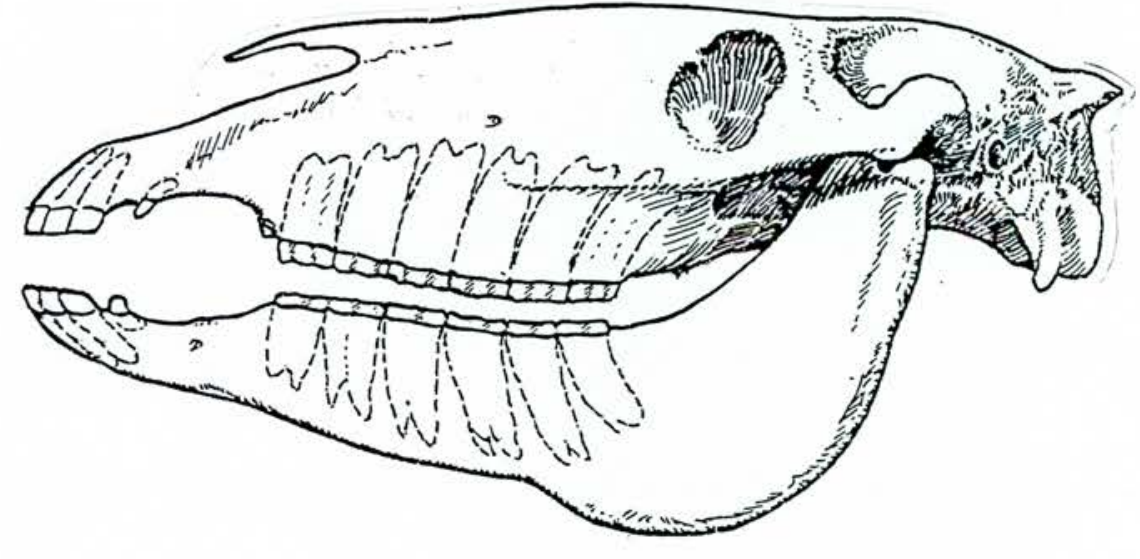




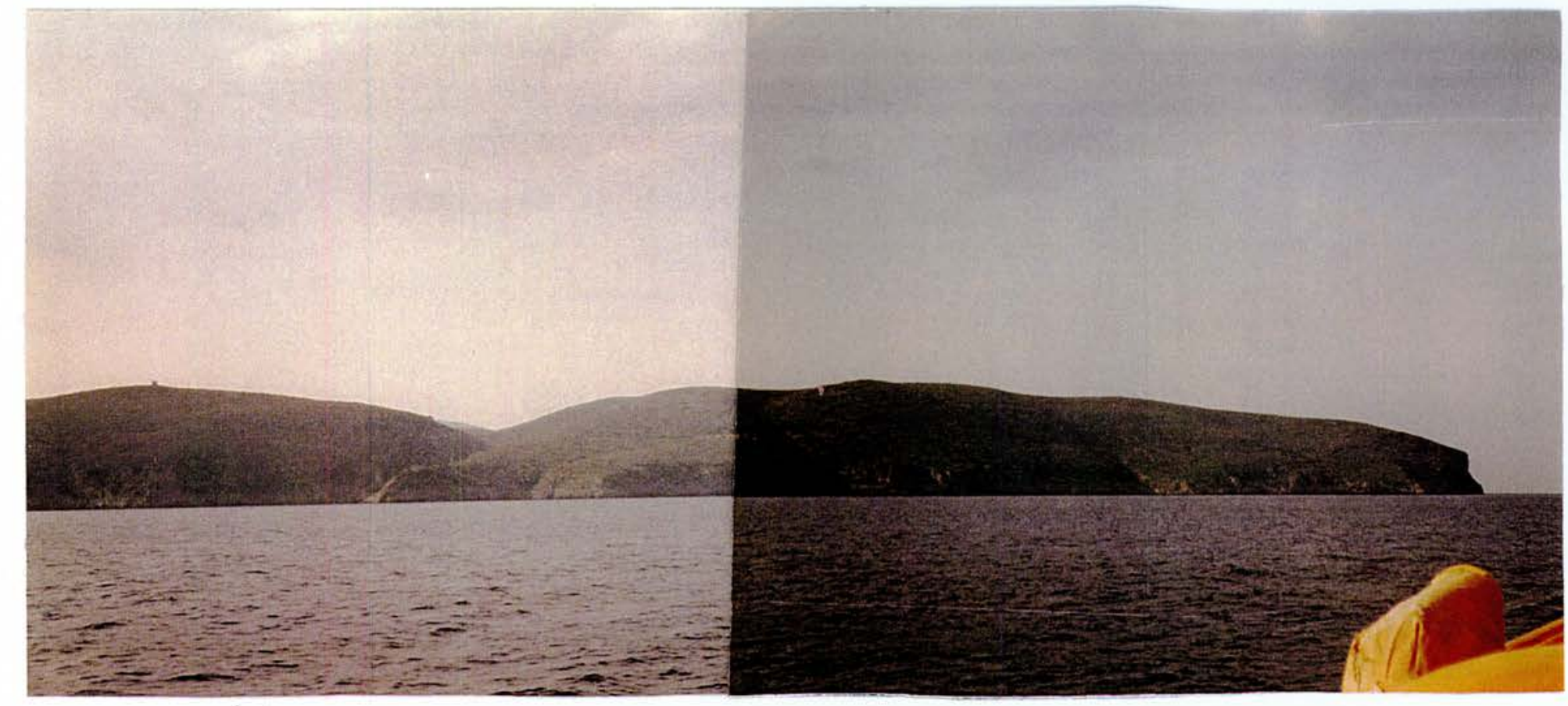

Fig. 62. The southeast coast of the Peloponnese, between Cape Klemmisi and Limenas Yeraka.

Upon this promontory, to the left of the picture, a modern tower stands on the skyline, conspicuous despite its small size. Even from a distance of over a mile, the rectangular silhouette is easily distinguished from the otherwise smooth, featureless crest of the promontory. Ancient towers, tombs, and temples built in similar location would have been equally visible to mariners at sea. 

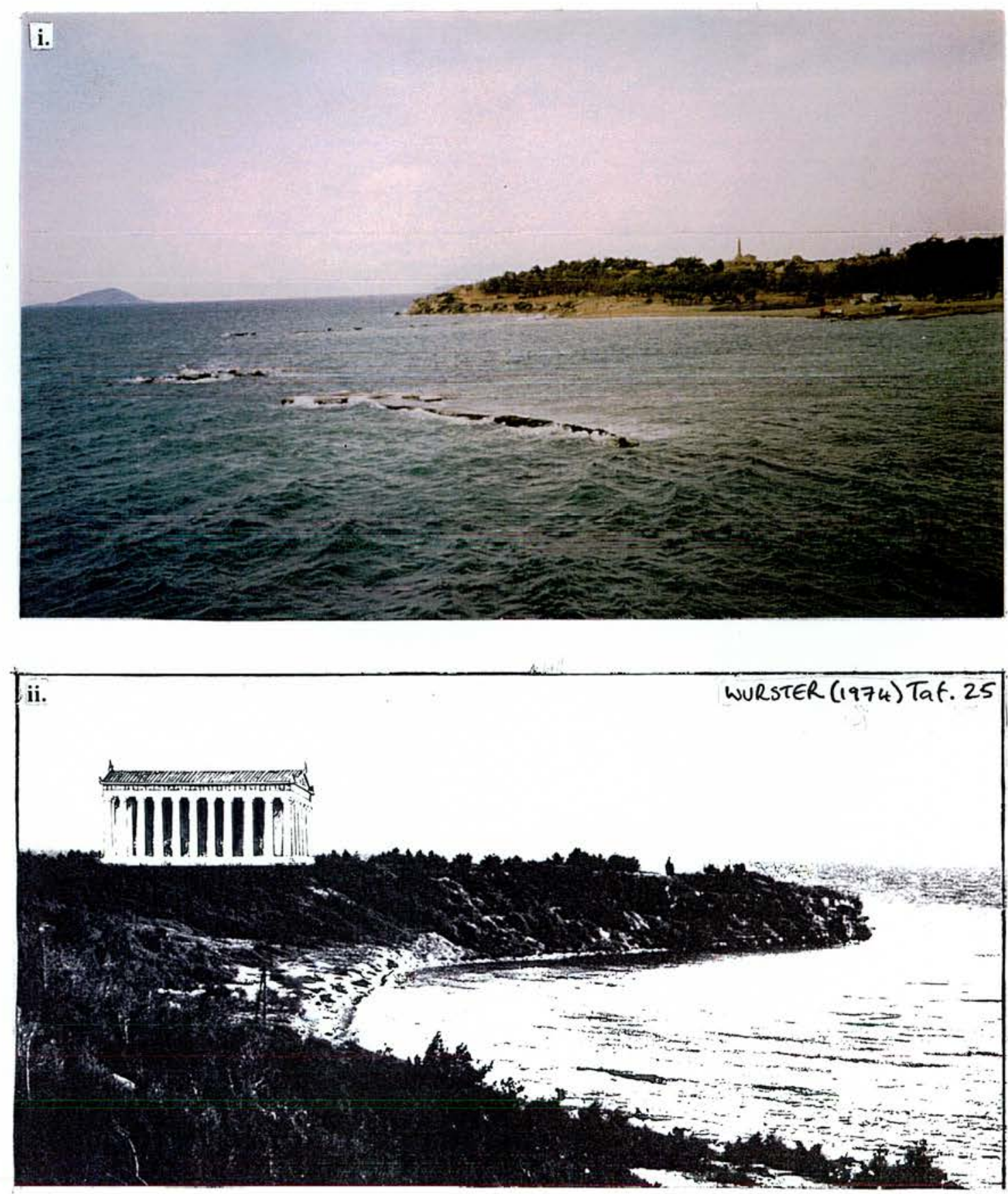

Fig. 63. The temple of Apollo, Aigina.

i. This photograph of the single remaining erect column from the temple, taken from the south, illustrates its clear visibility from out to sea.

ii. Wurster's reconstruction of the view of the complete temple from the north emphasises its prominent position and appearance; it should be noted, however, that this view does not take into account other buildings which stood near the temple and may have partially hidden it. Nevertheless, the temple was clearly visible from out to sea, and would have been an important reference point for those navigating the difficult approaches to this part of the island's coast. 


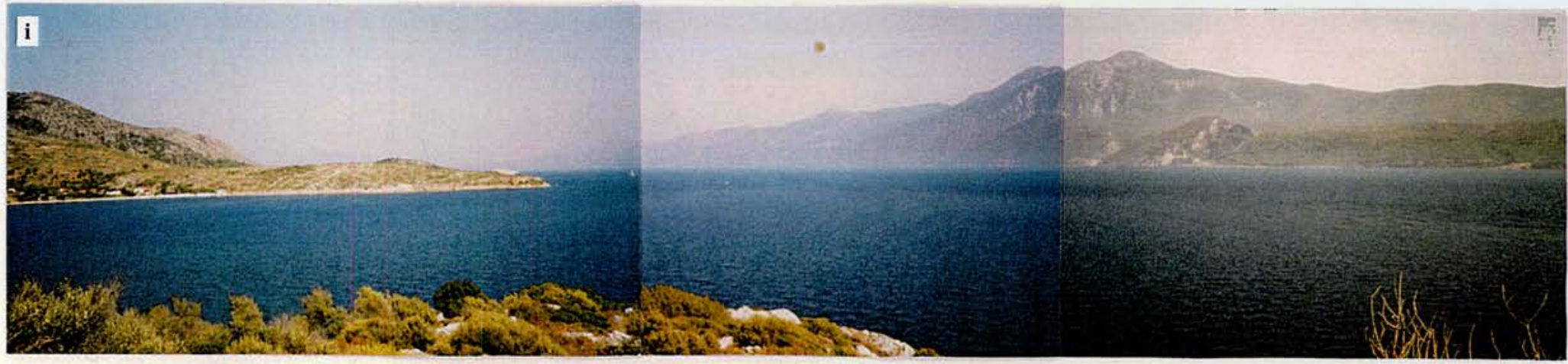

\section{ii}

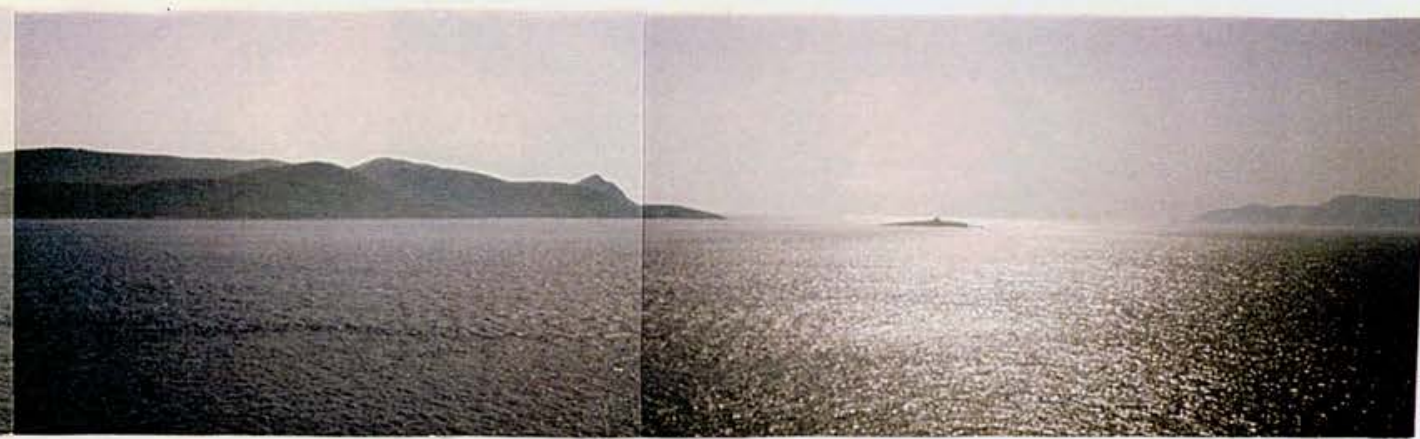

Fig. 64. Views (i) southeast and (ii) southwest across the Samian Strait to Mykale.

The navigation of this long, narrow strait was complicated by variable currents and winds, and by the island at the western entrance (fig.ii). Fixed landmarks were thus particularly useful to mariners navigating the strait, and two such landmarks could be found in the Samian Poseidonion, which stood near the point from which these photographs were taken, and the Panionion, which stood on the slopes of Mykale, overlooking the eastern entrance to the strait. Both shrines had lines of sight along the full length of the strait, and so were ideally placed to be used as landmarks. 


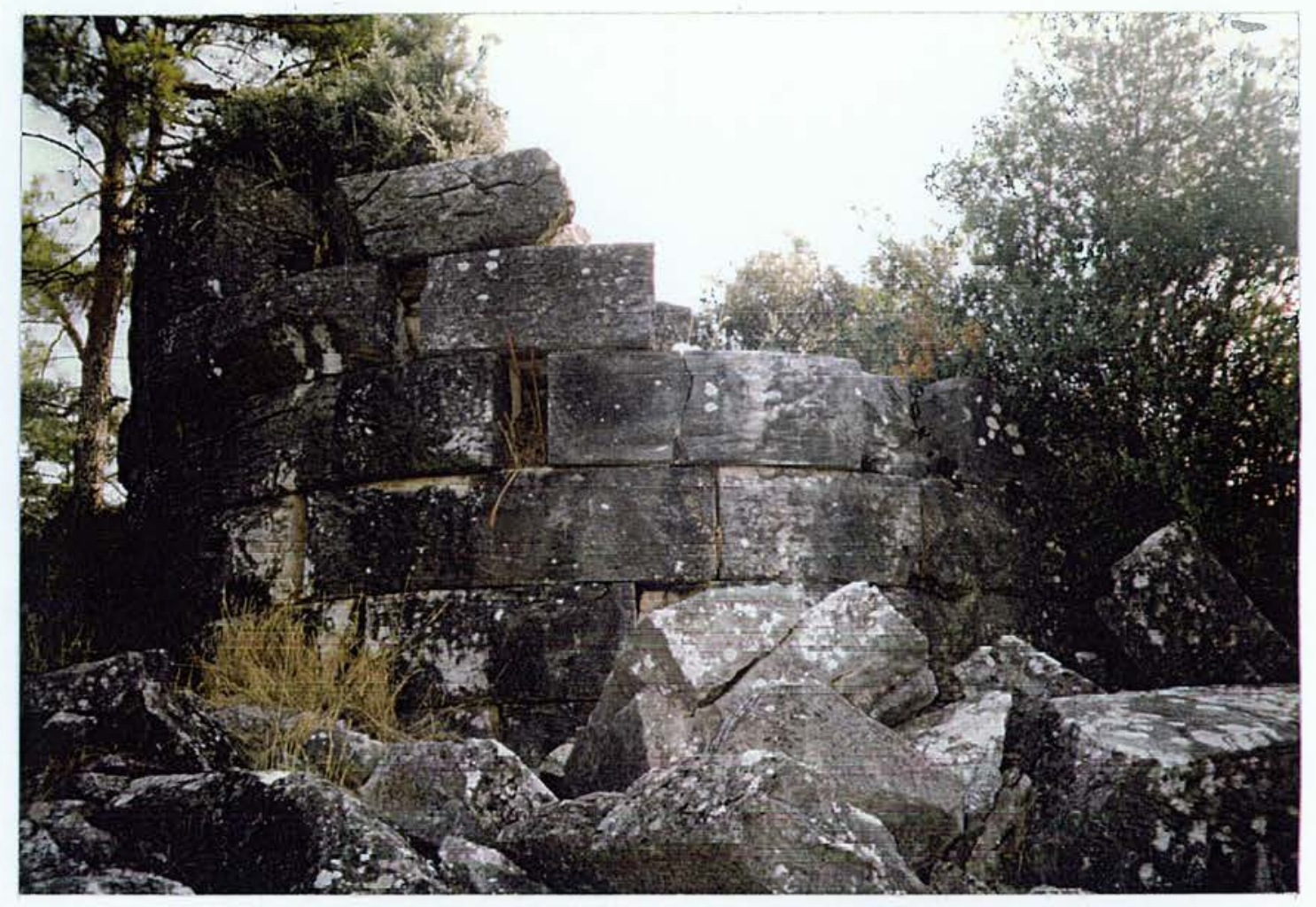

Fig. 65. Monument of Akeratos, Cape Pirgos, Thasos.

This round tower stood upon a headland on Thasos as a memorial to one Akeratos; it served also as a navigational marker for ships rounding the headland in order to make harbour in the adjacent bay. 


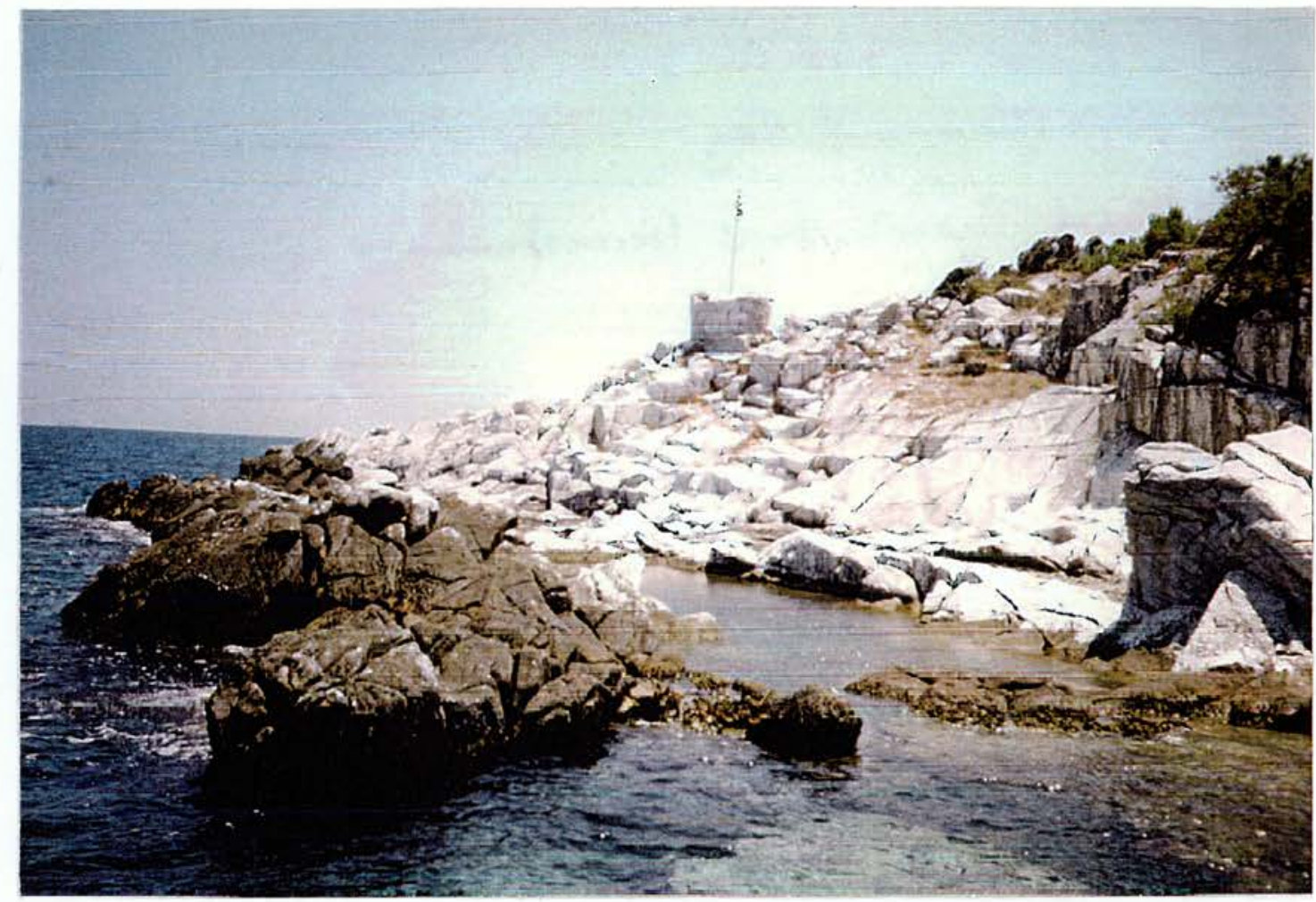

Fig. 66. The tower at Cape Phanari, the northeast point of Thasos.

The tower has recently been rebuilt, but occupies its original position. Its function was presumably as a landmark for those sailing in the vicinity, particularly, one might think, for those sailing to the quarry at the same site, the remains of which are visible in the foreground. 


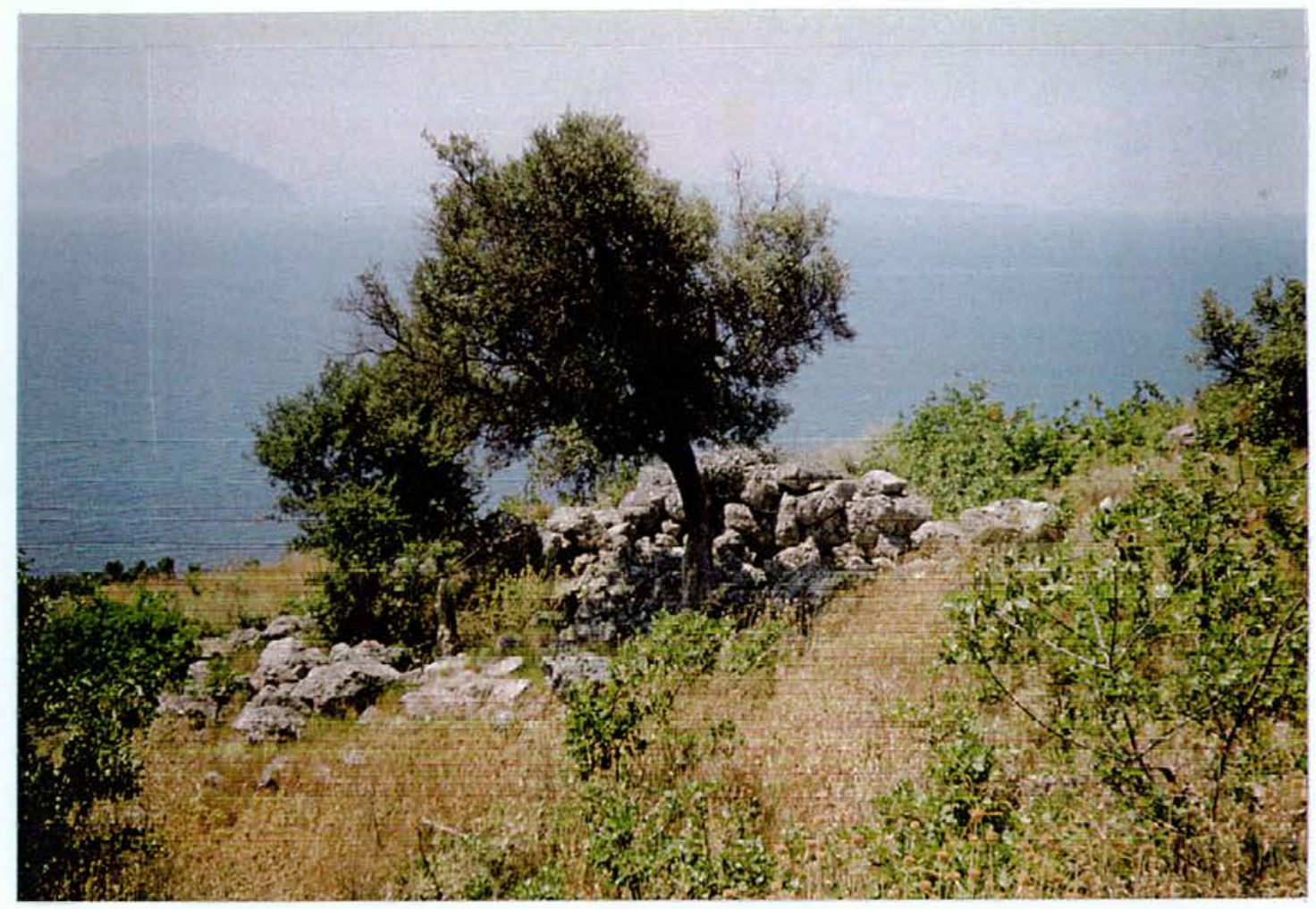

Fig. 67. The tower at Kastri in southern Leukas.

The Hellenic tower commands excellent views, both across the southern shores of the island, and across the southern approaches to the island (see fig.66). Equally, given its prominent position, the tower would have been a notable landmark for those sailing up to the southern shores of Leukas. 


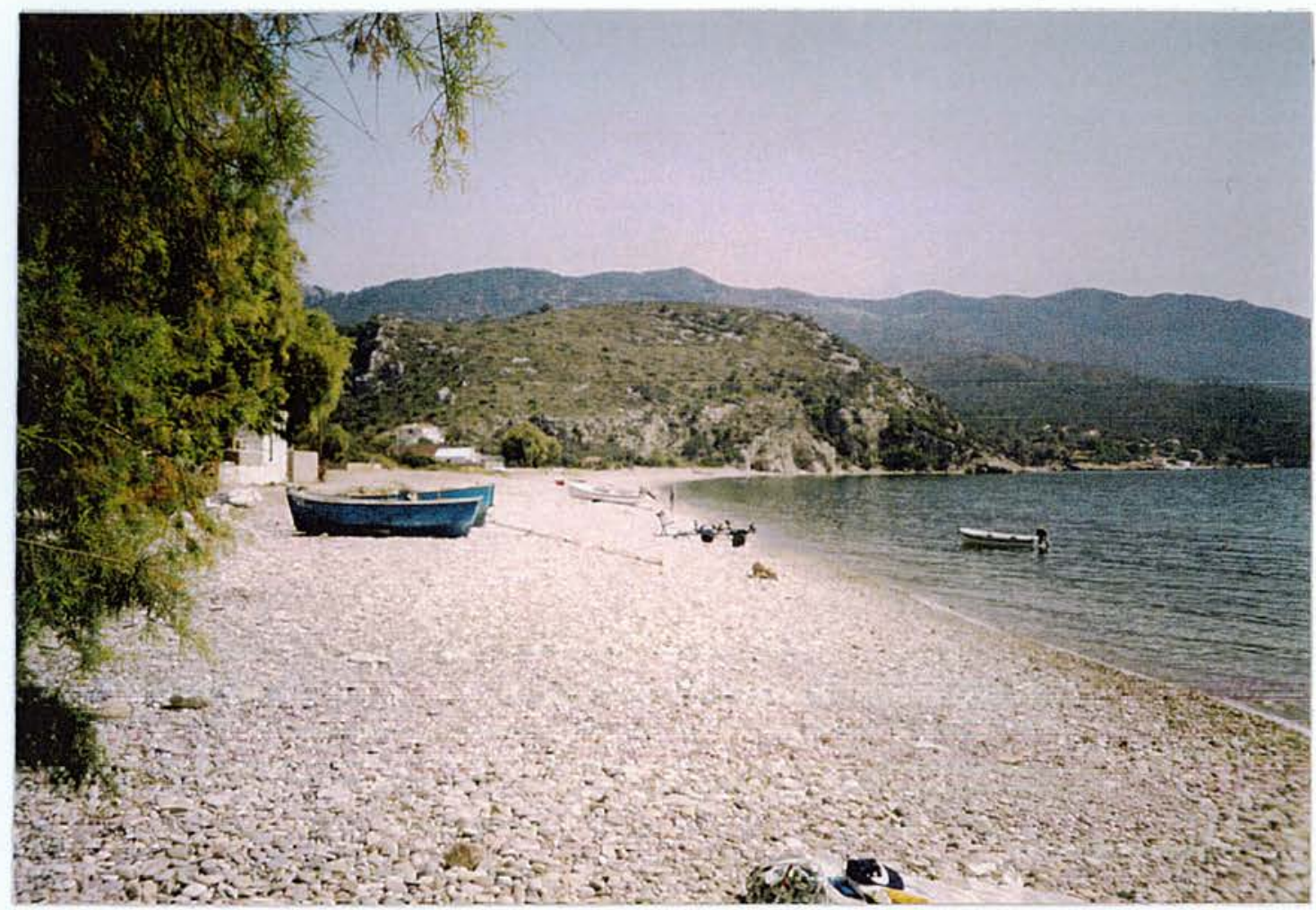

Fig. 68. A pebble beach on the south coast of Samos.

Here, as at countless other locations around the coasts of Greece, a gently sloping beach provides an easy landing place where ships could simply be beached and dragged out of the water. 
The main geographical index includes all named settlements, regions, seas, and features of natural topography mentioned in the text, appendices, and notes (other than those featured solely in personal names such as Quintus of Smyrna). Separate indices of meteorology, of astronomy, of topography together with oceanography, and of temples, shrines and sanctuaries, follow the general index.

Abarnis: p.86.

Abydos: pp.86, 143, 178, 215.

Achaia: pp.32, 93, 169 n.75.

Achaia Phthiotis: p.171.

Achaian Rhion: see Rhion (Achaia).

Achaians, harbour of the (Asia Minor): p.144.

Achelous, river: pp.31f., 120. n.67.

Acheron, river (Black Sea): p. 103.

Acheron, river (Thesprotia): n.297.

Acherousian headland/height/chersonesos: see Acherousias, Cape.

Acherousias, Cape: pp.39, 103, 174. nn.297, 427, 518,.

Actium: n.219.

Adramyttion, Bay of: pp.75, 142f., 170.

Adriatic Sea: pp.9, 41, 47, 50ff., 56, 63f., 77$80,100,108,114,117,122,125,127$, 131ff., 189, 191, 200, 208f., 215. $\mathrm{nn} .31,121,242,325,466,580,587$,

Aegean Sea: pp.9f., 12, 14, 18-21, 25, 28ff., $41,43-7,50,52,56,63,782 \mathrm{f}, 75,77-80$, $85-8,91,93,99,104,106,108,114 \mathrm{f}$., 122,125 ff., 130,148 ff., 154 ff., 158,161 f., 167f., 170f., 183f., 191f., 203, 208f., 212ff., 221ff., 231, 236, 240, 243, 268, 270.

nn.13, 131, 147, 174, 177, 229, 241, 248, 264f., 273, 278, 289f., 301, 351, 389, 403, $419,425,466,480,495,509,519,567$, 587.

Aegyptos: see Nile.

Africa: pp.10, 17, 40, 47, 49, 52, 79f., 131, $136,141,165,218,227,229,232,251$, 258, 262, 264, 266. nn.336, 383, 536, 597, 609f., 631.

Aigaleon: p.19.

Aige: p.142.

Aigialos: p.159f.

Aigina: pp.7, 30, 70 160, 215, 236, 273, 275. nn.232, 277, 389, 432, 588.

Aigion: p.144. n. 425 .

Aipy: p. 149.

Aitolia: p.32.

Akanthos: p.77f.

Akarnania: pp.87, 120, 148. nn. 52, 254, 259.

Akeratos, memorial of: p.176. $\mathrm{nn} .425,430$.

Akragas: p. 225 .

Akrathos headland: p.168.

Akritas: pp.20, 78f., 106, 273. n. 401 .

Akrokeraunia: see Keraunia.

Akrotiri: n.423.

Akte peninsula (Piraeus): pp.98, 112f., 117, 120. $\mathrm{nn} .73,421$.

Alkimos, headland of (Piraeus): pp.38, 173.

Alexandria: pp.35, 116f., 131, 164f., 175f., $183,189,218,238$. nn.220, 358, 418 .

Algeria: n.631.

Alpheios, river: pp.31, 149, 151f., 196. n. 381 .

Alps: p.51.

Amastris: pp.111, 147.

Amisos: n.433.

Amnisos: pp.95, 102. n.277.

Ampelos: p.142.

Ancona: p. 190.

Andonis, Cape: p.70.

Andros: pp.29, 45, 86, 93. nn.253, 278, 389 .

Anemourion, Cape: p.147.

Anigros, river: p.117 n.333.

the Ant: pp.94, 213. nn.274f., 406.

Anthedon: n.543.

Antikythera: n.525.

Antissa: pp.32, 121.

Antron: p.94. 
Aperopia: see Dokos.

Apennine moutain: pp.74, 145, 160.

Aphetai: p.125f. n. 264 .

Aphytis: p.142.

Apollonia: p.75.

Arabian Gulf: n.418,

Araxos: pp.73, 162f. $\mathrm{nn} .230,375$.

Arene: p. 149 (see also Samikon).

Areopolis: $n .533$.

Ares, Isle of: nn.228, 316, 481 (see also Aristias island).

Argennon: pp.91, 170. n.66.

Arginousai islands: pp.170, 179.

Argolic peninsula: pp.7, 20, 69, 81, 93, 111, 113, 160, 275. nn. $271,323$.

Argos: pp.100, 155, 160.

Argos, Gulf of: pp.20, 100, 108. nn.158, 293, 312.

Argyphea: p.149.

Aristias island: n.228 (see also Ares, Isle of).

Artanes river: p.116.

Artemision: pp.94, 125, 171, 213f. nn.264, 272, 425, 427, 434, 497, 639.

Artemita: p.32.

Asia: pp.48, 80, 115, 143, 157f., 184. n. 418

Asia Minor: pp.14, 18, 21, 30, 40f., 46, 50, 52, 63, 74f., 90ff., 99, 115, 123, 143f., 151, 156, 163, 170f., 177, 215, 222, 225, $268,272$.

nn.13, 66, 147, 231, 241, 265, 281, 382, $388,418,431,485,557,575$ (see also Asia).

the Ass of Antron: p.94. n.406.

Assa: p.142.

Astakos: p.120.

Astakapra: p.219.

Asteris: n.416.

Atalante: p.274f.

Athens: pp.109, 148, 160, 162, 242. nn. 313, 365, 381, 509, 519.

Athos, Mt. and peninsula: pp.77ff., 126, 142, 167, $212 \mathrm{f}$. nn. 350,486 .

Atlantic (Ocean): pp.13, 40, 48f., 84, 127, 192, 211, 222, 231, 237, 255. nn.349, 479, 532, 609 .

Attica: pp.19, 74, 99, 101, 157, $160 \mathrm{f}$. nn. 10, 229, 232, 272, 406, 495.

Aulis: pp.93, 114, 214. n. 272 .
Axios, river (mod. Vardar): pp.14, 31. nn.10, 67 .

Ay. Ioanni Tholou Bay: n.273.

Ay. Helena, Cape: nn.66, 423.

Ay. Stephanos island: n.273.

Ay. Pavlos, Nisi: n.324

Azarium: p.218.

Azores: pp.48f., 255.

Azov, Sea of: see Maiotis, Lake.

Babouras, Cape: n.423.

Balearic islands: n.504.

Barbarikon: p.219.

Barygaza: p.218f.

Belerium (Land's End): p.149.

Bianco, Cape: see Argennon.

Bithynia: p.130.

Bithynian Sea: p.39.

Black Cape: see Melaina prom. (Black Sea).

Black Corcyra: p.170.

Black Sea: pp.10, 13, 40f., 44, 57, 74, 85f., $103,110,115,127,130,147,159,169 f .$, 184, 192f., 209, 225, 243. nn.249, 316, 334, 351, 365, 374, 389, 418f., 426, 433, 454, 473, 483.

Bodrum: n.13.

Boiotia: p.19 n.543.

Bosporos: pp.9, 40, 44-7, 60, 82, 84ff., 94, 136, 170, 173, 184, 200, 209, 225, 243. nn.114, 117, 147, 240, 249, 418f., 433, $454,509$.

Bouporthmos: n.318.

Britain: p.149. n.617.

Brundisium: pp.149f., 153, 189. nn. 379, 580 .

Byzantion: p.142f.

Caesarea: p.104.

Calm Harbour (Piraeus): see Kophos Limen (Piraeus).

Calm Harbour (Torone): see Kophos Limen (Torone).

Cavo Grosso: see Thyrides.

Cayster, river: pp.14, 31 .

Chalkidike: pp.20, 32, 97, 126, 212. nn. $350,418,423,425$.

Chalkis (Aitolia): n.254.

Chalkis (Euboia): pp.47, 162, 181, 193.

Chalkis (Peloponnese): p.149.

Charybdis: p.83f. n. 489 .

Cheimerion: p. 75 . nn.230, 297, 393.

Chelidoniai, Cape/islands: n.485. 
Chelontas: p. 147

nn. $225,406$.

Chersonesos (Black Sea): p.147.

Chersonesos prom. (Euboia): p.45.

Chersonesos, Thracian: see Thracian Chersonesos.

Chian strait: pp.30, 83, 90f., 93, 133, 156, $215,268,272$. nn.66, 266, 281, 382 .

China Sea: n.575.

Chios: pp.30, 46, 91, 97, 155f., 158, 170, 268.

nn.66, 174f., 266, 278, 281, 299, 382, $388,418,423$.

Cilicia: pp.74, 104. n.418.

Clashing Rocks: see Cyaneae.

Colonna, Cape: see Lakinion.

Columna: p.84.

Corcyra: pp.29, 75, 110, 114, 128, 153f., 179, 273, 276. nn.219, 264, 316f., 351, 381, 384, 386f., 392f. (see also Drepane, Scheria).

Corcyra channel: p.83. nn. 393, 418, 431.

Corinth: n.564.

Corinth Canal: n.560.

Corinthian Gulf: pp.47, 82f., 87f., 90, 98, 101, 161f., 177, 214, 269, 271, $274 \mathrm{f}$. nn.121, 242, 254, 258f., 288, 296, 406, 425, 434, 480, 566, 580, 639.

Cretan Sea: pp.43, 226.

Crete: pp.7, 40f., 44, 79-82, 95, 102, 104ff., $114,123,125,134,146,151 \mathrm{ff} ., 161$, 163f., 168ff., 180, 189, 222, 226. nn.7, 231, 241, 277, 350, 376, 428, 480, 518.

Cumae: pp.181, 193.

Cyaneae: pp.94, 130, 171, 184 nn.454, 487.

Cyclades: pp.18, 29f., 162f., 212. nn. 398, 495.

Cyprus: pp.104f., 147f. nn.7, 89, 232, 519, 635 .

Cyrenaica: n. 631.

Dalmatia: pp.19, 25, 28, 122. n. 325 .

Dardanelles: see Hellespont.

Dardania: p.86.

Delos: pp.96, 108f., 270. nn. $278,485,502$.

Delphi: pp.74, 119, 214, 271. n.639.

Delphinion Bay: n.273.

Derrhis: p.167.
Diktynnaion: p.153 n. 428 .

Dneister, river: see Tyras.

Dodekanese: n.13.

Dokos: p.112f. n.174f.

Dokos strait: n.271.

Dolicha: n.375,

Dolops, tomb of: p.172.

Don, river: see Tanais.

Doro, Cape/Cavo: see Geraistos

Doro channel: pp.45f., 86f., 93, 99, 106, 109, $115,163$. nn.116, 253, 327.

Drepane: p. 110 n.316 (see also Corcyra).

Drepanon: pp.32, 169. n.75.

Ducato, Cape: see Leukatas.

Dyme: p.149.

Eastern Sea: see Black Sea.

Echinades: pp.32, 120. n.74.

Eetioneia (Piraeus): p.113.

Egypt: pp.31, 40, 50, 52, 81, 116, 141, 148, $152,189,200,209,222,225,227,259$. nn.376, 383, 485, 516, 518f., 624, 631 .

Eileithyia, cave of (Crete): p.95.

Eion on the Strymon: p.115.

Elaia (Asia Minor): p.144.

Elaious (Hellespont): p.179.

Elaitic Gulf: p.144.

Elea (Lukania): n.543.

Eleia (Peloponnese): pp.31, 161.

Elis: pp.101, 149, 273. nn.381, 418 (see also Eleia).

Emborio: pp.97f., 268. nn.278, 281, 284.

English Channel: p. 163. nn.359, 407, 431.

Epeiros: pp.19f., 97, 122, $149 f$. nn.25, 27, 52, 200, 321, 384, 580.

Ephesos: p.14. n.389.

Epidamnos: p.150.

Epidauros Limera: p.275.

Epizephyrion: see Zephyrion (Italy).

Eretria: n.495.

Erythrai: 170. n.414.

Erythraion: p.170.

Erythrinoi: p.170.

Ethiopia: p.259.

Etna: p. 170.

Etruscan Sea: see Tyrrhenian Sea. 
Euboia: pp.20, 23, 25, 29, 45, 63, 71f., 87, 92ff., 99, 104, 106, 122-6, 132, 155ff., $160,162,169,171,178,183,195,208$, 213f., 222, 273.

nn.27, 49, 116, 205, 263, 272, 278, 327, 342, 421, 425, 427, 434, 450f., 509.

Euboian Sound: pp.32, 46f., 87, 93f., 104, 106, $213 \mathrm{f}$. nn.263, 272, 421, 427, 512.

Eurasia: pp. 17, 48f.

Euripos: pp.12, 46f., 83, 133, 162. nn.120f., 240, 272.

Europe: pp.19, 21, 40, 49-52, 62, 184, 222, 225, 237, 255, 258, 264. nn.124, 587, 618, 628, 631.

Eurotas, river: p. 19. n.618.

Euxine (Pontos): see Black Sea.

Fair Havens: see Kaloi Limenes.

Farewell, Cape: n.373.

Fear, Cape: n.230.

Foulweather, Cape: n.230.

France: p.60.

Gaeta promontory: n.427.

Galepsos: p.142.

Garganon promontory: p.190.

Gaudos: p.165.

Gelidonya, Cape: see Chelidoniai.

Geraistos: 91, 99, 123, 155-8, 179, 184. nn.269, 389, 398, 418, 451, 509.

Gibraltar, (Strait of): pp.13, 40, 44f., 79, 84f., $90,163,211,231$. nn.245, 504, 532, 618.

Good Hope, Cape of: n.230.

Gozo: see Gaudos.

Grand Harbour (Piraeus): pp.38, 98, 113, 173.

Greece: passim.

Greenland: n.373.

Grynion: p.144.

Gyrai: n.585.

Gythion: p.164. n. 383 .

Hades: pp.217, 226, 236.

Halys, river: p. 160 .

harbour of the Achaians: see under Achaians.

Harmatos, promontory: p.144.

Hekabe-sema: see Kynossema.

Helike (Achaia): p.93f.

Helike the Bear (Black Sea): pp.57, 160.

Helios, Isle of: n.518.

Helle(s), Cape: p. 169 n. 423 .
Hellespont: pp.9, 13, 20, 25, 40f., 43-6, 60, $73,75,82,84-7,90,99,119,136,155$, 169, 172f., 177ff., 184, 200, 208f., 215, 225.

nn.49, 111, 231, 240f., 248, 253, 287, 289, 365, 393, 404, 423, 432, 440, 509, 639.

Helos, Plain of: p.19.

Herakleia: p.178. nn.297, 418, 433.

Herakleion (Italy): pp.74, 145, 160.

Hermione: pp.111, 113. n. 318, 418 .

Hermionic promontory: see Skyllaion (Argolis).

Hermonassa: p.164.

Herone: p. 219.

Hierapolis: p.81.

Hieron: p. 224.

Hippuris: p.226.

Hollow Syria: n.514.

Hollows of Euboia: pp.23, 71f., 124, 126.

Hydra island.: pp.111, 113 nn. 174, 271.

Hydra promontory: p.144.

Hydros: p.149f.

Hyria: n.325.

Iapygia, (Cape): pp.74, 145, 149f., 154, 161. nn. 325, 386.

Iasos: n.543.

Iasos, Gulf of: n.418.

Iberia: pp.19, 163, 221.

Ichthys, Cape: pp.31, 101, 151, 273. nn. $225,381,406$.

Ida, Mount (Crete): n.350.

Ida, Mount (Troad): pp.86, 143, 149.

Ikaria: pp.45, 162, 170. nn. 170, 253, 302, 427.

Ilissos, river: pp.112, 116.

Illyria: pp.150, 189. n. 368 .

Imbros: p.73.

Inhospitable Sea: see Black Sea.

Ionia (Asia Minor): n.502.

Ionian Gulf: pp.74, 145, 149, 153f., 160.

Ionian islands: pp.17,25, 29, 153, 168, 274. nn.49, 384.

Ionian Sea: pp.9, 41, 43, 78, 150, $153 \mathrm{f}$. nn. $49,242,325,631$.

Ipnoi: pp.71, 78. n. 225 .

Iraklion: n.277.

Issa: p.32.

Issos, Gulf of: p.163.

Isthmia: nn.224, 418, 638. 
Isthmus of Corinth: pp.80, $161 \mathrm{f}$.

Italy: pp.10, 19, 24, 40f., 46, 50f., 74, 81, $114,128,136,145,149-54,161,170$, 181, 191, 208f., 221, 227, 270, 276. nn.235, 240, 325, 351, 362, 380f., 384, 386f., 392, 396, 418, 425, 427, 430, 519, $545,631,634$.

Ithaka: pp. $27 \mathrm{ff} ., 92,146,217,230$. nn. $401,500,518$.

Ithome: p. 19 .

Kalamoti: n.281.

Kalauria: pp.30, 270 nn.269, 418, 638.

Kaloi Limenes: pp.105, 114. n.324.

Kalypso, Isle of: nn.500, 555.

Kanai promontory: p.143.

Kanastraion: pp.142, 167.

Kanastron: see Kanastraion.

Kaphereus promontory: pp.45, 157, 183, 193. n.450.

Kapreai: p.24, 30.

Kara Burnu: see Melaina (Asia Minor).

Kara Burun: see Melaina (Black Sea).

Karambis, Cape: pp.57, 71, 147, 160, 178. nn.351, 374, 483.

Karia: pp.81, 137, 143. n.13.

Karpathos: p.165.

Karteros: see Amnisos.

Karystos, Bay of: pp.87, 99f., 106, 109, 305.

Kastri: n.423.

Kauda: p. 105.

Kaunos: p.92.

Kenaion, Cape: pp.32, 179. nn. 75,425 .

Kenchreai: p. 160.

Keos: p. 100. nn.232, 291, 389.

Kephallenia: pp.92, 147, 274. n. 381 .

Kephissos, river: pp.98, 112, 117.

Keramidhi: n.225.

Keraunia(n mountains.): pp.75, 100, 149f., $154,190$. nn. $25,230,321$.

Kestrine: n.297.

Kianos Gulf: nn.316, 418.

Kios: n.316.

Kimaros: see Korykos.

Kimolos: pp.30, 153.

Kirke, island of: p.102.

Kithairon: p.19.

Knidos: pp.104, 174.

Knossos: p. 149. n.277.

Koila, ta: see Hollows of Euboia.

Kolchis: p.218.

Kolias headland: p.112.

Komi headland: n.273.

Kophos Limen (Piraeus): p.113. n.321.

Kophos Limen (Torone): pp.97, 167. nn. 283, 321.

Koressia: p. 100

Korsia: p.162.

Kortuoros: p.164.

Korykos: pp.91, 162, 165.

Kos: n.375.

Kriou Metopon (Black Sea): pp.147, 193. nn.351, 374, 406, 483.

Kriou Metopon (Crete): p.163. n.406.

Krisaian Sea: p.19.

Krommyos promontory: p.147.

Kroton: nn.387, 638.

Krounoi: p.149.

Kumuthi point: n.66.

Kynosoura (Attica): nn.406, 495.

Kynosoura (Salamis): p.169.

Kynossema: pp.173f., 184. nn. 393, 404, 432, 639.

Kyrenaia: pp.162f. n. 376 .

Kyrene: pp.146, 217, 229. n.519.

Kythera: pp.81, 152, 162, 165, 168, 275. nn.375, 383, 392, 425, 482.

Kyzikos: p. 170. n. 340 .

Lakinion, (Cape): pp.150, 154f., 270. nn.387, 638 .

Lakonia: pp.20, 78f., 108, 149, 152, 224, 275. nn.225, 376, 383, 418, 425, 427, 618 .

Lakonian Gulf: pp.19, 79, 149, 164. nn. 383, 401 .

Land's End: see Belerium.

Lasea: p.105.

Lekton promontory: pp.75, 143, 149. n. 175 .

Lefkandi: n.421.

Legrena Bay: pp.99f., 109, 111. n. 290 .

Lemnos: pp.28, 45. n.419.

Lephtari rock: see the Ant.

Lesbos: pp.28, 32, 91, 121, 149, 155f., 158, 170. nn.287, 388, 509, 638.

Leuka: p.170. 
Leukai: p. 170 .

Leukas: pp.25, 32, 120, 147, 154, 169, 179. nn. $49,74,174,387,423,437,519,524$.

Leukatas: pp.147, 169 nn. 109, 219.

Leuke (Black Sea): p.170.

Leuke (Crete): p.170.

Leuke Akte (Euboia): pp.162f., 169.

Leuke Akte (Libya): pp. 165, 169.

Leuke Akte (Propontis): p.169.

Leukimme: n.639.

Leukopetra, Cape: pp.74, 145, 160, 169.

Leukophrys: p. 170 (see also Tenedos).

Leukosia: pp.24, 30, 170.

Levkas: see Leukas.

Libya: pp.50, 80, 119, 151f., 165, 217f., 222, 229, 251, 259.

nn. 144, 567, 618 .

Libyan Sea: p.43.

Lichades islands: nn.75, 425 .

Lichas, tomb of: n.425.

Lilybaion: p.151.

Lochias promontory: pp.35, 116.

Lokris (Greece): see Opuntian Lokris.

Lokris (Italy): pp.74, 145.

Lookout, Cape: n.641.

Lukania: nn.418, 543.

Lykia: p. 104.

Macedonia: pp.52, 56, 115, 150. n. 628 .

Maeander, river: pp.14, 31 . nn.10, 67.

Magnesia: pp.45, 78f., 94, 104, 123, 172, 195,213 nn. 290,421

Maiotis, Lake: pp.120, 219.

Majorca: nn.545, 557, 572.

Malea: pp.13, 20, 29, 41, 43, 78-82, 95, 102, $106,119,126,134,148 f$., $155,158,162$, 164, 195, 208, 275. nn.174f., 234, 302, 383, 401, 418, 425.

Maliac Gulf: p.167.

Malta: see Melita.

Marathon: pp.160, 212. nn. 10, 278, 406, 495.

Marshall Islands: n.478.

Massilia: n.425.

Mastiko, Cape: n.109.

Matapan: see Tainaron.

Mediterranean Sea: passim.

Megalonisi: n.324.

Megara: pp.69, 121. n. 431 .

Megas Limen: see Grand Harbour.

Mekyberna: p.142.
Melaina promontory (Asia Minor): p.170. n.175.

Melaina promontory (Black Sea): pp.115, $130,170$. n. 410 .

Melaina promontory (Chios): p.170. n.410.

Melanos promontory: 170 .

Melanthios river: p.164.

Melantian rocks: pp.162, 170, 226.

Melas Gulf: pp.43, 73.

Melita: p.165. n.631.

Melos: p.30, $152 \mathrm{f}$.

Mende: pp.142, 225. nn. $365,418,423,425$.

Messene (Sicily): 84.

Messenia: pp.19, 79, 117, 154, 171, 273. nn. 10, 333 .

Messenian Gulf: pp.19f., 79, 108, 144, 151. n. 401 .

Messina, Straits of: pp.46f., $69,80,83,110$, 133, 163, 277. nn.120f., 240, 392, 427.

Methana peninsula: pp.30, 275.

Methone: pp.273, 275 .

Miletos: n.418.

Mimas, Mount: pp.91f., 155, 170. n.269f.

Minoa: p.121. n. 340 .

Miseno, Cape: n.427.

Molykreion: p.271f.

Molykreian Rhion pp.101, 177, 271, 275. nn.254, 296, 418, 639.

Monemvasia: p.104.

Moni islet: $\mathrm{n} .432$.

Mounychia: pp.98, 112f. n. 320 .

Mykale: pp.87, 162, 174, 270. nn.232, 375 .

Mykoni channel: nn.253, 418.

Mykonos: pp.29, 45, 86 . n.253.

Myra: p.104.

Myrina: p.144.

Myrtoan Sea: p.43.

Mytilene: pp.121, 158, 223f. nn. 74, 509 .

Naupaktos: pp.87f., 101, $271 \mathrm{f}$. nn.254, 295f., 639.

Nauplia: pp.100, 161. n.293.

Neapolis (Africa): pp.146, 218, 229.

Neapolis (Chalkidike): p.142. 
Negropont: see Euripos.

Neriton: n.401.

New Zealand: n.437.

Nicaria: see Ikaria.

Nile, river: pp.116, 225. nn.68, 518.

Nisaia: p. 121. n. 340 .

Nisidia islet: p.70.

Nisyros island: p.30. nn. 266, 375.

Nisyros (Karpathos): p.165.

North Carolina: n.641.

North Sea: p.237f.

Nymphaion: p.167.

the Oinotrides: pp.24, 30 .

Oitylos: p.144.

Oiniadai: p. 120

Oinoussai islands: n.382.

Olympia: 151, 196. n.381.

Olympos: pp.82, 125.

Olynthos: p.142.

Onchesmos: n.418.

Onougnathos: pp.13, 29, 162. nn. 8, 375, 427.

Opuntian Lokris: p.273f.

Opous: p.273.

Orikos: p.100. n. 321 .

Ortygia (Delos): n.485.

Ortygia (Syracuse): n.485.

Ossa: p.125.

the Ovens: see Ipnoi.

Pachynos, Cape: pp.150f., 162f., $165 f$.

Pagasai, Gulf of: p.167. nn.264, 290, 316, 418f.

Pakistan: p.48.

Palamidhi: p. 100 n.293.

Palinuri, Cape: n.427.

Pallene peninsula: pp.142, 167. nn. 371, 418 .

Pamisos, river: p.151.

Pamphylia: p.104.

Panionion: pp.174, 177, 270. nn. $418,638$.

Panormos (Achaia): p.145. n. 321 .

Panormos (Thesprotia): n.321.

Paphlagonia: pp.147, 171. n.406.

Papike promontory: p.219.

Parnon: pp.19f., 104. n.27.

Parthenios, river: p.111.

Patrai: p. 145 . n.425.

Patras: n.259.

Peiresiai: p. 172.

Pelion: pp.36, 71, 126.

Peloponnese: pp.13, 19f., 23, 25, 31f., 41ff., 50, 73, 78ff., 101, 104, 106, 117, 122, $125,143,147-52,154,156 f$., 161f., 210 , 270, 273-6.

nn. $24,49,238,254,259,345,377,381$, 386, 416, 418, 425, 533, 567.

Pelorias, Cape: pp.84, 151. n. 427.

Pentapolis: pp.131, 251.

Perachora: p.98. nn. 12, 284, 288.

Perkote: p.86.

Persian Gulf: n.418.

Phaistos: n.89.

Phaleron: p.112f. nn.278, 319.

Phanari, Cape: n.423.

Pharos: pp.31, 35, 116, 174ff., 183. n. 425 .

Phasis, river: p.225.

Pheia: pp.101, 115, 273, 275. nn.294, 381.

Phlegra: see Pallene.

Phoenicia: p.222. n.519.

Phoinikous: p.91.

Phoinix: p. 105.

Phokaia: p. 170.

Phokas, Cape: nn.388, 638.

Phokis: p.19.

Phorkys, harbour of (Ithaka): p.27.

Phourkari: n.323.

Phykous: pp.161, 163.

Pillars of Hercules: see Strait of Gibraltar.

Piloros: p. 142.

Piraeus: pp.32, 38, 98, 108, 112f., 117, 120f., 162f., 173, 183. nn.73f., 278, 322, 421, 425, 432, 545.

Pithekoussai: pp.24, 30.

Pityeia: p.86.

Platea: p.217.

Plemmyrion: p.73. n. 230 .

Pleuron: p. 120.

Pompeii: n.372.

Pontos: see Black Sea.

Pori, Cape: n. 225

Poros: see Kalauria.

Port Splantza: n.393. 
Porto Kaio (Porto Quaglio): nn.485, 618.

Poseidian headland: see Poseidonion (Gulf of Pagasai).

Poseidion: see Poseidonion (Gulf of Pagasai).

Poseidonion (Alexandria): p.131. nn.220, 418.

Poseidonion (Arabia): n.418.

Poseidonion (Black Sea): n.418.

Poseidonion (Chalkidike): p.32. nn. 418, 423, 425.

Poseidonion (Chios): nn.418, 423.

Poseidonion (Cilicia): n.418.

Poseidonion (Lukania): n.418.

Poseidonion (Milesian): nn.418, 425.

Poseidonion (Gulf of Pagasai): pp.110, 167. n. 418 .

Poseidonion (Persian Gulf): n.418.

Poseidonion (Propontis): n.418.

Poseidonion (Samikon): n.418.

Poseidonion (Samos): pp.174, 177. $\mathrm{nn} .418,423$.

Poseidonion (Thesprotia): nn.418, 431.

Posidhi, Cape: p.32. n.423.

Potidaia: p.142. n. 425 .

Priapos: p. 170.

Prochyte: pp.24, 30.

Propontis: pp.43f., 143, 169f., 178, 218. nn. 316, 340, 418.

Prote: pp.154, 171, 274. n.416.

Protesilaos, tomb of: n.423.

Psara: see Psyria.

Psyria: p.155. n. 388 .

Pylos (Messenia): pp.116, 155, 274f. nn. 10, 263, 416, 434, 567.

Pylos (Triphylia): p.149.

Pyrgos, Cape (Aigina) p.70.

Pyrgos, Cape (Thasos): p.176. n.423.

Pyrrha (Achaea Phthiotis): p.170.

Pyrrha (Asia Minor): p. 170.

Pytho, Pythian shrine: pp.74, 269 (see also Delphi).

Ras-al-Razat: see Phykous.

Red Sea: p.218.

Rhebas, river: pp.130, 170. $\mathrm{nn} .426,433$.

Rhegion: pp.74, 84, 145, 160, 169.

Rhion (Achaia): pp.89, 101, 145, 177, 272, 275.

nn. $175,254,392,418,425,639$.

Rhion (Aetolia): see Molycrian Rhion.
Rhion (Messenia) p.144f.

Rhion, strait of: pp.101, 177, 271. nn.257, 259, 431, 639.

Rhodes: pp.52, 92, 163f., 189, 214, 225, 272. nn. 147, 299, 455, 557.

Rhoiteion: pp.86, 174, 178. n. 425 .

Rhone, river: p.60. n. 425 .

Rome: pp.104, 106, 134, 142, 180, 229. n.386.

Sacred Cape: p.163.

Sahara: pp.48, 52, 62 . n.631.

St. Catherine, Cape: p.123.

St. George, Cape: p.123. n. 225 .

St. Vincent, Cape: see Sacred Cape.

Salamis (Saronic Gulf): pp.82, 89, 169, 214. nn.254, 263f., 278, 312, 423, 431, 442, 502.

Salamis (Cyprus): n.232.

Salmone: see Salmonion.

Salmonion: pp.104f., 163, 189. n.231.

Salmydessos: n.334.

Same: p.92 (see also Kephallenia).

Samian strait: pp.46, 90ff., 174, 177, 270. nn.266, 271, 418, 431.

Samikon: pp.149, 270. nn. $418,425,638$.

Samos: pp.25, 46, 92, 96, 162f., 174f., 177. nn. $174,232,375,418,425,502,532$.

Samothrace: pp.25, 28, 73. nn. 49,350 .

Sane: p.142.

Sangarios river: p.178.

Santorini: see Thera.

Sardinia: p.40.

Saronic Gulf: pp.30, 69f., 108f., 144, 153, 163, 270, 274. nn.229, 264, 290, 312, 418.

Sarte: p.142.

Sason: p. 150 .

Satyros, monument of: p.173.

Scamander, river: p. 31 .

Scheria: pp.25f., 95, 102, 111. nn. 317, 402, 438 (see also Corcyra).

Schoinous: p.161ff.

Sepias, Cape (ancient): pp.21, 78, 96, 125, 167. $\mathrm{nn} .225,406$.

Sepias, Cape (modern): nn.225, 232, 414.

Serce Limani: nn.284, 557.

Sermyle: p. 142 . 
Sestos: pp.143, 178f., 215.

Sicilian Sea: pp.84, 151, 154.

Sicily: pp.10, 27, 40, 46, 74, 80, 84, 136, 145, 150-4, 162f., 165f., 218, 227, 229, 274-7. nn. $240,376,380 f ., 383$, 386f., 392, 396, $425,567,576,631$.

Sicily, Strait of: see Straits of Messina.

Sidon: p.104.

Sigeion: p.178f. nn.231, 278, .

Sigri, Cape (Magnesia): p.123.

Sigrion promontory (Lesbos): p.158.

Singitic Gulf: p.167. n.371.

Singos: p.142.

Sinope: pp.110, 115, 178. nn. $419,433$.

Siphnos: n. 423 .

the Sirens: pp.24, 30.

Sithonia: p. 142.

Skiathos: pp.94, 172, 213. nn.232, 274, 414.

Skione: p.142.

Skironian rocks: n.269.

Skopelon Kolones: n.426.

Skopelos: n.414.

Skyllaion (Argolis): pp.7, 69, 144, 152, 160. n.221.

Skyllaion (Italy): pp.69, 111. n. 392 .

Skyros: pp.94, 213.

Smyrna, Gulf of: nn.158, 312.

Solygeia: p.274. n. 434 .

Soonautes: see Acherusias, Cape.

Sounion: pp.7, 20, 43, 74, 81, 99f., 108ff., $144,148,152,157160,162,169$. nn.290, 313, 375, 392, 418, 427.

Soupia: n. 323 .

Spercheios, river: p. 31 . n.67.

Spetses: n.271.

Sphakteria: pp.116, 226, $274 \mathrm{f}$. nn. $263,332,345,434,567$.

Sporades: p. 226.

Steno channel: $\mathrm{nn} .253,418$.

Stormy Cape: see Cheimerion.

Stratos: n.254.

Stryme: p.96.

Strymon, river: pp.56, 115.

Strymonic Gulf: p.167.

Stymplegades: see Cyaneae.

Sudan: p.48.

Sweden: n.431.

Sybota islands: $\mathrm{n} .219$.

Syracuse: pp.73, 227. $\mathrm{nn} .263,572$.

Syrtis, (Gulf of): pp.47, 105, 133, 211, 232. $\mathrm{nn} .336,536$.

Tainaron: 7, 20, 23, 42, 74, 78ff., 106, 122, $144,148,150$ f., $159,161-4$. nn. 109, 174, 225, 269, 376, 383, 401, $405,418,485,618$ (see also Taygetos).

Tanais, river: p.120.

Taposiris: p.131. n. 220 .

Taranto: see Taras.

Taras: pp.80, 151, 265. nn. 519, 545 .

Tarentine Gulf: 154.

Tarentum: see Taras.

Tarquinia: n.545.

Tartessos: n.532.

Tauris: pp.147, 169.

Taygetos: p.19. n.618 (see also Tainaron).

Telos: p.30.

Tenedos: pp.149, 155f., 170. n.287.

Tenos: pp.29, 45, 86, 94. nn. 174, 253, 418,

Tethys Sea: p.17.

Thalamai: p.144.

Thasos: pp.28, 77, 96, 115, 176. nn.279, 330, 423, 514 .

Thassopoulo: p.115.

Themistokles, tomb of (Piraeus): pp.38, 173, 183. nn. $421,425,430$.

Thera: pp.30, 170, 217. n.519.

Therambos: p. 142 .

Therma: pp.94, 142.

Thermaic Gulf: pp.14, 47, 133, 142, 167. n. 158 .

Thermodon river: p.103.

Thermopylai: pp.47, 213. nn.263, 497.

Thesprotia: nn.297, 393, 418 .

Thessalonikeia: p. 20 .

Thessaly: pp.20f., $25,29,45,52,56,97,122$, 125f., 132, 195, 208. nn.27, 49, 225, 628 .

Thrace: pp.52, 73, 114f., 169. n. 628 .

Thracian Bosporos: see Bosporos.

Thracian Chersonesos: pp.43, 73, 86 . n. 230 .

Thunder, Cape: see Keraunia.

Thouriates Gulf: see Messenian Gulf.

Thyamis, River: n.297 
Thynias, Isle of: p.130.

Thyrides: p. 42 . n.225.

Thyron: p.149.

Tisaean headland: n.419.

Toronaean Gulf: pp.142, 154, 167.

Torone: pp.97, 142.

Trepidation, Cape: n.230.

Triphylia: p.117. n. 333 ,

Tritonian Lake: pp.105, 119, 147, 218. nn. 336, 437.

Troad peninsula: p.75.

Trogilian prom.: see Mykale.

Troizen: $\mathrm{n} .428$.

Troy: p.71, 81, 92f., 95, 114, 155f., 166, 183. n. 360 .

Turlo, Cape: p.70

Tyras, river (mod. Dneister): p.170.

Tyrrhenian Sea: pp.50, 84. n.387.

Vardar, river: see Axios.

Varlam: see Cheimerion.

Via Egnatia: p. 150.

Vibo: n. 372 .

Vlicho: n.437.

Volos: n.545.

West Indies: n.484.

Wrath, Cape: n.230.

Zagora: n.278.

Zakynthos: pp.29, 154, 274. nn. $384,386,416$.

Zea harbour: pp.98, 112f. nn. 320,545 ,

Zeleia: p.149.

Zephyrios Limen: p.74. n. 228 .

Zephyrion (Cilicia): p.74. nn.228, 230.

Zephyrion (Italy): pp.74, 145. $\mathrm{nn} .228,230$.

Zoster, Cape: n.232.

\section{Meteorological index.}

Anticyclonic winds: $\mathrm{n} .631$.

Bird Winds: pp.262-6. n.628f., $631 f$., 635 (see also Ornithian winds).

Bora: pp.50ff., 56, 60, 76ff., 80, 107f., 113f., $125,208 f$. nn.159, 234f., 325, 466, 628 .
Boreas: pp.35, 52, 77, 81, 114, 125, 187, 212, 214, 238, 255, 263.

$\mathrm{nn} .232,326,466,518,581,587$.

calms (ie. absence of wind): pp.53, 60, 93, 99 , 108, 125, 129f., 134ff., 190, 199, 204, 243, 260, 262. nn. $356,360,362,470,509,516,576$, 580 .

Chelidonias: p.266. n.637.

Cyclonic winds: pp.50ff., 85, 126. n.631 (see also under individual wind names, eg. Bora).

depressions: pp.48-52, 62ff, 78f., 108f., 114, $125,128,209,222 f$., 249, 251, 255f., 258 , 264. nn.191, 580f. 587, 628, 631.

diurnal winds: pp.85, 90, 92, 103, 109, 135 , 181, 201, 208f. 214, 244. $\mathrm{nn} .158,264,436,609$ (see also land and sea, mountain and valley winds).

Etesians: pp.12, 49f., 60, 63, 71, 75ff., 79, 82, 85ff., 91f., 95, 99f., 104, 106, 108f., 113f., 125f., 129, 134, 200f., 204, 209, $221 \mathrm{ff}$., 244, 246, 263f.

nn.131, 133, 174, 203, 229, 247ff., 259 , $272,289,358,466,504$ ff., 509, 580, 587, 609.

fog: pp.61, 168, 179ff., 184, 187, 191, 202, $210,228,250$. nn. $124,178,183$.

Hellespontias: p.52. n. $466,580,587$.

Katabatic winds: p.54, 56, 92, 107, 114, 135, 209, 214. nn.159f., 524, 628, 634 .

Khamsin: see Sirocco.

Land breeze: pp: 52-6, 76, 79, 87f., 90f., 109f., 129f., 140f., 143, 155, 201f., 204f., 208f., 222f., 225, 230, 232-5, 244. nn.151, 153ff., 234, 258f., 264, 312, 316, 510, 577f., 609 .

Leukonotoi: n.629.

Leveche: see Sirocco.

Lips: pp.52, 255. nn. $144,146,466,581$.

Livas: pp.52, 56, 60, 107, 114. nn. $159,587$.

Meltemi: pp.12, 60.

Mistral: pp.51, 60.

Mountain winds: pp.53-7, 76, 88. $\mathrm{nn} .151,153,258$.

'Northeaster': p.105.

Notos: pp.52, 65, 86, 187, 222, 226. nn. 146, 466, 586f.

Ornithian winds: pp.263, 266. 
Ornithian winds cont's: n.629 (see also Bird Winds).

rain: pp.31, 59, 61-5, 78, 96, 114, 125f., 132, $139,187,210,222,224,240,250,258$, 261. nn.146, 171, 181, 200, 205, 230, 480, $558,581,585,587 \mathrm{f}$.

Sea breeze: pp.52-6, 63, 76, 79, 88f., 90f., 100, 108ff., 129f., 140f., 143, 155, 201f., 204f., 208f., 222f., 225, 232, 234f., 244. nn.151, 153ff., 229, 234, 258, 264, 293, $312,316,510,577 \mathrm{f} ., 609$.

Sirocco: pp.50ff., $60,63,76,81,85,91,101$, 108f., 113, 125, 225.

nn.145ff., 203, 205, 234, 249, 466, 509, 631.

Squalls: pp.12, 57-60, 75, 79, 82, 92f., 95, 106, 108, 113, 125, 129f.,132, 198f., 228f., 261. nn.163, 169f., 174, 234, 272, 301f., 304f.,

Strymonian wind: pp.56, 92, $114 \mathrm{f}$. $\mathrm{nn} .326,581$.

Swallow wind: see Chelidonias.

Thraskias: pp.52, 56, 114. nn. $466,587,628$.

thunder: pp.59, 63ff., 75, 95f., 125f., 129, $132,238,250$. nn.207, 213, 301.

Valley winds: pp.54-7, 76, 88. n. 258 .

Zephyros: pp.49, 209, 226, 255, 264-7, $269 f$. nn.249, 466, 509, 609, 632-5, 637.

\section{Astronomical index.}

Arcturus: pp.224f., 247.

the Asses: 224.

the Asses' Manger: see under Crib.

Bootes: p. 186

Cancer: p. 250 .

the Crib: pp.224, 250 . nn. 514,595 .

Great Bear: pp.186, 224. nn.461, 463, 514.

Hyades: n. 147.

the Kids: pp.223, 247. nn. 583,636 .

Kochab: p. 186.

Little Bear: pp.186, 224. nn. 463,514 .

Moon: pp.139, 180f., 226, 228, 230, 250. n.526.

Orion: pp.186, 223, 247, 254. nn. 583,636

Pleiades: pp.96, 186, 247. nn.514, 583, 636 .
Polaris: p. 186.

Sun and stars (in navigation): pp.163, 185, 187, 202, 204, 223f., 250, 256. nn.439, 458-61, 463, 480, 522, 525, 581, $587,628,637$.

\section{Oceanographic and topographical index.}

(For named seas consult main index)

\section{Bays: passim.}

Caves: 23f., 26f., 39, 66, 95. nn.42, 225.

Cliffs: pp.15, 20, 22, 24-8, 38f., 42, 44f., 60, 66, 70, 97, 100, 102, 104, 122-6, 130. 132, $151,169,174$ f.. 181, 184, 195, 197. nn.54, 89, 225, 269, 283, 288, 302, 343, 388, 405. Currents (sea): pp.9, 12f., 31f., 35, 39-46, 60 , 66, 68, 72f., 77-91, 97, 99f., 102, 114f., 118, $129,132 \mathrm{f} ., 136,156,178,180 f ., 184,190 \mathrm{ff} .$, 196ff., 202, 208f., 211, 215, 218f., 232, 234, 243, 269. nn.13, 87, 99, 104, 113f., 116f., 120, 231f., 241f., 245ff., 249, 251, 253, 257 , 266, 269, 288ff., 436, 478, 485, 516, 538, 608.

Deposition: pp.13f., 31f., 42, 47, 98, 103, 117-22, 195ff., 210. nn.10, 68, 74, 122, 425, 437.

Headlands: passim.

Islands: passim.

Natural harbours: 27f., 37, 97f., 100f., 112, 196f., 199, 232, 268, 276. nn.278, 283f., 288, 388, 533.

Promontories: passim.

Rocks, reefs, etc.: pp.26-30, 35, 66, 69-72, 76f., 82, 93ff., 102f., 107, 122, 124, 129ff., 131, 133ff., 138f., 142, 166, 174f., 177, 180f., $184,195,197 f$., 205, 213, 215, 218f., 228, 232, 242f., 261. nn.13, 66, 220, 232, 274, 277, 406, 432, 438, 492, 533.

Tides: pp.47, 73, 83f., 88, 110, 118, 121, 129, 132f., 201f., 206, 210f., 232ff., 237, 245. nn. $122,359,532,535 \mathrm{ff}$.

\section{Temples, shrines, and sanctuaries.}

(See also the following entries in themain index: Artemision, Delos, Delphi, Diktynnaion, Geraistos, Isthmia, Panionion, Perachora, Poseidonion, Posidhi, Sacred Cape, Sounion, Tainaron. Some tombs are also listed there.)

Aias (Rhoiteion): p.174.

Aphaia (Aigina): p.7.

Apollo (Aigina): nn.277, 432.

Apollo (Delos): p.270. 
Apollo (Delphi): p.74, 119, 214, 269ff.

Apollo (Grynion): p.144.

Apollo (Leukas): p.169.

Apollo (Malea): p.275. n.425.

Apollo (Naupaktos): p.272. n.639.

Apollo (Troizen): n.428.

Byzantines, temple of the: p.184. n.454.

Chalkedonian temple/hieron: pp.178, 184. nn. $433,454$.

Harbour sanctuary (Emborio): p.97. nn.281, 430.

Hera (Lakinion): p. 270.

Hera (Perachora): n.288.

Hera (Samos): p. 175. $\mathrm{nn} .425,428$.

Poseidon (Bosporos): n.418.

Poseidon (Geraistos): pp.179, 184. nn.388, 418.

Poseidon (Helike): p.93f.

Poseidon (Hermione): nn.318, 418.

Poseidon (Isthmia): nn.244, 418, 638.

Poseidon (Kalauria): p.271. n.418.

Poseidon (Malea): n.418.

Poseidon (Molykreian Rhion): pp.177, 272. n. $418,431,639$.

Poseidon (Rhion, Achaia): p.177. nn.418, $425,431,639$.

Poseidon (Samikon): p.270. n.425.

Poseidon (Sounion): n.418.

Poseidon (Tainaron): pp.74, 159. nn.376, 383,418 ,

Poseidon (Tenos): n.418.

Tindareus, sons of (Acherousia): p.174.

Zeus (Chalkedon): see Chalkedonian temple. Zeus (Kenaion): p.179.

Zeus, Hera, and Dionysos (Lesbos): nn.388, 638. 


\section{INDEX LOCORUM}

References to page numbers and notes are given in parentheses; where passages of more than a few words are quoted, this is indicated by bold type.

Acts 27.1-18 (pp.104f., 117, 134), 27.12 (n.324), 27.18-45 (pp.117f., 134, 138f., 180, 229, n.575).

Ael.On Animals 1.52 (p.262), 3.13 (p.259), 3.14 (p.259), 7.7 (pp.253f., 259, n.607), 7.8 (p.253), 7.24 (p.43f.), 15.5 (n.642).

Aesch.Agam.8ff. (n.441), 191ff. (p.114, n.120), 281-312 (n.441), 565f. (n.360), 590 ff. (n.455), 653 (p.181), 653ff. (p.114), 657 (p.114), 661-6 (p.181), 1005-13 (n.575), 1233f. (p.69) 1416ff. (p.114).

Aesch.Eum.555ff. (n.547), 564 (n.547).

Aesch.Pers.596 (n.89), 880 (n.89).

Aesch.Pr.B.726f. (n.334).

Aesch.Supp.764-772 (n.546).

Aesch.fr.17 (n.425), fr.57 (p.114).

Alcaeus A6.1-8 (p.239, n.557), L1.7f. (p.246), G1 (nn.388, 638), Z 2 (n.557), Z $212 \mathrm{ff}$. (nn.546, 548).

Anth.Pal.5.169.1ff. (p.255), 5.209.1f. (n.437), 6.5 (n.527), 6.11 (n.527), 6.23 (p.23f.), 6.28 (n.527), 6.33.1f. (n.437), 6.70 (p.236), 6.89 (p.22), 6.164 (n.428), 6.166 (n.428), 6.245 (p.238, n.428), 6.251 (p.169), 7.264 (nn.421, 427), 7.266 (n.427), 7.266f. (n.421), 7.269 (n.427), $7.271-5$ (n.421), 7.272 (n.427), 7.272f. (n.581), 7.275 (n.238), 7.276f. (n.421), 7.279 (n.421), 7.282 (n.421), 7.285 (n.421), 7.287 (n.421), 7.289 (n.450), 7.291f. (n.421), 7.293 (n.360), 7.303 (n.326), 7.345 (p.173), 7.374 (n.421), 7.392 (n.581), 7.395 (nn.421, 581), 7.397 (nn.232, 421), 7.404 (n.36), 7.495 (n.581), 7.498 (nn.238, 325), 7.500 (n.421), 7.502 (n.326), 7.502f. (n.581), 7.505 (n.421), 7.534 (n.581), 7.539 (n.581), 7.584 (p.81), 7.591f. (n.421), $7.652-4$ (n.421), 7.653 (nn.147, 581), 7.668 (n.609), 7.699 (n.302), 7.738 (n.232), 10.1 (p.265f., n.637), 10.2 (n.637), 10.2.1ff. (p.262, n.616), 10.4ff.
Anth.Pal. cont'd. (nn.633, 637), 10.7 (n.249), 10.14 (n.633), 10.15 (nn.609, 637), 10.16 (n.633), 10.17 (p.269).

Ap.Bibl.2.1.5 (n.450), 3.15 .8 (n.221), Ep.6.7 (p.184, n.450), Ep.6.11 (n.450).

Ap.Rhod.Arg.1.519-23 (p.36, n.316), 1.521 (n.419), 1.580-608 (n.419), 1.582-90 (pp.172, 173), 1.593 (p.78), 1.922-8 (pp.73, 74, n.3), 1.925-35 (p.86, n.3), 1.936ff. (n.340), 1.1159ff. (p.55, n.3), 1.1273ff. (p.109, nn.3, 151, 316), 1.1279 (n.418), 2.317-407 (p.217f.), 2.328 (n.487), 2.345-50 (p.130), 2.360ff. (p.57, n.3), 2.360-7 (p.160), 22.498 (nn.131, 505), 2.550ff. (p.45), 2.557ff. (n.487), 2.568f. (p.39, n.42), 2.648-59 (n.419), 2.650 (n.426), 2.651 (p.170), 2.659 f. (p.173), 2.727f. (p.103, n.518), 2.728-32 (p.39, nn.3, 54), 2.743-51 (p.103), 2.750 (n.534), 2.806ff. (p.174), 2.833-6 (p.173), 2.841-4 (p.173), 2.851ff. (n.427), 2.911 f. (n.419), 2.911-7 (p.173), 2.930-45 (n.419), 2.941 (p.171), 2.964f. (p.103), 2.970f. (p.103), 2.1030ff. (nn.228, 481), 2.1192-5 (p.218), 2.1228ff. (n.316), 4.920ff. (pp.69, 84), 4.1223f. (p.110, nn.3, 151, 316), 4.1240ff. (pp.80, 232, n.336), 4.1240-44 (p.232f., n.358), 4.1240-71 (p.47), 4.1259-78 (p.232f., n.358), 4.1537-53 (p.218), 4.1554-83 (p.119), $4.1556-9$ (p.218), 4.1572-83 (p.147), 4.1573ff. (n.437), 4.1696-1720 (pp.226, 227f.), 4.1707 (p.170).

App.Mith.Wars.12.24f. (n.264), 12.26 (p.92).

Arat.Phaen.152-5 (n.580), 300ff. (pp.225, 227), 752-777 (pp.248, 252), 778-818 (n.594), 819-831 (n.596), 832ff. (n.592), 845ff. (n.596), 892-908 (n.595), 913 ff. (nn.585, 607), 924ff. (n.589), 938ff. (n.591), 988ff. (n.590), 994 (n.595), 1010ff. (p.262), 1024f. (n.605), 1028-32 (p.260, n.619), 1075-81 (p.260), 1112-20 
Arat.Phaen.cont'd.: (n.590), 1142ff. (pp.252, 265), 1145-8 (pp.248, 252), 1148-52 (n.593), 1153f. (pp.252, 265).

Archilochos fr.79a.3 (n.334).

Archilochos: see also Theophr.Signs 45.

Aristides 2.148 (n.370).

Aristoph.Birds.594-7 (p.252f.), 710f. (p.259), 713 ff. (p.265, n.615), 714 (p.262).

Aristoph.Eq.541-4 (n.223), 543 (n.524). Aristoph.Hipp.312 (n.642).

Arist.Anem.Thes.973b18f. (p.114).

Arist.De Mundo395a4 (p.262f., n.629).

Arist.H.A.542b4 (n.580), 548a24 (n.44), 570a26-571b2 (n.480), 596b30-597a3 (n.610), 597a21-24 (pp.257, 258, n.636), 597a27ff. (n.610), 597a32-b1 (p.258), 597b9-13 (pp.258, 264), 599b16f. (p.230), 600a10 (p.262), 614b18-22 (p.258f.).

Arist.Mech.7.851b6 (n.577).

Arist.Met.338a (n.87), 346b24-33 (p.61), 354a6-11 (p.46), 354a22f. (n.532), 359b34ff. (p.61), 361b23f. (nn.356, 516), 361 b24 (p.263), $362 \mathrm{a} 14$ (n.629), 362a23ff. (n.628), 362a23-31 (pp.262, 263, n.629), 364b3ff. (n.587) 370b17ff. (n.176).

Arist.Pol.1253b29 (n.223).

Arist.Probl.26.4f. (p.54), 26.7 (p.249f., n.205), 26.12 (p.263), 26.13 (p.254), 26.17 (p.65, n.586), 26.19 (n.587), 26.20 (n.587), 26.24 (p.250), 26.30 (p.56), 26.38 (n.587), 26.39 (n.587), 26.40 (p.54), 26.41 (n.587), 26.45 (n.587), 26.46 (n.587), 26.47 (n.587), 26.52 (n.609), 26.56 (p. 250$)$.

Arr.Anab.2.1.2 (p.158, n.389), 7.1 .3 (n.386).

Asclepiades: see Anth.Pal.5.169.1ff.

Athen.5.207b (n.572), 12.536ab (n.418), 15.676ab (n.428).

Bacc.Ep.3.72-4 (p.81), 15.13-22 (n.89).

Battle of the Frogs and Mice 59-75 (p.138).

Caes.G.W.3.13 (pp.232, 234, 237).

Callim.Hymn to Artemis 228f. (n.428).
Cic.Ad.Att.5.9.1f. (nn.219, 580), 7.2.1 (n.580), 16.6.1 (n.362)

Contest of Homer and Hesiod 1.260ff. (n.480)

Democ.14.3 (p.263, nn.580, 626, 635), 14.7 (p.263, nn.580, 626, 635)

Dem.4.31 (pp.85, 244), 4.34 (n.389), 8.14 (pp.85, 244), 18.194 (p.245), 32.5 f. (p.227), 33.44 (p.236), 34 (n.365), 35 (n.365), 35.10 (p.224f., n.581), 35.11 (n.575), 50.22 (n.576), 50.22ff. (pp.96, 225, 227, 230, 243), 56.30 (p.225).

Dicaearchus 110 (n.89), 130 (n.398)

Diodorus the Periegete: see $F G r H 372$ F 35

Diod.Sic. 5.22 (p.149), 12.49 (n.442f.), 13.39f. (p.215), 13.40 .6 (n.639), 17.108 (n.376), 17.111 (n.376), 18.9 (n.376), 18.21 (n.376), 20.104 (n.376)

Dionysios son of Calliphon, Description of Greece 130ff. (n.398).

Eur.Cyc.292-5 (n.418)

Eur.Hek.26-54 (n.421), 1273 (p.173f.)

Eur.Hel.479ff. (n.618), 766f. (pp.71, 183), 1126-31 (pp.71, 183)

Eur.Iph.A.9ff. (p.93), 87-93 (p.93), 350-360 (p.93)

Eur.I.T.6ff. (n.120), 262f. (p.22), 436 (p.169, n.481), 1327ff. (p.107) 1350f. (p.107), 1379-81 (p.107), 1390-8 (p.107), 1403-6 (p.107), 1412f. (p.107)

Eur.Rhes. $95-8$ (p.181f.)

Eur.Troad.84 (p.71)

FGrH 372 F 35 (pp.38, 173, n.421)

Heliodorus of Emesa, Ethiopian Story 4.16 (p.230)

Heraclides Creticos 1.23f. (n.543)

Herodian 4.2.8 (n.446)

Hdt.1.23 (p.7, n.428), 1.62 (p.230), 1.65 .1 (n.382), 2.5 (n.68), 2.5 .2 (n.525), 2.10 (p.32, nn.74, 337), 2.25 (n.146), 3.45 (p.96), 3.60 (p.96), 3.134ff. (p.77), 3.138 (n.325), 4.44 (n.394), 4.85ff. (nn.394, 454), 4.85.2 (n.473), 4.150f. (p.217), 
Hdt. cont'd: 4.152 (n.545), 4.152ff. (n.532), 4.156f. (n.519), 4.179 (pp.77, 119, 218, n.358), 6.44 (p.77), 6.95 (pp.78, 212), 6.102 (p.212), 6.107 (p.212), $6.115 f$. (p.160), 6.116 (n.278), 7.10f. (n.28), 7.16 (p.33), 7.22 f. (p.78), 7.24 (n.147), 7.25 (p.169), 7.35f. (n.28), 7.36 (p.119), 7.4650 (n.28), 7.49 (pp.21, 96, 126, 214), 7.59 (n.534), 7.122f. (pp.142, 164), 7.128 (n.501), 7.130 (n.501), 7.168f. (p.82), 7.170 (n.325), 7.175 ff. (n.497), 7.178 (p.214), 7.179 (pp.70, 94, n.442), 7.183 (p.94), 7.188 (nn.225, 580), 7.188f. (pp.21, 78, 96), 7.189 (p.214), 7.193 (n.290), 7.194.1-3 (n.264), 7.198 (p.47), 8.8 (n.639), 8.9 (n.434), 8.10.1 (n.263), 8.12 f. (p.125f.), 8.13 (n.226), 8.15 (n.41), 8.60 (n.263), 8.84 (n.264), 8.86 (n.264), 8.118 (p.115, nn.364, 575), 8.129 (p.47), 8.132 (n.502), 9.3 (n.441), 9.90ff. (n.502), 9.96 (n.502), 9.114 (p.87, n.231).

Hes.W\&D. 448-51 (pp.257, 262), 504ff. (p.114, n.143), 547ff. (p.114), 550-3 (n.213), 564ff. (p.247, n.581), 568f. (pp.257, 262, n.598), 609-90 (n.507), 618ff. (n.581), 624ff. (p.95, n.534), $663 \mathrm{ff}$. (n.506), 663-77 (pp.221f., 235, 247), 67482 (p.262, n.616), 678-82 (p.267).

Hipp.Epid.7.105 (p.262, n.628).

Hom.Il.2.394f. (n.77), 2.394-7 (p.37), 2.791-4 (p.276, n.431), 4.422f. (n.77), 4.422-6 (pp.34, 36), 4.425 (n.438), 7.4ff. (n.360), 7.58 (n.437), 7.85-91 (p.172), 9.4ff. (p.114, n.77), 11.296ff. (nn.174, 301), 11.304-9 (n.77), 11.619-22 (p.53f.), 11.747 (n.174), 12.252f. (n.174), 13.795ff. (p.59, nn.77, 301), 14.283 (p.149), 14.394ff. (n.77), 15.381-4 (p.33), 15.619-622 (p.34), 15.624ff. (n.77), 18.207-14 (n.443), 19.375-9 (nn.440, 445), 20.51 (n.174), 21.316-323 (p.31), 23.850-9 (n.487).

Hom.Od.1.57f. (p.193f.), 1.234-43 (n.421), 1.485f. (p.95), 2.388 (p.230), $2.411 \mathrm{f}$ (p.238), 2.434 (n.518), 3.150ff. (n.388), 3.150-82 (p.155), 3.172 (p.92), 3.177f. (p.157, n.451), 3.276-300 (pp.81, 95), 3.278 (p.7, n.427), 4.270-7 (n.518), 4.354-7 (p.31), 4.360-4 (n.360), 4.512-22 (p.81), 4.605f. (p.29), 4.786 (p.230), 4.846 (n.416), 5.123 (n.485), 5.256ff. (n.555), 5.269-77 (p.186, n.464), 5.276f.
Hom.Od. cont'd. (n.500), 5.293 (n.508), 5.306-12 (n.421), 5.393 (n.84), 5.400-7 (pp.27, 102, 126), 5.401 (n.438), 5.410-4 (pp.25, 126), 5.410-6 (p.102), 5.418 (p.98f.), 5.436-44 (p.102), 5.440 (p.98f.), 5.441ff. (p.102), 5.451ff. (p.102), 6.262-5 (pp.95, 111), 7.279f. (n.402), 9.21f. (n.401), 9.67f. (n.548), 9.76ff. (p.81), 9.135-51 (p.95), 9.142-8 (pp.181, 228), 9.283-6 (p.76), 9.546 (n.534), 10.28ff. (nn.440, 445, 518), 10.87-97 (pp.27f., 37, 95, 97), $10.487-515$ (p.217), 11.71-8 (p.172, n.421), 11.121f. (n.421), 12.8f. (p.172, n.421), 12.37ff. (p.217f., n.489), 12.62 (n.487), 12.73-6 (n.489), 12.73-110 (p.84), 12.200ff. (p.69), 12.229ff. (n.224), 12.230-59 (p.84), 12.286-90 (pp.226, 228, n.518), 12.346 (n.428), 12.373f. (n.437), 13.70-95 (n.518), 13.96ff. (pp.28, 37, 97, n.77), 14.246 (n.508), 14.252-8 (n.518), $15.34-9$ (p.146), 15.292-300 (n.518), 15.471-84 (n.518), 16.364f. (p.92), 16.366ff. (n.518), 19.185ff. (pp.82, 95, 102), 23.267-84 (n.421), 24.80-4 (p.172), 24.287-96 (n.421).

H.H.Ap.181 (n.89), 391-426 (p.149), 487f. (n.534).

H.H.Dion.1-12 (p.148), 27ff. (p.148).

Hor.Ep.1.7 (n.632), 1.13 (n.632).

I.G.XII, 8, add. 683 (p.176, n.423).

$I G$ XII, Suppl. 347, II (n.330).

$I G 91.878$ (n.36).

Leonidas of Tarentum: see Anth.Pal.10.1.

Little Iliad fr.11 (n.444).

Livy.31.45.10 (n.389), 32.17 .3 (p.160).

Lycophron.Alex.722 (n.418).

Menip.Perg.Perip. 5604 (n.433), 5622 (n.433), 5703ff. (pp.116, 170), 5704f. (n.433), 5717f. (n.433), 5720f. (n.418), 5902f. (n.374), 6001f. (n.433), 6020 (n.433), 9r20-27 (p.164), 9r29f. (n.228), 10r21-9 (p.164), 13r4ff. (p.164).

Menip.Perg. in Steph.Byz.: see Steph.Byz. sv. $\mathrm{X} \alpha \lambda \kappa \eta \delta \omega v$ 
Opp.Hal.1.383 (n.438), 3.244 (p.265), 3.630 ff. (n.642), 4.640 (p.229), 5.652 (n.438).

\section{P.Hib. 27.59 (p.262).}

Paus.1.1.1 (n.418), 1.1.2 (n.421), 1.44.5 (p.121, n.340), 2.29 .6 (pp.70, 215), 2.30 .3 (p.7), 2.32.2 (n.428), 2.33 .3 (n.418), 2.34 .7 (p.7, n.221), 2.34 .9 (p.111, n.317), 2.34.9ff. (n.418), 3.22.10 (n.427), 3.23.1 (nn.8, 375, 396), 3.24 .7 (n.428), 3.25 (n.428), 3.25 .4 (n.418), 5.6 .3 (n.333), 7.22 .7 (p.145, nn.321, 396), 8.7 .2 (p.75), 8.24 .5 (n.337), 9.11 .3 (n.427), 9.11 .14 (n.428), 10.11 .6 (n.639).

Per.Maris.Eryth.26 (n.437),41-44 (p.219).

Per.Pont.Eux.8r43 (p.170), 8v25ff. (n.374).

Philos.Imag.1.12.27-31 (p.184, n.440), 2.15 (pp.71, 166), 2.17 (pp.243, 255, n.360).

Pind.I.2.39-42 (p.225), 4.11f. (n532), 4.56f. (p.82).

Pind.N.3.20ff. (p.231, n.532), 3.26ff. (p.148), 4.69f. (n.532), 6.40 (n.638), 7.17f. (p.252).

Pind.O.3.43ff. (n.532).

Pind.P.1.29 (p.170), 4.20f. (n.336), 4.24f. (n.545), 4.202ff. (p.86), 4.203-9 (n.418).

Pl.Crito 43C-D (p.108f.).

Pl.Ion 535f. (n.525).

Pl.Phaedo 58A-B (p.108f.), 110A (n.44).

Pliny.H.N. 2.46 (n.466), 2.46 (n.634), 2.47 (pp.263, 266, n.636), 4.6 (nn.418, 425), 4.12 (p.170), 5.31 (p.170), 6.1 (n.297), 10.30 (p.192), 18.82 (n.205), 18.85 (n.608), 18.87 (n.608), 18.88 (p.253).

Plut.Agesilaos.6.4 (n.389).

Plut.Cleomenes.22.5 (n.376), 38.4 (n.376).

Plut.Mor.160C-C (n.428), 161F, A (parts) (p.159), 303CD (n.360), 581F-582A (p.253).

Plut.Them.8 (n.639), 14f. (p.90, n.151), 32 (p.173, n.421), 32.5 (p.38).

Polyaenus 3.11 .13 (p.239, n.367).

Pol.1.25-8 (n.576), 4.39 (n.454), 4.39ff. (pp.120, 219), 4.43.3-10 (p.46), 10.42-7
Pol. cont'd: (n.444), 16.29.8-14 (p.46).

Pomp.Mela.1.110 (p.193).

Propert.El.1.8.13f. (pp.75, 100), 3.7 (n.421), 3.7.28f. (p.176).

ps-Scylax Perip. 1 (n.532), 8 (p.172), 27f. (p.75), 30 (n.317), 35 (n.338), 46 (n.416), 47 (n.418), 52 (p.144), 57 (p.162, n.418), 58 (p.178, n.418), 68 (p.169, n.329), 69 (p.170), 70 (p.164),71 (n.228), 72 (p.74), 79 (n.339), 81 (p.170), 83 (n.485), 85 (p.74).

Ps-Scymn.ad.Nic.reg.998ff. (n.374).

ps-Xen. Ath.Pol.2.13 (p.273).

Quintus Smyrnaeus, Fall of Troy 1.318ff. (n.438), 1.318-23 (p.76), 2.216ff. (p.33, n.3), 9.374-384 (p.24, 26, n.3), 11.226232 (p.35, n.3), 14.497-501 (p.238, n.548).

Sappho fr.17 (n.388).

schol.ad.Arat.Phaen.27 (n.461). schol.ad.Aristoph.Frogs. 1356 (n.428). schol.ad.Eur.Orestes 432 (n.450). schol.ad.Hes.W\&D.663ff. (n.506). schol.ad.Lycoph.344: see Little Iliad fr.11. schol.ad.Pind.N.3.35 (n.225).

Scymn.Perieg.311f. (p.74), 511 ff. (p.20), 724-9 (n.334), 825ff. (n.374), 935-7 (n.374).

SEG 18 (1962) \#153 (n.425).

$S I G^{3}$ III 1229. (p.81, n.236).

Solon fr.12.41-6 (p.235).

Soph.Achaion Syllogos. fr.142, col. ii, 3-5 (p.166, n.400), fr.143 (n.522).

Soph.Ajax. 1216-22 (p.148).

Soph.Ant.332-7 (p.226), 592 (n.438).

Soph.Elec.335 (n.549).

Soph.Tr.752 (n.89), 780 (n.89).

Soph.fr.371 (nn.430, 437), fr, 432 (n.522), fr.432.6 (p.182).

Stad.Mar.Magn.175 (n.418). 
Steph.Byz. sv. X $\alpha \lambda \kappa \eta \delta \omega \nu$ (n.433).

Str.Geog.1.1.7 (nn.272, 496), 1.1.17 (n.427), 1.2.23 (n.68), 1.2.30 (n.68), 1.3.4f. (n.19), 1.3.8 (n.338), 1.3.11f. (p.46), 1.3.16 (p.30), 1.3.18 (nn.337, 416), 1.3.18f. (p.32), 1.3.19 (n.339), 2.1.7f. (nn.395, 474), 2.1.40 (n.22), 2.4.2ff. (n.474), 2.4.3 (p.163, n.395), 2.4 .8 (n.22), 2.5 .7 (p.143), 2.5.17 (p.19), 2.5 .24 (pp.164, 189, n.467), 3.1.9 (n.424), 3.2 .5 (p.221), 3.5.5 (n.424), 4.1 .8 (n.425), 4.5 .2 (p.163), 5.2.6 (n.396), 6.1 .1 (n.543), 6.1 .5 (pp.69, 111, nn.392, 396), 6.1.6. (pp.24f., 30, 170), 6.1.7 (pp.74, 145, 160, 169), 6.1.11 (n.396), 6.2 .1 (p.151, n.395f.), 6.2 .3 (p.84), 6.2.11 (p.165), 6.3.5 (pp.75, 150, 154, n.396), 6.3 .7 (n.379), 6.3 .8 (p.150, n.396), 6.3.10 (p.189, nn.108, 395), 7.3.16 (p.170, n.424), 7.4.3 (pp.115, 147, nn.351, 396, 406, 483), 7.5.8 (n.321), 7.6.2 (n.480), 7.6.21-6 (n.454), 7.7.4 (p.43, n.395), 7.7.5 (p.75, nn.385, 396, 418), 7.fr.32 (pp.97, 145, 167, n.418), 7.fr.51 (n.396), 7.fr.52 (p.43), 7.fr.55 (p.169), 7.fr.56 (n.108), 8.1.3 (pp.19, 145, 167),8.2.1 (p.143f., n.395ff.), 8.2.2 (n.108), 8.2.3 (nn.418, 425), 8.3.12 (nn.381, 418), 8.3.13 (nn.418, 638), 8.3.14f. (n.333), 8.3.17 (n.425), 8.3.18 (n.638), 8.3.20 (nn.418, 424f., 638), 8.3.33 (n.397), 8.4.4ff. (n.401), 8.4.5 (p.144), 8.5.1 (pp.42, 161f., 163, 165, nn.8, 225, 376, 418), 8.5.1ff. (n.401), 8.6.2 (pp.71f., 100), 8.6.4 (p.162), 8.6.12f. (p.7, n.221), 8.6.14 (pp.74, 100, nn.418, 638), 8.6.16 (p.236), 8.6.20 (pp.79, 81, 148), 8.7.1f. (p.94), 8.7.2 (n.638), 8.7 .5 (p.161), 9.1 .2 (p.162), 9.1 .4 (p.120f.), 9.1 .22 (pp.162, 169), 9.1.24 (p.112), 9.2 .1 (p.20), 9.2 .8 (p.162), 9.2 .9 (nn.272, 427, 496), 9.2 .15 (p.19), 9.2.21 (p.167), 9.5 .13 (n.396), 9.5.14 (p.94), 9.5.22 (p.71), 10.1 .7 (p.157, n.418), 10.2.8 (p.169, nn.74, 338), 10.2.15 (p.147, n.396), 10.2.18 (n.396), 10.2.19 (nn.337, 374, 396), 10.4.2 (n.406), 10.4.5 (pp.165, 189, nn.395f., 406, 469), 10.5 .1 (p.153, n.396), 10.5.11 (n.418), 10.5.17 (pp.165, 169), 10.5.18 (n.396), 11.2 .7 (p.173, n.433), 11.3.10 (p.171), 11.4.2 (n.89), 12.3.2 (p.178, n.396), 12.3.10 (p.111), 12.3.11 (pp.111, 178, n.396), 12.3.27 (n.144), 12.8.11 (p.170), 13.1.5 (p.149), 13.1 .6 (p.143), 13.1.22 (p.177f.), 13.1 .28 (p.173), 13.1.30
Str.Geog.cont'd.(p.174), 13.1 .31 (p.178, n.396), 13.1 .46 (p.170), 13.1.51 (p.171, n.396), 13.2.1 (n.396), 13.2.2 (nn.74, 339), 13.3.5 (p.144, n.396), 14.1.2 (n.418), 14.1.3 (n.418), 14.1.12ff. (p.177, n.375), 14.1.13 (pp.162, 170), 14.1.14 (p.174, n.418), 14.1 .20 (p.174, n.418), 14.1.33 (p.170, n.418), 14.1.35 (p.170, nn.396, 418), 14.2.1 (n.418), 14.2.19 (nn.375, 396), 14.2.20 (p.74, n.638), 14.2.21 (n.543), 14.2.22 (n.418), 14.5.3 (p.147, n.396), 14.5 .4 (p.74), 16.2.13 (n.89), 16.4.18 (n.418), 17.1.6 (pp.116, 174, n.358), 17.1.6f. (n.89), 17.1.9 (n.418), 17.1 .14 (p.169), 17.1.16 (p.35).

Synesius Letters 4 (pp.131, 138, 139, 141, 218, 223, 238, 251, nn.220, 421).

Theoc.Id.3.26 (n.642), 7.52-62 (p.223f.), 7.53f. (nn.503, 581), 7.57 (n.503), 11.42f. (n.437), 13.25ff. (nn.503, 581), 22.4ff. (p. 240), 22.4-22 (pp.224, 227, n.548), 22.14 (n.558), 22.21 (n.595).

Theoc.Ep. 25 (n.514), 25.5 (nn.503, 581).

Theophr.Char.25 (n.368).

Theophr.Enq.Pl.5.7.1ff. (n.573), 7.15.1 (n.637).

Theophr.Vent. 4 (p.250), 5 (p.249, nn.205, 585, 587), 9 (n.587), 12 (n.594), 26 (p.54), 27 (pp.54, 125, n.594), 28 (p.223, nn.154, 272, 512), 29 (pp.46, 60), 31 (n.609), 32 (p. 109), 33 (n.89), 34 (p.58), 38 (n.609), 39 (n.594), 40 (n.609), 41 ff. (n.609), 45 (n.609), 47 (n.609), 51 (n.594), 52 (n.587), 53 (pp.54, 56) 53f. (p.72).

Theophr.Signs 1 (n.585), 3 (pp.57, 212, n.585), 10f. (n.596), 19 (p.254, n.608), 20 (p.63, nn.146, 205, 588), 21 (nn.205, 589), 22 (p.63, nn.205, 588, 592), 23 (n.595), 24 (nn.205, 588), 25 (p.65), 26 (n.596), 28 (nn.585, 607), 29 (nn.438, 585, 587), 31 (nn.585, 590), 32f. (n.589), 34 (nn.205, 588), 35 (pp.56, 63, 114 , nn.205, 585), 35f. (n.587), 36 (nn.146, 585), 38 (p.260, n.596), 40 (p.254, $\mathrm{nn} .605,608), 43$ (nn.205, 588, 590, 595), 45 (nn.205, 585, 588, 590), 47 (nn.605, 607), 50 (n.596), 51 (nn.205, 588, 590, 595), 52 (p.258), 57 (n.591).

Thuc. 1.10 .4 (n.364), 1.13 (n.564), 1.25 .4 (n.317), 1.30 (p.75, n.639), 1.36.2 
Thuc. cont'd: (pp.153, 154, n.392), 1.37.3 (p.153f.), 1.44 .3 (n.386), 1.46 (p.75), 1.46.4f. (nn.297, 392), 1.48 (n.434), 1.93 .3 (p.112, n.278), 1.104 .2 (n.519), 1.110 .4 (n.519), 2.13.3f. (n.263), 2.23 (p.101, n.416), 2.25 (pp.101, 273, n.416), 2.25 .4 (n.333), 2.27 (p.273), 2.32 (p.274), 2.69 .1 (p.87), 2.81-4 (n.434), $2.83 \mathrm{ff}$. (p.275), 2.83 .2 (p.89), 2.83 .3 (nn.254f., 259), 2.83 .5 (n.259) 2.83.5-84.3 (p.89, n.254), 2.84 (pp.88, 214, n.566), 2.84.1 (n.259), 2.84 .2 (n.264), 2.84 .3 (n.566), 2.84 .4 (p.271), 2.86 .3 (n.284), 2.87 (p.88), 2.91 (n.296), 2.91 .1 (p.272), 2.91 .4 (p.214), 2.92 .4 (p.272, n.639, n.639), 2.92 .5 (p.272), 2.93.4-94.1 (n.442f.), 2.102.2-5 (pp.31, 120, n.337), 3.3-3.4.1 (n.509), 3.3.4 (n.389), 3.22.7ff. (n.442), 3.49 (n.567), 3.49 .4 (n.560), 3.51 (p.120, n.340), 3.77f. (n.264), 3.80.2 (p.179), 3.81 .1 (p.179, n.74), 4.2 .4 (p.274), 4.3 (p.274), 4.8 .6 (pp.116, 274, n.416), 4.13.2f. (n.416), 4.23 .2 (nn.332, 345), 4.24 (p.84), 4.26 .3 (n.567), 4.26 .7 (nn.332, 345), 4.27 .1 (p.226, n.416), 4.31f. (n.434), 4.41-4 (p.274), 4.42f. (n.434), 4.45 .2 (p.275), 4.53 (p.152, n.392), 4.53-6 (p.275), 4.111f. (n.444), 4.129 (nn.418, 425), 5.2 .2 (p.97), 5.52 (p.275, n.392), 5.53 (p.160f.), 6.3 (n.89), 6.13 .1 (p.154), 6.30 .1 (n.386), 6.33f. (n.387), 6.34.4f. (n.386), 6.44.1 (n.576), 6.104 (p.80, n.519), 7.19 (p.80, nn.376, 383), 7.20 (p.275), 7.23 .2 (n.576), 7.26 (p.275, n.425), 7.31 .1 (n.381), 7.33.4 (n.386), 7.50 (pp.80, 145, 218, 229, n.567), 7.50.1f. (n.576), 7.67 (n.263), 8.4 (n.392), 8.34 (p.91f.), 8.39 (p.225f.), 8.101f. (nn.442, 445), 8.101.2f. (n.567), 8.101 .3 (p.179), 8.102.1 (p.179, n.453).

Veg.Epit.Rei.Milit.4.39 (n.507).

Verg.G.4.305ff. (n.632).

Vell.Pat.1.4.1 (pp.181, 193).

Xen.Anab.5.8.20 (p.245, n.223), 7.5.12f. (n.334), 7.8.15 (n.443).

Xen.Hell.1.1.16 (n.558), 1.6.27 (p.170), 1.6 .28 (n.558), 2.4 .31 (n.321), 3.4.4 (n.389), 5.1 .23 (n.290), 5.4 .61 (n.389), 6.2 .2 (n.297), 6.2.2f. (n.386), 6.2.4 (n.386), 6.2 .9 (p.154, n.386), 6.2.28ff.
Xen.Hell. cont'd. (n.567), 6.2.31 (n.381), 6.2 .34 (nn.442, 455).

Xen.Oec.8.14 (n.223),

Xen. $W \& M .1 .1$ (p.74).

Zen.4.68 (p.97). 


\section{SOURCES}

Acts - Meijer and van Nijf (1992) \#217, p.168ff.

Ael. On Animals - Aelian: On the Characteristics of Animals. trans. A.F. Schofield. 3 vols. London William Heinemann 1958-9.

Aesch. Agam., Eum., Pers., Pr.B., Supp., fragments - Aeschylus. trans. H. Weir Smyth. 2 vols. London William Heinemann 1956-7.

Alcaeus - D. Page, Sappho and Alcaeus. Oxford Clarendon Press 1955.

Anth.Pal. - The Greek Anthology. trans. W. R. Paton. 5 vols. London William Heinemann 1916-8.

Ap. Bibl. - Apollodorus: The Library. trans. J.G. Frazer. 2 vols. London William Heinemann 1939-46.

Ap.Rhod. Arg. - Apollonius Rhodius: The Argonautica, trans. R.C. Seaton. London William Heinemann 1912.

App. Mith.Wars - Appian's Roman History. vol.2. trans. H. White. London William Heinemann 1912.

Arat. Phaen. - Aratus. trans. G.R. Mair. London William Heinemann 1921.

Archilochos fr. - Greek Lyric Poetry: a selection of early Greek lyric, elegaic and iambic poetry. D.A. Campbell. London Macmillan 1967.

Aristides - Aristides. trans. C.A. Behr. 4 vols. London William Heinemann 1973.

Aristoph.Birds, Eq., Hipp. - Aristophanes. trans. B. Bickley Rogers. 3 vols. London William Heinemann 1930.

Arist.Anem.Thes. - Aristotle: Minor Works. trans. W.S. Hett. London William Heinemann 1955.

Arist.De Mundo - Aristotle: On Sophistical refutations, On Coming To Be and Passing Away, On the Cosmos. trans. D.J. Furley. London William Heinemann 1955.

Arist.H.A. - Aristotle: Historia Animalium. trans. A.L. Peck. 3 vols. London William Heinemann 1965-70.

Arist.Mech. - Aristotle: Minor Works. trans. W.S. Hett. London William Heinemann 1955.

Arist.Met. - Aristotle: Meteorologica. trans. H.D.P. Lee. London William Heinemann 1952.

Arist.Pol. - Aristotle: Politics. trans. H. Rackham. London William Heinemann 1959.

Arist.Probl. - Aristotle: Problems. vol.2, books XXII-XXXVIII trans. W.S. Hett. London William Heinemann 1957.

Arr.Anab. - Arrian. trans. E. Iliff Robson. 2 vols. London William Heinemann 1929-33.

Athen. - Athenaeus: The Deipnosophists. trans. C.B. Gulick. 7 vols. London William Heinemann $1951-7$.

Bacc.Ep. - R.C. Jebb, Bacchylides. The Poems and Fragments. Cambridge CUP 1905.

Battle of the Frogs and Mice - Hesiod, the Homeric Hymns, and Homerica. trans. H.G. EvelynWhite. London William Heinemann 1929.

Caes.G.W. - Caesar, Gallic Wars 3.13, translated in Meijer and van Nijf (1992) \#209, p.163f.

Callim.Hymn to Artemis - Callimachus and Lycophron. trans. A.W. Mair. London William Heinemann 1921.

Cic.Ad.Att. - Cicero: Letters to Atticus. trans. E.O. Winstedt. 3 vols. London William Heinemann 1912-19.

Contest of Homer and Hesiod - Hesiod, the Homeric Hymns, and Homerica. trans. H.G. EvelynWhite. London William Heinemann 1929.

Democ. - fragments of Democritus collected in: H. Diels (ed.), Die Fragmente der Vorsokratiker. 2 vols. Weidemannsche Verlagsbuchhandlung Berlin-Grunwald 1952; and K. Freeman, Ancilla to the Pre-Socratic Philosophers. Oxford Basil Blackwell 1948.

Dem. - Demosthenes: Private Orations. trans. A.T. Murray, vols. 1 and 3. London William Heinemann 1936-9.

- Demosthenes I: Olynthiacs, Philippics, Minor Public Speeches, Speech against Leptines I-XVII, XX. trans. J.H. Vince. London William Heinemann 1970.

- Demosthenes II: De Corona and De Falsa Legatione XVIII, XIX. trnas. C.A. Vince and J.H. Vince. London William Heinemann 1963. 
Dicaearchus - M. Letronne, Fragments des Poemes Geographiques de $\underline{\text { Scymnus }} \underline{\text { de }} \underline{\text { Chio et }} \underline{\text { du }}$ faux Dicearque. Paris Librairie de Gide, 1840.

Diod.Sic. - Diodorus of Sicily. trans. C.H. Oldfather. 12 vols. 1960-2.

Dionysios son of Calliphon, Description of Greece - Geographici Graeci Minores. vol.1. C. Muller (ed.). Paris Firmin Diderot 1855.

Eur.Cyc., Hek., Hel., Iph.A., I.T., Rhes., Troad. - Euripides. trans. A.S. Way. 4 vols. London William Heinemann 1946-7.

FGrH - F. Jacoby (ed.), Die Fragmente der griechischen Historiker. Leiden 1923-58.

Heliodorus of Emesa, Ethiopian Story - Heliodori: Aethiopicorum. I. Bebber (ed.) Leipzig Teubner 1855.

Heraclides Creticus - translated in Meijer and van Nijf (1992) \#72, p.53f.

Herodian - Herodian. trans. C.R. Whittaker. London William Heinemann 1969.

Hdt. - Herodotus, trans. A.D. Godley. 4 vols. London William Heinemann 1981-2.

Hes.W\&D. - Hesiod, the Homeric Hymns, and Homerica. trans. H.G. Evelyn-White. London William Heinemann 1929.

Hipp.Epid. - Hippocrates. vol.7, trans. W. D. Smith. London Harvard University Press 1994.

Hom. Il. - Homer: The Iliad. trans. A.T. Murray. 2 vols. London William Heinemann 1946-7.

Hom.Od. - Homer: The Odyssey, trans. A.T. Murray. 2 vols. London William Heinemann 1919.

H.H.Ap., H.H.Dion. - Hesiod, the Homeric Hymns, and Homerica. trans. H.G. Evelyn-White. London William Heinemann 1929.

Hor.Ep. - Horace: the Odes and Epodes. trans. C.E. Bennett. London William Heinemann 1914.

Little Iliad fr. - Hesiod, the Homeric Hymns, and Homerica. trans. H.G. Evelyn-White. London William Heinemann 1929.

Livy - Livy. vol.IX. books 31-4. trans. E.T. Sage. London William Heinemann 1985.

Lycophron.Alex. - Lycophronis: Alexandra. G. Kinkel. Leipzig Teubner 1880.

Menip.Perg.Perip. - The Tradition of the Minor Greek Geographers. A. Diller. American Philological Association Monograph XIV. Basil Blackwell Oxford 1952.

Opp.Hal. -Oppian, Colluthus, Tryphiodorus. trans. A.W. Mair. London William Heinemann 1928.

P.Hib. - The Hibeh Papyri, pt.i. B.P. Grenfell and A.S. Hunt (eds.). London Egyptian Exploration Society 1906.

Paus. - Pausanias: Description of Greece. 5 vols. trans. W.H.S. Jones. London William Heinemann 1918-1935

Per.Maris.Eryth. - translated in Meijer and van Nijf (1992) \#165, p.126f.

Per.Pont.Eux. - The Tradition of the Minor Greek Geographers. A. Diller. American Philological Association Monograph XIV. Basil Blackwell Oxford 1952.

Philos.Imag. - Philostratus: Imagines. Callistratus: Descriptions, trans. A. Fairbanks. London William Heinemann 1960.

Pind.I., N., O., P. - Pindar. trans. J. Sandys. London William Heinemann 1957.

Pl.Crito, Phaedo - Plato: Euthyphro, Apology, Crito, Phaedo, Phaedrus. trans. H.N. Fowler. London William Heinemann 1917.

Pl.Ion - Plato: the Statesman, Philebus, Ion. trans. W.R.M. Lamb. London William Heinemann 1925.

Pliny.H.N. - Pliny: Natural History. vols. 1-3, 5. trans. H. Rackham. London William Heinemann 1958-61.

Plut.Agesilaos, Cleomenes, Them. - Plutarch's Lives. vols.2, 5, 10. trans. B. Perrin. London William Heinemann 1914-20

Plut.Mor. - Plutarch's Moralia. vols.2, 4, (trans.F.C. Babbitt) \& 7 (trans. P.H. de Lacy and B. Einarson). London William Heinemann 1954-9.

Polyaenus - Pol.3.11.13 cited in Greek $\underline{\text { Oared Ships }} \underline{900-322}$ B.C. J.S. Morrison and R.T. Williams. Cambridge University Press (1968) p. $288 \# 21$.

Pol. - Polybius: The Histories. trans. W.R. Paton. 6 vols. London William Heinemann 1922-7. Pomp.Mela - Pomponii Melae: De Chorographia, libri tres. C. Frick. Leipzig Teubner 1880. Propert.El. - Propertius: Elegies. trans. G.P. Gould. London Harvard Universiry Press 1990. ps-Scylax Perip. - Il Periplo di Scilace: Studio sul primo portolano del Mediterraneo. A. Peretti. Giardini Editori e Stampatori, Pisa 1979. 
ps-Scymn.ad.Nic.reg. - The Tradition of the Minor Greek Geographers. A. Diller. American Philological Association Monograph XIV. Basil Blackwell Oxford 1952.

ps-Xen. Ath.Pol. - Xenophon: Scripta Minora. Pseudo-Xenophon: Constitution of the Athenians. trans. G.W. Bowersock. London William Heinemann 1984.

Quintus Smyrnaeus, Fall of Troy - Quintus Smyrnaeus: The Fall of Troy, trans. A.S. Way. London William Heinemann 1913.

Sappho - D. Page, Sappho and Alcaeus. Oxford Clarendon Press 1955.

schol.ad.Arat.Phaen. - Commentariorum in Aratum: Reliquiae. E. Maass (ed.) Berlin Weidmann 1958.

schol.ad.Aristoph.Frogs - Jo. Tzetzae. Commentarii in Aristophanem Pars IV, Fasc.III: Commentarium in Ranas et in Aves. W.J.W. Koster (ed.) Scripta Academica Groningana. J.B. Wolters Groningen 1962.

schol.ad.Eur.Orestes - Scholia Graeca in Euripidis tragoedias. vol.1. G. Dindorf (ed.) Oxon Typographeo Academico 1863.

schol.ad.Hes.W\&D. - Scholia Vetera in Hesiodi Opera et Dies. A. Pertusi (ed.). Pubblicanzioni dell'Universita Cattolica del S. Cuore nuova seria volume LIII. Societa Editrice "Vita e Pensiero" Milano 1955.

schol.ad.Lycoph. - see Little Iliad fr.11.

schol.ad.Pind. $N$. - Scholia vetera in Pindari carmina. vol.3. A.B. Drachmann (ed.). Amsterdam A.M. Hakkert 1964.

Scymn.Perieg. - M. Letronne, Fragments des Poemes Geographiques de Scymnus de Chio et $\underline{\text { du }}$ faux Dicearque. Paris Librairie de Gide, 1840.

Solon fr.12 - translated in Meijer and van Nijf (1992) \#419, p.30.

Soph.Ajax, Elec. - Sophocles: Ajax, Electra, Oedipus Tyrannus, trans. H. Lloyd-Jones. London Harvard University Press 1994.

Soph.Ant, $T r$. - Sophocles: Antigone, The Women of Trachis, Philoctets, Oedipus at Colonus. trans. H. Lloyd-Jones. London Harvard University Press 1994.

Soph.fr. - The Fragments of Sophocles, with additional notes from the papers of $\underline{\text { Sir R.C. Jebb and }}$ Dr. W.G. Headlam. A.C. Pearson (ed.). 3 vols. Cambridge CUP 1917.

Stad.Mar.Magn. - reference (no citation) in vol.2, p.662 (s.v. Posidium 4.) of Dictionary of Greek and Roman Geography. W. Smith (ed.). London Walton and Maberly 1857.

Steph.Byz. - H. Stephano, Thesaurus Graecae Linguae. 7 vols. London 1816-8.

Str.Geog. - The Geography of Strabo. trans. H.L. Jones. 8 vols. London William Heinemann 1949.

Synesius Letters - translated in Meijer and van Nijf (1992) \#218, pp.170ff.

Theoc.Ep., Id. - A.S.F. Gow, Theocritus. 2 vols. Cambridge CUP 1952.

Theophr.Char. - The Characters of Theophrastus. trans. J.M. Edmonds. London William Heinemann 1961.

Theophr.Enq.Pl., Signs - Theophrastus: Enquiry into Plants and minor works On Odours and Weather Signs. trans. A. Hort. 2 vols. London William Heinemann 1961

Theophr.Vent. - Theophrastus De Ventis: edited with introduction, translation, and commentary. V. Countant and V.L. Eichenlaub. University of Notre Dame Press, Notre Dame Indiana, 1975.

Thuc. - Thucydides: History of the Peloponnesian War. trans. C.F. Smith. 4 vols. London Harvard University Press 1991.

Veg.Epit.Rei.Milit. - translated in Meijer and van Nijf (1992) \#213, p. 165.

Verg.G. - Virgil. vol.1. trans. H.R. Fairclough. London William Heinemann 1916.

Vell.Pat. - Velleius Paterculus: Compendium of Roman History. Res Gestae Divi Augusti. trans. F.W. Shipley. London William Heinemann 1979.

Xen.Anab., Hell. - Xenophon: Hellenica, Anabasis, trans. C.L. Brownson. 2 vols. London William Heinemann 1922.

Xen.Oec. - Xenophon: Memorabilia and Oeconomicus. trans. E.C. Marchant. London William Heinemann 1959.

Xen.W\&M. - Xenophon: Scripta Minora. trans. E.C. Marchant. London William Heinemann 1984.

Zen. - Corpus Paroemiographorum Graecorum. Tomus I. A.L. Leutsch and F.G. Schneidewin (eds.) Hildesheim G. Olms 1958. 


\section{BIBLIOGRAPHY}

Alerstam (1975) - T. Alerstam, 'Crane Grus Grus migration over sea and land.', Ibis 117 (1975).

AR - Archaeological Reports, published annually by the Society for the Promotion of Hellenic Studies and the British School at Athens.

Archontidou-Argyri, Simossi, and Empereur (1989) - A. Archontidou-Argyri, A. Simossi, and J-Y. Empereur, 'The underwater excavations at the ancient port of Thasos, Greece.', IJNA 18.1 (1989).

Baker-Penoyre and Tod (1909) - J. ff. Baker-Penoyre and M.N. Tod, 'Thasos. Part I. Inscriptions.' JHS 29 (1909)

Barry (1968) - R.G. Barry \& R.J. Chorley, Atmosphere, Weather, and Climate. London, Methuen, 1968.

Basch (1982) - L. Basch, 'Some Observations on the Interpretation of Representations of Ancient Ships II.', MM 68 (1982).

Basch (1983) - L. Basch, 'A further note on ancient two-masters.', MM 69 (1983).

Bateson and Nisbet (1961) - P.P.G. Bateson and I.C.T. Nisbet, 'Autumn Migration in Greece.', Ibis 103a (1961).

Beckinsdale (1956) - R.P. Beckinsdale, Land, Air and Ocean. $2^{\text {nd }}$ ed. London Duckworth and Co. Ltd. 1956.

Bigelow and Edmondson (1947) - H.B. Bigelow and W.T. Edmondson, Wind Waves at Sea, Breakers, and Surf. U.S. Navy Hydrographic Department, publication 602. Washington 1947

Bintliff (1977) - J.L. Bintliff, Natural Environment and Human Settlement in prehistoric Greece, parts i-ii, BAR Supplementary series 28 (i) \& (ii), Oxford, 1977.

Bintliff (1982) - J.L. Bintliff, 'Climatic change, archaeology, and Quaternary science in the eastern Mediterranean region.', in Harding (1982).

Bisbee (1936) - H. Bisbee, 'Samikon' Hesp. 6 (1937).

Blackman (1966) - D.J. Blackman, 'The Harbour at Perachora.' BSA 61 (1966).

Blackman (1982) - D.J. Blackman, 'Ancient Harbours I.', IJNA 11.2 (1982).

Blackman and Branigan (1975) - D.J. Blackman and K. Branigan, 'An Archaeological Survey of the South Coast of Crete.' BSA 70 (1975)

Boardman (1967) - J. Boardman, Excavations in Chios 1952-1955: Greek Emporio. BSA supplementary volume 6, London Thames and Hudson 1976.

Boisacq (1950) - E. Boisacq, Dictionnaire Etymologique de la Langue Grecque, 4th. ed., Heidelberg 1950 Carl Winter.

Braswell (1988) - B.K. Braswell, A Commentary on the fourth Pythian ode of Pindar. Walter de Gruyter Berlin New York 1988.

Braudel (1975) - F. Braudel, The Mediterranean and the Mediterranean World in the Age of Philip II. vol.1., trans. S Reynolds. London Fontana 1975.

Broneer (1959) - O. Broneer, 'Excavations at Isthmia, fourth campaign, 1957-8.' Hesp. 28 (1959).

Bryant (1991) - E. Bryant, Natural Hazards, Cambridge CUP 1991.

Bunbury (1959) - E.H. Bunbury, $\underline{A}$ History of Ancient Geography among the Greeks and Romans from the earliest ages till the fall of the Roman Empire. 2 vols., Constable and Co., Ltd. London 1959.

Burnett (1994) - A.P. Burnett, 'Hekabe the Dog.', Arethusa 27, 1994.

Cambitoglou (1981) - A. Cambitoglou, Archaeological Museum of Andros: Guide to the finds from the excavations of the Geometric town at Zagora. Athens 1981.

Campbell (1967) - D.A. Campbell, Greek Lyric Poetry. MacMillan, London Melbourne \& Toronto 1967.

Carpenter (1948) - R. Carpenter, 'The Greek Pentration of the Black Sea.', AJA 52, 1948.

Cary (1949) - M. Cary, The Geographic Background of Greek and Roman History. Oxford, Clarendon Press, 1949. 
Cary and Warmington (1929) - M. Cary and A.H. Warmington, The Ancient Explorers, London Methuen and Co. 1929.

Casson (1912-13) - S. Casson, 'The Topography of Megara,', BSA 19 (1912-13).

Casson (1950) - L. Casson, 'The Isis and her Voyage.', TAPA 81 (1950).

Casson (1951) - L. Casson, 'Speed under sail of ancient ships.' TAPA 82 (1951).

Casson (1959) - L. Casson, The Ancient Mariners: seafarers and sea-fighters of the Mediterranean in ancient times. Victor Gollancz Ltd., London 1959.

Casson (1971) - L. Casson, Ships and Seamanship in the Ancient World. Princeton University Press, Princeton, N.J., 1971.

Casson (1974) - L. Casson, Travel in the ancient world. London Allen and Unwin 1974.

Casson (1980) - L. Casson, 'Two-masted Greek ships.', IJNA 9 (1980).

Charnock and Deacon (1978) - A. Charnock and Sir G. Deacon (eds.), Advances in oceanography. 1978 Plenum Press New York.

Chevallier (1966) - R. Chevallier (ed.), Melanges d'Archeologie et d'Histoire offerts a Andre Piganiol 3. Ecole Practique des Hautes Etudes, Paris 1966.

Choremis (1974) - A.K. X $\Omega$ PEMH $\Sigma$, 'EI $\Delta H \Sigma E I \Sigma$ E $\Xi$ EYBOIA $\Sigma$.', AAA 7 (1974).

Chowdharay-Best (1976) - G. Chowdharay-Best, 'Ancient Maritime Law.', MM 62 (1976).

Clarke (1912) - W.E. Clarke, Studies in Bird Migration. London, Gurney and Jackson; Edinburgh, Oliver and Boyd, 1912.

Coates and Morrison (1993) - J. Coates and J. Morrison, 'The sea trials of the reconstructed Athenian trireme Olympias: a reply to Lucien Basch.', MM 79 (1993).

Cole (1984) - S.G. Cole, Theoi Megaloi: the cult of the Great Gods at Samothrace. Leiden E.J. Brill 1984

Couper (1989) - A. Couper (ed.), The Times Atlas and Encyclopaedia of the Sea, Times Books Ltd., London, 1989.

Coutant and Eichenlaub (1975) - V. Countant and V.L. Eichenlaub, Theophrastus De Ventis: edited with introduction, translation, and commentary. University of Notre Dame Press, Notre Dame Indiana, 1975.

Cummer (1978) - W. Cummer, 'The Sanctuary of Poseidon at Tainaron, Lakonia.', AM 93 (1978).

Curtius (1851) - E. Curtius, Peloponnesos: eine historisch-geographische Beschreibung der halbinsel. vol.1, Gotha 1851 .

Curtius (1852) - E. Curtius, Peloponnesos: eine historisch-geographische Beschreibung der halbinsel. vol.2, Gotha 1852.

Curtius (1861) - E. Curtius, 'Beitrage zur geographischen Onomatologie der griechischen Sprache.', Gottingische gelehrte Anzeigen, Nachr. 1861.

Dale (1967) - A.M. Dale, Euripides: Helen. Oxford, Clarendon Press 1967.

Day (1927) - J. Day, 'The K $\Omega \Phi O \Sigma \Lambda$ IMHN of the Piraeus.' AJA 31 (1927).

Defant (1961) - A. Defant, Physical Oceanography. 2 vols. Pergamon Press, Oxford, London, New York, Paris, 1961.

De Lucca (1969) - C. De Lucca, 'Bird Migration over the Maltese Islands.', Ibis 111 (1969).

Der Kleine Pauly - K. Ziegler, W. Sontheimer, and H. Gartner, Der Kleine Pauly Lexikon der Antike. 5 vols. A. Druckenmuller, Munich, 1952-1975.

Dicks (1966) - D.R. Dicks, 'Solstices, Equinoxes, and the Presocratics.', JHS 86 (1966).

Dicks (1970) - D.R. Dicks, Early Greek Astronomy to Aristotle. London Thames and Hudson 1970.

Diels (1952) - H. Diels (ed.), Die Fragmente der Vorsokratiker. 2 vols. Weidemannsche Verlagsbuchhandlung Berlin-Grunwald 1952.

Diller (1952) - A. Diller, The Tradition of the Minor Greek Geographers. American Philological Association Monograph XIV. Basil Blackwell Oxford 1952.

Dinsmoor (1970) - W.B. Dinsmoor Jr., A Guide to Sounion. Athens 1970.

Dorpfeld (1927) - W. Dorpfeld, Alt-Ithaka. 2 vols. Munchen Richard Uhde 1927.

Dunbabin (1948) - T.J. Dunbabin, 'The Western Greeks.', Oxford Clarendon Press 1948.

Dunbar (1995) - N. Dunbar, Aristophanes: Birds, edited with introduction and commentary. Oxford Clarendon Press 1995. 
Edlund (1987) - I.E.M. Edlund, The Gods and the Place: location and function of sanctuaries in the countryside of Etruria and Magna Graecia (700-400 B.C.). Skrifter utgivna av Svenska institutet i Rom, $4^{\circ}$, XLIII, Stockholm 1987.

Elkins (1983) - N. Elkins, Weather and Bird Behaviour. T. and A.D. Poyser, Calton, 1983.

Emanuele (1977) - P.D. Emanuele, 'Ancient square rigging, with or without lifts.', IJNA 6.3 (1977).

Etienne and Braun (1986) - R. Etienne and J.P. Braun, Tenos: le sanctuaire $\underline{\text { de }} \underline{\text { Poseidon et }}$ d'Amphitrite. 3 vols. Athens Ecole francaise d'Athens 1986

Fehling (1989) - D. Fehling, Herodotus and his 'sources': Citation, Invention, and Narrative Art. ARCA Classical and Medieval Texts, Papers and Monographs 21, trans. J.G. Howie.

Francis Cairns (Publications) Ltd. Leeds 1989.

Fenton (1993) - P.C. Fenton, 'The navigator as natural historian.', MM 79 (1993).

FGrH - F. Jacoby (ed.), Die Fragmente der griechischen Historiker. Leiden 1923-58.

Fraenkel (1950) - E.Fraenkel, Aeschylus' Agamamnon edited with a commentary. 3 vols. Oxford Clarendon Press 1950.

Frazer (1898) - J.G. Frazer, Pausanias's Description of Greece, translated with a commentary. 6 volumes. London Macmillan and Co. Ltd., 1898.

Freeman (1948) - K. Freeman, Ancilla to the Pre-Socratic Philosophers. Oxford Basil Blackwell 1948.

Frisk (1970) - H. Frisk, Griechisches Etymologisches Worterbuch, 2 vols., Heidelberg 1970 Carl Winter.

Frost (1963) - H. Frost, 'From Rope to Chain: on the development of anchors in the Mediterranean.', MM 49 (1963).

Frost (1972) - H. Frost, 'Ancient harbours and anchorages in the East Mediterranean.' in Underwater Archaeology., UNESCO Paris 1972

Frost (1977) - F.J. Frost, 'Phourkari: a villa complex in the Argolid, Greece.' IJNA 6 (1977).

Frost (1980a) - F.J. Frost, 'Skyllaieis, a district of Troizenia.', AJA 84 (1980) (and cf. ch.2, n.3a)

Frost (1980b) - F.J. Frost, Plutarch's Themistocles: a historical commentary. Princeton University

Press, Princeton N.J., 1980.

Frost (1982) - H. Frost, 'The birth of the stocked anchor and the maximum size of early ships thoughts prompted by tdiscoveries at Kition-Bamboula, Cyprus.', MM 68 (1982).

Frost (1993) - H. Frost, 'Stone Anchors: a reassessment reassessed.', MM 79 (1993).

Gallant (1985) - T.W. Gallant, A Fisherman's Tale. Miscellanean Graeca fasciculus 7. Belgian Archaeological Mission in Greece/State University of Gent, Gent 1985.

Garland (1987) - R. Garland, The Piraeus from the fifth to the first century B.C. London Duckworth 1987

Garnett and Boardman (1961) - R. Garnett and J. Boardman, 'Underwater reconnaissance off the island of Chios, 1954.', BSA 56 (1961).

Gianfrotta (1977) - P.A. Gianfrotta, 'First elements for dating of stone anchor stocks.', IJNA 6 (1977).

Gifford (1993) - E.W.H. Gifford, review of J.E. Coates, S.K. Platis, and J.T. Shaw, The trireme trials 1988; report on the Anglo-Hellenic sea trials of Olympias. (Oxford Oxbow 1990), MM 79 (1993)

Gleichen and Reynolds (1951) - E. Gleichen and J.H. Reynolds, Alphabets of Foreign Languages. 2nd edition. Permanent Committee on Gographical Names for British Official Use, London 1951

Glover (1932) - T.R. Glover, Greek Byways. Cambridge CUP 1932.

Gomme (1933) - 'A forgotten factor of Greek naval strategy.' JHS 53, 1933.

Gomme (1956a) - A.W. Gomme, Historical Commentary on Thucydides. vol.2, Books II-III. Oxford Clarendon Press 1956.

Gomme (1956b) - A.W. Gomme, Historical Commentary on Thucydides. vol.3, Books IV-V. Oxford Clarendon Press 1956.

Gomme, Andrewes, and Dover (1981) - A.W. Gomme, A. Andrewes, and K.J. Dover, $\underline{\text { A Historical }}$

Commentary on Thucydides vol.5 Book VIII. Oxford, Clarendon Press 1981.

Gow (1952) - A.S.F. Gow, Theocritus. 2 vols. Cambridge CUP 1952.

Grenfell and Hunt (1906) - B.P. Grenfell and A.S. Hunt (eds.), The Hibeh Papyri, pt.i. London Egyptian Exploration Society 1906. 
Griffith (1983) - M.Griffith (ed.), Prometheus Bound. Cambridge CUP 1983.

Hammond (1945) - N.G.L. Hammond, 'Naval Operations in the South Channel of Corcyra.' JHS 65 (1945)

Hammond (1967) - N.G.L. Hammond, Epirus: the geography, the ancient remains, the history and the topography of Epirus and adjacent areas. Oxford Clarendon Press 1967.

Hammond (1968) - N.G.L. Hammond, 'The Camp and Battle of Marathon.', JHS 88 (1968).

Harden Jones, Greer Walker, and Arnold (1978) - F.R. Harden Jones, M. Greer Walker, and G.P.

Arnold, 'Tactics of fish movement in relation to migration strategy and water circulation.' in Charnock and Deacon (1978).

Harding (1982) - A. Harding (ed.), Climatic Change in Later Prehistory. Edinburgh EUP 1982.

Harland (1925) - J. Penrose Harland, 'The Kalaurian Amphictyony.' AJA 29 (1925).

Heubeck, West, and Hainsworth (1988) - A. Heubeck, S. West, \& J.B. Hainsworth, A Commentary on Homer's Odyssey, vol. 1, Clarendon Press Oxford 1988.

Heubeck and Hoekstra (1989) - A. Heubeck and A. Hoekstra, A Commentary on Homer's Odyssey, vol. 2, Clarendon Press Oxford 1989.

Hodge (1975) - A.T. Hodge, 'Marathon: the Persians' Voyage.', TAPA 105 (1975).

Holladay (1988) - A.J. Holladay, 'Further thoughts on trireme tactics.' G\&R 35.2 (1988).

Hollinshead (1979) - M.B.B. Hollinshead, Legend, Cult and Architecture at three sanctuaries of Artemis. PhD thesis, Bryn Mawr College, 1979.

Hornblower (1991) - S. Hornblower, A Commentary on Thucydides. vol. I, Books I-III. Clarendon Press Oxford 1991.

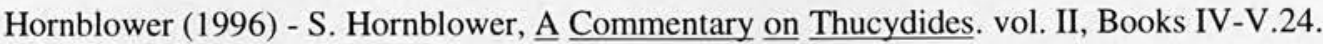
Clarendon Press Oxford 1991.

Hornell (1946) - J. Hornell, 'The Role of Birds in Early Navigation.' Antiquity 20 (1946).

Horrocks (1981) - N.K. Horrocks, Physical Geography and Climatology. $3^{\text {rd }}$. ed. Longman, London, 1981.

How and Wells (1912) - W.W. How and J. Wells, A Commentary on Herodotus. 2 vols. Oxford Clarendon Press 1912.

Howell (1955) - E. Howell, 'The meaning of OINOПA.', G\&R 2 (1955).

Howie (1989) - J.G. Howie, 'The Phaeacians in the Odyssey: Fable and Territorial Claim.', $\underline{\text { Shadow }}$ 6 (1989).

Hunt (1940-5) - D.W.S. Hunt, 'Sailing directions for the island of Chios', appendix C of 'An Archaeological survey of the island of Chios', BSA 41 (1940-5).

Hunter (1973) - V.J. Hunter, Thucydides the Artful Reporter. Hakkert Toronto 1973.

Jacobsen and Smith (1968) - T.W. Jacobsen and P.M. Smith, 'Two Kimolian dikast decrees from Geraistos in Euboia.' Hesp. 37 (1968).

Janko (1992) - R. Janko, The Iliad: a commentary. vol. iv: books 13-16. Cambridge CUP 1992 Jebb (1905) - R.C. Jebb, Bacchylides. The Poems and Fragments. Cambridge CUP 1905.

Jebb and Pearson (1917) - A.C. Pearson (ed.) The Fragments of Sophocles, with additional notes from the papers of Sir R.C. Jebb and Dr. W.G. Headlam. 3 vols. Cambridge CUP 1917.

Jeffrey (1976) - L.H. Jeffrey, Archaic Greece: the City-States c.700-500 B.C. Ernest Benn Ltd, London and Tonbridge, 1976.

Karageorghis (1991) - V. Karageorghis (ed.), The civilisations of the Aegean and their diffusion in Cyprus and the Eastern Mediterranean, 2000-600 B.C. Proceedings of an international symposium, 18-24 September 1989. Pierides Foundation, Larnaca 1991

Kelly (1966) - T. Kelly, 'The Calaurian Amphictyony.' AJA 70 (1966).

Kenny (1947) - E.J.A. Kenny, 'The Ancient Docks on the Promontory of Sounion.' BSA 42, 1947.

King (1972) - C.A.M. King, Beaches and Coasts, $2^{\text {nd }}$. edition, Edward Arnold, London, 1972.

Kyrieleis (1993) - H. Kyrieleis, 'The Heraion at Samos', in Marinatos and Hagg (1993)

Labaree (1957) - B.W. Labaree, 'How the Greeks sailed into the Black Sea.' AJA 61 (1957).

Lazenby (1987) - J.F. Lazenby, 'The Diekplous.' G\&R 34.2, (1987).

Leaf (1888) - W. Leaf, The Iliad. 2 vols. London Macmillan and Co. 1888.

Leake (1830) - W.M. Leake, Travels in the Morea. 3 vols. London J. Murray 1830.

Leake (1835) - W.M. Leake, Travels in Northern Greece. 4 vols. London J. Rodwell 1835. 
Lee (1952) - Aristotle: Meteorologica with an English translation. Loeb edition, London William Heinemann Ltd., 1952.

Lehmann (1978) - L.Th. Lehmann, 'The mystery of the Graeco-Roman steering oar.' IJNA 7.2 (1978).

Lehmann-Hartleben (1923) - K. Lehmann-Hartleben, Die antiken Hafenanlagen des Mittelmeeres. Klio, Beiheft XIV, Leipzig 1923.

Lemos (1991) - A.A. Lemos, Archaic Pottery of Chios: the decorated styles. 2 vols. Oxford University Committee for Archaeology Monograph 30, Oxford 1991.

Letronne (1840) - M. Letronne, Fragments des Poemes Geographiques de Scymnus de Chio et du faux Dicearque. Paris Librairie de Gide, 1840.

Liddell and Scott - H.G. Liddell and R. Scott, $\underline{A}$ Greek-English Lexicon. $6^{\text {th }}$ ed. Oxford Clarendon Press 1869.

Lloyd (1972) - A.B. Lloyd, 'Triremes and the Saite navy.', JEA 58 (1972).

Lloyd (1975) - A.B. Lloyd, 'Were Necho's triremes Phoenician?', JHS 95 (1975).

Lobel and Page (1955) - E. Lobel and D. Page, Poetarum Lesbiorum Fragmenta. Oxford Clarendon Press 1955.

Luce (1976) - J.V. Luce, 'Asteris and the Twin Harbours.' JHS 96 (1976).

McAllister (1969) - M.H. McAllister, 'A temple at Hermione.' Hesp.38 (1969).

McCaslin (1980) - D.E. McCaslin, Stone Anchors in Antiquity: Coastal Settlements and Maritime Trade-routes in the Eastern Mediterranean ca. 1600-1050 B.C. Paul Astroms Forlag Goteborg 1980.

McGrail (1983) - S. McGrail, 'Cross-Channel Seamanship and Navigation in the late First Millenium B.C.' Oxford Journal of Archaeology 2.3, 1983.

McGrail (1991) - S. McGrail, 'Early Sea Voyages', IJNA 20.2, 1991.

McLeod (1960) - W.E. McLeod, 'Boudoron, an Athenian fort on Salamis.', Hesp. 29 (1960).

Mair (1928) - Oppian, Colluthus, Tryphodorus. trans. A.W. Mair. Loeb edition. London, W. Heinemann Ltd. 1928.

Mantzourani and Theodorou (1991) - E.K. Mantzourani and A.J. Theodorou, 'An attempt to delineate the sea-routes between Crete and Cyprus during the Bronze Age.' in Karageorghis (1991).

Manual $=$ Admiralty Weather Manual 1938, Admiralty Hydrographic Dept., London, 1941.

Marinatos and Hagg (1993) - N. Marinatos and R. Hagg, Greek Sanctuaries: New Approaches. Routledge, London and New York, 1993.

Marsigli (1978) - Count L.F. Marsigli, 'Internal Observations on the Thracian Bosphorus, or True Channel of Constantinople, Represented in Letters to Her Majesty, Queen Christina of Sweden.' in M.B. Deacon (ed.), Oceanography: Concepts and History. Benchmark Papers in Geology 35. Dowden Hutchinson and Ross Inc., Stroudsburg Penn., 1978.

Mediterranean Pilot III, IV = Great Britain Admiralty Hydrographic Dept., The Mediterranean Pilot, vols.3 (1919) \& 4 (1918), $5^{\text {th }}$ ed. Taylor, Garnett, Evans, \& Co. London.

Meigs (1961) - P. Meigs, 'Some Geographical Factors in the Peloponnesian War.', Geographical Journal 51 (1961).

Meijer (1986) - F. Meijer, $\underline{\text { A History }}$ of Seafaring in the Classical World. Croon Helm, London and Sydney, 1986.

Meijer and van Nijf (1992) - F. Meijer and O. van Nijf, Trade, Transport and Society in the Ancient World: a sourcebook. Routledge, London and New York 1992.

Melentis (1977) - J.K. Melentis, 'The Dinaric and Aegean arcs: Greece and the Aegean Sea.', in Nairn, Kanes, and Stehli (1977).

Merritt (1923) - B.D. Merritt, 'Scione, Mende, and Torone.' AJA 27 (1923).

Met. Office (1967) - Meteorological Office, Meteorology for Mariners. HMSO London 1967.

Mooney (1912) - G.W. Mooney, 'The Argonautica of Apollonius Rhodius with introduction and commentary.', Longmans Green and Co. London 1912.

Moreau (1938) - R.E. Moreau, 'Bird-Migration over the Northwestern part of the Indian Ocean, the Red Sea, and the Mediterranean.' Proceedings of the Zoological Society of London 108, Series A (1938).

Moreau (1953) - R.E. Moreau, 'Migration in the Mediterranean Area.', Ibis 95 (1953).

Moreau (1960) - R.E. Moreau, 'Autumn migrants in Greece.', Ibis 102 (1960). 
Moreau (1961) - R.E. Moreau, 'Problems of Mediterranean-Saharan Migrations.', Ibis 103 (1961).

Morgan (1989) - C. Morgan, 'Archaeological evidence for Dark Age cult at Isthmia.' AJA 93 (1989).

Morrison (1974) - J.S. Morrison, 'Greek naval tactics in the 5th century BC.' IJNA 3.1 (1974)

Morrison (1979) - J.S. Morrison, 'The first triremes.' MM 65 (1979).

Morrison (1984) - J.S. Morrison, 'Some problems in trireme reconstruction.' IJNA 13.3 (1984).

Morrison (1988) - J.S. Morrison, 'The sea-trials of the trireme: Poros 1987.' IJNA 17.2 (1988).

Morrison and Coates (1986) - J.S. Morrison and J.F. Coates, The Athenian Trireme: the history and reconstruction of an ancient Greek warship. Cambridge CUP 1986.

Morrison and Williams (1968) - J.S. Morrison and R.T. Williams, Greek Oared Ships, 900-322BC. Cambridge CUP 1968.

Muckelroy (1978) - K. Muckelroy, Maritime Archaeology. Cambridge CUP 1978.

Muller (1855-1861)- C. Muller, Geographici Graeci Minores. 2 vols. Paris Firmin Diderot 1855 (vol.1) and 1861 (vol.2).

Murray (1987) - W.M. Murray, 'Do Modern Winds Equal Ancient Winds?' Med.Hist.Rev.2.2 (1987).

Murray (1995) - W.M. Murray, 'Ancient Sailing Winds in the Eastern Mediterranean: The Case for Cyprus.', in Proceedings of the International Symposium, Cyprus and the Sea, Nicosia $25-$ 26 September, 1993. Nicosia 1995.

Mylonas (1948) - G.E. Mylonas, 'Homeric and Mycenaean Burial Customs', AJA 52 (1948).

Myres (1896) - J.L. Myres, 'An attempt to reproduce the maps used by Herodotus', The Geographical Journal 8.6, 1896.

Myres (1911) - J.L. Myres, 'The geographical aspect of Greek colonisation.' Proceedings of the Classical Association 8 (1911)

Nairn, Kanes, and Stehli (1977) - A.E.M. Nairn, W.H. Kanes, and F.G. Stehli (eds.), The Ocean Basins and Margins vol.4A: The Eastern Mediterraean. New York and London Plenum Press 1977.

Neumann (1973) - J. Neumann, 'The sea and land breezes in the classical Greek literature.', Bull.Am.Met.Soc. 54 (1973).

Neumann and Metaxas (1979) - J. Neumann and D.A. Metaxas, 'The Battle between the Athenian and Peloponnesian fleets, 429 B.C., and Thucydides' "Wind from the Gulf (of Corinth)".', Meteorologische Rundschau 32 (1979).

$\underline{\text { New }}$ Pilot - Great Britain Admiralty Hydrographic Dept., New Piloting Directions for the Mediterranean Sea. London, J. W. Norie and Co. 1831.

Nibbi (1993) - A. Nibbi, 'Stone anchors: the evidence re-assessed.', MM 79 (1993).

OCD - S. Hornblower and A. Spawforth (eds.), The Oxford Classical Dictionary. 3rd. edition, OUP Oxford and New York 1996.

Ormorod (1924) - H.A. Ormorod, Piracy in the Ancient World. Liverpool University Press Liverpool, Hodder and Stoughton Ltd. London, 1924

Osborne (1986) - R. Osborne, 'Island Towers: the case of Thasos.' BSA 81 (1986)

Page (1955) - D. Page, Sappho and Alcaeus. Oxford Clarendon Press 1955

Papageorgiou et al. (1993) - S. Papageorgiou, M. Arnold, J. Laborel, S.C. Stiros, 'Seismic uplift of the harbour of ancient Aigeira, Central Greece.', IJNA 22.3 (1993).

Parker (1992) - A.J. Parker, Ancient Shipwrecks of the Mediterranean and the Roman Provinces. BAR International Series 580, Oxford Tempus Reparatum 1992.

Payne (1940) - H. Payne, Perachora vol.1, Oxford Clarendon Press 1940.

Pensabene (1978) - P. Pensabene, 'A cargo of marble shipwrecked at Punta Scifo near Crotone (Italy).', trans. A. Martin, IJNA 7.2 (1978).

Peretti (1979) - A. Peretti, Il Periplo di Scilace: Studio sul primo portolano del Mediterraneo. Giardini Editori e Stampatori, Pisa 1979.

Picard (1988) - O. Picard, ANA

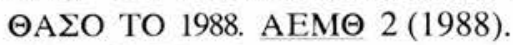

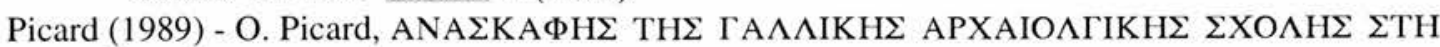

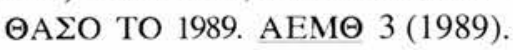


Pinar-Erdem and Ilhan (1977) - N. Pinar-Erdem and E. Ilhan, 'Outlines of the stratigraphy and tectonics of Turkey, with notes on the geology of Cyprus.', in Nairn, Kanes, and Stehli (1977).

Pirazzoli et al. (1994) - P.A. Pirazzoli, S.C. Stiros, M. Arnold, J. Laborel, F. Laborel-Deguen, and S. Papageorgiou, 'Episodic uplift deduced from Holocene shorelines in the Perachora Peninsula, Corinth area, Greece.', Technophysics 229 (1994).

Pleket (1964) - H.W. Pleket, Epigraphica: texts on the economic history of the Greek world. Vol.1. Leiden E.J. Brill 1964.

Pollard (1977) - J. Pollard, Birds in Greek Life and Myth. Thames and Hudson, Plymouth 1977.

Pritchett (1963) - W. Kendrick Pritchett, 'Xerxes' Fleet at the "Ovens".' AJA 67 (1963).

Princeton - R. Stillwell (ed.), The Princeton Encyclopedia of Classical Sites. Princeton University Press Princeton N.J. 1976.

Pryor (1988) - J.H. Pryor, Geography, Technology, and War. Cambridge CUP 1988.

Puoilloux (1954) - J. Pouilloux, Recherches sur l'histoire et les cultes de Thasos. Ecole francaise d'Athenes Etudes thasiennes vol.1. Paris E. de Boccard 1954.

Quinn (1961) - J.D. Quinn, 'Cape Phokas, Lesbos - Site of an archaic sanctuary for Zeus, Hera, and Dionysus?', AJA 65 (1961).

Radcliffe (1921) - W. Radcliffe, Fishing from the earliest times. London. J. Murray 1921.

Rankov (1994) - B. Rankov, 'Reconstructing the past: the operation of the trireme reconstruction 'Olympias' in the light of the historical sources.', MM 80 (1994).

Renfrew and Wagstaff (1982) - C. Renfrew and M. Wagstaff (eds.), An Island Polity: the archaeology of exploitation in Melos. Cambridge CUP 1982.

Rhodes (1988) - P.J. Rhodes, Thucydides, History II. Aris and Phillips Ltd, Warminster 1988.

Rice Holmes (1909) - T. Rice Holmes, 'Could ancient ships work to windward?', CQ 3 (1909).

Roberts (1995) - O.T.P. Roberts, 'An explanation of ancient windward sailing: some other considerations.', IJNA 24.4 (1995).

Rose (1933) - J.H. Rose, The Mediterranean in the Ancient World. Cambridge CUP 1933.

Rouge (1966a) - J. Rouge, 'Le droit de naufrage et ses limitations en Mediterranee avant l'etablissement de la domination de Rome.' in Chevallier (1966).

Rouge (1966b) - J. Rouge, Recherches surl'organisation du commerce maritime en Mediterranee sous l'Empire romain. Paris S.E.V.P.E.N. 1966

Rouge (1981) - J. Rouge, Ships and fleets of the Ancient Mediterranean, trans. S. Frazer. Wesleyan University Press, Middletown, Conneticut, 1981.

Rusten (1989) - J.S. Rusten (ed.), Thucydides: The Peloponnesian War Bk.II Cambridge CUP 1989. Rutherford (1992) - R.B. Rutherford (ed.), Homer. Odyssey books XIX and XX. Cambridge CUP 1992.

Schachter (1992) - A. Schachter, 'Policy, cult, and the placing of Greek sanctuaries.' in Le Sanctuaire grec. Entretiens sur l'antiquite classique Tome 37. Fondation Hardt Geneva 1992.

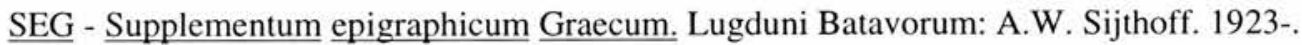

Semple (1932) - E.C. Semple, The Geography of the Mediterranean Region: its relation to ancient history. London, Constable 1932.

Severin (1954) - T. Severin, 'Early Navigation: the human factor.', Mariner's Mirror 40.1, 1954.

Shaw (1993) - T. Shaw (ed.), The Trireme Project. Operational Experience 1987-90: lessons learnt. Oxbow Monograph 31, Oxford 1993.

Shipley (1987) - G. Shipley, A History of Samos, 800-188 B.C. Oxford OUP 1987.

Smith (1854-7) - W. Smith (ed.), Dictionary of Greek and Roman Geography. 2 vols. London Walton and Maberly, John Murray, 1854 (vol.1) and 1857 (vol.2).

Smith (1919) - Thucydides, with an English translation by C. Foster Smith. 4 vols. London Heinemann 1919.

Snider (1978) - G.L. Snider, 'Hesiod's Sailing Season.', AJAH 3 (1978).

Snodgrass (1971) - A.M. Snodgrass, The Dark Age of Greece. Edinburgh University Press 1971.

Sobel (1995) - D. Sobel, Longitude: The True Story of a Lone Genius Who Solved the Greatest Scientific Problem of His Time. London Fourth Estate 1995.

Stanford (1953) - J.K. Stanford, 'Spring migration in Cyrenaica.', Ibis 95 (1953). 
Starr (1989) - C.G. Starr, The Influence of Sea Power on Ancient History. Oxford 1989.

Steffy (1985) - J.R. Steffy, 'The Kyrenia Ship: an interim report on its hull construction.' AJA 89 (1985).

Stiros (1995) - S.C. Stiros, 'Palaeogeographic reconstruction of the Heraion-Vouliagmeni Lake coast since Early Helladic times.', BSA 90 (1995).

Stronk (1986) - J. Stronk, 'Wreckage at Salmydessos.' Thracia Pontica 3 (1986).

Tarn (1908) - W.W. Tarn, 'The Fleet of Xerxes.', JHS 28 (1908).

Tataki (1983) - A.B. Tataki, Sounion: The temple of Poseidon. Ekdotike Athenon S.A., Athens 1983.

Taylor (1971) - E.G.R. Taylor, The Haven Finding Art: a history of navigation from Odysseus to Captain Cook. Hollis and Carter, London, Sydney, Toronto. For the Institute of Navigation 1971.

Themelis (1968) - P.G. Themelis, 'Thyron-Epitalion.', AAA 1 (1968).

Thompson (1929) - D'A.W. Thompson, 'Science and the Classics.' Proc.Cl.Ass.26 (1929).

Thompson (1936) - D'A.W. Thompson, A Glossary of Greek Birds. St. Andrews University Publications no.39, new edition: OUP, London, Humphrey Milford 1936.

Thurneysson (1979) - O. Thurneysson, 'Another view of the ancient rudder.' IJNA 8.1 (1979).

Tilly (1994) - A. Tilly, 'Sailing to windward in the ancient Mediterranean.', IJNA 23.4 (1994).

Tipps (1985) - G.K. Tipps, 'The Battle of Ecnomus.', Historia 34 (1985).

Tozer (1873) - Rev. H.F. Tozer, Lectures on the Geography of Greece. London, John Murray 1873.

Trenhaile (1987) - A.S. Trenhaile, The Geomorphology of Rock Coasts. Oxford, Clarendon Press 1987.

Van Andel and Runnels (1988) - T.H. Van Andel and C.N. Runnels, 'An essay on the 'emergence of civilisation' in the Aegean world.' Antiquity 62 (1988).

Vaughan (1960) - R. Vaughan, 'Notes on autumn migration in Greece and Crete.', Ibis 102 (1960).

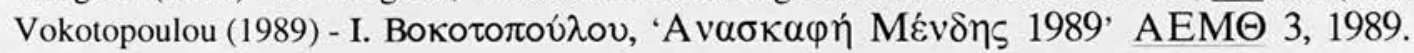

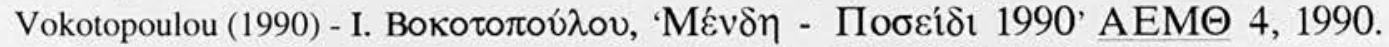

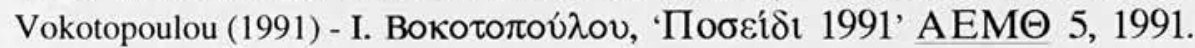

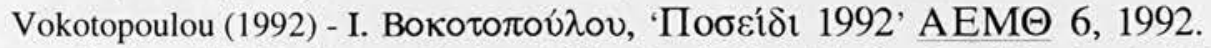

von Gerkan (1915) - A. von Gerkan, Milet Band I Heft IV: Der Poseidonaltar bei Kap Monodendri. Berlin G. Reimer 1915.

Wace (1906) - A.J.B. Wace, 'The topography of Pelion and Magnesia.' JHS 26 (1906).

Wace and Hasluck (1907-8) - A.J.B. Wace and F.W. Hasluck, 'South-Eastern Laconia.', BSA 14 (1907-8).

Wachsmuth (1967) - D. Wachsmuth, ПOMПIMO $\Sigma$ O $\triangle$ AIMON: untersuchung zu den antiken Sakralhandunger bei Seereisen. Berlin 1967.

Walbank (1957) - F.W. Walbank, A Historical Commentary on Polybius. vol. I, Books I-VI. 1957 Oxford Clarendon Press.

Walker (1962) - D.S. Walker, The Mediterranean Lands. $2^{\text {nd }}$. ed. London \& New York, 1962, Methuen and Wiley.

Wallace (1972) - P.W. Wallace, 'The tomb of Themistocles in the Peiraieus.' Hesp. 41 (1972).

Waterhouse and Hope-Simpson (1961) - H. Waterhouse and R. Hope-Simpson, 'Prehistoric Lakonia part 2.', BSA 56 (1961).

Weld-Blundell (1895-6) - H. Weld-Blundell, 'A Visit to Cyrene in 1895.', BSA 2 (1895-6).

West (1978) - M.L. West, Hesiod: Works and Days, edited with prolegomena and commentary. Oxford Clarendon Press 1978.

Wide and Kjellberg (1895) - S. Wide and L. Kjellberg, 'Ausgrabungen auf Kalauria.', AM 20 (1895).

Williams (1958) - R.T. Williams, 'Early Greek Ships of Two Levels.' JHS 78 (1958).

Wilson (1987) - J. Wilson, Athens and Corcyra: strategy and tactics in the Peloponnesian War. Bristol Classical Press Bristol 1987.

Woodhouse (1897) - W.J. Woodhouse, Aetolia, its Geography, Topography, and Antiquities. Oxford Clarendon Press 1897.

Wynne-Thomas (1978) - R.J.L. Wynne-Thomas, Legacy of Thasos. London Springwood Books 1978. 
Young (1951) - J.H. Young, 'Studies in South Attica: Country Estates at Sounion.', AJA 55 (1951). Young (1956) - J.H. Young, 'Ancient Towers on the Island of Siphnos.' AJA 60 (1956).

Zachos (1984) - C.L. Zachos, 'EYKTITON AIПY', BSA 79 (1984).

Zimmern (1973) - A. Zimmern, The Greek Commonwealth. 5th ed., revised, Oxford Clarendon Press, 1931. 


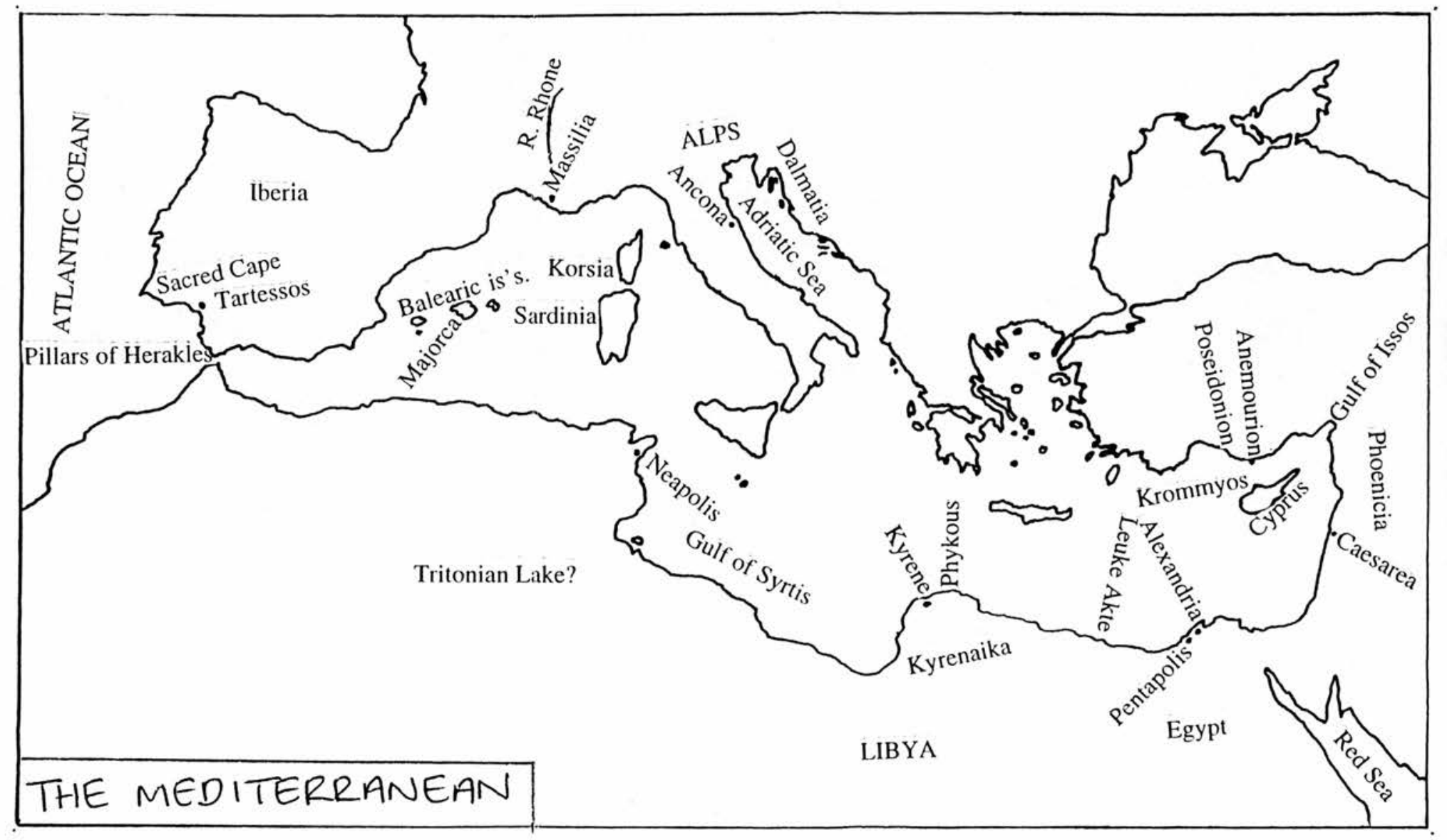




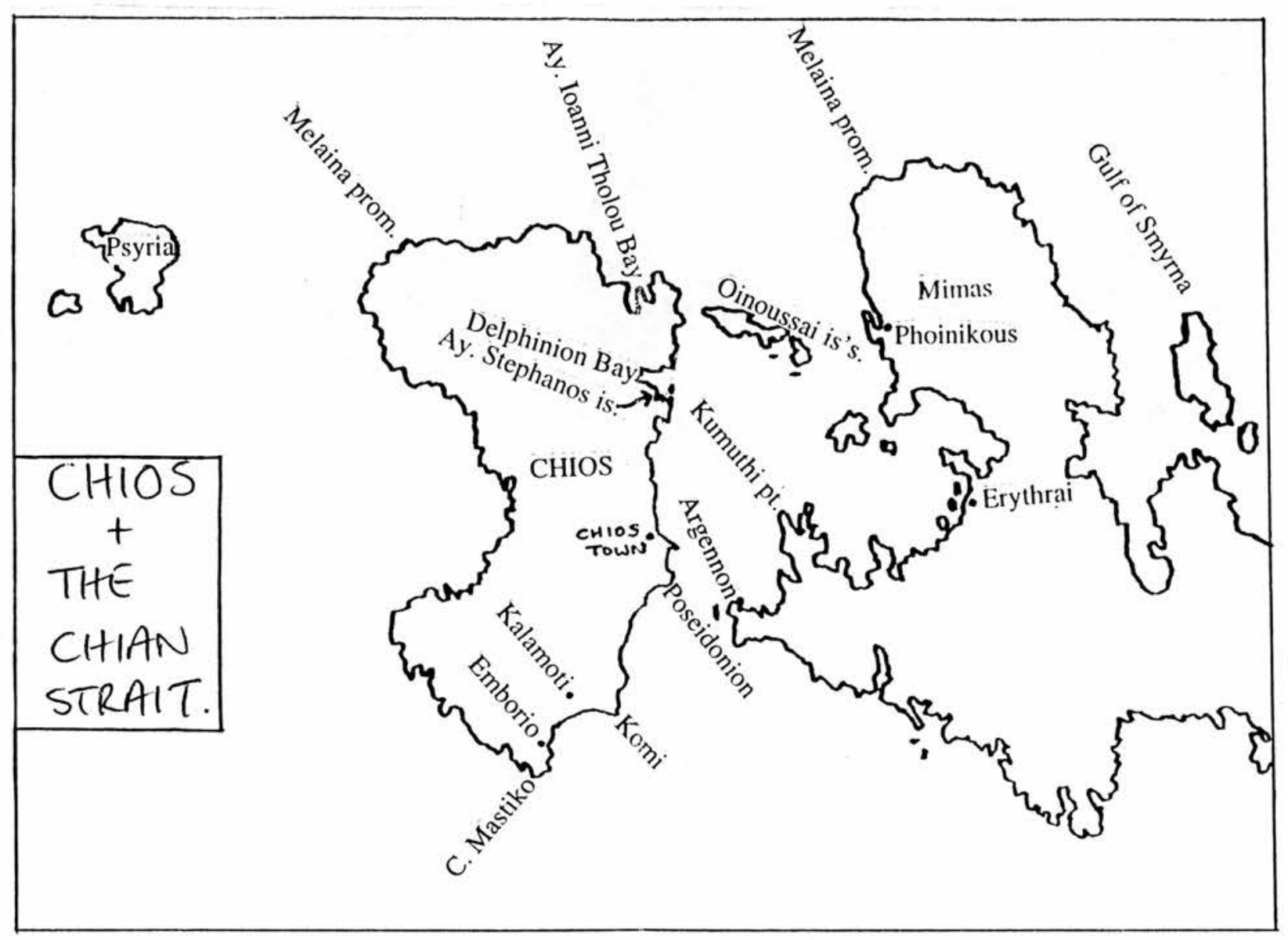




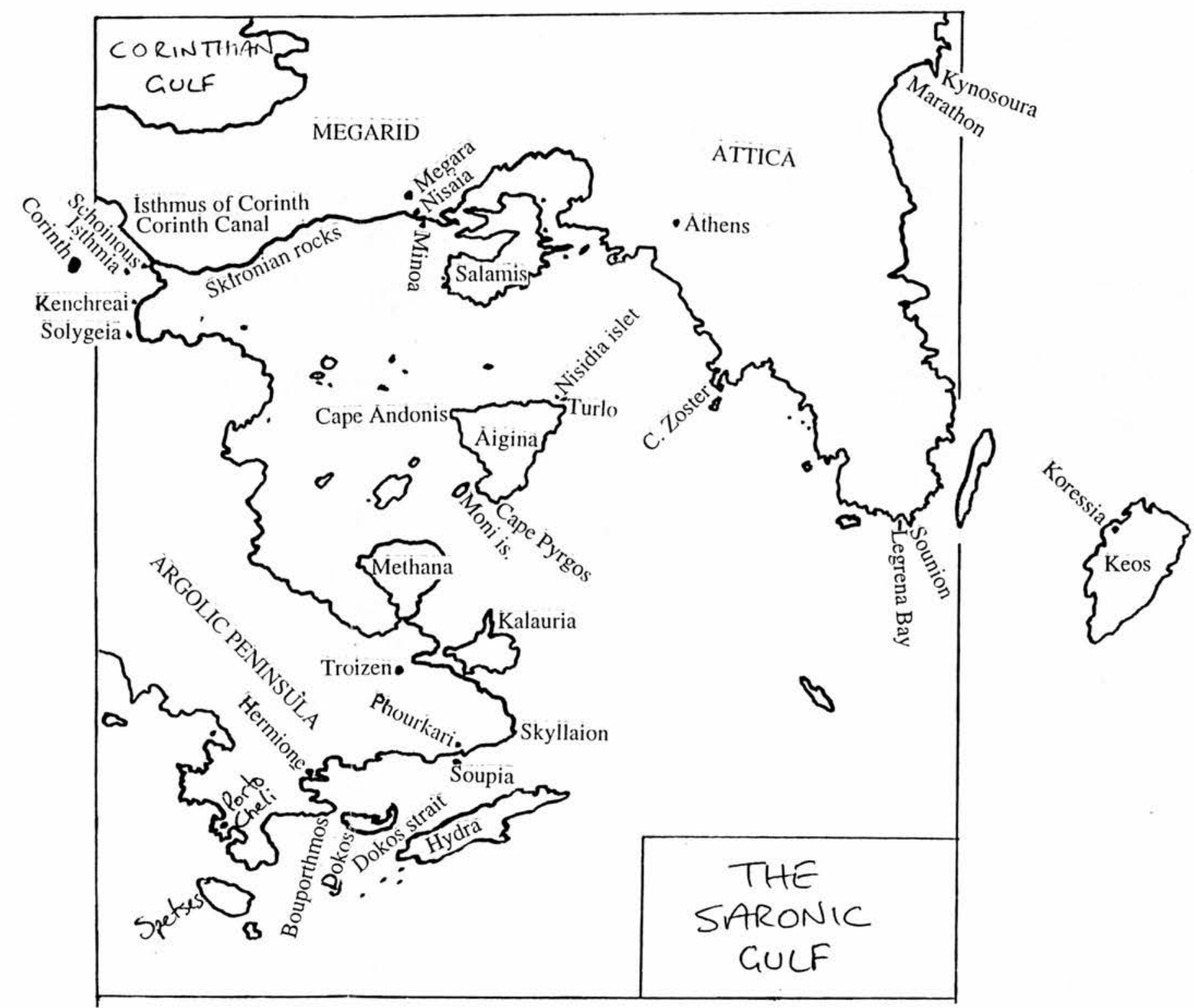




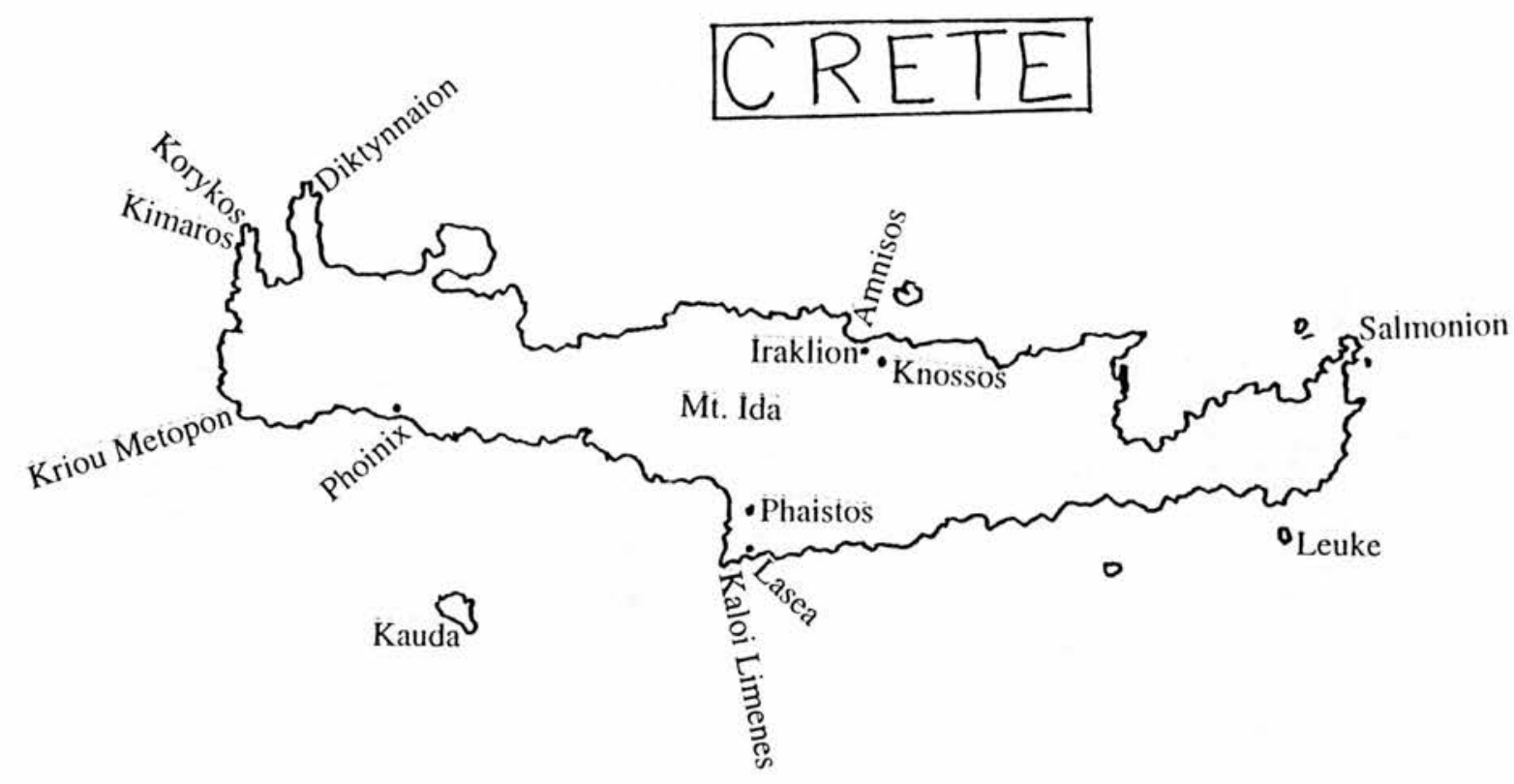




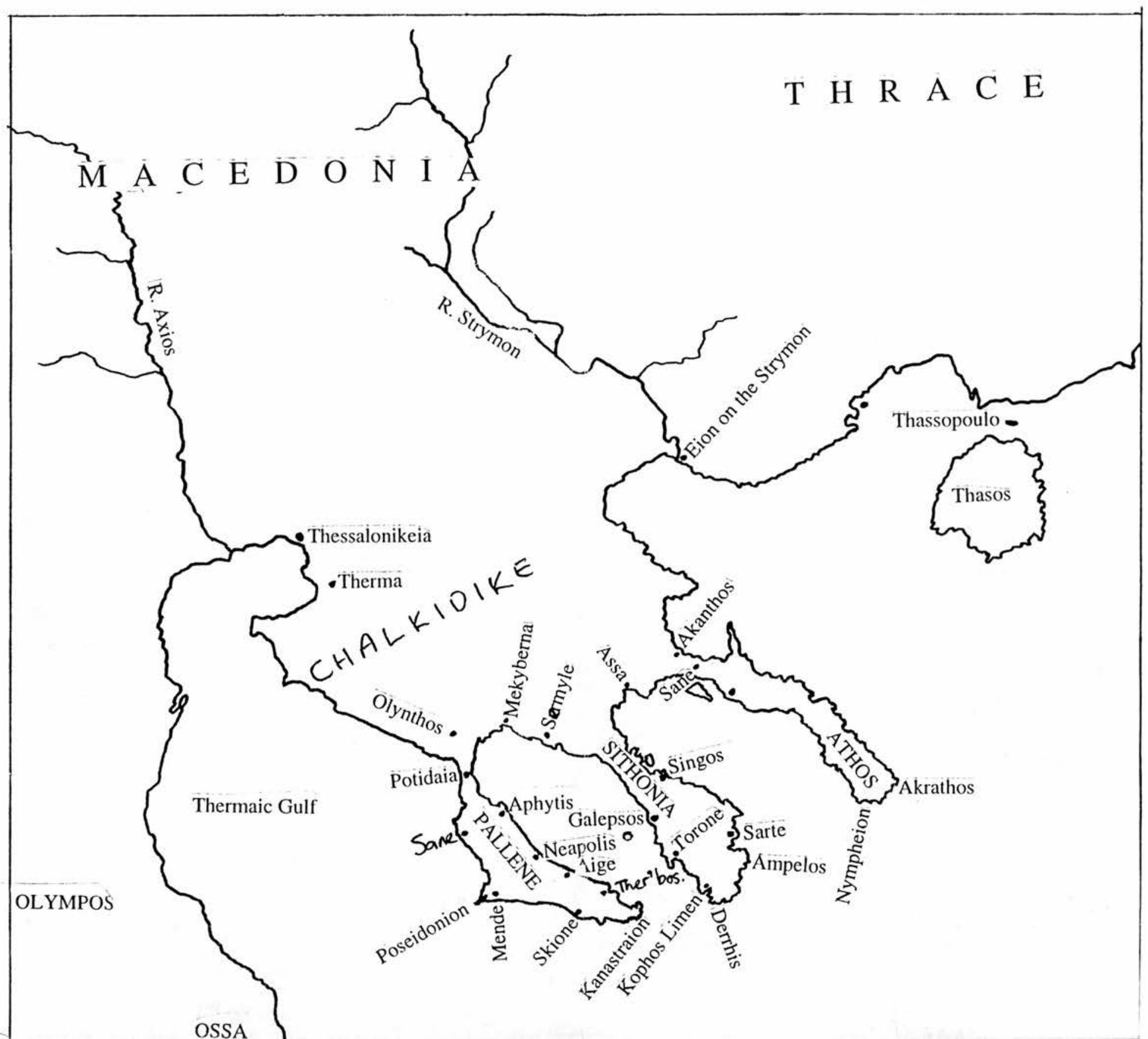




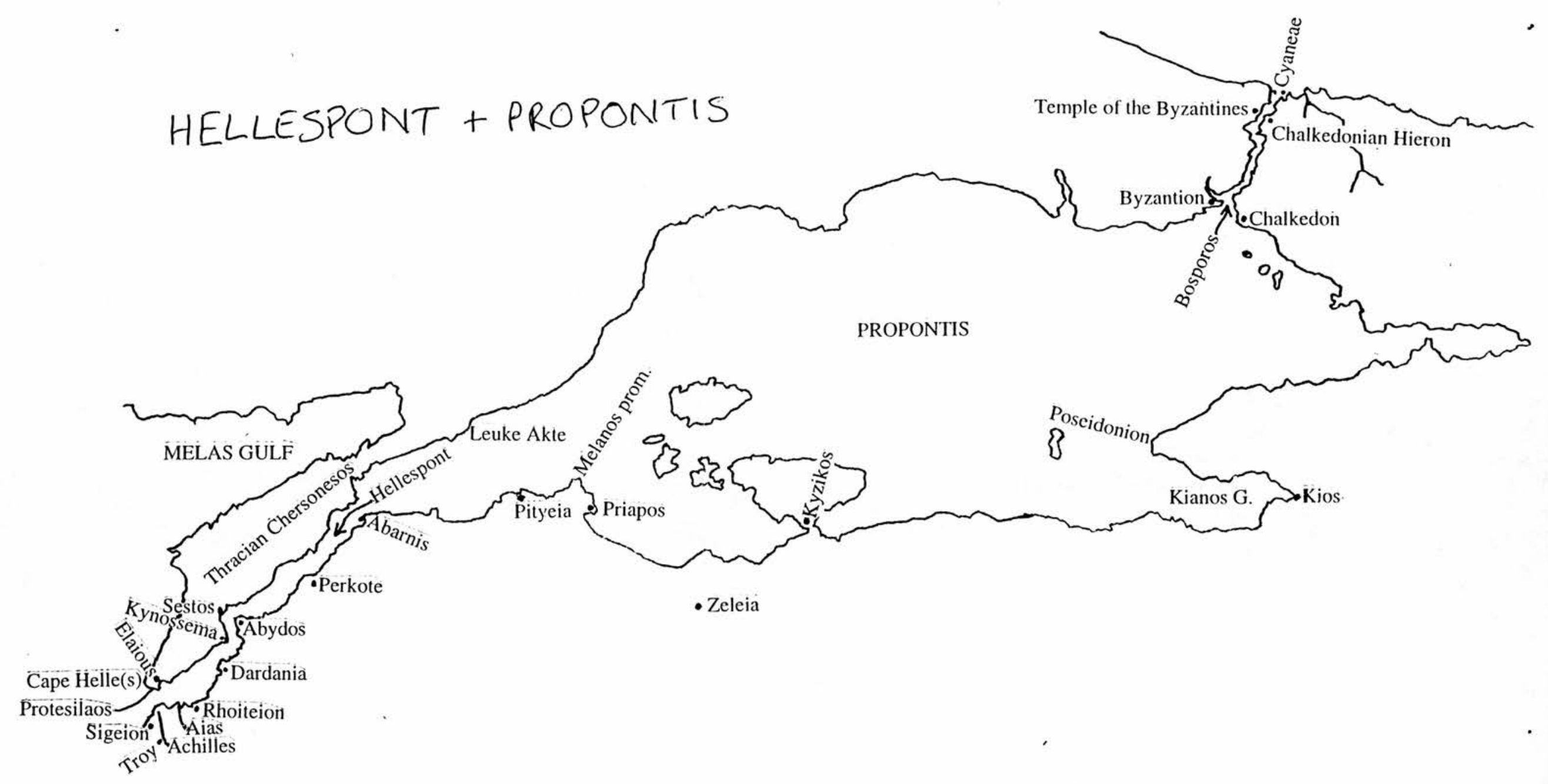




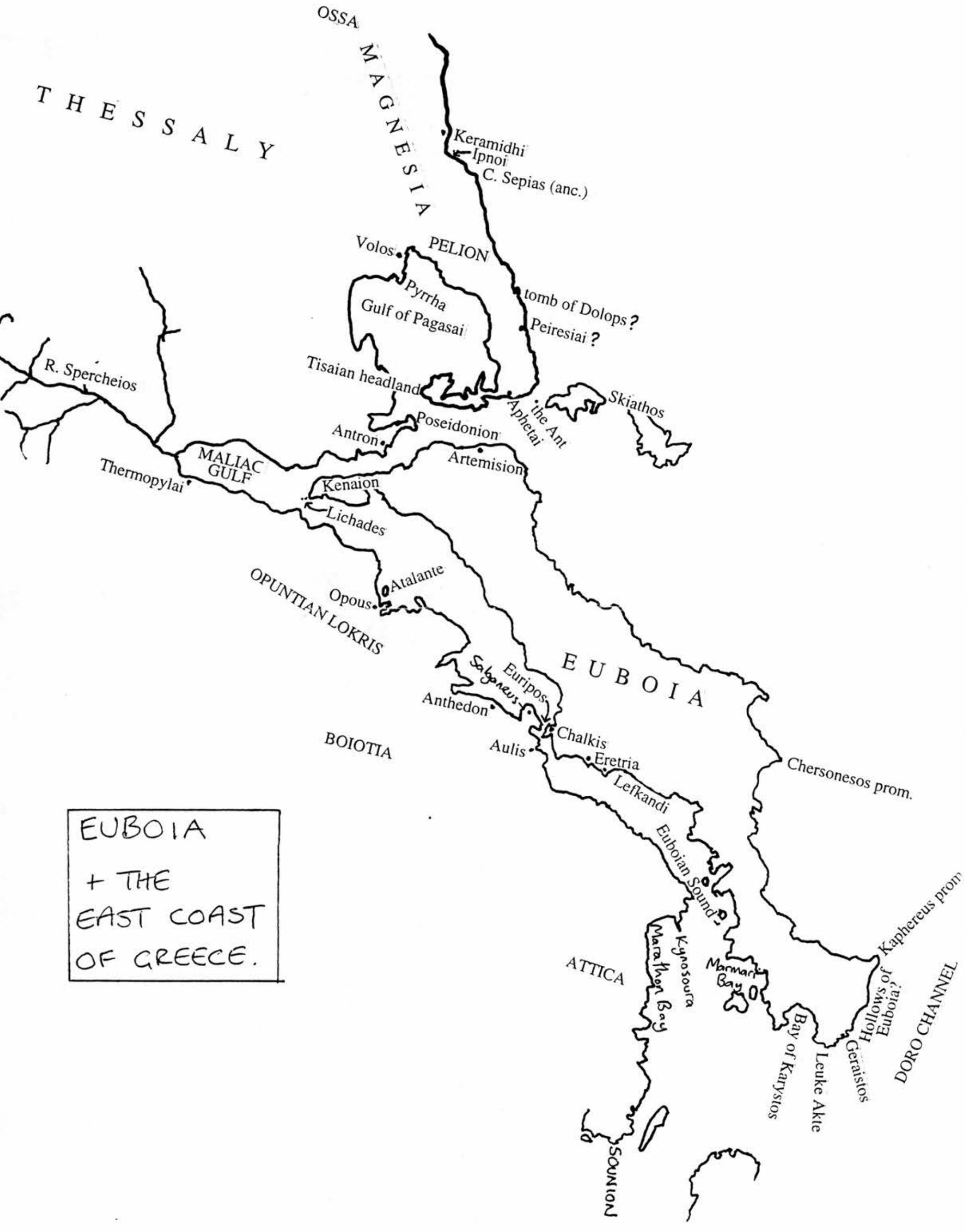




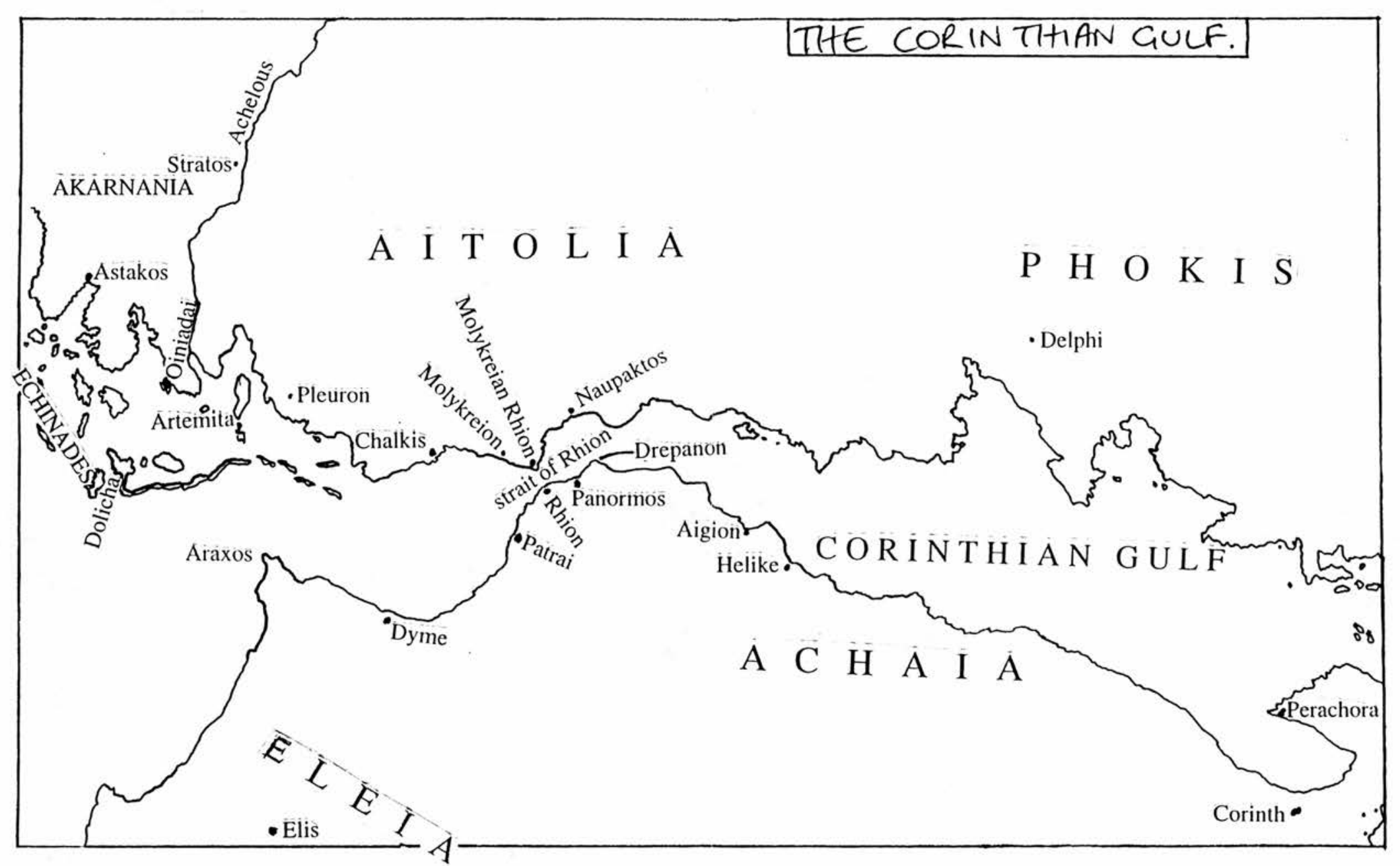




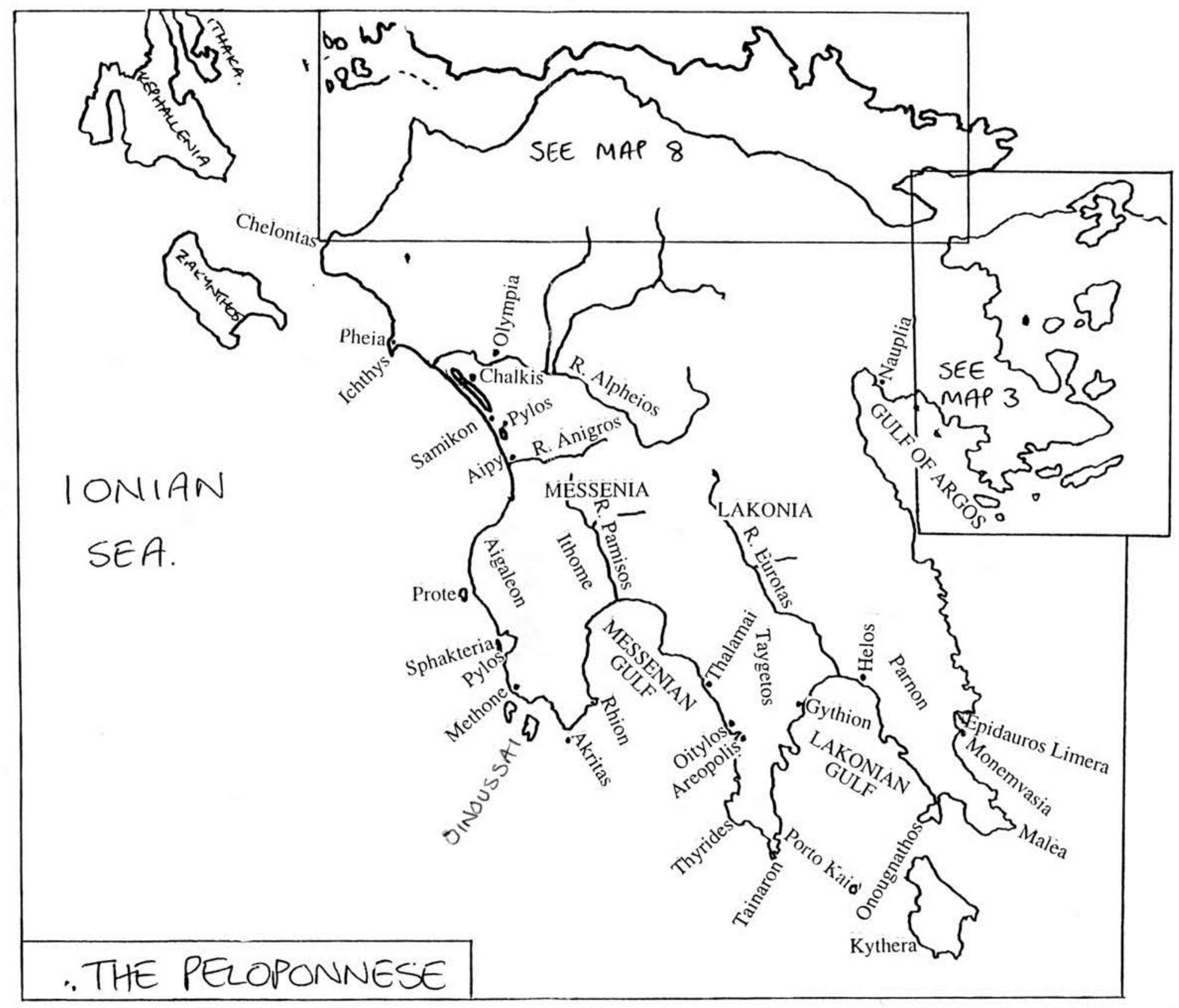




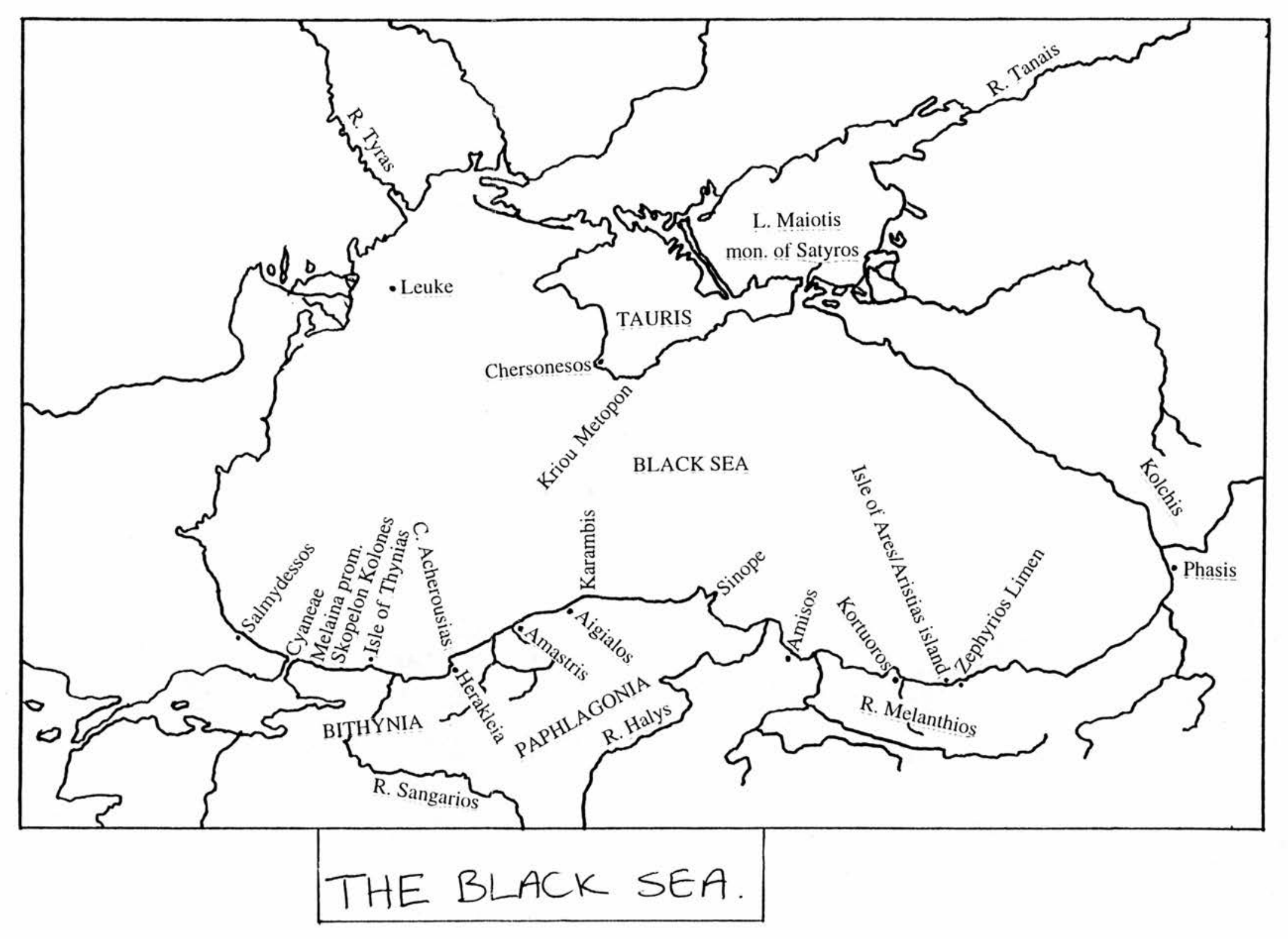




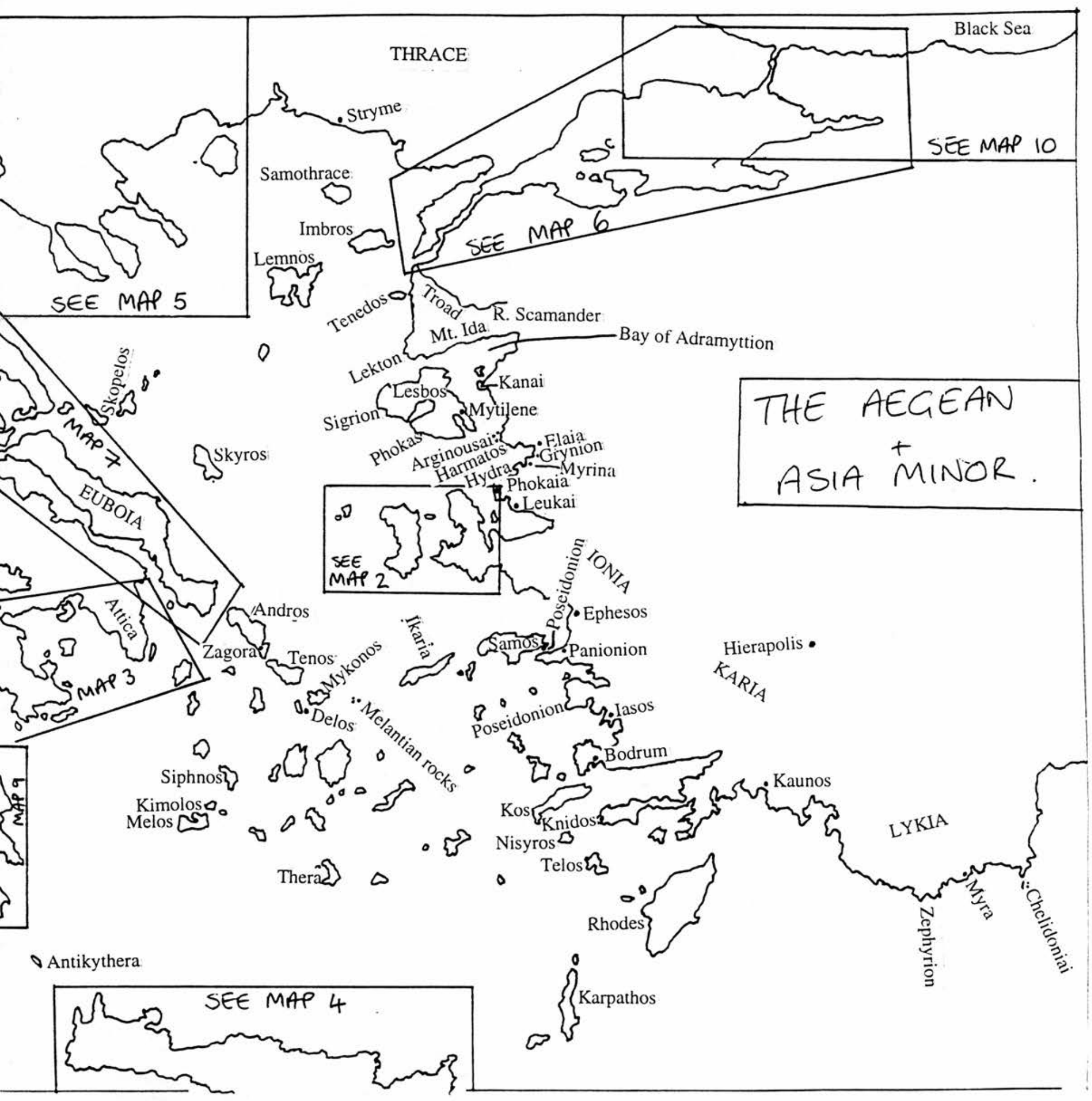




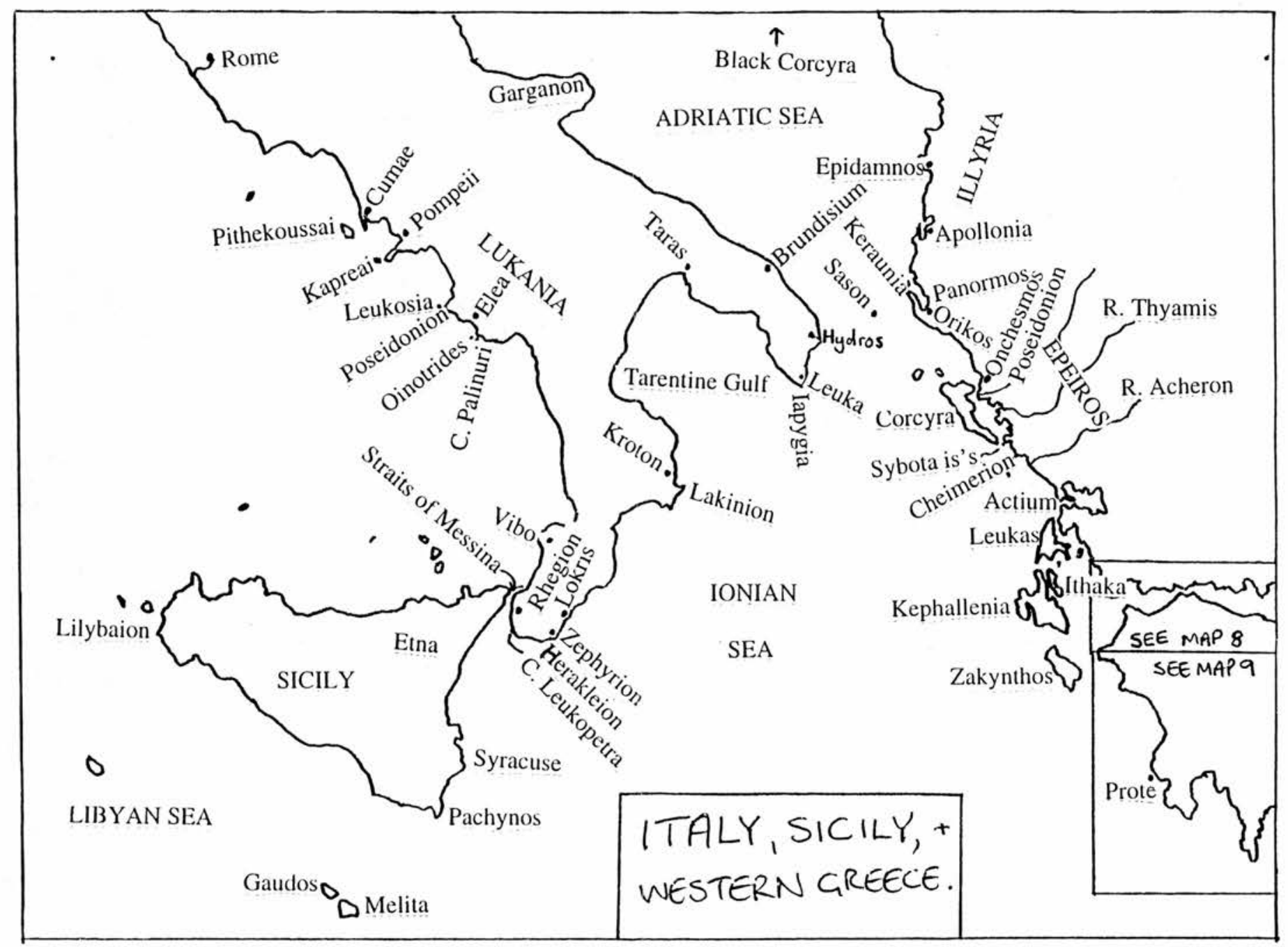

